


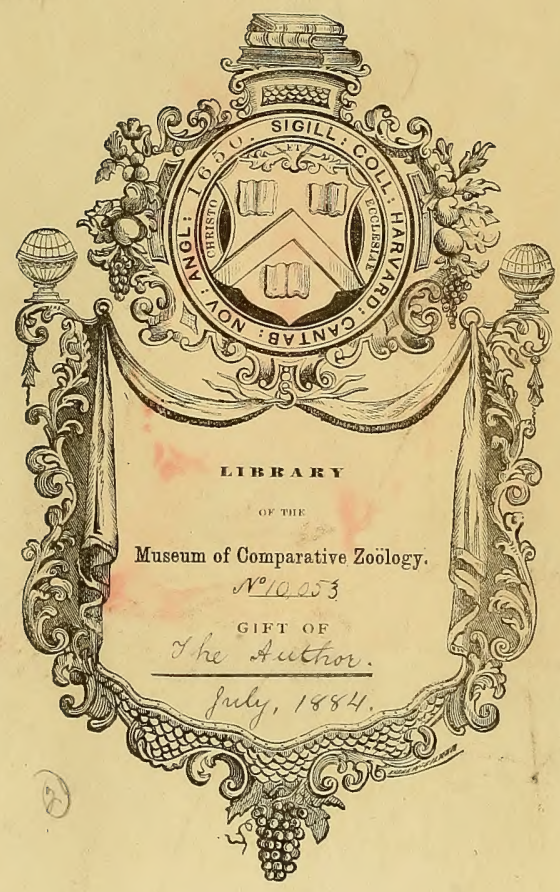






Of the Muserm of Componative Loologr of Lowrvard College; Cambridge, Marf. $3022 \geq 8$, from the pout of the autror.- 



\section{NEMATODEN}

\section{DER NIEDERLÄNDISCHEN FAUNA.}

EINE SYSTEMATISCH-FA UNISTISCHE MONOGRAPHIE

\section{$D^{R}$. J. G. DE MAN}

IN

MIDDELBURG, NIEDERLANDE.

vormals Conservator am zoologischen Museum in Leiden.

Mit vier und dreissig lithographirten Tafeln.

LEIDEN. - E. J. BRILL.

1884. 

MEINEN ELTERN

UND

DER ZEELÄNDISCHEN GESELLSCHAFT DER WISSENSCHAFTEN

IN MIDDELBURG

G E W I D M E T. 



\section{ORWORT.}

Als ich im Jahre 1880 die Diagnosen der zahlreichen Formen von frei in der reinen Erde und im süssen Wasser lebenden Nematoden veröffentlichte, welche ich durch Untersuchungen eines grossen Theiles der Niederlande entdeckt hatte, beabsichtigte ich später diese Thiere monographisch zu behandeln und durch genaue Zeichnungen abzubilden, welche bei helminthologischen Studien dieser Art so sehr nothwendig sind, und ausserdem meine Arbeit auch durch eingehende Nachforschungen des anatomischen Baues und der Biologie zu vervollständigen.

Leider hat es mir in der darauf folgenden Zeit nicht gelingen wollen, diesen zweiten Theil meiner Wünsche zu erfüllen, nicht nur wegen der Schwierigkeit dieser Untersuchungen, sondern besonders weil es mir an der dazu erforderlichen Zeit und Gelegenheit mangelte: ein halbjähriger Aufenthalt in Erlangen, wo ich das Vorrecht hatte eine schöne Sammlung von Gephyreen zu bearbeiten, dann die Erfüllung meiner damaligen Amtsgeschäfte am Leidener Museum, schliesslich eine Krankheit im Laufe des vorigen Jahres, welche mir das Arbeiten sehr beschwerlich machte, verhinderten mich dasjenige zu bieten, was ich versprochen hatte.

Die vorliegende Arbeit enthält deshalb bloss eine systematische Bearbeitung der von mir in den Niederlanden gefundenen Formen. Im allgemeinen Theile handle ich in kurzen Zügen zuerst über die geschichtliche Entwickelung der Kenntniss dieser Thiere, wobei es wohl als eine historische Curiosität angemerkt werden muss, dass der erste Entdecker eines freilebenden Nematoden, des Essigälehens, P. Borel, im Jahre 1656 seine Arbeit der Obrigkeit derselben Stadt widmete, in welcher jetzt die Zeeländische Gesellschaft der Wissenschaften ihren Sitz hat. Dann wird die Art des Fangens und Praeparirens, die örtliche und zeitliche Verbreitung in den Niederlanden, die Lebensweise und schliesslich die Classification besprochen. Im systematischen Theile findet man im Anfang eine Tabelle zur Bestimmung der Gattungen, dann die Beschreibung sämmtlicher von mir beobachteten Gattungen und Arten, mit den Bestimmungstabellen der letzteren; ausserdem erwähne ich alle übrigen, von den Autoren beschriebenen, von mix aber bis jetzt nicht aufgefundenen Arten. Auf vier und dreissig Tafeln sind fast alle Arten abgebildet und zwar meist die Weibchen: ich that dies nicht nur weil die Männchen mehrerer Arten gänzlich unbekannt sind, sondern namentlich auch darum, weil in vielen Gattungen die Weibchen verwandter Arten sich viel schwerer unterscheiden lassen als die Männchen. Ausserdem zeichnete ich fast von jeder Art einzelne Körpertheile in stärkerer Vergrösserung ab; von denjenigen Arten, welche nicht abgebildet worden sind, oder von welehen zwar die ganzen Thiere, aber nicht einzelne Körpertheile gezeichnet wurden, waren schon in meiner ersten Hol- 
ländisch geschriebenen Nematodenarbeit Zeichnungen gemacht: für die Bestimmung der jetzt nicht oder nux theilweise abgebildeten Arten ist es darum wünschenswerth auch die Tafeln meiner früheren Arbeit zu Rathe zu ziehen.

Das Buch ist gedruckt in der Verlagsbuchhandlung der Firma E. J. BriLL in Leiden und die Tafeln sind in der Anstalt des Herrn Jон. IJкема im Haag verfertigt und zwar die Tafeln I, II und IV nach einer etwas anderen Methode als die übrigen, welche nach einigen von den gewöhnlichen abweichenden Processen gestochen worden sind. Der Druck der Tafeln ist vom Herrn W. O. VerMaAs im Haag, der seine Aufgabe mit grösster Sorgfalt und Eifer ausgeführt hat.

Auf meine Anfrage schickten mir einige Herren aus verschiedenen Theilen Europa's rasenartige Stücke feuchter Erde aus der Umgebung ihrer Wohnorte zu und zwar die Herren Dr. Eugen von Daday in Klausenburg, Carl von Deschmann in Laibach, Dr. Th. von Heldreich in Athen, Olaf Jensen in Christiania, Dr. Paul Mayer in Neapel, Dr. Ladislaus Örley aus Sydenham bei London, W. Repiachoff in Odessa, N. Zograff in Moskau und Dr. Viguier in Montpellier; allen diesen Herren sage ich für ihre grosse Bereitwilligkeit meinen aufrichtigen Dank.

Auch sei es mir erlaubt der Zeeländischen Gesellschaft der Wissenschaften in Middelburg, welche mich mit grösster Liberalität finanziell unterstützt hat, meinen besten Dank öffentlich auszusprechen. Während die Gesellschaft mir durch diese Unterstützung, die Herausgabe der Abbildungen der theilweise auf Zeeländischem Boden gefundenen Thierformen erleichterte, hat sie dadurch von neuem das Bestreben gezeigt, auch auf naturhistorischem Gebiete, wie immer, fördernd auf zu treten.

Middelburg, im Januar 1884. 


\section{IN HA LTS VERZEIC HNISS.}

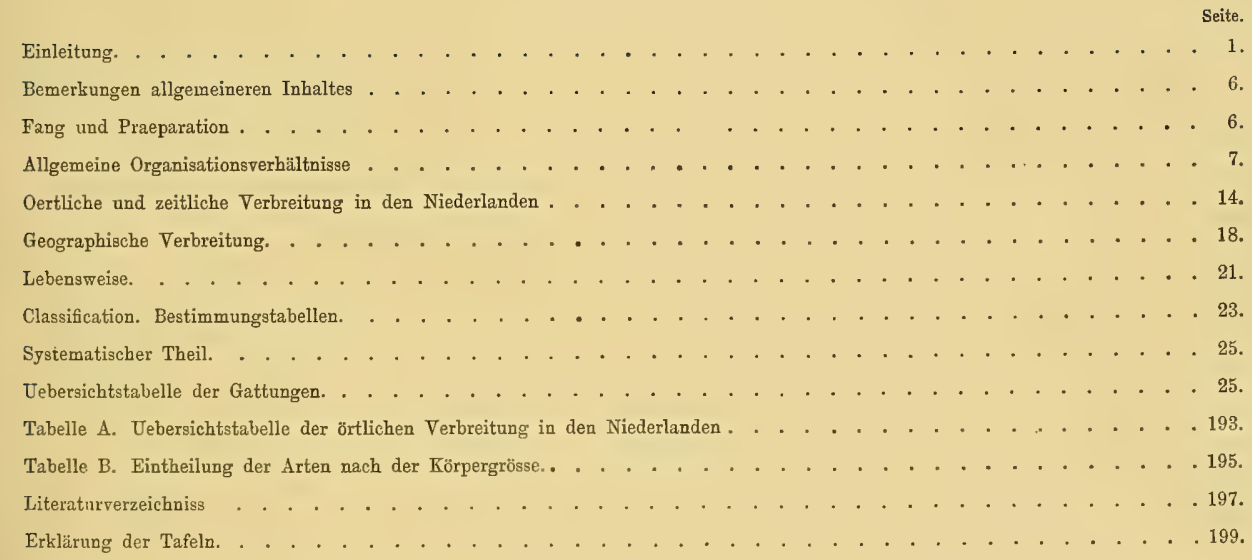




\section{REGISTER DER GATTUNGEN UND ARTEN.}

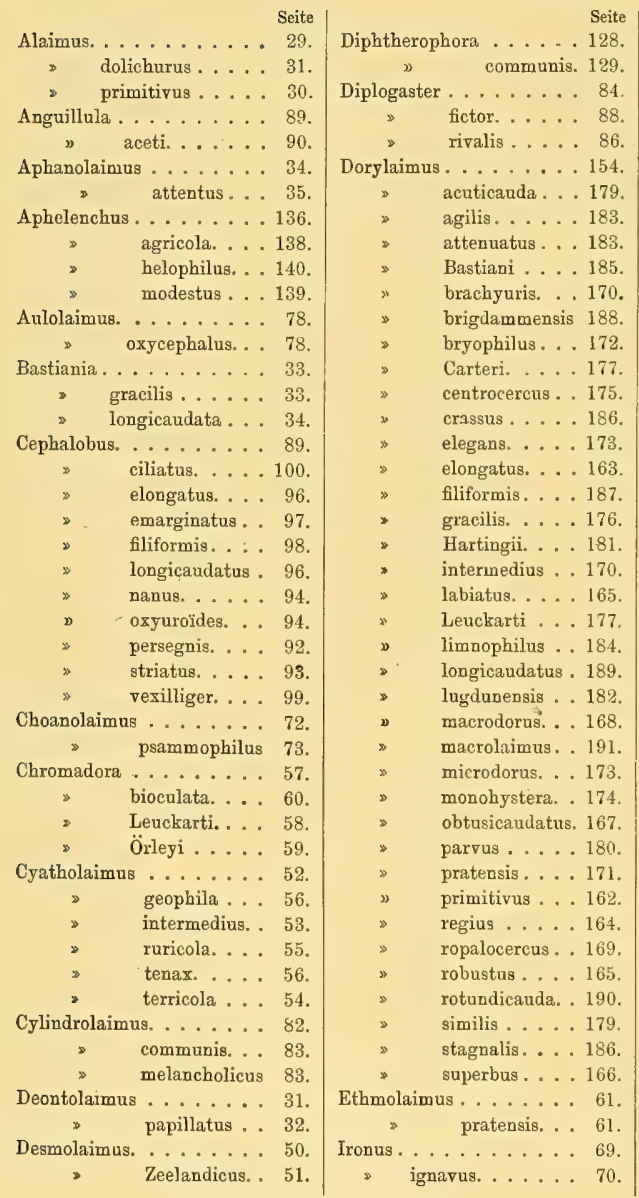

Seite | Seite Ironus longicaudatus. . . 71. Rhabditis brevispina . . 122 Leptolaimus. . . . . 8 81. , filiformis . . 123. „ papilliger.. 81. Macroposthonia. . . . 124. » annulata. . 124 Microlaimus. ...... 51 globiceps ... 52. Monohystera ..... 35 . , agilis..... 43 .

„ bulbifera. .... 44 .

\ispar .... 41.

filiformis. ...4 41.

macrura.... 39

* microphthalma 38.

» paludicola... 37.

, similis $\therefore . .40$.

simplex ... 43

\$ vulgaris ... 39

Mononchus ....... 62 . - brachyuris... 66 . macrostoma.. 63. » papillatus ... 64 y parvus.... 65 tridentatus. . 67. Odontolaimus. . . . . 127. » chlorurus. . 127. Oncholaimus ...... 67 . 2 thalassophygas 68 . Plectus . . . . . . 104. * auriculatus. . . . 116 - cirrhatas. . . . 110. , communis .... 115. . geophilus. ..... 112. granulosus. . . . 107. longicaudatus... 114. otopborus .... 117 palustris . . . . 112. parietinus .... 109 parrus...... 115. $>$ rhizophilus. .... 113. $>$ Schneideri . . . . 108. \% tenuis ......111. Prismatolaimus. . . . . 79. \$ dolichurus. 80 > intermedius 79 . Rhabditis. . . . . . 118.

$$
\text { , intermedia . . 122. }
$$

\$ monohystera . 121.

Rhabdolaimus . . . . . 125.

$$
\text { ๖ aquaticus. } 126 .
$$

\$ terrestris. . 126.

Sphaerolaimus . . . . 71 .

$\quad$ gracilis. . 72

Spilophora. . . . . . 57.

> geophila.... 58

Teratocephalus. . . . . 101. crassidens. 102. palustris. . 103. terrestris . 102.

Trilobus. . . . . . . 74

, gracilis ..... 75

, pellucidus .... 76.

Tripyla. . . . . . 44. $\gg$ affinis. ..... . 48

, arenicola..... 49.

, filicaudata..... 47.

¿ monohystera. ... 49.

, papillata.... 47

, setifera..... 46 .

Tylencholaimus . . . . 132 minimus . 134 mirabilis. . 133. Zeelandicus 135.

Tylenchus . . . . . . 140 agricola ... 150. Davainei. . . 151. dubius . . . 145 . filiformis . . . 152 gracilis. . . . 148 . intermedius .. 149. lamelliferus . . 146 leptosoma. . . 150. macrophallus. . 153. pratensis .... 147. robustus . . . 144.

Tylolaimophorus . . . . 130 vypicus. 130.

Tylopharynz. . . . . 131 striata. ... 131 


\section{EIN LEITUN G.}

Obgleich ich nicht beabsichtige, eine ausführliche Beschreibung der allmählichen Entwicklung unserer Kenntniss der frei lebenden Nematoden zu geben, so will ich doch einen flüchtigen Blick werfen auf die Arbeiten der Forscher, welche sich, seit dem Anfang des Gebrauchs des Mikroskopes, mit der Erforschung der Natur und der Eigenschaften dieser meist winzig kleinen Thiere beschäftigt haben, wobei ich mich vorzugsweise auf die Land- und Süsswassernematoden beziehen werde.

Der französische Leibarzt, P. Borel (I) war der erste, der diese Thiere beobachtete: er erwähnt nämlich schon im Jahre 1656 das merkwürdige Essigälchen, Anguillula aceti, worüber andere Forscher später wichtige Beobachtungen gemacht haben, wie van Leeuwenhoek, Göze und Czernay (II), der im Jahre 1849 eine Monographie desselben veröffentlichte. Aber erst in diesem Jahrhundert wurden unsere Thiere genauer von vielen Forschern untersucht, so dass schon im Jahre 1865 etwa achtzig Arten von frei lebenden, meist marinen, Nematoden beschrieben waren.

Es waren namentlich Dujardin, Diesing, Carter und Eberth, welchen wir diese Fortschritte verdanken. Der französische Gelehrte Dujardin, Verfasser der "Histoire naturelle des Helminthes ou vers intestinaux", (III) bildete sich zuerst einen Begriff von dem grossen Formenreichthum dieser Würmer und machte uns mit mehreren neuen Arten bekannt, welche er genauer beschrieb, als es seine Vorgänger gethan hatten. Diesing (IV), der berühmte Helmintholog, stellte eine bessere Classifikation auf, während Carter (V) nicht nur zehn neue Arten beschrieb, sondern auch die anatomischen Verhältnisse aufklärte. Sehliesslich erweiterte Eberth (VI) durch seine, im Jahre 1863 erschienenen Untersuchungen über Nematoden auch sehr unsere Kenntniss der anatomischen Organisation und beschrieb ausserdem drei und zwanzig neue Arten des Mittelmeeres.

Da erschien im Jahre 1865 der englische Gelehrte, H. Charlton Bastian, in London, mit einer grossen Monographie über Anguilluliden in den Transactions of the Linnean Society (VII), und mit dem vollsten Rechte kann diese Arbeit als bezeichnend betrachtet werden für eine neue Periode in der Kenntniss der frei lebenden Nematoden. Nicht weniger als zwanzig neue, sehr natürliche Gattungen und hundert neue Arten werden in diesem Werke genau beschrieben, das sowohl über Land- 
als Meernematoden handelt. Die Land- und Süsswasserformen werden in dreizehn Gattungen eingeordnet, von welchen vier von früheren Autoren aufgestellt worden waren (Dorylaimus und Rhabditis von Dujardin, Anguillula von Ehrenberg und Diplogaster von Max Schultze), während die neun übrigen neu waren (Monohystera, Trilobus, Mononchus, Ironus, Tripyla, Plectus; Aphelenchus, Cephalobus und Tylencluss). Auf den fünf Tafeln wurden immer nur die beiden Körperenden jeder Art abgebildet. Im nächsten Jahre erschien darauf Bastian's wichtige Arbeit über die Anatomie und Physiologie der Nematoden, (VIII), worin die Kenntniss ihrer Organisation und Lebensweise bedeutend erweitert wurde: sieben Tafeln sind dieser Arbeit beigefügt, welche in den Philos. Transactions erschien.

Ebenso erschienen im Jahre 1865 Davaine's Recherches sur l'Anguillule du Vinaigre (IX), und auch Greeff $(X)$ theilte in den Sitzungsberichten der niederrbeinischen Gesellschaft mit, dass er sich mit dem Studium der, in der Gegend von Bonn und an der Belgischen Nordseeküste lebenden, Anguilluliden beschäftigt hatte; er glaubte die Hauptanhaltspunkte für eine systematische Behandelung besonders in der Form der Mundwerkzeuge suchen zu müssen. In einer zweiten Mittheilung (XI) besprach derselbe Verfasser die augenführenden Nematoden, die er in Salinen zu Kreuznach und zu Münster am Stein beobachtet hatte, ohne sie zu beschreiben. Er stellte die Frage auf, ob die rothen Augen vielleicht unter dem Einflusse des Salzwassers entstanden wären, und meinte sogar dass die augenführenden Formen für die Meeresfauna characteristisch seien.

Im Jahre 1866 gab Schneider, (XII) damals Privatdocent zu Berlin, seine berühmte „Monographie der Nematoden" heraus. Diese Arbeit verdankte ihre Entstehung einem Auftrage, welchen der Verfasser erhielt, die helminthologische Sammlung des Berliner zoologischen Museums zu katalogisiren und zu ordnen. Daher kommt es, dass unter den 180 von Schneider beschriebenen Arten nur 30 frei lebende sind, und wenn ich noch hinzufüge, dass Bastian's grundlegende Monographie ihm erst dann bekannt wurde, als der systematische Theil seines Werkes schon gedruckt war, so wundert es uns nicht, dass diese Arbeit in Bezug auf die Kenntnis der freilebenden wenig nenes gewährte oder bot. Die Gattung Rhabditis Duj. trennt er mit Unrecht in die beiden Gattungen Pelodera und Leptodera. Etwa 17 neue Arten werden beschrieben [Enoplus (3 marin), Dorylaimus (1), Pelodera (4), Leptodera (9).] Von grösstem Interesse und Gewicht dagegen sind die Mittheilungen über die anatomische Organisation und die Entwickelungsgeschichte unserer Thiere und acht und zwanzig schöne Tafeln illustriren diese bedeutungsvolle Arbeit.

In demselben Jahre erschienen die merkwürdigen Untersuchungen des französischen Gelehrten Pérez (XIII) über die Anatomie und Physiologie, von Rhabditis terricola Duj., in welcher mit zahlreichen, schönen Abbildungen ausgestatteten Arbeit der ganze anatornische und histologische Bau dieses Thieres, sowie seine Entwickelungsgeschichte sehr ausführlich und deutlich beschrieben und aus einander gesetzt werden. Zu gleicher Zeit theilte Menge (XIV) seine Untersuchungen mit über von ihm im Bernstein beobachteten Anguilluliden, welche Beobachtungen zweifelsohne vom grossem Interesse sind.

Im Jahre 1869 gab Claus (XV) seine Beobachtungen über die Organisation und Fortpflanzung 
von Leptodera appendiculata heraus, und zwei Jahre später veröffentlichte A. Schmidt (XVI) seine Mittheilungen über den gefährlichen Rübennematoden, in der Zeitschrift des Vereins für RübenIndustrie im Zollverein.

In einer dritten Mittheilung über die frei im Wasser und in der Erde lebenden Nematoden, namentlich die Meeresbewohner, theilt Greeff (XVII) einige morphologische und anatomische Betrachtungen mit, über die von ihm beobachteten, obgleich ebenso wenig wie früher beschriebenen Arten. Er betrachtet nämlich die dorsale und die ventrale Körperfläche als die natürlichen Seitenflächen, während die als solche angenommenen Seitenfächen nun in natürlicher Lage die Rücken- und Bauchfläche bilden. Auch scheint er den Cephlalobus ciliatus Linstow damals schon beobachtet zu haben. Etwa zu gleicher Zeit veröffentlichte Vernet (XVIII) seine Untersuchungen über die Fortpflanzung von zwei hermaphroditischen Rhabditis-Arten, von welchen eine als neu beschrieben wurde (Rhabditis Leuckarti).

In demselben Jahre $18 \% 2$ beobachtete von Frauenfeld (XIX) zwei Fälle des Vorkommens von Anguillulen in Pflanzengeweben, $I^{0}$ an den Blättern von Leontopodium alpinum, und $2^{0}$ an runzlich verdickten und einigermassen knorplich verhärteten Stellen der fiederschnittigen Blätter von Falcaria Rivinii: die Thiere werden aber nicht weiter beschrieben.

Im folgenden Jahre erschien wieder eine grössere Arbeit über frei lebende Nematoden und zwar von Bütschli (XX), damals wohnhaft zu Frankfurt a. Main. Bastian's Monographie erregte in ihm das Verlangen auch in der Umgebung seines Wohnortes die, von dem Engländer entdeckten Formen zurückzufinden und auf diese Weise einen Beitrag zu diesem Theile der Fauna seines Landes zu liefern. Bütschli's Arbeit erschien in den Verhandlungen der Deutschen Akademie und war ausschliesslich denjenigen Formen gewidmet, welche in der Erde und im süssen Wasser leben. Sein Bestreben wurde mit dem besten Erfolge bekrönt. Mehr als die Hälfte der von ihm beobachteten (61) Arten war neu für die Wissenschaft, und unter diesen gab es sogar einige, auf welchen mit allem Rechte eine neue Gattung hătte aufgestellt werden können, wie denn auch später geschehen ist. Besonders aber erweiterte er die Kenntniss der anatomischen Organisation, während er auch die Resultate früherer Forscher in Bezug auf diesen Gegenstand besprach. Schön bearbeitete Tafeln begleiten diese Abhandlung. Im nächsten Jahre gab derselbe Forscher, der sich zu Kiel wohnhaft niedergelassen hatte, schon wieder eine wichtige Arbeit heraus (XXI); diesmal regten ihn besonders die Forschungen des französischen Gelehrten Marion, welcher die freilebenden Nematoden des Golfes von Marseille in einer grösseren Abhandlung (XXII) bearbeitet hatte, an, auf dieselbe Weise die marinen Rundwürmer des Kieler Hafens kennen zu lernen. Obgleich diese Arbeit demgemäss speciell über marine Arten handelt, werden doch noch sechs neue Landbewohner beschrieben, und auch hier giebt der Verfasser wieder beträchtliche Beiträge zur genauern Kenntniss der anatomischen Struetur, während er genöthigt war, viele Meinungen Marion's zu widerlegen.

Darauf beschreibt Fr. Löw (XXIII) ansführlich, einen nenen Tylenchus (Millefolii), der im Wie- 
nerwalde an einigen Stellen des Phalzauthales, in kleinen ovalen gallenartigen Auftreibungen an den untersten, meist einen kleinen Rasen bildenden Blättern der gemeinen Schafgarbe (Aclillea millefolium L.) gefunden wurde, stets aber in sehr geringer Zahl. Zu gleicher Zeit meint Villot (XXIV) in einer Abhandlung über die frei lebenden und parasitischen Nematoden der Küsten von Bretagne, dass die sogenannten freilebenden als „semiparasitisch" zu betrachten seien, als Thiere welche in der Nähe von Mollusca, Ascidiae, Molgulae und Annulata leben und schlechterdings nicht scharf von denjenigen Arten zu trennen seien, welche ihr ganzes Leben hindurch als Parasiten leben.

Bald darauf erschien wieder eine kleine Arbeit von Bütschli (XXV), in welcher fünf neue Arten beschrieben und Beitrüge zur genauern Kenntniss schon bekannter Arten geliefert wurden: so macht er uns zum ersten Mal hier mit dem Männchen einer Mononclsus-Art bekannt. Ungefähr in derselben Zeit erschienen dann meine "Onderzoekingen over vrij in de aarde levende Nematoden". (XXVI). Auch in meinem Vaterlande waren diese Thiere noch nie untersucht worden, und auch ich erwartete eine reiche Ernte. Ich beobachtete mehr als fünfzig Arten, von welchen ungefähr drei Fünftel neu für die Wissenschaft waren; auch einige neue Gattungen war ich auf zu stellen genöthigt: Tylopharynx, Tylencholaimus, Teratocephahus, Leptolaimus und Bastiania, theils für schon bekannte, theils für ganz neue Arten. Von grossem Interesse war die Entdeckung von einigen Formen, welche ihren Characteren nach zu Gattungen gehörten, deren Vertreter bis jetzt nur im Meere gefunden waren, nicht nur in den Kanülen von Brackwasser und in dem, von diesem imbibirten Boden unseres Landes, sondern sogar in der feuchten Erde der holländischen Wiesen und Sümpfe (z. B. Clromadora Leuckarti). Zahlreiche Abbildungen fügte ich hinzu, aber mein Bestreben um die Gattungen zu Familien zu vereinigen, stellte sich später als voreilig heraus.

Zu gleicher Zeit schrieb A. Braun (XXVII) über von Anguilluliden verursachte, Gallen, während Kühn (XXVIII) eine Notiz über den Rübennematoden (Heterodera Schachti) veröffentlichte. Bald darauf erschienen im Archiv für Naturgeschichte die „Helminthologischen Beobachtungen” (XXIX) des Herrn von Linstow in Ratzeburg, in welchen dieser eiferige Helmintholog über mehrere frei in der reinen Erde oder im Ratzeburger See lebende Nematoden handelt, von welchen elf als neue Arten beschrieben werden, während für eine sogar eine nene Gattung, Diplolaimus, gebildet wird. Viele, nicht ganz genaue Abbildungen sind diesen Beobachtungen hinzugefügt. Die übrigen neuen Arten sind Angehörige der Gattungen Dorylaimus, Aphelenchus, Trilobus, Monohystera, Chromadora (zwei Arten aus dem Ratzeburger See) und Rhabditis. Im folgenden Jahre veröffentlichte derselbe Forscher (XXX) schon wieder Beschreibungen never Formen und zwar eines neuen Tylenchus und zweier anderen interessanten Arten, für welche sogar die neuen Gattungen Mitrephorus und Acrobeles aufgestellt werden.

Nach der Erwähnung einer neuen Monohystera-Art (bulbosa), welche von Gromma (XXXI) in der „Aralo-Caspian Expedition” beschrieben wurde, welche Beschreibung mir aber nicht zugänglich ist, komme ich zu den Untersuchungen G. Joseph's (XXXII) über die, in den Krainer TropfsteinGrotten einheimischen, frei lebenden Rundwürmer, welche im zweiten Jahrgange (1879) des Zoologischen Anzeigers erschienen. Besonders interessant ist die Entdeckung eines, dem Plectus granulosus verwandten, 
aber bedeutend grösseren Nematoden (o $11-13 \mathrm{~mm}$, 우 9-10 mm. lang) im schlammigen Sande der Reccagrotte, welcher aber auch im Meeressande in der Nähe der Mündung der unterirdisch strömenden Recca zurückgefunden wurde, wo er mit ächten marinen Arten, wie Oncholaimus vulgaris, leben soll. Dieses Thier muss also durch Wanderung aus dem Meere flussaufwärts bis in die Grotte gelangt sein. Leider hat der Verfasser noch keine ausführliche Beschreibung oder Abbildung dieses interessanten Grottenrundwurmes herausgegeben, der vielleicht einer neuen Gattung angehören wird.

In einer dritten Abhandlung (XXXIII) beschreibt von Linstow wieder vier neue freilebende Arten, Angehörige der Gattungen Dorylaimus, Diplogaster und Rhabditis.

Im Jahre 1880 erschien die preisgekrönte Monographie der Anguilluliden des Herrn Dr. Örley zu Budapest, in ungarischer Sprache mit deutschem Résumé (XXXIV). Obwohl Verf. seine Arbeit nur als einen Leitfaden für seine Landsleute betrachtet, trägt sie nichtsdestoweniger einen wissenschaftlichen Charakter und giebt einen Beitrag zur Kenntniss der Ungarischen Nematodenfauna. Alle bis dahin beschriebene Arten von frei in der Erde und im süssen Wasser oder im Brackwasser lebenden Nematoden werden systematisch aufgeführt und ausserdem fünf neue Arten bekannt gemacht. Auch theilt Örley die Resultate seiner Untersuchungen über die anatomische Organisation und die Entwickelung dieser Thiere mit. Mehrere gut ausgeführte Tafeln illustriren diese Abhandlung.

Im Anfang desselben Jahres wurden von mir (XXXV) die Diagnosen der neuen Gattungen und Arten herausgegeben, welche den Gegenstand der vorliegenden Abhandlung bilden.

In den letzten Tagen dieses Jahres theilte ich (XXXVI) dann noch die Beschreibungen von drei neuen Arten, sowvie Betrachtungen über einige andere schon bekannte Formen mit. 


\title{
BEMERKUNGEN ALLGEMEINEREN INHALTES.
}

\author{
FANG UND PRAEPARATION.
}

Da ich nicht beabsichtigte, den feineren anatomischen und histologischen Bau der Thiere kennen zu lernen, welche den Gegenstand dex vorliegenden Abhandlung bilden, so war die Untersuchungsmethode sehr einfach.

Aus der Oberfläche einer Wiese oder einer mit Pflanzen berwachsenen Stelle wird mittelst eines Taschenmessers ein Rasen feuchter Erde ausgeschnitten. Zu Hause wird dann auf einer kleinen runden Glasplatte eine geringe Quantităt dieser Erde mit ein wenig Wasser vermischt und so unter das Mikroskop gebracht: nach einiger Uebung bemerkt man dann bald an der eigenthümlichen Bewegung der Erd- und Sandkörnchen die Anwesenheit auch der kleinsten Arten, welche man mit einer feinen Nadel aufhebt und in einen Tropfen Wasser bringt, den man zuvor auf einen anderen Objektträger gebracht hat. Auf diese Weise ist man im Stande, eine grosse Zahl von Exemplaren in einem Tropfen zu vereinigen und in einer feuchten Kammer einige Tage für eine spätere Untersuchung auf zu heben, nachdem man den Tropfen mit einigen Erdkörnchen vermischt hat. Wenn man nun eine bestimmte Art untersuchen will, so bringt man das Thier wieder mittelst einer feinen Nadel in einen Tropfen Wasser auf einem anderen Objektträger, und bedeckt es dann mit einem dünnen Deckgläschen, das an einer oder zwei Seiten auf einem oder zwei anderen Deckgläschen ruht, damit das winzige Thierchen nicht zerquetscht werde. Darauf wird der Objektträger einen Augenblick über einer kleinen Alkohol- oder Oelflamme erwärmt, wodurch das Thier getödtet wird: nach einiger Uebung gelingt es öfters, dass der sterbende Wurm sich fast ganz gerade ausstreckt, wodurch es viel leichter ist, denselben abzuzeichnen. Um Letzteres auszuführen, wird das Exemplar an allen Theilen höchst genau mit dem Mikrometer gemessen und werden diese Maasse mit einer bestimmten Vergrösserung auf das Papier gebracht.

Die Untersuchung des süssen Wassers und des Brackwassers ist noch einfacher, weil man unsere Thiere bald zwischen den feinen Fäden der Conferven und Lemnaceen erspäht. Bekanntlich 
liegen diese Würmer immer auf einer lateralen. Seite: wenn man nun aber die dorsale oder die ventrale Seite beobachten will, so entfernt man die Deckgläschen, worauf das, den Wurm bedeckende Deckglăschen ruht, und erhălt dann die "gewünschte Lage durch eine kleine Verschiebung desselben.

Um die Thiere aufzuhellen, genügt es, dieselben in eine Lösung von Glycerinessigsäure zu bringen (2 Theile Glycerin $+11 \frac{1}{3}$ Theil Essigsäure). -

\section{ALLGEMEINE ORGANISATIONSVERHÄLTNISSE.}

Obgleich ich, wie schon aufgemerkt wurde, keine Gelegenheit hatte, anatomische oder histologische Untersuchungen anzustellen, so glaube ich doch, dass es nützlich sein werde, eine Betrachtung der allgemeinen Organisationsverhältnisse rorausgehen zu lassen.

Es haben bekanntlich die freilebenden Nematoden im Gegensatze zu denjenigen, welche als Parasiten leben, nur eine geringe Körpergrösse; unter den 143 in dieser Arbeit aufgeführten Arten überschreiten nur 4 die Grösse von $5 \mathrm{~mm}$; es sind alle Angehörige der Gattung Dorylaimus und zwar der regius, stagnalis, robustus und der elongatus. Die Zahl derjenigen, welche kleiner sind als $0,5 \mathrm{~mm}$. oder höchstens diese Länge erreichen, beträgt 12, und 103 Arten giebt es, welche zwar länger sind als $0,5 \mathrm{~mm}$, aber die Grösse von $2 \mathrm{~mm}$. nicht überschreiten. Für die Eintheilung nach der Körpergrösse verweise ich auf die Tabelle $B$ hin.

Im Allgemeinen haben unsere einheimischen, frei in der Erde und im süssen Wasser lebenden Nematoden eine mehr oder weniger ausgepragte schlanke Gestalt: bisweilen ist die Körperdicke im Verhältniss zur Länge gering, so dass der Körper fadenförmig ist, wie bei der hänfigen Bastiania gracilis, Dorylaimus elongatus, filiformis, oder umgekehrt verhältnissmässig bedeutend, so dass das Thier eine sehr plumpe Gestalt besitzt: Spilophora geophita, Choanolaimus, Cephalobus nanus, vexilliger, ciliatus und mehrere andere Arten. Bei der Mehrzahl verjüngt sich der Körper ziemlich stark sowohl nach vorn als nach hinten, bei einigen Formen aber nur sehr wenig, so dass er der ganzen Lănge nach denselben Durchmesser besitzt (Choanolaimus). Der Schwanz, der linter dem After gelegene Körpertheil, hat eine sehr wechselnde Länge und Gestalt und ist für jede Art characteristisch gebaut: entweder ist er sehr kurz, stumpf, kegelförmig oder abgerundet, oder er ist mehr verlängert, zugespitzt oder sogar fadenförmig. Selten hat er beim Männchen eine ganz andere Gestalt als beim Weibchen (Dorylaimus stagnalis, macrolaimus); bei einigen Gattungen (Rliabditis, Macroposthonia, Tylenchus) trăgt der Schwanz des Männchens eine "Bursa", welche beim Weibchen fehlt. Die Haut ist glatt oder quergefurcht: eine glatte Cuticula findet sich z. B. bei Monolystera, Mononchus, Trilobus, Ironus, Dorylaimus, eine quergefurchte bei Tripyla, Cyatholaimus, Cephalobus, Plectus, Tylenchus. Selten trifft man Arten mit gefurchter Cuticula bei einer Gattung, wo die Haut sonst glatt ist (Monolystera agilis). In den meisten Füllen werden 
die Hautringe durch Querlinien begrenzt; bisweilen lösen sich die letztern aber bei stärkerer Vergrösserung in Querreihen von runden oder mehr ovalen Punkten auf: Cyatholaimus ruricola, Chromadora Örleyi, Choanolaimus. Bei einigen Arten zeigen die Seitenfelder interessante Eigenthümlichkeiten der äusseren Bedeckungen. So sieht man bei Spilophora geophila zwei longitudinale Reihen von Körnchen längs jeder Seitenlinie, bei der häufigen Chromadora Leuckarti mehrere Längsreihen von reihenweise angeordneten Körperchen von länglicher Gestalt (Taf. VIII, fig. :30c) und beim Choanolaimus sind die Körperchen auf den Seitenfeldern grösser als am übrigen Körper, und wechseln mit einer zweiten Reihe auf der Mitte jedes Ringes ab, welche auf den Seitenfeldern fehlt (Taf. X, Fig. 42c). Aehnliche Verhältnisse trifft man bei Teratoceplatus crassidens und palustris an. Selten ist die Cuticula schön längsgestreift, wie bei Aulolaimus und Tylopharynx; ebenso zeigen die verhältnissmåssig breiten Seitenfelder des Aphelenchus agricola eine feine Längsstreifung.

Bei vielen finden sich Seitenmembranen, bei anderen fehlen dieselben vollständig, so bei Monoliystera, Tripyla, Mononchus, Tylencholaimus, Dorylaimus. Ziemlich allgemein verbreitet sind dieselben bei den Gattungen Cephalobus, Plectus und Tylenchus; ihre relative Breite ist bei den einzelnen Arten verschieden: nicht selten sind sie schwer zu unterscheiden. Bei dem sich träg bewegenden Tylenchus lamelliferus unserer Wiesen trägt die Cuticula, ausser zwei Seitenmembranen, noch vier submediane, über den ganzen Körper hinlaufende, vorspringende Membranen, worauf sich die Querringel der Haut fortsetzen. Eigenthümliche lamelläre hautartige Ausbreitungen finden sich am Kopfende bei Plectus auriculatus und otophorus. Nicht selten trägt die Cuticula feine Borsten, welche meist in vier, den Submedianlinien entsprechenden Reihen stehen, wie bei einigen Monohysteren, und Cliromadora bioculata; in anderen Fällen stehen sie mehr zerstreut und bei dem häufigen Chromadora Leuckarti beobachtet man in geringer Entfernung hinter dem Kopfende vier längere Börsten. Ebenso bei Tripyla monohystera. Bei einigen Gattungen fehlen die Borsten immer, z. B. bei Dorylaimus.

Zu den Sinnesorganen rechnen wir die Augenflecke und die Seitenorgane. Die ersteren fand ich nux bei vier Arten, von welchen zivei (Monohystera paludicola und Chromadora bioculata) das süsse Wasser bewohnen, die zwei anderen in der fenchten Erde an Pflanzenwurzeln leben (Monohystera microphthalma und Chromadora Örleyi); beim M. paludicola ist der Augenfleck unpaar, mit zwei Linsen versehen, bei den drei anderen aber sind die Augenflecke paarig. Dieselben kommen also nur sehr selten, sogar bei den im süssen Wasser lebenden, vor.

Die Seitenorgane, deren functionelle Bedeutung noch immer räthselhaft ist und welche Bütschli als die Homologa der Halspapillen vieler parasitischen Nematoden betrachtet, kommen in verschiedenen Formen bei vielen Arten vor, felllen aber wieder bei anderen, wie z. B. den Cephaloben und Tylenchen.

In den meisten Fällen sind diese Organe, welche in geringer Entfernung hinter dem Kopfende liegen, kreisrund oder elliptisch (Monolystera, Plectus, Odontolaimus, u. a.), und bisweilen mit einem centralen dunklen Flecke versehen (Monoliystera vulgaris, filiformis). Beim Aphanolaimus sind sie auffallend gross, oval und so breit, dass sie fast die ganze Breite des Kopfendes einnehmen; auch sind sie 
hier sehr nach vorn gerückt. Diplogaster rivalis, der unsere süssen Gewässer bewohnt, hat die Seitenorgane beim Månnchen gross, oval, hervorragend, beim Weibchen viel kleiner, rinnenförmig. Bei unseren, in der Erde lebenden Cyatholaimen sind dieselben meist spiralisch, ebenso bei dem, die Dünengegenden bewohnenden Choanolaimus. Die beiden Prismatolaimen haben linienförmige Seitenorgane und bei den Rhabdolaimen sind sie so klein, dass man sie erst in der Profilansicht beobachtet. Bei Tripyla kommen gleichfalls Homologa dieser Seitenorgane vor; bei einigen Arten beobachtete ich in der Medianansicht, in geringer Entfernung vom Kopfende, feine Linien in schräger Richtung vom Integument ausgehend (Taf. $V$, fig. $20 \mathrm{~b}$ und $21 \mathrm{~b}$ ).

Bei den Dorylaimen liegen allgemein an der Uebergangsstelle der abgesetzten Kopfregion in den Körper, eine Art laterale Halspapillen, welche auch Bütschli schon beim D. stagnalis erwähnt (Beiträge, pag. 25), welche man aber erst in der Profilansicht zu Gesichte bekommt: beim D. primitivus u. a. A. sah ich bei dieser Ansicht eigenthümliche blasse Gebilde aus denselben hervortreten (Taf. XXTV, fig. 103a, 103e). Vielleicht sind alle diese Organe einander homolog.

Das vordere Körperende, an dessen Ende die Mundöffnung liegt, ist entweder nackt und unbewaffnet, oder mit Borsten, Lippen oder Papillen ansgestattet. Gänzlich unbewaffnet ist es bei den Gattungen Alaimus, Microlaimus, Macroposthonia, Rhabdolaimus und bei einigen Angehörigen der Gattungen Rhabditis und Tylenchus; häufig aber ist dann der vorderste Theil des Kopfendes durch eine geringe Einschnürung von demselben abgetrennt. In anderen Fällen ist das Kopfende mit einem Kranze von zwei, drei oder sechs Lippen bewaffnet, welche aber continuirlich in den Körper übergehen: bei den Dorylaimen ist dieser lippentragende Theil dureh eine Einschnürung vom Körper abgetrennt. Wåhrend diese Lippen fast immer unbeweglich sind, macht die eigenthümliche Gattung Ironus hiervon eine bemerkenswerthe Ausnahme: die drei Lippen sind hier beweglich und können sich nach aussen umstülpen. Ganz abwaichend gebildete Kopfenden zeigen die Teratocephalen und einige Plecti und Cephaloben.

Bisweilen sind die Lippen aber sehr wenig entwickelt, rudimentär und stellen sich als kaum bemerkbare Vorsprünge dar, wie z. B. bei Monohystera filiformis, und manchen Arten der Gattungen Aphelenchus, Tylenchus, Plectus und Dorylaimus. Hånfig sind sie mit "Papillen" in einem, zwei oder drei Kreisen bewaffnet: Tripyla, Mononchus, Choanolaimus und bei vielen Arten der Gattungen Cephalobus, Dorylaimus u. s. w. - Nicht selten treten, statt der Papillen, steife Borsten auf, wie bei manchen Tripylen, und man sieht hieraus, was schon Bütschli bemerkte, dass Papillen und Borsten Gebilde sind, welche in einander übergehen. Eine sehr schöne Entwickelung zeigen die Borsten bei Cephalobus ciliatus (Taf. XV, fig. 61). Bei vielen Formen beobachtet man am Kopfende, gleichviel ob es mit Papillen ausgestattet ist oder nicht, feine Borsten, deren 6 oder 10 in einem Kreise die Mundöffnung umgeben: so bei Monolystera, Cyatholaimus, Chromadora, Plectus, u. s. w.; bei anderen aber, wie Dorylaimus, Mononchus, Tylenchus, Cephalobus, findet sich nichts dergleichen.

Die Mundôffnung führt entweder gleich in das Lumen des Oesophagus oder erst in ein „Vestibulum", das mit der Mundhöhle communicirt, oder in die Mundhöhle selbst. Das erstere findet z. B. statt 
bei der häufigen Bastiania gracilis; man sieht den Streifen, der das Oesophageallumen bezeichnet, ununterbrochen bis zum vorderen Kopfrande fortlaufen. Auch bei den höher entwickelten Tripylen, deren Kopfende mit kräftigen, Papillen und Borsten tragenden, Lippen ausgestattet ist, fehlt eine Mundhöhle, und der Oesophagus läuft bis an die Lippen fort: bezeichnend für diese Gattung ist eine locale Verdickung der Chitinintima des Oesophagus mit zahnartigem Vorsprung in einiger Entfernung hinter der Mundoffnung (Vergl. Taf. IV, fig. 1\%a, 18a), welche Verdickung aber bei den auch in anderen Beziehungen von den typischen Arten abweichenden Tripyla monohystera und arenicola nicht gefunden wird.

Bei den meisten Gattungen aber kommt eine Mundhöhle in grösserer oder kleinerer Ausdehnung vor.

Sehr klein, schüsselförmig ohne irgend eine Bewaffnung ist die Mundhöhle bei den Monohysteren, wo dieselbe sich in das spaltförmig geöffnete Chitinrohr des Oesophagus fortsetzt (Vergl. z. B. Taf. III, fig. 11a). Die Mundhöhle der Desmolaimen (Taf. VI, fig. 23a) unterscheidet sich von derjenigen der genannten Gruppe durch das Auftreten von drei concentrischen parallelen, kreisförmigen, chitinösen Verdickungsleisten, von welehen die innere am Boden der Mundhöhle hin verläuft.

Bei anderen Gruppen ist die Mundhöhle, obwohl immer noch einfach und unbewaffnet, grösser und mit stärker chitinisirten Wänden versehen, und zwar becherförmig bei Trilobus, trichterförmig bei Choanolaimus, kurz prismatisch bei Prismatolaimus, verlängert prismatisch bei Cylindrolaimus. Die dreiseitige röhrenförmige Mundhöhle der Cephaloben ist durch das Auftreten von mehreren localen Verdickungen der Wand characterisirt (Vergl. z. B. Taf. XII, fig. 55a), und auch die Plecti und die âchten Rhabditiden haben eine dreiseitige, röhrenförmige, mit starken Chitinwänden versehene Mundhöhle, welche bei den erstgenannten meist in der Mittellinie etwas verengt ist. Die Mundhöhle der Leptolaimen ist derjenigen der Cylindrolaimen ähnlich, aber ihre Wände sind viel dünner und weniger stark chitinisirt. Eine sonderbare Gestalt erhält dieselbe bei der Gattung Aulolaimus, wo die Mundhöble ausserordentlich verlängert, dünn und röhrenförmig ist, sodass ihre Länge diejenige des eigentlichen Oesophagus weit übertrifft. Bei der kleinen Gruppe der Rhabdolaimen endlich ist die Mundhöhle ebenso sehr verlängert, sehr enge, von drei dünnen chitinösen Stäben begrenzt, welche nach hinten $\mathrm{zu}$ ein wenig convergiren, und je an ihrem Vorderende mit einem kleinen hakenförmigen Körperchen im Zusammenhange stehen.

Die Gattung Sphaerolaimus, von welcher eine Art im Meere, die zweite aber an den Wurzeln von Pflanzen lebt, welche am Ufer von Brackwassergräben wachsen, hat eine geräumige Mundhöhle, deren chitinöse Wände mit vielen localen Chitinverdickungen versehen sind, und bildet deshalb einigermassen den Uebergang zu denjenigen Gattungen, bei welchen die Mundhöhle mit einem oder mehreren, beweglichen oder unbeweglichen, zahnartigen Vorsprüngen gewaffnet ist.

Am einfachsten verhält sich der omnivage Cyatholaimus tenax, dessen sehr kleine, becherförmige Mundhöhle mit einem kaum bemerkbaren zahnartigen Vorsprunge gewaffnet ist; er führt zu den drei anderen erdbewohnenden Cyatholaimen herüber, bei welchen dieselbe viel grösser, aber gleichfalls becherförmig 
ist und einen deutlichen dorsalen Zahn trägt, während die Winde des vorderen Theiles mit longitudinalen Verdickungen versehen sind. Aehnlich, aber ohne diese Verdickungen hat sie die Gattung Microlaimus. Viel kürzer ist die Mundhöhle der Spilophoren und Chromadoren, welche einen dorsalen Zahn am Boden besitzen, wăhrend die Wände (wenigstens bei unseren erdbewohnenden Arten) locale Chitinverdickungen zeigen: an dieselben schliesst sich Ethmolaimus an, aber hier liegt noch ein verlängert prismatischer Theil zwischen dem zahntragenden, schüsselförmigen vorderen Theile und dem Oesophageallumen. Eine grosse gerïumige, sechsseitige, stark chitinisirte Mundhöhle mit einem kräftigen unbeweglichen Zahne in der dorsalen Kante, besitzt Mononchus, während noch ein kleines „Vestibulum" zwischen ihr und der Mundöffrung liegt; Mononchus tridentatus, wo die Mundhöhle mit drei gleich grossen Zähnen bewaffnet ist, führt zu der Gattung Oncholaimus, deren Mundhöhle drei nach vorn gerichtete, mehr oder weniger ausgebildete, zahnartige unbewegliche Vorsprünge zeigt. Ganz eigenthümlich verbält sich Odontolaimus: hier leitet die Mundöffnung in ein kurzes, dünnwandiges Vestibulum, dann in die Mundhöhle; diese ist sehr langgestreckt und enge, nach hinten allmählich verjüngt, mit chitinisirten Wänden; am Vorderende befindet sich ein dreieckiger, dorsal und median gestellter chitinöser Zahn.

Wåhrend bei allen diesen Gattungen die zahnartigen Vorsprünge unbeweglich sind, machen Ironus und die zwei in meinem Werke aufgeführten Diplogaster-Arten hiervon eine bemerkenswerthe Ausnahme. Bei Ironus ist die Mundhöhle sehr verlängert, röhrenförmig, mit chitinisirten Wänden, und an ihrem Beginn liegen drei gebogene, hakenförmige Zähne, welche durch eine Ausstülpung der beweglichen Lippen nach aussen getrieben werden können. Bei einer Diplogaster-Art findet sich ein, bei der zweiten zwei bewegliche Zähne, welche klaffend bewegt werden.

Ausser den genannten Gruppen, giebt es noch mehrere, theilweise sehr artenreiche Gattungen, bei welchen die Mundöfnung in ein meist sehr kleines Vestibulum führt, worin Stachelbildungen liegen, deren Lumen die Mundhöhle vertritt. Bei der seltenen Gattung Tylopharynx beobachtet man im Kopfende, drei an ihrem Hinterende in Chitinkugeln auslaufende Chitinstäbe, welche nach vorn hin convergiren und ein Lumen umschliessen, das nach hinten unmittelbar mit dem Oesophageallumen zusammenhängt: dieses Lumen betrachte ich als die Mundhöhle. Aehnliche Verhaltnisse bieten, wie es scheint, die Gattungen Diphtherophora und Tylolaimophorus, aber ihre Untersuchung ist sehr schwer. Aus der, bei Tylopharynx bestehenden Einrichtung muss der Stachel der Tylencholaimen abgeleitet werden: dieser besteht ans drei, vorn sich vereinigenden, hinten aber geknöpften und ein deutliches Lumen umschliessenden Chitinståben, welche vorn von einem kleinen Vestibulum umgeben werden: das Lumen stellt wieder die Mundhöhle dar.

Bei den Aphelenchen und Tylenchen haben sich die drei Chitinstäbe einander so genähert, dass man kein Lumen mehr zu beobachten im Stande ist, obwohl es doch vorhanden sein muss, da sonst die Nahrungsaufnahme unbegreiflich wäre. Bei den Aphelenchen fehlen nicht selten die hinteren Knöpfe, worin die Stäbe auslanfen. Ein kleines Vestibulum umgiebt bei beiden Gattungen diesen Stachel, dessen Länge und Dicke bei den einzelnen Arten sehr verschieden ist. 
So kommen wir schliesslich zu der letzten Gattung, der artenreichen Gruppe der Dorylaimen, deren Stachel selten die Form einer Nadel ( $D$. elongatus, maximus), meistens die einer Gănsefeder besitzt und ein deutliches Lumen hat, das die Mundhöhle vertritt, sich nach hinten in den Oesophagus fortsetzt, und an der Spitze in ein Vestibulum ausmündet, welches bei den meisten Arten sich als ein enger, röhren- oder becherförmiger, den vorderen Theil des Stachels umschliessender Raum darstellt. Am Boden dieses Vestibulums, dessen Wånde sehr dünn sind, ist die Chitinhaut in Gestalt eines Ringes etwas verdickt und von diesem geht eine zarte Membran zum Stachel, welche den letzteren in seinen kleinen Bewegungen nach vorne hin zurückhält. Bei zwei Arten (D. macrolaimus und rotundicauda) ist das sonst sehr enge Vestibulum sehr gross und breit und mit starken chitinisirten Wänden bekleidet, welche locale Verdickungen zeigen.

Der folgende Theil des Verdauungstractus wird, wie bekannt, durch den Oesophagus gebildet, welcher sich bei den einzelnen Gattungen verschieden gestaltet. Im Allgemeinen ist sein Lumen enge und von chitinisirten Wänden bekleidet; dasselbe wird aber von einer mehr oder weniger dicken Muskelschicht umgeben, welche in den meisten Fällen von radiär verlaufenden Muskelfibrillen gebildet wird. Er ist entweder cylindrisch oder stellenweise dicker; einen cylindrischen Oesophagus finden wir z. B. bei Mononchus, obwohl er auch hier nach hinten zu meistens etwas dicker wird. Bei vielen Arten ist er an seinem hinteren Ende angeschwollen, ohne ein erweitertes Lumen in dieser Anschwellung zu besitzen (z. B. Odontolaimus, Tylolaimophorus); in anderen Fallen ist das Lumen in diesem angeschwollenen Theile erweitert und geräumiger und bildet dann einen sogenannten Bulbus, z. B. bei Microlaimus, Spilophora, Chromadora; bei wieder anderen, (Tylenchus) hat der Oesophagus einen Bulbus in seiner Mitte, während er am hinteren Ende von neuem angeschwollen ist. Bei den Cephaloben, Teratocephalen, Plectiden und ächten Rhabditiden trägt der am Hinterende liegende Bulbus einen mehr oder weniger complicirten Klappenapparat. Bei den Dorylaimen ist der hintere Theil des Oesophagus auf eine grössere oder kleinere Strecke hin verdickt. Bisweilen liegen an der Uebergangsstelle des Oesophagus in den Darm Drüsen, wie z. B. sehr ausgeprägt bei den Tripylen. . Der Darm wird gewöhnlich von Zellreihen gebildet, welche mehr oder weniger deutlich zu erkennen und mit grösseren oder kleineren Körnchen ausgefüllt sind; bei einigen findet sich ein eigener Enddarm, wie z. B. bei Dorylaimus.

Gehen wir jetzt zu einer Betrachtung der Geschlechtsorgane über. Die in diesem Werke heschriebenen Arten sind alle getrennten Geschlechtes; es ist mir keine hermaphroditische vorgekommen. Bei den Männchen können wir von inneren und üusseren Geschlechtsorganen sprechen, obwohl die letzteren öfters fehlen, während die Weibchen in den meisten Fällen keine oder nur negative äussere Merkmale haben.

Bei den Männchen bestehen die inneren Geschlechtsorgane aus der Geschlechtsdrüse, welche entweder ein- oder zweitheilig ist, und, zusammen mit dem Darme, in eine Kloake ausmündet, welche durch den After nach aussen correspondirt. Ist der Hoden einfach, so stellt er einen einfachen Schlauch dar, der mehr oder weniger weit nach vorn reicht; so z. B. bei vielen Monohysteren und Cephaloben. In anderen Fällen ist er symmetrisch zweitheilig, und seine Aeste sind nach vorn und 
hinten gerichtet, wie bei Tripyla, Dorylaimus. Es giebt immer zwei Spicula, welche öfters von einem oder zwei sogenannten accessorischen Stücken begleitet werden. Die Grösse und Gestalt dieser Organe ist für die einzelnen Gattungen und Arten characteristisch; während sie meist einfacher Natur sind, treten sie bei einigen Formen mehr complicirt auf. So zeigen die Spicula von Ironus und der meisten Dorylaimen eigenthümliche Streifen, welche ich als locale Verdickungen betrachte und deren Zahl und Verlauf gute Artmerkmale abgeben. Wir kommen später natürlich bei den Gattungs- und Artbeschreibungen ausführlicher auf diese Organe zurück.

Die äusseren männlichen Geschlechtsorgane fehlen bei mehreren Formen, wie bei vielen Monohysteren, Chromadora bioculata, und Microlaimus; - aber bei der Mehrzahl kommen dieselben vor. So trifft man bei vielen Gattungen praänale Papillen an, welche entweder in der Medianlinie der Bauchseite oder in zwei Reihen mehr lateralwärts liegen; auch finden sich öfters ausserdem noch postanale Papillen, welche also auf dem eigentlichen Schwanz liegen. Bloss präanale und zwar mediane Papillen findet man z. B. bei den Gattungen Alaimus, Bastiania, einigen Chromadoren, und den meisten Dorylaimen. Bei der Gattung Deontolaimus liegen mehrere mediane Papillen in einer Längsreihe an der vorderen ventralen Körperfläche. Praänale und postanale Papillen trifft man z. B. bei Mononchus und Plectus an. Bei einigen Formen (Aphanolaimus, Leptolaimus und Plectus) finden sich eigenthümliche präanale, in der Medianlinie der Bauchseite gelegene Organe: chitinisirte Ausfuhrröhren von Drüsen; bei der zweiten Gattung liegen ausserdem vor diesen noch andere Papillen. Bei Ironus steht gleich bei und vor dem After eine einzelne steife Borste. Bei den Diplogaster-Arten beobachtet man ebenso prä- und postanale Borstenpapillen, deren Lage bezeichnend ist für die Art. Die männlichen Tylenchen und auch die Gattung Macroposthonia besitzen eine Bursa; diese kommt auch den ächten Rhabditiden zu und trägt hier mehrere für die Art characteristische Papillen. Schliesslich fügen wir noch hinzu, dass der Schwanz des Männchens oft eine andere Gestalt und eine andere Länge hat als der des Weibchens.

Wăhrend die Ausmündungsöffnung der männlichen Geschlechtsorgane mit dem After zusammenfällt, haben die weiblichen Genitalien eine eigene Ausmündungsöffnung, welche in den meisten Fällen mehr oder weniger der Körpermitte genähert ist. Die weiblichen Geschlechtsorgane sind entweder symmetrisch zweitheilig oder unpaar angelegt. Das erstere findet z. B. bei den meisten Dorylaimen, bei den Gattungen Plectus, Desmolaimus, Spilophora, Chromadora, Oncholainus statt: die Vulva liegt dann mehr oder weniger in der Mitte und die 0varien sind entweder zurückgeschlagen, wie meistens der Fall ist, oder dieselben strecken sich in ihrer ganzen Länge nach vorn und nach hinten aus, ohne zurückgebogen zu sein, wie z. B. bei der Gattung Desmolaimus (Taf. VI, fig. 23). Thre relative Ausdehnung ist bei den einzelnen Arten sehr verschieden, wie z. B. aus einer Vergleichung von Dorylaimus pratensis (Taf. XXVII, fig. 114) mit Dorylaimus Leuckarti (Taf. XXIX, fig. 121) hervorgeht. Bisweilen ist der Uterus mit kräftiger Ringmuskulatur versehen, wie bei den Gattungen Ironus und Trilobus. Bei vielen Arten sind die weiblichen Genitalien unpaar und liegen an einer Seitc der Vulva, welche bei diesen Thieren mehr oder weniger von der Körpermitte entfernt liegt. So 
ist sie bei den meisten Monohysteren, bei den unächten Tripylen (Tripyla monolystera und arenicola), bei vielen Tylenchen und Aphelenchen, u. s. w., mehr oder weniger nach hinten gerückt und die Geschlechtsröhre streckt sich dann nach vorn hin aus. Sehr weit nach hinten liegt die Vulva z. B. bei dem winzigen Tylenchus macroplatlus (Taf. XXIV, fig. 102). Das Ovarium kann auch bei diesen Formen zurückgeschlagen sein oder nicht, und nicht selten ist der Uterus mit einem hinteren Ast ausgestattet, wie besonders bei den Aphelenchen der Fall ist (Taf. XXI, Fig. 90). Bei anderen ist die weibliche Geschlechtsöffnung mehr nach vorn gerïckt und die Geschlechtsröhre streckt sich nach hinten aus (z. B. bei Tylencholaimus Zeelandicus und Dorylaimus ïmnophilus).

Nur zwei Arten sind vivipar: es sind Diplogaster rivalis aus dem süssen Wasser unserer Gräben und der seltene Cephalobus filiformis aus der feuchten Erde.

Die Zahl der producirten Eier ist sehr gering; es werden nur ein, zwei oder bis vier Eier entwickelt, selten eine grössere Zahl (Dorylaimus superbus und crassus). Wo sich nur ein einziges Ei entwickelt, wird dasselbe bei einigen Formen sehr gross, z. B. bei Tylencholaimus minimus, Cephalobus nanus, Cyatholaimus ruricola. Die Eier sind meist oval mit glatter Schale, selten wie beim Plectus granulosus unserer Wiesen, mit Stacheln bedeckt (Taf. XVI, fig. 65).

Zum Schluss wollen wir noch einen Blick werfen auf den sog. Gefässporus und auf die Schwanzdrüse. Der Gefässporus ist eine bei mehreren Gattungen, wie Cephalobus, Plectus, Tylenchus, Aphelenchus, in der ventralen Medianlinie der vorderen Körperhälfte vorkommende Ausmündungsöffnung, und zwar meist der zwei Seitengefässe, deren es übrigens bei den Tylenchen nur ein einziges geben soll. Bei Plectus soll es nach Bütschli mehr die Ausfuhröffnung einer Art Ventraldrüse sein, welche aus vielen, den Oesophagus umgebenden Zellen bestehen soll. Der Ausfuhrkanal hat auch bei dieser Gattung einen viel verwickelteren Verlauf als bei den anderen, nach welcher Eigenschaft sie ihren Namen empfangen hat. Bei den meisten liegt der Getässporus vor dem hinteren Ende des Oesophagus, nur bei Aphelenchus liegt er hinter dem Ende; seine Lage ist für die einzelnen Arten characteristisch.

Die Schwanzdrüse liegt in dem Schwanze und mündet an dessen Ende meist durch eine eigene Ausfuhrröhre aus, wobei sie ein Secret ausscheidet, wodurch das Thier sich an anderen Objekten fest zu kleben im Stande ist. Während sie bei vielen Gattungen (wie Monohystera, Tripyla, Plectus) vorkommt, fehlt sie wieder bei anderen (Mononchus, Dorylaimus). Die Ausfuhrröhre ist bisweilen für die Art bezeichnend, wie z. B. für die beiden Arten der Gattung Rhabdolaimus.

\section{OERTLICHE UND ZEITLICHE VERBREITUNG IN DEN NIEDERLANDEN.}

Wie es mit mehreren Deltaländern grosser Flüsse der Fall ist, findet man auch in meinem Vaterlande, ungeachtet seiner geringen Grösse, mehrere Grundarten, welche, in Bezug auf ihrer Zusam- 
mensetzung und die, auf ihnen wachsenden Pflanzen, unter einander grosse Verschiedenheiten aufweisen. Es wird deshalb nothwendig sein, diese verschiedenen Grundarten und Gewässer, so viele von mir untersucht worden sind, etwas näher zu betrachten. Ein grosser Theil der zwei westlichen Provinzen, Nord- und Süd-Holland, wird von niedrigen Wiesen gebildet, welche von zahllosen grösseren und kleineren Flüssen, Kanälen und Gräben von süssem Wasser durchschnitten werden; die Flora dieser aus reinem Thonboden bestehenden Wiesen besteht hauptsächlich aus grasartigen Pflanzen, Gramineen, von welchen zahlreiche Arten sehr häufig sind: aber zwischen diesen Gräsern wachsen auch andere Pflanzen, Ranunculaceen, Trifolium-Arten, Plantago, Compositen und viele anderen. An den Ufern der Flüsse und Gräben findet man aber auch noch andere Gewächse, welche auf den Wiesen weniger håufig vorkommen oder sogar gänzlich fehlen.

Meine Untersuchungen zeigen nun, dass, ausser den omnivagen Nematoden, unter welchen ich diejenigen verstehe, welche zwar nicht im süssen Wasser oder in Brackwasser leben, aber sich übrigens in allen Bodenarten der Niederlande finden, es noch viele andere Arten giebt, welche ausschliesslich in diesem feuchten reinen Thonboden vorkommen, und nicht in den trockneren und sandigern Dünen- oder Heidegegenden angetroffen werden. Ich will diese Arten als Wiesennematoden unterscheiden, aber zu gleicher Zeit bemerken, dass es unter diesen einige giebt, welche die eigentlichen Wiesen, andere, welche die Ufer der Kanäle und Gräben vorziehen, während die übrigen sich in Bezug hierauf gleichgültig verhalten. Verlassen wir diese niedrigen Wiesen und Marschgründe, und begeben wir uns in die schönen Dünengegenden, welche die Niederlande gegen die Nordsee beschützen, so finden wir am Fusse dieser Sanddünen ausgedehnte Felder, wo der Boden mit vielem Sand vermischt ist und eine eigenthümliche Flora wächst: hier leben der Sanddorn, Hippophae rhamnoides, eine Art von Lieschgras, Phleum arenarium, von Hauhechel, Ononis repens, von Veilchen, Viola hirta, von Wiesenraute, Thalictrum minus, von Fetthenne, Sedum purpurascens und acre, von Labkraut, Galium verum, von Kreuzwurz, Senecio Jacobaea und zahlreiche andere Arten. An den Wurzeln dieser Pflanzen in jenem sandigern Boden leben ebenso sehr viele Nematoden, von welchen viele zu den Omnivagen gehỏren, andere aber für diesen sandigen Boden eigenthümlich sind, weshalb ich dieselben mit dem Namen Sandnematoden bezeichnen werde.

Weniger genau wurden die Waldgegenden von mir erforscht: dieselben scheinen aber keine eigenthümliche Nematodenfauna zu besitzen, und die in diesem Boden lebenden Arten findet man auch in den anderen Gegenden.

Auch die hochgelegenen Heideländer der östlichen Provinz Gelderland, welche mit zahllosen Heidegewächsen, als Calluna vulgaris und Erica tetralix bedeckt sind, werden, ausser von omnivagen Arten, besonders von Sandnematoden bewohnt: nur eine Art, der Tylolaimophorus, scheint für diese Gegenden eigenthümlich zu sein.

Im Süden der Niederlande fliesst der Scheldefluss ins Meer. Dieser Fluss, welcher aus Belgien kommt, und sich, bis vor wenigen Jahren, bei seiner Ausmündung in zwei Aeste theilte, bildet mit anderen Flüssen ein, aus mehreren Inseln bestehendes Deltaland, woraus die Provinz 
Zeeland besteht. Die westlichste ans Meer grenzende Insel Walcheren wird von mehreren Kanälen und Wassergräben durchschnitten, welche alle mehr oder weniger mit dem Meere in Verbin. dung stehen: süsses Wasser giebt es dort nicht; alle Gräben und Kanäle, welche diese Insel durchschneiden, sind mit Brackwasser gefüllt. Sowohl in diesem Brackwasser als an den Ufern der von diesem Wasser befeuchteten Wiesen wächst eine eigenthümliche Flora: in dem Wasser der Wasserriemen, Zostera marina und ein Paar Arten von Hahnenfuss, Batrachium Baudoti und Petiveri, am Ufer u. a. der blaue Strahlen tragende Aster 'Tripolium, die Artemisia maritima, die Salicornia herbacea und viele andere aehnliche Gewächse. An den Wurzeln dieser Uferpflanzen leben, wieder ausser den omnivagen Arten, mehrere höchst interessante Nematoden, welche man weder im Meere, noch in den anderen Gegenden der Niederlande antrifft, und welche ich deshalb Brackwassernematoden nennen werde (als Abkürzung von Brackwassererde-Nematoden), weil sie in von Brackwasser befeuchteter Erde leben. Zweifelsohne leben diese Arten auch überall dort in unserem Lande, wo dieselben Verhältnisse auftreten.

Ausser der Erde untersuchte ich noch die Süsswasserfauna: auch im süssen Wasser leben mehrere Arten, welche sich nie in die Erde zu begeben scheinen; aber ausser diesen ächten Süsswassernematoden, beobachtete ich hier nicht selten Arten welche gewöhnlich in der Erde leben, obgleich ihre Zahl eine sehr geringe ist.

Es scheint also, dass man die in den Niederlanden frei in der Erde und im süssen Wasser lebenden Nematoden unter die fünf folgenden Categorien eintheilen kann:

A. Omnivage Arten.

$B$. Wiesennematoden.

C. Sandnematoden.

D. Brackwassernematoden.

$E$. Süsswassernematoden.

Obgleich ich in Bezug auf das Vorkommen aller von mir beobachteten Arten auf Tabelle A. hinzuweisen mir erlaube, will ich schon jetzt einige der hăufigsten und am meisten characteristischen Arten aus jeder dieser fünf Gruppen erwähnen:

Zu den häufigsten omnivagen Nematoden gehören:

Monohystera simplex.

, filiformis.

Bastiania gracilis.

Teratocephalus terrestris.
Cephalobus oxyuroides.

Plectus granulosus.

Rhabdolaimus terrestis.

Tylenchus filiformis.

Dorylaimus obtusicaudatus.

Zu den häufigsten Wiessennematoden rechne ich:

Monohystera macrura.

Cyatholaimus intermedius.

tenax.
Plectus cirratus.

Diphtherophora communis.

Dorylaimus brigdammensis. 
Chromadora Leuckarti.

Dorylaimus longicaudatus.

Prismatolaimus intermedius.

Die am meisten characteristischen Sandnematoden sind etwa die folgenden:

Tripyla arenicola.

Mononchus parvus.

Choanolaimus psammophilus.

Plectus parietinus.
Plectus auriculatus.

Tylolainophorus typicus (Heideboden).

Dorylaimus bryoplitus.

" rotundicauda.

Die bis jetzt bekannt gewordenen Brackwassernematoden sind die folgenden:

Deontolaimus papillatus.

Monohystera miorophthalma.

Desmolaimus Zeelandicus.

Microlaimus globiceps.

Spilophora geophila.
Chromadora Orleji.

Oncholaimus thalassophygas.

Sphaerolaimus gracilis.

Leptolaimus papilliger und

Tylencholaimus Zeelandicus.

Die häufigsten süsswassernematoden schliesslich sind:

Monolystera paludicola.
,$\quad$ similis.

Chromadora bioculata.

Diplogaster rivalis.

fluviatilis.
Plectus tenuis.
palustris.
Rhabdolaimus aquaticus.
Dorylaimus stagnalis.
$\quad$ filiformis.

Mit dem oben Gesagten glaube ich genügend die bemerkenswerthe Thatsache in 's Licht gestellt zu haben, dass die frei in der Erde und im Wasser lebenden Nematoden zum grossen Theile an bestimmte Bodenarten und an süsses Wasser gebunden sind, für welche Thatsache vorlăufig keine Erklärung zu geben ist. Nur in Bezug auf die Brackwasserformen habe ich schon in einer früheren Abhandlung ${ }^{2}$ ) mitgetheilt, dass ich überzeugt bin, dass diese Arten sich aus verwandten, das Meer bewohnenden Formen entwickelt und sich dem neuen Medium angepasst haben.

Ja sogar von einigen Wiesennematoden muss ich diese Entwickelung aus marinen Arten annehmen, z. B. von den sehr häufigen Chromadora Leuckarti und Cyatholaimus intermedius, welcher letztere dem Cyatholaimus dubiosus Btsli, der in einigen Faden Tiefe die Kieler Bucht und deren Strandzone bewohnt, so sehr verwandt ist, dass ich in meiner ersten Abhandlung den, in der Erde lebenden Cyath. intermedius als mit dem im Meere sich aufhaltenden dubiosus identisch betrachtete. Uebrigens ist es meiner Meinung nach jetzt noch unmöglich, den phylogenetischen Stammbaum der freilebenden aufzustellen, weil uns nicht allein die marinen Arten noch sehr ungenügend bekannt sind, sondern wir ausserdem die landbewohnenden Arten in anderen Welttheilen überhaupt nicht kennen. Auch

1) Onderzoekingen over vrij in de aarde levende Nematoden, in: Tijdschr. der Nederl. Dierk. Vereen., Deel II, pag. $162 \mathrm{u.f.}$ 
eine Gruppirung in Familien sogar, wie ich zu voreilig in meiner ersten Abhandlung vorzunehmeu versuchte, muss derselben Ursache wegen vorläufig unterbleiben.

Ich muss aber im Gegentheile auf eine andere bemerkenswerthe Erscheinung aufmerksam machen, nämlich auf die Thatsache, dass einige Arten äusserst häufig vorkommen und fast in jedem Rasen angetroffen werden, während andere sehr selten sind und uns daher nur zufällig unter die Augen kommen. Während man darauf rechnen kann, in jedem feuchten Rasen Exemplare von Monohystera simplex, Plectus granulosus zu finden, trifft man andere Arten nur sehr zufällig an, sodass es fast vergeblich ist, dieselben absichtlich auf zu suchen. So fand ich während der Jahre als ich mich mit diesen Studien beschäftigte, nur einmal den Dorylaimus macrodorus, obgleich in zahlreichen Exemplaren. Zu diesen sehr seltenen Arten gehören weiter noch Ethmolaimus pratensis, Aulolaimus oxycephalus, Cephalobus longicaudatus und filiformis, Plectus Schneideri, Rhabditisfiliformis, Macroposthonia annulata, Apheienchus modestus und helophilus, Dorylaimus regius und mehrere andere Arten dieser letzten Gattung.

Gerade so auffallend ist die Erscheinung, dass, indem bei unseren Thieren die Geschlechter getrennt sind, bei einigen die beiden Sexen gleich häufig angetroffen werden, während man bei anderen die Männchen oder die Weibchen äusserst selten beobachtet, ja sogar bei vielen noch gar nicht aufgefunden hat, und dass diese Erscheinung bei gewissen Gattungen auftritt. So kamen mir von allen Tylenchus-Arten die beiden Geschlechter gleich häufig vor, während von den dreizehn Plectus-Arten, welche in den Niederlanden leben, die Männchen von nur zwei Arten gefunden wurden, nämlich des omnivagen granulosus, dessen Männchen eben so häufig ist als das Weibchen, und des, in der Wiesenerde lebenden cirratus, von welchem das Männchen nur einmal von mir beobachtet ist. Besonders in der Gattung Dorylaimus blieben mir die Männchen unbekannt, welche Thatsache besonders darum zu bedauern ist, weil die Arten dieser Gruppe ohne die Kenntniss der Mănnchen schwer zu unterscheiden sind. Von den 143 Arten, welche in dieser Arbeit beschrieben werden, sind von 82 Arten die beiden Geschlechter, von 59 nur die Weibchen, von 2 nur die Männchen bekannt geworden.

Jetzt möchte ich noch einmal aufmerksam machen auf das Vorkommen dieser Thiere nach den Zeiten des Jahres. Als allgemeines Resultat meiner zahlreichen Untersuchungen in dieser Hinsicht, kann ich mittheilen, dass man geschlechtsreife Individuen unserer Thiere das ganze Jahr hindurch antrifft, ohne also an gewisse Zeiten gebunden zu sein. Zwar kann ich dies von vielen Arten nicht mit genügender Gewissheit sagen, weil es seltene Formen sind, welche ich nur in einigen Monaten beobachtete, aber ich glaube dass es auch bei diesen statt finden wird, wie es von den häufigeren erwiesen worden ist.

\section{GEOGRAPHISCHE VERBREITUNG.}

Sehr wenig wissen wir noch über die geographische Verbreitung der freilebenden Nematoden, höchst dürftig sind die Angaben welche wir über dieselbe besitzen. Doch ist ihre Kenntniss von 
grosser Bedeutung, nicht nur von allgemein wissenschaftlichem Standpunkt, sondern weil sie uns Anhaltspunkte für die Kenntniss der gegenseitigen Verwandtschaft, der phylogenetischen Entwickelung und der Natur des Bodens gewährt.

Was zuerst die marinen Formen betrifft, so beziehen sich die Untersuchungen auf die Nordischen Meere Europa's (Englische Küsten, Kieler Bucht) und das Mittelmeer; aus den Forschungen Eberth's, Marion's und den meinigen wissen wir, dass im Mittelmeer grössentheils andere Arten gefunden werden als in den Nordischen Meeren Europa's. Es unterliegt also Keinem Zweifel, dass die verschiedenen Meere der Welt von sehr verschiedenen Arten bevölkert sind, dass z. B. die im Indischen Ocean lebenden Nematoden zu anderen Arten gehören als diejenigen welche im Golf von Mexico gefunden werden.

Wenn wun die früher von mir ausgesprochene Vermuthung richtig ist, dass die sog. Brackwassernematoden sich alle oder theilweise aus marinen Formen entwickelt haben, so werden wir auch in anderen Welttheilen, deren Küsten von anderen Meeren bespült werden, andere Brackwasserformen antreffen mûssen.

Was schliesslich die, in der reinen Erde, in faulenden Substanzen, in Pflanzen oder im süssen Wasser lebenden Nematoden betrifft, so beziehen sich die vorliegenden Angaben fast ausschliesslich auf Europa, denn die wenigen Mittheilungen Carter's und Leidy's über, in der Gegend von Bombay und Philadelphia beobachtete Formen sind fast werthlos.

Durch meine Untersuchungen ist jetzt die Niederländische Nematodenfauna am vollständigsten bekannt geworden; nach den Niederlanden folgen in dieser Hinsicht Deutschland und Ungarn, wo Bütschli, von Linstow, Örley und ich selbst diesen Würmern nachgeforscht haben, schliesslich England, besnnders durch die Arbeiten Charlton Bastian's. An mehrere Herren Collegen in verschiedenen Gegenden Europa's richtete icb die freundliche Bitte mir feuchte, mit Moos oder Gräsern bewachsene Rasen aus ihrer Gegend zuzuschicken, um dieselben auf unsere Thiere zu untersuchen; leider haben Einige meinem Wunsche nicht entsprochen, während die mir geschickte Erde aus Athen, Odessa und Neapel keine Würmer enthielt. Eine schöne, gut ausgewählte Sendung feuchter Rasen, in welcher 24 Arten beobachtet wurden, empfing ich durch die Güte des Herrn Carl von Deschmann aus Laibach in Krain. Der Freundlichkeit des Herrn Olaf Jensen verdanke ich "einen feuchten Rasen aus der kleinen Halbinsel Bygdö unweit Christiania, welcher mich mit 20 Arten bekannt machte. Eine dritte Sendung aus der Umgebung Londons empfing ich von meinem verehrten Collegen Herrn Dr. Örley in Budapest, während auch die vierte aus der Gegend von Montpellier, welche ich Herrn Dr. Viguier verdanke, mehrere Formen enthielt. - Schliesslich hatte ich selbst, während meiner Anwesenheit in Erlangen im Winter 1881/82 und während einer Reise durch die Schweiz, die Gelegenheit mehrere Formen aufzufinden. Spater hoffe ich diese Studien über die geographische Verbreitung unserer Thiere fortzusetzen, muss mich vorläufig aber mit demjenigen begnügen, was ich gefunden habe.

Als allgemeines Ergebniss aus diesen allerdings dürftigen Angaben spreche ich die Meinung aus, 
dass (etwa mit Ausnahme der Brackwasserarten, über deren Vorkommen in anderen Ländern noch keine Nittheilungen vorliegen) ein grosser Theil der in den Niederlanden beobachteten Arten auch in Deutschland, Ungarn, Frankreich, England und Norwegen, also wahrscheinlich in ganz Europa gefunden wird. So kommt in Deutschland fast die Hälfte der, von mir in den Niederlanden aufgefundenen Arten vor. - Uebrigens unterliegt es keinem Zweifel, dass in diesen Ländern, besonders aber in entferntern Gegenden Europa's, z. B. Italien oder Griechenland, ausser diesen noch Arten leben, welche in den Niederlanden fehlen oder umgekehrt.

Die Formen, welche von mir selbst in der, aus anderen Theilen Europa's stammenden feuchten Erde beobachtet wurden, theile ich jetzt mit:

\section{A. Baiern (Erlangen).}

Alaimus primitivus.

" dolichurus.

Bastiania gracilis.

Aphanol. attentus.

Monolystera macrura.

"vulgaris.

, filiformis.

, simplex.

Tripyla setifera.

Cyatholaimus terricola.

"tenax.

Alaimus primitivus.

, dolichurus.

Bastiania gracilis.

Monohystera macrura.

, filiformis.

, simplex.

Cyatholaimus tenax.

Mononchus papillatus.
Ethmolaimus pratensis.

Mononchus macrostoma.

Ironus ignavus.

" longicaudatus.

Cephalobus persegnis.

Teratocephalus teriestris.

$$
\text { " crassidens. }
$$

Plectus granulosus.

» cirratus.

, longicaudatus.

Odontolaimus chlorurus.

B. Krain (Laibach).

Mononchus brachyuris.

"tridentatus.

Cylindrolaimus communis.

Cephialobus striatus.

Plectus geophilus.

" rlizophilus.

Rhabdolaimus terrestris.

Odontolaimus chlorurus.
Tylenchalaimus minimus. Tylenchus dubius.

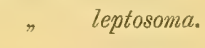

, agricola.

Dorylaimus obtusicaudatus.

, brachyuris.

" parvus.

" lugdunensis.

, stagnalis.

" Brigdammensis.

, longicaudatus.

Diphtherophora communis.

Tylencholaimus minimus.

Tylenchus robustus.

Dorylaimus obtusicaudatus.

" superbus.

" gracilis.

" Brigdammensis.

, longicaudatus.

\section{Schweiz.}

(Roth-See bei Luzern, Altdorf und Schönegg am Vierwaldstätter See.)

Bastiania gracilis.

Aphanolaimus attentus.
Prismatol. intermedius.

, dolichurus.
Plectus granulosus.

, cirratus. 
Monohystera simplex.

Cyatholaimus terricola.

tenax.
Mononchus macrostoma.

". brachyuris.

D. Frankreich (Montpellier).
Odontolaimus chlorurus.

Dorylaimus intermedius.

$$
\begin{array}{cc}
\text { Monohystera macrura. } \\
" & \text { vulgaris. } \\
" & \text { filiformis. } \\
& \text { simplex. } \\
\text { Cyatkolaimus } & \text { tenax. }
\end{array}
$$

Plectus granulosus.

"longicaudatus.

Diphtherophora communis.

Tylenchus Davainei.

Dorylaimus Brigdammensis.

E. England (Sydenham).

Alaimus primitivus.

Bastiania gracilis.

Monohystera filiformis.

$$
\text { , simplex. }
$$

Tripyla filicaudata.

Prismatol. intermedius.

Mononchus papillatus.

F. Norwegen (Halbinsel Bygdö unweit Christiania).

Alaimus primitivus.

Bastiania gracilis.

Monohystera simplex.

Cyatholaimus tenax.

Mononchus papillatus.

" brachyuris.

Prismatolaimus intermedius.
Teratocephalus terrestris.

crassidens.

Cephalobus elongatus.

Plectus granulosus.

» rhizoplithes.
Cephalobus persegnis.

"nanus.

" ciliatus.

Teratocephalus terrestris.

Plectus rlizophilus.

" communis.

" otophorus.
Plectus otophorus.

Tylenchus dubius.

pratensis.

n intermedius.

Doryl. obtusicaudatus.
Tylenchus agricola.

Dorylaimus obtusicaudatus.

" macrodorus.

" Carteri.

, acuticauda.

Aphelenchus agricola.

\section{LEBENSWEISE.}

Wie es scheint, leben alle in meiner Arbeit beschriebenen freilebenden Nematoden von vegetativer Nahrung, obwohl es mir nie gelungen ist, die directe Nahrungsaufnahme zu beobachten; die den Gattungen Dorylaimus, Tylènchus, Aphelenchus angehörigen Formen saugen wohl mit ihrem Stachel Pflanzensäfte auf, denn eine andere Nahrungsaufnahme ist bei ihnen nicht möglich. Der Darm ist häufig mit blassen Fettkügelchen angefüllt, welche bisweilen, wie bei einigen Dorylaimen, eine verschiedene Farbe besitzen und gelblich oder röthlich aussehen können. Ich erlaube mir aber, 
zwei Beobachtungen mitzutheilen, welche auch für die Aufnahme von thierischen Stoffen zu sprechen scheinen: ich beobachtete nämlich einen jungen Dorylaimus (obtusicaudatus B.), der den Stachel quer in den Körper eines Cephalobus gestochen hatte und denselben wahrscheinlich aussog. Die zweite Beobachtung bezieht sich auf einen Mononchus, der einen Dorylaimus bis weit in den Oesophagus hinein verschluckt hatte und so mit sich fortschleppte.

Sehr verschieden verhalten sich diese Thierchen in Bezug auf ibre Bewegungen: während einige sich schnell, hin und her schlängelnd, fortbewegen, regen sich andere höchst träge und langsam. So kriecht der nicht seltene Alaimus primitivus sehr träge und langsam dahin, macht die häufige Bastiania gracilis lebhafte wurmartige Bervegungen und schlängelt sich der eben so häufige Plectus granulosus schnell und gesehwind hin und her.

Beobachtet man einen Tropfen Wasser, worin, inmitten grüner Algen und Conferven, der schöne vivipare Diplogaster rivalis schnell hin und her schwimmt, so sieht man offters, dass das Thier einen Augenblick ganz unbeweglich seiner ganzen Länge nach gerade ausgestreckt da liegt; es bleibt so einige Zeit liegen und darauf fangen seine schnellen wurmartigen Bewegungen wieder von neuem an. Auch mehrere Arten der Gattung Monolystera wie Monoh. macrura, similis, dispar, filiformis, zeigen diese eigenthümliche Erscheinung.

Wie fast alle Thiere, so werden auch die unseren bisweilen von Parasiten heimgesucht: als solche deute ich nämlich einige Organismen, welche in einigen seltenen Fällen von mir beobachtet wurden.

So fand ich im December in feuchter, von Brackwasser imbibirter Erde einen weiblichen $\mathrm{Ce}$ phalobus oxyuroides, dessen ganze Leibeshöhle, mit Ausnahme der beiden Körperenden, mit zahllosen, stäbchenförmigen, theilweise regelmässig in Querreihen sitzenden Parasiten angefüllt war (Taf. XXXIV Fig. 143), welche eine Länge von $2-3 \mu$ hatten. Das Thierchen, offenbar durch diese Körperchen angeschwollen, war ganz wohlauf.

Ein anderes Mal, im März, fand ich einen ganz erwachsenen, drei Eier tragenden Mononchus macrostoma in feuchter Wiesenerde in der Nähe von Leiden: hier enthielt nicht die Leibeshöhle, wie beim Cephalobus, sondern der Darmkanal, mehrere unbewegliche pflanzliche Parasiten; dieselben hatten eine kurz-ovale Gestalt, waren $1 / 25 \mathrm{~mm}$. lang und $1 / 40 \mathrm{~mm}$. breit, von einer dünnen Schale umhüllt, und umschlossen sehr zahlreiche birnförmige, radiär geordnete Körperchen, von welchen jedes in einer kleinen Höhle eingebettet war. Die Zahl dieser in eine kurze Spitze auslaufenden Körperchen war übrigens bei den einzelnen Parasiten versehieden gross (Taf. XXXIV Fig. 144). Die dritte Beobachtung stützt sich auf ein junges, unreifes, noch zwei Stacheln tragendes Exemplar des häufigen Dorylaimus Brigdammensis, im Juli 187\%. Zahlreiche eigenthümliche Parasiten fanden sich hier in der Leibeshöhle, während die inneren Organe alle gut erhalten waren; die Gestalt dieser Parasiten, deren Länge zwisehen $29 \mu$ und $34 \mu$ wechselte, war spindelförmig, obgleich an einem Ende mehr zugespitzt als am anderen; dabei waren sie seitlich symmetrisch, bisweilen aber an einer Seite mehr convex gebogen; eine feste Schale umgab den Inhalt, worin ich einen Kern beobachtete. Es hatten diese Parasiten grosse Aehnlichkeit mit Eiern von Echinorynchus. (Vgl. Taf. XXXIV fig. 145). 
Auch in den zwei letzten Fällen waren die Thierchen ganz wohlauf.

Ebenso beobachtete ich beim Trilobus gracilis aus dem Boden eines Süsswassergrabens im October zahllose kleine stäbchenförmige Körperchen, wie Bacterien aussehend und in der Leibeshöhle der Musculatur anliegend. Eine eigenthümliche Erscheinung bietet auch der Schwanz des Odontolaimus chlorurus; fast immer bemerkt man in demselben kleine chlorophyllgrüne Körperchen, deren Bedeutung oder Entstehung es mir nicht gelang zu erklären.

Auch beobachtete ich im Monat September, im humusreichen Waldboden, Exemplare der Bastiania gracilis, von welchen einige bei durchfallendem Lichte gelblichgrün gefärbt erschienen, welche Farbe, wie beim Odontolaimus, durch zahlreiche gelblichgrüne Körnchen verursacht wurde, welche in den Seitenfeldern, besonders an den beiden Körperenden, zerstreut lagen.

\section{CLASSIFIKATION. BESTIMMUNGSTABELLEN.}

Was zuerst die Classifikation betrifft, so habe ich mehrere neue Gattungen und eine grosse Anzahl neuer Arten zu bilden mich genöthigt gesehen. Welche sind im Allgemeinen die Gattungscharactere, nach welchen Organen sind die Gattungen von den früheren Autoren und von mir aufgestellt worden?

Als Antwort auf diese Frage theile ich mit, dass in erster Linie die An- oder Abwesenheit einer Mundhöhle und die Gestalt derselben, resp. der in ihr liegenden Stachelbildungen, dann weiter die Bildung und der Bau des Kopfendes (An- oder Abwesenheit von Lippen), schliesslich das Vorhandensein oder Fehlen und die Lage und der Bau von Papillen, oder von einer Bursa beim Männchen die Charactere sind, nach welchen die Gattungen gebildet worden und immer werden müssen. Bei einigen gewährt auch der Bau des Oesophagus gute Gattungscharactere (z. B. Tylencholaimus, Plectus), dann weiter das Vorhandensein oder Fehlen der Seitenorgane (Rhabditis, Plectus, Cephalobus) und der Bau der Geschlechtsorgane.

Die Artenunterscheidung bietet im Gegensatze zu derjenigen der Gattungen nicht selten grössere Schwierigkeiten dar. Die Artencharactere sind natürlich sehr verschieden: es sind die absoluten Maasse des Körpers und die durch dieselben bedingte allgemeine Gestalt, der Bau des Kopfendes und der Mundhöhle (wenn dieselbe vorhanden ist) und die Grösse und Gestalt des Schwanzes. Dann weiter die Zahl der männlichen Papillen, die relative Ausdehnung der weiblichen Geschlechtsorgane, die Zahl der Kopfborsten, die Gestalt und Lage der Seitenorgane, der Bau des Ausfuhrrohres der Schwanzdrüse, die Lage des Gefässporus u. s. w. Besonders in den Gattungen Dorylaimus, Tylenchus, Plectus und Monohystera ist die Artenunterscheidung bisweilen sehr schwierig, besonders dann wenn die Männchen nicht bekannt sind.

Artvarietäten kommen selten vor, doch müssen wir auch diesen Rechnung tragen. Oefters 
variirt der Schwanz vieler Dorylaimen, z. B. des D. Bastiani Btsli, wie überhaupt an diesem Körpertheile auch bei mehreren anderen Formen öfters Varietäten auftreten (Plectus fusiformis).

Eine sonderbare Erscheinung ist auch die Thatsache, dass bei einigen Gattungen die Arten sehr zahlreich sind, während andere nur aus einer oder zwei bestehen. Während die Gattung Dorylaimus 48 und die Gattung Rhabditis 40 Arten zählen, giebt es in den Niederlanden nicht weniger als dreizehn Land- und Süsswassergattungen, welche bis jetzt aus nur einer Art bestehen. Von den etwa 40 überhaupt bekannten Gattungen, deren Arten alle oder theilweise in der reinen Erde und im süssen Wasser leben, giebt es nur sechs, bei welchen die Zahl der Land- und Süsswasserarten grösser ist als zehn (Monohystera, Diplogaster, Cephalobus, Plectus, Dorylaimus).

Was num aber die in den Niederlanden lebenden Arten betrifft, so glaube ich nach der ziemlich langen Dauer meiner Untersuchungen die Vermuthung aussprechen zu dürfen, dass mir jetzt wohl drei Viertel, wo nicht eine grössere Anzahl derselben bekannt geworden ist: ich rede immer von den Arten, welche in der reinen Erde und im süssen Wasser gefunden werden. In meiner ersten Arbeit habe ich versucht, die bekannten freilebenden Erd- und Süsswassernematoden wenigstens theilweise in Familien zu gruppircn: später ist dies auch von Örley für die ganze Ordnung der Nematoden versucht worden, und zwar ebenfalls auf Grund phylogenetischer Betrachtungen. Ungeachtet jetzt durch meine Untersuchungen eine viel bedeutendere Zahl von Formen bekannt geworden ist, glaube ich es doch für verfrüht halten zu müssen, diese Thiere schon jetzt in Familien zu gruppiren: es müssen, wie ich früher schon sagte, erst noch die in anderen Welttheilen lebenden Land- und Süsswassernematoden, die in Pflanzen und faulenden Stoffen vorkommenden Arten, so wie die im Meere lebenden untersucht werden, so wie eine Vergleichung mit den als Parasiten lebenden Gruppen statt gefunden haben, um mit Erfolg eine solche Eintheilung in Familien durchführen zu können. Nichtsdestoweniger kann ich, was z. B. die Land- und Süsswassernematoden betrifft, diese wenigstens theilweise nach ihren anatomischen Verwandschaftsgraden zusammenstellen, ohne sie in Familien zu gruppiren.

So bilden die Gattungen Cephalobus, Teratocephalus, Plectus und Rhabditis, meiner Meinung nach, eine ganz natürliche Gruppe, ebenso die Formenreihen der Tylencholaimen, Aphelenchen, Tylenchen und Dorylaimen, welche sich meinetwegen aus Formen, welche den Gattungen Diphtherophora, Tylolaimophorus und Tylopharynx ähnlich waren, entwickelt haben mögen. Auch die Gattungen, deren Mundhöhle mit einem oder mehreren Zăhnen bewaffnet ist, sind jedenfalls alle oder theilweise mit einander verwandt.

Es sei mir zum Schluss erlaubt, Einiges zur Erklärung der dichotomischen Tabelle hinzuzufügen. Es sind sowohl in der Gattungstabelle als in denjenigen der Arten bloss diejenigen Gattungen und Arten aufgenommen, welche in meinem Werke beschrieben werden, und was ihren Gebrauch betrifft, so muss ich bemerken, dass sie nur zur Erleichterung der Uebersicht der Formen aufgestellt sind, während es immer zu genauer Bestimmung der Gattung, resp. der Art absolut nothwendig ist, auch die Beschreibung zu Rathe zu ziehen. 
SYSTEMITISCHER THEIL.

\section{UEBERSICHTSTABELLE DER GATTUNGEN.}

1. Mundhöhle fehlend . . . . . . . . . . . . . . . 2.

Mundhöhle vorhanden. . . . . . . . . . . . . $\%$

2. Kopfende nackt, ohne Lippen, Papillen oder Borsten. . . . . 3.

Kopfende mit Lippen, Papillen oder Borsten gewaffnet. . . . 4 .

3. Schwanz des Männchens ohne Bursa, Cuticula ungeringelt. . . I. Alaimus.

Schwanz des Männchens mit Bursa, Cuticula geringelt. . . XXVII. Macroposthoni .

4. Kopfende ohne Lippen . . . . . . . . . . . . . . . 5.

Kopfende mit Lippen... . . . . . . . . . VI. Tripyla.

5. Seitenorgane nicht auffallend gross . . . . . . . . . 6.

Seitenorgane sehr nach vorn gerückt, und auffallend gross. . IV. Apha nolaimus.

6. Beim Männchen am Vorderende des Körpers eine mediane ventrale

Reihe von zahlreichen kreisförmigen Papillen. Brackwassernema-

toden

II. Deontolaimus.

Beim Männchen keine solche Papillen am Vorderende, sondern eine mediane prăanale Reihe von Papillen, gleich vor dem After. Omnivag

III. Bastiania.

7. Mundhöhle von sehr verschiedener Gestalt, nie mit Zähnen oder Stachelbildungen gewaffnet. . . . . . . . . . . . .

Mundhöhle von sehr verschiedener Gestalt mit Zähnen, Haken oder Stachelbildungen gewaffinet . . . . . . . . . . 21

8. Oesophagealbulbus, wenn überhaupt vorhanden, nie mit einem Zahnapparat versehen. . . . . . . . . . : . 9 
Oesophagea]bulbus vorhanden und mit Zahnapparat gewaffnet. . 18.

9. Mundhöhle kurz, nicht besonders verlängert. . . . . . . . 10.

Mundhöhle mehr oder weniger verlängert, meist röhrenförmig . 15.

10. Mundhöhle klein, mit sehr dünnen Wänden. . . . . . . 11.

Mundhőhle sehr deutlich, mit dicken chitinisirten Wänden . . 12.

11. Mundhöhle schwach entwickelt, ohne concentrische Verdickungsleisten . . . . . . . . . . . . . . . . . . . . . Mundhöhle becherförmig, mit drei concentrischen, chitinősen Verdickungsleisten. Brackwasser-nematoden . . . . . . . . .

V. Monohystera.

VII. Desmolaimus.

12. Mundhöhle weit, mit vielen eigenthümlichen, localen Chitinverdickungen. (Die einzige, in der Erde lebende Art ist Brackwasser-nematode). . . . . . . . . . . . . . . . . Mundhöhle ohne locale Chitinverdickungen . . . . . . . 13

13. Mundhöhle trichterförmig . . . . . . . . . . . . . . 14.

Mundhöhle von kurz prismatischer Gestalt; Seitenorgane linienförmig . . . . . . . . . . . . . . . . . . . . .

XIX. Prismatolaimus.

14. Kopfende mit Papillen und Borsten gewaffnet; gleich hinten der Mundhöhle im Oesophageallumen ein zahnartiger Vorsprung . . Kopfende nur mit Papillen versehen; kein zahnartiger Vorsprung hinter der Mundhöhle, Seitenorgane gross, spiralig . . . . .

XVII. Trilobus.

XVI. Choanolaimus.

15. Mundhöhle ausserordentlich verlängert, röhrenförmig, länger als der Oesophagus; Kopfende ohne einige Bewaffnung . . . . . Mundhöhle verlångert, stets kürzer als der Oesophagus . . . . 16.

16. Mundhöhle sehr enge, von drei dünnen chitinösen Stäben begrenzt, welche nach hinten zu ein wenig convergiren und welche jeder an seinem Vorderende mit einem kleinen hakenformigen Körperchen in Zusammenhange stehen. Kopfende ohne Papillen, Lippen oder Borsten . . . . . . . . . . . . . Mundhöhle röhrenförmig, überall gleich weit . . . . . . . 14

1\%. Mundhöhle mit sehr dünnen Wänden; Kopfende ohne Lippen, Papillen oder Borsten. Brackwassernematoden . . . . . . . Mundhöhle mit chitinösen deutlichen Wänden; Kopfende mit Borsten . . . . . . . . . . . . . . . . .

18. Die chitinösen Wände der röhrenförmigen Mundhöhle stellenweise verdünnt und verdickt

Die chitinősen Wånde der röhrenförmigen Mundhöhle überall gleich dick.

XVIII. Aulolaimus.

16.

XXVIII. Rhabdolaimus.

$1 \%$

XX. Leptolaimus.

XXI. Cylindrolaimus. 
Kopfende stets ohne Borsten; beim Männchen zwei accessorische Stücke. . . . . . . . . . . . . XXII. Cephalobus.

Kopfende obne Borsten, von sechs, durch tiefe Rinnen getrennten Lappen gebildet; keine accessorische Stücke . . . . . XXIV. Teratocephalus.

20. Männchen ohne Bursa; Seitenorgane vorhanden. . . . . XXV. Plectus.

Männchen mit Bursa; Seitenorgane (wahrscheinlich) fehlend . . XXVI. Rhabditis.

21. Mundhöhle mit einem oder mehreren Zähnen bewaffinet, ohne Stachelbildungen. . . . . . . . . . . . . . . 22.

Mundhöhle mit Stachelbildungen, ohne Zähne . . . . . . . 29.

22. Im vorderen Theile der sehr verlängerten Mundhöhle drei Zähne, welche durch das Auseinandergehen der beweglichen Lippen nach aussen getrieben werden können . . . . . . . . . . Keine bewegliche Lippen am Kopfende . . . . . . . . . 23

23. Oesophagus mit einem mittleren Bulbus; Mundhöhle mit einem oder mehreren Zähnen . . . . . . . . . . . XXII. Diplogaster. Oesophagus ohne mittleren Bulbus . . . . . . . . . 24.

24. Mundhöhle weit und tief, mit drei unbeweglichen Vorsprüngen. (Die einzige in der Erde lebende Art ist Brackwasser-nematode). Mundhöhle mit nur einem Zahne. . . . . . . . . . . . 25

25. Kopfende ohne Borsten . . . . . . . . . . . . . 26. Kopfende mit Borsten. . . . . . . . . . . . . . . . $2 \%$

26. Oesophagus ohne hinteren Bulbus; Mundhöhle weit, Kopfende mit Papillen . . . . . . . . . , , . . . . . . . . Oesophagus mit hinterem Bulbus; Mundhöhle klein; Kopfende nackt, ohne Papillen; Seitenorgane kreisrund. Brackwasser-nematoden

XII. Mononchus.

7. Hinterer Theil des Oesophagus plötzlich erweitert, ohne einen Bulbus zu bilden, Mundhöhle sehr verlängert und enge. . . . Hinterer Theil des Oesophagus allmälig erweitert oder mit deutlich abgesetztem Bulbus . . . . . . . . . . . . .

28. Mundhöhle aus einem vorderen zahntragenden schüsselfôrmigen Theile und einem hinter diesem gelegenen prismatischen Theile gebildet, mit stark chitinisirten Wänden; Oesophagus mit Bulbus

XI. Ethmolaimus. Mundhöhle klein, becher- oder trichterförmig . . . . . . .

IX. Cyatholaimus. Spilophora.

X. Chromadora. 
29. Im Kopfende liegt ein einziger hohler, meist gănsefederförmiger Stachel. Oesophagus stets ohne Bulbus.

XXXVI. Dorylaimus.

Im Kopfende liegen ein oder drei, an ihrem Hinterende meist geknöpften Stacheln .

30. Drei hinten geknőpfte Stacheln, vorn von einem chitinösen „Käppchen" umgeben, liegen in der Mundhöhle . . . . . . . . . 31.

Nur ein Stachel in der Mundhöhle . . . . . . . . . . . 32

31. Oesophagus mit muskulösem mittleren Bulbus. . . . . . . XXXI. Tylopharynx.

Oesophagus bloss an seinem Hinterende etwas erweitert. Die Hăutungsmembran den Körper umhüllend

XXX. Diphtherophora.

32. Der Stachel ist vorn von einem, aus drei kurzen, gebogenen, an ihren Vorderenden verbundenen Stäbchen gebildeten „Käppchen" umgeben. Oesophagus ohne Bulbus, bloss hinten taschenförmig erweitert . . . . . . . . . . . . . XXXI. Tylolaimophorus. Der Stachel ohne „Käppchen” . . . . . . . . . . . . . 33.

33. Oesophagus ohne Bulbus, in seiner hinteren Halfte erweitert. . . XXXII. Tylencholaimus. Oesophagus mit Bulbus . . . . . . . . . . . . . . . 34

34. Oesophagus mit mittlerem Bulbus; Männchen mit Bursa . . . XXXV. Tylenchus. Oesophagus mit hinterem Bulbus; Männchen ohne Bursa... . XXXIV. Aphelenchus.

\section{VERZEICH ISS}

der übrigen, bis jetzt beschriebenen Gattungen freilebender, nicht mariner Nematoden, welche in diesem Werke nicht behandelt werden oder von mir nicht beobachtet wurden.

1. Anguillula Ehrenberg (Einzige Art, A. a ceti Ehrb., das allgemein bekannte Essigälchen). Vergl. die note der Beschreibung der Gattung Cephalobus.

2. Diplolaimus Linstow (Archiv für Naturgeschichte, XLII Jahrgang, Heft I, pag. 16, Taf. II, fig. 38). (Einzige Art: Diplol. gracilis Linstow, ebendaselbst; lebt im Sande des Bodens des Ratzeburger Sees).

3. Mitrephorus Linstow (Archiv für Naturgeschichte, XLIII Jahrgang, Heft I, pag. 2, Taf. I, fig. 2). (Einzige Art: Mitreph. haemisphaericus, Linstow, ebendaselbst, lebt im Wasser des Ratzeburger Sees; diese Form scheint mir meiner Gattung Teratocephalus nahe verwandt zu sein).

4. Heterodera Schachti Schmidt, der Rübennematode, beschrieben in der Zeitschrift des Vereins für Rüben-Industrie im Zollverein, 1871. 


\section{BESCHREIBUNG DER GATTUNGEN UND ARTEN.}

\section{Alaimus d. M. ').}

(von $\alpha$ privativum und rasıós, Mundhöhle).

In dieser, verhältnissmässig am einfachsten gebauten Gattung ist der Körper mehr oder weniger langgestreckt, und verschmälert er sich nach beiden Enden hin. Die Cuticula ist glatt, ungeringelt, ohne Seitenmembran und ohne Borsten. Die Seitenorgane sind kreisförmig. Das Kopfende ist nicht abgesetzt, oline Lippen, Papillen oder Borsten, gänzlich ungewaffnet. Ein ventraler Gefässporus fehlt. Bs giebt keine Spur einer Mundhöhle; der Oesophagus ist langgestreckt, und schwillt nach hinten nur wenig und ganz allmälig an. Die Geschlechtsorgane sind beim Weibchen einseitig unpaar und strecken sich nach hinten aus. Die Spicula haben keine accessorische Stücke. Vor dem After beobachtet man beim Männchen eine mediane Reihe von 3-5 Papillen. Eine Schwanzdrüse fehlt.

Vorkommen und Lebensweise: Die zwei dieser Gruppe angehörigen Arten sind wahrscheinlich omnivag und leben in der feuchten Erde an Pflanzenwurzeln.

TABELLE DER ARTEN.

1. Schwanz nicht fadenförmig; Entfernung der weibl. Geschlechtsöffnung vom Oes. stets grösser als die halbe Länge desselben . . . . . . . . . . . . . 1. primitivus.

2. Schwanz fadenförmig; Entfernung der weibl. Geschlechtsöffnung vom Oes. so lang wie oder kürzer als die halbe Länge desselben . . . . . . . . . 2. dolichurus

1) Sämntliche, in dieser Arbeit aufgeführte Gattungen und fast alle Arten wurden schon im vorläufigen Berichte (XXXV) kurz beschrieben: ich weise deshalb nur einmal auf diesen Bericht hin, um ihn nicht später mehr zu citiren, ausser wenn es absolut nöthig ist. 


\section{Alaimus primitivus d. M.}

Taf. I, fig. 1.

$\sigma^{7} 1 \mathrm{Mm}$., ㅇ 1,2 Mm. \& beim Männchen 50-60, beim Weibchen 40-50. $\beta=4 . \gamma=10-14{ }^{1}$ ).

Der Körper dieses eigenthümlichen Thieres ist, besonders beim Männchen, sehr schlank und nach beiden Enden hin sehr verschmälert. Das ganz nackte Kopfende läuft kegelförmig zu mit abgerundetem Vorderende (fig. 1 a) und die sehr kleinen Seitenorgane liegen in geringer Entfernung vom letzteren; man beobachtet sie am besten bei einer medianen Lage und sie stellen sich dann als kleine Vertiefungen dar, mit innerem, dahin führendem Gange (fig. 1 b). Der Oes. schwillt nach hinten allmälig zu (fig. 1c) und der Darm ist körnig. Die weibliche Geschlechtsöffnung liegt vor der Körpermitte: illre Entfernung vom Oes. ist stets grösser als die halbe Länge dieses Organs; die weibl. Genitalien strecken sich nach hinten aus, sind aber kürzer als die halbe Entfernung der Geschlechtsoffnung vom After. Bütschli, der diese Art auch beobachtete, fand die Geschlechtsorgane noch ganzlich unentwickelt bei einer Grösse von 1,17 Mm.; ich fand aber 0,8 Mm. lange Weibchen mit Geschlechtsöffnung und theilweise entwickelten Genitalien: - auch Männchen hatten bei derselben Länge schon die Spicula und die Geschlechtsröhre völlig entwickelt. - Die Spicula sind klein, nicht gebogen. Vier oder fünf niedrige präanale Papillen beobachtet man beim Männchen. Der, nach der Bauchseite gebogene, zugespitzte Schwanz hat, sowohl beim Männchen als beim Weibchen, eine ziemlich veränderliche Länge und Gestalt.

Fundort ${ }^{2}$ ) und Lebensweise. Dieses Thier kommt ziemlich häufig vor und bewohnt, sowohl die feuchten Marschgründe unserer Wiesen als auch den sandigen Boden der Dünenstriche. És bewegt sich höchst langsam und träge wie fast keine zweite Art. - Die Weibchen sind häufiger als die Männchen.

Geographische Verbreitung. England (Sydenham), Deutschland (Erlangen, Laibach, Frankfurt a. M. (Bütschli), Stade (von Linstow).

Fundzeit. Ich beobachtete erwachsene Exemplare in allen Monaten des Jahres.

Anmerkungen. Es făllt dieses sonderbare Thier gleich auf durch seine ganz einfache Organisation sowie auch durch seine grosse Trägheit und Langsamkeit der Bewegung: meistens sieht man es ganz regungslos zwischen den Erd- und Sandkörnchen liegen. Es wurde schon von Bütschli, (XX, p. 122, Taf. XI, fig. $6^{\%}$ ) und von von Linstow (XXIX, pag. 15) beobachtet: weil er nie geschlechtsreife

1) Die Maasse sind in Millimetern angegeben und gelten für das erwachsene Thier. Zur Verkürzung wird das Verhâltniss der Gesammtlänge zur mittleren Dicke des Körpers durch $\alpha$, das Verhältniss der Gesammtlänge zur Länge des Oes. (wozu eventuell die Mundhöhle oder die Stachelbildungen, wie bei Tylenchus, Dorylaimus u. s. w. mit gerechnet werden) durch $\beta$ und das Verhältniss der Gesammtlänge zur Länge des Schwanzes durch $\gamma$ ausgedrückt.

2) Diese Angabe des „Fundortes" bezieht sich bei jeder Art auf das Vorkommen in den Niederlanden, während die $\gg$ Geographische Verbreitung.' die Länder angibt, wo die betreffende Art auch noch beobachtet wurde. 
Thiere fand, vermuthete der erstere dass unseres Thierchen den Jugendzustand der Sphärularia Bombi repräsentirte. Von Linstow fand es unter Moos auf den Stader Festungswällen und meinte eher an einem Jugendzustand des Myoryctes Weismanni Eberth denken zu müssen. Jetzt ist dieses Räthsel aufgelöst.

\section{Alaimus dolichurus dM.}

Monohystera dolichura, de Man, XXVI, pag. 100, Taf. XI und XII, fig. 46a-c.

Taf. I, fig. 2.

б $0,8 \mathrm{~mm}$., ㅇ $0,9 \mathrm{~mm}$. $\alpha$ beim $\sigma^{7} 70-90$, beim 우 65-75: $\beta=4 . \gamma$ beim $\sigma^{7} 21 / 2-3$, beim 오 $3-5$.

Diese Art hat einen sehr schlanken, fast fadenförmigen Körper, dessen Vorderende sich sehr verschmälert: das vorderste Kopfende sah ich bisweilen ein wenig abgesetzt, (XXVI, Taf. XI, fig. 46a) Die ziemlich kleinen, kreisrunden Seitenorgane liegen auf einem siebenzehntel der Oesophaguslänge vom Vorderende entfernt. Der Oes. wird nach hinten allmälig dicker und im Darm sieht man nur wenige Körnchen, sodass die Thiere sehr durchscheinend sind. Die weibliche Geschlechtsöffnung liegt, wie bei der vorigen Art, vor der Körpermitte: ihre Entfernung vom Oes. ist so lang wie oder kürzer als die halbe Länge dieses Organs; die weibl. Genitalien strecken sich nach hinten aus, sind aber kürzer als die halbe Entfernung der Vulva vom After: die Geschlechtsöffnung fehlt noch bei einer Länge von $0,6 \mathrm{~mm}$. Die Spicula sind ein wenig gebogen und klein, nur $14 \mu$ lang bei einer Körperlänge von $0,64 \mathrm{~mm}$. Beim Männchen finden sich drei niedrige, ziemlich weit von einander liegende präanale Papillen, welche öfters schwer zu beobachten sind. Der Schwanz ist bei beiden Geschlechtern gleich gestaltet, fadenförmig, haarfein auslaufend.

Fundort und Lebensweise. Diese, dem Al. primitivus nahe verwandte Art bewohnt dieselben Gründe wie dieser, die feuchten Marschgründe unserer Wiesen wie die sandigen Dünengegenden. Mănnchen und Weibchen kommen bei der ziemlich hăufigen Art gleich zahlreich vor.

Geographische Verbreitung: Deutschland (Erlangen, Laibach).

Fundzeit: Ich beobachtete geschlechtsreife Exemplare das ganze Jahr hindurch.

\section{Deontolaimus d. M.}

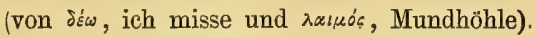

Bei diesen Thieren ist der Körper sehr langgestreckt und verschmälert er sich nach beiden Enden hin. Die Cuticula ist sehr fein quergeringelt, trägt keine Borsten; eine Seitenmembran ist vielleicht vorhanden. Ein abgesetztes Kopfende giebt es nicht; es ist abgerundet, ohne Lippen oder Papillen, aber mit feinen Borsten versehen. Seitenorgane wurden nicht beobachtet, so wie auch kein ventra- 
ler Gefässporus, Eine Mundhöhle fehlt ganz und gar. Der cylindrische Oes. schwillt nach hinten nur wenig und allmälig an und sein dünnes Lumen setzt sich noch eine kurze Strecke in den Darm hinein fort (fig. 3b); dieser letztere ist zweifelsohne zellig. Die Spicula (3f) sind gebogen, und mit einem stabforrmigen accessorischen Stücke versehen; die männliche Geschlechtsröhre streckt sich ziemlich weit nach vorn hin aus. Beim Männchen (nicht beim Weibchen) liegen am Vorderende des Körpers eine mediane ventrale Reihe von zahlreichen kreisförmigen Papillen (fig. 3a und 3d), welche sich über den ganzen oesophagealen Theil bis ein wenig hinter dem Darmanfange ausstreckt; ausserdem findet sich eine einzelne mediane ventrale Papille auf dem Schwanze, etwas hinter der Mitte (fig. 3e). Es giebt eine Schwanzdrüse, mit kleiner spitzer Ausführungsröhre.

Vorkommen und Lebensweise. Die einzige Art lebt an den Wurzeln von, in feuchter, von brackischem Wasser imbibirter Erde wachsenden Pflanzen: ein ächter Brackwassernematode.

\section{Deontolaimus papillatus dM.}

Taf. I, fig. 3.

$\sigma^{7} 1,1 \mathrm{~mm}$. (ᄋ nicht gemessen) $\alpha=50-60 . \beta=5 . \gamma=14$.

Dem, in der Gattungsbeschreibung mitgetheilten, ist noch das folgende hinzuzufügen.

Der Körper ist fadenförmig und trägt vier ziemlich kurze Borsten am Kopfende. Der Schwanz des Männchens (fig. 3e) verschmälert sich allmälig und hat eine abgerundete Spitze, welche eine kleine kurze Ausfuhrröhre trägt. Die Spicula sind schlank, gebogen, verbreiten sich nach hinten zu und haben ein stabförmiges accessorisches Stück; ihre Länge beträgt $0,024 \mathrm{~mm}$., bei einer Totallänge von $0,95 \mathrm{~mm}$. Am Vorderende liegen $2 \%$ Papillen, von welchen die vorderste ein wenig hinter den Borsten des Kopfes, die hinterste etwas hinter dem Ende des Oes. gelegen ist; bei jüngeren Exemplaren beobachtet man eine kleinere Anzahl dieser Papillen.

Fundort und Lebensweise. Das sich sehr lebhaft bewegende Thier bewohnt die feuchte Erde, welche von brackischem Wasser imbibirt ist, auf der Niederländischen Insel Walcheren, an den Wurzeln der dort wachsenden Pflanzen. - Es ist ziemlich selten und bis jetzt in keinem anderen Lande beobachtet.

Fundzeit. Diese Art ist in der Monat August erwachsen.

Anmerkung. Das Männchen dieser Art, welche dem Alaimus primitivus sehr ähnlich ist, ist gleich zu erkennen an der eigenthümlichen Papillenreihe am Vorderende, welche bei keiner anderen Art gefunden wird. Das Weibchen ist noch unvollstandig bekannt. Die Form schliesst sich aber am nächsten den Gattungen Alaimus und Bastiania an. 


\section{Bastiania d. M.}

de Man, XXVI, pag. 95.

Die Bastianien haben einen sehr schlanken, nach beiden Enden hin verschmälerten Körper. Die Haut ist quergeringelt, nie trägt sie Borsten; eine Seitenmembran fehlt. Die Seitenorgane sind spiralig. Ein ventraler Gefässporus ist nicht vorhanden. Das Kopfende ist abgerundet, nicht abgesetzt, ohne Lippen oder Papillen, aber mit Borsten gewaffnet. Eine Mundhöhle fehlt vollständig. Der Oes. ist langgestreckt und schwillt nach hinten nur wenig und ganz allmälig an; dort wo er in den Darm übergeht, liegen mehrere Drüsen. Der Darm hat bei durchfallendem Lichte eine blasse Farbe und scheint mir aus zwei Zellenreihen zu bestehen; ich beobachtete keine Kerne in diesen Zellen, welche gänzlich mit zahlreichen gleich grossen Körnchen gefüllt sind. Die weibl. Geschlechtsorgane sind paarig symmetrisch. Die Spicula sind plump, olne accessorische Stücke. Beim Männchen liegt eine mediane Reike von präanalen Papillen gleich vor dem After. Die Schwanzdrüse hat einen Ausführungsgang.

Vorkommen und Lebensweise. Die zwei Arten dieser Gattung bewohnen die feuchte Erde; die eine ist omnivag, die zweite wurde nur einmal beobachtet.

TABELLE DER ARTEN.

1. Schwanz kegelförmig; weibl. Geschlechtsöffnung weit hinter der Körpermitte . . 1. gracilis.

2. Schwanz verlängert; weibl. Geschlechtsöffnung in der Mitte des Körpers . . . 2. longícaudata

1. Bastiania gracilis d. M.

de Man, XX்VI, pag. 95, Taf. XI, Fig. 43a-c.

Taf. II, Fig. 5.

$\sigma^{7} 1,2 \mathrm{~mm}$., ㅇ $1,1 \mathrm{~mm}$. \& beim $\sigma^{7} \% 0-85$, beim ㅇ $60-\% 5$. $\beta=4-4^{1} \frac{1}{2} \cdot \gamma$ beim $\sigma^{7} 20-28$, beim ㅇ $20-23$.

Dieses sehr schlanke Thier hat einen fadenförmigen Körper mit wenig verjüngtem Vorderende. Die Haut ist stark geringelt. Am abgerundeten Kopfende stehen sechs dünne Borsten, vier submediane und zwei laterale. Die Seitenorgane sind deutlich spiralig, (fig. 5a) und erscheinen in Profil (fig. 5b) als eine Vertiefung. Das Lumen des Oes. stellt sich als ein dünner Streif dar: an seinem hinteren Ende liegen mehrere Drüsen. Ueber den Darm ist schon in der Gattungsbeschreibung gehandelt. Die weibl. Geschlechtsöftnung liegt weit hinter der Körpermitte, fast auf der Grenze des mittleren und hinteren Körperdritttheils; die weiblichen Genitalien strecken sich an beiden Seiten der Vulva gleich weit aus. Beim Männchen stehen 11-13 ziemlich grosse mediane Papillen vor dem After; die Geschlechtsröhre (fig. 5) ist ziemlich lang. Die Spicula (fig. 5c) sind ziemlich plump. Der Schwanz ist bei beiden Geschlechtern gleich gestaltet, kegelförmig, bisweilen ein wenig gebogen, mit kurzem Ausführungsröhrchen der Schwanzdrüse.

Fundort und Lebensweise. Diese Art ist sellr häuffg und wahrscheinlich omnivag: sie bewohnt 
die feuchte Erde der Wiesen und der Waldgegenden und fallt gleich durch ihre eigenthümlichen, wurmartigen, lebhaften Bewegungen auf. Was die sonderbare gelblich grüne Farbe einiger, von mir beobachteten Exemplare betrifft, weise ich nach Seite 23 hin.

Geographische Verbreitung. England (Sydenham), Deutschland (Erlangen, Laibach), Schweiz (Altdorf).

Fundzeit. Das ganze Jahr hindurch. -

2. Bastiania longicaudata d. M.

Taf. $\Pi$, fig. 6.

오 $0,8 \mathrm{~mm} ., \sigma^{7}$ unbekannt. $\alpha=40-50 . \beta=5 . \gamma=8$.

Der Körper dieser seltenen Art ist schlank, aber in geringerem Maasse als bei der vorigen, und nach beiden Enden hin ziemlich verschmälert. Wie bei B. gracilis stehen sechs Borsten am Kopfende, und der Oes. verhălt sich wie bei dieser Art. Die Vulva liegt in der Mitte des Körpers und die weiblichen Genitalien strecken sich symmetrisch an ihren beiden Seiten aus (fig. 6). Der Schwanz ist verlängert, verjüngt sich regelmåssig und hat einen sehr feinen kegelförmigen Ausführungsgang der Schwanzdrüse (fig. 6b).

Fundort und Lebensweise. Diese Art wurde nur einmal von mir beobachtet, im Monat October in feuchter Erde des, in der Nähe von Haag gelegenen Waldes. Sie bewegt sich lebhaft.

Anmerkung. Sie unterscheidet sich von B. graeilis gleich durch den längeren Schwanz und die Lage der weiblichen Geschlechtsöffnung.

\section{Aphanolaimus d. M.}

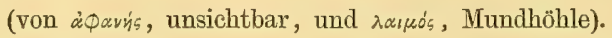

Die Körpergestalt ist nicht schlank, nach beiden Enden hin verschmälert. Die Haut ist schön und stark quergeringelt, und mit einer Seitenmembran versehen. Das Kopfende ist nicht abgesetzt, obne Lippen oder Papillen, aber mit Borsten gewaffnet. Die Seitenorgane sind ausserordentlich gross, und so breit, dass sie fast die ganze Breite des Kopfendes einnehmen. Wahrscheinlich fehlt der Gefässporus und auch die Seitengefässe. Auch eine Mundhöhle fehlt vollständig, und die Mundöffnung führt gleich in den Oesophagus, der cylindrisch ist, und nach hinten gar nicht anschwillt. Der Darm ist feinkörnig. Die weiblichen Geschlechtsorgane sind paarig symmetrisch. Beim Männchen liegt vor dem After eine mediane Reihe von chitinisirten Ausführungsgängen von Drüsen. Auch finden sich präanale und postanale laterale Borstenpapillen bei demselben. Die Spicula sind mit einem accessorischen Stücke versehen. In der Schwanzhöhle liegt eine Drüse mit kurzer Ausführungsröhre.

Die einzige Art ist: 


\section{Aphanolaimus attentus d. M.}

Taf. I, fig. 4.

$\sigma^{2} 90,56 \mathrm{~mm} . \alpha=24-28 . \beta=4^{1 / 1}-5 . \quad \gamma=6$.

Diese eigenthümliche Art hat eine nicht schlanke Körpergestalt, welche sich nach beiden Enden hin ziemlich stark verjüngt. Am abgerundeten Kopfende beobachtet man sechs ziemlich lange Borsten. Die höchst characteristischen, ungefähr kreisförmigen Seitenorgane sind sehr weit nach vorn gelegen, nahe bei dem Mundende, und ragen convex nach aussen hervor, unmittelbar bei und hinter den Kopfborsten (fig. 4b, 4a). Die Seitenmembran ist sehr schmal, aber deutlich. Der Oes. ist an seinem hinteren Ende gar nicht angeschwollen, aber hat überall dieselbe Dicke. Die weibliche Geschlechtsöffnung liegt ein wenig hinter der Körpermitte, und die weiblichen Genitalien sind paarig symmetrisch, aber ziemlich kurz. Beim Männchen liegt vor dem After eine mediane Reihe von fünf chitinisirten Ausführungsgängen von Drüsen, von welchen der vorderste etwas weiter vom vierten entfernt liegt als die übrigen von einander (fig. 4e). Auch beobachtete ich ein Paar lateraler Borstenpapillen vor dem After, etwa auf der Höhe des inneren Spicula-endes. Am eigentlichen Schwanze, deshalb postanal, liegen drei Paar lateraler Borstenpapillen, ein ventrales Paar ungefähr auf der Mitte des Schwanzes, ein ventrales zwischen diesem und dem After und ein dorsales auf der Grenze des mittleren und hinteren Dritttheiles. Die Spicula sind schlank, ein wenig gebogen, mit einem kuizen, etwas gebogenen, accessorischen Stücke (fig. 4c). Der Schwanz ist bei Männchen und Weibchen gleich beschaffen, schlank, allmälig und regelmässig verschmälert, und trägt an seinem Ende eine kurze Ausführungsröhre.

Fundort und Lebensweise. Diese eigenthümliche, und seltene Art bewohnt die feuchte Erde der Wiesen und Marschgründe an den Wurzeln von Gramineen u. s. w., gehört also zu den Wiesennematoden; sie bewregt sich höchst träge und langsam. Männchen und Weibchen kommen gleich häufig vor.

Geographische Verbreitung. Deutschland (Erlangen), Schweiz (Schönegg am Vierwaldstättersee).

Fundzeit. Ich beobachtete das Thier einen grossen Theil des Jahres hindurch in geschlechtsreifem Zustande; nur in einigen Monaten fand ich es nicht, das vielleicht der Seltenheit des Thierchens zugeschrieben werden muss.

Anmerkung. Es füllt der Aphanolaimus gleich auf, sowohl durch die ausserordentlich starke Querringelung der Haut als durch seine ungemein grossen Seitenorgane.

\section{Monohystera Bast.}

Bastian, VII, 9\%. Bütschli, XX, pag. 24.

Die artenreiche Gattung Monohystera, wozu ich in Nachfolgung Bütschli's auch die Bastianschen Gattungen Theristus und Tachyhodites rechne, bilden eine sehr natürliche Gruppe. 
Diese Thiere haben eine mehr oder weniger langgestreckte Gestalt, welche sich nach beiden Körperenden bald mehr bald minder verschmälert. - Die Cuticula ist meist glatt, selten geringelt und trägt ofters submedian gestellte Borstenreihen. Was die Muskulatur betrifft, sind die Monohysteren polymyarier. Am Kopfende, welches selten ein wenig abgesetzt ist (M. macrura), stehen bei den meisten Arten Borsten: höchst selten ist eine Spur von Lippen vorhanden. Die Mundhöhle ist sehr klein, meist schüsselförmig, mit sehr dünnen Wänden, olne einige Bewaffnung, und der vordere Theil des Chitinrohrs des Oes. ist meist trichterförmig erweitert und setzt sich gleich in die Mundhöhle fort. Der Oes. ist cylindrisch und ist öfters an seinem Ende verdickt; höchst selten endigt er in einen wahren Bulbus (M. bulbifera d. M.). Der Darm zeichnet sich, bei durchfeillen dem Lichte, bei einigen durch eine sehr dunkle Farbe aus, besonders an der hinteren Hälfte, bei anderen (z. B. M. agilis) ist er heller braun: nach Bütschli baut er sich bei den ersteren aus einer Anzahl langgestreckter, in einer einfachen Reihe hinter einander stehender Zellen auf, welche bei sehr dunklem Inhalt helle Kerne zeigen, bei der zweiten Gruppe aber aus zwei alternirenden Zellenreihen, in welchen die Vertheilung der Körner gleichmässiger ist. Zwischen dem Hinterende des Oes. und dem Darme liegen öfters mehrere zellige Drüsen. Eine Ventraldrüse fehlt, wenigstens bei den, von mir beobachteten Arten. Ocellen hie und da vorhanden. Seitenorgane stets anwesend, kreisförmig oder elliptisch, bisweilen mit centralem Fleck (M. vulgaris). Weibliche Geschlechtsorgane am häufigsten unpaar, und die Geschlechtsöffnung ist dann sehr nach hinten gerückt, selten (z. B. bei der marinen M. setosa) symmetrisch paarig; bei den ersteren streckt sich dann die Geschlechtsröhre mehr oder weniger weit nach vorn hin aus. Zahl der ziemlich grossen Eier sehr beschränkt; selten vivipar (z. B. M. stagnalis B.). Beim Männchen finden sich keine prä- oder postanale $P a$ pillen: bisweilen aber zeigt die Cuticula an der Bauchseite vor dem After eine feine Ringeling (M. filiformis). Spicula mehr oder weniger gebogen, meist mit einfachem accessorischem Stücke, selten fehlt es (z. B. M. agilis d. M.). Schwanzdrüse stets vorhanden, nach Bütschli aus drei grossen einzelligen Drüsen bestehend, mit kleinem Ausführungsröhrchen.

Vorkommen und Lebensweise. Die Monohysteren leben in der Erde an den Wurzeln von Pflanzen, im süssen Wasser und im Meere. Von den 14 bis jetzt bekannt gewordenen Arten aus der Erde und dem süssen Wasser wurden 10 von mir in den Niederlanden beobachtet. Die Thierchen bewegen sich im Allgerneinen sehr lebhaft.

UEBERSICHT DER VON MIR BEOBACHTETEN MONOHYSTEREN.

1. Ein oder zwei Ocelli im Vorderende . . . . . . . . . . . . . . . 2.

Keine Ocelli . . . . . . . . . . . . . . . . . . . 3.

2. Nur ein Ocellus von rother Farbe mit zwei Linsen, in ziemlich grosser Entfernung hinter den Seitenorganen gelegen; ovipar. Im süssen Wasser . . . 1. paludicola.

Unmittelbar hinter den Seitenorganen zwei kleine rothe, etwas violetfarbige

Ocelli. Brackwassernematode. . . . . . . . . . . 2. microphthalma.

3. Oes. ohne hinteren Bulbus. . . . . . . . . . . . . . . . . 4 . 
Oes. mit Bulbus am Hinterende; die Körperlänge beträgt nur 0,33 m.m. . . . 10. bulbifera.

4. Darm bei durchfallendem Lichte von sehr dunkler, schwärzlicher Farbe . . . 5.

Darm bei durchfallendem Lichte hell braun gefürbt . . . . . . . . . . 8.

5. Entfernung der weibl. Geschlechtsöffnung vom After kürzer als die Länge des Schwanzes . . . . . . . . . . . . . 6 . . . . . . . . .

Entfernung der weibl. Geschlechtsöffnung vom After länger als die Länge des Schwanzes; Körpergestalt plump . . . . . . . . . . . . . . . . 6. dispar

6. Vorderende sehr verschmälert; Kopfende abgesetzt; weibl. Geschlechtsöffnung in der Körpermitte . . . . . . . . . . . . . . . . . . . . . 3. macrura

Vorderende mässig verschmälert, Kopfende nicht abgesetzt; weibl. Geschlechtsöffnung hinter der Körpermitte . . . . . . . . . . . . . . . . . 7

\%. Entfernung der Seitenorgane vom Vorderrande so gross wie die Breite des Vorderrandes. Erdbewohner.

4. vulgaris.

Entfernung der Seitenorgane vom Vorderrande grösser wie die Breite des Vorderrandes. Im süssen Wasser. . . . . . . . . . . . . . . . . 5. similis.

8. Körper mässig schlank; Lippen angedeutet, einige Drüsen an der weibl. Geschlechtsöffnung

7. filiformis.

Körper sehr schlank; keine Lippen, keine Drüsen an der Vulva . . . . . . 9.

9. Weibchen nur 0,5 m.m. lang, Vorderende sehr verschmälert, Seitenorgane weit nach hinten gerückt, sechs Kopfborsten . . . . . . . . . . . . 8 simplex.

Weibchen bis 1,6 m.m. lang, Vorderende wenig verjüngt, Seitenorgane in geringer Entfernung vom Vorderrande, zehn Kopfborsten . . . . . . . . 9. agilis.

Verzeichniss der übrigen, noch beschriebenen, von mir aber in den Niederlanden bis jetzt nicht beobachteten Monohysteren aus der Erde und dem süssen Wasser.

1. stagnalis Bast. = ocellata von Linstow. (Bastian, VII, pag. 97, Taf. IX, fig. 9-11, von Linstow, XXIX, pag. 12, Taf. II, fig. 31), England, Deutschland (Ratzeburger See).

2. longicaudata Bast. (Bastian, VI, pag. 98, Taf. IX, fig. 5, 6) England.

3. rivularis Bast. (Bastian, VII, pag. 9\%, Taf. IX, fig. 3, 4). England.

4. villosa Btsli (Bütschli, VII, pag. 64, Taf. V und VI, fig. 28). Deutschland (bei Frankfurt), Ungarn (nach Örley.)

\section{Monohystera paludicola d. M.}

Taf. II, fig. $\%$.

$\sigma^{7}+1,3 \% \mathrm{~mm} . \alpha=35 . \beta=6 . \gamma$ beim $\sigma^{7}=8$, beim $q=6-\%$.

Thiere von schlanker Gestalt, nach vorn ziemlich verschmälert. Cuticula glatt, ohne Borsten. 
Das Kopfende ist nicht abgesetzt, ohne eine Spur von Lippen, mit sechs kurzen Borsten bewaffnet. Die Mundhöhle verhält sich typisch. Die Seitenorgane (fig. 7a, \%c.) sind kreisförmig, mässig gross, nicht weit vom Vorderrande entfernt. Der Ocellus liegt auf $1 / 5$ der Länge des Oes. vom Vorderrande entfernt, erscheint in der Flächenansicht unpaar (fig. Yb), ist mit zwei kleinen, hellen linsenartigen Körperchen versehen, und hat bei auffallendem Lichte eine karminrothe Parbe. Der Oes. ist nach hinten allmälig erweitert und der Darm ist, wenigstens in seiner hinteren Abtheilung, von sehr dunkler Färbung. Das Thier ist ovipar; die Eier sind ziemlich klein. Die weibl. Geschlechtsöffnung liegt auf $1 / 3$ der Gesammtlänge vom Schwanzende entfernt; die weibl. Geschlechtsröhre ist einseitig und streckt sich bis in die Nähe des Hinterendes des Oes. aus. Der Schwanz hat bei beiden Geschlechtern dieselbe Gestalt, verschmälert sich in den zwei vorderen Dritteln ziemlich langsam, dann aber schneller mit dem letzten Drittel fadenformig. Die Spicula sind sehr verlängert und dünn, so lang wie der Schwanz beim Männchen und mit sehr rudimentärem accessorischem Stücke versehen: ihre Länge betrăgt 0,17 m.m. bei einer Körperlänge von 1,36 m.m. - Die Schwanzdrüse hat ein kleines Ausführungröhrchen. Die Cuticula ist beim Männchen an der Bauchseite vor dem After geringelt. (fig. \%e).

Fundort und Lebensweise. Diese Art bewohnt sehr häufig das süsse Wasser unserer Holländischen Gräben und scheint hier die M. stagnalis Bast. zu vertreten. Ihre Bewegungen sind lebhaft. Sie wurde bis jetzt nicht in anderen Ländern beobachtet.

Fundzeit. Das Thier fand ich im August geschlechtsreif.

Anmerkung. M. paludicola unterscheidet sich von M. stagnalis durch eine schlankere Körpergestalt, einen einfachen unpaaren Ocellus, und durch relativ längere Spicula: auch ist sie nicht vivipar, sondern ovipar.

\section{Monohystera microphthalma d.M.}

Taf. II, fig. 8 .

$\sigma^{7}$ 우 $0, y$ m.m. a beim or $35-40$, beim 우 $30 . \beta=5-6 . \gamma=3-4$.

Die seltene microphthalma hat eine ziemlich schlanke Körpergestalt, und das Vorderende ist wenig verjüngt. Die Haut ist ganz glatt, und trägt keine Borsten. Das Kopfende ist ein wenig abgesetzt, niedrig, scheibenförmig und mit sechs feinen, mässig kurzen Borsten gewaffnet. Die Seitenorgane sind kreisförmig, nicht weit vom Mundende entfernt, ohne centralen Fleck (fig. 8b); unmittelbar hinten ihnen finden sich zwei kleine rothe, ein wenig violettfarbige Ocelli (fig. 8b). Der Oes. schwillt nach hinten allmälig an. Der Darm zeigt die sehr dunkle, schwärzliche Färbung. Die weibl. Geschlechtsöffnung liegt nur sehr wenig hinter der Mitte und die Geschlechtsröhre ist einseitig, unpaar. Der Schwanz ist bei Männchen und Weibchen fadenförmig und läuft sehr fein aus: an der Spitze endigt er in ein nicht abgesetztes, cylindrisches Ausführungsröhrchen der Schwanzdrüse (fig. 8f.). 
Die Spicula sind schlank, gebogen, und das accessorische Stück ist mit einem dreieckigen, nach hinten gerichteten Fortsatze versehen.

Fundort und Lebensweise. Diese Art wurde bis jetzt nur auf der Insel Walcheren beobachtet, und lebt in feuchter von Brackwasser imbibirter Erde an den Wurzeln von Gräsern und Brackwasserpflanzen. Sie bewegt sich sehr lebhaft.

Fundzeit. Geschlechtsreif und erwachsen in August.

Anmerkung. Die M. microphthalma ist der M. macrura am nächsten verwandt, von welcher sie sich aber durch den Besitz der Ocellen gleich unterscheidet.

\section{Monohystera macrura d. M.}

Taf. III, fig. 9 .

$\sigma^{7}+0,77$ m.m. $\alpha$ beim $\sigma^{7} 45$, beim 우 $30-45 . \beta=5-\% . \gamma=2^{11} /_{2}-3$.

Auch diese Art, welche dieselbe Grösse erreicht als die vorige, ist sehr schlank und ihr Vorderende ist selır verschmälert. Die Cuticula ist glatt; hie und da, besonders am Schwanze des Männchens, sieht man auf ihr einige feine Börstchen. Das Kopfende ist abgesetzt, niedrig, scheibentörmig mit sechs sehr kleinen Borsten versehen. Die Seitenorgane sind mässig gross, kreisförmig, in einer dreimal so grossen Entfernung vom Mundende gelegen als die Breite des Vorderrandes beträgt. Der Oes. ist cylindrisch, an seinem Hinterende kolbig angeschwollen. Der Darm ist bei durehfallendem Lichte sehr dunkel, schwärzlich. Die weibl. Geschlechtsöffnung liegt in der Mitte des Körpers und die weibl. Genitalien, welche bei 0,4 m.m. langen Thieren schon entwickelt sind, sind einseitig und nach vorn hin ausgestreckt. Der Schwanz ist bei beiden Geschlechtern ziemlich ähnlich gestaltet, sehr verlängert, allmälig verjüngt und läuft haarfein aus. Die Spicula sind schlank, gebogen und das accessorische Stück trägt einen nach hinten gerichteten Fortsatz.

Fundort und Lebensweise. Diese Art ist sehr häufig und bewohnt die feuchte Erde der Wiesen und Marschgründe, so wohl in Gegenden wo nur süsses als dort wo nur brackisches Wasser gefunden wird. Sie bewegt sich sehr lebhaft und hat die sonderbare Eigenschaft öfters den Schwanz in einer rechten Ecke gebogen, zu tragen. - Meist trifft man Exemplare an, welche etwas kürzer sind als die angegebenen Maasse, etwa Thiere welche 0,5-0,6 m.m. lang sind.

Fundzeit: Es scheint diese Art das ganze Jahr hindurch in geschlechtsreifem Zustande vorzukommen.

Geographische Verbreitung: Deutschland (Erlangen, Laibach), Frankreich (Montpellier).

4. Monohystera vulgaris d. M.

Taf. III, fig. 10 .

ㅇ 1 m.m., $\sigma^{7}$ unbekannt. $\alpha=25-30 . \beta=5 . \gamma=3-4$.

Die Körpergestalt dieser Art ist mässig schlank, nach vorn hin ist sie ziemlich verschmälert. 
Die ganz glatte Cuticula trägt hie und da Börstchen über die gesammte Körperoberfläche zerstreut. Das Kopfende ist nicht abgesetzt und mit sechs mässig langen Borsten bewaffnet. Die Seitenorgane sind klein, kreisförmig, bisweilen mit centralem Fleck, in einer eben so grossen Entfernung vom Mundende gelegen als die Breite des Vorderrandes beträgt. Der Oes. schwillt nach hinten allmälig an. Der Darm hat eine sehr dunkle Färbung. Die weibl. Geschlechtsöffnung ist ungefähr auf $\%$ der Gesammtlänge vom Hinterende des Körpers entfernt, und ihre Entfernung vom After ist viel kürzer als die Länge des Schwanzes; sie ist schon bei 0,56 m.m. langen Thieren vorhanden, sowie auch die einseitige , unpaare Geschlechtsröhre, welche sich ziemlich weit nach vorn hin ausstreckt. Das Thier ist schon geschlechtsreif und eitragend, als es die Länge von 0,7 m.m. erreicht hat, selten trifft man 1 m.m. lange Exemplare an, meist aber kleinere. Der Schwanz ist fadenförmig, allmälig und regelmässig verschmälert.

Fundort und Lebensweise. Diese Art ist sehr häufig und bewohnt die feuchte Erde der Wiesen, Marschgründe und Waldgegenden, an den Wurzeln von Gräsern, Moosen und allen dort wachsenden Pflanzen. Ganz erwachsene, 1 m.m. lange Thiere fand ich im Schlamme eines Süsswassergrabens. Das Thierchen ist sehr lebhaft und sonderbar ist es, dass die Männchen mir noch unbekannt geblieben sind.

Fundzeit. Das ganze Jahr hindurch.

Geographische Verbreitung. Deutschland (Erlangen), Frankreich (Montpellier).

5. Monohystera similis Btsli.

Bütschli, XX, pag. 62, Taf. V, fig. 30a-b.

Taf. III, fig. 11 .

ㅇ 0,9 m.m., of unbekannt. $\alpha=30 . \beta=4 \frac{1}{2}-6 . \gamma=5$.

Anch diese Art gehört zu den typischen MIonohysteren, hat einen mässig schlanken Körper und das Vorderende ist sehr verschmälert. Die Cuticula ist glatt. Das Kopfende ist nicht abgesetzt und trägt sechs sehr kurze Borsten, aber keine Spur von Lippen. Die Seitenorgane sind kreisförmig, klein und sind verhältnissmässig mehr nach hinten gelegen als bei Monohystera vulgaris (fig. 11a). Der Oes. schwillt nach hinten allmälig an und der Darm hat eine sehr dunkle Färbung. Die weibl. Geschlechtsöffnung liegt ungefähr auf $1 / 3$ der Körperlänge vom Hinterende entfernt; ihre Entfernung vom After ist kürzer als die Länge des Schwanzes. Dieser ist allmälig verschmälert, läuft aber nicht haarfein aus, und ist mit einem kegelförmigen Ausführungsröhrchen der Schwanzdrüse versehen (fig. 11c).

Fundort und Lebensweise. Die M. similis bewohnt häufig das süsse Wasser und scheint in der Erde nicht vorzukommen; sie ist sehr lebhaft.

Fundzeit. Geschlechtsreif und eitragend beobachtete ich diese Art in den Monaten April und Mai.

Geographisclee Verbreitung. Deutschland (Main, Bütschli). 
Anmerkung. Diese Art ist der vorigen nahe verwandt, unterscheidet sich aber durch das, nach vorn hin mehr verschmälerte Vorderende und einen kïrzeren Schwanz.

6. Monohystera dispar Bast.

Bastian VII, pag. 9\%, Taf. IX, fig. 1 und 2.

Synon: Monohystera crassa Btsli, Bütschli XX, pag. 63.

Taf. III, fig. 12.

우 $0,8 \mathrm{~m} . \mathrm{m}$. (nach Bastian 1,1 m.m. erreichend). $\alpha=20-25 . \beta=41 / 2-51 / 2 \cdot \gamma=6-\%$.

Dieses Thierchen hat eine sehr plumpe Körpergestalt; das Vorderende verschmälert sich fast nicht, und ist breit abgestutzt. Die Cuticula ist glatt und trägt keine Börstchen. Das Kopfende ist nicht abgesetzt nnd mit sechs sehr kurzen Börstchen versehen, ohne eine Spur von Lippen. Die kreisförmigen Seitenorgane sind klein und liegen in geringer Entfernung vom Mundende (fig. 12a). Der Oes. ist cylindrisch und schwillt nach hinten allmälig an (fig. 12b). Der Darm ist bei dieser Art am dunkelsten gefärbt, ja erscheint ganz schwärzlich, und die hinteren Lappen am Ende des Oes. sind sehr ausgeprägt. Die weibl. Geschlechtsöffnung liegt ungefähr auf $1 / 3$ der Körperlänge vom Hinterende entfernt; ihre Entfernung vom After is stets länger als die Länge des Schwanzes. Dieser verjüngt sich allmälig und hat ein kurzes kegelförmiges Ausführungsröhrchen der Schwanzdrüse.

Fundort und Lebensweise. Diese niedliche Art ist ziemlich häufig und bewohnt die feuchte Erde der Wiesen und Marschgründe; auch fand ich sie in Waldgegenden. Thre Bewegungen sind sehr lebhaft und sie hat, wie mehrere Arten dieser Gattung, die sonderbare Eigenschaft, sich gerade ausgestreckt unbeweglich zu halten, wenn ihr Gefahr zu drohen scheint. (Vgl. Seite 22).

Fundzeit. Ich fand eitragende Exemplare in December; sie kommt aber auch in den Sommermonaten geschlechtsreif vor.

Geographische Verbreitung. England (Bastian), Deutschland (Frankfurt a.M. nach Bütschli).

7. Monohystera filiformis Bast.

Bastian, VII, pag. 98, taf. IX, fig. 7 und 8.

Synon: Monohystera rustica Btsli, Bütschli XX, pag. 63.

Taf. III, fig. 13 .

Männchen 0,7 m.m.; wahrscheinlich erreicht es aber auch die Grösse des Weibchens, welches bis 1 m.m. lang wird. $\alpha$ beim $\sigma^{7} 30-35$, beim ㅇ 30. $\beta=5-6 . \gamma=4-6$ nach der Grösse. 
Auch bei dieser Art beobachtete ich dieselbe eigenthümliche Erscheinung wie bei M. vulgaris. Während die, in der Erde lebenden Thiere nie grösser sind als 0,7 m.m. (bei beiden Geschlechtern) und bei dieser Grösse eitragend, fand ich im Schlamme aus dem Boden eines Süsswassergrabens weibliche Exemplare, welche die Länge von $1 \mathrm{~m} . \mathrm{m}$. erreicht hatten: diese Thiere kamen gänzlich mit den erdbewohnenden Formen überein, nur waren sie in der Mitte des Körpers dicker, eine Folge der stärkeren Entwickelung der Geschlechtsorgane. Ist es nicht möglich, dass diese Thiere sich im vorgerückten Alter in den nassen Schlamm hineinbegeben, behufs der geschlechtlichen Entwickelung? - Ich vermuthe dies wirklich, weil ich mir diese Erscheinung sonst nicht erklăren kann.

Der Körper ist mässig schlank, nach vorn hin wenig verjüngt. Die glatte Cuticula trägt hie und da zerstreute Börstchen. Das nicht abgesetzte Kopfende zeigt eine Andeutung von Lippen und ist mit sechs kurzen Börstchen versehen. Die kleinen Seitenorgane sind kreisförmig und haben in den meisten Fällen einen centralen Fleck. Der Oes. (fig. 13b) ist in seiner Mitte verschmälert und an seinem Hinterende knopfartig angeschwollen. Der Darm hat eine nicht dunkle Färbung, sondern sieht bei durchfallendem Lichte hell braun aus und hat an seinem Anfange mehrere Drüsen. Die weibl. Geschlechtsöffnung und die weibl. Geschlechtsorgane sind nach Bütschli, dessen M. rustica zweifelsohne mit dieser Art identisch ist, schon bei wenig über 0,4 m.m. langen Thieren vorhanden; die kleinsten Exemplare mit Geschlechtsöffnung und Genitalien, welche ich beobachtete, waren 0,57 m.m. lang, während Exemplare von 0,45 m.m. noch keine Spur einer Geschlechtsöffnung oder von Spicula zeigten. Bei $0, \%-1 \mathrm{~m} . \mathrm{m}$. langen Weibchen liegt die Vulva auf $1 / 3$ der Körperlänge vom Hinterende entfernt, bei jüngeren auf $3 / 7$ der Gesammtlänge; die Geschlechtsröhre ist einseitig und streckt sich ziemlich weit nach vorn hin aus; an der Vulva finden sich einige Drüsen. Das Ei eines 0,7 m.m. langen Thieres hatte eine Länge von 0.04 m.m. Der Schwanz hat bei beiden Geschlechtern die gleiche Gestalt, ist fadenförmig und allmälig verjüngt, mit kurzem dreieckigem Ausführungsröhrchen. Die Spicula (fig. 13e) sind gebogen, viel kleiner als der Schwanz, mit kleinem accessorischem Stücke, ohne nach hinten gerichteten Fortsatz. Die Haut ist beim Männchen vor dem After quergeringelt.

Fundort und Lebensweise. Diese selir liäufige Art ist omnivag; man findet sie in den Wiesen wie im sandigen Boden der Dünenstriche und auch im Walde. Lebhaft sind ihre Bewegungen und auch sie hat die Gewohnheit sich bisweilen gerade ausgestreckt und unbeweglich zu halten, wenn sie Gefahr zu spüren meint.

Geographische Verbreitung. England (Sydenham, Gegend des Flusses Blackwater nach Bastian), Deutschland (Erlangen, Laibach, Gegend von Frankfurt a.M.), Frankreich (Montpellier).

Fundzeit. Das ganze Jahr hindurch. In Februar fand ich eitragende Thiere in der Erde, und die $1 \mathrm{~m} . \mathrm{m}$. langen Exemplare aus dem Schlamme des Süsswassergrabens beobachtete ich in October: ich fand die Art aber auch in fast allen anderen Monaten in geschlechtsreifem Zustande. 
8. Monohystera simplex d. II.

Taf. IV, fig. 14 .

Q $0,5 \mathrm{~mm} ., \sigma^{7}$ unbekannt. $\alpha=35-45 . \beta=4-4^{1} / 2 . \gamma=31 / 2-4$.

Der Körper dieser Art ist sehr schlank, und verschmälert sich sehr nach vorn hin. Die glatte Cuticula trägt mehrere, hie und da zerstreute Börstchen. Das Kopfende ist nicht abgesetzt, ohne Lippen, mit sechs mässig grossen Borsten versehen. Die kreisförmigen Seitenorgane sind weit nach hinten gerïckt. Der 0es. schwillt wenig nach hinten an. Der Darm erscheint bei durchfallendem Lichte nicht dunkel, sondern sehr hell gefärbt. Die weibl. Geschlechtsöffnung liegt auf $3 / 7$ der Gesammtlänge vom Hinterende entfernt. Der Schwanz ist fadenförmig, regelmässig verschmälert und läuft haarfein aus mit spitzem Ausführungsröhrchen der Schwanzđrüse.

Fundort und Lebensweise. Diese Art ist omnivag und so liäufig, dass man sie stets in jedem Rasen antrifft: sowohl im sandigen Boden der Dünen- und Heidestriche, im Walde wie in der feuchten Erde von Wiesen und Marschgründen lebt die einfach gebaute M. simplex. Das Thierchen bewegt sich lebhaft; sonderbar ist es, dass das Männchen mir noch unbekannt blieb.

Fundzeit. In allen Monaten des Jahres wurde diese Art beobachtet in geschlechtsreifem Zustande. Geographische Verbreitung. England (Sydenham), Deutschland (Erlangen, Laibach), Schweiz (Ufer vom Roth See bei Luzern), Frankreich (Montpellier).

9. Monohystera agilis d. M.

Taf. IV, fig. 15 .

$\sigma^{7} 1 \mathrm{~mm}$., ㅇ $1,6 \mathrm{~mm}$. a beim $\sigma^{7} 45$, beim $ᄋ$ 35-45. $\beta$ beim $\sigma^{7} 5$, beim ganz erwachsenen $ᄋ$ 6-8. $\gamma=7-9$.

Eine selir scllanke, wurmartige, fadenförmige, nach vorn sehr wenig verjüngte Gestalt hat die 11. agilis. Die Haut erscheint bei dieser Art âusserst fein quergeringelt; die Ringelung scheint aber auf einer inneren Schicht beschränkt. Ueber der gesammten Körperoberfläche stehen zahlreiche grosse, in den vier Submedianlinien gestellte Börstchen zerstreut und zwar beim Männchen sowohl als beim Weibchen.

Das Kopfende ist nicht abgesetzt, oline Lippen, trägt aber zeln lange Borsten, sechs grosse, von welchen die vier submedianen noch jede von einer kleineren begleitet ist. (Fig. 15a). Die kleinen Seitenorgane sind kreisförmig und liegen in geringer Entfernung vom Mundende. Der Oes. ist cylindrisch und schwillt nach hinten wenig an. Der Darm erscheint bei durchfallendem Lichte hellbraun gefärbt und nicht dunkel wie bei den typischen Monohysteren. Die weibl. Geschlechtsöffnung liegt stets auf ${ }_{5}$, der Gesammtlänge vom Hinterende entfernt; ihre Entfernung vom After ist zweimal so lang als die Länge des Schwanzes. Die weibl. Geschlechtsröhre ist einseitig und mässig lang; ich beobachtete stets nur ein einziges Ei. Der Schwanz hat beim Männchen wie beim Weibchen die gleiche Gestalt, sieht ziemlich plump 
aus und ist allmälig und regelmässig zugespitzt. Die Spicula (Fig. 15d) sind schlank, ohne accessorisches Stück.

Fundort und Lebensweise. Unsere Art ist ein ziemlich häufiger Bewrohner der feuchten Wiesen und Marschgründe; auch findet man sie in der humusreichen Erde des Waldes so wie an den Wurzeln von Pflanzen, welche am Ufer von Süsswasser- oder Brackwassergräben wachsen. Sie bewegt sich lebhaft, wurmartig.

Fundzeit. Ich fand die Art sowohl im Winter wie im Sommer geschlechtsreif und beobachtete sie mit entwickelten Genitalien im Frühjahre und im Herbst.

Geographische Verbreitung. Bis jetzt nur in den Niederlanden aufgefunden.

Anmerkung. M. agilis mihi scheint die in Deutschland lebende M. villosa Btsli in den Niederlanden zu vertreten und unterscheidet sich von ihr gleich durch die Lage der weibl. Geschlechtsöfnung. Auch scheinen die, auf dem Körper stehenden Borsten bei der Deutschen Art bloss beim Weibchen vorzukommen.

10. Monohystera bulbifera d. M.

Tafel IV, Fig. 16.

.q $0,33 \mathrm{~mm}$., $\sigma^{7}$ unbekannt. $\alpha=25 . \beta=5 . \gamma=7$.

Eine abweichende Art, welche ich, weil das Männchen unbekannt blieb, vorläufig zu den Monohysteren bringe. Die Körpergestalt ist ziemlich plump, das Vorderende wenig verschmälert. Die Cuticula ist glatt und ohne Borsten. Das Kopfende ist nicht abgesetzt, ohne Lippen, mit vier sehr feinen Börstchen versehen. Die Seitenorgane sind eirund (oder spiralig?) mit centralem Fleck. Der Oes. ist cylindrisch und schwillt nach hinten zu einem ächten Bulbus an. Der Darm hat eine sehr helle Farbe. Die weibl. Geschlechtsöftnung liegt in der Mitte des Körpers; die Genitalien sind einseitig, unpaar. Der Schwanz hat eine plumpe Gestalt, ist regelmässig zugespitzt und hat ein sehr kurzes Ausführungsröhrchen der Schwanzdrüse.

Fundort und Lebensweise. Dieses winzige Thierchen wurde nur einmal im sandigen Boden der Dünenstriche unweit Haag von mir angetroffen und ist gewiss sehr selten. Es bewegt sich lebhaft und ist im September exwachsen.

Anmerkung. Diese Art unterscheidet sich gleich durch den ächten Bulbus, welcher bei den anderen einheimischen Monohysteren fehlt.

VI. Tripyla Bast. Btsli.

Bastian, VII, pag. 115. Bütschli, XX, pag. 48 und XXI, pag. 33.

Die Tripylen bilden eine natürliche Gruppe, welche auf einer höheren Stufe der Organisation steht als die vorige Gattung. Es sind Thiere mit mehr oder weniger schlanker Körpergestalt, welche sich nach 
vorn hin weniger verschmälert als nach hinten. Die Haut ist geringelt oder glatt. Am Kopfende stehen drei Lippen in der bekannten Anordnung, welche von dem Halstheile des Körpers nicht scharf abgesetzt sind, sondern darin übergehen. Auf diesen Lippen stehen allein Papillen oder Papillen und Borsten, und zwar immer in drei Reihen, welche entweder allein aus Papillen oder theilweise aus Borsten bestehen.

Eine IIundhöhle fehlt vollständig; der deutlich fibrilläre Oes. ist cylindrisch, an den beiden Enden meist ein wenig angeschwollen; in einiger Entfernung von der Mundóffnung ist das Chitinrohr local verdickt mit einem zahnartigen Vorsprunge, der wohl bei der Nahrungsanfnahme functionnirt. Zwischen dem hinteren Ende des Oes. und dem Darme sieht man eine mehr oder weniger grosse Ansammling körniger, drüsenartiger Zellen. Der Darm ist, wenigstens bei den typischen Arten, deutlich aus polygonalen Zellen zusammengesetzt. Das Nervensystem ist undeutlich. Ein ventraler Gefässporus fehlt. Ocellen nie vorhanden. Was die Seitenorgane betrifft, so kommen zweifelsohne Homologa derselben bei einigen Arten vor: bei diesen sah ich nämlich, in einiger Entfernung vom Mundende, in der Medianansicht feine Fäden, vom Integument in schräger Richtung nach innen verlaufen, (Vergl. z. B. Taf. V, fig. $20 b$ und 21b). Die weibl. Geschlechtsorgane sind paarig symmetrisch, oder unpaar, einseitig: die Vulva wird öfters von Drüsen umstellt (z. B. filicaudata, papillata), und die Ovarien sind zurückgebogen. Die wenig zahlreichen Eier sind ziemlich gross. Auch die männliche Geschlechtsröhre ist bei den typischen Arten zweitheilig, sodass ihre Aeste nach vorn und hinten gerichtet sind. Selten fehlen die männlichen Papillen; bei den, von mir beobachteten Männchen der typischen Arten dagegen liegen zahlreiche Papillen in einer medianen Reihe an der Bauchseite, welche vom After bis zum Kopfende fortläuft. Die Spicula sind von plumper Gestalt ohne oder mit kleinem accessorischem Stücke: öfters zeigen dieselben einen eigenthümlichen dunklen Faden in der Mittellinie (Vergl. z. B. Fig. 1\%c). Die Schwanzspitze ist bei den typischen Arten mit einer characteristischen Spinnwarze versehen, welche die ganze Breite des Schwanzendes einnimmt, und nicht in eine Röhre ausgezogen ist: solch eine feine Röhre sieht man aber bei den beiden abweichenden Arten, welche auch in mehreren anderen Beziehungen von den typischen Formen unterschieden sind.

Fundort und Lebensweise. Man kennt jetzt zehn Arten dieser Gattung, von welchen eine im Meere lebt. Im Allgemeinen sind sie nicht sehr häufig: von den, in den Niederlanden beobachteten Formen, lebt eine ausschliesslich im sandigen Boden der Dünenstriche, während die anderen in der feuchten Thonerde von Wiesen, Waldgegenden und Marschgründen gefunden werden. Es sind alle lebhafte, bewegliche Thiere.

\section{DEBERSICHTSTABELLE DER BEOBACHTETEN ARTEN.}

1. Weibl. Geschlechtsorgane paarig symmetrisch, Schwanzende ohne abgesetztes Ausführungsröhrchen der Schwanzdrüse . . . . . . . . . . . . . . . 2.

Weibl. Geschlechtsorgane einseitig, unpaar; Schwanzende mit kleinem, abgesetztem Ausführungsröhrchen. . . . . . . . . . . . . . . . . . . . . 5.

2. Kopfende mit Papillen und Borsten . . . . . . . . . . . . . . 3. 
Kopfende bloss Papillen tragend. . . . . . . . . . . . . . . . . 4

3. Körper ziemlich schlank; Schwanz schlank, nicht fadenförmig, 1/6 -1/7 der Körperlänge lang . . . . . . . . . . . . . . . . 1. setifera.

Körper sehr schlank; Schwanz sehr schlank, fadenförmig, 1/4-1/5 der Totallänge messend

2. filicaudata.

4. Grössere Art; weibl. Geschlechtsöffnung fehlt bei einer Körperlänge von 1,6 mm. 3. papillata. Kleinere Art; weibl. Geschlechtsorgane bei einer Körperlänge von 1,4 mm. vollkommen entwickelt.

$$
\text { 4. affinis. }
$$

5. Weibl. Geschlechtsöffnung $1 / \%$ der Totallänge vom Hinterende entfernt. Schwanz kurz, regelmässig verschmälert. 5. monohyster $\alpha$. Weibl. Geschlechtsöffnung 1/3 der Gesammtlänge vom Hinterende entfernt. Schwanz sehr kurz, kegelförmig . .

6. arenicola.

Die übrigen, noch beschriebenen, von mir aber nicht aufgefundenen Arten sind:

1. marina Btsli, Bütschli, XXI, pag. 33, Strandzone der Kieler Bucht.

2. glomerans Bast., Bastian, VIl, pag. 115, England, im Süsswassersehlamme.

3. salsa Bast., Bastian, VII, pag. 116, England, im Brackwasser.

4. intermedia Btsli, Bütschli, XX, pag. 52, feuchte Erde, Frankfurt a. M.

1. Tripyla setifera Btsli.

Bütschli, XX, pag. 51, Taf. VI, Fig. 36a-f.

de Man, XXVI, pag. 90.

Taf. IV, Fig. $1 \%$.

$\sigma^{7}$ \& $1, \% \mathrm{~mm} . \alpha=30-35 . \beta=5 . \gamma=6--7$ (nach Bütschli 8).

Diese Art hat eine ziemlich schlanke Gestalt, mit wenig verschmälertem Vorderende. Die Cuticula ist fein geringelt. Gleich um die Mundöffnung steht ein Kreis von Papillen auf den Lippen; hinter diesen befinden sich sechs grosse Borsten, auf welchen wieder ein äusserster Kreis von Papillen folgt. (Fig. 1\%a). Im Chitinrohre des Oes. liegt in einiger Entfernung vom Mundende ein zahnartiger Vorsprung. Des. und Darm zeigen nichts besonderes. Die weibl. Geschlechtsorgane sind paarig symmetrisch, ziemlich kurz; die Vulva liegt ein wenig hinter der Körpermitte. Die Spicula haben eine plumpe Gestalt mit einem einzigen Verdickungsstreife und mit rudimentärem accessorischem Stucke. Eine mediane Reihe von präanalen Papillen beim Mannchen, welche sich vom After bis in die Năhe des Kopfendes ausstreckt. Der Schwanz ist schlank, allmälig verschmälert.

Fundort und Lebensweise. Dieses Thier ist nicht häufig und lebt sowohl in der feuchten Erde der Holländischen Wiesen wie anch in der humusreichen Erde des Waldes. Es bewegt sich lebhaft.

Geographische Verbreitung. Deutschland (Erlangen, Frankfurt a. M. nach Bütschli).

Fundzeit. Ich fand die Art in den ersten sechs Monaten des Jahres und zwar geschlechtsreif im Januar. 
2. Tripyla filicaudata d. M.

Taf. IV, Fig. 18.

$\sigma^{7} 1,7 \mathrm{~mm}$., ㅇ $2 \mathrm{~mm} . \alpha=40-45$. $\beta$ beim $\sigma^{7} 5$, beim 오 $6 . \gamma=4-5$.

Der Körper hat eine sehr schlanke Gestalt, mit wenig verschmälertem Vorderende. Die Haut ist fein geringelt. Das Kopfende ist durch eine geringe Einschnürung ein wenig abgesetzt (Fig. 18a); um die Mundöffnung findet man erst einen Kreis von kleinen kegelförmigen Papillen, zvei auf jeder Lippe: darauf folgen sechs kraftige Borsten und etwas hinter diesen noch sechs kleinere (Fig. 18a). Das Chitinrohr des Oes. zeigt eine starke locale Verdickung mit chitinösem Vorsprunge: der Oes. ist cylindrisch und schwillt nach hinten etwas an; zwischen ihm und dem Darme liegt eine grosse Ansammlung von zelligen Drüsen. Auch sieht man einige Drüsen am Enddarm. Die weibl. Geschlechtsöffnung befindet sich in der Körpermitte oder ein wenig vor der Mitte; die Genitalien sind paarig symmetrisch, gross; an der Vulva liegen einige Drüsen. Es wird nur ein einziges grosses Ei producirt. Die Spicula haben eine plumpe Gestalt mit centralem Verdickungsstreife, und werden von keinen accessorischen Stücken begleitet. Beim Männchen liegen 14-15 präanale Papillen vor dem After, welche sich von diesem bis in die Nähe des Mundendes ausstrecken. Der Schwanz ist selh verlängert, fadenförmig, fein auslaufend mit abgestutzter Endspitze und eigenthümlicher Spinnwarze, meist nach innen nach der Bauchseite gebogen und beim Männchen wie beim Weibchen gleich gestaltet.

Fundort und Lebensweise. Ich fand diese schöne Art, welche sich lebhaft bewegt, stets in feuchter, von süssem Wasser durchtränkter Erde der Wiesen und Marschgründe; sie ist ziemlich häufig.

Geograplische Verbreitung: England (Sydenham).

Fundzeit. Die Trip. flicaudata ist im Frühjahre so wie im Herbste geschlechtsreif: sowohl in Mårz wie in November fand ich eitragende Weibchen und erwachsene Männchen.

Annerkung. Einmal beobachtete ich in April ein Weibchen dieser Art, welches, statt einer, zwei Geschlechtsöffnungen, nicht weit von einander gelegen, besatz: gewiss eine Monströsität.

\section{Tripyla papillata Btsli.}

Bütschli, XX, pag. 52, Taf. VI, Fig. $35 a-b$ und XXV, pag. 381, Taf. XXIV, Fig. 11.

Taf. V, Fig. 19.

$\sigma^{7}$ ㅇ $3,2 \mathrm{~mm} . \alpha=35-40 . \beta=6-7 . \eta$ beim $\sigma^{7} 6$, beim $q=8$.

Die schöne Tripyla papillata, die grösste unserer einheimischen Arten, besitzt eine schlanke Gestalt und das Vorderende ist wenig verschmälert. Lie Haut zeigt eine schöne Querringelung. Auf den Lippen liegen drei Kreise von kleinen Papillen gleicher Grösse (Fig. 19a). Die locale Verdickung im Chitinrohre des vorderen Theiles des Oes. ist nur schwach entwickelt; der letztere ist an beiden Enden etwas angeschwollen, und die Drüsen am Hinterende sind gross. Der Darm zeigt nichts besonderes und der Ring der Nervensystems ist deutlich zu sehen. Die weibl. Geschlechtsöffnung, welche bei 1,6 mm. langen Thieren noch vollständig fehlt, liegt beim erwachsenen Weibchen ein wenig hinter der Mitte des Körpers. An der 
Vulva finden sich einige Drüsen und die Geschlechtsorgane sind paarig symmetrisch. Bütschli beobachtete vier Eier im Uterus. Die Spicula sind plump, mit dünnen Wänden, mit chitinösem Streife in der Mittellinie und mit rudimentären accessorischen Stücken. Eine mediane Reihe von Papillen vor dem After beim Männchen. Der Schwanz hat bei beiden Geschlechtern die gleiche Gestalt, verschmålert sich nämlich ganz allmälig und regelmässig.

Fundort und Lebensweise. Ich beobachtete diese seltene Art in der feuchten Erde der Wiesen; die Thiere bewegen sich sehr lebhaft. - Bütschli fand sie im süssen Wasser.

Geograplische Verbreitung. Deutschland (Main nach Bütschli).

Fundzeit. Geschlechtsreife Exemplare fand ich sowohl im Frühjahre wie im Sommer.

4. Tripyla affinis $d$. M.

Taf. V, Fig. 20.

J $ᄋ 1,4 \mathrm{~mm} . z=25-30 . \beta=5-6 . \gamma=5-6$.

Diese Art ist verhältnissmässig wenigcr schlank als die vorige, der sie übrigens nahe verwandt ist. Das Vorderende ist wenig verjüngt. Die Haut ist quergeringelt. An den drei Lippen beobachtet man drei Kreise von kleinen Papillen; diejcnigen des mittleren Kreises sind ein wenig grösser als die der beiden anderen. (Fig. 20a). Gleich hinter den Papillen des dritten Kreises liegen laterale Organe, welche ich als die Homologa der Seitenorgane betrachte (Fig. 20b). In medianer Lage sieht man an diesen Stellen einen feinen Faden in schräger Richtung nach innen verlaufen, den ich als zu diesen Organen gehörig betrachte. Der Verdauungstractus und das Nervensystem verhalten sich wie bei der papillata. Die weibl. Geschlechtsöffnung liegt in oder ein wenig hinter der Mitte des Körpers; die Genitalien sind paarig symmetrisch und ziemlich kurz, bei einer Körperlänge von 1,4 mm. gänzlich entwickelt und eitragend. Ich fand höchstens zwei Eier im Uterus: die Länge derselben beträgt $0,094 \mathrm{~mm}$. Bei einer Körperlänge von $1 \mathrm{~mm}$. beobachtet man nur noch die eirunde Genitalanlage. Die Spicula sind plump, dünnwändig, ohne chitinösen Streif in der Mittellinie, mit rudimentăren accessorischen Stücken. Vor dem After sieht man beim Männchen eine mediane Reihe von 14, in gleichen Abständen gelegenen Papillen, welche bis in die Nähe des Mundendes vorkommen; die vorderste liegt gleich hinter der localen Verdickung in der Chitinröhre des Kopfendes, die hinterste ungefähr beim inneren Ende der Spicula. Der Schwanz zeigt bei beiden Geschlechtern die gleiche Gestalt, ist nämlich allmälig und regelmässig verschmälert, am Ende ein wenig verdickt.

Fundort und Lebensweise. Diese Art ist ziemlich häufig und bewohnt die feuchte Erde der Wiesen und Marschgründe an den Wurzeln der dort wachsenden Pflanzen. Sie bewegt sich lebhaft.

Geographische Verbreitung. Ausser den Niederlanden nirgendwo sonst beobachtet.

Fundzeit. Die Art wurde sowohl im Frühjahre (März) wie im Hochsommer geschlechtsreif beobachtet: im Frühjahre kommen aber auch junge Exemplare mit erwachsenen zugieicher Zeit vor.

Anmerkung. Auch die Trip. intermedia Btsli ist unserer Art nächst verwandt; sie unterscheidet sich aber von dieser gleich durch den ganz allmälig und regelmässig verschmälerten Schwanz. 


\section{Tripyla monohystera d. M.}

Taf. V, Fig. 21.

of $1,8 \mathrm{~mm} . \sigma^{7}$ unbekannt, $\alpha=45-55 . \beta=5 . \gamma=12$.

Diese und die folgende Art weichen von den jetzt betrachteten Tripylen in mehreren Beziehungen ab, so dass ich sie als unechte bezeichnen will.

Die erste hat einen sehr schlanken, fadenförmigen Körper mit wenig verjüngtem Vorderende. Die Haut ist glatt, ungeringelt. Das nicht abgesetzte Kopfende zeigt drei Lippen: gleich um die Mundöfnung, liegt auf diesen Lippen ein vorderer Kreis von ziemlich grossen Papillen; hinter den Papillen stehen sechs grosse, kräftige. Borsten und ein wenig hinter den letzteren beobachtet man noch vier anderen, welche ein wenig kürzer sind und submedian gestellt. In geringer Entfernung hinter den Borsten der zweiten Reihe kommen die eigenthümlichen Organe vor, welche ich als Homologa der Seitenorgane betrachte: in medianer Lage des Kopfendes (Fig. 21b) sieht man nämlich laterale Querrinnen, von welchen ein feiner Faden nach innen verläuft. Die Seitenfelder sind gross. Der langgestreckte Oes., in dessen Chitinröhre keine locale Verdickung zu sehen ist, schwillt nach hinten allmälig, aber wenig an; die Drüsen an seinem hinteren Ende sind sehr schwach entwickelt. Der Darm sieht anders aus als bei den vier vorigen Arten: die feinen Körnchen sind nämlich gleichmässig zerstrent und nicht zu kleinen Häufchen gruppirt; vielleicht steht diese Erscheinung mit einer anderen histologischen Structur in Zusammenhange. Die weibl. Geschlechtsöffnung ist sehr weit nach hinten gerückt, und liegt auf 1/5 der Gesammtlänge vom Hinterende des Körpers entfernt, während ihre Entfernung vom After 11/2 mal so lang ist als die Länge des Schwanzes. Die Geschlechtsröhre ist einseitig, unpaar, nach vorn hin ausgestreckt und kurz; der Uterus scheint aber einen kurzen hinteren Ast zu besitzen. Der Schwanz (Fig. 21c) ist kurz, regelmässig verschmälert und trägt, im Gegensatze zu den ächten Tripylen, eine sehr kurze Ausführungsröhre der Schwanzdrüse (Fig. 21d).

Fundort und Lebensweise. Die wurmartig und lebhaft sich bewegende Art bewohnt die feuchte Erde der Marschgründe an den Wurzeln von Gräsern und anderen dort wachsenden Pflanzen und gehört zu den nicht sehr häufigen Formen.

Geographische Verbreitung. Noch in keinem anderen Lande aufgefunden.

Fundzeit. Ich fand geschlechtsreife Exemplare fast das ganze Jahr hindurch (März, Sommermonate, November).

\section{Tripyla arenicola d. M.}

Taf. V, Fig. 22.

ㅇ 1,4 mm., $\sigma^{\top}$ unbekannt. $\alpha=30 . \beta=6 . \gamma=20$.

Dieses Thier ist weniger schlank als die vorige Art, und sein Körper verjüngt sich nach vorn zu wenig. Die Haut ist glatt, ungeringelt. Am Kopfende stehen, wie immer, drei, nicht kräftige 
Lippen mit einem vorderen Kreise von kleinen Papillen und einem darauf folgenden Kreise von sechs sehr kräftigen Borsten, von welchen jede submediane noch von einer kleineren Borste begleitet ist. (Fig. 22a). Das Chitinrohr des Oes. zeigt keine locale Verdickung und dieser schwillt nach hinten ganz allmälig und regelmässig an. Die Drüsen am hinteren Ende des Oes. sind ziemlich ausgeprägt und der Darm hat dieselbe Structur wie bei der Tripyla monolystera. Die weibl: Geschlechtsöffnung liegt auf $1 / 3$ der Gesammtlänge vom Hinterende entfernt und die kurze Geschlechtsröhre ist einseitig, unpaar und nach vorn gerichtet: auch hier hat der Uterus einen hinteren Ast. Der Schwanz (Fig. 22c) ist sehr kurz, kegelförmig mit abgerundeter Spitze, welche ein sehr kurzes kleines Ausführungsröhrchen der Schwanzdrüse trägt (Fig. 22d).

Fundort und Lebensweise. Die lebhafte arenicola ist ein typischer Sandnematode und bewohnt ausschliesslich die feuchte sandige Erde der Dünenstrichen, wo sie aber häufig vorkommt.

Geographische Verbreitung. Noch in keinem anderen Lande aufgefunden.

Fundzeit. Das Thier ist in März und August geschlechtsreif und erwachsen.

Anmerkung. Es würde mich nicht wundern, wenn die Männchen dieser und der vorigen Art auch wesentliche Unterschiede von den Månnchen der echten Tripylen zeigen würden: vorläufig mögen sie allen in derselben Gattung vereinigt bleiben.

\section{Desmolaimus d. M.}

(von $\delta \varepsilon \sigma \mu \delta \xi$, eine Leiste und r.sısós, Mundhöhle).

Die seltene Gattung Desmolaimus weicht in mancher Beziehung von den übrigen Gattungen ab. Der Körper hat eine mässig schlanke Gestalt, welche sich nach beiden Enden hin verschmälert. Die Cuticula ist glatt, ungeringelt, ohne Seitenmembran. Das nicht abgesetzte Kopfende zeigt keine Lippen oder Papillen, trägt aber Borsten. Die Seitenorgane sind kreisförmig. Die Mundhöhle ist sehr klein, becherförmig, mit sehr dünnen Wänden und mit drei concentrischen, parallelen, kreisförmigen, chitinösen Verdickungsleisten ( $\delta \varepsilon \sigma \mu \circ)$ versehen, von welchen die innerste längs dem Boden der Mundhöhle verläuft. Der Oes. ist in seinem vorderen Theile cylindrisch und schwillt dann etwas hinter seiner Mitte zu einem grossen Bulbus, worin das Lumen erweitert ist, an; der, zwischen dem Bulbus und dem Darme liegende Theil erweitert sich ebenso nach hinten, ist aber nicht mit radiären Muskelfibrillen versehen wie der vordere Theil und wie der Bulbus, (Fig. 23a). Das Lumen des Oes. stellt sich als ein enges Chitinrohr dar. Der Darm ist bei durchfallendem Lichte sellr dunkel gefärbt, obwohl nicht so intensiv als beim Sphaerolaimus gracilis und seine Wand ist aus mehreren Reihen von körnigen Zellen zusammengesetzt; der Enddarm ist sehr kurz. Die weibl. Geschlechtsorgane sind paarig symmetrisch; die Ovarien sind nicht, wie meistens der Fall ist, umgebogen, sondern vollkommen gestreckt und sehr kräftig entwickelt. Die zwei Spicula sind klein, gebogen, mit einfachem, grossem accessorischem Stücke, welches in zwei, nach hinten gerichteten, Fortsätze ausläuft. (Fig. 23h). Beim Männchen finden sich 
keine Papillen, aber der Schwanz trägt mehrere Borsten. Das Ende des Schwanzes ist etwas angeschwollen, mit einfacher Ausführungsöffnung der Schwanzdrüse.

Die einzige bis jetzt bekannte Art ist:

1. Desmolaimus Zeelandicus d. M.

Taf. VI, Fig. 23.

$\sigma^{7} 1,8 \mathrm{~mm}$., ㅇ 1,7 mm. $\approx=30-35$. Verhältniss der Entfernung der Mundöffnung zum Hinterende des Bulbus zur Gesammtlänge wie 1: 11. $-\gamma=11$.

Der Körper ist ziemlich schlank, mit wenig verjüngtem Vorderende; einige Borsten sind über der Körperoberfläche zerstreut. Das Kopfende ist abgestutzt, und trägt sechs ziemlich kurze, dünne Borsten. Die Seitenorgane (Fig. 23a, 23b) sind gross und liegen in geringer Entfernung hinter der Mundhöhle: sie stellen eine Vertiefung dar im Integument mit kleinem centralem Fleck. Mundhöhle und Verdauungstractus wurden schon in der Gattungsdiagnose beschrieben: der, hinter dem Bulbus liegende Theil des Oes. ist ein wenig länger als dieser Bulbus, vor welchem in geringer Entfernung der Ring des Nervensystems sich befindet. Die weibl. Geschlechtsöffnung, welche bei einer Körperlănge von $1 \mathrm{~mm}$. noch fehlt, liegt etwas hinter der Mitte des Körpers und die beiden Geschlechtsröhren strecken sich bis in die Năhe des Oes., resp. des Afters aus; ich fand ein einziges Ei im Uterus, welches $0,07 \mathrm{~mm}$. lang war. Auch über die Spicula, das accessorische Stück und die postanale Borsten beim Männchen, welche vielleicht als Borstenpapillen aufgefasst werden müssen, wurde schon oben gehandelt. Der Schwanz hat bei beiden Geschlechtern die gleiche Gestalt: er verschmälert sich langsam und ist an seinem Ende etwas angeschwollen.

Fundort und Lebensweise. Der Desmolaimus ist ein lebhaftes Thierchen, das die feuchte, von Brackwasser imbibirte Erde auf der Zeeländischen Insel Walcheren bewohnt. Hier kommt die Art ziemlich häufig vor, sowohl Männchen wie Weibchen; übrigens wurde sie noch nirgendwo sonst beobachtet.

Fundzeit. Ich fand die Art im August geschlechtsreif.

\section{Microlaimus d. M.}

Die Gattung Microlaimus ist die erste einer ganzen Gruppe, welche durch das Vorhandensein eines oder mehrerer Zähne in der Mundhöhle characterisirt ist: unter den Gliedern dieser Gruppe ist sie aber eine der am einfachsten gebauten.

Die Körpergestalt ist ziemlich schlank, sich nach beiden Enden hin verschmälernd. Die Haut ist geringelt, ohne Seitenmembran. Die Kopfregion ist abgesetzt, knopfartig, olne Lippen oder Papillen oder Borsten. Die Mundhöhle ist klein, becherförmig, mit chitinösen Wünden versehen, und mit einem 
schwachen dorsalen Zähnchen gewaffnet. Die Seitenorgane sind kreisförmig. Der Oes. ist cylindrisch, nach hinten zu einem Bulbus mit erweitertem Lumen angeschwollen. Der Darm besteht aus mehreren Zellen, welche einen körnigen Inhalt besitzen. Die weibl. Geschlechtsorgane sind paarig symmetrisch. Die Spicula sind schlank, gebogen, mit zwei stabförmigen accessorischen Stücken versehen; keine Papillen am Schwanz des Männchens. Die Schwanzdrüse mit kurzem Ausführungsröhrchen.

Die einzige Art ist:

1. Microlaimus globiceps d. M.

Taf. VI, Fig. 24.

$\sigma^{7} 0,65 \mathrm{~mm}$., ㅇ $0,56 \mathrm{~mm}$. $\alpha$ beim $\sigma^{7} 32-33$, beim $ᄋ 26-2 \% \cdot \beta=6-6^{1}{ }_{2} \cdot \gamma$ beim $\sigma^{7}=11$, beim ㄱ $7-8$.

Diese niedliche Art hat eine ziemlich schlanke Gestalt, beim Männchen mehr als beim Weibchen, mit mässig verschmälertem Vorderende. Die Haut ist schön geringelt mit ziemlich breiten Querringen. Die Kopfregion ist kolbig, abgesetzt, ohne Borsten. Das Zälhnchen steht in der halben Länge der Mundhöhle, ungefähr bei der linteren Grenze des kolbigen Kopfendes. Die grossen Seitenorgane (Fig. 24b, 24c) liegen in geringer Entfernung hinter der Mundhöhle, und haben keinen centralen Fleck. Die weibl. Geschlechtsöffnung ist ein wenig hinter der Körpermitte, die Geschlechtsorgane strecken sich ziemlich weit aus. Ich fand nur ein einziges Ei im Uterus, das $0,043 \mathrm{~mm}$. lang' war bei einem $0,53 \mathrm{~mm}$. langen Thiere. Die männlichen Genitalien beschrieb ich schon oben. Der Schwanz hat beim Männchen eine kürzere und plumpere Gestalt als beim Weibchen: beim ersteren ist er verlängert kegelförmig, beim letzteren von schlankerer Gestalt.

Fundort und Lebensweise. Auch der ziemlich seltene Microlaimus, ein echter Brackwassernematode, bewohnt die feuchte, von brackischem Wasser durchtränkte Erde an den Wurzeln von hier lebenden Pflanzen, und wurde bis jetzt nur auf der Insel Walcheren beobachtet. Er bewegt sich lebhaft und das Weibchen ist in seinem äusseren Vorkommen dem Leptolaimus, in dessen Gesellschaft er lebt, sehr ähnlich.

Fundzeit. Diese Art ist im Frühjahre (März) und im Sommer (August) geschlechtsreif.

\section{Cyatholaimus Bast.}

Es wurden von mir vier Arten angetroffen, welche ich vorläufig zu dieser Gattung bringe. Es ist mir aber wahrscheinlich, dass dieselbe später in zwei Gruppen getrennt werden muss, von welchen der Cyathol. ocellatus Bast. und der Cyathol. dubiosus Btsli als die respectiven Repräsentanten zu betrachten sind. Was nun die vier, von mir beobachteten Formen anlangt, gehört der Cyath. intermedius ohne Zweifel zu der, von Cyath. dubiosus Btsli vertretenen Gruppe, während die drei anderen als von dieser Type allmälig divergirende Formen angesehen werden müssen. 
Die, unseren vier Arten gemeinsamen Charaktere sind die folgenden:

Der Körper ist mässig langgestreckt, und verschmälert sich besonders nach hinten. Die Haut ist sehr fein geringelt, und die Ringel lösen sich bei stärkerer Vergrösserung meist in Punktreihen auf: die Längslinien sind meist reichlich entwickelt, und enthalten, wenigstens beim intermedius, grosse, körnige Zellen. Am Kopfende sind Lippen melr oder weniger entwickelt, und Borsten vorhanden. Die Seitenorgane sind meist spiralig und der Gefässporus fehlt. Die Mundhöhle ist meist geräumig und mässig gross, selten sehr klein; ihre Wände sind chitinös und mit einem dorsalen Zahne bewaffnet. Der Oes. ist cylindrisch und an seinem Hinterende erweitert oder zu einem Bulbus angeschwollen. Der Darm ist spärlich mit Körnchen besetzt. Die weibl. Geschlechtsorgane sind wahrscheinlich immer paarig symmetrisch, die Männchen haben keine Papillen, die Spicula sind einfach gebaut und mit zwei accessorischen Stücken versehen. Es findet sich immer eine Schwanzdrüse, aber der Ausführungsgang ist bei den einzelnen Arten verschieden.

Von den Microlaimen unterscheiden sich unsere Thiere besonders durch den Besitz von Lippen.

UEBERSTCHTSTABELtE DER VIER BEOBACHTETEN ARTEN.

1. Grössere Arten von $1,3 \mathrm{~mm}$. Körperlänge . . . . . . . . . . . . . . . 2.

Kleinere Arten, nur 0,5-0,6 mm. lang . . . . . . . . . . . . . . . 3.

2. Schwanz kegelförmig plump; Cuticula ausserordentlich fein geringelt. Spiralige

Seitenorgane in gleicher Höhe mit dem Zahne der Mundhöhle . . . . . . 1. intermedius.

Schwanz ziemlich schlank, allmälig verschmälert; Cuticula nicht so fein geringelt.

Spiralige Seitenorgane in gleicher Höhe mit dem Zahne der Mundhöhle. . . 2. terricola.

3. Mundhöhle sehr verlängert, tief; spiralige Seitenorgane am Grund der Mund-

höhle gelegen . . . . . . . . . . . . . . . . . . 3. ruricola.

Mundhöhle sehr klein, undeutlich, mit rudimentärem Zahne. Seitenorgane wahr-

scheinlich kreisförmig, hinter der Mundhöhle . . . . . . . . . . 4. tenax.

\section{Cyatholaimus intermedius $d$. M.}

Synon: Cyatholaimus dubiosus d. M. (nec Btsli), de Man, XXVI, pag. 84, Pl. X, Fig. 39a-b.

Taf. VI, Fig. 25.

$\sigma^{7} \circ$ 1,3 mm. $\alpha=30-35 . \beta=\gamma-8$. $\gamma$ beim Männchen $9-10$, beim Weibchen $10-12$.

In ihrer äusseren Gestalt hält diese Art mehr oder weniger zwischen Cyath. dubiosus Btsli aus der Kieler Bucht und Cyathol. proximus Btsli aus demselben Meere das Mitte und bezieht daher ihren Namen. Der Körper ist mässig schlank, das Vorderende ist weniger verjüngt als beim. Cyath. dubiosus, dem unsere Art höchst ähnlich ist. Die Haut ist ausserordentlich fein geringelt, viel feiner 
als bei den so eben genannten, in der Ostsee lebenden Thieren. Das Kopfende (Fig. 25b) trägt zehn måssig lange Borsten, welche am Grund der ziemlich niedrigen Lippen angeheftet sind; man unterscheidet sechs grőssere und vier kleinere, welche submedian gestellt sind. Die Längslinien enthalten grosse körnige Zellen, sowohl die lateralen als die medianen. Die Mundhöhle ist becherförmig, längsgestreift mit spitzem, grossem, dorsal gelegenem Zahn. Die Seitenorgane sind spiralig und liegen in gleicher Höhe des dorsalen Zahnes. Der Oes. ist cylindrisch, ist aber in seiner Mitte ein wenig verschmälert. Der Darm ist körnig und der Enddarm kurz. Die weibl. Geschlechtsöffnung befindet sich in der Mitte des Körpers; die Geschlechtsorgane sind paarig symmetrisch, nicht gross, mit umgebogenen Ovarien. Ich beobachtete drei Eier im Uterus. Die Spicula und die accessorischen Stücke sind gebildet wie beim dubiosus Btsli; die ersten sind klein und gebogen, die letzteren nach vorn hin keilförmig erweitert. Vier kurze Börstchen stehen beim Männchen vor dem After. Der Schwanz ist kegelförmig, plump, mit röhrenförmigem Ausführungsgange der Schwanzdrüse

Fundort und Lebensweise. Einer der hăufigeren freilebenden Rundwürmer ist der Cyath. intermedius: ich fand ihn nie in den Dünen- oder Heidegründen, auch nie im süssen Wasser, sondern stets häufig in der feuchten Erde von Wiesen und Marschgründen, ebenso in der humusreichen Erde vom Wälde. Männchen und Weibchen kommen gleich häufig vor.

Geographische Verbreitung. Ausser den Niederlanden wurde unsere Art nirgendwo sonst beobachtet.

Fundzeit. Diese Art traf ich das ganze Jahr hindurch in geschlechtsreifem Zustande an.

\section{Cyatholaimus terricola d. M.}

Taf. VII, Fig. 26.

우 1,3 mm., o unbekannt. $\alpha=30-35 . \beta=\% . y=8$.

Diese Art hat ganz das aussere Vorkommen der vorigen, unterscheidet sich aber gleich durch den längeren Schwanz. Der Körper ist mässig schlank, das Vorderende wenig verschmälert. Die Haut ist ein wenig minder fein geringelt als bei der vorigen Art; bei stärker Vergrösserung scheinen die Ringe aus Querreihen von grossen, runden Körnchen $\mathrm{zu}$ bestehen, welche aber wahrscheinlich kleine runde Bläschen unter der Haut sind. (Fig. 26c). Das nicht abgesetzte Kopfende trägt niedrige abgerundete Lippen und zehn mässig lange Borsten, von welchen vier submediane kleiner sind als die übrigen. Die Mundhöhle ist verlängert, tief, mit chitinösen Wänden und einem ziemlich grossen dorsalen Zahn; in seinem vorderen Abschnitte beobachtet man abgebrochene, longitudinale Verdickungsstreifen. Die spiraligen Seitenorgane liegen stets in der halben Länge der Mundhölle, da wo der Zahn sich befindet. Der Oes. ist nach hinten kolbig angeschwollen, und der Darm ist körnig mit engem Lumen. Die weibl. Geschlechtsöffnung liegt ein wenig vor der Körpermitte, die weibl. Geschlechtsorgane sind nicht gross und wahrscheinlich paarig symmetrisch. Der Schwanz ist ziemlich schlank, allmälig verschmälert mit kegelförmiger Ausführungsröhre der Schwanzdrüse. 
Fundort und Lebensweise. Diese Art ist viel seltener als die vorige und bewohnt die feuchte Erde der Wiesen; auch im Walde fand ich sie. Sie bewegt sich lebhaft.

Geographische Verbreitung. Deutschland (Erlangen), Schweiz (Roth See unweit Luzern).

Fundzeit. Unsere Art ist im Frühjahre geschlechtsreif: im August fand ich ein 0,9 mm. langes Thier, dessen Genitalien noch unvollkommen entwickelt waren, obgleich die Geschlechtsöffnung schon vorhanden war.

\section{Cyatholaimus ruricola d. M.}

Taf. VII, Fig. $2 \%$.

б우 $0,6 \mathrm{~mm} . \alpha=25-30 . \beta=5-6 . \gamma=\%$.

Diese Art ist der vorigen sehr ähnlich, erreicht aber kaum die halbe Grösse. Der Körper ist mässig schlank, das Vorderende wenig verschmälert. Die Cuticula ist fein geringelt; bei, stärker Vergrösserung scheint die Ringelung aus Querreihen von mässig grossen, runden Körnchen gebildet zu sein. Das Kopfende ist nicht abgesetzt, mit ziemlich hohen, abgerundeten Lippen und sechs feinen, ziemlich langen Borsten. Die Mundhöhle ist selır verlängert, (Fig. 2\%b), tief, mit chitinösen Wänden, mit einem kleinen dorsalen Zahn, welcher in ihrem mittleren Abschnitt gelegen ist; der vordere Abschnitt ist längsgestreift. Die spiraligen Seilenorgane liegen stets an Grund der Mundliöhle. Der Oes. ist cylindrisch, und schwillt nach hinten zu einem mässig grossen Bulbus an; der Darm ist feinkörnig. Die weibl. Geschlechtsöffnung liegt ein wenig vor der Körpermitte, die Genitalien sind kurz und wahrscheinlich paarig symmetrisch: bei einem $0,4 \% \mathrm{~mm}$. langen Thiere fand sich noch keine äussere Geschlechtsöffnung, bloss nur eine kleine Genitalanlage. Das Ei (Fig. 2\%) ist gross. Die Spicula haben eine ziemlich plumpe Gestalt mit (wahrscheinlich nur einem) stabförmigen accessorischen Stücke. Keine Papillen oder Borsten kommen prä- oder postanal beim Månnchen vor. Der Schwanz ist schlank, allmälig verschmälert, und endigt mit einer ziemlich langen Ausführungsröhre (Fig. 27d) der Schwanzdrüse.

Fundort und Lebensweise. Diese Art ist ziemlich häufig und bewohnt die feuchte Erde von Wiesen und Marschgründen, wie auch des Waldes. Das Männchen traf ich nur einmal an. Sie bewegt sich sehr lebhabt.

Geographische Verbreitung. Vielleicht ist das, von Bütschli im Main beobachtete Thier mit dem ruricola identisch (Bütschli, XX, pag. 72, Taf. VII, Fig. 2\%).

Fundzeit. Ich fand geschlechtsreife, eitragende Thiere im Hochsommer (August, September), aber auch im Frühjahre (März). 


\section{Cyatholaimus tenax d. M. ${ }^{1}$.}

Synon: Monhystera tenax, d. M, de Man, XXVI, pag 99.

Taf. VII, Fig. 28.

우 $0,5 \mathrm{~mm}$. , $\sigma^{7}$ unbekannt. $\alpha=2 \%-33 . \beta=5-6 . \gamma=5-\%$

Es -ist diese kleine Art die am meisten divergirende dieser Gruppe, was sich vielleicht noch mehr bestätigen lassen würde, wenn das Männchen bekannt wäre. Der Körper ist mässig schlank, nach beiden Enden hin, besonders aber nach hinten, verschmälert. Die Cuticula ist sehr fein geringelt. Das nicht abgesetzte Kopfende zeigt sehr rudimentäre Lippen und sechs sehr kleine Borsten. Die Mundhöhle ist sehr klein, becherförmig mit chitinösen, ein wenig eckigen Wänden, sodass das Vorhandensein eines dorsalen Zahnes sehr wahrscheinlich ist. Die Seitenorgane sind vermuthlich kreisförmig, in geringer Entfernung hinter der Mundhöhle gelegen. Der Oes. ist cylindrisch, und schwillt nach hinten zu einem echten, müssig grossen Bulbus an. Die weibl. Geschlechtöffnung liegt in der Körpermitte, die Genitalien sind wahrscheinlich paarig symmetrisch. Die Länge des Schwanzes ist ein wenig veränderlich: er hat eine schlanke Gestalt, ist allmälig und regelmässig verjüngt, mit kegelförmigem, abgesetztem Ausführungsgange der Schwanzdrüse (Fig. 28d).

Fundort und Lebensweise. Eine sehr häufige Art, welche die feuchte Erde der Wiesen und Marschgründe bewohnt; eigenthümlicherweise fand ich sie in den Dünen oder Heidegründen nie. Es hat dieses Thierchen eine einiger Massen wankende, täumelnde Bewegung und es dreht das Kopfende in alle Richtungen, was die anderen freilebenden nie thun. Uebrigens bewegt es sich lebhaft.

Geographische Verbreitung. Deutschland (Erlangen, Laibach), Schweiz (Roth See unweit Luzern), Frankreich (Montpellier).

Fundzeit. Ich beobachtete geschlechtsreife Thiere das ganze Jahr hindurch. Eine sonderbare Erscheinung bei dieser sehr häufigen Art ist wieder das Fehlen des Männchens.

Anmerkung. Bei einer mässig schwachen Vergrösserung scheinen die Kopfborsten, die rudimentären Lippen und die Seitenorgane zu fehlen, während der Bau der kleinen Mundhöhle undeutlich zu erkennen ist; man braucht dafür stärkere Vergrösserungen. Es bildet übrigens diese Art einiger Massen den Uebergang von den Monohysteren zu den Cyatholaimen.

1) Es lebt in der feuchten, von brackischem Wasser durchtränkten Erde auf der Insel Walcheren noch eine fünfte Art, welche ebenso zu dieser Gruppe gehört und neu ist. Leider habe ich keine Zeichnungen dieses Thieres gemacht, sodass ich nur die Notizen über dasselbe mitzutheilen im Stande bin.

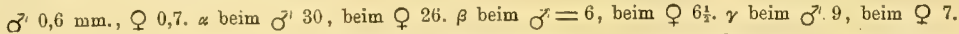

Der Körper verschmälert sich nach vorn hin weniger als beim Cyath. tenax: dieser Art wie auch dem Cyath. ruricola ist diese neue Art am meisten verwandt. Die Mundhöhle sieht anders aus als beim tenax: sie ist grösser als bei d.eser Art, kleiner als beim ruricola. Der Oes. endigt in einen Bulbus und die Cuticula ist sehr fein quergeringelt.

Männchen und Weibchen dieser, im August geschlechtsreifen Art, welche ich Cyath. geophila nennen will, kommen eben häufig vor. 


\section{Spilophora Bast. Chromadora Bast.}

Die vier folgenden Arten werden unter den Gattungsnamen beschrieben, unter welchen sie früher von Max Schultze und mir bekannt gemacht worden sind. Sie gehören gewiss zu keiner anderen, in dieser Arbeit ernannten Gattung, aber die Charaktere dieser Gattungen können erst dann genau angegeben werden, als die im Meere lebenden Repräsentanten besser erforscht sein werden.

Ich beschränke mich darum darauf, nur die hauptsächlichsten Merkmale anzugeben, wodurch diese vier Formen sich von den übrigen in meiner Arbeit beschriebenen Arten unterscheiden lassen und deshalb mitzutheilen, dass bei zwei derselben Ocellen gefunden werden, dass die Mundhöhle wenig tief, becher- oder schüsselförmig ist und einen dorsalen Zahn am Boden trägt, dass der Oes. immer in einen grossen Bulbus endigt, dass die weibl. Geschlechtsorgane paarig symmetrisch sind, dass die Haut immer quergeringelt ist und bei zwei Arten eigenthümliche Verzierungen an den Seitenfeldern gefunden werden, und dass es bei allen eine Schwanzdrüse giebt mit kegelförmigem Ausführungsröhrchen.

Fundort und Lebensweise. Von den vier, unten zu beschreibenden Arten bewohnt eine das süsse Wasser, gehören zwei zu den Brackwassernematoden, während die vierte in der feuchten Erde von Wiesen und Marschgründen gefunden wird; es sind allen sich lebhaft bewegende Thierchen, bei welchen die Männchen eben so häufig sind wie die Weibchen. Eigenthümlich allerdings ist die Erscheinung des Vorkommens dieser Arten in der Erde und im süssen Wasser; sie erweist von neuem, dass man zwischen Land- und Meernematoden keine scharfe Grenze ziehen darf.

\section{UEBERSICHTSTABELLF DER VIER IN DER ERDE UND IM SUESSEN WASSER LEBENDEN, VON MIR BEOBACHTETEN SPILOPHOREN UND CHROMADOREN.}

1. Ocellen vorhanden . . . . . . . . . . . . . . . . . . . 2

Ocellen fehlend . . . . . . . . . . . . . . . . . . 3.

2. Körper ziemlich schlank, mit vier Längsreihen von kräftigen Borsten überdeckt. Keine präanale Papillen beim Münnchen. Süsswasserbewohner . . . . . . . 4. bioculata. Körper nicht schlank, mit nur einigen Börstchen am Vorderende. Vierzehn oder fünfzehn präanale Papillen beim Männchen. Brackwassernematode . . , . . . . 3. Örleyi.

3. Körper von sehr plumper Gestalt; zwei longitudinale Reihen von Körnchen längs jeder Seitenlinie. Keine prăanale Papillen beim Männchen. Brackwassernematode. (Spilophora). 1. geophila. Körper von schlanker Gestalt; mehrere Längsreihen von reihenweise angeordneten Körperchen von länglicher Gestalt längs jeder Seitenlinie; acht präanale Papillen beim Männchen. . . . . . . . . . . . . (Chromadora) 2. Leuckarti. 
1. Spilophora geophila d. M.

de Man, XXVI, pag. 85, Taf. X, Fig. 40a-b.

Taf. VII, Fig. 29.

$\sigma^{7} 0,9 \mathrm{~mm}$., ㅇ $1 \mathrm{~mm} . \alpha=20 . \beta=6-\%$, $\gamma$ beim $\sigma^{\gamma} 8-9$, beim $\%-8$.

Diese Art besitzt eine sehr plumpe Gestalt, das Vorderende verjüngt sich sehr, mehr noch das Schwanzende. Die Cuticula ist fein geringelt, mit zwei longitudinalen Reihen von Körnchen längs jeder Seitenlinie. Ueber der gesammten Körperoberfläche sind einige wenige Borsten zerstreut. Das Kopfende (Fig. 29a) ist nicht abgesetzt, trägt sechs mässig grosse Borsten. Die Mundhöhle ist klein, schüsselförmig, mit chitinösen Wänden und mit kleinem, am Boden sitzendem, dorsalem Zahn. Ocellen fehlen. Im vorderen Theile des kurzen, cylindrischen, zu einem sehr grossen Bulbus anschwellenden Oes. beobachtet man die eigenthümlichen, chitinösen „Apophysen". Hinter dem Anfange des Darmes liegt die Ventraldrüse: der Darm besteht aus mehreren Zellenreihen, die Zellen mit körniger Inhalt gefüllt. Die weibl. Geschlechtsöffnung liegt ungeführ in der Körpermitte; an der Vulva finden sich einige Drüsen; die Genitalien sind paarig symmetrisch, ziemlich kurz mit umgeschlagenen Ovarien. Die Spicnla sind schlank, gebogen, mit zwei schlanken, dünnen, stabförmigen, accessorischen Stücken. Keine Papillen am Schwanzende des Männchens. Beim letzteren ist der Schwanz mässig kurz, kegelförmig, beim Weibchen hat er eine schlankere Gestalt.

Fundort und Lebensweise. Die eigenthümliche Spilophora geophila ist eine der häufigeren Brackwassernematoden. Zahlreich trifft man diese Art in der feuchten, von brackischem Wasser getränkten Erde, am Rande von Brackwassergräben, auf der Insel Walcheren an: lebhaft ist das Thier, das zweifelsohne aus dem Meere in die brackische Insel hineingewandert ist, und sich vielleicht aus einer, der Chrom. caeca Bast. verwandten Form entwickelt hat. Männchen und Weibchen kommen gleich häufig vor.

Geographische Verbreitung. Bis jetzt nirgendwo sonst beobachtet.

Fundzeit. Im Frühjahre (März, April) fand ich das Thier in geschlechtsreifem Zustande; zu gleicher Zeit trifft man aber auch alle andere Lebensstadien an.

\section{Chromadora Leuckartid. M.}

de Man, XXVI, pag. 88, Taf. X, Fig. $41 a-d$.

Taf. VIII, Fig. 30.

o'우 $1,2 \mathrm{~mm} . \alpha=30-40 . \beta=\%-8, \gamma=\%-8$.

Eine viel schlankere Gestalt als die vorige Art besitzt die von mir schon in meiner ersten Arbeit beschriebene Chromadora Leuckarti. Das Vorderende ist mässig verschmälert. Die Cuticula ist 
fein geringelt; auf jeder Seitenlinie sieht man mehrere Längsreihen von Körperchen von länglicher Gestalt (Fig. 30c); kleine, submedian gestellte Börstchen sind über der gesammten Körperoberfläche zerstreut. Das Kopfende ist nicht abgesetzt: ein oder zwei Kreise von kleinen Papillen umgeben die Mundöffnung; ausserdem befindet sich eine hervorragende grössere laterale Papille in geringer Entfernung hinter derselben. Am Kopfende stehen vier ziemlich lange dünne Borsten, und ein wenig mehr nach hinten (auf $1 / 5$ der Länge des Oes.) stehen. immer vier längere, aber ebenso dünne Borsten. Die Mundhöhle ist sehr wenig tief, becherförmig, mit dorsalem Zähnchen am Boden, während der vordere Theil mehrere longitudinale Verdickungen der Wand zeigt. Der Oes. ist cylindrisch, an seinem vorderen Theile kugelförmig erweitert, (Fig. 30b), und schwillt nach hinten zu einem mässig grossen Bulbus an. Die Darmwand ist mit feinen Körnchen gefüllt. Die weibl. Geschlechtsöffnung liegt ein wenig vor der Körpermitte; die mässig grossen Genitalien sind paarig symmetrisch, mit umgeschlagenen Ovarien. Ich fand stets nur ein einziges, mässig grosses Ei im Uterus. Die Spicula sind schlank, gebogen, mit zwei langen, gebogenen, accessorischen Stücken versehen. Stets liegen acht präanale Papillen am Schwanze des Männchens, welcher dieselbe, regelmässig verschmälerte Gestalt, wie beim Weibchen, besitzt.

Fundort und Lebensweise. Diese Art ist sehr hăufig und lebt in der feuchten, von süssem oder Brackwasser imbibirten Erde der Wiesen und Marschgründe. Auch traf ich sie im süssen Wasser zwischen Conferven an. Lebhaft sind die Bewegungen dieses Thierchens, bei welchem die Männchen ebenso häufig vorkommen als die Weibchen.

Geographische Verbreitung. Noch nirgendwo sonst beobachtet.

Fundzeit. Erwachsene Thiere dieser Art beobachtete ich in fast allen Monaten des Jahres.

3. Chromadora Örleyi d. M.

de Man, XXXVI, pag. 139.

Taf. VIII, Fig. 31.

$\sigma^{7} 0$ 0, $74 \mathrm{~mm} . \alpha=22-25 . \beta=6-\left.6^{1}\right|_{2} . \gamma$ beim Männchen $8{ }_{12}^{1}-9$, beim Weibchen $7^{1} / 2-81 / 2$.

Der Körper hat eine ziemlich plumpe Gestalt und ist mässig nach beiden Enden hin verschmälert. Die Cuticula ist sehr fein geringelt, ohne besondere Skulptur auf den Seitenfeldern; bei starker Vergrösserung aber scheinen die Querringe aus Reihen von sehr vielen ovalen Körperchen gebildet zu sein. Am vorderen Theile des Körpers sind einige wenige Börstchen zerstreut. Das Kopfende ist nicht abgesetzt, abgestutzt, mit vier kurzen Börstchen versehen; die Mundhöhle zeigt einen dorsalen Zahn am Boden und einige longitudinale Verdickungsstreife in der Wand (Fig. 31b). Die beiden violetfarbigen rothen Ocelli auf $1 / 5$ der Länge des Oes. vom Vorderende entfernt. Dieser endigt mit grossem rundlichem Bulbus; der Darm zeigt zahlreiche grosse und kleine Körner. Der Schwanz hat bei beiden Geschlechtern die gleiche Gestalt, verschmälert sich ziemlich schnell, mit kegelförmigem 
Ausführungsröhrchen (Fig. 31e). Die weibl. Geschlechtsöffnung, welche bei 0,53 mm. langen Thieren noch fehlt, liegt gerade auf der Mitte des Körpers; die Genitalien sind paarig symmetrisch, müssig gross, mit umgeschlagenen Ovarien und produciren zwei grosse Eier. Beim Männchen stehen 13-15 Papillen vor dem After, in gleicher Entfernung von einander: über das Vorkommen dieser Papillen vergl. Fig. 31d. Die Spicula sind ein wenig gebogen, schlank, mit zwei langen, dünnen, gebogenen, stabförmigen accessorischen Stücken versehen.

Fundort und Lebensweise. Diese schöne Art zeigt lebhafte Bewegungen und bewohnt die feuchte; von brackischem Wasser durchtränkte Erde auf der Insel Walcheren, mit Oncholaimus thalassophygas, Leptolaimus u. s. w.

Geographische Verbreitung. Bis jetzt nirgendwo sonst beobachtet.

Fundzeit. Chrom. Örleyi ist im Monat September geschlechtsreif: zu gleicher Zeit trifft man Jugendformen an.

Anmerkung. Diese Art, welche ich mir erlaubt habe Herrn Dr. Örley in Buda-Pest zu widmen, ist der Chrom. chlorophthalma d. M. aus dem Mittelmeere nächst verwandt und hat ganz den Habitus dieser Art, unterscheidet sich aber von ihr auf dem ersten Blick durch die Farbe der Ocellen; wahrscheinlich bietet das noch unbekannte Männchen der chlorophthalma noch mehrere Unterschiede. Auch ist sie der Chrom. viridis von Linstow aus dem Ratzeburger See (von Linstow, XXIX, pag. 14, Taf. XX, Fig. 34, 35) und der Chrom. germanica Btsli (Bütschli, XXI, pag. 48, Taf. VI, Fig. 25a-b), aus der Kieler Bucht verwandt.

4. Chromadora bioculata Max Schultze.

Bütschli, XX, pag. \%0, Taf. V und VI.

Taf. VIII, Fig. 32.

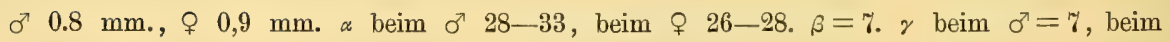
우 $6-61 / 2$.

Die Körpergestalt dieser Art ist mässig schlank, nach vorn hin ziemlich verschmälert. Die Cuticula ist fein geringelt, ohne weitere Skulptur; die gesammte Körperoberfläche trägt beim Männchen wie beim Weibchen vier Längsreihen von kräftigen Borsten. Das Kopfende ist nicht abgesetzt, ohne Lippen oder Papillen, ist aber mit einem Kreise von sechs grossen Borsten gewaffnet. Die Mundhöhle (Fig. 32a, 32b) ist klein, schüsselförmig, mit chitinösen Wänden und mit kleinem dorsalem, am Boden gelegenem Zahne; ihre Wände zeigen longitudinale Verdickungsstreife. Sie leitet in einen erweiterten Theil des Lumens des Oes., welcher noch vor den rothbraunen Ocellen in den engen Theil übergeht. Der Oes. schwillt nach hinten zu einem grossen Bulbus an; nach Bütschli ist der Darm aus polyedrischen Zellen in ziemlicher Anzahl im Umkreis gebildet. Die weibl. Geschlechtsorgane sind paarig symmetrisch; die Geschlechtsöffnung liegt in der Körpermitte oder ein 
wenig vor der Mitte. Die männliche Geschlechtsröhre streckt sich ungefähr über ${ }^{4} / 5$ der Entfernung des Oesophagealbulbus vom After aus; keine Papillen finden sich am Schwanz des Männchens. Die Spicula sind klein, schlank, gebogen, mit zwei stabförmigen, nach vorn hin keilförmig erweiterten accessorischen Stücken. (Fig. 32d.) Der Schwanz hat eine schlanke Gestalt und ist beim Männchen meist ein wenig kürzer als beim Weibchen. Die Schwanzdrüse soll nach Bütschli ähnlich gebaut sein wie bei Trilobus und Monohystera und der Schwanz endigt mit kegelförmigem Ausführungsröhrchen dieser Drüse.

Fundort und Lebensweise. Dieses lebhafte Thier bewrohnt häufig das süsse Wasser der Teiche und Gräben, in der Erde kommt es nicht vor.

Geographische Verbreitung. Deutschland (Im Main, nach Bütschli.)

Fundzeit. Ich fand geschlechtsreife Exemplare im Monat Mai.

\section{Ethmolaimus d. M.}

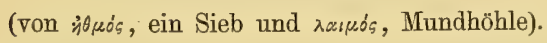

Die Ethmolaimen characterisiren sich besonders durch den Bau der Mundhöhle. Thr Körper hat eine nicht schlanke Gestalt, das Vorderende ist wenig verschmälert. Die Haut ist geringelt, ohne Seitenmembran. Das Kopfende ist abgestutzt, ohne Lippen oder Papillen, trägt aber Borsten. Seitenorgane vorhanden ${ }^{1}$ ). Die Mundhöhle ist von chitinösen Wänden bekleidet und besteht aus zwei Theilen, der vordere Theil ist schüsselförmig mit longitudinalen Verdickungsstreifen an den Wänden und mit einem dorsalen Zahn am Boden; dieser Boden wird von einer kreisförmigen Chitinleiste gebildet, welche den vorderen Theil vom folgenden, verlängert prismatischen Theil der Mundhöhle trennt. Der Oes. ist cylindrisch, und schwillt nach hinten zu einem Bulbus an. Die weibl. Geschlechtsorgane sind paarig symmetrisch. Das Thier hat eine Schwanzdrüse mit kegelförmigem Ausführungsgange.

Die einzige Art ist der

\section{Ethmolaimus pratensis d. M.}

Taf. VIII, Fig. 33. und Taf. XXXIV, Fig 33c.

ㅇ $0,75 \mathrm{~mm} ., \sigma^{7}$ unbekannt. $\alpha=25 . \beta=6 . \gamma=6$.

Der Ethmolaimus fällt gleich auf durch die dickwändige Mundhöhle, welche bei einer schwachen Vergrösserung wie ein schwarzer Streif im vorderen Kopfende erscheint.

Leider kann ich den Bau der Seitenorgane nicht genau angeben, weil mir bloss eine Zeichnung, welche dieselben in Profil darstellt, vorliegt (Taf. XXXIV, Fig. 33c), aber keine Beschreibung. 
Das Thier besitzt einen nicht schlanken Körper, mit wenig verschmälertem Vorderende. Die Cuticula ist äusserst fein geringelt. Das Kopfende ist nicht abgesetzt, mit vier ziemlich langen, haarfeinen Borsten versehen. Die Mundhöhle ist $1 / 6-1 / 7$ der Länge des Oes. lang und fällt durch ihre dicken Chitinwände gleich auf. Die Geschlechtsöffnung liegt ungefähr in der Körpermitte; die Geschlechtsorgane sind ziemlich kurz und die Vagina ist dünnwăndig. Der Schwanz hat eine schlanke Gestalt, ist allmälig verschmälert und trägt einen abgesetzten, kegelförmigen Ausführungsgang der Schwanzdrüse (Fig. 33b).

Fundort und Lebensweise. Diese seltene Art lebt in der feuchten Erde der Wiesen und Marschgründe in Süsswassergegenden, und bewegt sich lebhaft.

Geograplische Verbreitung. Deutschland (Erlangen).

Fundzeit. Ich fand geschlechtsreife Thiere in den Wintermonaten (Februar, November.)

\section{Mononchus Bast.}

Auch die Mononchen, wie so viele andere Gattungen freilebender Nematoden, sind durch den Bau der Mundhöhle characterisirt.

Im Allgemeinen haben diese Thiere eine schlanke Gestalt mit glatter ungeringelter, nie Borsten tragender Haut. Um die nicht weite Mundöffnung stehen zwei Kreise von Papillen, von welchen die vorderen sich öfters auf rudimentären Lippen befinden. Bei einigen Arten ist dieser papillentragende Theil vom übrigen Körper durch eine Einschnürung abgetrennt, bei anderen aber nicht. Die Mundöffnung führt erst in ein kurzes Vestibulum, das im papillentragenden Theile gelegen ist und dieses in die Mundhöhle. Dieselbe ist sechsseitig und chitinwändig; in der dorsalen Kante steht ein einziger Zahn; nur beim M. tridentatus finden sich drei kleinere Zähne, auf gleicher Höhe gestellt. Während bei den meisten die Wände der Mundhöhle glatt sind, zeigen dieselben beim M. brachyuris eine eigenthümliche Querstreifung. Im. Boden trifft man öfters eine Anzahl stärker chitinisirter Stücke an: dieser hintere Theil der Mundkapsel wird vom Oes. umgeben und geht allmälig in das gleichfalls sechsseitige, stark chitinisirte Lumen desselben über; die Wand des Oes. ist stark muskulös. Die Mundkapsel wird von zwei starken Muskelbändern, welche in der Medianlinie des Körpers liegen, an der Leibeswand festgeheftet (Vergl. z. B. Fig. 35a). Am vorderen Theile des Oes. beobachtet man stets deutlich den Nervenring. Die Darmwand ist aus mehreren körnchenreichen Zellen aufgebaut und der Enddarm ist kurz. Die weibl. Geschlechtsorgane sind paarig symmetrisch und die Ovarien sind umgeschlagen; nur wenige Eier findet man im Uterus.

Die Geschlechtsröhre des Männchens ist, wie bei den Dorylaimen, paarig und am hinteren Körperende liegen sowohl präanale wie postanale Papillen. Die zwei meist gebogenen Spicula werden von einem oder zwei accessorischen Stücken begleitet. Präanal zeigt die Haut nicht selten an beiden Seiten eine schräge Streifung. 
Der Schwanz ist bei den einzelnen Arten sehr verschieden gestaltet und eigenthümlich jedenfalls ist die Erscheinung, auf welche schon Bütschli aufmerksam machte, dass das Kürzerwerden des Schwanzes mit der stärkeren Ausprăgung der Mundpapillen gleichen Schritt hält.

Fundort und Lebensweise. Die Mononchen bewohnen allen die feuchte Erde, oder das süsse Wasser; es sind lebhaft sich bewegende Thiere, bei welchen die Männchen seltener vorkommen als die Weibchen.

UEBERSICHTSTABELLE DER, VON MIR BEOBACHTETEN MONONCBEN.

1. Mundhőhle mit einem Zahne . . . . . . . . . . . . . . . 2.

Mundhöhle mit drei Zăhnen . . . . . . . . . . . . 5. tridentatus.

2. Schwanz schlank, die drei hinteren Viertel fadenförmig . . . . . . . . . 1. macrostoma. Schwanz sehr kurz . . . . . . . . . . . . . . . . . . . . . . 3.

3. Seitenwände der weiten Mundhöhle nicht quergestreift; Schwanz zugespitzt . . 4.

Seitenwände der ziemlich engen Mundhöhle quergestreift; Schwanzspitze abgerundet . . . . . . . . . . . . . . . . 4. brachyuris.

4. Grössere Art; der Zahn liegt im vorderen Abschnitt der Mundhöhle . . . . 2. papillatus.

Kleinere Art; der Zahn liegt im mittleren Abschnitt der Mundhöhle . . . . 3. pa rvus.

Ausser diesen wurden noch die folgenden Arten beschrieben:

Mon. truncatus Bast. (Bastian VII, pag. 101, Pl. IX, Fig. 25, 26). England.

Mon. tunbridgensis Bast. (Bastian VII, pag. 102, Pl. IX, Fig. 31, 32). England.

Mon. eristatus Bast. (Bastian VII, pag. 102, Pl. IX, Fig. 33, 34). England.

Zweifelhafte Arten sind:

1․ Mon. muscorum Duj. (Dujardin, III, pag. 237), vielleicht mit dem papillatus identisch und

$2^{\circ}$. Mon. fovearum Duj. (Dujardin, III, pag. 236), der meinem tridentatus verwandt ist.

1. Mononchus macrostoma Bast.

Bastian VII, pag. 101, Pl. IX, Fig. 29, 30.

Taf. IX, Fig. 34 .

o' 1,9 mm., \& 2,5 mm. $\alpha=30-35 . \beta=4 . \gamma=9$, (nach Bastian 11).

Der Körper dieser schönen Art hat ein schlankes Vorkommen; das Vorderende ist wenig verschmälert. Der papillentragende Theil des Kopfendes ist von übrigen Körper durch keine Einschnürung abgetrennt, hat eine abgestutzte Vorderfläche, während zwei Kreise von Papillen die Mundöffnung 
umgeben; der innere Kreis besteht aus sechs sehr niedrigen Papillen, während der äussere aus sechs etwas grösseren, kegelförmigen gebildet wird. Die Mundhöhle (Fig. 34a, 34b) ist länglich, tief, und erreicht $1 / 10$ - 1/1, der Länge des Oes.; ein wenig vor der Mitte liegt der dorsale, kräftige Zahn. In der ventralen Wand der Mundkapsel, gleich vor dem Niveau des Zahnes, beobachtet man zwei lineare, submedian und transversal gelegene Chitinleisten (Fig. 34a); gänzlich auf dem Boden sehe ich zwei kleine Zähnchen. Der Oes. ist nach hinten nur wenig erweitert; Darm und Enddarm zeigen nichts besonderes. Die weibl. Geschlechtsöffnung ist schon bei einer. Länge von $1.8 \mathrm{~mm}$. vorhanden und liegt in geringer Entfernung hinter der Körpermitte; paarig symmetrisch sind die Genitalien und drei Eier beobachtete ich im Uterus. Beim Weibchen ist der Schwanz (Fig. 34c) schlank, die drei hinteren Viertel sind fadenförmig, ganz am Ende aber ist er ein wenig angeschwollen, und vier äusserst kleine Papillen kommen an demselben vor. Der Schwanz des Männchens hat dieselbe Gestalt wie der des Weibchens. Die Spicula sind sehr schlank, dünn, in eine sehr stumpfe Ecke gebogen, mit centralem Verdickungsstreife und werden von zwei ebenso schlanken, aber viel kürzeren accessorischen Stücken begleitet (Fig. 34c). Vor dem After ist die Cuticula an beiden Seiten schräg gestreift; zwanzig Papillen, welche nahe bei einander gelegen sind und kaum hervorragen, liegen in die Medianlinie vor dem After, und drei mediane ventrale wie auch einige laterale Papillen beobachtet man auf dem eigentlichen Schwanz.

Fundort und Lebensweise. Diese schöne, lebhafte, ziemlich häufige Art bewohnt die feuchte Erde der Wiesen und Marschgründe; auch traf ich einmal eine Anzahl derselben in einer Lache von süssem Wasser in den Dünenstrichen Hollands an. Bei dieser Art beobachtete ich die eigenthümlichen pflanzlichen Parasiten, von welchen auf Seite 22 die Rede gewesen (Taf. XXXIV, Fig. 144a und $b$ ).

Geographische Verbreitung. Deutschland (Erlangen), Schweiz (Roth See bei Luzern).

Fundzeit. Geschlechtsreif ist unsere Art im Herbste und im Frühjahre (Februar, Mãrz, November); wahrscheinlich aber wohl das ganze Jahr hindurch. Die Männchen sind selten.

Anmerkung. Es ist der macrostoma, der jedentalls mit der Bastian'schen Art identisch ist, der einzige langschwänzige Mononchus, den ich beobachtet habe. Der allerdings verwandte truncatus unterscheidet sich durch schwächere Papillen am Kopfende, eine plumpere Gestalt und einen mehr gedrungenen Schwanz. (Vergl. Bütschli, XX, Taf. XIX, Fig. 18b).

2. Mononchus papillatus Bast.

Bastian, VII, pag. 101, Pl. IX, Fig. 27 u. 28.

Bütschli, XX, pag. 76 , Taf. III, Fig. 19a-b.

Synon: Mononchus Bastiani d. M., de Man, XXVI, pag. 107, Pl. XIII, Fig. 49a-c.

Taf. IX, Fig. 35.

ㅇ 2,6 mm., $\sigma^{7}$ unbekannt. $\alpha$ wechselt von $25-35$ nach dem Alter. $\beta=4-4^{1} /{ }_{2} \cdot \gamma$ wechselt von 15-25 nach dem Alter. 
Eine mässig schlanke Gestalt hat der Mon. papillatus, und wenig verschmälert ist das Vorderende. Der papillentragende Theil des Kopfendes ist abgesetzt und zwei Kreise von Papillen umgeben die Mundöffnung (Fig. 35a). An der Uebergangsstelle dieses papillentragenden Theiles in den Körper beobachtet man, an den lateralen Seiten, eine Rinne, ähnlich derjenigen, welche bei den Dorylaimen vorkommt, (Vergl. de Man, XXVI, Taf. XIII, Fig. 49b). Die Mundhöhle hat eine prismatische Gestalt, der Zahn ist ziemlich klein und steht im vorderen Abschnitt der Mundhöhle. Der Oes. ist nach hinten nur wenig erweitert, und Darm und Enddarm zeigen nichts abweichendes. Die weibl. Geschlechtsorgane sind bei $1,5 \mathrm{~mm}$. langen Individuen schon vollkommen entwickelt; die Geschlechtsöffnung liegt beim Beginn des letzten Körperdritttheils: ihr Abstand vom After ist stets um $1 / 3$ länger als die Länge des Oes. Die Geschlechtsorgane sind paarig symmetrisch, kurz: nur ein einziges Ei traf ich im Uterus an. Kurz, kegelförmig und zugespitzt ist der, meist nach der Bauchfläche gebogene Schwanz.

Fundort und Lebensweise. Diese, durch die Gestalt ihres Schwanzes und die Lage des Zahnes in der Mundhöhle characterisirte Art ist ziemlich selten und lebt in der feuchten Erde auf Wiesen und Marschgründen sowohl in Süsswasser- als Brackwassergegenden.

Geographische Verbreitung. Deutschland (Laibach, Frankfurt a. M. nach Bütschli), England (Sydenham, und Broadmoor, Berks nach Bastian).

Fundzeit. Geschlechtsreife, eitragende Thiere beobachtete ich in den Wintermonaten (Januar, Februar, März, November); unsicher also bleibt es ob auch in den Sommermonaten unsere Art geschlechtsreif vorkommt. Das Männchen blieb mir unbekannt.

Anmerkung. Mon. muscorum Duj. (Dujardin, III, p. 23\%) ist wahrscheinlich mit dieser Art identisch.

3. Mononchus parvus d. M.

Taf. IX, Fig. 36 .

ㅇ $1,1 \mathrm{~mm}$. , $\sigma^{7}$ unbekannt. $\alpha=20 . \beta=3{ }^{1} / 3_{3}-3^{2} /{ }_{3} \cdot \gamma=15$.

Der Körper hat eine plumpe Gestalt und ist nach vorn hin wenig verjüngt. Der papillentragende Theil des Kopfendes ist abgesetzt und trägt zwei Kreise von Papillen, von welchen diejenigen des vorderen Kreises mässig gross sind. Die Mundhöhle ist länglich, prismatisch und trägt einen schwachen, dorsalen Zahn, welcher stets im mittleren Abschnitt der Mundhöhle gelegen ist; kleine Zähnchen befinden sich am Boden der Mundhöhle, nicht weit vom Beginn des Oes. Dieser ist stets ein wenig länger als 1/4 der Gesammtlänge. Die weibl. Geschlechtsoffnung liegt in geringer Entfernung vor dem Beginn des letzten Körperdritttheils: ihre Entfernung vom After ist ungefähr so lang wie der Oes. Die weibl. Geschlechtsorgane sind paarig symmetrisch und sehr kurz: ich beobachtete ein einziges Ei im Uterus, das 1/10 mm. lang war. Der Schwanz ist kurz, kegeltörmig, zugespitzt und nach der Bauchfläche gebogen. 
Fundort und Lebensweise. Der kleine Mononchus ist ein häufiger Sandnematode: er lebt im sandigen Boden der Holländischen Dünenstriche und das Thierchen bewegt sich lebhaft.

Geographische Verbreitung. Nirgendwo sonst beobachtet.

Fundzeit, Im März, aber auch in den Sommermonaten traf ich geschlechtsreife Thiere an.

\section{Mononchus brachyuris Btsli.}

Bütschli, XX, pag. $7 \%$, Taf. III u. IV, fig. 20a-e und de Man, XXVI, pag. 112.

Taf. IX, Fig. $3 \%$.

$\sigma^{7} 1, \% \mathrm{~mm}$., ㅇ $1,5 \mathrm{~mm}$. \& beim $\sigma^{7}=35-40$, beim ㅇ $25-30 . \beta=31 / 2-4 . \gamma$ beim $\sigma^{7}=35$ und beim $q=35-50$.

Eine ziemlich schlanke Gestalt, besonders beim Männchen, zeigt der brachyuris, der sich nach vorn hin wenig verjüngt. Nur ein einziger Kreis ziemlich hoher Papillen umgiebt die Mundöffnung auf dem abgesetzten Kopfende. Die Mundhöhle (Fig. 3\%a) ist becherförmig, ziemlich enge, mit grossem dorsalen, hakenförmig nach vorn gebogenen Zahne; die Seitenwände zeigen eine characteristische Querstreifung. Der Oes. ist nach hinten allmälig erweitert und der Nervenring liegt ziemlich weit nach vorn. Die weibl. Geschlechtsöffnung liegt ein wenig vor dem letzten Körperdritttheil; die Geschlechtsorgane sind paarig symmetrisch, und kurz; in geringer Entfernung von der Geschlechtsöffnung liegt an jeder Seite in der Medianlinie ein papillenförmiges Gebilde, welches auch schon von Bütschli beobachtet wurde. Die Spicula sind schlank, gebogen, mit einer chitinösen Rinne oder Streife in der Mittellinie versehen; das accessorische Stück ist zweitheilig und umfasst die Spicula. (Vergl. de Man, XXVI, Taf. XIII, Fig 51). Beim Männchen stehen 10-11 mässig hohe Papillen vor dem After; auch einige Papillen finden sich am eigentlichen Schwanz, sowohl auf der dorsalen als ventralen Seite. Der Schwanz hat bei beiden Geschlechtern eine ziemlich gleiche Gestalt, nur ist er beim Mannchen ein wenig länger als beim Weibchen, sehr kurz und etwas nach der Bauchseite gebogen.

Fundort und Lebensweise. Diese sich lebhaft bewegende Art ist wohl omnivag; sie bewohnt nicht nur die feuchten Wiesen und Marschgründe, auch im Walde und im sandigen Dünenboden kommt der brachyuris häufig vor.

Geographische Verbreitung. Deutschland (Laibach, Gegend von Frankfurt a. M. nach Bütschli), Schweiz (Altdorf.)

Fundzeit. Ich fand diese sehr häufige Art das ganze Jahr hindurch. Die Männchen sind nicht sehr selten. 
5. Mononchus tridentatus d. M.

de Man, XXVI, pag. 109, Taf. XIII, Fig. 50.

Taf. X, Fig. 38.

$\sigma^{7} 2, y \mathrm{~mm}$. 오 $3,6 \mathrm{~mm}$. $\alpha=30-40 . \beta=4-5$. \% beim ơ $10-12$, beim 오 8-9.

Durch das Auftreten von drei Zähnen in der Mundhöhle bildet diese Art einiger Massen den Uebergang zu der Gattung Oncholaimus.

Der Körper ist mässig schlank, das Vorderende wenig verschmälert. Zwei Kreise von Papillen umgeben die Mundöffnung und der papillentragende KopftheiI ist etwas abgesetzt. Die Mundhöhle ist prismatisch, mit drei ziemlich schwachen, in der Ebene desselben Querschnittes an den Seitenwänden angehefteten Zähnen gewaffnet, welche etwas vor der Mitte der Mundhöhle liegen. Der Oes. ist nach hinten allmälig erweitert; der Darm hat ein anderes Vorkommen wie bei den typischen Mononchen, indem die Körnchen gleichmässig zerstreut sind. Die weibl. Geschlechtöffnung liegt stets ein wenig vor dem Beginn des letzten Körperdritttheils; die Geschlechtsorgane sind paarig symmetrisch und ziemlich lang. Die Spicula sind schlank, gebogen, mit centralem Verdickungsstreife und werden von einem zweitheiligen, gezähnten, die Spicula umschliessenden, accessorischen Stücke begleitet. Beim Männchen stehen 15-17 Papillen vor dem After und die Cuticula ist dort an beiden Seiten schräg gestreift. Am Schwanz des Männchens, welcher zwar etwas kürzer ist als der des Weibchens, aber übrigens eine gleichartige Gestalt besitzt, indem er sich regelmåssig verschmälert und an seinem Ende etwas angeschwollen ist, beobachtet man sowohl dorsale wie ventrale Papillen (de Man, XXVI, Taf. XIII, Fig. $50 b$ und c): und zwar zwei Paar an der vorderen Hälfte der ventralen und zwei Paar an der hinteren Hälfte der dorsalen Fläche.

Fundort und Lebensweise. Bis jetzt wurde diese ziemlich seltene Art nur in der feuchten Erde von. Wiesen und Marschgründen beobachtet und zwar an den Wurzeln von, am Ufer von Süsswassergräben wachsenden Pflanzen.

Geograplische Verbreitung. Deutschland (Laibach.)

Fundzeit. Geschlechtsreife Thiere traf ich im Sommer und im Herbste an (Mai, Juli, October, November).

Anmerkung. Der Mon. fovearum Duj. scheint mir eine andere Art zu sein, indem der Schwanz des Weibchens kürzer ist und die Vulva in der Mitte des Körpers liegt.

\section{Oncholaimus Duj.}

Die Oncholaimen leben fast allen im Meere; nur eine Art entfloh demselben und nachdem sie eine Zeit lang im Brackwasser gelebt hatte, passte sie sich dem Leben in der feuchten, von 
brackischem Wasser durchtränkten Erde allmälig an, und wandelte sich zu gleicher Zeit in eine neue Art um, welche ich thalassophygas, d. h. den dem Meere entflohenen, nennte. Die Oncholaimen sind den Mononchen sehr ăhnlich, und unterscheiden sich hauptsächlich durch drei in Innern der Mundhöhle nach vorn gerichtete, zahnartige unbewegliche Vorsprünge, so wie durch einige andere Eigenthümlichkeiten: einen einfachen Hoden u. s. w.

\section{Oncholaimus thalassophygas d. M.}

de Man, XXVI, pag. 104, Taf. XII, XIII, Fig. 48.

Taf. X, Fig. 39.

$\sigma^{7} 2,4 \mathrm{~mm}$, ㅇ $3,5 \mathrm{~mm}$. $\alpha=35-40 . \beta$ beim $\sigma^{7}=6$, beim $\&=6{ }^{1} / 2-\%, \gamma$ beim $\sigma^{7}=20$, beim 우 $=20-24$.

Dieses merkwürdige Thier hat eine schlanke Gestalt, mit ziemlich viel verschmälertem Vorderende. Das Kopfende ist nicht abgesetzt, ohne Borsten; ein Kreis von 4-6 sehr kleinen Papillen umgiebt die Mundöffnung in geringer Entfernung von derselben (Vergl. de Man, XXVI, Taf. XII, Fig. $48 a$ und Taf. XIII, Fig. 48b). Die Mundhöhle enthält drei zalnartige Vorsprünge, einen grösseren kegelförmigen und zwei anderen, welche schwächer und so ziemlich gleich gestaltet sind. Der Oes. ist nach hinten allmälig erweitert: den Ring des Nervensystems erkennt man deutlich. Die Körnchen der Darmwand sind gleichmässig verbreitet, nicht zu einzelnen Häufchen gruppirt. Die weibl. Geschlechtsöffnung liegt bei ganz erwachsenen, 3,5 mm. langen Individuen ein wenig hinter der Körpermitte, bei jüngeren $3 \mathrm{~mm}$. langen gerade in der Mitte des Körpers; die, höchstens vier Eier producirenden Geschlechtsorgane sind paarig symmetrisch, ziemlich kurz, mit umgeschlagenen Ovarien. Schon bei $3 \mathrm{~mm}$. langen Weibchen fand ich zwei Eier im Uterus. Beim Weibchen ist der Schwanz schlank, ziemlich regelmässig verschmälert, mit knopfartig verdickter Endspitze, an welcher man eine kleine Ausführungspapille der Schwanzdrüse erkennt (Fig. 39a). Die Spicula (Vergl. de Man, XXVI, Taf. XII, Fig. 48c) sind sehr lang, dünn und schlank, 1/10 mm. lang bei einer Körperlänge von 2,4 mm., während das accessorische Stück sehr klein und oval ist. Prăanal ist die Cuticula beim Männchen schräg gestreift; gleich vor und bei dem After sieht man eine mediane Reihe von 5-6 gebogenen Borsten; der Schwanz verschmälert sich hinter dem After plötzlich und läuft dann in gleicher Stårke bis an die, ein wenig verdickte Endspitze fort; er hat eine laterale Borstenpapille am Wurzel des verschmälerten Theiles und ausserdem beobachtet man zahlreiche hie und da zerstreute Borsten, deren Stellung vielleicht constant ist.

Fundort und Lebensweise. Ausschliesslich kenne ich diese eigenthümliche Art nur noch von der Insel Walcheren, wo sie häufig in der feuchten, von brackischem Wasser durchtränkten Erde an den Wurzeln der dort wachsenden Pflanzen lebt. Das Thier bewegt sich lebhaft und Männchen und Weibchen kommen gleich häufig vor. 
Fundzeit. Geschlechtsreife, erwachsene Thiere beobachtete ich in den Monaten März, April und August.

Anmerkung. Es scheint mir, dass der an den Englischen Küsten lebende Onchol. fuscus Bast. (Bastian, VII, pag. 136, Pl. XI, fig. 139, 140) unserer Art am nächsten verwandt ist: und wahrscheinlich sind diese beiden Formen auch phylogenetisch mit einander am engsten verbunden.

\title{
XIV. Ironus Bast.
}

\author{
Bastian, VII, pag. 103.
}

Die kleine Gruppe Ironus weicht von allen anderen freilebenden Rundwürmern durch die eigenthümliche Bildung des Kopfes und der Mundhöhle ab. Es sind schlanke Thiere, deren Körper sich nach beiden Enden hin, besonders aber nach hinten verjüngt; die glatte Cuticula trägt keine Seitenmembran, keine Borsten. Die Muskulatur ist nach Bütschli polymyarisch. Die, durch eine Einschnïrung vom übrigen Körper abgetrennte Kopfregion hat an den Iateralen Seiten die, auch bei Dorylaimus vorkommenden Lateralrinnen und besteht aus drei Lippen, welche mit Papillen besetzt sind und an ihrer Basis Borsten tragen. Diese Lippen sind aber beweglich, sodass sie aus einander gehen, wodurch die ganze Mundhöhle und der Oes. nach vorn gezogen werden. Diese Mundhöhle stellt sich als eine lange, enge cylindrische Rölhre dar mit cbitinisirten Wänden, welche besonders in der abgesetzten Kopfregion stark verdickt sind; an diesen verdickten Stellen finden sich drei Zähne, welche gebogen und hakenförmig an der Mittellinie der drei Lippen angeheftet sind. Natürlich werden diese Zähne bei der Bewegung der Lippen nach aussen hin gewendet. Bei jüngeren Thieren (Taf. X, Fig. 40a) beobachtet man, in geringer Entfernung hinter der Kopfregion, in der Wand der Mundhöhle, noch drei kleinere Zähne, welche etwa die Gestalt eines Haifischzahnes haben und natürlich zu gleicher Zeit mit der Mundhöhle bewogen werden; diese Zähnchen bilden sich wahrscheinlich später in die definitiven Zähne der Mundhöhle um, während die in der Jugend in der Mundhöhle sich befindenden Zähne dann nur provisorische sein würden. Wenn diese Vermuthung richtig ist, so haben wir hier eine analoge Erscheinung wie bei der Bildung des Stachels der Dorylaimen. Der muskulöse Oes. ist langgestreckt, nach hinten allmålig erweitert; die Chitinbekleidung des Lumens hört etwas vor dem Ende des Oes. auf und das Lumen setzt sich noch, von sehr dünnen Wänden begrenzt, eine kurze Strecke in den vorderen Theil des Darmes fort (Fig. 40c). Dieser ist aus vielen Zellenreihen aufgebaut und die Körnchen sind zu Häufchen gruppirt. Ein Gefässporus fehlt und über die Existenz einer Schwanzdrüse bin ich ungewiss: nach Bütschli soll sie vorhanden sein. Die weibl. Geschlechtsorgane sind paarig symmetrisch, die Ovarien umgeschlagen und Uterus und Eileiter zeigen kräftige Ringmuskulatur. Die Spicula haben eine plumpe Gestalt, zeigen einen sogenannten centralen Verdickungs- 
streif und, mit den Spiculis verbundene accessorische Stücke. Beim Männchen kommt eine präanale Borstenpapille vor, aber eigentliche Papillen hat es nicht.

Es giebt bis jetzt nur zwei Arten, welche sich, wie folgt, unterscheiden lassen:

Grössere Art bis 3,8 mm. lang; Schwanz verhältnissmässig kurz. . . 1. ignavus Bast.

Kleinere Art, nur die Hälfte der Länge der vorigen erreichend; Schwanz sehr lang, fadenförmig . . . . . . . . . . 2. longicaudatus d. M.

1. Ironus ignavus Bast.

Bastian, VII, pag. 104, Pl. IX, Fig. 34a, $34 b$.

Bütschli, XXV, pag. 384, Taf. XXV, Fig. 15a-e.

Synon: Ironus tenuicaudatus d. M., de Man, XXVI, pag. \%.

Taf. X, Fig. 40 .

구 $3,8 \mathrm{~mm} ., \alpha=50-60 . \beta=6 . \gamma=14-22$, sehr variirend.

Die grössere der zwei Ironus-arten hat eine sehr schlanke Gestalt, welche sich nach beiden Enden hin verschmälert. Die kolbige Kopfregion ist abgesetzt und trägt zwei sehr kleine Papillen auf der Höhe von jeder der drei beweglichen, aus einander gehenden Lippen; am Grund der Kopfregion stehen vier măssig kleine, submediane Borsten. Die Mundhöhle ist 1/5 der Länge des eigentlichen Oes. lang. Die weibl. Geschlechtsöffnung liegt bei jüngeren Thieren (von 2-2,4 m.m.) vor, bei erwachsenen von 3,8 m.m. hinter der Körpermitte. Die weibl. Geschlechtsorgane sind ziemlich lang, mit umgeschlagenen Ovarien und mit kräftiger Ringmuskulatur am Uterus und Eileiter (Fig. 40). Der Schwanz hat eine ein wenig veränderliche Gestalt, ist mehr oder weniger schnell zugespitzt und fadenförmig. Die Spicula (Fig. 40c) sind plump, etwas gebogen, mit dünner Membran am Vorderrande und mit einfachem, nach innen zweitheiligem, centralem Verdickungsstreife. Gleich bei und vor dem After beobachtet man beim Männchen eine einzige steife Borste.

Fundort und Lebensweise. Diese Art ist ziemlich häufig, bewegt sich lebhaft und bewohnt die feuchte, oder von süssem Wasser durchtränkte Erde der Wiesen und Marschgründe.

Geographische Verbreitung. Deutschland (Erlangen, Frankfurt a. M. nach Bütschli.) England nach Bastian.

Fundzeit. Geschlechtsreife Thiere beobachtete ich in den Monaten Februar und November; über das Vorkommen in den anderen Monaten liegen mir leider keine Angaben vor.

Anmerkung. Zweifelsohne hat auch Bastian dieselbe Art untersucht, aber seine Thiere waren jung, noch nicht erwachsen. 


\section{Ironus longicaudatus n. sp.}

Taf. XXXIV, fig. 140 .

우 $1,9 \mathrm{~mm} . \alpha=45-50 . \beta=6-6^{1} / 2 . \gamma=31 / 3-3^{2} / 3$.

Ausser den angegebenen Maassen kenne ich von dieser Art nur die Abbildung, welche ich auf Taf. XXXIV habe drucken lassen.

Auch sie hat einen schlanken Körper, welcher sich nach vorn ein wenig verengt, während er nach hinten in einen langen, haarfeinen Schwanz endigt. Die Kopfregion ist abgesetzt und die Mundhöhle ist ein wenig länger als ein Drittel der Länge des Oes. Dieser verschmälert sich allmälig nach hinten. Die weibl. Geschlechtsöffnung liegt vor der Mitte, und iltre Entfernung vom Hinterende des Oes. ist kleiner als die Strecke zwischen ihr und dem After. Die Genitalien sind ziemlich kurz und ich beobachtete ein einziges grosses Ei. Der Schwanz ist etwas länger als ein Viertel der Körperlänge und fein fadenförmig.

Fundort. Auch diese Form, welche nicht so häufig ist als die vorige Art, bewohnt die feuchte Erde.

Geographische Verbreitung. Deutschland (Erlangen).

\section{Sphaerolaimus Bast.}

Bei den eigenthümlichen Sphaerolaimen trifft man Thiere mit mässig schlankem Körper an; die Cuticula ist glatt oder quergeringelt, ohne Seitenmembran und trăgt Borsten. Das abgesetzte Kopfende ist mit Borsten gewaffnet, trägt aber keine Lippen oder Papillen; die Mundhöhle ist gross, mit chitinösen Wänden und mehreren characteristischen localen Chitinverdickungen versehen. Der Oes. ist cylindrisch und muskulös; der Darm zellig, und die Zellen sind mit sehr dunklen Körnchen gefüllt, sodass die Darmwand bei durchfallendem Lichte sehr dunkel erscheint wie bei einigen Monohysteren. Die weibl. Geschlechtsöffnung ist weit nach hinten gerückt und die Geschlechtsröhre einseitig, unpaar, nach vorn gerichtet. An der Vulva befindet sich eine Drüse.

Beim Männchen kommen keine prä- oder postanale Papillen vor; die Spicula sind schlank, enge, gebogen mit einfachem, herz- oder schildförmigen, accessorischen Stücke. Ocellen fehlen. Bei der marinen Art findet sich eine Ventraldrüse, welche beim gracilis zu fehlen scheint, beim hirsutus aber auf der Mitte des oesophagealen Körpertheiles ausmündet. Kreisförmig sind die Seitenorgane und eine Schwanzdrüse kommt ebenso vor.

Fundort und Lebensweise. Die Sphaerolaimen sind bewegliche Thiere, welche den Habitus und das Vorkommen einiger Monohysteren haben; so scheint der gracilis der Monolı. dispar Bast sehr ähnlich. Eine Art lebt im Meere, die andere in brackischer feuchter Erde. 
Diese zwei Arten, von welchen die eine an den Englischen Küsten und auch in der Kieler Bucht lebt, lassen sich leicht durch die folgenden Charactere unterscheiden:

Grössere Art $(2,5 \mathrm{~mm}$.$) , Haut quergeringelt. Wände der Mundkapsel lăngsge-$ streift oder granulirt. Meeresnematode . . . . . . . . . . 2. hirsutus Bast. Kleinere Art (1,5 mm.), Haut glatt, nicht quergeringelt. Wände der Mundhöhle nicht lüngsgestreift oder granulirt. Brackwassernematode . . . . 1. gracilis d. M.

1. Sphaerolaimus gracilis d. M.

de Man, XXVI, pag. 102. Pl. XII, Fig. 4\%.

Taf. X, fig. 41 .

$\sigma^{7} 1,4 \mathrm{~mm}$., ㅇ $1,5 \mathrm{~mm} . \alpha=30 . \beta=5 . \gamma=8-9$.

Der Körper hat eine ziemlich schlanke Gestalt, mit wenig verjüngtem Vorderende. Die glatte Cuticula ist ungeringelt, und Börstchen sind über dex gesammten Körperoberfläche zerstreut. Das abgesetzte Kopfende trägt zwei Kreise von kräftigen Borsten, aber keine Lippen oder Papillen. Die ziemlich grossen Seitenorgane sind kreisförmig. Die geräumige Mundhöhle hat chitinöse, nirgendwo längsgestreifte oder granulirte Wände mit vielen characteristischen localen Chitinverdickungen. Der Oes. ist nach hinten allmälig erweitert, und auch an seinem Anfange etwas verdickt. Der Darm erscheint bei durchfallendem Lichte sehr dunkel, sodass man auf dem ersten Blick in unseren Thieren eine Monohystera $\mathrm{zu}$ sehen glaubt. Auf $1 / 3$ der Gesammtlänge vom Hinterende entfernt, liegt die weibl. Geschlechtsöffnung; an der Vulva findet sich eine Drüse (Taf. X, Fig. 41c) und die einseitige Geschlechtsröhre ist weit nach vorn hin ausgestreckt. Die schlanken Spicula sind gebogen, mit einfachem, herz- oder schildförmigem, accessorischem Stücke. (Taf. X, Fig. $4 \mathbf{l} a$ und $b$ ). Der Schwanz ist schlank, allmälig verschmälert, und an seinem Ende etwas verdickt; an diesem verdickten Ende mündet die Schwanzdrüse aus, und stehen zwei kleine abstehende Börstchen.

Fundort und Lebensweise. Diese Art wurde nur noch auf der Insel Walcheren beobachtet, wo sie häufig ist und die feuchte, von brackischem Wasser durchtränkte Erde bewohnt.

Fundzeit. Geschlechtsreif ist der Sphaerolaimus gracilis in den Monaten März, April und August. Männchen und Weibchen kommen gleich häufig vor.

\section{Choanolaimus.}

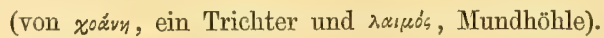

Eine sehr plumpe Gestalt haben die Choanolaimen, deren Körper fast durchweg den gleichen 
Durchmesser hat, weil er sich nach vorn hin fast gar nicht verschrnälert. Die Haut ist quergeringelt, mit körnichter Skulptur, trägt keine Seitenmembran und Borsten kommen auf derselben nicht vor. Das Kopfende ist nicht abgesetzt, abgerundet, und zwei Reihen von Papillen stehen um die Mundöffnung, wăhrend Borsten nicht an demselben gefunden werden. Die geräumige Mundhöhle ist trichterförmig, mit chitinösen IVänden bekleidet und besteht aus einem vorderen erweiterten und einem hinteren verschmälerten Theile; Zühne oder locale Chitinverdickungen kommen in derselben nicht vor. Die grossen Seitenorgane sind spiralig. Der Oes. ist cylindrisch, nach hinten nicht erweitert, muskulös; zwischen seinem Hinterende und dem Darme liegen einige Drüsen. Der̉ Darm ist zellig, und erscheint bei durchfallendem Lichte sehr dunkel, weil die Zellen mit dichtgedrängten kleinen dunklen Körnchen gefüllt sind. Die weibl. Geschlechtsorgane sind paarig symmetrisch, und die Ovarien umgeschlagen. Die wenig gebogenen Spicula werden von zwei stabförmigen, accessorischen Stücken begleitet. Keine Papillen kommen beim Männchen vor. Der Schwanz ist kurz, abgerundet, ohne Schwanzdrüse.

Die einzige bekannte Art ist:

1. Choanolaimus psammophilus d. M.

Taf. X, Fig. 42 .

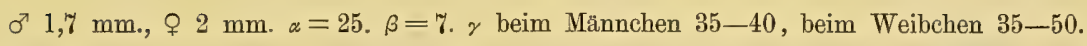

Eine plumpe Gestalt und einen Körper mit fast überall gleichem Durchmesser besitzt der psammoptilus. Die Cuticula ist feingeringelt; jeder Ring besteht aus einer Reihe von kleinen Körnchen und jedesmal liegt eine zweite Reihe von gleich kleinen Körnchen in der Mitte jedes Ringes: auf den Seitenfeldern (Fig. $42 c$ und $d$ ) sind die erstgenannten Körnchen grösser, während die anderen fehlen. Das abgestutzte Kopfende zeigt zwei Kreise kurzer Papillen um die Mundöffnung. Die spiraligen Seitenorgane liegen auf der Mitte der Mundhöhle: sieht man dieselben in Profil, so beobachtet man zwei Hervorragungen, von welchen die vordere kleiner ist als die hintere (Fig. 42b). Die Mundhöhle ist trichterförmig, mit chitinösen Wünden bekleidet; der hintere, engere Theil wird vom Oes. umgeben. Dieser letztere ist muskulös, zeigt ein enges Lumen und hat eine cylindrische Gestalt; an seinem Hinterende liegen mehrere Drüsen. Der sehr dunkle Darm hat einen zelligen Bau, und die Zellen sind mit dichtgedrängten dunklen Körnchen gefüllt. Der Enddarm ist sehr kurz. Die Geschlechtsorgane fehlen noch vollständig bei $1,2 \mathrm{~mm}$. langen Thieren; beim Weibchen liegt die öffnung der paarig symmetrischen Geschlechtsorgane beim Anfang des letzten Körperdritttheils; sie sind nicht gross und die Ovarien sind umgeschlagen. Der Schwanz hat bei beiden Geschlechtern ungefähr die gleiche Gestalt, nur ist er beim Weibchen etwas kürzer; er ist nämlich sehr kurz, kegelförmig, abgerundet. Keine Papillen beobachtet man am hinteren Körperende des Männchens; die Spicula sind schlank, mit dünnen Wänden und werden von zwei dünnen stabförmigen accessorischen Stücken begleitet. Eine Schwanzdrüse wie auch ein ventraler Gefässporus fehlen vollständig. 
Fundort und Lebensweise. Diese eigenthümliche Art, welche sich von allen anderen gleich unterscheidet durch die gedrungene Gestalt ihres Körpers und ihre dunkle Farbe bei durchfallendem Lichte, ist ein ächter Sandnematode und bewohnt, wie es scheint, ausschliesslich, in den Niederlanden wenigstens, die sandigen Dünengegenden, wo sie an den Wurzeln von Galium verum, Sedum acre, Hippophae u.s.w. hăufig gefunden wird. Das Thier bewegt sich lebhaft und rollt sich bei Berührung gänzlich auf, wie es auch einige andere Arten zu thun pflegen.

Geographische Verbreitung. Bis jetzt nirgendwo sonst beobachtet.

Fundzeit. Geschlechtsreif ist der psammophilus in den Wintermonaten (November-März); unsicher ist es mir, ob sie auch im Sommer geschlechtsreif vorkommt. Männchen kommen gleich häufig vor wie Weibchen.

\section{Trilobus Bast.}

$$
\begin{aligned}
& \text { Bastian, VII, pag. } 99 . \\
& \text { Bütschli, XX, pag. } 53 .
\end{aligned}
$$

Die kleine Gruppe der Triloben lässt sich leicht durch die folgenden Merkmale unterscheiden. Es sind schlanke Thiere, deren Körper sich mehr nach hinten als nach vorn verschmãlert. Die Haut ist glatt, und trägt öfters Borsten. Die Muskulatur ist, nach Bütschli, diejenige eines Polymyariers und die Mảrksubstanz häufig sehr körnig. Auch kommen breite Seiten sowie schmale Medianfelder vor. Eine Seitenmembran fehlt. Um die Mundöffnung stehen rudimentäre Lippen mit Papillen und um diese ein Kranz von steifen Borsten. Die Mundhöhle ist becherförmig oder ähnelt einem umgekehrten Kegel; ihre Wände sind chitinös; aber sie trägt keine Zähne oder locale Chitinverdickungen. Etwas hinter ihr liegt im Lumen des Oes., wo dasselbe etwas erweitert ist, ein zahnartiger Vorsprung. Der cylindrische, muskulöse Oes. ist hinten meist angeschwollen; an seinem Hinterende befinden sich $d r e i$ anselnliche Drüsen, von welchen der Gattungsnamen abgeleitet worden ist. In der Darmwand sind häufig polygonale Zellen sichtbar, oder die Grenzen derselben sind verwischt; der Enddarm ist kurz. Der Ring des Nervensystems ist deutlich. Ein ventraler Gefässporus fehlt. Die weibl. Geschlechtsorgane sind paarig symmetrisch, nach beiden Seiten hin ausgestreckt, mit umgeschlagenen Ovarien; die Vagina wird von einer starken Ring- und Längsmuskulatur umgeben. Auch die Uteri zeigen eine starke Ringmuskulatur; die Zahl der Eier ist beschränkt. Die männliche Geschlechtsdrüse ist ebenso zweitheilig; es giebt zwei Spicula mit einfachem accessorischem Stücke. Vor dem After findet sich eine mediane Reihe von Papillen, durch welche man einen zarten Achsenfaden laufen sieht, sodass die Papillen ohne Zweifel nervöser Natur sind. Die Schwanzdrüse soll nach Bütschli dreizellig sein, und mündet am angeschwollenen Schwanzende aus.

Fundort und Lebensweise. Die beweglichen Triloben bewohnen den Schlamm der Süsswassergräben, das süsse Wasser oder die feuchte Erde; sie haben, wie die Choanolaimen, die Gewohnheit sich aufzurollen. 
Die zwei beobachteten Arten lassen sich durch die folgenden Charactere unterscheiden:

1. Schwanz nicht besonders verlängert; Spicula wenig gebogen; präanale Papillen auf ziemlich gleichen Entfernungen . . . . . . . . . . . . 1. gracilis.

Schwanz verlängert, fadenförmig; Spicula schlank, gebogen; präanale Papillen auf sehr ungleichen Entfernungen von einander gelegen . . . . . . . . 2. pellucidus.

Ausser diesen zwei Formen wurden noch die drei folgenden beschrieben:

1. Trilobus octiespapillatus, (von Linstow, XXIX, pag. 11, Taf. II, Fig. 28). Deutschland, verwandt am gracilis Bast.

2. Trilobus longicauda, (von Linstow, XXIX, pag. 12, Taf. II, Fig. 29, 30). Deutschland. Diese Art ist dem pellucidus verwandt, vielleicht ein junges Exemplar dieser Art.

3. Trilobus longus Leidy, (Leidy, Proc. Acad. Philadelphia, V, p. 225), Süsswassergräben in der Nähe von Philadelphia.

Wahrscheinlich aber sind die beiden von Linstow'schen Arten mit den Bastian'schen identisch.

1. Trilobus gracilis Bast.

Bastian, VII, pag. 99, Pl. IX, Fig. 20-22.

de Man, XXXVI, pag. 140.

Taf. XI, Fig. 43.

$\sigma^{7} 2-2,6 \mathrm{~mm}$., ㅇ $2,1 \mathrm{~mm}$. $-3 \mathrm{~mm}$. \& beim $\sigma^{7} 35-45$, beim ㅇ $\left.35-40 . \beta=6-6^{2}\right)_{3} \cdot \gamma$ beim $\sigma^{x}$ $15-16$, beim 오 $7-10^{1} \%_{2}$.

Der schöne Trilobus gracilis ist schlank, besonders das Männchen, und verschmälert sich nach vorn hin weniger als nach hinten. Feine Börstchen sind über der gesammten Körperoberfläche zerstreut. Am nicht abgesetzten Kopfende beobachtet man rudimentäre Lippen und auf diesen sechs (oder zehn) kurze Papillen gleich um die Mundöffnung, während, etwas hinter diesen, zehn kurze Borsten vorkommen, und zwar sechs grössere und vier kürzere, submedian gestellte (Fig. 43a). Die kleine becherförmige Mundhöhle setzt sich in einen erweiterten Theil des Lumens des Oes. fort, worin sich ein zahnartiger Fortsatz befindet. Der vordere etwas verdickte Theil des cylindrischen Oes. umfasst die Mundhöhle; nach hinten schwillt er allmälig an. Der Ring des Nervensystems ist deutlich, und die lappenförmigen Drüsen am Ende des Oes. sind sehr ausgeprägt. Die Körnchen der Darmzellen sind öfters zu Hăufehen gruppirt und der Enddarm ist sehr kurz.

Bei 1,9 mm. langen Thieren findet sich nur noch die kleine ovale Genitalanlage: eine Geschlechtsöffnung, resp. Spicula, fehlen noch vollständig. In Bezug auf die Geschlechtsorgane beobachtete ich noch das folgende. In den Monaten April und Juni fand ich geschlechtsreife Individuen, ebenso im Monat Oktober: die ersteren waren aber stets kleiner als die letzteren, während junge in Oktober gefundene Individuen, bei welchen noch keine Spur von Genitalien vorhanden war, die Länge hatten der im Frühjahre beobachteten geschlechtsreifen Exemplare. Eine Erklïrung dieser 
Erscheinung, worauf ich schon früher (de Man, XXXVI, pag. 140) aufmerksam machte, kann ich auch jetzt nicht geben.

Die Ausmündungsöffnung der paarig symmetrischen weiblichen Geschlechtsorgane liegt in einiger Entfernung vor der Körpermitte, sowohl bei Thieren, welche 2,1 mm. lang sind als bei denjenigen, welche die Länge von $3 \mathrm{~mm}$. erreicht haben. Die Genitalien sind ziemlich kurz, und die zurückgeschlagenen Ovarien strecken sich bei eitragenden Individuen bis an die Vulva aus; die blinden Enden scheinen sich bisweilen von neuem zurückzubiegen (Fig. 43). Die höchste beobachtete Zahl der Eier, deren Länge bei einem 2,15 mm. langen Weibchen $0,0 \% \mathrm{~mm}$. betrug, war fünf. Die männliche Geschlechtsdrüse ist, nach Bütschli, zweitheilig; die Spicula (Fig. $43 c$ und $43 f$ ) sind ziemlich plump, nicht gebogen und werden von einem accessorischen Stücke begleitet, das aus einem H-förmigen Mittelstücke und zwei Seitenstücken besteht; das Mittelstück ist vorne bogenförmig abgerundet. Vor dem After liegen sechs gleiche mediane Papillen, von welchen die vordere sich etwas vor dem inneren Ende der Spicula befindet; diese Papillen, welche zweifelsohne nervöser Natur sind, liegen auf ziemlich gleichen Entfernungen von einander. Bei einem, 2,6 mm. langen Männchen betrug die Entfernung der vordersten Papille vom After 0,31 mm., war also zweimal so lang als der Schwanz. Der Schwanz des Weibchens (Fig. 43b) ist schlank, allmälig verschmälert und hat ein knopfartig angeschwollenes Ende, worin die Schwanzdrüse ausmündet. Beim Männchen (Fig. 43d) hat der Schwanz eine kürzere, mehr gedrungene Gestalt.

Fundort und Lebensweise. Diese schöne häufige Art, welche, als ihr Gefahr droht, sich in eine Spirale aufrollt, bewohnt nicht nur die feuchte Erde, welche von süssem oder brackischem Wasser durchtränkt ist, sondern wuch das süsse Wasser selbst, in Gräben und Teichen. Männchen sind fast eben häufig als Weibchen. Öfters beobachtet man in ihrer Leibeshöhle zahllose kleine stabförmige Körperchen, welche gegen die Muskelschicht zu liegen scheinen: vielleicht eine Art Bakterien.

Geographische Verbreitung. Deutschland (im Main nach Bütschli), England nach Bastian.

Fundzeit. In Bezug auf das zeitliche Vorkommen mache ich auf das schon erwähnte Faktum aufmerksam, dass die geschlechtsreifen Thiere in den Monaten April und Juni kleiner sind als in den letzten Monaten des Jahres (Oktober), sodass ich die Existenz von zwei Generationen vermuthe.

2. Trilobus pellucidus Bast.

Bastian, VII, pag. 100, Pl. IX, Fig. 23, 24.

Bütschli, XXV, pag. 37\%, Taf. XXIV, Fig. 10a-d.

Synon: Trilobus leptosoma d. M.; de Man, XXXV, pag. 30.

Vergl: de Man, XXXVI, pag. 140-142.

Taf. XI, Fig. 44.

$\sigma^{7} 2,4 \mathrm{~mm}$. 우 $2,5-4 \mathrm{~mm}$. $\alpha=40-50$. $\beta$ beim $\sigma^{7}=6-7$, beim $q=5-6 . \gamma$ beim $\sigma^{7}$ (von 2,4 $\mathrm{mm}$.) $=8$, beim $q=7-11$. 
Auch bei dieser Art scheint es zwei Generationen zu geben, von welchen diejenige, welche in der ersten Hälfte des Jahres lebt, sich durch geringere Grösse unterscheidet von derjenigen der zweiten Jahreshälfte. Während in August beobachtete eitragende Weibchen nur die Länge von 2,5 mm. erreichten, waren bei $2,9 \mathrm{~mm}$. langen Individuen, welche ich in November auffand, die Geschlechtsorgane noch kaum entwickelt und war bei einem 2,1 mm. langen Weibchen aus demselben Monate die Geschlechtsöffnung nur eben angelegt. Nach Bütschli erreicht das Weibchen aber die Länge von 4 mm. Das Männchen beobachtete ich nicht, sodass ich nur die Angaben Bütschli's mitzutheilen im Stande bin.

Es hat diese Art eine verhältnismässig sclllankere Körpergestalt als die vorige, mit welcher sie übrigens im äusseren Vorkommen sehr übereinstimmt. Ueber der gesammten Körperoberfläche stehen kurze Börstchen in Längsreihen auf den Submedianlinien. Am nicht abgesetzten Kopfende, beobachtet man sechs rudimentäre Lippen, welche gleich um die Mundöffnung zehn kurze Barstenpapillchen tragen. In geringer Entfernung hinter diesen stehen zelı Borsten und zwar sechs grosse kräftige und vier kleinere submedian gestellte. Die Mundhöhle ist klein, trichterförmig und setzt sich unmittelbar in das nicht erweiterte Lumen des Oes. fort: eine geringe Strecke hinter ihr ist dasselbe aber ein wenig erweitert und trägt dort einen zahnartigen Fortsatz (Fig. 44a). Der cylindrische, muskulöse Oes. ist an der Stelle, wo ihn der schräg verlaufende Nervenring umgiebt, enger als an den beiden Enden, von welchen das vordere die Mundhöhle umfasst. Nach Bütschli finden sich in geringer Entfernung hinter dem Kopfende sehr schwach entwickelte Halspapillen. Die Drüsen am Hinterende des Oes. sind deutlich ausgeprägt. In der Darmwand sind die Körnchen gleichmässig zerstreut; der Enddarm ist kurz. Die weibl. Geschlechtsorgane sind paarig symmetrisch; die Ausmündungsöffnung derselben liegt bei eitragenden, 2,5 mm. langen Individuen der ersten Generation etwas linter der Mitte (auf $4 / 9$ der Gesammtlänge vom Schwanzende entfernt), bei erwachsenen Thieren der zweiten Generation aber vor der Mitte. Die Geschlechtsorgane stimmen mit denjenigen des Tril. gracilis ziemlich überein : vier Eier beobachtete ich bei Weibchen der ersten Generation.

Das Männchen zeigt bedeutende Unterschiede vom Männchen des gracilis. Zwar finden sich auch hier sechs präanale mediane Papillen, aber ilhe Anordnung ist verschieden, weil sie auf sehr ungleichen Entfernungen von einander liegen. Die beiden Spicula sind scllanker und gekrümmter und das kleine accessorische Stück ist durch einen liurzen, jedoch breiten hinteren Fortsatz zur Anheftung von Rückziehmuskeln gekennzeichnet. (Bütschli).

Sehr characteristisch ist der Schwanz; er hat bei beiden Geschlechtern ungefähr die gleiche Gestalt, verschmälert sich allmälig und läuft fadenförmig aus, am Ende kaum angeschwollen. (Vergl. Fig. 44b). Während er bei $2,5 \mathrm{~mm}$. langen Weibchen der ersten Generation 1/7 der Gesammtlänge misst, ist er, nach Bütschli, bei $4 \mathrm{~mm}$. langen Weibchen nur $1 / \mathrm{n}_{11}$ der Totallänge lang.

Fundort und Lebensweise. Diese schöne, Jebhafte Art ist minder häufig als der Trilobus gracilis; sie bewohnt die feuchte, vom Wasser durchtränkte Erde und den Schlamm der Flüsse und Gräben. Wie die genannte Art, rollt auch sie sich in eine Spirale auf. Die Männchen scheinen seltener zu sein als die Weibchen. 
Geographische Verbreitung. Deutschland (im Main nach Bütschli), England nach Bastian. Fundzeit. Geschlechtsreif in zwei Generationen (Juni, August und November).

\section{Aulolaimus d. M.}

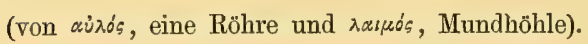

Die Aulolaimen besitzen eine ziemlich schlanke Körpergestalt, und sind nach beiden Körperenden hin zugespitzt. Die Cuticula ist glatt, ungeringelt und trägt keine Seitenmembran und keine Borsten. Das vorn abgestutzte, nicht abgesetzte Kopfende ist ganz nackt, hat keine Lippen, Papillen oder Borsten. Seitenorgane fehlen ebenso. Die Mundöffnung führt in eine lange dünne und enge Rölire, mit chitinösen Wänden bekleidet, welche die Mundhöhle darstellt; dieselbe ist viel länger als der Oesophagus, dessen enges Lumen dreiseitig ist. Der Darm ist gleichmässig fein gekörnt. Die weibl. Geschlechtsorgane sind paarig symmetrisch. Die Spicula sind schlank, gebogen, mit nach hinten umgebogenem accessorischem Stücke. Eine geringe Zahl medianer Papillen beobachtet man beim Männchen vor dem After. Wahrscheinlich fehlt eine Schwanzdrüse.

Obwohl unvollkommen bekannt, unterscheidet sich diese Gattung von allen anderen durch die eigenthümliche verlängerte Gestalt der Mundhöhle.

Die einzige bis jetzt bekannte Art ist der

1. Aulolaimus oxycephalus d. M.

Taf. XI, Fig. 45.

$\sigma^{2}$ 우 $0,8 \mathrm{~mm} . \alpha=30 . \beta=5-51 / 2 . \gamma$ beim $\sigma^{7} 12$, beim $ᄋ 9$.

Eine mässig schlanke Gestalt und ein nach vorn hin zugespitztes Körperende zeigt dieses Thier. Schön längsgestreift (Fig. 45c) ist die Cuticula. Das Kopfende läuft sehr spitz zu, ist abgestutzt und zeigt gar keine Bewaffnung. Die Mundhöhle (Fig. 45) ist zweimal so lang als der eigentliche Oesophagus. Die weibl. Geschlechtsöftnung liegt ein wenig hinter der Körpermitte; über den Bau der weibl. Geschlechtsorgane kann ich leider nichts mittheilen. Die Spicula (Fig. 45c) sind halbkreisförmig gebogen, schlank, und vom einem, nach hinten gerichteten accessorischen Stücke begleitet. Drei niedrige mediane Papillen, dicht bei einander gelegen, beobachtet man vor dem After. Der Schwanz istallmälig verschmälert und zugespitzt.

Fundort und Lebensweise. Dieses sehr seltene, träge sich bewegende Thier bewohnt die sandigen Gründe der Holländischen Dünenstriche. 
Geograplische Verbreitung. Bis jetzt nur in den Niederlanden beobachtet.

Fundzeit. Geschlechtsreife Thiere fand ich in den Monaten Oktober und November.

\section{Prismatolaimus d. M.}

Die, zur kleinen Gruppe der Prismatolaimen gehörigen Würmer haben eine schlanke Körpergestalt und ihr Körper verschmälert sich nach vorn weniger als nach hinten. Die Cuticula ist fein geringelt, trägt keine Seitenmembran. Das nicht abgesetzte Kopfende ist vorn abgerundet, trägt keine Lippen oder Papillen, und ist mit Borsten gewaffnet. In einiger Entfernung hinter dem Vorderrande liegen die linienförmigen Seitenorgane, welche nur schwer zu beobachten sind, am besten in der Profilansicht. Charakteristisch ist die Mundhöhle; dieselbe hat eine kurz prismatische Gestalt, ist gänzlich ungevaaffnet und von chitinösen Wänden bekleidet. Sie geht in das vorn trichterförmig erweiterte Lumen des Oes. über. Dieser ist cylindrisch und muskulös, nach hinten kaum erweitert und zeigt ein enges, chitinwändiges Lumen; an seinem Uebergange in den Darm liegen keine Drüsen oder körnige Zellen. Die stark körnige Darmwand soll nach Bütschli aus mässig grossen Zellen gebildet sein und der Enddarm ist kurz. Ueber das Nervensystem, das in jedem Falle schwer zu beobachten ist, liegen mir keine Notizen vor. Ein ventraler Gefåssporus fehlt. Die weibl. Geschlechtsorgane sind einseitig, und der Uterus besitzt einen hinteren Ast. Beim Männchen findet sich eine mediane Reihe präanaler Papillen, welche sich bis weit über das Hinterende des Oes. hinaus nach vorn hin ausstreckt. Die Spicula sind schlank, ohne accessorische Stücke. Eine Schwanzdrüse mit kleiner Ausführungsröhre ist vorhanden.

Die zwei Arten dieser Gattung unterscheiden sich auf der folgenden Weise:

1. Kopfende mit 6 Borsten; weibl. Geschlechtsöffnung hinter der Körpermitte . . 1. intermedius. Kopfende mit 10 Borsten, weibl. Geschlechtsöffnung vor der Körpermitte . . 2. dolichurus.

1. Prismatolaimus intermedius Btsli.

Synon: Monhystera intermedia Btsli, Bütschli, XX, pag. 67 , Taf. VI, fig. $33 \alpha-b$ und de Man, XXVI, pag. 98.

Taf. XI und XII, Fig. 46 .

$\sigma^{7} 0,7 \mathrm{~mm}$. , 우 $0,75 \mathrm{~mm} . \alpha=35-45 . \beta=31 / 2-4 . \gamma=3-4$.

Der Körper dieser, schon von Bütschli beobachteten Art ist schlank und verschmälert sich ziemlich nach vorn hin. Die Cuticula ist fein geringelt. Am vorn abgestutzten, nicht abgesetzten Kopfende stehen 6 ziemlich kräftige Borsten. Die linienförmigen Seitenorgane liegen in mässiger 
Entfernung vom Vorderrande, (Fig 46a); in der Profilansicht sieht man dieselben am besten, als kleine Hervorragungen an jeder Seite des Körpers (Fig. 46b). Der langgestreckte Oes. ist in seiner Mitte ein wenig verschmälert und dcr Darm erscheint gleichmässig fein gekörnt. Die weibl. Geschlechtsöfnung liegt hinter der Körpermitte, auf $\%$ der Gesammtlänge vom Hinterende entfernt; ilire Entfernung vom After ist halb so gross als der Abstand, worauf sie vom Oes. gelegen ist. Die Genitalien strecken sich nach vorn hin aus und der hintere Ast des Uterus ist sehr kurz. Beim Männchen streckt sich eine mediane Reihe von 35-3y Papillen vor dem After aus, von welchen die vorderste ungefähr in der Mitte des oesophagealen Theiles des Körpers, die hinterste in der Nähe des inneren Endes der Spicula gelegen ist; diese Papillen (Fig. 46f) sind sehr niedrig, von eirunder Gestalt und liegen auf gleichen Abständen von einander. Die schlanken Spicula (Fig. 46e) sind etwas gebogen und werden von keinen accessorischen Stücken begleitet. Der Schwanz ist bei beiden Geschlechtern gleich gestaltet, fadenförmig und läuft haarfein aus; an der Spitze beobachtet man ein sehr kleines, kegelförmiges Ausführungsröhrchen der Schwanzdrüse. (Fig. 46c).

Fundort und Lebensweise. Dieses lebhafte Thierchen ist sehr häufig und bewohnt die feuchte Erde von Wiesen und Marschgründen, wie auch den sandigen Boden der Dünenstriche. Die Männchen sind äusserst selten.

Geographische Verbreitung. England (Sydenham), Schweiz (Roth See unweit Luzern), Deutschland (Frankfurt a. M. nach Bütschli).

Fundzeit. Das ganze Jahr hindurch beobachtet man erwachsene Individuen dieser häufigen Art.

2. Prismatolaimus dolichurus d. M.

Taf. XII, Fig. $4 \%$

$\sigma^{7}$ unbekannt, ㅇ $1,2 \mathrm{~mm} ., \alpha=45-55 . \beta=4-5 . \gamma=21 / 2-3$.

Durch mehrere Grösse, eine noch schlankere Körpergestalt, ein verhältnissmässig kürzeren Oes. und längeren. Schwanz unterscheidet sich der dolichurus von der vorigen Art. Die Haut ist fein geringelt. Das abgerundete Kopfende (Fig. 47a) ist kaum abgesetzt und trägt 6 kräftige Borsten, von welchen jede submediane noch von einer kleineren Borste begleitet ist. In Bezug auf die Gestalt und den Bau des Verdauungstractus kommt diese Art mit der vorigen überein. Die weibl. Geschlechtsöffnung liegt vor der Körpermitte, ungefälır auf $2 / 3$ der Totallänge vom Hinterende entfernt; ilkre Entfernung vom After ist stets grösser als der Abstand, worin sie vom Oes. gelegen ist. Das weibl. einseitige Geschlechtsorgan ist kurz, nach vorn hin ausgestreckt, während das Ovarium zurückgeschlagen ist; der hintere Ast des Uterus ist gross, länger als der Abstand der Umbiegungsstelle des Ovariums von der Vulva; bei $0,77 \mathrm{~mm}$. langen Thieren beobachtet man nur noch die kleine ovale Genitalanlage, während es noch keine ăussere Ausmündungsöffnung giebt. Der Schwanz ist fadenförmig und läuft haarfein aus.

Fundort und Lebensweise. Auch diese lebhafte Art ist ziemlich häufig und bewohnt den humusreichen Waldboden, z. B. die Wülder, welche in der Nähe der Holländischen Dünenstriche gefunden werden. 
Geographische Verbreitung. Schweiz (Roth See unweit Luzern). -

Fundzeit. Geschlechtsreife Weibchen beobachtete ich in den Monaten März, Juli und September.

Anmerkung. In meiner früheren Arbeit (XXXV, pag. 32) brachte ich mit Unrecht die kleinen, von mir aufgefundenen männlichen Individuen zu dieser Art; - das Männchen des dolichurus, für welchen auch die Zahl der Kopf borsten bezeichnend ist, kam mir noch nicht vor.

\section{Leptolaimus dM.}

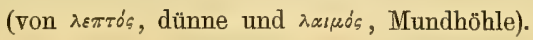

Die Leptolaimen haben eine mässig schlanke Gestalt, welche sich nach beiden Enden hin verjüngt. Die Cuticula ist quergeringelt, hat eine Seitenmembran, während hie und da Borsten über dieselbe zerstreut sind. Das Kopfende ist abgesetzt und nackt, olme Lippen, Borsten oder Papillen. Die Mundhöhle ist verlängert, rölrenförmig, sehr dünnwändig und gänzlich ungewaffnet; sie führt in einen cylindrischen Oes., der, schwach muskulös, an seinem hinteren Ende angeschwollen ist; sein Lumen ist überall sehr enge, dünnwändig. Der Darm ist fein gekörnt und der Enddarm kurz. Die Seitenorgane sind kreisförmig. Die weibl. Geschlechtsorgane sind paarig symmetrisch. Beim Männchen liegt eine mediane Reihe von Papillen vor dem After, welche sich von diesem über den ganzen Körper bis vor dem Hinterende des Oes. ausstrecken und von welchen die vier hintersten eine röhrenförmige Gestalt haben mit chitinisirten Wänden. Die Spicula sind schlank, mit einfachem accessarischem Stücke versehen. Der Schwanz ist ziemlich schlank, trägt beim Männchen mehrere laterale Borstenpapillen und hat eine knopfartig angeschwollene Spitze, worin die Schwanzdrüse ausmündet.

Die einzige Art ist der

1. Leptolaimus papilliger d. M.

de Man, XXVI, pag. 92, Taf. X und XI, Fig. 42a-e.

8우 $0,55 \mathrm{~mm} . \alpha=30-33, \beta=4-4^{1} / 2, \gamma=\%$.

Es hat diese kleine Art das Vorkommen des Teratocephalus terrestris, ihrer starken Hautringelung wegen. Der Körper ist ziemlich schlank, das Vorderende sehr verjüngt. Die Seitenmembran ist schmal und hie und da sind Borsten über den Körper zerstreut. Das Kopfende (1. c. Taf. X. Fig. $42 b)$ ist durch eine Einschnürung abgesetzt, abgerundet, ohne Lippen, Papillen oder Borsten. Die Mundhöhle ist sehr enge, röhrenförmig, und von sehr dünnen Wänden bekleidet. Der Oes. ist an seinem Ende angeschwollen, ohne einen Bulbus zu bilden. Die ziemlich kleinen runden Seitenorgane liegen auf der Mitte der Mundhöhle. Die weibl. Geschlechtsöffnung befindet sich in der Körpermitte und die Genitalien sind paarig symmetrisch; im Uterus fand ich nur ein einziges Ei. Beim Männchen 
beobachtet man 22-25 mediane Papillen vor dem After, von welchen die vorderste vor dem hinteren Ende des Oes. liegt; die vier hintersten sind röhrenförmig, mit clitinisirten Wünden und müssen wohl als Ausmündungsröhren von Drüsen angesehen werden, wăhrend die übrigen eine eirunde Gestalt haben, wenn man sie von oben betrachtet. Die schlanken Spicula sind kaum gebogen, mit einfachem accessorischem Stücke. Der Schwanz hat bei beiden Geschlechtern so ziemlich die gleiche Gestalt, und verschmälert sich allmälig, während die Spitze knopfförmig angeschwollen ist; beim Männchen stehen zwei Paare von lateralen Borstenpapillen auf der Mitte des Schwanzes, und vielleicht sind auch die anderen, von mir früher abgebildeten Borsten (Fig. 42e) constant.

Fundort und Lebensweise. Der lebhafte Leptolaimus bewohnt die feuchte, von brackischem Wasser durchtränkte Erde auf Walcheren, gehört also zu den typischen Brackwassernematoden. Es ist die Art dort ziemlich häufig und die Männchen kommen ebenso viel vor als die Weibchen.

Geographische Verbreitung. Bis jetzt nur auf dieser Insel gefunden.

Fundzeit. Geschlechtsreif ist unsere Art in den Sommermonaten (August).

\section{Cylindrolaimus d. M.}

Wie fast alle Gattungen freilebender Rundwürmer, ist auch die kleine Gruppe Cylindrolaimus durch den Bau des vorderen Theiles des Verdauungstractus und der Geschlechtsorgane charakterisirt. Es haben diese Thiere eine mässig schlanke Körpergestalt, welche sich nach beiden Enden hin verschmälert. Die Cuticula ist feingeringelt, ohne Seitenmembran und Borsten kommen auf derselben nicht vor. Das nicht abgesetzte Kopfende zeigt keine Lippen, oder Papillen, ist aber mit Borsten gewaffnet. Die Mundhöhle stellt sich als eine verlängerte cylindrische oder vielleicht prismatische Rölire dar, welche mit chitinösen IVänden bekleidet ist. Der cylindrische Oes. ist, nach seinem Hinterende zu, sehr wenig erweitert und das enge chitinwändige Lumen setzt sich eine kurze Strecke in den Darm hinein fort. Die Darmwand ist wahrscheinlich zellig, und erscheint gleichmässig fein gekörnt; der Enddarm ist sehr kurz. Der Ring des Nervensystems ist öfters deutlich zu sehen und ein ventraler Gefässporus fehlt. Die kreisförmigen, sehr nach vorn gerückten Seitenorgane stellen sich in der Profilansicht als Vertiefungen in der Haut dar. Ueber den Bau der weibl. Geschlechtsorgane blieb ich zweifelhaft; vielleicht sind sie wie bei. den Prismatolaimen gebaut, doch besteht die Möglichkeit, dass sie paarig symmetrisch sind. Beim Männchen beobachtet man eine einzelne mediane Papille in geringer Entfernung vor dem After. Die schlanken Spicula zeigen keinen centralen Verdickungsstreif und werden von keinen accessorischen Stücken begleitet. Der Schwanz ist meist verlängert und zeigt ein abgerundetes Ende, bisweilen ein feines Spitzchen tragend; die Schwanzdrüse mündet hier aus.

Die zwei bis jetzt bekannten Arten unterscheiden sich durch die folgenden Charaktere: 
1. Grössere Art (1,1 mm.); die weibl. Geschlechtsöffnung fehlt noch bei $0,72 \mathrm{~mm}$. langen Thieren . . . . . . . . . . . . . . 2. melancholicus. Kleinere Art $(0,64 \mathrm{~mm}$.)

\section{Cylindrolaimus communis d. M.}

Taf. XII, Fig. 48.

우 $0,64 \mathrm{~mm} ., \sigma^{7}$ unbekannt, $\alpha=25-30, \beta=5-6, \gamma=\gamma-9$.

Der kleinere der beiden Cylindrolaimen hat einen ziemlich schlanken Körper, der sich nach beiden Enden hin gleichmässig aber wenig verschmälert. Äusserst fein geringelt ist die Cuticula. Am Vorderrande des abgerundeten Kopfendes stehen vier sehr kurze Börstchen. Die verlängerte enge Mundhöhle erreicht 1/5-1/6 der Länge des eigentlichen Oes.; dieser ist nach hinten zu ein wenig erweitert und sein enges, chitinwändiges Lumen setzt sich eine kurze Strecke in den Darm hinein fort (Fig. 48b). Der letztere zeigt zahllose Körnchen ungleicher Grösse in seinen Wänden. Die verhältnissmässig kleinen Seitenorgane sind sehr weit nach vorn gerückt und liegen beim Anfang der Mundhöhle; ilır Durchmesser beträgt ungefähr $1 /{ }_{8}$ der Länge der letzteren. Die weibl. Geschlechtsöffnung, welche sehr wenig hervorragt (Fig. 48f), liegt etwas hinter der Körpermitte und die Genitalien liegen für den grōsseren Theil hinter ihr; nur ein kurzer Ast streckt sich nach vorn hin aus. Ich beobachtete ein einziges Ei im Uterus, das $0,06 \mathrm{~mm}$. lang war. Der Schwanz verschmälert sich sehr allmälig, aber nur wenig und hat eine abgerundete Spitze, welche ein sehr feines Ausführungsröhrchen der Schwanzdrüse trägt (Figg, 48c).

Fundort und Lebensweise. Diese, sich träge bewegende Art ist ein ziemlich häufiger Bewohner sowohl der feuchten Erde der Wiesen wie auch des sandigen Dünenbodens.

Geographische Verbreitung. Deutschland (Laibach).

Fundzeit. Erwachsene Thiere beobachtete ich in den Monaten März, April, August und November; wahrscheinlich also kommt die Art das ganze Jahr hindurch vor.

\section{Cylindrolaimus melancholicus d. M.}

Taf. XII. Fig. 49.

o $1,1 \mathrm{~mm}$., ㅇ $1,3 \mathrm{~mm} . \alpha=30-35, \beta=7-9, \gamma=10-12$.

Der Körper ist schlanker als bei der vorigen Art und verschmälert sich wenig nach vorn hin. Äusserst fein geringelt ist die Cuticula. Das nicht abgesetzte Kopfende ist demjenigen des Cylindrol. communis ähnlich, und ist mit 4 sehr kurzen Borsten gewaffnet. Ziemlich gross sind die Seitenorgane in Verlältniss zur Länge der Mundhöhle; ihr Durchmesser beträgt etwa 1/4 der Länge der letzteren und sie sind in Bezug auf dieselbe weniger nach vorn hin gerückt als beim communis. Oes. und Darm verbalten sich wie bei dieser Art. Ungefähr in der Mitte oder ein wenig hinter der Mitte des Körpers 
liegt die weibl. Geschlechtsöffnung, welche bei $0,72 \mathrm{~mm}$. langen Individuen noch vollständig fehlt; bisweilen ragt die Körperwand an beiden Seiten derselben ein wenig hervor (Fig. 49d). Der Schwanz hat eine plumpe Gestalt, verjüngt sich allmälig aber sehr wenig und hat ein abgerundetes Ende (Fig. 49e), das durch eine feine Ausführungsröhre der Schwanzdrüse durchbohrt wird, während ein feines Spitzchen wie beim communis, bei unserer Art vollständig fehlt. Beim Männchen liegt eine mediane, sehr niedrige Papille vor dem After, ełwa auf der halben Länge der Spicula (Fig. 49g); diese haben eine schlanke Gestalt, sind ein wenig gebogen und laufen nach vorn hin in zwei Spitzen aus.

Fundort und Lebensweise. Auch der melancholicus ist ein träges, langsames Thier, das sowohl die feuchte Wiesenerde wie auch den sandigen Boden der, in der Nähe der Holländischen Dünen gelegenen Wiesen bewohnt und ziemlich viel vorkommt.

Geographische Verbreitung. Sonst nirgendwo beobachtet.

Fundzeit. Geschlechtsreif beobachtete ich die Art im Frühlinge und im Spätherbst (März, April, Oct. Nov. Dec.). -

\section{Diplogaster Max SchuItze.}

V. Carus, Icones Zoötomicae. Taf. VIII, Fig. 1.

Bastian, VII, p. 116.

Bütschli, XX, p. 22. und XXV, p. $36 \%$.

Bei der Gattung Diplogaster, welche Max Schultze schon vor sechs und zwanzig Jahren für den gewöhnlichen Dipl. micans oder rivalis aufstellte, trifft man mehr oder weniger langgestreckte Thiere an, deren Körper sich nach vorn hin meist etwas verjüngt, und nach hinten in einen mehr oder weniger langen zugespitzten Schwanz ausläuft. Die Cuticula ist nicht nur quergeringelt, sondern zeigt öfters auch eine deutliche Längsstreifung. Das Kopfende ist nicht abgesetzt, meist mit ziemlich grosser Mundfläche; um die Mundöffnung beobachtet man bisweilen Lippen, so wie einen oder zwei Kreise von kleinen Borstenpapillchen. Bei einigen Arten steht ausserdem noch eine bisweilen längsgerippte Hautfalte unmittelbar um die Mundöffnung. Seitenorgane, welche schon Bastian erwähnt und Bütschli beim Männchen des, im süssen Wasser lebenden D. rivalis auffand, fand ich nicht nur bei dieser Art zurück, sondern auch beim D. fictor: sie sind bei diesen Arten verschieden gestaltet und zeigen ausserdem beim rivalis die Eigenthümlichkeit, dass sie beim Männchen anders gebaut sind wie beim Weibchen. Die Mundhöllle ist weit und öfters recht tief, mit starken chitinösen Wänden bekleidet und ist an ithrem Boden mit einem grossen, oder zwei oder drei kleineren Zühinen bewaffnet, welche beweglich sind; bisweilen sind diese Zähne rudimentär (D. gracilis nach Bütschli). Die Wand der Mundhöhle 
zeigt bei einigen Arten eine Längsstreifung oder chitinisirte Bänder. Der Oes. hat zwei Anschwellungen, von welchen die vordere einen ächten Bulbus darstellt; nur der vordere Theil des Oes. mit dem Bulbus ist fibrillär, der hinter dem Bulbus liegende Theil nicht und die hintere Anschwellung enthält keinen Klappenapparat. Der Darm besteht, nach Bütschli (XX, pag. 120), beim rivalis aus nicht mehr wie drei Zellenreihen und der Enddarm ist kurz.

Der Ring des Nervensystems umgiebt den Oes. gleich hinter dem Bulbus. Das Gefässsystem ist nach Bütschli paarig oder unpaar und mündet hinter dem Bulbus aus. Bei den meisten Arten sind die weibl. Geschlechtsorgane paarig symmetrisch mit zurückgeschlagenen Ovarien; bisweilen aber sind dieselben unpaar. Die Thiere sind meist ovipar, selten lebendig gebährend (rivalis). Der Hoden ist, nach Bütschli, beim rivalis einfach. Beim Männchen kommt eine Bursa vor oder nicht, so wie Papillen, welche bei den bursalosen Arten meist borstenförmig über die Haut hervorragen. Wie Bütschli (XXV, pag. 36\%) hervorhebt, sind diese Papillen oder Borstenpapillen bei den einzelnen Arten auf einer bestimmten Weise angeordnet, sodass man sie auf die drei, aus je drei Papillen bestehenden Gruppen der ächten Rhabditiden zurückzuführen im Stande ist; bisweilen kommt eine zehnte Papille vor (D. striatus). Es giebt zwei Spicula und ein accessorisches Stück, deren Gestalt bei den einzelnen Arten sehr verschieden ist. Der Schwanz des Weibchens ist meist dem des Männchens ähnlich und zeigt bisweilen eine laterale Papille (rivalis). Eine Schwanzdrüse, welche nach Bastian vorkommen sollte, finde ich ebenso wenig wie Bütschli.

Fundort und Lebensweise. Obgleich jetzt schon 14 Arten der Gattung Diplogaster beschrieben worden sind, sind nur sechs genügend bekannt, weil von diesen die beiden Geschlechter genau beobachtet wurden. Es sind die D. longicauda Claus, rivalis Leydig, fictor Bast, similis Btsli, striatus Btsli. und gracilis Btsli; die acht übrigen sind kaum mehr wieder zu erkennen und es wäre am besten dieselben über Bord zu werfen.

Was den Aufenthalt dieser Arten betrifft, so leben drei in der Erde, vier im süssen Wasser, fünf in Mist, eine in faulenden Pilzen und, wie ich hinzufügen kann, auch in faulenden Kartoffeln, während von einer Art die Lebensweise nicht angegeben wurde. Im Allgemeinen scheinen die, in der Erde lebenden Arten selten zu sein.

Die zwei, von mir beobachteten, im süssen Wasser lebenden Arten lassen sich durch die folgenden Charaktere unterscheiden '):

1. Mundhöhle mit einem Zahne; der, hinter dem vorderen Bulbus gelegene Theil des

Oes. halb so lang als der übrige Theil. Vivipar . . . . . . . . . . . . 1. rivalis.

Mundhöhle mit zwei Zähnen; der, hinter dem vorderen Bulbus gelegene Theil des

Oes. misst $2 / 3$ der Länge des übrigen Theiles. Oripar . . . . . . . . . . . 2. fictor.

1) In Jahre 1874 beobachtete ich, auch in reiner fenchter Erde, eine Diplogaster-art, und zwar ein Weibchen, von welcher bloss die Grossenverhältnisse in meiner ersten Arbeit, (XXVI, pag. 82), angegeben worden sind. Obgleich es jetzt unmöglich ist, dies Form wieder zu erkennen, ist durch dieselbe doch das Vorkommen einer, in der Erde lebenden Art in den Niederlanden erwiesen. 
Die übrigen, von den Autoren beschriebenen Arten sind die folgenden:

A. In der Erde:

D. albus Bast. (Bastian, VII, p. 117, Pl. X, Fig. 74, 75.) Bloss das Weibchen. England.

D. filiformis Bast. (Bastian, VII, p. 11\%, Pl. X, Fig. 76-78). Männchen und Weibchen. England.

D. inermis Btsli. (Bütschli, XXI, pag. 22, Taf. I, Fig. 3). Deutschland.

B. Im süssen Wasser :

D. striatus Btsli. (Bütschli, XXV, p. 372, Taf. XXIII, Fig. 4a-c). Beide Geschlechter. Im Main.

D. viviparus Linstow. (von Linstow, XXXIII, pag. 166, Taf. XI, Fig. 3 und 4). Deutschland (Hameln).

C. In Kuhmist:

D. coprophages d. M. (de Man, XXVI, pag. 82, Pl. X, Fig. 38a-c). Weibchen. Holland.

D. filicaudatus Btsli. (Bütschli, XXI, pag. 22, Taf. I, Fig. 4). Weibchen. Deutschland.

D. monhysteroides Btsli. (Bütschli, XXI, pag. 23). Weibchen. Deutschland.

D. similis Btsli. (Bütschli, XXV, pag. 370, Taf. XXII, Fig. $2 a-b$ ). Beide Geschlechter. Deutschland.

D. gracilis Btsli. (Bütschli, XXV, pag. 373, Taf. XIII, Fig. 3a-c). Beide Geschlechter. Deutschlind.

D. In faulenden Pilzen und Kartoffeln.

D. longicauda Claus. (Bütschli, XXV, pag. 369, Taf. XXIII, Fig. 1a-c). Beide Geschlechter. Deutschland.

E. Unbekannter Fundort.

D. macrodon Örley. (Örley, XXXIV, pag. 102 und 165, Taf. V und VI, fig. 24). Ungarn.

1. Diplogaster rivalis Leydig.

Bütschli, XX, pag. 120, Taf. XI, Fig. 68 und XXV, pag. 3\%1,

Taf. XXIII, Fig. $5 a-b$ und Taf. XXIV, Fig. $5 c$.

Taf. XII, Fig. 50.

$\sigma^{7} 2 \mathrm{~mm}$. ㅇ $2,6 \mathrm{~mm} . \alpha=60-65$. $\beta$ beim or $7-7 y_{2}$, beim $q$ 8 $-9 . \gamma$ beim $\sigma^{7} 8-10$, beim $q 6-\%$ 
Diese Art besitzt eine selir schlanke Körpergestalt, welche man fast fadenförmig nennen könnte, und verschmälert sich allmälig, obgleich wenig, nach vorn hin, während der Körper nach hinten in einen haarfeinen Schwanz ausläuft. Die Cuticula ist zwar sehr fein-, aber doch deutlich geringelt und zeigt auch einige Längsstreifung. Das nicht abgesetzte Kopfende zeigt eine abgestutzte Vorderfläche, worauf sich eine mehr oder weniger buchtige Hautfalte erhebt, welche die Mundöffnung umgiebt. Gleich um diese Falte beobachtet man einen Kreis von sechs sehr kurzen Borsten (Fig. 50a); beim Männchen, nicht aber beim Weibchen, kommt noch ein zweiter Kreis von eben kurzen Börstchen um den ersten vor (Vergl. Bütschli, XXV, Taf. XXIII, Fig. 5a). Die Seitenorgane liegen ein wenig hinter der Mundhöhle und zeigen, eigenthümlicher Weise, beim Männchen ein anderes Vorkommen wie beim Weibchen: beim ersteren (Fig. 50c, 50d) sind sie gross und von ovaler Gestalt, beim letzteren (Fig. $50 a, 50 b)$ dagegen viel kleiner, fast rinnenförmig und ragen kaum hervor; nach Bütschli's Abbildung sollen die männlichen Seitenorgane kreisrund sein.

Die Muskulatur ist nach Bütschli diejenige eines Meromyariers und das Seitengefäss soll nur auf einer Seite vorhanden sein: der Gefässporus (Fig. 50) mündet in der Mitte zwischen dem Nervenring und dem Darmanfang aus.

Die Mundhöhle (Fig. 50a, 50b) ist weit, mit chitinisirten Wänden bekleidet, welche drei ringförmig sie umgebende Chitinleisten tragen; die vorderste dieser Verdickungen verläuft etwa in der Mitte, während die beiden anderen mehr in schräger Richtung verlaufen. Am Boden der Mundhöhle erhebt sich ein kräftiger, kegelförmiger Zahn und zwar an der dorsalen Seite, welchen das Thier zu bewegen im Stande ist; ausserdem finden sich noch ein oder zwei sehr kleine zahnartige Gebilde am Boden (Fig. 50a). Der, hinter dem vorderen Bulbus gelegene Theil des Oes. ist nicht fbrillär und stets halb so lang als der vordere stark muskulöse übrige. Theil; das Lumen wird im vorderen fibrillären Theile von einer stark chitinisirten Wand umgrenzt. Der Darm erscheint gleichmässig gekörnt und wird, nach Bütschli, aus nicht mehr wie drei Zellenreihen gebildet. Die Seitenlinien sind nach ihm mässig breit und sollen eine Reihe grosser Kerne enthalten.

Das Thier ist vivipar; bei einem 2,4 mm. langen Exemplare beobachtete ich zwölf Embryonen. Die Geschlechtsöffnung liegt in der Mitte oder ein wenig vor der Mitte und die paarig symmetrischen Geschlechtsorgane strecken sich ziemlich weit nach beiden Seiten aus; die Ovarien sind umgeschlagen und sind bisweilen so lang, dass sie einander kreuzen. Der Schwanz des Weibchens (Fig. 50c) lăuft haarfein zu und trägt eine laterale Papille ein wenig hinter der Mitte.

Der Hoden ist, wach Bütschli, einfach und die Spicula (35 $\mu$ lang bei einem $2 \mathrm{~mm}$. grossen Thiere) sind schlank, gebogen und von einem erweiterten, plumpen, accessorischen Stïcke begleitet (Fig. 50i, 50k). Am Schwanz des Männchens, der eine ähnliche Gestalt hat wie der des Weibchens, finden sich zablreiche Papillen und Borstenpapillen, welche, was sehr sonderbar ist, sich theilweise anders verhalten, als von Bütschli (XXV, pag. 3\%1) angegeben worden ist. Die drei ventral gerichteten Borstenpapillen der ersten Gruppe (I), die zwei kleinen borstenlosen Papillen der zweiten Gruppe (II), sowie auch die hinterste Borstenpapille der dritten Gruppe (IIIc) befinden sich genau an denselben Stellen wie 
bei den, vom genannten Autor beobachteten Thieren; die Borstenpapille (IIIb) aber liegt stets mehr nach vorn lin, ungefähr bei den Papillen der zweiten Gruppe $(I I)$ und die Borstenpapille (IIIa) steht immer in geringer Entfernung hinter dem After. Ausserdem sehe ich noch eine ganz laterale borstenlose Papille (IV $a$ ), ungefähr mitten zwischen den Borstenpapillen (I $b)$ und ( $\mathrm{I} c$ ), welche von Bütschli nicht gesehen wurde: es ist wohl dieselbe Papille, welche an derselben Stelle beim Weibchen gefunden wird. (Vergl. Fig. $50 \mathrm{~g}$ und Fig. 50h). Ich betrachte diese Verschiedenheiten bloss als die Ausdruckung einer localen Varietät.

Fundort und Lebensweise. Diese schöne, sehr lebhafte Art ist ein sehr häufiger Bewohner des süssen Wassers, mitten zwischen Conferven und Algen, in den Gräben, Teichen und Flüssen Hollands. Sie hat, wie einige Monohysteren, die eigenthümliche Gewohnheit sich, wenn ihr Gefahr zu drohen scheint, ganz ausgestreckt unbeweglich zu halten. Den grossen Zahn der Mundhöhle bewegt das Thier öfters hin und her und dieser dient wohl für die Zerreibung der aufgenommenen Nahrung. Nach Bütschli kann es einen hohen Grad von Fäulniss ertragen.

Geographische Verbreitung. Deutschland (im Main nach Leydig und Bütschli).

Fundzeit. Das Thier ist im Frühling (April) geschlechtsreif.

\section{Diplogaster fictor Bast.}

Bastian, VII, pag. 116, Taf. X, Fig. 71-73.

Synon.: Diplog. Jluviatitis d. M., de Man, XXXV, pag. 36.

Taf. XIII, Fig. 51.

ठ万 $1,8 \mathrm{~mm}$. $\alpha$ beim $\sigma^{7} 60$, beim ठ $45-50 . \beta=6-6^{2} /{ }_{3} . \gamma=8-10$.

Diese, zweifelsohne auch von Bastian beobachtete Art erreicht nicht die Grősse der vorigen, mit welcher sie zusammen vorkommt. Ihre Körpergestalt ist sehr schlank, verschmälert sich ziemlich viel nach vorn hin und läuft nach hinten haarfein zu. Die Cuticula ist sehr fein geringelt, und trägt keine Borsten. In geringer Entfernung hinter dem Boden der Mundhöhle liegen die kleinen, walirscheinlich rinnenförmigen Seitenorgane, welche beim Männchen wie beim Weibchen gleichgestaltet sind: am besten erkennt man dieselben in der Profilansicht. Die Vorderflache des nicht abgesetzten Kopfendes ist abgestutzt; eine längsgerippte Hautfalte erhebt sich um die Mundöffnung. (Fig. 51c). Gleich hinter der Hautfalte steht an jeder lateralen Seite eine sehr kurze Borste (Fig. 51c), während die vier sonst vorkommenden submedianen vollständig fehlen. Die Mundhöhle ist tief, von chitinisirten Wänden bekleidet und trägt an iłrem Boden zwei (oder drei?) eben grosse, kräftige, eckige und spitze Zähne, welche in gleicher Höhe gelegen sind, einander in der Ruhe kreuzen und sich beim Leben fortwährend klaffend bewegen; der, vor diesen Zähnen gelegene Theil der Wand der Mundhöhle ist schwach längsgestreift. Der, hinter dem sehr kräftigen vorderen Bulbus des Oes. gelegene Theil ist ${ }^{2} / 3$. der Länge des übrigen stark 
muskulösen Theiles lang. Im vorderen muskulösen Theile ist die Chitinintima sehr stark, während dieselbe im hinteren Theile sehr dünn ist, (Fig. 51a). Die Darmzellen sind feinkörnig, durch helle Zwischenrăume von einander geschieden und der Enddarm ist kurz. Das Gefässsystem mündet etwas hinter der Mitte des, hinter dem vorderen Bulbus gelegenen Theiles des Oes. aus. Dieses Thier ist ovipar und nur ein einziges Ei beobachtete ich im Uterus; die weibl. Geschlechtsöffnung liegt ein wenig vor der Körpermitte und die paarig symmetrischen Geschlechtsorgane sind mässig lang mit umgeschlagenen Ovarien. Der Schwanz des Weibchens ist regelmässig verschmälert und läuft haarfein zu.

Beim Männchen findet man zwei kräftige, plumpe, gebogene Spicula, welche von einem langen, stabförmigen, accessorischen stücke begleitet sind (Fig. 51f). Der Schwanz des Männchens hat eine ähnliche Gestalt wie der des Weibchens, (Fig. 51e) und läuft fein zugespitzt aus. Die auf dem Schwanze vorkommenden Borstenpapillen haben die folgende Lage: von den drei ventralen Borstenpapillen der ersten Gruppe (I), befindet sich die Papille (Ia) vor dem After genau beim Hinterende der Spicula, die Papille (I $b$ ) etwas hinter dem After und die Papille ( $(\mathrm{I} c)$ ungefähr in der Mitte des Schwanzes; die zwei Papillen der zweiten Gruppe (II) sind sehr klein, sehr dicht bei einander und gerade vor der Papille (Ic) gelegen; von den drei lateralen Borstenpapillen der dritten Gruppe (III) endlich, liegt die Papille (III $a$ ) ein wenig vor dem After und hinter der Borstenpapille ( $\mathrm{I} a$ ), die Papille (III $b$ ) ein wenig der Papille (Ic) näher als der Papille (I $b$ ) und ist die Papille (III $c$ ) weit nach hinten gerückt; die beiden Papillen (III c) liegen nicht genau auf demselben Querschnitt des Schwanzes.

Fundort und Lebensweise. Diese Art bewohnt in Gesellschaft der vorigen, das süsse Wasser der Holländischen Teiche und Flüsse, ist aber minder hăufig. Sie ist sehr lebhaft, aber ich sah sie nie ganz ausgestreckt unbeweglich liegen wie den rivalis, obgleich Bastian auch ihr diese Eigenschaft zukennt. Die Männchen sind gleich häufig wie die Weibchen.

Geographische Verbreitung. England nach Bastian.

Fundzeit. Unsere Art ist im Frühling (Mai) geschlechtsreif.

\section{Cephalobus Bast. ${ }^{1}$ )}

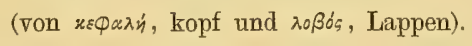

Die Cephaloben haben im Allgemeinen eine ziemlich plumpe oder wenig schlanke Körpergestalt, welche sich nach beiden Seiten mehr oder weniger verjüngt; nur beim fliformis hat das Thier ein

1) Diese Gruppe, deren Namen in jedem Falle etymologisch richtiger Cephallobus statt Cephalobus geschrieben wird, darf keineswegs mit der Gattung Anguillula Ebrb. vereinigt werden, wie Bütschli, XXV, pag. 374, vorgestellt hat. Eine Untersuchung der typischen Art der letztgenannten Gattung, des Essigälchens, lehrte mich das folgende:

Das Kopfende ist bei diesem Thiere abgerundet und zeigt keine Spur von Lippen, Papillen oder Borsten, welche letzteren 
fadenförmiges Vorkommen. Die Cuticula ist deutlich geringelt, und trăgt wohl immer eine Seitenmembran, während Borsten nicht auf derselben gefunden werden. Das Kopfende ist ein wenig abgesetzt oder nicht, und zeigt bei den typischen Arten drei mehr oder weniger ausgebildete, abgerundete Lippen, welche aber rudimentär sein können wie beim schon genannten, auch in anderen Beziehungen abweichenden filiformis. Die Lippen tragen bisweilen Papillen, wie beim oxyuroides u. a. A. Sehr abweichende Verhältnisse des Kopfendes trifft man bei Ceph. emarginatus, vexilliger und ciliatus an, welche aber ohne Zweifel auf den typischen Bau zurückgeführt werden können. Borsten, wie solche bei anderen Gattungen, wie Plectus u.s. w., hinter den Lippen vorkommen, trifft man bei Ceplialobus nie an. Seitenorgane fehlen. Die Mundhöhle hat eine längere oder kürzere röltrenförnige Gestalt, ist dreiseitig und verengt sich meist nach linten zu; illre clitinösen Wände zeigen immer einige locale Verdickungen, wodurch die Mundhöhle ein sehr characteristisches Vorkommen erhält. Der Oes. ist in seinem vorderen Abschnitte mehr oder weniger cylindrisch, selten angeschwollen (nanus) und verschmälert sich darauf mehr oder weniger plötzlich, um dann in einen, einen Klappenapparat tragenden Bulbus zu endigen. Der breite Darm besteht, nach Bütschli, aus nur wenigen Zellen im Umfang, deren Umrisse bei einigen Arten deutlich, bei anderen mehr verwischt sind; die Darmkörnchen sind meist sparsam vorhanden und nicht sehr gross und der Enddarm ist kurz.

Der Nervenring umfasst den hinteren verschmälerten, vor dem Bulbus liegenden Theil des Oes., ist aber bald mehr nach vorn gerückt (elongatus), bald liegt er unmittelbar vor dem Bulbus (nanus). In geringer Eutfernung von ihm mündet der mehr oder weniger geschlängelte Ausführungsgang des Gefässsystems, über welches ich keine Beobachtungen gemacht habe; nach Bütschli ist das Seitengefäss beim Ceph. rigidus Schn. = oxyuris Btsli, dünn, hell und geschlängelt. Auch soll bei dieser Art das Seitenfeld sich als ein nicht sehr breites, körniges Band darstellen. Die weibl. Geschlechtsöffnung mündet stets linter der Körpermitte und die weibl. Geschlechtsdrüse ist einseitig; der Uterus besitzt meist einen hinteren Ast, verläuft dann nach vorn und geht in das nach hinten sich umschlagende, nicht selten (persegnis) an seinem Ende wieder umgebogene Ovarium über. Die Thiere sind ovipar: nur der eigenthümliche und seltene filiformis macht auch in dieser Hinsicht eine bemerkens-

übrigens auch den Cephaloben constant fehlen. Die mässig grosse Mundöffnung führt in die Mundhöhle, welche beim erwachsenen Thiere ungefähr neun $\mu$ tief ist, und eine kegelförmige Gestalt hat, sich nach hinten allmälig verschmälernd; in der hinteren Hälfte besonders ist ihre Wand stark chitinisirt. Ausserdem sehe ich zwei oder drei zahnartige Fortsätze in der hinteren Hälfte, und zwar an beiden Seiten der Mundhöhle (Taf. XXXIV, Fig. 141); sind dies ja keine Zähne, dann sind es in jedem Falle doch Fortsätze. Beim Embryo (Taf. XXXIV, Fig. 142) ist die Mundhöhle derjenigen der Cephaloben sehr ähnlich, weil die fast parallelen Wände des optischen Querschnittes chitinisirt erscheinen, aber doch beobachtete ich am verengten Boden einen, an einer Seite gelegenen zalinartigen Fortsatz. Hieraus schliesse ich, dass der Bau des Kopfendes und der Mundhöhle zu viel von den, bei Cephalobus vorkommenden Verhältnissen abweicht, um die Gattung Anguillula mit derselben vereinigen zu können.

Das Essigälchen unterscheidet sich ausserdem noch von den Cephaloben durch das Fehlen der Seitengefüsse, resp. eines ventralen Gefässporus, durch die glatte, ungeringelte Cuticula und ihre eigenthümliche Lebensweise. Ihre Viviparität ist zwar auffallend, kommt aber auch beim Cephalobus filiformis vor.

Ob die ungenügend bekannte Ang. aquatica Btsli (Bütschli, XX, pag. 69, Taf. XI, Fig. 69) als eine zweite Art der Gattung Anguillula betrachtet werden muss, muss vorläufig dahingestellt werden. 
werthe Ansnahme. Die Zahl der Eier, welche man im Uterus beobachtet, ist klein; dieselben sind ziemlich gross, besonders beim Ceph. nanus, welcher zu den kleinsten freilebenden Nematoden gehört.

Die Geschlechtsdrüse der Männchen ist nach Bütschli einfach. Das Thier trägt zwei, meist etwas gebogene Spicula, welche von einem stabförmigen, accessorischen Stücke begleitet werden; selten giebt es deren zwei (elongatus, ciliatus). Der Schwanz unserer Thiere hat ein, nach den Arten sehr verschiedenes Vorkommen; während er bei einigen kurz, abgerundet ist, trifft man bei anderen zugespitzte, ja sogar verlängerte fadenförmige Schwänze an. Beim Männchen finden sich am hinteren Körperende mehrere Paare lateraler Papillen, deren Lage für die einzelnen Arten bezeichnend ist. Eine Schwanzdrüse scheint meist zu fehlen, nur beim abweichenden vexilliger meine ich eine gefunden zu haben.

Fundort und Lebensweise. Die Cephaloben, deren man jetzt ungefähr 15 Arten kennt, sind im Allgemeinen lebhafte Thiere von geringer Grösse, welche an Pflanzenwurzeln in der feuchten Erde leben; keiner bewohnt das süsse Wasser oder ist an Brackwassergegenden gebunden.

Die zehn, von mir in den Niederlanden aufgefundenen Arten lassen sich leicht durch die folgenden Charactere unterscheiden:

1. Kopfende abweichend gebaut, mit Dornen oder unbeweglichen Borsten gewaffnet. 2. Kopfende typisch.

2. Kopfende aus einem basalen Theile und einer darauf gestellten Krone von unbeweglichen Stücken gebildet . . . . . . . . . . . . 10. ciliatus.

Kopfende aus peripherischen Lappen aufgebaut, welche in einen kurzen Dorn auslaufen; ausserdem 3 (oder 6) steife in zwei Aestchen auslaufende Börstchen gleich um die Mundöffnung . . . . . . . . . . . 9. vexilliger.

3. Schwanz kurz, abgerundet . . . . . . . . . . . . . . . . 4 .

Schwanz zugespitzt, mehr oder weniger verlängert. . . . . . . . . . 6.

4. Lippen des Kopfendes ohne Papillen . . . . . . . . . . . . . . . 5.

Lippen papillentragend; Schwanz nicht selten keulenförmig, oder mit einem sehr kurzen, feinen Spitzchen versehen am abgerundeten Ende . . . 2. striatus.

5. Grőssere Art $(0,74 \mathrm{~mm}$.), Oes. in seinem vorderen Theile cylindrisch . . . 1. persegnis. Kleinere Art $(0,4 \mathrm{~mm}$.$) , Oes. in seiner Mitte angeschwollen. . . . . . . 8. na nus.$

6. Kopfende an den lateralen Seiten tief ausgeschnitten und dadurch scheinbar in zwei spitze Fortsătze auslaufend . . . . . . . . . . . \% emarginatus. Kopfende ohne spitze Fortsätze. . . . . . . . . . . . . . . . . \%

\%. Lippen ohne Papillen . . . . . . . . . . . . . . . . . . . 8. Lippen mit Papillen . . . . . . . . . . . . . . 4. oxyurö̈des.

8. Schwanz schlank, verlängert, ziemlich regelmässig verschmälert . . . . . 9. Schwanz plump, kegelförmig; Körper von schlanker Gestalt . . . . . 6. elongatus.

9. Körper von plumper Gestalt; Ovipar. . . . . . . . . . . . 5. long i c a udatus. Körper sehr schlank, Lippen rudimentär. Vivipar . . . . . . . . . 8. filiformis. 
Ausser diesen 10 Arten kennt man noch die folgenden:

Ceph. Bütschlii mihi $=$ persegnis Btsli. (Bütschli, XX, pag. 80, Taf. VIII, Fig. 51). Deutschland.

Ceph. rigidus Schn. = oxyuris Btsli. (Bütschli, XX, pag. 81. Taf VII, Fig. 42. Taf. VIII, Fig. $49 a-e$ und XXV, pag. 3\%4, Taf. XXIV, Fig. $6 a-b)$. Deutschland.

Ceph. gracilis Örley. (Örley, XXXIV, pag. 163, Taf. II, Fig. 9a-b.)

Auch stelle ich in dieser Gattung noch die Leptodera appendiculata Schn., welche sich nach Bütschli unmittelbar dem Ceph. rigidus anschliessen würde, so wie vorläufig auch Leptodera lirata Schn. aus feuchter Erde und faulenden Substanzen, weil ihr die Bursa fehlt, obgleich sie sich durch die Gestalt des Oes. an Rhabditis anschliesst.

1. Cephalobus persegnis Bast. (nec Btsli.).

Bastian, VII, pag. 124, Pl. X., Fig. 104-106.

Taf. XIII, Fig. 52.

$\sigma^{7}$ \% 0,74 mm. (nach Bastian erreicht das Männchen eine Länge von 0,82 mm.). $\alpha=20-25$. $\beta=4-5 . \gamma$ beim $\sigma^{7}=18$, beim $q=1 \%$.

Dieser typische, schon von Bastian beobachtete Vertreter unserer Gattung besitzt eine plumpe Körpergestalt, welche sich nach beiden Enden hin ziemlich verjüngt. Schön und deutlich geringelt ist die, eine mässig breite Seitenmembran tragende Cuticula. Das Kopfende ist nicht abgesetzt, trägt drei ziemlich niedrige abgerundete Lippen (Fig. 52a), welche keine Papillen tragen. Die kleine Mundhöhle verengt sich nur wenig nach hinten und erreicht etwa $1 / 10-1 / 11$ der Lange des Oes.; dieser ist ziemlich dünn, cylindrisch, verschmälert sich allmälig etwa bei der, auf der Grenze seines hinteren Viertels gelegenen Mündung des geschlängelten Ausführungsganges der Seitengefässe und endigt in einen verhältnissmässig kleinen Bulbus (Fig. 52). Die Darmzellen erkennt man deutlich und sie sind mit feinen Körnchen gefüllt; der Enddarm ist kurz.

Die weibl. Geschlechtsöffnung liegt beim Beginn des letzten Körperdritttheils; der Uterus hat einen hinteren Ast und das nach hinten umgeschlagene Ovarium biegt sich an seinem Ende wieder nach vorn hin um. Der Schwanz des Weibchens (Fig. 52c) ist kegelförmig, stumpf abgerundet, ohne Endspitzchen. Beim Männchen hat er ungefähr die ähnliche Gestalt und trägt auch hier kein Endspitzchen; er hat drei präanale und drei postanale, alle laterale, Papillen, die hinterste präanale liegt etwas vor dem After, die mittlere ein wenig vor dem Hinterende der Spicula und etwas hinter der Mitte des Abstandes, worin die vorderste vom After entfernt ist. Die vorderste postanale Papille liegt ungefăhr in der Mitte des Schwanzes und die mittlere ein wenig näher bei der vordersten als bei der hintersten. Die Spicula sind schlank, gebogen, mit schlankem, accessorischem Stücke (Fig. 52b). 
Fundort und Lebensweise. Das Thier ist ziemlich häufig, und bewohnt die feuchte, oder ein wenig von süssem Wasser durchtränkte Erde von Wiesen und Marschgründen; es ist lebhaft in seinen Bewegungen. Die beiden Geschlechter sind gleich häufig.

Geographische Verbreitung. Deutschland (Erlangen). England nach Bastian.

Fundzeit. Ich beobachtete die Art in geschlechtsreifem Zustande sowohl im Frühling (Febr., April, Mai), wie auch in den letzten Monaten des Jahres (Nov., Dec.).

\section{Cephalobus striatus Bast.}

Bastian, VII, pag. 125, Pl. X, Fig. 10\%, 108.

Bütschli, XX, pag. 81, Taf. VII, Fig. 50a-c.

Synon. : Cephalobus bursifer, de Man, XXVI, pag. 65, Taf. VIII, Fig. 28a-g.

Taf. XIII, Fig. 53.

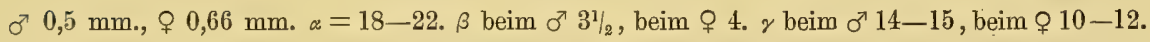

Auch diese Art wurde schon vom Englischen Helminthologen beobachtet und hat ebenso eine plumpe Gestalt, welche sich nach beiden Enden hin verjüngt. Die Cuticula ist schön geringelt, mit ziemlich schmaler Seitenmembran. Das halbkugelförmige, ein wenig abgesetzte Kopfende wird aus drei ziemlich hohen, aber fast gänzlich unter einander verbundenen Lippen gebildet, welche sehr kleine Papillen tragen (Fig. 53a). Die Mundhöhle, der Oes. und dessen Bulbus sind fast gänzlich wie bei der vorigen Art gebildet, und ebenso verbält sich der übrige Theil des Verdauungstractus.

Das Gefässsystem mündet durch einen stark geschlängelten Ausführungsgang etwa auf der Grenze des hinteren Dritttheiles des Oes. aus, dort wo der vordere breitere Theil des Oes. ziemlich plötzlich in den dünnen Theil übergeht, und der Nervenring liegt ungefähr in der Mitte zwischen dem Porus und dem vorderen Rande des Bulbus.

Die weibl. Geschlechtsöffnung, welche bei $0,48 \mathrm{~mm}$. langen Thieren noch vollständig fehlt, liegt ein wenig vor dem letzten Körperdritttheil; das nach hinten umgeschlagene Ovarium biegt sich in seinem, hinter der Vulva gelegenen, Theile noch zweimal um (Vergl. de Man, XXVI, Taf. VIII, Fig. 23b). Das Ei ist ziemlich gross. Der Schwanz des Weibchens ist schlanker als beim Ceph. persegnis, ist meist etwas vor seinem Ende verschmälert und erhält dadurch eine keulenförmige Gestalt (Fig. 53b); nicht selten trägt er ein sehr kurzes feines Spitzchen am abgerundeten Ende. Der Schwanz des Männchens ist fast ganz gleichartig gestaltet wie beim Weibchen und mit drei präanalen und drei postanalen lateralen Papillen versehen, welche eine fast ganz ähnliche Lage haben wie beim Cepl. persegnis. Auch die Spicula und das accessorische Stück sind denselben Organen der vorigen Art fast vollkommen ähnlich; die ersteren sind kaum $0,02 \mathrm{~mm}$. lang.

Fundort und Lebensweise. Auch dieses lebhafte Thierchen kommt häufig vor und bewohnt die 
feuchte oder ein wenig von süssem Wasser imbibirte Erde der Holländischen Wiesen und Marschgründen. Die Männchen sind ebenso häufig wie die Weibchen und man unterscheidet die Art bald von den ihr verwandten Formen durch die keulenförmige Gestalt des Schwanzes und die Anwesenheit von Papillen auf den Lippen' des Kopfendes.

Geographische Verbreitung. Deutschland (Laibach, Gegend von Frankfurt a. M. nach Bütschli), England nach Bastian.

Fundzeit. Im geschlechtsreifen Zustande beobachtete ich das Thier in den Monaten Februar, August, October und December.

3. Cephalobus nanus d. M.

Taf. XIII, Fig. 54.

ㅇ $0,4 \mathrm{~mm}$., $\sigma^{7}$ unbekannt. $\alpha=16 . \beta=3-3^{1 / 1} / 3 \cdot \gamma=22-25$.

Mit Tylenchus macrophallus und Monohystera bulbifera gehört diese Art zu den kleinsten, von mir in der Niederlanden beobachteten Arten. Der Körper hat eine selır plumpe Gestalt, welche sich nach beiden Enden hin wenig verjüngt. Die Cuticula ist fein geringelt, eine Seitenmembran beobachtete ich aber nicht. Das Kopfende ist nicht abgesetzt und trägt drei sehr niedrige abgerundete Lippen, auf velchen keine Papillen vorkommen. Die Mundhöhle ist wie bei den vorigen Arten gebaut, der Oes. aber ist characteristisch: in seinem vorderen Theile ist er cylindrisch, darauf schwillt er sehr an, um schliesslich bis am mässig grossen Bulbus wieder allmälig zu verschmälern. Die Darmwand zeigt grössere und kleinere Körnchen. Der Ausführungsgang des Gefässsystems liegt in geringer Entfernung vor dem Bulbus; zwischen diesem und der Ausmündungsöffnung umfasst der Nervenring den Oes. Die weibl. Geschlechtsöffnung liegt beim Beginn des letzten Körperdritttheils. Ich sah ein einziges grosses Ei im Uterus. Sehr kurz, stumpf abgerundet ist der Schwanz.

Fundort und Lebensweise. Dieses ziemlich lebhafte Thierchen scheint selten zu sein, vielleicht aber wurde es öfters der geringen Grösse wegen übersehen; es bewohnt die feuchte, oder von süssem oder brackischem Wasser durchtrünkte Erde der Hollăndischen Wiesen.

Geograplische Verbreitung. Bis jetzt in keinem anderen Lande beobachtet.

Fundzeit. Geschlechtsreif fand ich das Thier im Frühling. (Mărz, April).

4. Cephalobus oxyuroides d. M.

de Man, XXVI, pag. 63, Taf. VII, Fig. $26 \alpha-b$

Taf. XIV, Fig. 55 .

o 0,64 , ㅇ 0,7 mm. $\alpha=20-25 . \beta=4$. $\gamma$ beim $\sigma^{7} 12-13$, beim \& 8-9.

Der erste der spitzschwănzigen Cephaloben ist ein Thier, dessen Gestalt nicht schlank ist, das 
sich aber nach beiden Enden hin verschmälert. Die Cuticula ist feingeringelt und mit einer ziemlich breiten Seitenmembran versehen. Das Kopfende ist ein wenig abgesetzt und wird aus deutlichen, kleine Papillen tragenden Lippen gebildet (Fig. 55a). Die Mundhöhle ist ganz typisch gebaut, $1 / 10-1 / 11$ der Länge des Oes. lang; dieser ist in seinem vorderen Theile etwas erweitert, verschmälert sich aber plötzlich beim Gefässporus (Fig. 55b) und endigt dann in einen mässig grossen Bulbus. Die Darmzellen sind feinkörnig. Der Gefässporus ist etwa $1 / 3$ der Länge des Oes. vom Darmanfang entfernt. Die weibl. Geschlechtsorgane sind schon bei $0,5 \mathrm{~mm}$. langen Thieren entwickelt. Die Geschlechtsöffnung liegt ${ }^{2 / 5}$ der Gesammtlänge vom Hinterende des Körpers entfernt und der, linter ithr gelegene Theil der Genitalien streckt sich über einen Kürzeren Raum aus als der halbe Abstand zwischen Vulva und After beträgt (Fig. $55)$; ich beobachtete ein einziges $\mathrm{Ei}$ im Uterus, das $0,055 \mathrm{~mm}$. lang war. Beim Weibchen ist der Schroanz (Fig. 55c) schlank, allmälig verschmälert und selı fein zugespitzt.

Beim Männchen hat der Schwanz eine ein wenig veränderliche Gestalt, weil er meist keine (Fig 55d), bisweilen aber woll eine abgesetzte Endspitze hat (Fig. 55f). Im ersten Falle trägt er eine, ziemlich dorsal gelegene laterale Papille in geringer Entfernung vor der Spitze (Fig. 55d, h), im zweiten Falle fehlt diese Papille; ausserdem beobachtet man am hinteren Körperende des Männchens $\%$, der Mittellinie der Bauchseite genäherte, laterale Papillen und zwar zwei vor dem After, von welchen die eine beim inneren Ende der Spicula, die andere in einer etwas grösseren Entfernung vom After nach vorn hin gelegen ist; dann eine Papille gleich bei und hinter dem After, die vierte ein wenig vor und die fünfte ein wenig hinter der Mitte des Schwanzes, die sechste und siebente endlich dicht zusammenstehend, nicht weit von der Schwanzspitze, in geringer Entfernung hinter der dorsalen Papille (h); die Lage dieser Papillen erkennt man aus den Figuren 55d und 55e deutlich. Die Spicula sind schlank und werden von zwei stabförmigen accessorischen Stücken begleitet.

Fundort und Lebensweise. Diese sehr häufige Art, deren Männchen eben so viel vorkommt als das Weibchen, ist omnivag: sie bewohnt nicht nur die feuchte oder von süssem oder brackischem Wasser mehr oder weniger getränkte Erde der Wiesen, sondern auch den sandigen Boden der Dünengegenden. Bei dieser Art fand ich die eigenthümlichen Parasiten, welche auf Seite 22 erwähnt und auf Taf. XXXIV, Fig. 143, abgebildet worden sind.

Geographische Verbreitung. In keinem anderen Lande bis jetzt beobachtet.

Fundzeit. Ich fand geschlechtsreife Individuen dieser Art fast das ganze Jahr hindurch; es muss wohl dem Zufall zugeschrieben werden, dass ich das Thier in den Monaten März-Juli nicht begegnete.

Anmerkung. Der Cepllalobus rigidus Schneider, welcher von Bütschli, XXV, pag. 3\%4, unter dem Namen Anguillula rigida aufgeführt wird, unterscheidet sich von unserer Art durch mehrere Grösse, den weniger schlanken Schwanz des Weibchens, durch die, sich bis in die Nühe des Afters ausstreckenden, weiblichen Gescllechtsorgane und einige andere Eigenthümlichkeiten. 
5. Cephalobus longicaudatus Btsli.

Bütschli, XX, pag. 82, Taf. VII, Fig. $46 d$.

Taf. XIV, Fig. 56.

$\sigma^{7}$ \& $0,8-0,9 \mathrm{~mm} . \alpha=23-24 . \beta=4-41 / 2 \cdot \gamma=\%$.

Der longicaudatus kommt in seinem äusseren Vorkommen viel mit dem oxyuroüdes überein, wird aber etwas grösser und unterscheidet sich gleich durch das Fehlen der Kopfpapillen und den längeren Schwanz. Das Thier hat eine ziemlich plumpe Gestalt, welche sich nach beiden Enden hin verschmälert, besonders nach hinten. Die schön geringelte Cuticula trägt eine mässig breite Seitenmembran. Das nicht abgesetzte Kopfende (Fig. 56a) wird aus abgerundeten, ziemlich niedrigen, Lippen oline Papillen gebildet. Die Mundhöhle ist typisch gebaut und erreicht $1 / 11$ der Länge des Oes.; dieser ist cylindrisch (Fig. 56), wenig angeschwollen, geht beim Gefässporus in einen schmäleren Theil über und endigt mit măssig grossem Bulbus. Die Darmwand zeigt nur sparsam zerstreute, ziemlich grosse Körnchen. Der Gefässporus ist ungefähr $1 / 3$ der Länge des Oes. vom Hinterende desselben entfernt. Nach Bütschli ist die weibl. Geschlechtsöffnung schon bei $0,56 \mathrm{~mm}$. langen Thieren deutlich und liegt bei den erwachsenen auf $2 / 5$ der Gesammtlänge vom Schwanzende entfernt; der Uterus hat einen kurzen hinteren Ast und das, nach hinten umgeschlagene Ovarium streckt sich hinter der Vulva ein wenig weiter aus als der halbe Abstand zwischen der Vulva und dem After (Fig. 56). Beim Weibchen ist der Schwanz (Fig. 56b) schlank, ziemlich regelmässig verjüngt und läuft sehr spitz zu.

Der Schwanz des Männchens (Fig. 56c) verschmälert sich erst sehr wenig, aber wird ungefähr in seiner Mitte plötzlich sehr dünn und läuft in einen haarfeinen Theil aus; wahrscheinlich trägt er ebensoviele Papillen wie der oxyuroïdes, obgleich ich nur zwei, der Mittellinie der Bauchseite genäherte, laterale Papillen beobachtete und zwar eine ein wenig hinter dem After, die andere da, wo der Schwanz sich plötzlich verschmälert. Die Spicula (Fig. 56d) sind schlank und werden von zwei stabförmigen accessorischen Stücken begleitet.

Fundort und Lebensweise. Diese seltene Art zeigt lebhafte Bewegungen und bewohnt die feuchte, sandige Erde in der Nähe der Dünenstriche der Insel Walcheren. Das Männchen blieb mir leider unbekannt.

Geographische Verbreitung. Deutschland (Gegend von Frankfurt a. M. nach Bütschli).

Fundzeit. Geschlechtsreife Thiere fand ich im Sommer (August).

6. Cephalobus elongatus d. M.

Taf. XIV, Fig. $5 \%$

$\sigma^{7} 0,8 \mathrm{~mm}$. , ㅇ $0,9 \mathrm{~mm} . \alpha=30-35 . \beta=4$. $\gamma$ beim $\sigma^{7} 15-18$, beim ㅇ $14-15$. 
Durch eine schlankere Gestalt und einen kürzeren Schwanz unterscheidet sich der übrigens verwandte elongatus von der vorigen Art.

Das Thier ist schlank, schlanker als einige andere kurzschwänzige Art dieser Gattung, nach beiden Enden hin verschmålert. Die geringelte Cuticula ist mit einer Seitenmembran versehen, welche mässig breit ist. Das Kopfende (Fig. 5\% $a$ ) ist nicht abgesetzt und wird aus drei abgerundeten, ziemlich niedrigen Lippen olne Papillen gebildet. Die Mundhöhle ist typisch gebaut, verlängert und wird nach hinten enger, während sie 1/12 der Länge des Oes. lang ist; dieser ist langgestreckt, cylindrisch, ein wenig hinter dem Gefässporus (Fig. 5\% ) plötzlich verschmälert, um in den verhältnissmässig kleinen Bulbus zu endigen. Die feinkörnigen Darmzellen sind durch helle Zwischenräume von einander getrennt. Die Ausführungsöffnung des sehr geschlängelten Seitengefässes (oder der Seitengefässe?) mündet in geringer Entfernung hinter der Mitte des Oes. aus und der Nervenring befindet sich ein wenig vor dem Porus (Fig. 5\%).

Die weibl. Geschlechtsöffnung liegt beim Beginn des letzten Körperdritttheils und der, hinter illr gelegene Theil der Geschlechtsorgane ist ein wenig kürzer als der halbe Abstand zwischen Vulva und After. Beim Weibchen ist der Schwanz (Fig. 5\%b) plump, kegelförmig, zugespitzt. Beim Mănnchen (Fig. 5\%d) ist er meist kürzer als beim Weibchen, kegelförmig, zugespitzt und trägt fünf, der Mittellinie der Bauchseite genäherte, laterale Papillen: zwei präanal, die eine beim Hinterende der Spicula, die andere etwas mehr nach vorn hin, dann eine Papille gleich bei und hinter dem After, schliesslich eine ungefähr in der Mitte und eine nahe beim Hinterende des Schwanzes. Die Spicula sind schlank, etwas gebogen, mit zwei stabförmigen accessorischen Stücken.

Fundort und Lebensweise. Dieses Thier ist ziemlich hăufig und berrohnt nicht nur die feuchte, oder von süssem oder brackischem Wasser getränkte Erde der Wiesen und Marschgründe, sondern auch den sandigen Dünenboden an den Wurzeln der dort wachsenden Pflanzen. Das Männchen ist ebenso häufig wie das Weibchen.

Geographische Verbreitung. England (Sydenham).

Fundzeit. Ich beobachtete die Art fast das ganze Jahr hindurch in geschlechtsreifem Zustande.

\%. Cephalobus emarginatus d. M.

Taf. XIV, fig. $\check{8}$.

우 $0,6 \mathrm{~mm} ., \sigma^{7}$ unbekannt. $\alpha=25 . \beta=4, \gamma=14$.

In Gesellschaft der vorigen Art fand ich einmal einen weiblichen Cephalobus, der ohne Zweifel einer

Der Körper ist ziemlich schlank, und verschmälert sich nach vorn hin in geringerem Grade als der elongatus. Die geringelte Cuticula trägt eine Seitenmembran. Das Kopfende ist abgesetzt, halbkugelförmig, und ist an den lateralen Seiten vorn tief ausgeschnitten, (vielleicht auch an den dorsalen und ventralen Seiten); dadurch läuft es dem Anscheine nach in zwei spitze Fortsätze aus (Fig. 58a). Im Uebri- 
gen ist diese Art dem Cephalobus elongatus höchst ähnlich. Der Schwanz ist kegelförmig, plump, zugespitzt.

Fundort und Lebensweise. Das Thier wurde in feuchter Wiesenerde auf der Insel Walcheren beobachtet; später fand ich es nicht zurück. Seine Bewegungen sind lebhaft.

\section{Cephalobus filiformis d. M.}

\section{Taf. XIV, Fig. 59.}

$\sigma^{7} 1 \mathrm{~mm}$., ㅇ $1,2 \mathrm{~mm}$. $\alpha$ beim $\sigma^{7} 40-45$, beim \& 50. $\beta=5-51 /_{2} \cdot \gamma=8-9$.

Eine selr schlanke, fadenförmige Gestalt zeigt der Ceph. filiformis, dessen Körper sich nach beiden Seiten verjüngt, besonders nach hinten. Die Culicula ist äusserst fein geringelt; eine Seitenmembran wurde nicht beobachtet. Das nicht abgesetzte, abgerundete Kopfende trägt rudimentäre Lippen, olıne Papillen. Die Mundhöhle (Fig. 59a) ist verhältnissmässig weit, nicht tief, (nur $8 \mu$ ), übrigens typisch, d. h. wie bei den anderen Arten, gebaut. Der Oes. ist in seinem vorderen Theile cylindrisch, verschmälert sich dann und endigt schliesslich in einen verhältnissmässig kleinen Bulbus. Die Wand des Darmes ist gleichmässig fein gekörnt. Die Ausmündungsöffnung des Gefässsystems mündet ungefähr beim Beginn des hinteren Viertels des Oes. aus. Das Thier ist vivipar. Die weibl. Geschlechtsöffnung ist weit nach linten gerückt und liegt auf der Grenze des hinteren Körperviertels; der Uterus hat vielleicht einen sehr kurzen hinteren Ast, aber die Geschlechtsdrüse streckt sich selir weit nach vorn hin aus und das blinde Ende des Ovariums ist auf eine sehr kurze Strecke wieder nach hinten umgebogen (Fig. 59e). Schön konnte ich die allmähliche Entwickelung der Embryonen beobachten. Der Schwanz des Weibchens (Fig. 59f) verschmälert sich auf der vorderen Hälfte nur wenig, dann aber schneller und ist an seinem Ende abgerundet, ohne in eine Spitze auszulaufen.

Auch die männliche Geschlechtsdrüse streckt sich ziemlich weit nach vorn hin aus (Fig. 59); die Spicula (Fig. 59d) sind klein, schlank, nach innen zu erweitert, mit kurzem accessorischem Stücke. Eigenthümlicherweise läuft der Schwanz des Männchens, der schlank ist und sich ziemlich regelmässig verschmälert, in eine feine Spitze aus (Fig. 59c), während er, wie gesagt, beim Weibchen ein abgerundetes Ende hat. Ich beobachtete auf ihm fünf, der Mittellinie der Bauchseite genäherte, laterale Papillen und zwar eine vor dem After etwas vor dem Hinterende der Spicula, die zweite gleich bei und hinter dem After, schliesslich drei Papillen auf der vorderen Hälfte des Schwanzes, von welchen die mittlere ein wenig näher bei der hintersten als bei der vordersten lag.

Bei $0,64 \mathrm{~mm}$. langen Thieren findet man noch keine Spur von Geschlechtsorganen.

Fundort und Lebensweise. Diese merkwürdige, lebhafte Art ist äusserst selten; ich beobachtete sie in der feuchten, von süssem Wasser ein wenig durchtränkten Erde der Holländischen Wiesen. Männchen und Weibchen sind gleich häufig.

Geographische Verbreitung. Bis jetzt nirgendwo sonst gefunden. 
Fundzeit. Ein erwachsenes Männchen traf ich im Monat Februar, ein reifes Weibchen mit lebenden Embryonen in August an.

Anmerkung. Diese Art ist namentlich deshalb interessant, weil sie vivipar ist und durch hre fadenförmige Gestalt und die rudimentäre Lippen von den anderen Cephaloben sehr abweicht. Mir ist keine zweite Art bekannt mit fadenförmigem Schwanze, der beim Männchen spitz ausläuft, beim Weibchen aber abgerundet endigt.

\section{Cephalobus vexilliger d. M.}

Taf. XV, Fig. 60 .

Oㅇำ $0,42 \mathrm{~mm} ., \alpha=14-18 . \beta=31 / 4-31 / 2 \cdot \gamma=11-13$.

Diese kleine sonderbare Art hat ein sehr plumpes Vorkommen, mit sehr wenig verschmälertem Vorderende. Die Cuticula ist geringelt, mit schmaler Seitenmembran. Das Kopfende (Fig. 60a, 60b) ist sehr niedrig und breit, ein wenig abgesetzt, und aus $(6)$ peripherischen Lappen gebildet, welche in einen kurzen Dorn auslaufen; gleich um die Mundöffnung, auf der breiten Vorderfläche des Kopfendes stehen 3 (oder 6) steife, in zwei Aeștchen auslaufende Börstchen. Ausserdem beobachtet man in der medianen Lage am Kopfende vier submedian verlaufende Linien (Fig. 60b), deren Bedeutung zweifelhaft blieb. Die Mundhöhle ist sehr klein, nicht tiet, übrigens wie bei den typischen Cephaloben gebaut. Auch der Oes. verhält sich ganz typisch: in seinem vorderen Theile ist er breiter, verschmälert sich dann nach hinten und endigt mit verhaltnissmässig grossem Bulbus, der einen kräftigen Klappenapparat enthält; die Darmwand ist ziemlich grobkörnig. Der Gefässporus liegt in geringer Entferaung vor dem Bulbus, auf gleicher Höhe des Nervenringes, welcher deutlich ist. Die weibl., etwas hervorragende Geschlechtsöffnung befindet sich beim Anfang des letzten Körperdritttheils; es giebt einen hinteren Ast des Uterus, und der vordere Theil streckt sich weit nach vorn hin aus. Beim Weibchen ist der Schwanz (Fig. 60c) kegelförmig, zugespitzt, mit dreieckiger, spitzer Ausführungsröhre einer Schwanzdrüse und mit einer lateralen Papille in der Mitte. Die Spicula (Fig. 60d) sind schlank, gebogen, mit stabförmigem accessorischem Stücke versehen. Am Schwanz des Männchens, welcher mehr oder weniger gleichgestaltet ist wie beim Weibchen, fand ich zwei laterale Papillen, die eine etwas hinter der Mitte, die andere ein wenig vor dem Ende des Schwanzes (Fig. 60e).

Fundort und Lebensweise. Diese eigenthümliche, seltene Art lebt nicht nur im sandigen Dünenboden meines Vaterlandes, sondern auch in der feuchten, humusreichen Erde des Waldes. Das Thierchen bewegt sich lebhatt und beide Geschlechter sind gleich håufig.

Geograplische Verbreitung. Bis jetzt nirgendwo sonst beobachtet.

Fundzeit. In den Monaten Januar und October wurde er geschlechtsreif angetroffen. 
10. Cephalobus ciliatus v. Linstow.

Synon: Acrobeles ciliatus, von Linstow, XXX, pag. 2, Taf. I, Fig. 3.

Taf. XV, Fig. 61.

o $0,9 \mathrm{~mm}$., 우 $0,45-0,8 \mathrm{~mm} . \alpha=15-19 . \beta=4-41_{2} . \gamma$ beim $\sigma^{7} 10-11$, beim 우 9-10.

Einer der schönsten freilebenden Rundwürmer ist wohl der Ceph. ciliatus, der vom kundigen Helminthologen, Herrn Dr. von Linstow entdeckt und als Vertreter einer neuen Gattung, Acrobeles, beschrieben wurde, meiner Ansicht nach aber mit Unrecht, weil das Thier sich nur durch die allerdings eigenthümliche Kopfkrone von den anderen Cephaloben unterscheidet.

Es hat dieses Thier eine sehr plumpe Gestalt und der Körper verschmälert sich ziemlich viel nach beiden Seiten hin. Breit und stark geringelt ist die, eine ziemlich breite Seitenmembran tragende, Cuticula. Das Kopfende (Fig. 61a, 61b) ist ein wenig abgesetzt und besteht aus einem basalen Theile und einer darauf gestellten Krone von unbeweglichen Stücken. Diese Krone wird aus drei, um die Mundöffnung gestellten, an ihrem Grunde vereinigten, breiten Platten gebildet, welche sich jede in zwei, nach vorn gerichtete, ein wenig gebogene und divergirende, mehr oder weniger zugespitzte, unbewegliche Stäbe theilen: die dorsale Platte ist symmetrisch gebaut, die beiden ventralen zwar asymmetrisch, aber symmetrisch in Bezug auf einander; diese sechs Stäbe tragen jeder eine doppelte Reihe von feinen, quer gestellten, Härchen oder Börstchen. Auch der basale Theil des Kopfes läuft in unbewegliche, einiger Massen nach aussen gerichtete, zugespitzte Stäbe aus, welche sich fast bis dahin ausstrecken, wo sich die Platten der Krone theilen; die genaue Zahl dieser basalen Stäbe (3, 4 oder 6) konnte ich nicht bestimmen.

Mundhöhle, Oes. und Darm verhalten sich wie bei den anderen Cephaloben; der Oes. ist vorn ziemlich breit, wird dann schmåler und endigt mit ziemlich grossem Bulbus. Der Gefässporus liegt eigenthümlicherweise beim Weibchen mehr nach vorn hin als beim Männchen.

Die weibl. Geschlechtsöffnung liegt $\%_{5}$ der Gesammtlänge vom Schwanzende entfernt und die Geschlechtsorgane verhalten sich wohl wie bei den anderen Cephaloben. Der Sehwanz ist kegelförmig, zugespitzt und ist bei beiden Geschlechtern gleich gestaltet. Beim. Männchen beobachtet man $8 P_{a-}$ pillen (Fig. 61c, 61d): zwei vor dem After, von welchen die eine beim inneren Ende der Spicula, die andere in einer mehr als doppelten Entfernung vom After nach vorn hin gelegen ist, beiden der Mittellinie der Bauchseite genähert; dann eine Papille gleich bei und hinter dem After, die vierte und fünfte Papille dicht bei einander in der Mitte des Schwanzes und zwar die eine der Mittellinie der Bauchseite genähert, die andere ganz lateral; die drei letzten Papillen endlich gleich bei einander etwas vor dem Hinterende des Schwanzes, von welchen eine mehr dorsal, die zweite ganz lateral, die dritte aber mehr ventral gestellt ist. Die Spicula sind kräftig, ziemlich plump, von zwei dünnen stabförmigen, nach den lateralen Seiten gebogenen, accessorischen Stücken begleitet. 
Fundort und Lebensweise. Diese niedliche, häufige Art, welche sich lebhaft bewegt, bewohnt die feuchte sandige Erde der Holländischen Wiesen; sehr häufig ist sie an den Wurzeln der, in den, in der Năhe unserer Holländischen Dünenstriche gelegenen, sandigen Wiesengründen lebenden Pflanzen. Männchen kommen ebenso viel vor wie Weibchen.

Geographische Verbreitung. Deutschland (von Linstow), Insel Ischia bei Neapel.

Fundzeit, Fast das ganze Jahr hindurch traf ich diese schöne, durch den sonderbaren Bau ihres Kopfendes auf dem ersten Blick erkennbare Art an.

XXIV. Teratocephalus d. M.

\author{
de Man, XXVI, pag. 60.

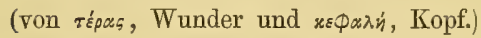

Die Gattung Teratocephalus bildete ich im Jahre $18 \% 5$ für einen Wurm, welcher von Bütschli zur Gattung Anguillula gebracht war, für dessen Anguillula terrestris. Wie ich aber auf Seite 90 gezeigt habe, muss nur das Essigälchen vorlåufig als der Vertreter der Gattung Anguillula betrachtet werden, während vielleicht auch noch die Ang. aquatica zu derselben gehört. Am meisten nähern sich die Teratocephalen den Cephaloben, von welchen sie sich hauptsächlich durch die eigenthümliche Bildung des Kopfendes sowie durch den Mangel von accessorischen Stücken unterseheiden. Die Cuticula ist glatt oder geringelt, eine Seitenmembran beobachtete ich nur bei einer Art. Das Kopfende ist abgesetzt oder nicht und wird von sechs, durch tiefe Rinnen getrennten Lappen gebildet, auf welchen keine Papillen vorkommen. Mundhöhle, Oes. und Darm verhalten sich wie bei den Cephaloben. Seitenorgane wurden bei zwei Arten beobachtet, und ein ventraler Gefässporus findet sich bei allen. Die weibl. Geschlechtsorgane scheinen paarig oder unpaar zu sein und beim Männchen fehlen die accessorischen Stücke, sowie die bei Cephalobus vorkommenden Schwanzpapillen. Eine Schwanzdrüse fehlt.

Fundort und Lebensweise. Von den drei jetzt bekannten Teratocephalen leben zwei in der Erde, eine im süssen Wasser: es sind kleine lebhafte Thierchen, von welchen die Männchen äusserst selten sind.

Die drei bekannten Arten unterscheiden sich durch die folgende Charactere:

1. Kopfende abgesetzt . . . . . . . . . . . . . . . . . 2.

Kopfende nicht abgesetzt, Zahnapparat im Oesophagealbulbus sehr kräftig . . . 3. palustris.

2. Schwanz verlängert, haarfein zulaufend. Zahnapparat schwach . . . . . 1. terrestris.

Schwanz kurz, kegelförmig. Zahnapparat kräftig . . . . . . . . 2. erassidens. 


\section{Teratocephalus terrestris (Btsli) d. M.}

Synon.: Anguillula terrestris, Bütschli, XX, pag. 69, Taf. VII, Fig. 43. De Man, XXVI, pag. 61, Taf. VII, Fig. 25.

Taf. XV, Fig. 62.

$\sigma^{7} 0,4 \mathrm{~mm}$., ㅇ $0,5 \mathrm{~mm}$. a beim $\sigma^{7} 40$, beim ㅇ $30-35$. $\beta=4 . \gamma$ beim $\sigma^{7} 5-6$, beim ㅇ $4-4 \frac{1}{2}$.

Der Körper ist schlank, besonders beim Männchen, versehmälert sich mässig nach vorn hin, während er nach hinten in einen sehr schlanken, allmälig verjüngten, haarfein zulaufenden Schwanz endigt, und zwar bei beiden Geschlechtern. Stark geringelt ist die, eine schmale Seitenmembran tragende Cuticula. Das Kopfende (Fig. 62a, 62b) ist abgesetzt, und aus sechs, nach vorn gerichteten, und durch tiefe Rinnen getrennten Lippen zusammengesetzt. Etwa auf der Höhe des Bodens derselben liegen die kleinen, wohl kreisförmigen Seitenorgane, welche man am besten in der Profilansicht (Fig. 626) beobachtet. Die Mundhöhle ist klein, ziemlich weit, übrigens wie bei Cephalobus gebaut. Der langgestreckte, eylindrische Oes. endigt in einen verhältnissmässig kleinen Bulbus, der einen schwachen, einfach gebauten Zalnapparat enthält (Fig. 62c). Die Darmwand ist mit zahlreichen grössẹeren und kleineren Körnchen gefüllt. Der Gefässporus liegt etwas hinter der Mitte des Oes. Die weibl. Geschlechtsöffnung befindet sich ein wenig hinter der Körpermitte, und die weibl. Geschlechtsdrüse streckt sich nach vorn hin aus, mit nach hinten umgeschlagenem 0varium. Die Spicula (vergl. de Man, XXVI, Taf. VII, Fig. 25) sind sehr schlank und dünn, halbkreisförmig gebogen, ohne accessorische Stücke.

Fundort und Lebensweise. Diese kleine Art, deren Männchen sehr selten ist, gehört zu den häufigsten erdbewohnenden Nematoden und darf mit vollstem Rechte zu den omnivagen Arten gerechnet werden: nicht nur in der mehr oder weniger feuchten Erde von Wiesen und Marschgründen, auch im Walde und im sandigen Boden der Holländischen Dünenstrichen kommt das Thierchen sehr viel vor; es bewegt sich lebhaft.

Geographische Verbreitung. Deutschland (Erlangen, Frankfurt a. M. nach Bütschli), England (Sydenham).

Fundzeit. Wăhrend ich das erwachsene Männchen in Juni beobachtete, traf ich das Weibchen fast das ganze Jahr hindurch an.

2. Teratocephalus crassidens d. M.

Taf. XV, Fig. 63.

q $0,5 \mathrm{~mm} ., \sigma^{7}$ unbekannt. $\alpha=23-25 . \beta=4 . \gamma=9$.

Es fällt dieses eigenthümliche Thierchen, wie auch die folgende Art, gleich auf durch den kräftigen Zahnapparat im Bulbus des Oes., der sich bei durchfallendem Lichte als ein dunkler Fleck darstellt. Im Gegensatze 
mit dem terrestris hat es eine nicht schlanke Körpergestalt, mit sehr wenig verjüngtem Vorderende. Die Cuticula ist zwar glatt, ungeringelt, wird aber von, einander sehr genäkerten Querreihen von sehr feinen Körnchen in den Seitenlinien geschmückt, von welchen die, in der Mitte jeder Querreihe gelegenen etwas grösser sind als die übrigen (Fig. 63c). Das Kopfende ist abgesetzt, zeigt denselben Bau wie beim terrestris, obwohl es verhältnissmässig niedriger und breiter ist. Die Mundhöhle ist mässig kurz und nicht tief, übrigens wie bei den Cephaloben gebaut (Fig. 63a). Die sehr grossen, kreisförmigen Seitenorgane liegen in einiger Entfernung hinter der Mundhöhle und ragen einiger Massen hervor, wie man in der Profilansicht bald erkennt (Fig. 63b). Auch der Oes. hat denselben Bau wie bei Cephalobus, und endigt mit einem ziemlich grossen Bulbus, der den ausserordentlich kräftigen Zahnapparat umschliesst, welcher aus dicken Chitinplatten gebildet wird (Fig. 63c). Darm feinkörnig. Der einfach verlaufende Ausmündungsgang des Gefässsystems mündet beim Beginn des letzten Dritttheils des Oes. aus, und der ziemlich breite Nervenring liegt gleich vor dem muskulösen Bulbus. Die weibl. Geschlechtsöffnung liegt nur wenig hinter der Körpermitte und die weibl. Geschlechtsorgane sind paarig symmetrisch und sehr kurz, mit umgeschlagenen Ovarien. Der Schwanz ist, im Gegensatze des terrestris, kurz, kegelförmig, zugespitzt und zeigt eine laterale Papille in geringex Entfernung hinter dem After.

Fundort und Lebensweise. Auch diese Form muss als eine ziemlich hăufige omnivage Art angesehen werden, welche nicht nur die feuchte Erde von Wiesen und Marschgründen, und den humusreichen Boden des Waldes bewohnt, sondern auch in den Dünenstrichen lebt.

Geograplische Verbreitung. Deutschland (Erlangen), England (Sydenham).

Fundzeit. Ich beobachtete das Thier sowohl im Sommer wie im Winter und vermuthe, dass geschlechtsreife Individuen das ganze Jahr hindurch vorkommen. Das Männchen blieb mir unbekannt.

\section{Teratocephalus palustris d. M.}

Taf. XVI, Fig. 64 。

ㅇ $1 \mathrm{~mm}$. , $\sigma^{7}$ unbekannt. $\alpha=35-40 . \beta=4-4^{1} / 2 \cdot \gamma=10$.

Auf dem ersten Blick unterscheidet sich diese Form, von welcher ich nur wenige Exemplare zu untersuchen im Stande wàr, von den beiden anderen Teratocephalen durch das nicht, durch eine Einschnürung abgesetzte Kopfende. Der Körper ist sellr schlank, nach beiden Seiten, besonders aber nach hinten verschmälert. Die Cuticula ist sehr fein geringelt und zeigt eine doppelte Längsreihe von Körnchen in den Seitenlinien (Fig. 64d), welche mehr oder weniger wie beim crassidens aussehen. Das Kopfende (Fig. 64a) ist nicht abgesetzt, abgerundet und von den sechs elliptischen Rinnen durchschnitten, welche man bei allen Teratocephalen findet. Seitenorgane beobachtete ich nicht, obgleich die Möglichkeit besteht, dass dieselben übersehen wurden. Die Mundhöhle ist wie bei Cephalobus gebaut. Der Oes. ist langgestreckt, cylindrisch, ein wenig in seiner Mitte verschmälert, mit stark chitinisirter Intima, und endigt mit kleinem Bulbus, worin sich ein ebenso kräftiger Zahnapparat befindet, 
wie beim Terat. crassidens (Fig. 64). Der Darm zeigt sparsam, aber gleichmässig zerstreute Körnchen. Der einfach verlaufende Ausführungsgang des Gefässsystems liegt gleich hinter der Mitte des Oes. und der Nervenring befindet sich gerade vor dem Porus (Fig. 64). Die weibl. Geschlechtsöffnung liegt ein wenig hinter der Mitte und die weibl. Geschlechtsorgane sind wahrscheinlich paarig symmetrisch, aber dehnen sich an beiden Seiten der Geschlechtsöffnung nur auf eine geringe Strecke hin aus. Der Schwanz ist schlank (Fig. 64b), allmälig verschmälert und läuft sehr spitz und fein zu.

Fundort und Lebensweise. Ich beobachtete diese zweifelsohne seltene Art in Lachen von süssem Wasser, wie solche in unseren Holländischen Dünenstrichen gefunden werden; ich fand sie in Gesellschaft von mehreren Süsswassernematoden, z. B. des Trilobus gracilis, des Diplogaster rivalis u. a. A. Das Thier, dessen Männchen mir unbekannt blieb, bewegt sich ziemlich lebhaft.

Geographische Verbreitung. Bis jetzt nirgendwo sonst beobachtet.

Fundzeit. Ich fand die Thiere im Sommer (Juni).

\section{Plectns Bast.}

Bastian, VII, pag. 118.

Die artenreiche Gruppe der Plecti schliesst sich den Cephaloben und Rhabditiden unmittelbar an. Es sind meist kleinere Thiere, welche nur selten die Länge von $2 \mathrm{~mm}$. überschreiten; ihre Körpergestalt ist bei den einzelnen Arten sehr verschieden, es giebt Thiere mit plumper, mit ziemlich schlanker und mit sehr schlanker Gestalt, und dieselbe ist nach beiden Seiten hin stets mehr oder weniger verschmälert; der Schwanz ist kurz oder verlängert, mehr oder weniger zugespitzt, nie aber stumpf abgerundet wie bei anderen Nematoden. Stets ist die, öfters feine Börstchen tragende Cuticula quergeringelt und scheint immer mit einer Seitenmembran versehen zu sein; die Seitenfelder zeigen einen körnigen Bau und bei einigen Arten (granulosus, parietinus) beobachtet man in denselben eine doppelte Reihe kernartiger Gebilde ansehnlicher Grösse. Nach Bütschli sind die Plecti polymyarier. Seitenorgane wurden bei fast allen Arten beobacltet; sie sind rund oder elliptisch und liegen meist ziemlich weit nach vorn gerückt. Das Kopfende ist abgesetzt oder nicht, und trägt bei mehreren Arten mehr oder weniger entwickelte Lippen, welche nie mit Papillen versehen sind; hinter dem Vorderrande stehen meist einige feine Borsten, vier oder sechs. Eigenthümlich gestaltet ist das Kopfende bei Plectus auriculatus und otophorus, bei welchen es mit lamellären Hautausbreitungen versehen ist.

Die Mundöffnung führt durch ein kurzes Vestibulum in die mehr oder weniger verlängerte, röhrenförmige, dreiseitige Mundhöhle, deren Wände chitinisirt sind; beim granulosus ist der Anfangstheil schüsselförmig erweitert, beim Schneideri liegen sogar zwei Erweiterungen hinter einander; bei anderen ist der hintere Theil der Mundhöhle viel enger, und nach Bütschli soll in diesem Falle nur der vordere Theil bei der Häutung erneuert werden und deshalb für sich mit der Mundhöhle der übrigen 
Nematoden homolog sein. Für diese Vermuthung spricht allerdings auch seine Angabe, welche ich bestätigen kann, dass nämlich der Oes. diesen hinteren Theil der Mundhöhle umschliesst, sodass dieser Theil als ein Theil der Oesophagealintima betrachtet werden kann (Vergl. z. B. Fig. 71a). Der vordere Theil des Oes. ist cylindrisch und endigt mit einem Bulbus, der einen mehr oder weniger complicirten Klappenapparat umschliesst: öfters ist er auf einer Strecke vor dem Bulbus schmäler als an seinem vorderen Theile; sein Lumen wird von chitinösen Wänden bekleidet und ist meist unmittelbar hinter der Mundhöhle erweitert, wie aus dem Auseinandergehen der, im optischen Querschnitte die Chitinwände des Lumens bezeichnenden Chitinstäbe erscheint (Vergl. z. B. Fig. 72 $a$ ). Die Darmwand besteht aus mehreren Reihen körniger Zellen. Der schräg verlaufende Nervenring umgiebt den Oes. meist in seiner Mitte und die Ausmündungsöffnung des Gefässsystems liegt fast immer gleich hinter ihm. Nach Bütschli sollen die Plecti keine Seitengefässe haben und "soll hier bloss der chitinisirte Ausführungsgang des Gefässsystems bestehen, der sich mit drüsigen Zellen, welche den Oes. umlagern, in Verbindung gesetzt hat." (Bütschli, XX, pag. 87); dieser Gang ist meist ziemlich gewunden, und es ist von dieser Eigenschaft dass Bastian den Namen Plectus abgeleitet hat.

Die weibl. Geschlechtsöffnung liegt fast immer ungefähr in der Körpermitte und die weibl. Geschlechtsorgane sind paarig symmetrisch, mit umgeslagenen Ovarien. Die Zahl der Eier ist beschränkt; dieselben sind oval oder elliptisch, selten, wie beim granulosus, mit Stacheln besetzt. Die männliche Geschlechtsdrüse ist nach Bütschli einfach; die Spicula werden von einem accessorischen Stücke begleitet. Beim Männchen beobachtet man sowohl prä-, wie auch postanale Papillen; bei den kurzschwänzigen granulosus und Schneideri finden sich ausserdem vor dem After in der ventralen Medianlinie zwei bis vier chitinisirte Ausführungsröhren von Drüsen; bei dem dritten, mir bekannten Männchen (cirratus) fehlen dieselben. Eine Schwanzdrüse kommt allen zu, welche durch eine kleine, spitze Ausführungsröhre am Schwanzende ausmündet.

Die Plecti bilden, meiner Ansicht nach, eine ebenso natürliche Gruppe, wie die Cephaloben und Rhabditiden. Die Unterscheidung der Arten ist aber ziemlich schwer, sodass genaue Abbildungen und ausführliche Angaben über die Maasse und den Bau zur Bestimmung nothwendig sind.

Fundort und Lebensweise. Von den jetzt bekannten 19 Arten der Gattung Plectus, leben die meisten in der Erde an den Wurzeln von Pflanzen, bisweilen auch an den Wurzeln von, auf Bäumen oder Steinen wachsenden Moospflanzen; anderen im süssen Wasser. Eine Art (tritic $)$ kommt zwischen den Blattscheiden des Waizens vor. Die meisten Arten sind ziemlich häufig, die Männchen aber, etwa mit Ausnahme des granulosus, ausserst selten und bis jetzt nur bei drei Arten bekannt. Es sind meist lebhafte, bewegliche Thiere.

\section{UEBERSICHT DER BHOBACHTETEN ARTEN.}

1. Kopfende mit medianen lamellären hautartigen Ausbreitungen . . . . .

Kopfende ohne solche Ausbreitungen . . . . . . . . . . . . . . 
verschmälert, dann aber in gleicher Stärke fortlaufend und sich nur wenig verjüngend .

Kleinere Art $(0,36 \mathrm{~mm}$.). Schwanz ziemlich schlank, bald hinter dem After sehr verschmälert und dann auf drei Vierteln seiner Lănge in gleicher Stärke zur Spitze fortlaufend 13. otophorus.

3. Im etwas abgesetzten, sehr hohen, mit buchtigen Seitenwänden versehenen Kopfende liegen zwei schüsselförmige Höhlen, welche die Mundöffnung mit der Mundhöhle verbinden. Schwanz sehr kurz, kegelförmig.

2. Schneideri. Im nicht auffallend hohen Kopfende liegt keine (selten eine) schüsselförmige Höhle zwischen Mundöffnung und Mundhöhle . . . . . . . . . .

4. Grössere Arten, länger als $1 \mathrm{~mm}$. . . . . . . . . . . . . . .

Kleinere Arten, kürzer als $1 \mathrm{~mm}$. . . . . . . . . . . . . .

5. Schrvanz kurz, kegelförmig

Schwanz mehr oder weniger verlängert, schlank.

6. Körper bei den, 1,\%-1,9 mm. langen, erwachsenen Thieren sehr schlank; Mundhöhle an ihrem Vorderende kugelförmig erweitert, Kopfende mit Lippen.

1. granulosus. Körper von sehr plumper Gesta]t, Mundhöhle nicht kugelförmig erweitert, Kopfende mit Lippen

3. parietinus.

\%. Körper mässig schlank; Lippen deutlich ausgeprägt, Körpergestalt und Schwanzlänge characteristisch 4. cirratus.

Körper sehr schlank, Lippen rudimentär oder fehlend . . . . . . .

8. Schwanz $1 / 11$ der Gesammtlänge lang .

5. tenuis.

Schwanz $1 / 8$ der Gesammtlänge lang .

6. palustris.

9. Lippen vorhanden; Körper nicht schlank, Schwanz verlängert, sehr schlank.

Körper bis $0,73 \mathrm{~mm}$. lang

8. $r h i z 0 p h i l u s$.

Lippen fehlend .

10. Körper von schlanker Gestalt; Schwanz cylindrisch, 1/10-1/12 der Totallänge, ziemlich schlank, allmälig aber sehr wenig verschmälert mit abgerundeter Spitze 7. geophilus.

Körper wenig schlank oder plump .

11. Schwanz verlängert, sehr schlank, 1/6 der Gesammtlänge lang .

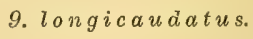
Schwanz kurz

12. Kopfende zugespitzt, mit abgerundetem Vorderrande . . . . . . 10. parvus. Kopfende abgestumpft, Mundhöhle kurz .

11. communis.

Ausser diesen 13 Arten wurden noch die folgenden beschrieben:

1. Plectus tritici Bast. (Bastian VII, pag. 120, Pl. X, Fig. 91, 92). England. 
2. Plectus velox Bast. (Bastian VII, pag. 119, Pl. X, Fig. 85, 86). England. Höchst wahrscheinlich ist diese Art mit dem acuminatus Bast. (Bastian, VII, pag. 120, Pl. X, Fig. 8\%, 88) identisch.

3. Plectus de Mani Örley. (Örley, XXXIV, pag. 162, Taf. I, Fig. 2a-d.) Ungarn.

4. Plectus armatus Btsli, (Bütschli, XX, pag. 90, Taf. VII, Fig. 45). Deutschland.

5. Plectus triplogaster Örley, (Örley, XXXIV, pag. 162, Taf. 1, Fig. 1a-b.) Ungarn.

6. Plectus assimilis Btsli, (Bütschli, XX, pag. 93, Taf. VIII, Fig. 54). Deutschland.

Zu den zweifelhaften Arten rechne ich:

Plectus ornatus Btsli, (Bütschli, XX, pag. 94, Taf. VII, Fig. 41). Deutschland, nach Örley ein junges Exemplar des parietinus Bast.

Plectus sp. Btsli. (Bütschli, XX, pag. 94, Taf. VIII, Fig. 48). Deutschland, nach örley ein junges Exemplar des longicaudatus Btsli.

\section{Plectus granulosus Bast.}

Bastian, VII, pag. 120, Pl. X, Fig. 93, 94.

Bütschli, XX, pag. 92, Taf. VII, Fig. $47 b$, und Taf. VIII, Fig. $47 a$ und $c$. de Man, XXVI, pag. 68, Pl. VIII, Fig. 29a-c.

Taf. XVI, Fig. 65.

$\sigma^{7} 1,9 \mathrm{~mm}$., $ᄋ$ 1,7 mm., a beim $\sigma^{7} 40$, beim $ᄋ$ 35. $\beta=51 / 2 . \gamma$ beim $\sigma^{7} 15-17$, beim $917-20$.

Von allen anderen Arten dieser Gruppe unterscheidet sich der granulosus gleich durch die Kïrze des Schwanzes und die Gestalt der Mundhöhle. Der Körper ist bei den erwachsenen Thieren sehr schlank, bei jüngeren aber verhältnissmässig weniger und verschmälert sich ziemlich viel nach beiden Enden hin. Sehr fein quergeringelt und eine schmale Seitenmembran tragend ist die Cuticula; die Seitenfelder zeigen eine doppelte Reihe grosser kernartiger Gebilde, nach welchen das Thier seinen Namen empfangen hat. Das Kopfende ist nicht abgesetzt, Fig. 65a, und trägt drei (vielleicht aber sechs) Lippen, ohne Papillen und gleich hinter ihnen, vier sehr kurze submediane Börstchen. In geringer Entfernung hinter dem lippentragenden Theile, befinden sich die kleinen, etwas vor der Mitte der Mundhöhle gelegenen Seitenorgane. Die rölrenförmige Mundhöhle ist verlängert, chitinwändig, an ihrem Vorderende halblugelförmig erweitert und verjüngt sich sehr wenig nach hinten zu. Der Oes. ist cylindrisch, verschmälert sich etwas hinter seiner Mitte und endigt mit ziemlich kräftigem Bulbus. Die Darmwand ist feinkörnig. Der Gefässporus liegt ein wenig hinter der Mitte des Oes. und der Nervenring befindet sich vor ihm.

Die weibl. Geschlechtsöffnung liegt in der Körpermitte und die mässig grossen, paarig symmetrischen, weibl. Geschlechtsorgane haben ziemlich kleine, umgeschlagene Ovarien: zwei Eier beob- 
achtete ich im Uterus; dieselben haben eine ovale Gestalt und sind über ilirer ganzen Oberfäche mit kurzen Stacheln besetzt. Die männliche Geschlechtsdrüse ist, nach Bütschli, einfach und zerfällt durch eine Verengerung in zwei Abschnitte, den eigentlichen Hoden und den Samenleiter; die Spicula, Fig. $65 b$, sind schlank, gebogen, mit complicirtem, die Spicula umschliessendem, accessorischem Stücke, das einen nach hinten gerichteten Fortsatz trägt. Der Schwanz ist bei beiden Geschlechtern ziemlich gleichartig gestaltet, seltr kurz, kegelförmig, nach der ventralen Seite gebogen und trïgt an seinem Ende ein sehr kurzes Ausführungsröhrchen der Schwanzdrüse. Beim Männchen finden sich zahlreiche Papillen am hinteren Körperende, so wie vier (bei jüngeren Thieren drei) Ausfültrungsröliren von Drïsen, mit chitinösen Wänden, welche in der ventralen Medianlinie vor dem After ausmünden; die hinterste mündet etwa auf der Mitte der Spicula, die zweite ungefähr vor ihrem inneren Ende, die dritte in einer zweimal so grossen Entfernung von der zweiten als diese von der hintersten, während die vierte wieder vor der dritten ausmündet. Die Papillen vertheilen sich auf der folgenden Weise: eine mediane liegt gleich vor und eine laterale gleich bei dem After, dann aber finden sich noch drei laterale vor dem After, von welchen die mittlere in gleicher Distanz von den beiden anderen entfernt ist und sich ein wenig vor dem inneren Ende der Spicula befindet. Am eigentlichen Schwanze beobachtet man einige mediane, sowohl ventrale, wie-dorsale Papillen, ein wenig vor seiner Spitze und schliesslich vier laterale Papillen, von welchen die drei hinteren, einander genähert, in der Mitte des Schwanzes gelegen sind, die vorderste aber sich nur in geringer Entfernung hinter dem After befindet. (Fig. 65b). Die Geschlechtsorgane sind schon bei $1 \mathrm{~mm}$. langen Thieren (nach Bütschli beim Männchen sogar bei einer Länge von $0,8 \mathrm{~mm}$.) entwickelt.

Fundort und Lebensweise. Unsere Art gehört zu den häufigeren freilebenden Rundwürmern und ist ausserdem omnivag, indem er nicht nur die mehr oder weniger feuchte Erde von Wiesen und Marschgründen, oder den humusreichen Boden der Waldgegenden bewohnt, sondern auch häufig an den Wurzeln der, im sandigen Dünenboden lebenden Pflanzen gefunden wird. Das Thier ist sehr lebhaft und beide Geschlechter kommen gleich häufig vor.

Geographische Verbreitung. Deutschland. (Erlangen, Frankfurt a. M. nach Bütschli). Schweiz (Altdorf). Frankreich (Montpellier). England.

Fundzeit. Geschlechtsreife Individuen dieser Art traf ich in allen Monaten des Jahres an.

\section{Plectus Schneideri d. M.}

Taf. XVI, Fig. 66 .

$\sigma^{7} 0, \% 4 \mathrm{~mm}$. 우 $0,9 \mathrm{~mm} . \alpha=25 . \beta=4-5 . \gamma$ beim $\sigma^{7} 14$, beim ㅇ $15-18$.

Die Körpergestalt dieser, dem granulosus am nächsten verwandten Art ist mässig schlank, und die fein geringelte Cuticula trägt eine schmale Seitenmembran (Fig. 66d). Das Kopfende (Fig. 66b) ist ein wenig abgesetzt, sehr hoch, mit buchtigen Seitenwänden, ohne Lippen oder Papillen, mit vier sehr 
kurzen, sich an seinem Grunde befindenden, submedianen Börstchen. Seitenorgane wurden nicht beobachtet. Zwischen der Mundöffnung und der prismatischen, sehr verlängerten und sehr dünnwăndigen Mundhöhle liegen hinter einander zwei schüsselförmige Höllen, im abgesetzten Kopfende. (Beim granulosus giebt es nur eine solche Erweiterung.) In Hinsicht auf den Bau des Verdauungstractus und die Lage des Gefässporus verhält sich diese Art wie die vorige. Die weibl. Geschlechtsöffnung ist sehr weit, aber dzinnwändig, und liegt ein wenig hinter der Körpermitte (Fig. 66d). Bei beiden Geschlechteirn ist der Schwanz gleichartig gestaltet, selır hurz, legelförmig, mit abgerundetem Ende, welches ein kleines Spitzchen trägt. Beim Männchen liegen zwei chitinisirte Ausfüllrungsrölıren von Drüsen vor dem After, von welchen die hinterste bei der Mitte, die vorderste ein wenig vor dem inneren Ende der Spicula gelegen ist. Diese letzteren sind denjenigen des granulosus ähnlich, das accessorische Stück ist aber. kleiner und anders gebaut. Papillen wurden beim Männchen nicht beobachtet, sind aber doch wahrscheinlich vorhanden.

Fundort und Lebensweise. Es wurden bis jetzt von dieser âusserst seltenen Art nur drei Exemplare $\left(1 \sigma^{7}, 2\right.$ 9) beobachtet und zwar das Männchen und ein 0,8 $\mathrm{mm}$. langes Weibchen im sandigen Boden der Insel Ischia während meines Aufenthaltes in der zoologischen Station zu Neapel im Jahre $18 \% 6$, so wie ein zwreites $0,9 \mathrm{~mm}$. langes Weibchen in feuchter, von süssem Wasser durchtränkter Erde unweit Leiden.

Fundzeit. Die Italienischen Exemplare beobachtete ich im Monat Mai, das dritte Mitte September.

Anmerkung. Zweifelsohne wird die Art noch grösser als oben angegeben worden ist, und ist noch Manches in Bezug auf den. Bau der Geschlechtsorgane und der männlichen Schwanzpapillen unbekannt geblieben.

3. Plectus parietinus Bast.

Bastian, VII, pag. 118, Taf. X, Fig. $79,80$.

Bütschli, XX, pag. 89, Taf. III, Fig. 1\%, Taf. VII, Fig. $46 a-c$ und Fig. 39, Taf. VIII, Fig. 52.

Taf. XVI, Fig. 67 .

$\sigma^{7}$ unbekannt, of $1,3 \mathrm{~mm} . \alpha=16-20 . \beta=4-5 . \gamma=13-19$.

Es hat dieses Thier ein sehr plumpes Vorkommen, es verschmälert sich aber ziemlich stark und gleichmässig nach beiden Seiten hin. Die Cuticula ist sehr fein geringelt und ist mit einer sehr schmalen Seitenmembran versehen; die Seitenfelder zeigen dieselbe doppelte Reihe kernartiger Gebilde, welche auch beim granulosus so deutlich sind. Das abgesetzte Kopfende (Fig. 6\%a) wird von sechs abgerundeten papillenlosen Lippen gebildet; unmittelbar hinter ihnen stehen vier (oder sechs) sehr kurze Börstchen. Die kleinen Seitenorgane sind sehr nach vorn gerückt. Die verlängerte Mundhöhle wird nach hinten $\mathrm{zu}$ allmälig schmäler. In seinem vorderen Theile ist der Oes. cylindrisch 
nachher verengt er sich und schwillt zu einem kugelförmigen Bulbus an. Die Darmzellen sind körnig und durch helle Zwischenrüume von einander getrennt. Die Geschlechtsorgane, resp. die Ausmündungsöffnung derselben fehlt noch bei $0,9 \mathrm{~mm}$. langen Thieren, liegt aber bei erwachsenen sehr wenig vor der Körpermitte; die weibl. Geschlechtsorgane sind paarig symmetrisch, aber ziemlich kurz. Der Schwanz ist sehr plump gestaltet, kegelförmig, zugespitzt, mit feinem Ausführungsröhrchen.

Fundort und Lebensweise. Es ist diese Art ein ziemlich häufiger Bewohner der sandigen Dünenstriche, welche die Niederlande gegen das Meer beschützen. Sie bewegt sich ziemlich lebhaft, das Männchen blieb mir aber unbekannt.

Fundzeit. Im Frühling, im Hochsommer und im Herbst wurden erwachsene Thiere beobachtet.

Anmerkung. Die Länge des Schwanzes variirt sehr bei den, von mir aufgefundenen Thieren: bei einem Individuum von 1,32 mm. erreichte er $1 / 19$, bei einem anderen von 1,29 mm. aber $1 / 14$ der Gesammtlänge.

Es ist mir noch gar nicht sicher, ob die von mir beobachtete Art wohl mit der Bastian'schen identisch ist: die letztere scheint mir einen nach vorn hin weniger sich verjüngenden Körper und einen dünneren Schwanz zu besitzen, auch wurde sie nicht in der Erde, sondern an den Wurzeln von, auf Dächern und Mauern wachsenden Moosen und Parmelien aufgefunden. Vorläufig aber darf meine Art den Namen parietinus behalten.

\section{Plectus cirratus Bast.}

Bastian, VII, pag. 119, Pl. X, Fig. 81, 82.

de Man, XXVI, pag. 69, Taf. VIII, Fig. 30a-b.

Taf. XVII, Fig. 68.

ơ $0,9 \mathrm{~mm}$. , ㅇ 1,3 mm. (nach Bastian 1,6 mm. erreichend). $\alpha=25-30 . \beta=4-5 . \gamma$ beim $\sigma^{7} 9$, beim $ᄋ$ 8-9.

Der Körper dieser Art ist mässig schlank, und nach beiden Seiten sehr verschmälert. Die Cuticula ist ausserst fein geringelt und trägt eine mässig breite Seitenmembran; einige feine Borsten kommen am Schwanze vor. Das Kopfende ist abgesetzt, und wird von sechs abgerundeten Lippen gebildet, welche verhältnissmässig deutlich ausgeprägt sind. Gleich hinter den Lippen stehen sechs sehr kurze Borsten. Die elliptischen Seitenorgane liegen ein wenig vor der Mitte der Mundhöhle. Diese letztere ist verlängert, chitinwändig und verschmälert sich allmälig nach hinten; der cylindrische Oes. wird ein wenig hinter seiner Mitte enger und schwillt schliesslich zu einem grossen, einen kräftigen Klappenapparat umfassenden, muskulösen Bulbus an. Die Darmwand ist feinkörnig. Der ventrale Gefässporus mündet in geringer Entfernung hinter der Mitte des Oes. aus. Die weibl. Geschlechtsöffnung liegt ein wenig vor der Körpermitte (nach Bastian bei seinen etwas grösseren Thieren eine geringe Strecke hinter der Mitte); die Geschlechtsorgane sind paarig symmetrisch, strecken 
sich aber nicht weit aus, und sind bei $0,9 \mathrm{~mm}$. langen Thieren noch unvollkommen entwickelt; zwei ziemlich grosse Eier mit glatter Schale beobachtete ich im Uterus. Der Schwanz des Weibchens (de Man, XXVI, Taf. VII, Fig. 30b) ist ziemlich schlank, und verschälert sich allmälig. Beim Månnchen (Fig. 68c) hat er eine mehr plumpe Gestalt und einige Papillen beobachtet man sowohl vor als hinter dem After: eine kleine mediane Papille liegt in geringer Entfernung vor dem After, in der Nähe des inneren Endes der Spicula, dann eine laterale Papille etwas hinter dem After, endlich zwei, einander sehr genäherte, mediane, ventrale Papillen ein wenig hinter der Mitte des Schwanzes. (Vielleicht giebt es aber noch mehrere Papillen!). Chitinisirte präanale Ausführungsröhren von Drüsen, wie solche bei Plectus granulosus und Schneideri vorkommen, giebt es bei dieser Art nicht. Die Spicula (Fig. 68d) sind plump, zeigen einen centralen Verdickungsstreif in der vorderen Hälfte, und werden von einem stabförmigen, kurzen accessorischen Stücke begleitet, welches an seinem Hinterende einen rudimentären, nach innen und hinten gerichteten Fortsatz trägt.

Fundort und Lebensweise. Es lebt der ziemlich häufig vorkommende cirratus in der feuchten, von süssem Wasser durchtränkten Erde von Wiesen und Marschgründen, bisweilen hält er sich aber auch im süssen Wasser selbst auf. Das Männchen dieser lebhaften Art ist äusserst selten.

Geographische Verbreitung. Deutschland (Erlangen). Schweiz (Roth See bei Luzern). England.

Fundzeit. Fast in allen Jahreszeiten wurden geschlechtsreife Individuen von mir beobachtet.

5. Plectus tenuis Bast.

Bastian, VII, pag 119, Pl. X, Fig. 83, 84 .

Taf. XVII, Fig. 69.

O7 unbekannt, ㅇ $1,2 \mathrm{~mm} \cdot \alpha=40 . \beta=4-41_{2} \cdot \gamma=11$.

Bei dieser Art findet man einen sehr schlanken, nach beiden Seiten verschmälerten Körper; die Haut ist ausserst fein geringelt. Eine Seitenmembran wurde zwar nicht beobachtet, dürfte aber doch noch vorhanden sein. Das Kopfende ist nicht abgesetzt, abgestumpft, zeigt eine Andeutung von sehr kleinen Lippen und trägt vier kurze, hinter denselben stehende Borsten. Die kleinen Seitenorgane liegen so ungefähr in der Mitte der Mundhöhle, welche röhrenförmig und ziemlich lang ist, 1/6 der Länge des Oes. erreichend, sich nach hinten allmälig verschmälernd. Der langgestreekte Oes. endigt mit verhältnissmässig kleinem, ovalem Bulbus, der einen kräftigen Zahnapparat umfasst, und der Darm erscheint gleichmässig fein gekörnt. Der Gefässporus befindet sich ein wenig hinter der Mitte des Oes., während unmittelbar vor ihm der Nervenring den Oes. umfasst. Die weibl. Geschlechtsöffnung liegt in der Körpermitte, und die Geschlechtsorgane sind paarig symmetrisch und ausserordentlich kurz, d. h. strecken sich nur auf eine geringe Strecke an beiden Seiten der Vulva aus; zwei Eier fand ich im Uterus. Der Schwanz (Fig. 69b: ist schlank, allmälig verschmälert mit kurzem Ausführungsröhrchen der Schwanzdrüse. 
Fundort und Lebensweise. Diese sehr lebhafte Art bewohnt das süsse Wasser der Holländischen Teiche und Gräben.

Geographische Verbreitung. England nach Bastian.

Fundzeit. Eitragende Thiere beobachtete ich in den Monaten April und Juli.

Anmerkung. Bastian beschrieb diese Art nach jungen Thieren, wie aus den, von ihm angegebenen Grössenverhältnissen erscheint.

\section{Plectus palustris d. M.}

Taf. XVII, Fig. 70 .

$\sigma^{7}$ unbekannt, 우 $1, \%, \alpha=45 . \beta=5 . \gamma=8$.

Diese Art ist der vorigen höchst verwandt, unterscheidet sich aber gleich durch den verhältnissmässig längeren und schlankeren Schwanz. Es hat dieser Plectus eine sehr schlanke Gestalt, sodass man dieselbe fast fadenförmig nennen kann. Nach vorn hin verschmålert der Körper sich weniger als nach hinten zu. Aeusserst fein geringelt ist die Cuticula, welche eine sehr schmale Seitenmembran trägt. Das Kopfende ist nicht abgesetzt, ein wenig zugespitzt, mit abgestumpftem Vorderrande, ohne eine Andeutung von Lippen, und trägt vier kurze submediane Börstchen. Die MFundhöhle verschmälert sich ein wenig nach hinten und erreicht $1 / 3$ der Länge des Oes. Die ziemlich grossen Seitenorgane liegen ungefähr auf der Mitte der Mundhöhle. Der langgestrecktc Oes., dessen Bulbus und Zahnapparat verhalten sich wie bei. der vorigen Art. Die weibl. Geschlechtsöffnung liegt ein wenig vor der Mitte des Körpers und die paarig symmetrischen Genitalien dehnen sich nur auf eine geringe Strecke an beiden Seiten der Vulva aus; ein einziges Ei beobachtete ich im Uterus. Der Schwanz (Fig. \%0b) ist schlank, regelmässig verjüngt, mit spitzem, kurzem Ausführungsröhrchen der Schwanzdrüse.

Fundort und Lebensweise. Auch diese Art bewohnt das süsse Wasser der Holländischen Teiche und Gräben und bewegt sich lebhaft. Das Männehen blieb unbekannt.

Geographische Verbreitung. Bis jetzt nirgendwo sonst beobachtet.

Fundzeit: Das Thier ist in Mai geschlechtsreif, eitragend.

7. Plectus geophilus d. M.

Taf. XVII, Fig. $\% 1$.

$\sigma^{7}$ unbekannt, ㅇ $0,53 \mathrm{~mm}$. $\alpha=30-35 . \beta=31 / 4-3^{2} / 3^{2} \cdot \gamma=10-12$.

Der kleine geoplitus hat einen scllanken Körper, der sich nach beiden Seiten hin wenig verschmälert. Die sehr fein geringelte Cuticula trägt eine ziemlich breite Seitenmembran (Fig. $71 c$ ). Das nicht abgesetzte Kopfende zeigt keine Spur von Lippen, trägt aber 4 (oder 6) sehr kurze Börstchen, (Fig. 71a). Die kleinen, kreisförmigen Seitenorgane liegen in der Mlitte der Mundhöhle; diese 
letztere ist verlängert, hat etwa $1 / 7$ der Länge des Oes., und verjüngt sich allmälig nach hinten, wo ihre Wände undeutlich abgegrenzt sind. Der Oes. ist langgestreckt und endigt mit verhältnissmässig kleinem Bulbus, der einen schwachen Zahnapparat umfasst. (Fig. 716). Der Darm zeigt nur sparsam zerstreute Körnchen. Die weibl. Geschlechtsöffnung liegt ein wenig hinter der Körpermitte und die kurzen, sich nur über eine geringe Strecke ausdehnenden weibl. Geschlechtsorgane scheinen mir paarig symmetrisch zu sein. Höchst characteristisch ist der Schwanz; derselbe hat eine cylindrische, ziemlich schlanke Gestalt, verschmälert sich allmälig aber seltr wenig, und hat eine abgerundete Spitze, welche mit einem kleinen Ausführungsröhrchen der Schwanzdrüse versehen ist. (Fig. $71 d$ ).

Fundort und Lebensweise. Dieses lebhafte Thierchen, dessen Männchen unbekannt blieb, ist ziemlich selten, muss aber als omnivag betrachtet werden, weil es nicht nur die feuchte, oder von süssem oder brackischem Wasser durchtränkte Erde der Holländischen Wiesen bewohnt, sondern auch im Walde und im sandigen Dünenboden gefunden wurde.

Geographische Verbreitung. Deutschland (Laibach).

Fundzeit. Geschlechtsreife Weibchen traf ich in allen Jahreszeiten an.

8. Plectus rhizophilus d. M.

Taf. XVII, Fig. 72.

o unbekannt, ㅇ $0,73 \mathrm{~mm} . \alpha=20-25 . \beta=4 . \gamma=7-8$.

Es hat diese Art eine nicht schlanke Gestalt, und ihr Vorderende ist ziemlich verschmälert. Einige feine Börstchen stehen auf der gesammten Körperoberfläche zerstreut, besonders am Schwanze. Die äusserst fein geringelte Cuticula ist mit einer. sehr schmalen Seitenmembran versehen. Das nicht abgesetzte Kopfende wird von sechs Lippen gebildet, und trägt hinter ihnen vier submedian gestellte Börstchen (Fig. 72a). Die mässig grossen Seitenorgane liegen zur halben Höhe der Mundhöhle. Diese ist verlängert, verengt sich nach hinten und ist in ihrem vorderen Theile weiter und mit dickeren Wïnden versehen als melı nach hinten. Der cylindrische Oes. endigt mit mässig grossem Bulbus, der einen kräftigen Zahnapparat (Fig. 72d) umfasst; in der Darmwand erscheinen die körnigen Zellen deutlich von einander durch helle Zwischenräume getrennt. Die weibl. Geschlechtsöffnung befindet sich ungefăhr in der Körpermitte, und die paarig symmetrischen Geschlechtsorgane liegen nur eine geringe Strecke an beiden Seiten der Vulva; die Ovarien sind verhältnissmässig gross. Bei einem $0,64 \mathrm{~mm}$. langen Thiere beobachtete ich ein einziges, $0,05 \mathrm{~mm}$. langes Ei und die weibl. Genitalien fehlen noch vollständig bei Exemplaren, welche nur noch die Grösse von $0,4 \% \mathrm{~mm}$. erreicht haben.

Die Gestalt des Schwanzes ist ein wenig variabel (vergl. Fig. $72 b$ und Fig. 12c); im Allgemeinen ist derselbe verlängert, sehr schlank, verschmälert sich allmälig, aber wenig und endigt mit kurzem Ausfïlrungsröhrchen der Schwanzdrüse.

Fundort und Lebensweise. Es liebt der rhizoplitus besonders die minder feuchte oder sandige 
Erde, wo er an den Wurzeln von Pflanzen gefunden wird. So traf ich ihn in der feuchten Wiesenerde, und im humusreichen Boden des Waldes an, aber. auch in der sandigen Erde der Dünenstriche und der, im östlichen Theile der Niederlande gelegenen Heidegründe. Hier wie auch im Walde scheint das Thier besonders bäufig vor zu kommen.

Geographische Verbreitung. Deutschland (Laibach). England (Sydenham).

Fundzeit. Sowohl im Sommer wie im Winter wurden eitragende Thiere von mir angetroffen.

Anmerkung. Ich kann nicht umhin, die Vermuthung auszusprechen dass vielleicht eine der drei, von Bastian als $P$. velox, acuminatus und fusiformis unterschiedenen Arten mit meinem rhizophilus identisch ist. Vorläufig ist es mir aber nicht möglich, eine derselben zu identificiren.

9. Plectus longicaudatus Btsli.

Bütschli, XX, pag. 92, Taf. VI, Fig. 38a-b.

Taf. XVIII, Fig. 73.

$\sigma^{7}$ unbekant, $ᄋ \quad 0,5 \mathrm{~mm} . \alpha=25 . \beta=4 . \gamma=6$.

Bei dieser, der vorigen nahe verwandten kleinen Art findet man einen wenig schlanken Körper, der sich nach vorn hin ziemlich, nach hinten aber sehr verjüngt. Die Cuticula ist äusserst fein geringelt und trägt eine verhältnissmässig breite Seitenmembran. Das Kopfende (Fig. 73a) ist abgerundet, olne eine Spur von Lippen und trägt vier mässig lange Borsten. Die verlängerte Mundhöhle ist derjenigen des geophilus selir ähnlich, indem der vordere dickwändige Theil enweitert ist, der grössere hintere aber enge und sehr verschmälert. Der cylindrische Oes. ist beim, nur wenig hinter seiner Mitte gelegenen Gefässporus verschmälert und schwillt zu einem relativ kleinen Bulbus an. Der, in diesem liegende Zahnapparat ist sehr einfach gebildet (Fig. 73c) und unterscheidet sich durch einen viel weniger complicirten Bau von demjenigen des rhizoplitus. In der Darmwand erkennt man nur kleine, sparsam zerstreute Körnchen. Die weibl. Geschlechtsöffnung liegt ungefähr in der Mitte, und die mässig grossen weibl. Geschlechtsorgane sind, wie mir scheint, paarig symmetrisch. Der Schwanz ist verlängert, sehr schlank, allmälig aber wenig verschmälert und trägt einige feine Börstchen (Fig. พ3b).

Fundort und Lebensweise. Diese nicht sehr häufige Art bervohnt die feuchte oder von süssem oder brackischem Wasser mehr oder weniger durchtränkte Erde unserer Wiesen. Das Thierchen, dessen Männchen unbekannt blieb, bewegt sich lebhaft.

Geographische Verbreitung. Deutschland (Erlangen, Frankfurt a. M. nach Bütschli). Frankreich (Montpellier.)

Fundzeit. Erwachsene Thiere beobachtete ich in den Monaten Februar, März und August; das Thierchen scheint also im Sommer und im Winter geschlechtsreif vorzukommen. 
10. Plectus parvus Bast.

Bastian, VII, pag. 120, PI. X, Fig. 89, 90 .

Synon: Plectus fusiformis, de Man, XXVI, pag. 71, Pl. VIII, Fig. 31a-e.

Taf. XVIII, Fig. 74.

o unbekannt, 우 $0,57 \mathrm{~mm} . \alpha=18-20 . \beta=4 . \gamma=10-11$.

Diese kleine, zweifelsohne auch vom Englischen Helminthologen gesehene Art hat eine plumpe Körpergestalt, welche sich nach beiden Seiten verjüngt. Die Cuticula ist äusserst fein geringelt mit ziemlich breiter Seitenmembran. Das nicht abgesetzte Kopfende ist zugespitzt und zeigt einen gebogenen abgerundeten Vorderrand, oline eine Spur von Lippen; es ist mit vier feinen Borsten versehen. Die mässig grossen, kreisförmigen Seitenorgane (Fig. 14a) liegen in der Mitte der Mundhöhle. Diese letztere ist röhrenförmig und wird nach linten allmälig enger. Der Oes. ist cylindrisch, verschmälert sich dann etwas nach hinten und schwillt schliesslich zu einem mässig grossen Bulbus mit Klappenapparat an. In der Darmwand sind die feinen Körnchen gleichmässig zerstreut. Die weibl. Geschlechtsöffnung befindet sich gerade in der Körpermitte und die paarig symmetrischen Genitalien sind ziemlich gross und produciren ein verhältnissmässig grosses Ei. Der Schwanz ist kurz, verschmälert sich ein wenig hinter dem After und läuft dann in gleicher Stärke zum Hinterende fort.

Fundort und Lebensweise. Dieses Thierchen ist in den Niederlanden sebr selten, und das Mănnchen ist noch gänzlich unbekannt. Ich fand es in feuchter Erde einer Wiese unweit Leiden an den Wurzeln von Gramineen und später in feuchtem Humus zwischen den Wurzeln einer, auf einem alten Baum wachsenden Moospflanze.

Geographische Verbreitung. England nach Bastian.

Fundzeit. Die eitragenden Thiere beobachtete ich in den Monaten November und December.

Anmerkung. Diese Art bildet einiger Massen den Uebergang des Plectus longicaudatus zum communis: während sie sich nämlich durch ihre plumpe Gestalt und die Form des Schwanzes der letzteren Art anschliesst, hat sie ein, demjenigen des longicaudatus sehr ăhnliches Kopfende, indem es zugespitzt und abgerundet ist, und nicht breit abgestumpft wie beim communis.

11. Plectus communis Btsli.

Bütschli, XX, pag. 91.

de Man, XXVI, pag. 73, PI. IX, Fig. 33a-b.

Taf. XVIII, Fig. \%5.

$\sigma^{7}$ unbekannt, ㅇ $0,5 \mathrm{~mm} . \alpha=15-18 . \beta=4 . \gamma=8-10$.

Im äusseren Habitus ist diese Form der vorigen Art sehr ahnlich, sie unterscheidet sich aber 
auf dem ersten Blick durch das breit abgestumpfte Vorderende. Der Körper hat eine plumpe Gestalt, und verschmälert sich nur wenig nach vorn hin. Die Cuticula ist sehr fein geringelt, mit mässig breiter, obwohl deutlicher Seitenmembran; über der gesammten Körperoberfläche stehen feine Börstchen zerstreut. Das Kopfende ist nicht abgesetzt, hat eine breite, abgestumpfte Vorderfläche, ohne eine Spur von Lippen, trägt aber vier submediane, sehr nach vorn gerichtete Börstchen. (Fig. 75a). Die Seitenorgane sind elliptisch, quer und verhältnissmässig sehr nach vorn gerückt. Die ziemlich kurze röhrenförmige Mundlö̈le hat über ihrer ganzen Länge den gleichen Durchmesser und wird nach hinten zu nicht enger. Der Oes. ist cylindrisch, wird nach hinten etwas enger und endigt mit relativ kleinem Bulbus. Die Darmwand ist typisch gebaut. Die weibl. Geschlechtsöffnung liegt in der Körpermitte und die paarig symmetrischen Geschlechtsorgane sind gross: ein einziges grosses Ei beobachtete ich im Uterus. Der Schwanz ist kurz, verschmälert sich ein wenig hinter dem After und läuft dann in gleicher Stärke zum Hinterende fort.

Fundort und Lebensweise. Seinem Namen entgegen ist der communis gar nicht so häufig; es ist ein lebhaftes Thierchen, das man unter den anderen Plecti gleich an seiner plumpen Gestalt, seinem abgestumpften Kopfende und seiner überall gleich weiten Mundhöhle erkennt. Es bewohnt nicht nur die feuchte Wiesenerde, auch im Waldboden und in den Dünenstrichen kommt unsere Art vor. Das Männchen blieb unbekannt.

Geographische Verbreitung. Deutschland (Frankfurt a. M. nach Bütschli.)

Fundzeit. Fast in allen Jahreszeiten wurden erwachsene Thiere dieser Art von mir angetroffen.

12. Plectus auriculatus Btsli.

Bütschli, XX, pag. 91, Taf. VII, Fig. $44 a-b$.

Taf. XVIII, Fig. 76.

$\sigma^{7}$ unbekannt, of $0,5 \mathrm{rmm} . \alpha=15-16 . \beta=4 . \gamma=14$.

Diese und die folgende Art weichen von allen anderen Plecti durch den eigenthümlichen Bau ihres Kopfendes ab. Beim selr plump gestalteten auriculatus verjüngt sich der Körper nach beiden Seiten hin. Hie und da stehen auf der, eine schmale Seitenmembran tragenden, äusserst fein geringelten Cuticula einige feine Börstchen zerstreut. Das Kopfende (Fig. \%6a) characterisirt sich durch eine dorsale und eine ventrale lamelläre hautartige Ausbreitung, worauf die Querringel der Haut sich fortsetzen; am Vorderrande des Kopfes stehen vier (oder mehr) bewegliche Borsten. Die kleinen, elliptischen Seitenorgane liegen in der Mitte dieses Kopfendes. Die verlängerte Mundhöhle verschmälert sich allmälig nach hinten zu; der cylindrische Oes. verjüngt sich nach hinten und endigt mit relativ kleinem Bulbus und die körnigen Darmzellen werden durch helle Zwischenräume von einander getrennt. Die weibl. Geschlechtsöffnung befindet sich in der Körpermitte, und die grossen umgeschlagenen Ovarien 
der sehr kurzen, paarig. symmetrischen Geschlechtsorgane kreuzen einander (Fig. 76.) Der Schwanz (Fig. 76b) hat ein plumpes Vorkommen, verschmälert sich schneller bis auf seine Mitte, läuft dann aber in gleicher Stärke fort, sich nur wenig verengend.

Fundort und Lebensweise. Diese eigenthümliche Art traf ich bis jetzt nur im sandigen Boden der, nicht weit von unseren Dünenstrichen gelegenen Wiesen an, wo sie ziemlich häufig vorkommt. Das Thier, dessen Männchen unbekannt blieb, bewegt sich lebhaft.

Geographische Verbreitung. Deutschland (Frankfurt a. M. nach Bütschli).

Fundzeit. Erwachsene Thiere fand ich im Frühling, im Sommer und im Herbst; ich vermuthe also, dass auch von dieser Art, wie von so manchen anderen, in allen Jahreszeiten geschlechtsreife Individuen vorkommen.

\section{Plectus otophorus d. M.}

Synon: Plectus auriculatus, de Man, XXVI, pag. 74, PI. IX, Fig. 34a-b.

\section{Taf. XVIII, Fig. $7 \%$.}

$\sigma^{7}$ unbekannt, $ᄋ 0,36 \mathrm{~mm} \cdot \alpha=18-20 . \beta=3 / 4-4 . \gamma=8-9$.

Es gehört auch dieses niedliche Thierchen zu den kleinsten freilebenden Nematoden, wie Monohystera bulbifera und Tylenchus mácrophallus. Es hat eine plumpe Gestalt mit wenig verschmälertem Vorderende, während der Körper sich nach hinten zu viel mehr verjüngt. Die Cuticula ist feingeringelt, mit mässig breiter Seitenmembran versehen; hie und da stehen einige Börstchen über der Körperoberfläche zerstreut. Die breite, abgestumpfte Vorderfläche des Kopfendes ist vierlappig; sowohl an der dorsalen wie an der ventralen Seite befindet sich eine, nach vorn in eine feine Spitze auslaufende, lamelläre Hautausbreitung, welche sich nach den lateralen Seiten hin mit gebogenen Flächen ausstreckt, und sich nach hinten zu in eine breitere, auch median gelegene, am Kopfwande sich inserirende, nach aussen lin abgerundete Lamelle verlängert; auch an jeder der lateralen Seiten des Kopfes sehe ich eine kleinere Hautplatte, welche sich mit dünnen Platten an den beiden grösseren medianen Ausbreitungen zu verbinden scheint. Die typisch gebaute Mundhöhle verschmälert sich nur wenig nach hinten und ist länger als die lamellären Ausbreitungen des Kopfendes. Die kreisförmigen Seitenorgane beobachtet man auf der Mitte der Mundhöhle. Der cylindrische Oes. wird nach hinten zu schmäler und endigt mit măssig grossem Bulbus, der einen ziemlich kräftigen Zahnapparat umfasst; im Darme sind die feinen Körnchen der Darmzellen nur sparsam verbreitet. Der Gefässporus liegt etwas hinter der Mitte des Oes. Die weibl. Geschlechtsöffnung liegt in der Körpermitte und die paarig symmetrischen Genitalien strecken sich nur über einen kurzen Raum an beiden Seiten der Vulva aus. Der Schwanz (Fig. $7 \% b$ ) ist ziemlich schlank, verschmälert sich sehr bald hinter dem After und läuft dann auf drei Vierteln seiner Länge in gleicher Stärke zur Spitze fort.

Fundort und Lebensweise. Diese Art ist nicht selten im sandigen Boden der Holländischen 
Dünengegenden und Heidegründe; ich beobachtete sie aber auch in der feuchten, von süssem oder brackischem Wasser getränkten Wiesenerde.

Geographische Verbreitung. England (Sydenham).

Fundzeit. Geschlechtsreife Exemplare fand ich während eines grossen Theiles des Jahres, (Frühling, Sommer, Herbst).

Anmerkung. Vom auriculatus Btsli unterscheidet sich diese Art durch den Bau des Kopfes und die Gestalt des Schwanzes, während sie ausserdem stets kleiner ist.

\section{Rhabditis Duj.}

Die artenreiche Gattung Rhabditis verbindet die freilebenden Nematoden mit denjenigen, welche als Parasiten vorkommen, indem man in derselben Arten antrifft, welche nicht frei, sondern in den Körpertheilen von anderen Thieren leben. Die Zahl der, von mir beobachteten, in der reinen Erde lebenden Formen beträgt aber nur vier und ich will mich darum, indem ich fast gar keine Untersuchungen über die anderen Arten angestellt habe, darauf beschränken, den, diesen vier Formen gemeinsamen Bau zu schildern. Am Ende werde ich schliesslich die jetzt bekannten Arten zusammenstellen. Was nun die vier erwähnten Formen betrifft, so sind es meist plump gestaltete, selten einiger Massen schlanke Thiere, deren Körper sich nach vorn hin allmälig verschmälert, und nach hinten in einen mehr oder weniger verlängerten, spitzig endigenden Schwanz ausläuft. Die Cuticula ist glatt oder geringelt; eine Seitenmembran wurde bei zwei Arten beobachtet. Das Kopfende ist meist abgesetzt; es ist entweder abgerundet, ohne Lippen, Borsten oder Papillen, oder es wird von drei, oder sechs Lippen aufgebaut, welche Papillen oder Borsten tragen. Die Mundhöhle ist derjenigen einiger Plecti ähnlich und stellt eine dreiseitige, chitinwändige Rölre dar, welche meist in ihrer ganzen Länge den gleichen Durchmesser hat. Sie führt in den muskulösen Oes., an welchem man meist zwei Anschwellungen beobachtet, von welchen die hintere ein ächter Bulbus mit kräftigem Zahnapparat ist, der nach Bütschli (XX, pag. 99) nicht etwa eine Kau-, sondern eine Pumpvorrichtung darstellt; das innere Chitinrohr des Oes. wird von drei Platten gebildet. Die Darmwand wird von zwei Zellenreihen aufgebaut. Gleich vor dem hinteren Bulbus umfasst der immer deutliche Nervenring den Oes. und etwa auf gleicher Höhe oder ein wenig nach hinten mündet das Gefüsssystem.

Die weibl. Geschlechtsöffnung liegt meist ungefähr in der Körpermitte, selten ist dieselbe nach hinten gerückt; in diesem Falle war die Geschlechtsröhre einseitig, während bei den anderen die Genitalien paarig symmetrisch, sich an beiden Seiten der Vulva ausstrecken, mit umgeschlagenen Ovarien.

Nur von einer Art beobachtete ich das Männchen; dasselbe besitzt eine, den Schwanz nicht 
umfassende Bursa mit Papillen, Spicula ohne accessorische Stücke, während der Bau der Geschlechtsröhre mir unbekannt blieb. Eine Schwanzdrüse fehlt.

Fundort und Lebensweise. Wie schon erwähnt, wurden meine vier Arten alle in der reinen feuchten Erde angetroffen, also nie in faulenden Substanzen. Mit Ausnahme der Rhabditis monohystera, kamen die Arten mir nur sehr selten vor.

Verzeichniss von allen bis jetzt beschriebenen Arten der Gattung Rhabditis Duj. ${ }^{1}$ ).

A. Als Parasiten lebende, abweichend gebildete Arten:

R. flexilis Duj., aus den Speicheldrüsen von Limax cinereus. (Vergl.: Schneider, XII, pag. 156, Taf. X, Fig. 1). Deutschland, Frankreich.

"Angiostoma Duj., aus dem Darme von Limax ater. (Vergl.: Schneider, XII, pag. 15\%, Taf. X, Fig. 2). Deutschland, Frankreich:

" me mbranosa Schn., aus dem Darme eines Brasilianischen Frosches. (Vergl.: Schneider, XII, pag. 15\%, Taf. XI, Fig. 10).

B. Arten, welche in feuchter Erde und in faulenden Substanzen leben, und hermaphrodit sind:

R. dolichura Schn. (Schneider, XII, pag. 315, Taf. X, Fig. 10). Deutschland.

„ dentata Schn. (Schneider, XII, pag. 315, Taf. X, Fig. 7). Deutschland.

„ foecunda Schn. (Schneider, XII, pag. 315, Taf. X, Fig. 11). Deutschland.

" Leuckarti Vernet. (Vernet, XVIII).

C. Abweichend gebaute Arten aus faulenden Pilzen:

R. Schneideri Btsli. (Bütschli, XX, pag. 116, Taf. X, fig. 63 $\alpha$, Taf. XI, fig. 63b). Deutschland.

„Clausii Btsli. (Bütschli, XX, pag. 118, Taf. X, fig. 62a-b). Deutschland.

D. Im Meere lebende Art.

R. marina Bast. (Bastian VII, pag. 129, Pl. X, Fig. 60-62). England.

1) In einem werthrollen Aufsatze: „Ueber die Lebensgeschichte der sog. Anguillula stercoralis und deren Beziehungen zu der sog. Ang. intestinalis", in den Berichten der math.ppys. Classe der Königl. Sächs. Gesellschaft der Wissenschaften 1882 erschienen, trennt Leuckart neuerdings einige, bisher zu den Rhabditiden gestellte, vornehmlich durch ihre beterogone Entwickelungsweise characterisirte Thieren von denselben unter dem neuen Namen Rhabdonema ab, und zwar die Ang. stercoralis und intestinalis, von welchen die erste eine im Freien sich entwickelnde Zwischengeneration aus dem Entwickelungscyclus der zweiten repräsentirt, als Rhabd. strongylö̈des, und weiter die beiden, bis jetzt als Ascaris nigrovenosa und rubrovenosa bekannten Formen aus den Lungen von Rana temporaria und Bufo cinereus. 
E. Arten, meist aus feuchter Erde und faulenden Substanzen, von welchen beide Geschlechter bekannt sind:

R. ornata Bast. (Bastian, VII, pag. 130, Pl. X, Fig. 65-67). England.

" acris Bast. (Bastian, VII, pag. 130, Pl. X, Fig. 68-70.) England.

" terricola Duj. (Vergl.: Pérez, XIII). Frankreich.

» strongyloides Schn. (Schneider, XII, pag. 152, Taf. X, Fig. 9). Deutschland.

” teres Schn. (Schneider, XII, pag. 153, Taf. X, Fig. 8). Deutschland.

” papillosa Schn. (Schneider, XII, pag. 153, Taf. XI, Fig. 3). Deutschland.

„ Pellio Schn. (Schneider, XII, pag. 154, Taf. XI, Fig. 11 und Bütschli, XX, pag. 112, Taf. IX, Fig. 59a-d, Taf. X, Fig. 59e). Deutschland.

”brevis pin a Claus. (Claus, Ueber einige... etc. Zeitschr. f. w. Z. Bd. XII, S. 354). Deutschland.

„ oxyuris Claus. (Claus, 1. c.). Deutschland.

, pellioides Btsli. (Bütschli, XX, pag. 111, Taf. XI, Fig. 66). Deutschland.

„Bütschlii d. M. (de Man, XXVI, pag. 7\%, Pl. IX, Fig. 36a-d). Holland.

" agilis v. Linst. (von Linstow, XXIX, pag. 14, Taf. II, Fig. 36 und 37). Deutschland.

, fluviatilis Btsli. (Bütschli, XXV, pag. 365, Taf. XXIV, Fig. 8). Deutschland.

„ curvicaudata Schn. (Schneider, XII, pag. 158, Taf. X, Fig. 4). Deutschland.

„ producta Schn. (Schneider, XII, pag. 158, Taf. X, Fig. 5). Deutschland.

„ inermis Schn. (Schneider, XII, pag. 158, Taf. X, Fig. 6). Deutschland.

„ macrolaima Schn. (Schneider, XII, pag. 159, Taf. XI, Fig. 5). Deutschland.

" elongata Schn. (Schneider, XII, pag. 159, Taf. X, Fig. 3). Deutschland.

„ aspera Btsli. (Bütschli, XX, pag. 113, Taf. IX, Fig. 58a-e). Deutschland.

" longicaudata (Bast.) Btsli. (Bastian, VII, pag. 130, Pl. X, fig. 63 und 64 und Bütschli, XX, pag. 114, Taf. X, Fig. $60 a-e$, Taf. XI, fig. 65a-b). England, Deutschland.

" intermedia d. M. (de Man, XXXV, pag. 5\%). Holland.

"gracilicauda d. M. (de Man, XXVI, pag. 79, Pl. IX, Fig. 3\%a-e). Holland.

„ macroura v. Linst. (von Linstow, XXXIII, pag. 16\%, Taf. XI, Fig. 5). Deutschland.

» heterura Örley. (Örley, XXXIV, pag. 164, Taf. III, fig. 12). Ungarn.

F. Arten aus feuchter Erde, von welchen man bis jetzt nur das Weibchen kennt:

R. hrevispina Btsli. (nec Claus). (Bütschli, XX, pag. 104, Taf. XI, Fig. 55). Deutschland.

„ filiformis Btsli. (Bütschli, XX, pag. 106, Taf. IX, Fig. 56). Deutschland. Holland.

” monohystera Btsli. (Bütschli, XX, pag. 106, Taf. VIII, Fig. 53a-b). Deutschland. Holland.

Die vier, von mir aufgefundenen Arten unterscheiden sich durch die folgenden Charactere:

1. Grössere Art $(1,1 \mathrm{~mm}$.); Kopfende trägt drei Lippen mit sechs kaum hervorragenden Papillen, ohne Borsten; die weibl. Geschlechtsorgane sind paarig . 2. brevispina. 
Kleinere, höchstens $0, y \mathrm{~mm}$. lange Arten . . . . . . . . . . . . . 2.

2. Kopfende mit Borsten . . . . . . . . . . . . . . . . . 3.

Kopfende halbkugelförmig, ohne Lippen oder Borsten; Schwanz des Weibchens verlängert, haarfein auslaufend . . . . . . . . . . . 4. filiformis.

3. Weibl. Geschlechtsorgane unpaar; Schwanz des Weibchens kegelföımig, zugespitzt . . . . . . . . . . . . . . . . . 1. monohystera.

Weibl. Geschlechtsorgane paarig; Schwanz des Weibchens verschmälert sich bald hinter dem After plötzlich, und läuft dann sehr fein fort. . . . . . 3. intermedia.

1. Rhabditis monohystera Btsli.

Bütschli, XX, pag. 106, Taf. VIII, Fig. 53a-b.

de Man, XXVI, pag. $\% 6$, Pl. IX, Fig. 35.

Taf. XVIII, Fig. 78.

\% unbekannt, ㅇ $0,6 \mathrm{~mm}$. (nach Bütschli sogar 0,7 mm.). $\alpha=20 . \beta=41 / 2 \cdot \gamma=\gamma-9$.

Es weicht diese Rhabditis von den drei anderen gleich durch die nach hinten gerückte Lage der weibl. Geschlechtsöffnung und die einseitige Geschlechtsröhre ab. Es hat das Thier eine plumpe Gestalt, und der Körper verschmålert sich nach beiden Seiten, besonders aber nach hinten, wo es spitz ausläuft. Die fein geringelte Cuticula trägt eine Seitenmembran. Das Kopfende ist abgesetzt, und besteht aus sechs abgerundeten Lippen, von welchen jede eine mässig lange Borste trägt. Die röhrenförmige, ziemlich lange Mundhöhle zeigt überall den gleichen Durchmesser (Fig. 78a), der Oes. hat eine grosse, ovale, mittlere Anschwellung und endigt mit kräftigem hinterem Bulbus. Vor diesem liegt unmittelbar der sehr deutliche Nervenring, während sich hier auch der Gefässporus befindet. Die weibl. Geschlechtsöffnung ist sehr weit nach hinten gerückt und ungefähr 1/4 der Gesammtlänge vom Hinterende entfernt; ilire Entfernung vom After beträgt (bei den, von mir beobachteten Exemplaren) stets etwas mehr ats die Länge des Schwanzes. Die Geschlechtsröhre ist nach vorn hin gestreckt, unpaar; zwei Eier beobachtete ich im Uterus. Der Schwanz ist kegelförmig, zugespitzt.

Fundort und Lebensweise. Wie schon aufgemerkt wurde, ist diese Art die häufigste von allen einheimischen, in der reinen Erde lebenden Phabditiden und sie bewohnt die feuchte, von süssem oder brackischem Wasser durchtränkte Erde der Wiesen wie auch den sandigen Dünenboden.

Geographische Verbreitung. Deutschland (Frankfurt a. M. nach Bütschli).

Fundzeit. Ich beobachtete erwachsene Exemplare während der ersten Hälfte des Jahres, wahrscheinlich aber kommen von dieser Art geschlechtsreife Individuen das ganze Jahr hindurch vor.

Anmerkung. Nach einer Betrachtung der Bütschli'schen Abbildung soll bei den von diesem Gelehrten beobachteten Thieren die Entfernung der Vulva vom After kleiner gewesen sein als die Länge des Schwanzes. 
2. Rhabditis brevispina Claus.

Claus, in Zeitschr. f. w. Z. Bd. XII, S. 354 .

Taf. XVIII, Fig. 79.

Für die Länge des or sehe Claus, l. c. - q $1,1 \mathrm{~mm}, \alpha=20 . \beta=5-5{ }^{1} /{ }_{2} \cdot \gamma=9-9^{1} /{ }_{2}$.

Diese Art hat wie die vorige, eine plumpe Gestalt und verschmälert sich ziemlich viel nach vorn, mehr noch nach hinten, wo der Körper beim Weibchen in eine feine Spitze ausläuft. Die Cuticula ist glatt, nicht geringelt. Das Kopfende ist nicht abgesetzt und wird von drei, wenig hervorragenden Lippen gebildet, auf welchen sechs sehr wenig vorstehende Papillen gefunden werden. Die ziemlich kurze, röhrenförmige Mundhöhle hat überall den gleichen Durchmesser und erreicht nur $1 / 9$ der Entfernung der Mundöffnung zum Darme. Der Oes. hat eine gedrungene Gestalt, ist in seinem vorderen Theile ziemlich dick, schwillt zu einem kraftigen mittleren Bulbus an, verengt sich darauf sehr und endigt mit grossem hinterem Bulbus, der einen normalen Klappenapparat umfasst. Der Gefässporus liegt bei den, von mir beobachteten Thieren, an der vorderen Grenze des hinteren Bulbus; Claus sah ihn etwas mehr nach vorn gerückt. Die körnige Darmwand erscheint nicht dunkel bei durchfallendem Lichte, sondern hell. Die weibl. Geschlechtsöffnung liegt ein wenig hinter der Mitte, und die weibl. Geschlechtsorgane sind paarig symmetrisch, mit, bis in die Nähe der Vulva zurückgeschlagenen Ovarien; der, hinter der Vulva gelegene Theil der Geschlechtsorgane streckt sich nur wenig weiter aus als die halbe Entfernung zwischen Geschlechtsöffnung und After. Der Schwanz ist allmälig verschmälert, läuft sehr spitz zu und trăgt eine laterale Papille ungefähr in seiner Mitte. (Fig. $79 c$ und $79 d$ ).

Fundort und Lebensweise. Es bewohnt dieses seltene Thier die feuchte reine Erde der Holländischen Wiesen und es bewegt sich ziemlich lebhaft.

Geographische Verbreitung. Deutschland.

Fundzeit. Geschlechtsreife Thiere beobachtete ich im Winter. (December).

Anmerkung. Die, von Bütschli, XX, pag. 104, Taf. IX, Fig. 55, als brevispina beschriebene Art ist eine andere und unterscheidet sich besonders durch die mehr beträchtliche Ausdehnung der Genitalien und einen verhältnissmässig kürzeren Schwanz.

3. Rhabditis intermedia d. M.

Taf. XIX, Fig. 80 .

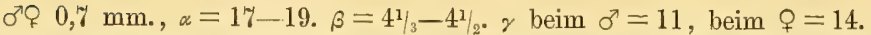

Auch diese Art ist selı plump gestaltet und verschmälert sich nach beiden Körperenden hin. Wahrscheinlich ist die Cuticula glatt, ungeringelt. Das Kopfende ist abgesetzt und wird von sechs Lippen 
gebildet, von welchen jede ein feines Börstchen trägt. Die Mundhöhle (Fig. 80a) ist verhältnissmässig weit, prismatisch, chitinwändig; der Oes. ist erst cylindrisch, olne mittlere Anschwellung, wird darauf schmäler und schwillt schliesslich zu einem, einen kräftigen Klappenapparat umfassenden Bulbus an. In geringer Entfernung vor diesem liegt der Gefässporus, sowie der schräg verlaufende, deutliche Nervenring. In der Darmwand beobachtet man zahlreiche ziemlich grosse, bei durchfallendem Lichte dunkelschwarz aussehende, Körnchen. Die weibl. Geschlechtsöffnung liegt ein wenig hinter der Mitte, über die Geschlechtsorgane liegen mir aber keine Notizen vor. Beim Weibchen (Fig. 80d) verschmälert sich der Schwanz eine geringe Strecke hinter dem After plötzlich, und läuft dann sehr fein aus. Beim Männchen (Fig. 80b, 80c) endigt der Körper in eine, über die Bursa frei hinausragende, fein auslaufende Spitze; der, über die Bursa hinaiusragende Theil des Schwanzes ist ungefähr so lang wie die Bursa. Dieselbe trägt zehn Papillen, welche ungefähr so gruppirt sind wie bei Rhabditis gracilicauda d. M. (de Man, XXVI, pag. 79, Taf. IX), aber die siebente Papille (vom Vorderende der Bursa zăhlend) liegt gleich bei der achten, sodass die vier hintersten Papillen einander sehr genähert sind. Gleich bei und vor dem After liegt eine mediane Papille. Die Spicula sind ziemlich schlank.

Fundort und Lebensweise. Nur zwei Exemplare ( $\sigma^{7}$ und क) dieser wohl seltenen Art wurden von mir im sandigen Boden einer, unweit der Holländischen Dünen gelegenen Wiese aufgefunden; bis jetzt traf ich dieselbe nirgendwo sonst an.

Fundzeit. Die Thiere fand ich im Monat October 18\%.

Anmerkung. Unsere Art ist der Rhabditis longicaudata Btsli und der Rhabd. gracilicauda d. M. sehr verwandt und zwischen diesen beiden Arten mehr oder weniger intermediär.

\section{Rhabditis filiformis Btsli.}

Bütschli, XX, pag. 106, Taf. IX, Fig. 56.

Taf. XIX, Fig. 81.

$\sigma^{7}$ unbekannt, \& $0,6 \mathrm{~mm} . x=27 . \beta=4^{1 / 2}-4^{2} / 3 \cdot \gamma=4$.

Die filiformis hat eine mässig schlanke Gestalt, und verjüngt sich sehr nach vorn hin, aber noch mehr nach hinten, wo sie in einen haarfeinen Schwanz endigt. Sehr fein geringelt ist die $\mathrm{Cu}-$ ticula, welche eine sehr schmale Seitenmembran trägt. (Fig. 81c). Das Kopfende ist etwas abgesetzt, halbkugelförmig und zeigt keine Spur von Lippen oder Borsten. Die Mundhöhle (Fig. 81b) ist röhrenförmig, langgestreckt und enge und ist etwa ${ }^{1 / 6}$ der Entfernung der Mundöffnung zum Darme lang. Der Oes. (Fig. 81a) ist in seinem vorderen Theile breit, cylindrisch, mit kräftigem mittlerem Bulbus, wird darauf sehr schmal und endigt mit ziemlich kleinem hinterem Bulbus, der einen normalen Klappenapparat enthält. Den deutlichen Nervenring beobachtet man gleich hinter der mittleren Anschwellung. Die weibl. Geschlechtsöffnung liegt ein wenig vor der Mitte, und von den paarig symmetrischen Geschlechtsorganen 
ist der, hinter der Vulva gelegene Theil ein wenig weiter ausgestreckt als der halbe Abstand zwischen Geschlechtsöffnung und After. Der Sehwanz ist sehr lang, verschmälert sich bald und läuft haarfein aus. Fundort und Lebensweise. Diese niedliche. Art gehört wie die beiden vorigen zu den selteneren Rundwürmern und bewohnt die reine feuchte, von süssem Wasser durchtränkte Erde der Holländischen Wiesen. Sie zeigt lebhafte Bewegungen.

Geographische Verbreitung. Deutschland (Frankfurt a. M. nach Bütschli).

Fundzeit. Es war im Monat December, dass ich diese Thierchen beobachtete.

\section{Macroposthonia d. M.}

$$
\text { (von paxpós, gross und } \pi \dot{\sigma} \sigma \theta n \text {, Glied). }
$$

Sehr einfach gebaut ist die Gattung Macroposthonia, deren Namen ich von der verhältnissmässig grossen Länge der Spicula ableitete; durch das Fehlen einer Mundhöhle schliesst sie sich den im Anfang dieser Arbeit beschriebenen Formen an, und ich stellte sie nur hier, weil das Männchen sich, durch den Besitz einer Bursa, den bursatragenden Gruppen Rhabditis und Tylenchus nähert.

Die Macroposthonien sind plump gestaltete Thierchen, deren deutlich quergeringelte Cuticula eine Seitenmembran trägt. Das Kopfende ist gänzlich nackt, ohne Lippen, Papillen oder Borsten. Eine Mundhöhle fehlt. Oes. und Darm sind undeutlich umgrenzt, und der letztere ist bisweilen mit zahlreichen Fettkörnchen aufgefüllt. Der Gefässporus liegt beim Anfang des Darmes. Beim Männchen (es wurden die Weibchen nicht beobachtet) wird der Schwanz ganz und gar von einer breiten Bursa umfasst, auf welche sich die Ringelung der Haut fortsetzt; diese Bursa trägt keine Papillen. Die Spicula sind schlank, verhältnissmässig sehr gross, ohne accessorische Stücke. Papillen kommen beim Männchen nicht vor und eine Schwanzdrüse fehlt ebenso. Die einzige Art ist:

1. Macroposthonia annulata d. M.

Taf. XIX, Fig. 82.

o $0,51 \mathrm{~mm} . \alpha=19-22 . \beta=4-41 / 2 \cdot \gamma=10-14$.

Dem, in der Gattungsbeschreibung mitgetheilten muss noch das folgende hinzugefügt werden. Das Vorderende des plump gestalteten Körpers ist mässig verjüngt. Die Hautringe sind sehr breit und schön, und die Seitenmembran ist ziemlich schmal. Der Oes. ist wahrscheinlich cylindrisch, ohne Erweiterungen und undeutlich umgrenzt. Das Kopfende (Fig. 82a) ist mässig zugespitzt und zeigt einen vorderen, sehr kleinen, etwas abgesetzten, scheibförmigen Theil. Der Schwanz ist kurz, 
kegelförmig und wird ganz von der Bursa umfasst. Die grossen, etwas gebogenen Spicula sind sehr schlank und erreichen die Länge des Schwanzes (Fig. $82 b$ und $c$ ). Gleich bei und hinter dem After erhebt sich eine grosse mediane Papille, worübẹ die Spicula hingleiten.

Fundort und Lebensweise. Die Macroposthonia bewegt sich ziemlich lebhaft, ist sehr selten und bewohnt die feuchte, von süssem Wasser getränkte Erde von Wiesen und Marschgründen. Bis jetzt wurde sie nirgendwo sonst beobachtet.

Fundzit. Es war in den Sommermonaten Mai-Juli, dass diese eigenthümlichen Thiere von mir aufgefunden wurden.

\section{Rhabdolaimus d. M.}

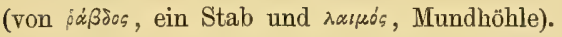

Die kleine Gruppe der Rhabdolaimen steht so ziemlich vereinzelt und der unterscheidet sich von allen anderen durch den characteristischen Bau der Mundhöhle. Es sind einfach gebaute Thiere mit ziemlich schlankem Körper, der sich nach beiden Seiten, besonders nach hinten sehr verjüngt. Die Cuticula erscheint wohl geringelt, aber ich vermuthe dass die Ringelung zu einer inneren Schicht beschränkt ist; eine Seitenmembran fehlt. Das Kopfende ist breit abgestumpft, und ganz nackt, olne Lippen, Papillen oder Borsten. In geringer Entfernung von der Vorderfläche liegen die kleinen, vielleicht kreisförmigen Seitenorgane. Die Mundöffnung führt in eine sehr enge, sehr verlängerte, von drei dünnen chitinösen Stäben begrenzte Mundhölle; die Stäbe convergiren ein wenig nach hinten zu und stehen jeder an seinem Vorderende mit einem kleinen (beweglichen?) hakenförmigen Körperchen in Zusammentiange. Der cylindrische Oes. schwillt nach hinten zu einem echten Bulbus an und der Darm zeigt nur sparsam zerstreute Körnchen. Die weibl. Geschlechtsorgane, deren Ausmündungsöffnung der Körpermitte genăhert ist, sind wahrscheinlich unpaar, wenngleich sie an beiden Seiten der Vulva ausgestreckt liegen. Beim Männchen fehlen die Papillen und die Spicula sind plump, ohne eigentliche accessorische Stücke; nur beobachtet man zwei kleine chitinöse Verdickungen in der Wand der Kloake, über welche die Spicula hingleiten. Eine Schwanzdrüse ist vorhanden und besitzt ein kegelförmiges Ausführungsröhrchen.

Fundort und Lebensweise. Von den zwei Arten dieser Gattung bewohnt die eine das süsse Wasser, die andere die feuchte Erde; es sind lebhafte, häufig vorkommende Thiere. Sie lassen sich durch die folgenden Charactere unterscheiden:

1. Ausführungsröhrchen der Schwanzdrüse kurz, $1^{1 / 2}$ Mal so lang als breit. Süsswasserbewohner . . . . . . . . . . . . . . 1. aquaticus. 
Ausführungsröhrchen der Schwanzdrüse sehr verlängert, viermal so lang als breit.

Lebt in der Erde. . . . . . . . . . . . . . 2. terrestris.

1. Rhabdolaimus aquaticus d. M.

Taf. XIX, Fig. 83.

$\sigma^{7}$ unbekannt, 우 $0,6 \mathrm{~mm} . \alpha=35-40 . \beta=5 . \gamma=3{ }^{2}-4$.

Die Gestalt dieses Thieres ist sellr schlank, und der Körper verjüngt sich viel mehr nach hinten als nach vorn $\mathrm{zu}$; keine Borsten sind über seiner Oberfläche zerstreut. Das Kopfende (Fig. 83a) ist abgestumpft und die Mundhöhle ist $1 / 4$ der Entfernung der Mundöffnung zum Darm lang. Der Oes. ist cylindrisch, endigt mit mässig grossem, ovalem, muskulösem Bulbus, dessen Lumen viel weiter ist als im eylindrischen Theile (Fig. 83b), und der Nervenring liegt ein wenig hinter seiner Mitte. Die weibl. Geschlechtsöffnung befindet sich ein wenig vor der Mitte und die Geschlechtsorgane, welche, wie ich vermuthe, unpaar sind, liegen an beiden Seiten der Vulva ausgestreckt. Der Schwanz ist schlank, verschmälert sich allmälig und endigt mit kurzem, kegelförmigem Ausführungsröhrchen der Schwanzdrüse, das kaum $1 \frac{1}{2}$ mal so lang ist als breit.

Fundort und Lebensweise. Es bewohnt diese lebhafte Art das süsse Wasser der Holländischen Teiche und Gräben; das Männchen fand ich nicht. Bis jetzt wurde sie nirgendwo sonst beobachtet.

Fundzeit. Erwachsen ist das Thier im Frühling (April, Mai); über das Vorkommen in den anderen Jahreszeiten liegen mir keine Angaben vor.

\section{Rhabdolaimus terrestris d. M}

Taf. XX, Fig. 84 .

ơ $0,45 \mathrm{~mm} . \alpha=2 \% \cdot \beta=4^{1} / 2 \cdot \gamma=3-3 \frac{1}{1} / 2$.

Der, in der Erde lebende Rhabdolaimus erreicht nie die Grösse seines, im Wasser sich aufhaltenden Verwandten, und hat dabei eine etwas weniger schlanke Gestalt. Das Kopfende ist wie beim aquaticus gebaut; die sehr kleinen Seitenorgane, welche man am besten in der Profilansicht beobachtet, liegen ungefähr zur halben Höhe der Mundhöhle. Der Oes. ist verhältnissmässig länger und endigt mit mehr knopfartig gestaltetem Bulbus (Fig. 8tb). Die weibl. Geschlechtsöffnung liegt etwas vor der Körpermitte, und auch die Geschlechtsorgane verhalten sich wie beim aquaticus. Das Ausführungsröhrchen der Schwanzdrüse (Fig. 84e) aber ist beim terrestris selır verlängert, kegelförmig, zugespitzt, und viermal so lang als breit. Das Männchen ist dem Weibchen ganz ähnlich; die männliche Geschlechtsröhre streckt sich über zwei Drittel der Länge des Darmes aus. Die Spicula (Fig. 84d) sind plump, zeigen einen buchtigen Vorderrand, ohne Verdickungsstreif und besitzen etwa die Länge von 1/60 mm.; 
zwei kleine chitinöse Verdickungen beobachtet man in der Nähe des Afters in der Spiculascheide, welche als accessorische Stücke fungiren.

Fundort und Lebensweise. Es gehört diese winzige Art $\mathrm{zu}$ den omnivagen Formen: nicht nur in der feuchten, von süssem oder brackischem Wasser mehr oder weniger durchtrănkten Erde unserer Wiesen, auch im sandigen Boden der Dünen- und Heidegründe kommt dieses Thier sehr häufig vor; das Männchen ist aber sehr selten. Es bewegt sich lebhaft und hat die Gewohnheit den schlanken Schwanz öfters gerade ausgestreckt zu halten, ohne ihn zu beugen.

Geographische Verbreitung. Deutschland (Laibach).

Fundzeit. Geschlechtsreife Thiere beobachtete ich im Frühling, im Sommer und im Herbst.

\section{Odontolaimus d. M.}

(von ỏou's, Zahn und rasıós, Mundhöhle).

Die Odontolaimen haben einen schlanken Körper, mit geringelter Cuticula, ohne Seitenmembran. Das Mundende ist abgerundet, ohne Lippen oder Papillen, aber mit Borsten gewaffnet. Die Mundöffnung führt in ein kurzes, dünnwändiges Vestibulum, dann in die Mundhöhle; diese letztere ist selır langgestreckt, selır enge, verjüngt sich allmälig nach hinten und hat chitinöse Wände, welche am vorderen Theile an der dorsalen Seite etwas dicker sind als sonst; beim Anfang der Mundhöhle liegt ein dreieckiger, dorsal und median gestellter, chitinöser Zahn. Die chitinöse Wand der Mundhöhle wird noch von einer breiten, wahrscheinlich fibrillären Wand umgeben, welche am vorderen Theile breiter ist, aber sich nach hinten regelmåssig verschmälert. Die Seitenorgane sind gross, kreisförmig und liegen ein wenig vor der Mitte der Mundhöhle. Der cylindrische Oes. schwillt hinten plötzlich an. Die weibl. Geschlechtsorgane liegen an beiden Seiten der Vulva ausgestreckt, sind daher wahrscheinlich zweitheilig. Eine Schroanzdrüse fehlt. Das Männchen ist unbekannt.

Die einzige Art nannte ich:

1. Ondontolaimus chlorurus d. M.

Taf. XX, Fig. 85 .

ㅇ $0,85 \mathrm{~mm} . \alpha=35-40 . \beta=6 . \gamma=4$.

Der Körper dieser Art ist schlank, nach vorn wenig verschmälert, mit hie und da über der Oberfläche zerstreuten Börstchen. Die Ringelung der Cuticula ist sehr fein. Das Kopfende (Fig. 85a, (856 trägt zehn Borsten, von welchen die vier submedianen kleiner sind als die anderen. Die Mundhöhle ist ungefähr $1 / 4$ des Abstandes zwischen der Mundöffnung und dem Anfang des Darmes lang; ihr Bau 
wurde schon oben beschrieben. Die Seitenorgane stellen eine schüsselförmige Vertiefung im Integument dar. Der Oes. ist in seinem vorderen Theile sehr enge, wird ein wenig linter seiner Mitte plötzlich erweitert und ist hier mit radiären Muskelfbrillen versehen. Die weibl. Geschlechtsöffnung befindet sich in der Körpermitte und die Genitalien liegen an ihren beiden Seiten ausgestreckt. Der Schwanz (Fig. 85c) ist schlank, verjüngt sich allmälig und läuft haarfein aus, an seinem Hinterende stets nach der Bauchseite umgebogen; im vorderen Theile des Schwanzes beobachtet man zahlreiche Körnchen, welche fast immer eine eigenthümliche gelblichgrüne Färbung zeigen.

Fundort und Lebensweise. Diese Art, welche ihren Namen chlorurus von der meist gelblichgrünen Färbung der, im Schwanze liegenden Körnchen empfangen hat, bewohnt ziemlich häufig, die feuchte, oder von süssem Wasser mehr oder weniger imbibirte Erde der Wiesen und Marschgründe Hollands. Sie bewegt sich lebhaft.

Geographische Verbreitung. Deutschland (Erlangen, Laibach). Schweiz (Altdorf).

Fundzeit. Erwachsene Thiere wurden fast das ganze Jahr hindurch beobachtet.

Anmerkung. Ich beobachtete auch Individuen, bei welchen die weibl. Geschlechtsöffnung sehr weit nach vorn gerückt war, ungefähr 1/3 der Gesammtlänge vom Kopfende entfernt; ihre Genitalien waren einseitig, unpaar, und streckten sich hinten der Vulva aus und der Schwanz war viel länger, 1/3 der Gesammtlänge erreichend; ich kann jetzt nicht sagen, ob diese Thiere nur einer Varietät des chlorurus oder wohl einer anderen Art zugehören.

XXX. Diphtherophora d. M.

(von $\delta \phi \theta_{\varepsilon}^{\prime} \rho \alpha$, eine Membran und $\Phi^{\prime} \rho \omega$, tragen).

Obwohl der Bau der Mundhöhle bei der Diphtherophora mir nicht völlig deutlich wurde, so unterliegt es doch keinem Zweifel, dass diese Form durch denselben sowie durch einige andere Eigenschaften genügend characterisirt ist.

Der Körper unseres Thieres ist mässig schlank, mit wenig verschmälertem Vorderende. Die glatte, ungeringelte Cuticula trägt keine Seitenmembran. Die Seitenfelder sind fein gekörnt. Das Kopfende (Fig. 86a) zeigt keine Lippen oder Borsten, sondern ist mit Papillen ausgestattet; Seitenorgane sind vorhanden. Die Mundöffnung fülırt in eine ovale, längliche, taschenförmige Höhle, worin die eigenthïmlichen chitinisirten Thile, welche die Mundhöhle characterisiren, gelegen sind: es sind drei, einander genăherte, rechte Stäbchen, von welchen jedes nach hinten in ein Knöpfchen ausläuft und von welchen die beiden dorsalen ein wenig mehr nach hinten zu verlängert sind als das kürzere ventrale; an ihrem Vorderende scheinen sie in Zusammenhang zu stehen mit einem chitinösen dreieckigen Käppchen, während sie an ihren geknöpften Hinterenden mit den drei Seitenwänden des Lumens des Oes. ver- 
bunden sind. Der enge Oes. schwillt an seinem Hinterende taschenförmig an und sein chitinwändiges Lumen ist überall, also auch im erweiterten Ende, sehr enge. Der Bau des Darmes blieb unklar, seine Wand enthält öfters kleine Häufchen zerstreut liegender Fetttröpfchen. Die weibl. Geschlechtsofffnung liegt ungefähr in der Mitte und die Genitalien sind paarig symmetrisch. Der Bau der männlichen Geschlechtsröhre blieb mir unbekannt; die Spicula sind wenig gebogen, ohne accessorische Stücke und wahrscheinlich liegt eine einzelne mediane Papille beim Männchen vor dem After. Auch eine Schwanzdrüse scheint bei diesen Thieren zu fehlen.

Fundort und Lebensweise. Die, die feuchte Erde bewohnenden Diphtherophoren haben die eigenthümliche Eigenschaft, die Häutungsmembran nur selır spät abzustossen und dieselbe noch, den Körper umhïlllend, bei sich zu tragen, wenn die Thiere schon ganz erwachsen und die Geschlechtsorgane schon ganz entwickelt sind.

\section{Diphtherophora communis d. M.}

Taf. XX, Fig. 86 .

$\sigma^{7} \bigcirc 0,75 \mathrm{~mm}$. \& beim $\sigma^{7}=30-35$, beim $ᄋ=25-2 \%$. $\beta=4-5 . \gamma$ beim $\sigma^{7}=12-14$, beim q $=12-15$.

Der wenig schlanke Körper ist beim Männchen, wie öfters der Fall ist, schlanker als beim Weibehen und wird nach vorn hin wenig schmäler mit abgestumpftem Kopfende. Noch lange Zeit nach der völligen Entwickelung der Geschlechtsorgane wird der Körper von der Häutungsmembran umgeben, welche sich durch die ziemlich schnellen Bewegungen des Thieres eigenthümlich faltet. Am abgestumpften Kopfende stehen sechs niedrige Papillen; die, fast nur in der Profilansicht sichtbaren Seitenorgane'ragen ein wenig hervor. Zahlreiche Drüsen liegen am Anfang des Darmes (Fig. 86b). Die Vulva liegt in der Körpermitte und die weibl. Geschlechtsorgane strecken sich an den beiden Seiten derselben ziemlich weit aus. Bei beiden Geschlechtern hat der Schwanz die gleiche Gestalt, indem er kegelförmig, kurz und an seinem Hinterende meist eckig nach der dorsalen Seite gebogen ist. Die Spicula sind ziemlich schlank, etwas gebogen; zwei lineare locale chitinöse Verdickungen in der Spiculascheide fungiren als accessorische Stücke. Beim inneren Ende der Spicula liegt eine einzelne mediane kleine Papille vor dem After.

Fundort und Lebensweise. Diese merkwürdige Art gehört zu den ziemlich viel vorkommenden Formen und lebt in der feuchten, von süssem oder brackischem Wasser imbibirten Erde unserer Wiesen.

Geographische Verbreitung. Deutschland (Laibach). Frankreich (Montpellier).

Fundzeit. Geschlechtsreif wurde diese Art im Winter beobachtet (November-April). 


\section{Tylolaimophorus d. M.}

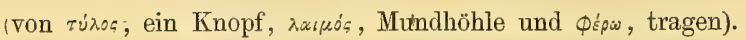

Bei diesen Thieren ist der Körper ziemlich schlank, und verjüngt sich wenig nach beiden Seiten hin. Die Cuticula ist geringelt, ohne Seitenmembran, und trägt nirgendwo Borsten. Das Kopfende (Fig. $8 \% a, 87 b$ ) ist abgerundet; sehr kleine stabförmige Papillen umgeben die Mundöffnung und diese werden von einem, etwas mehr nach hinten zu gelegenen Kreise von kegelförmigen Papillen umfasst. Im Kopfende liegt ein, wie bei den Tylencholaimen gebauter, also ein deutliches Lumen zeigender Mundstachel, der an seiner vorderen Spitze von einem Käppchen umgeben scheint zu sein, welches aus drei hurzen, gebogenen, an ihren Vorderenden verbundenen, Stäbchen gebildet wird. Die quergestellten, ovalen Seitenorgane sind sehr nach vorn gerückt, liegen ungefähr auf der Höhe des erwähnten Käppchens, und stellen in der Profilansicht eine Vertiefung im Integument dar. Der enge, nicht muskulöse Oes. ist an seinem Hinterende taschenförmig erweitert. Der zellige Darm hat eine, mit zahlreichen kleinen Körnchen gefüllte Wand und trägt am After einen kurzen, im Schwanze liegenden Blinddarm (Fig. 8\%c). Im Darme beobachtete ich mehrere ovale oder kugelrunde Nahrungsbälle, welche durch seine sehr starke Bewegung fortwährend hin und wieder bewogen werden; besonders im hinteren Theile des Darmes sah ich zahllose, fortwährend sich bewegende, äusserst kleine Körnchen. Der Nervenring liegt etwas hinter der Mitte des Oes. Die weibl. Geschlechtsorgane sind paarig symmetrisch. Eine Schwanzdrüse fehlt. Das Männchen blieb mir unbekannt.

Die einzige Art ist:

1. Tylolaimophorus typicus d. M.

Taf. XX, Fig. $8 \%$.

ㅇ $0,8 \mathrm{~mm}, \alpha=25 . \beta=51 / 2 . \gamma=30$.

Einen mässig schlanken, nach beiden Seiten wenig verschmälerten Körper hat der Tylolaimophorus; seine Haut ist fein quergeringelt. Das Kopfende ist nicht abgesetzt, abgestumpft, mit gebogener Vorderfläche; wahrscheinlich stehen sechs sehr kurze stabförmige Papillen gleich um die Mundöffnung, während sechs kurze kegelförmige Papillen den Rand der Vorderfläche des Mundendes schmücken. Der Mundstachel hat ungefähr die Länge von $1 / \%$ der Entfernung der Mundöffnung zum Darme ${ }^{1}$ ). Der Oes. hat ein sehr enges Lumen. Die weibl. Geschlechtsöffnung liegt etwas hinter der Körpermitte und die Geschlechtsorgane dehnen sich ziemlich weit nach beiden Seiten aus. Der Schwanz (Fig. $87 c$ ) ist kurz, abgerundet.

1) Unter der Länge des Mundstachels wird hier, wie auch bei den Gattungen Tylopharynx, Tylencholaimus, Aphelenchus und Tylenchus die Entfernung zwischen der Mundöffnung und dem binteren Ende des Stachels verstanden. 
Fundort und Lebensweise. Das lebhafte Thier, dessen Männchen mir unbekannt blieb, bewohnt den sandigen Boden der, im Osten der Niederlande gelegenen Heidegründe, wo ich es mit Tylencholaimus mirabilis gemeinschaftlich antraf.

Geographische Verbreitung. Bis jetzt nirgendwo sonst beobachtet.

Fundzeit. Ich traf diese Thiere im Monat Juli geschlechtsreif an.

\section{Tylopharynx d. M.}

de Man, XXVI, pag. 39.

Eine erneute Beobachtung der seltenen Tylopharynx bestätigte die, schon früher von mir ausgesprochene Vermuthung, dass in der eigenthümlichen Mundhöhle dieses Thieres ein sehr altes Verhalten bewahrt geblieben ist, von welchem sich die Mundhöhle der Tylencholaimen, Tylenchen und Aphelenchen ableiten lässt.

Bei Tylopharynx findet man einen schlanken Körper, der sich nach beiden Seiten hin verjüngt; eine feine Querringelung ist vorhanden. Der vorderste Theil des Kopfendes ist ein wenig abgesetzt, knopfförmig, ohne Lippen, Papillen oder Borsten, und stellt die Kopfregion dar, worin sich das Vestibulum befindet. Die Mundhöhle, ein enges, woll prismatisches Rohr wird von drei, geradlinigen Chitinstäben begrenzt, welche jeder, an ihrem hinteren Ende einen starken Chitinkugel tragen, und nach vorn hin zusammenkommen, wo sie die feine vordere Oeffnung der Mundhöhle umschliessen; nach linten zu setzen sie sich in die, das Oesophageallumen bekleidende Chitinwand continuirlich fort. Der Oes. hat einen muskulösen, mittleren Bulbus und schwillt an seinem hinteren Ende taschenförmig an. Ein ventraler Gefässporus fehlt, ebenso finden sich keine Seitenorgane. Die weibl. Geschlechtsorgane sind paarig.symmetrisch und die mässig grossen Ovarien umgeschlagen. Die Spicula werden von einem accessorischen Stücke begleitet; zahlireiche laterale Papillen liegen am Schwanzende des Männchens, so wohl vor wie hinter dem After. Eine Schwanzdrüse fehlt. Die einzige Art ist die

1. Tylopharynx striata d. M.

de Man, XXVI, pag. 40, Pl. VI, Fig. 15a-d.

Tat. XXXIV, Fig. 139.

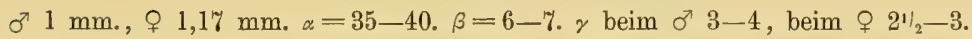

Die Tylopharynx ${ }^{1}$ ) besitzt einen schlanken Körper, der sich nach vorn hin ziemlich stark ver-

1) Die Tylopharynz besitzt, wie es mir scheint, eine sehr grosse Uebereinstimmung, sowohl in ihrem äusseren Vorkommen wie sogar in Bezug auf manchen Theilen ihrer inneren Organisation, mit dem von Bütschli, XXI, Seite 20, beschriebenen Aphelenchus foetidus aus Kuhmist. Vergl. Seite 136. 
jüngt und nach hinten in einen langen, haarfeinen Schwanz ausläuft. Die Cuticula ist sehr fein geringelt, ohne Seitenmembran und über ihrer gesammten Oberfläche verlaufen melirere erliabene Linien, auf welchen sich die Querringelung fortsetzt, und durch welche die Cuticula längsgestreift erscheint: ihre Entstehung am vorderen Kopfende erkennt man auf den Figuren 139a und 139b. Die Kopfregion ist ein wenig abgesetzt und zeigt vier submedian verlaufende, cuticuläre Verdickungen, wodurch dieselbe ein mehr oder weniger viereckiges Vorkommen empfängt. Den eigenthümlichen Bau der Mundhöhle, welche schon oben beschrieben wurde, erkennt man am besten bei einer medianen Lage des Thieres, weil ihr Bau in der Profilansicht (Fig. 139a) schwer zu verstehen ist; (die früher (XXVI, pag. 40) von mir gegebene Beschreibung und Abbildung ist also unrichtig!). Der Oes. besitzt einen mittleren sehr muskulösen Bulbus, dessen Lumen weiter ist als dasjenige des, vor ihm liegenden cylindrischen Theiles des Oes.; sowohl hier wie im Bulbus wird das Lumen von einer deutlichen Chitinwand begrenzt; hinter dem Bulbus ist der Oes. wieder sehr enge und schwillt nach hinten taschenförmig an. Die Darmwand ist mit zahlreichen kleinen Körnchen aufgefüllt. Die reibl. Geschlechtsöffnung liegt etwas mehr als 1/3 der Gesammtlänge von der Mundöffnung entfernt; die Geschlechtsorgane sind paarig symmetrisch, und strecken sich ziemlich weit aus, mit zuxückgeschlagenen Ovarien.

Die Spicula sind schlank, gebogen und von einem accessorischen Stücke begleitet. Beim Männchen stehen drei laterale Papillen vor dem After, von welchen die zwei vorderen der Mittellinie der Bauchseite genähert sind und die hinterste ganz lateral nicht weit vom After entfernt gelegen ist. Eine vierte Papille liegt ein wenig hinter der Mitte des vorderen breiten Theiles des Schwanzes und schliesslich beobachtete ich noch einige wenige Papillen dort, wo der kurze breite Theil des Schwanzes in den sehr langen, haarfein auslaufenden Endtheil übergeht. Bei beiden Geschlechtern hat der Schwanz dasselbe Vorkommen.

Fundort und Lebensweise. Diese äusserst seltene Art beobachtete ich zuerst in feuchter Erde einer unweit Leiden gelegenen Wiese, sowohl Männchen wie Weibchen; mehrere Jahre später fand ich ein erwachsenes Weibchen zurück, in sehr feuchter, von brackischem Wasser durchtränkter Erde einer Wiese, in welcher auch Tylench. lamelliferus, Monoh. agilis, Cyathol. intermedius lebten. In anderen Ländern wurde das Thier nocht nicht aufgefunden.

Fundzeit. Sowohl im Frühling (April) wie im Herbst (November) geschlechtsreif.

\section{Tylencholaimus d. M.}

de Man, XXVI, pag. 42.

Die kleine Gruppe der Tylencholaimen unterscheidet sich durch den Bau des Mundstachels und des

Oes. von allen anderen mir bekannten freilebenden Rundwürmern. Es sind mehr oder weniger 
schlanke Thiere, deren Körper sich nach vorn hin wenig verjüngt und nach hinten in einen kurzen, meist abgerundeten Schwanz endigt. Die Cuticula ist glatt, vielleicht aber eine innere Schicht geringelt, trägt keine Seitenmembran und Borsten kommen auf derselben nicht vor. Nach Bütschli soll die Muskulatur diejenige eines Polymyariers sein. Das vordere Kopfende ist ein wenig abgesetzt, wird nicht von Lippen gebildet, sondern ist mit Papillen ausgestattet. Gleich hinter ihm liegt im vorderen Körpertheile ein characteristisch gebauter Mundstachel; derselbe bestelt aus drei, sich nach vorn hin mit einander vereinigenden, an ihrem linteren Ende geknöpften Chitinstäben und umschliesst also ein deutliches Lumen: die Mundlöhle der Tylencholaimen. An diesem Stachel, der zweifelsohne an seiner Spitze durchbohrt ist, schliesst sich der cylindrische, in seiner vorderen Hälfte selir enge, hinten aber erweiterte Oes. an, welcher eine kräftige Muskulatur besitzt und ein dreiseitiges, chitinwändiges Lumen hat, das im erweiterten Theile viel weiter ist als in der vorderen engen Hälfte. Die Darmwand wird von polyedrischen Zellen gebildet. Ein ventraler Gefässporus fehlt, wie wahrscheinlich das Gefässsystem überhaupt. Die weibl. Geschlechtsorgane sind einseitig, unpaar und die Zahl der Eier ist sehr gering. Beim Männchen, dessen Geschlechtsröhre wohl ebenso einfach ist, beobachtet man eine mediane Reihe von wenigen Papillen vor dem After; die Spicuia haben eine plumpe Gestalt, mit centralem Verdickungsstreif; accessorische Stücke fand ich nicht. Eine Schwanzdrüse fehlt.

Fundort und Lebensweise. Die Tylencholaimen leben in der feuchten Erde an den Wurzeln von Pflanzen; es sind ziemlich häufige Thiere, und die höchst seltenen Männchen wurden nur noch von einer Art beobachtet.

Anmerkung. Wie ich schon in meiner ersten Arbeit hervorhob, sind die Tylencholaimen den Gattungen Tylopharynx, Tylenchus, und vielleicht auch Tylolaimophorus am nächsten verwandt und haben sich, mit diesen Formengruppen, aus einem gemeinschaftlichen Stamme, welchen ich unter dem Namen Tylolaimus bezeichnete, entwickelt.

Uebersicht der drei bekannten Arten der Gattung Tylencholaimus.

1. Geschlechtsröhre beim Weibchen nach vorn hin ausgestreckt . . . . . . 2. Geschlechtsröhre beim Weibchen nach hinten ausgestreckt; Schwanz kurz, abgerundet. Brackwassernematode. . . . . . . . . . . 3. Ze elandicus.

2. Grössere Art (1,1 mm.); Schwanz kegelförmig, mit abgerundeter Spitze . . 1. mirabilis. Kleinere Art (0,65 mm.), Schwanz sehr kurz, stumpf abgerundet. . . . . 2. minimus.

\section{Tylencholaimus mirabilis Btsli.}

Synon: Tylenchus mirabilis Btsl., Bütschli, XX, pag. 44, Taf. III, Fig. 14a-b.

Taf. XXI, Fig. 88.

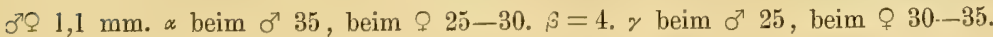


Dieser, am ersten beschriebene Vertreter unserer Gattung hat einen schlanken, nach beiden Enden hin wenig verschmälerten Körper; beim Männchen ist die Gestalt etwas schlanker als beim Weibchen. Das Kopfende (Fig. 88a) ist abgesetzt, ziemlich niedrig, scheibenförmig, mit einem Kreise von Papillen, deren es wahrscheinlich sechs giebt; der Mundstachel ist beim Männchen verhältnissmässig etwas kürzer als beim Weibchen; sein Bau ist ganz typisch. Etwa in seiner Mitte geht der. vordere enge Theil des Oes. in den hinteren erweiterten Theil über. Die Darmwand ist fein gekörnt. Oefters fand ich die ganze Leibeshöhle mit kleinen Fetttröpfchen ungleicher Grösse aufgefült, wie bei einigen Tylenchen. Die weibl. Geschlechtsöffnung liegt ein wenig melir als 1/3 der Gesammtlänge vom Hinterende entfernt; und die Geschlechtsröhre ist nach vorn hin ausgestreckt mit, nach linten umgebogenem Ovarium; im Uterus eines $0,85 \mathrm{~mm}$. langen Weibchens fand ich ein 0,08 mm. langes Ei. Die Geschlechtsorgane fehlen noch völlig bei $0,71 \mathrm{~mm}$. langen Thieren.

Beim Männchen beobachtet man eine Papille gleich vor und bei dem After, sowie drei oder vier, einander genäherte, ebenso mediane Papillen in einer, ein wenig grösseren Entfernung. Die Spicula sind plump, gebogen, mit centralen Verdickungsstreifen. Der Schwanz (Fig. 88b) ist kegelförmig, mit abgerundeter Spitze und erscheint an der dorsalen Seite ein wenig ausgehöhlt.

Fundort und Lebensweise. Es lebt der ziemlich träge mirabilis, was die Niederlande betrifft, nicht nur im sandigen Boden der, mit Erica und Calluna bewachsenen Heidegründe, sondern auch im feuchten Humus des Waldes. An diesen Stellen ist die Art gar nicht selten. Das Männchen aber traf ich nur einmal an.

Geographische Verbreitung. Deutschland (Im Schwanheimer Wald bei Frankfurt a. M., wo die Art von Bütschli entdeckt wurde).

Fundzeit. Sowohl im Winter wie im Sommer wurden erwachsene, eitragende Thiere beobachtet.

2. Tylencholaimus minimus d. M.

de Man, XXVI, pag. 43. Pl. VI, Fig. $16 a-b$.

Taf. XXI, Fig. 89.

ơ unbekannt, \& $0,65 \mathrm{~mm} . \alpha=22-30 . \beta=3 . \gamma=25 \cdot-30$.

Diese, mehr oder weniger schlank gestaltete Art ist die kleinste der Tylencholaimen und ihr Körper ist nach beiden Seiten hin ziemlich verschmälert. Das abgesetzte Kopfende ist anders gebaut wie bei der vorigen Art, ist nämlich aus zwei scheibenartigen, auf einander gestellten Theilen zusammengesetzt, und ein Kreis von kleinen Papillen schmückt die basale Scheibe. Der Mundstachel ist $1 /{ }_{12}-{ }^{1}{ }_{15}$ von der Länge des Oes. lang, und zeigt sich ähnlich gebaut wie beim mirabilis; der Oes. ist im grösseren vorderen Theile sehr enge, geht aber ein wenig hinter seiner Mitte plötzlich in den viel weiteren hinteren Theil über (Fig. 89). Die Darmwand zeigt zerstreute Häufchen von kleinen, gleich grossen 
Körnchen. Die weibl. Geschlechtsöffnung ist etwas weniger als 1/3 der Gesammilänge vom Hinterende des Körpers entfernt, und die Geschlechtsröhre dehnt sich ziemlich weit nach vorn hin aus, während das Ovarium nach linten zurückgeschlagen ist; der ganze Geschlechtstheil stellt ungefähr den, an einer Seite der Vulva gelegenen Theil der Geschlechtsorgane einer typischen Dorylaimus-art dar. Ich beobachtete nur ein einziges grosses $E i$ im Uterus, welches, bei einem $0,59 \mathrm{~mm}$. langen Thiere, etwa $0,08 \mathrm{~mm}$. lang war. Der Schwanz (Fig. 89a) ist sehr kurz, stumpf abgerundet.

Fundort und Lebensweise. Es bewohnt dieses Thierchen ziemlich häufig die feuchte, oder von süssem Wasser getränkte Erde unserer Wiesen und Marschgründe; in den Dünen- oder Heidegründen kommt es nicht vor, fand ich es wenigstens nie. Das Männchen blieb mir unbekannt.

Geographische Verbreitung. Deutschland (Erlangen, Laibach).

Fundzeit. Geschlechtsreife Thiere fand ich fast in allen Jahreszeiten, im Frühling, Sommer und Herbst.

3. Tylencholaimus Zeelandicus d. M.

de Man, XXVI, pag. 45, Pl. VI, Fig. $1 \% a-b$.

$\sigma^{7}$ unbekannt, ᄋ $1,2 \mathrm{~mm} . \alpha=30-35 . \beta=\% \cdot \gamma=35-45$.

Von den beiden schon beschriebenen Tylencholaimen unterscheidet sich der Zeelandicus gleich durch die nach vorn gerïckte Lage der Vulva und die Richtung der weibl. Geschlechtsröhre.

Er besitzt einen schlanken, nach beiden Seiten sich aber nur wenig verjüngenden Körper. Das, ein wenig abgesetzte Kopfende zeigt einen mehr oder weniger ähnlichen Bau wie bei der vorigen Art, indem man deutlich zwei, auf einander gestellte scheibenartige Theile an demselben erkennt. Der Stachel ist $1 /,-1 / 8$ der Entfernung zwischen der Mundöffnung und dem Darm lang und ist wie bei den vorigen Arten gebaut. Der vordere enge Theil des Oes. geht ungefähr in seiner Mitte plötzlich in den hinteren erweiterten Theil über. Die weibl. Geschlechtsöffnung ist, im Gegensatze zu den beiden vorigen Arten, sehr nach vorn gerïckt und $1 / 3$ der Gesammtlänge vom Kopfende entfernt; die Geschlechtsröhre streckt sich ziemlich weit nach hinten aus und ist schon bei $0,86 \mathrm{~mm}$. langen Thieren völlig entwickelt. Der Schwanz ist kurz abgerundet.

Fundort und Lebensweise. Es ist diese Art ein echter Brackwassernematode und wurde von mir bis jetzt ausschliesslich in feuchter, von brackischem Wasser getränkter Erde auf der Zeeländischen Insel Walcheren aufgefunden. Auch von dieser Art suchte ich das Männchen bis jetzt vergebens. Fundzeit. Im Frühling und im Sommer geschlechtsreif. 


\title{
XXXIV. Aphelenchus Bast.
}

\author{
Bastian, VII, pag. 121.

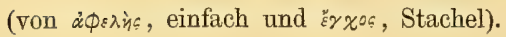

Die Aphelenchen bilden eine kleine Gruppe freilebender Rundwürmer, welche die folgenden characteristischen Eigenschaften zeigen.

Der Körper ist mehr oder weniger langgestreckt und ist, obgleich bisweilen undentlich, quergeringelt; beim, in mancher Hinsicht von den anderen Arten abweichenden Aph. foetidus beobachtete Bütschli sogar eine Längsstreifung der Cuticula; Borsten kommen auf der letzteren nicht vor. Die Seitenfelder sind wohl entwickelt und bisweilen (agricola) fein längsgestreift, eine Seitenmembran wurde nur selten beobachtet. Das Kopfende ist mehr oder weniger abgesetzt, knopfartig, selten mit Papillen versehen, welche dann aber meist sehr wenig entwickelt sind. Gleich hinter dem Kopfende, liegt der hohle Mundstachel, der, mit dem gleichnamigen Organ der Gattungen Tylencholaimus und Tylenchus homolog, öfters an seinem Hinterende geknöpft ist, während er bei anderen (z. B. beim agricola) an dieser Stelle nur einiger Massen verdickt erscheint: auch bei Aphelenchius vertretet das Lumen dieses, an seiner Spitze durchbohrten Stachels die Mundhöhle anderer Nematoden. In Bezug auf das Verhalten des Oes. weicht die Mehrzahl der Aphelenchen von den, ihnen nahe verwandten Tylenchen ab: beim foetidus hat er einen mittleren, muskulösen Bulbus, in welchem das chitinwändige Lumen erweitert ist und eine hintere, nicht muskulöse, aus wenigen grossen Zellen aufgebaute Anschwellung, worin das dünnwändige Lumen nicht erweitert ist. Von diesem, auch bei Tylenchus auftretenden Verhalten weichen die übrigen Arten ab, indem sich die Grenzen der beim foetidus vorkommenden hinteren Anschwellung und des Darmes völlig verwischen, sodass der, beim foetidus hinter dem Bulbus gelegene Theil des Oes, bei diesen Arten ein wesentlicher, vorderer Theil des Darmes wird. Diese, schon von Bütschli angegebene Auffassung wird anch durch die Lage des Gefässporus gleich hinter dem Bulbus erwiesen. Nach ihm soll sich der Darm wie bei Tylenchus verhalten und das Seitengefüss beim foetidus paarig sein; der Porus liegt, wie schon aufgemerkt wurde, stets ein wenig hinter dem Oesophagealbulbus. Während die weibl. Geschlechtsorgane beim foetidus paarig symmetrisch sind mit umgeschlagenen Ovarien, besitzen die anderen Arten nur eine unpaare, nach vorn gestreckte Geschlechtsröhre und ist der Uterus mit einern ziemlich langen hinteren Ast ausgestattet. Was das Männchen betrifft, so ist beim foetidus das blinde Ende des Hodens umgeschlagen; die Spicula haben bei den einzelnen Arten eine verschiedene Gestalt und werden bisweilen von einem schwach entwickelten accessorischen Stücke begleitet. Stets felltt den Männchen eine Bursa, aber der hintere Körpertheil derselben ist mit Papillen ausgestattet, sowohl, wie es scheint, mit medianen wie mit lateralen. Der Schwanz ist entweder kurz, abgerundet, oder mehr spitz und sogar etwas verlängert; eine Schwanzdrüse soll einigen Arten zukommen, welche an der Schwanzspitze ausmündet 
Fundort und Lebensweise. Die Aphelenchen, von welchen zehn Arten beschrieben worden, gehören zu den weniger häufig vorkommenden freilebenden Rundwürmern: sie wurden an sehr verschiedenen Stellen gefunden, in der Erde, im süssen Wasser, an den Wurzeln von Lichenen, zwischen Blattscheiden des Hafers, in faulenden Birnen, in Kuhmist und sogar eine Art im Darme einer Lacerta vivipara.

Die meisten sind aber ungenügend bekannt, und wahrscheinlich sind mehrere mit einander identisch.

Ausser den drei, von mir in den Niederlanden beobachteten, die Erde bewohnenden Arten, kennt man noch die folgenden:

Aph. avenae Bast. (Bastian, VII, pag. 122, Pl. X, Fig. 97, 98), England, zwischen Blattscheiden des Hafers.

" villosus Bast. (Bastian, VII, pag. 123, P1. X, Fig. 99-101), England, mit Plectus parietinus in einem Moosrasen.

” parietinus Bast. (Bastian, VII, pag. 123, Pl. X, Fig. 102-103), England, in Schüsselflechten (Parmelia parietina).

» pyri Bast. (Bastian, VII, pag. 123, Pl. X, Fig. 103a-103c), England, in faulenden Birnen.

" erraticus v. Linst. (von Linstow, XXIX, pag. 10, Taf. II, Fig. 24), Deutschland, im Darme von Lacerta vivipara.

” rivalis Btsli (Bütschli, XX, pag. 48, Taf. III, Fig. 16), Deutschland, im Main.

" foetidus Btsli (Bütschli, XXI, pag. 20, Taf. I, Fig. 5a-b, Taf. II, Fig. 5c). Deutschland, in Kuhmist.

Die folgenden sechs Arten sind einander nahe verwandt und zweifelsohne sind einige mit einander identisch:

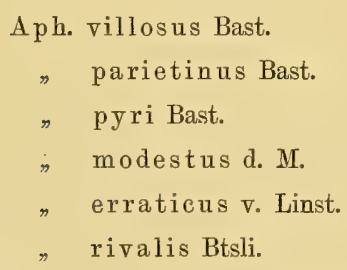

Die drei, von mir aufgefundenen, in der Erde lebenden Arten unterscheiden sich etwa, wie folgt:

1. Schwanz kurz, stumpf abgerundet ............... 1. agricola. 
Schwanz in eine Spitze auslaufend . . . . . . . . . . . . . . 2.

2. Körper mässig schlank, Schwanz kegelförmig zugespitzt. . . . . . . . 2. modestus.

Körper sehr schlank, fadenförmig; Schwanz verlängert . . . . . . . . . 3. helo philus.

\section{Aphelenchus agricolad. M}

de Man, XXXVI, pag. 142.

Synon: Aphelenchus avenae Btsli, Bütschli, XX, pag. 46, Taf. III, Fig. 15.

d. M., de Man, XXXV, pag. $6 \%$.

Taf. XXI, Fig. 90.

$\sigma^{7}$ unbekannt, 우 $0,75 \mathrm{~mm} . \alpha=32-3 \%, \beta=7-8 \%, \gamma=2 \%$

Der Körper dieses kleinen Thieres ist ziemlich schlank und verengt sich nur wenig nach vorn. Die Cuticula ist zwar sehr fein, aber doch deutlich quergeringelt; eine Seitenmembran wurde nicht beobachtet. Die Seitenfelder (Fig. 90c) sind ungefähr 1/3 des Körperdurchmessers breit und erscheinen. längsgestreift durch etwa 12 Streife; nach vorn hin beim Oesophagealbulbus werden die Seitenfelder sehr schmal und hören schliesslich auf, während sie nach hinten bis am Ende des Schwanzes fortlaufen (Fig. 90d). Das Kopfende (Fig. 90b) ist ein wenig abgesetzt, halbkugelförmig und zeigt eine Andeutung von Lippen oder Papillen. Der zarte, an seinem hinteren Ende nicht knopfförmig angeschwollene, sondern nur etwas verdickte Mundstachel ist $1 / 5-1 / 6$ der Entfernung der Mundöffnung zum hinteren Ende des Oesophagealbulbus lang und zeigt ein deutliches Lumen, das continuirlich in das Lumen des Oes. übergeht (Fig. 90a). Dieser ist cylindrisch, umfasst, etwas verdickt, den Mundstachel, und verengt sich sehr vor dem ziemlich grossen ovoïden Bulbus; sein Lumen ist stark chitinwändig und im Bulbus erweitert. Der vordere Theil des Darmes (Fig. 90) ist sehr enge und wird nach hinten allmallig breiter; mehrere Drüsen scheinen diesen Theil zu umgeben und wahrscheinlich liegt hier auch das Centralorgan des Nervensystems; in der Darmwand beobachtet man nur sparsam zerstreute Körnchen ungleicher Grösse. Der Gefässporus befindet sich in geringer Entfernung hinter dem Bulbus.

Die weibl. Geschlechtsöffnung ist sehr weit nach hinten gerückt, und liegt beim Anfange des hintersten Viertels der Gesammtlänge; die Geschlechtsröhre (Fig. 90) streckt sich seltr weit nach vorn lin aus und ist einfach und der Uterus hat einen linteren Ast, der ein wenig länger ist als der halbe Abstand zwischen Geschlechtsöffnung und After. Der stumpf abgerundete Schwanz trägt eine laterale Papille an seinem Ende (Fig. 90e).

1) Bei den drei hier beschriebenen Aphelenchen wird unter die Länge des Oes. die Entfernung der Mundöffnung zum Hinterende des Bulbus verstanden. 
Fundort und Lebensweise. Diese seltene trăge Art bewohnt den sandigen Boden der Niederlăndischen Dünenstrichen an den Wurzeln verschiedener Dünenpflanzen (Galium verum, Sedum acre u. s.w). Geographische Verbreitung. Deutschland (Gegend von Frankfurt a. M. nach Bütschli).

Fundzeit. Im Herbst wurden geschlechtsreife Thiere von mir beobachtet.

Anmerkung. Es ist mir nicht möglich, diese Form mit dem zweimal so grossen, übrigens aber nahe verwandten Aphel. avenae Bast. zu identificiren; letztere Art wurde dann auch zwischen den Blattscheiden des Hafers aufgefunden, hat also eine ganz andere Wohnstätte als unsere im Dünenboden lebende Form, welche auch wohl von Bütschli beobachtet worden ist.

\section{Aphelenchus modestus d. M.}

de Man, XXVI, pag. 59, Pl. VII, Fig. 24a-c.

$\sigma^{7} 0,64 \mathrm{~mm}$. , $\%$ 0,9 mm. $\alpha=30-35 . \beta=8-9 . \gamma$ beim $\sigma^{\gamma}=16$, beim $\rho=14$.

Obgleich ich vermuthe, dass diese Form mit einer Bastian'schen Art (z. B. mit dem Aph.pyri aus faulenden Birnen) identisch ist, führe ich dieselbe noch immer unter dem Namen modestus auf, eben weil ich noch keine, in faulenden Birnen lebende Aphelenchen zu untersuchen die Gelegenheit hatte. Leider wurde auch der modestus, von welchem ich im Jahre 1875 ein Männchen und in 1876 ein Weibchen beobachtete, später nicht mehr von mir zurückgefunden, sodass die Kenntniss dieser Art sehr unvollständig geblieben ist.

Das Thier besitzt einen ziemlich schlanken Körper, und die Cuticula ist sehr fein geringelt; die Seitenmembran ist sehr schmal. Das Kopfende ist abgesetzt und ich fand keine Spur von Lippen; der Mundstachel hat schwache Knötchen an seinem hinteren Ende und ist $1 / 7-1 / 6$ der Entfernung der Mundöffnung zum Hinterende des Oesophagealbulbus lang. Der Oes. ist in seinem Vorkommen demjenigen des Aph. agricola sehr åhnlich und läuft in einen ziemlich krăftigen Bulbus aus. Ebenso verhält sich der Darm wie bei der genannten Art, und auch der Gefässporus befindet sich gleich hinter dem Bulbus. Die weibl. Geschlechtsöftnung liegt ein wenig mehr als $1 / 4$ der Gesammtlänge vom Schwanzende entfernt. Die Spicula sind plump, gebogen, ohne accessorisches Stück. Der Schwanz ist kegelförmig, zugespitzt, mit sehr feinem Ausführungsröhrchen der Schwanzdrüse. Beim Männchen liegt gleich bei und hinter dem After eine laterale Papille, vielleicht auch eine Papille in der Mitte des Schwanzes, schliesslich eine laterale Papille gleich beim Hinterende.

Fundort und Lebensweise. Der modestus ist ein, wie schon aufgemerkt wurde, sehr seltenes Thier, welches in der feuchten Erde unserer Wiesen wie auch im sandigen Dünenboden vorkommt.

Fundzeit. Das Männchen wurde in April, das Weibchen, welches Spermatozoen in den Geschlechtsorganen enthielt, in Oktober aufgefunden. 
3. A phelenchus helophilus d. M.

(von "̈ $\lambda_{0 \zeta}$, eine Wiese).

Taf. XXI, Fig. 91.

б $0,8 \mathrm{~mm}$., ㅇ $1 \mathrm{~mm} . \alpha=55-65 . \beta=10-12 . \gamma$ beim $\sigma^{7}=20$, beim $q=14$.

Obgleich mir auch dieses Thier in mancher Hinsicht noch ungenügend bekannt ist, so brauche ich kaum zu sagen dass es sich schon durch seine so ausgeprägt fadenförmige Gestalt von allen anderen Aphelenchen unterscheidet. Der Körper (Fig. 91) ist sehr schlank, fadenförmig, und verschmälert sich wenig nach vorn, mehr nach hinten, wo er spitz ausläuft. Die Haut ist äusserst fein geringelt, eine Seitenmembran wurde nicht beobachtet. Das Kopfende (Fig. 91a) ist abgesetzt und zeigt eine Spur rudimentärer Lippen; der Mundstachel ist ziemlich kräftig, an seinem Hinterende knopfförmig angeschwollen und ist $1 / 7-1 / 6$ der Entfernung der. Mundöffnung zum hinteren Ende des kräftigen muskulösen Oesophagealbulbus lang; die Darmwand erscheint gleichmässig fein gekörnt. In geringer Entfernung hinter dem Bulbus liegt der Gefässporus.

Die weibl. Geschlechtsöffnung befindet sich bein Anfang des letzten Körperdrittlheils; die Geschlechtsröhre dehnt sich nach vorn hin aus und der Uterus hat einen hinteren Ast; das Ei ist verhältnissmässig Klein. Der Schwanz des Weibchens ist verlängert, allmälig verschmälert, zugespitzt, mit spitzem Ausführungsröhrchen der Schwanzdrüse. (Fig. 91b). Beim Männchen ist der Schwanz relativ kürzer; die Spicula mehr oder weniger wie bei der vorigen Art; die Kenntniss des männlichen Schwanzes blieb unvollständig.

Fundort und Lebensweise. Auch den helophitus traf ich bis jetzt nur zweimal an und zwar in feuchter, von süssem Wasser getränkter Erde, an den Wurzeln von Gräsern, unweit Leiden: ein Männchen in Mai, ein Weibchen in Februar; das letztere enthielt ein Ei im Uterus.

\title{
XXXV. Tylenchus Bast.
}

\author{
Bastian, VII, pag. 125 . \\ Bütschli, XX, pag. 31.
}

Die Tylenchen, eine artenreiche Gruppe freilebender Nematoden, unterscheiden sich von den verwandten, einen Mundstachel tragenden Gattungen hauptsächlich durch das Auftreten einer Bursa beim Männchen.

Es haben unsere Thiere im Allgemeinen ein ziemlich schlankes, öfters sogar sehr schlankes Vorkommen und der Körper verjüngt sich meist ziemlich stark nach vorn, ebenso nach hinten wo es entweder in einen kurzen, abgerundeten oder in einen, mehr oder weniger verlängerten spitzen 
Schwanz ausläuft. Die, nie Börstchen tragende Cuticula ist stets quergeringelt und die Ringelung ist bald enger (z. B. beim intermedius und leptosoma), bald weiter (agricola); die Seitenfelder sind ziemlich breit und eine Seitenmembran wurde bei vielen beobachtet; beim, in den Wiesen lebenden lamelliferus trägt der Körper, ausser der Seitenmembran, noch vier submediane, über dem ganzen Körper hinlaufende, vorspringende Lamellen, worauf sich die Ringelung der Haut fortsetzt. Seitenorgane kommen bei den Tylenchen nicht vor.

Das Kopfende ist entweder nicht oder wohl, obgleich nur wenig, vom Körper abgesetzt; es erscheint bald mit abgerundeter, bald mit breiter abgestumpfter Vorderfläche, und ist in den meisten Fällen völlig nackt ohne irgend einige Bewaffnung, obwohl man bei einigen Arten eine Andeutung von Lippen (Davainę), bei anderen (robustus, pratensis) chitinöse Verdickungsstreifen und Cuticularleisten bemerkt. Gleich hinter dem, im Kopfende liegenden Vestibulum befindet sich der Mundstachel, der sich von demjenigen der Tylencholaimen besonders dadurch auszeichnet, dass sich die drei, itın zusammensetzenden Clitinstäbe über illrer ganzen Länge mit einander. verbunden haben, sodass der Stachel anscheinend solide erscheint: es unterliegt aber keinem Zweifel, dass auch der Tylenchusstachel hohl und an seiner Spitze durchbohrt ist. Sehr verschieden ist der Grad seiner Ausbildung: sehr kräftig und gross bei einigen (robustus, pratensis), ist er bei anderen kleiner, während er bei wieder anderen ausserordentlich reducirt sein kann (intermedius, imperfectus); fast immer ist er an seinem hinteren Ende geknöpft. Ganz eigenthümlich verhalten sich der T. imperfectus und der macrophallus; bei erstgenannter, in faulenden Pilzen lebender Art hat das Weibchen einen zwar sehr kleinen, jedoch deutlichen Mundstachel, während derselbe beim Männchen nur durch ein kaum bemerkbares Spitzehen in der Mundhöhle vertreten wird; einen ähnlichen Geschlechtsunterschied zeigt der winzige, in der Erde lebende macrophallus, bei welchem der kräftig entwickelte Mundstachel beim Weibchen verhältnissmässig grösser und kräftiger ist als beim Männchen. Unmittelbar am Mundstachel schliesst sich das chitinwändige Lumen des Oes. an, dessen Wand den Stachel über seiner ganzen Länge umfasst; der Oes. ist bei den meisten Arten mehr oder weniger deutlich ausgebildet, zeigt eine kleinere mittlere schwach muskulöse Anschwellung, in welcher das Lumen erweitert ist, also einen Bulbus und eine hintere, bedeutendere, sich dem Darme anschliessende Erweiterung, in welcher man öfters Kerne bemerkt. Bisweilen aber ist der Oes. sehr schwer zu verfolgen, wie beim, an Mooswurzeln lebenden velatus oder dem, in faulenden Pilzen vorkommenden fungorum; ein eigenthümliches Verhalten schliesslich zeigt wieder der macrophallus, indem hier die mittlere Anschwellung, der Bulbus, beim Weibchen grösser und kräftiger ist als beim Männchen. Der Darm wird nach Bütschli von zwei Reihen alternirender, recht grosser Zellen gebildet; bei erwachsenen Thieren sind diese aber kaum zu erkennen, weil die Darmzellen gänzlich mit zahllosen, farblosen, das Licht stark brechenden Körnern gefüllt sind (Vergl. z. B. Taf. XXII, Fig. 94). Aehnliche helle, öfters grosse Körner kommen auch in der Markmasse der Muskulatur und im Schwanze vor.

Nach Bütschli soll es bei einigen Arten nur ein Seitengefäss geben, und der Porus liegt stets zwischen den beiden Oesophagealanschwellungen. 
Die weibl. Geschlechtsorgane sind entweder paarig symmetrisch, indem sie sich gleichmässig an beiden Seiten der, der Körpermitte genäherten Geschlechtsöffnung aushreiten, (robustus, dubius u. s. w.), oder das weibl. Geschlechtsorgan ist einseitig und streckt sich von der, mehr oder weniger nach hinten gerückten Geschlechtsöffnung nach vorn hin aus. Bei den ersteren schien es mir dass die Ovarien sich in ihrer ganzen Länge nach vorn, resp. nach hinten ausstreckten, ohne zurückgeschlagen zu sein, bei den letzteren findet sich meist ein, hinter der Vulva gelegener kurzer Ast, wie bei Aphelenchus. Die Eier sind ziemlich gross. Die männliche Geschlechtsdrüse bildet nach Bütschli einen einfachen, bis am Hinterende des Oes. sich ausdehnenden Schlauch und die Spermatozoen sind nach ihm, beim 7. Askenasyi, kleine, rundliche Gebilde mit einem dunklen Körperchen im Innern. Stets trägt das Männchen eine Bursa, welche entrveder den Schwanz völlig umfasst oder nur theilweise, sodass sie im letzteren Falle einen mehr oder weniger beträchtlichen Theil des Schwanzes freilässt; die Ringelung der Haut setzt sich auf die Bursa fort und bei mehreren Arten beobachtete ich eine laterale Papille oder Falte im postanalen Theile derselben. Es giebt zwei einfach gebaute, mehr oder weniger gebogene Spicula; bei den meisten Arten trifft man ein einziges, stabförmiges, mehr oder weniger gebogenes, accessorisches Stück an, beim $T$. fungorum aber ist es sehr gross und hat ungefähr die Gestalt einer, mit ihren zwei Zinken nach hinten gerichteten Gabel, beim pratensis sollen sogar zwei kurze accessorische Stücke vorkommen und bei wieder anderen (filiformis, leptosoma) fehlt ein accessorisches Stück völlig. Eine Schwanzdrüse haben unsere Thiere nicht.

Fundort und Lebensweise. Obgleich die Mehrzahl der jetzt, besonders durch meine Untersuchungen bekannten Tylenchen die reine feuchte Erde bewohnt, wo sie dieselbe Lebensweise führen wie die übrigen agricolen Nematoden, so haben andere eine sehr grosse Bedeutung als pflanzliche Parasiten. Diese letzteren, von denen man heute, ausser dem Nematoden der Runkelrübe, sieben Arten kennt, leben in verschiedenen Pflanzen: der bekannteste ist wohl der Schmarotzer der Weizenblüthe, T. tritici. Ohne Zweifel ist die Zahl dieser Schmarotzer viel grösser und es ist sogar möglich dass sie später die nicht als Parasiten lebenden in Artenzahl übertreffen werden. Eine Art soll nach von Linstow sogar im süssen Wasser leben. Eine auffallende Erscheinung in dieser Gattung ist auch die Thatsache, dass beide Geschlechter gleich häufig vorkommen, ganz im Gegensatze zu anderen Gruppen, wie z. B. den Plecti. Während einige Arten sich sehr träge und langsam bewegen, sind andere lebhaft, ja es giebt sogar, welche äusserst beweglich sind (intermedius).

Ausser den elf, von mir beobachteten, in der reinen Erde lebenden Arten, wurden noch die folgenden elf beschrieben, von welchen drei in der reinen Erde und eine im süssen Wasser leben, während die sieben anderen pflanzliche Parasiten sind:

A. In der reinen Erde:

T. obtusus Bast. (Bastian, VII, pag. 128, Pl. X, Fig. 11\%, 118). England, dem dubius Btsli năchst verwandt. o요. 
T. velatus Btsli. (Bütschli, XX, pag. 38, Taf. II, Fig. 13). Deutschland. Nur das Mănnchen bekannt.

T. terricola Bast. (Bastian, VII, pag. 127, Pl. X, Fig. 115, 116). England, nur das Weibchen bekannt.

B. Im süssen Wasser :

T. pillulifer v. Linst. (จ. Linstow, XXX, pag. 5, Taf. I, Fig. 1). Deutschland, ठํ․

C. Pflanzliche Parasiten.

T. tritici Bauer. (Vergl. Bastian, VII, pag. 126, Pl. X, Fig. 112-114). Der bekannte Schmarotzer der Weizenblüthe.

T. dipsaci Kühn. (Vergl. Bastian, VII, pag. 128).

T. fung orum Btsli. (Bütschli XX, pag: 41, Taf. II, Fig. 11 $a-c$ ). Deutschland, in faulenden Pilzen, Љํ.

T. imperfectus Btsli. (Bütschli, XXV, pag. 363, Taf. XXIV, Fig. ' $a-d$ ). Deutschland, in faulenden Pilzen, ợ.

T. Askenasyi Btsli. (Bütschli, XX, pag. 39, Taf. II, Fig. $8 a-g$ ). Deutschland (Taunus), in Hypnum cupressiforme, ðㅇ.

T. millefolii Löw. (Löw, XXIII, pag. 17-24, Pl. IB). Oesterreich, in der gemeinen Schafgarbe.

T. agrostidis Dies. (Vergl. Bastian, VII, pag. 128).

Die 11, von mir in der reinen feuchten Erde aufgefundenen Arten unterscheiden sich durch die folgenden Charactere:

1. Schwanz des Männchens ganz von der Bursa umfasst. Schwanz des Weibchens meist kurz und zwar meist stumpf abgerundet . . . . . . . .

2.

Schwanz des Männchens nicht ganz von der Bursa umfasst. Schwanz des Weibchens immer spitz zulaufend, in den meisten Füllen verlängert . . .

2. Schwanz des Weibchens kurz, abgerundet . . . . . . . . . . . .

Schwanz des Weibchens verlängert, ganz allmälig zugespitzt. Körper (mehr als $2 \mathrm{~mm}$. lang) fadenförmig. Mundstachel kräftig . . . . . . . . .

3. Weibl. Geschlechtsöffnung wenig hinter der Körpermitte, weibl. Geschlechtsorgane paarig symmetrisch. . . . . . . . . . . . . . . . .

Weibl. Geschlechtsöffnung weit nach hinten gerückt, weibl. Genitalien einseitig. Eine kleine, nur $0,6 \mathrm{~mm}$. lange Art 4. pratensis.

4. Cuticula ohne vier submediane vorspringende Lamellen
5. 
Cuticula mit vier submedianen, über den ganzen Körper hinlaufenden vorspringenden Membranen oder Lamellen; Mundstachel zart . . . . . .

5. Grössere Art (1,3-1,\% mm.), Kopfende mit chitinisirten Verdickungsstreifen. Mundstachel sehr kräftig . . . . . . . . . . . . . . . . . . Kleinere Art $(0,85 \mathrm{~mm}$.$) , Kopfende ohne chitinisirte Leisten. Mundstachel$ ziemlich kräftig . . . . . . . . . . . . . . . . . . . .

6. Mundstachel beim Männchen ebenso kräftig wie beim Weibchen . . . Mundstachel sehr gross, beim Weibchen aber grösser als beim Männchen: winzige Art $(0,33-0,37 \mathrm{~mm}$.$) , Vulva sehr nach hinten gerückt .$

\%. Mundstachel nicht auffallend klein . . . . . . . . . . . . . .

Mundstachel sehr schwach, 1/20-1/18 des Abstandes zwischen der Mundöffnung und dem Darme lang, Körper sehr schlank, 0,9-1 mm. lang . . . .

8. Grössere Arten von $1 \mathrm{~mm}$. . . . . . . . . . . . . . . . . Kleinere Arten $(0,6-0,66 \mathrm{~mm}$. lang) . . . . . . . . . .

9. Mundstachel kräftig, geknöpft . . . . . . . . . . . . . . . Mundstachel sehr zart, kaum geknöpft . . . . . . . . . . 10. filiformis.

10. Cuticula äusserst fein geringelt, die Vagina stellt sich als eine, schräg nach vorn hin gebogene Röhre dar . . . . , . . . . . . . . Cuticula breit geringelt, die Vagina eine kurze Röhre mit sehr dicken convexen Wänden

3. lamelliferus.

1. robustus.

2. $d u b i u s$.

$\%$.

11. macrophallus.

8.

6. intermedius.

9.

10.

9. Davainei.

7. leptosoma.

8. agricola.

1. Tylenchus robustus d. M.

de Man, XXVI, pag. 4\%, Pl. VI, Fig. 18a-c.

Taf. XXII, Fig. 92.

$\sigma^{7} 1,3 \mathrm{~mm}$., $ᄋ$ 1,\% mm., * beim $\sigma^{7}=35$, beim völlig erwachsenen Weibchen $=40$, bei jüngeren Thieren $=25-30 . \beta$ beim $\sigma^{x}=5-6$, beim erwachsenen Weibchen $=8 . \gamma$ beim $\sigma^{x}=40$, beim Q $=50-60$.

Es gehört der robustus zu den grösseren agricolen Arten; sein Körper ist bei den Thieren, welche ihren vollen Wachsthum erreicht haben, sehr, bei jüngeren Individuen aber weniger schlank gestaltet und verschmälert sich ziemlich nach vorn hin. Die Cuticula erscheint fein geringelt, mit mässig breiter Seitenmembran. Das Kopfende (Fig. 92a) ist ein wenig abgesetzt, halbkugelförmig, hoch, olne Lippen oder Papillen, mit zwei clitinisirten Verdickungsstreifen auf jeder der lateralen Seiten und mit vier, submedian verlaufenden Cuticulärleisten, welche nach hinten gerichtet sind, aber bald auflören; das Kopfende zeigt eine eigenthïmliche lichtgelbe Färbung. Der Mundstachel hat bei beiden Geschlechtern die gleiche Gestalt, ist sehr kräftig und ist $1 / 4-1 / 5$ des Abstandes der Mundöffnung zum Beginn des 
Darmes. Am Oes. erkennt man einen ovalen, hinteren Bulbus und in der grösseren hinteren Anschwellung findet man mehrere grosse Kerne; die Darmwand ist dicht mit grossen Körnchen aufgefüllt. In einiger Entfernung hinter dem Bulbus, mehr oder weniger dem Darmanfang genähert, mündet der Gefässporus.

Nur sehr wenig hinter der Körpermitte liegt die weibl. Geschlechtsöffnung und die paarig symmetrischen Geschlechtsorgane, welche schon bei $0,8 \mathrm{~mm}$. langen Thieren entwickelt sind, strecken sich an beiden Seiten der Vulva aus; ein ziemlich grosses Ei wurde im Uterus beobachtet. Beim Weibchen ist der Schwanz sehr kurz, abgerundet (Fig. 92c) und beim Männchen findet sich eine, den gleich kurzen Schwanz ganz umfassende breite Bursa (Fig. 92b) mit lateraler Papille im postanalen Theil. Die Spicula sind kräftig mit stabförmigem, accessorischem Stücke.

Fundort und Lebensweise. Es bewohnt diese sehr träge sich bewegende Art ziemlich hăufig sowohl die feuchte oder von süssem oder brackischem Wasser mehr oder weniger durchtränkte Erde der Wiesen wie auch den sandigen Dünenboden. Die Männchen sind viel seltener als die Weibchen.

Geographische Verbreitung. Deutschland (Laibach).

Fundzeit. Völlig erwachsene Thiere wurden im Frühjahre (März) beobachtet, zu gleicher Zeit kommen aber auch jüngere Thiere vor, und auch im August und im December wurden halberwachsene Individuen aufgefunden.

Anmerkung. Durch den Bau des Kopfendes und den sehr kurzen Schwanz, an welchem die Hautringelung sehr auffallend ist, unterscheidet sich unseres Thier von dem, ihm nahe verwandten dubius.

\section{Tylenchus dubius Btsli}

Bütschli, XX, pag. 39, Taf. II, Fig. $9 a-e$.

de Man, XXVII, pag. 49 , Pl. VII, Fig. $19 a-e$.

Taf. XXII, Fig. 93.

- $\sigma^{7}$ \% $0,85 \mathrm{~mm} . x=30 . \beta=5-6 . \gamma$ beim $\sigma^{7}=15-16$, beim $Q=13$.

Bei dieser, der vorigen und auch dem Tyl. obtusus Bast. jedenfalls nahe verwandten Art ist der Köper schlank, mit ziemlich verjüngtem Vorderende. Die Cuticula ist sehr fein geringelt. Das Kopfende (Fig. 93 ) ist ein wenig abgesetzt, halbkugelförmig, olne Lippen, Papillen oder clitinisirte Leisten; gleich hinter demselben aber bemerkt man vier schwache submediane Cuticularleisten. Der Mundstachel, bei beiden Geschlechtern gleich, ist ziemlich kräftig, deutlich geknöpft und ist ${ }^{1 / 7}$ des Abslandes der Mundöffnung zum Darme lang. Der Oes. zeigt einen kleinen mittleren Bulbus und an seinem Ende eine grössere Anschwellung. Zwischen dem Bulbus und dem Darme mündet der Gefässporus. Die weibl. Geschlechtsöffnung liegt ein wenig hinter der Körpermitte (Fig. 93) und die paarig symmetrischen Genitalien delnen sich an beiden Seiten der Vulva weit aus. Beim Weibchen ist der Schwanz cylindrisch, nach hinten wenig verschmälert, mit abgerundetem Hinterende. Beim Männchen findet sich eine, den 
fast ebenso langen Schwanz ganz umfassende Bursa (Fig. 93b) mit lateraler Papille im postanalen Theil; nach Bütschli sind die Spermatozoen klein und rundlich, und liegen unregelmässig neben einander. Die Spicula (Fig. 93c) sind kräftig, mässig schlank und von einem stabförmigen, accessorischen Stücke begleitet.

Fundort und Lebensweise. Diese, wie die vorige sich langsam bewegende Art ist sehr häufig und bewohnt die feuchte Erde der Holländischen Wiesen und Marschgründe, aber auch den sandigen Dünenboden; beide Geschlechter kommen gleich häufig vor.

Geographische Verbreitung. Deutschland (Erlangen, Frankfurt a. M. nach Bütschli). England (Sydenham).

Fundzeit. Das ganze Jahr hindurch wurden erwachsene, geschlechtsreife Individuen von mir beobachtet.

3. Tylenchus lamelliferus d. M.

Taf. XXII, Fig. 94.

$\sigma^{7} \varsubsetneqq 1 \mathrm{~mm} . \alpha=25-2 \%$. $\beta$ beim $\sigma^{x}=5 \frac{1}{2}$, beim $q=6 . \gamma$ beim $\sigma^{x}=26$, beim $q=18-21$.

Von allen anderen Arten dieser Gattung unterscheidet sich der lamelliferus durch die über die ganze Körperoberfläche verlaufenden Membranen oder Lamellen.

Das Thier hat eine måssig schlanke Körpergestalt und verjüngt sich ziemlich stark nach vorn hin. Aeusserst fein geringelt ist die Cuticula und, ausser einer Seitenmembran, noch mit vier submedianen, über den ganzen Körper linlaufenden, vorspringenden Membranen oder Lamellen versehen, (Fig. 94b), worauf sich die Hautringelung fortsetzt; dieselben fangen etwa in der Mitte des Mundstachels an und strecken sich bis an die Schwanzspitze aus. Das Kopfende (Fig. 94a) lüuft ziemlich spitz zu, ist nicht abgesetzt, wie bei den beiden vorigen Arten, hat einen abgerundeten Vorderrand, und trägt keine Lippen oder einige Verzierung; es ist ganz nackt. Der Mundstachel ist verlängert, bei beiden Geschlechtern gleichartig gestaltet, ist $1 / 6$ des Abstandes der Mundöffnung zum Anfange des Darmes lang, ist sehr dünn und zart, wiewoll deutlich knopjartig angeschwollen an linteren Ende. Der Oes. zeigt einen mässig grossen, mittleren Bulbus und die noch grössere hintere Anschwellung ist scharf vom, zwischen ihr und dem Bulbus liegenden sehr engen Theile abgesetzt. Ueber ihrer ganzen Länge ist die Wand des Darmes mit zahllosen, farblosen, das Licht stark brechenden Körnchen aufgefüllt. Der Gefässporus liegt in der Mitte zwischen dem hinteren Ende des Bulbus und dem Darmanfang. Die weibl. Geschlechtsöffnung befindet sich sehr wenig hinter der Körpermitte und die paarig symmetrisclien Geschlechtsorgane strecken sich weit nach beiden Seiten hin aus. Beim Weibchen (Fig. 94c) ist der Schwanz kegelförmig, zugespitzt mit abgerundeter Spitze. Beim Männchen (Fig. 94d) sieht man eine, den Schwanz ganz umfassende Bursa, welche ein wenig vor seinem Hinterende eigenthümlich verengt ist und eine laterale Papille etwas vor der Mitte ihres postanalen Theiles trägt. Die kräftigen Spicula werden von einem gebogenen stabförmigen accessorischen Stücke begleitet. 
Fundort und Lebensweise. Der langsam fortkriechende lamelliferus ist ein mässig häufiges Thier, das die feuchte oder sandige Erde unserer Wiesen bewohnt, an den Wurzeln von Gräsern.

Geographische Verbreitung. In keinem anderen Lande noch beobachtet.

Fundzeit. Im Winter beobachtete ich erwachsene, geschlechtsreife Thiere, in Februar und November.

\section{Tylenchus pratensis d. M.}

de Man, XXXVI, pag. 143.

Taf. XXII, Fig. 95.

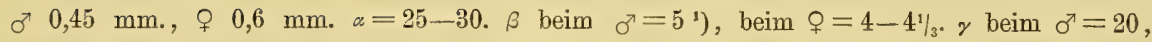
beim $ᄋ=25$.

Der pratensis unterscheidet sich von den anderen, von mir in der reinen Erde aufgefundenen Formen durch die einseitigen weibl. Geschlechtsorganen und den kurzen, abgerundeten Schwanz. Wahrscheinlich erreicht auch das Männchen die Grösse des Weibchens. Es hat diese Art einen mässig schlanken Körper, mit wenig verschmülertem Vorderende. Die Cuticula ist ausserst fein geringelt und trägt eine Seitenmembran, welche ungefähr $1 / 4$ der Körperdicke breit ist. Das Kopfende (Fig 95a) ist sehr niedrig, scheibenförmig, nur wenig abgesetzt, olne Lippen; auf jeder der lateralen Seiten beobachtet man zwei chitinisirte Längsstreifen (wie ungefähr beim robustus) und vier submediane, gebogen verlaufende Linien. Der Mundstachel ist selkr kräftig, mit starken Endknötchen versehen und ist beim Männchen 1/6, beim Weibchen 1/9 des Abstandes der Mundöffnung zum Darmanfang lang. Der Oes. besitzt einen ziemlich grossen, fast kugelförmigen mittleren Bulbus und ist nach hinten taschenförmig erweitert; die Darmwand ist über ihrer ganzen Länge mit zahllosen, das Licht stark brechenden Körnchen aufgefüllt. Der Gefässporus befand sich beim Männchen in sehr geringer Entfernung vor dem Hinterende des Oes., beim Weibchen lag er beim Anfang des letzten Dritttheils desselben. Die weibl. Geschlechtsöffnung ist weit nach hinten gerückt, etwas weniger als 1/4 der Gesammtlänge vom Hinterende entfernt; die Geschlechlsrölre ist einseitig, nach vorn hin ausgestreckt und der Uterus hat einen hinteren Ast. Beim Weibchen ist der Schwanz (Fig. 956) kegelförmig, kurz, stumpf abgerundet. Beim Männchen (Fig. 95c) wird der gleichgestaltete Schwanz ganz von der Bursa umfasst, welche denselben Bau zeigt wie bei den vorigen Arten; es fand sich eine einzelne Papille an jeder Seite nahe dem Schwanzende. Die Spicula sind ein wenig gebogen, und scheinen von zwei kurzen, gebogenen, accessorischen Stücken begleitet sein.

1) Diese Zahl ist wohl nngenau, weil beim einzigen, von mir gefundenen Männchen der Oes, ein wenig gewunden war. 
Fundort und Lebensweise. Dieses Thier ist gar nicht häufig und bewohnt die feuchte reine oder mehr sandige Erde der Wiesen und Marschgründe; es bewegt sich sehr langsam.

Geographische Verbreitung. England (Sydenham).

Fundzeit. Ein erwachsenes Weibchen traf ich in Februar, ein jüngeres in April an, während das einzige beobachtete Männchen in September aufgefunden wurde.

\section{Tylenchus gracilis d. M.}

Taf. XXIII, Fig. 96.

$\sigma^{7} 2,1 \mathrm{~mm}$., $q$ etwas länger als $2,2 \mathrm{~mm} . \alpha=65-70 . \gamma$ beim $\sigma^{7}=20$, beim noch nicht ganz erwachsenen, 2,2 $\mathrm{mm}$. langen Weibchen $=18$.

Durch ihre bedeutende Grösse, die fadenförmige Gestalt, die paarig symmetrischen weibl. Genitalien und den verlängerten zugespitzten Schwanz unterscheidet sich der gracilis von allen anderen, von mir beobachteten Tylenchen. Leider hatte das einzige aufgefundene Weibchen noch nicht seinen ganzen Wachsthum erreicht, sodass mir die Grösse des völlig erwachsenen Thieres unbekannt blieb, sowie mehrere Eigenthümlichkeiten des anatomischen Baues.

Der Körper dieser Art ist äusserst schlank, fadenförmig und verschmälert sich wenig nach vorn hin. Die Haut ist äusserst fein geringelt. Das Kopfende (Fig. 96b) ist ein wenig abgesetzt, ziemlich niedrig, mit gebogener Vorderflache, ohne Lippen, aber mit lateralen und submedianen chitinisirten Verdickungsstreifen gesmückt. Der Mundstachel ist kräftig, mit grossen Endknötchen versehen und 1/5 des Abstandes der Mundöffnung zum Hinterende des mittleren Bulbus lang; dieser Bulbus (Fig. 96a) ist ziemlich gross und der Abstand zwischen seiner hinteren Grenze und der Mundöffnung ist $1 / 20{ }^{1 / 19}$ der Gesammtlänge lang; den, hinter dem Bulbus liegenden Theil des Oes. konnte ich an den wenigen beobachteten Thieren nicht mit Bestimmtheit sehen. Die Darmwand erscheint fein gekörnt und der Gefässporus liegt in geringer Entfernung hinter dem mittleren Bulbus.

Die weibl. Geschlechtsöffnung (Fig. 96c) lag etwas hinter der Mitte und die Geschlechtsorgane sind jedenfalls paarig symmetrisch, sich an beiden Seiten der Vulva ausstreckend. Beim Weibchen ist der Schwanz (Fig. 96d) verlängert, ganz allmälig zugespitzt. Beim Männchen hat er (Fig. 96e) eine ähnliche Gestalt, und wird ganz von der Bursa umfasst; diese zeigt eine laterale Papille etwas hinter der Mitte ihres postanalen Theiles. Die kleinen Spicula sind ziemlich plump und von einem kurzen, etwas gebogenen, accessorischen Stücke begleitet.

Fundort und Lebensweise. Der gracilis ist eine sehr seltene Art, welche sowohl den humusreichen Waldboden wie auch die feuchte Erde der Hollandischen Wiesen bewohnt, und bis jetzt nirgendwo sonst beobachtet wurde. Das Thier bewegt sich ziemlich langsam.

Fundzeit. Sowohl im Sommer wie im Winter scheint das Thier geschlechtsreif vorzukommen. 
6. Tylenchus intermedius d. M.

Taf. XXIII, Fig. 9\%.

$\sigma^{7} 1 \mathrm{~mm}$. 우 0,9 mm. $\alpha=50-60 . \beta=6 . \gamma$ beim $\sigma^{7}=12$, beim $ᄋ=8-10$.

Unter den einheimischen Tylenchen mit einseitigen weibl. Geschlechtsorganen und bei welchen die Bursa den Schwanz nicht völlig umfasst, unterscheidet sich der intermedius durch die auffallende Kleinheit des Mundstachels; er nimmt in Bezug auf seinen Bau und seine Organisation eine intermediaire Stellung ein, zwischen dem, an Mooswurzeln lebenden Tyl. velatus Btsli, dem, die Endknospen der Zweige des Hypnum cupressiforme bewohnenden Tyl. Askenasyi und dem agricolen Tyl. leptosoma. Es hat unsere Art einen sellr schlanken Körper, der sich nach vorn hin ziemlich verjüngt. Die Cuticula ist sehr fein geringelt und trägt eine, bisweilen undeutliche Seitenmembran. Das Kopfende (Fig. 97b) ist halbkugelförmig, kaum abgesetzt, ganz nackt, olıe Lippen oder einige Verzierung. Der Mundstachel ist sehr schwach und klein, trägt zarte Endknötchen, und ist $1 / 20-1 / 18$ des Abstandes zwischen der Mundöffnung und dem Darme lang. Der Oes. (Fig. 9\%a) ist deutlich umgrenzt, besitzt einen verhältnissmässig seler kleinen, ovalen, mittleren Bulbus, und ist an seinem Hinterende taschenförmig erweitert; der cylindrische Theil des Oes. ist sehr enge. Die Darmwand enthălt zahllose, das Licht stark brechende Körnchen ungleicher Grősse. Der Gefässporus mündet ungefähr beim Anfang des letzten Dritttheils des Oes.

Die weibl. Geschlechtsöffnung (Fig. 9\%c) ist etwas weniger als $1 / 3$ der Gesammllänge vom Schwanzende entfernt und die weibl. Geschlechtsröhre ist einseitig und streckt sich nach vorn hin aus; der Uterus hat aber auch einen hinteren Ast. Beim Weibchen ist der Sclwwanz verlängert, allmälig zugespitzt. Beim Männchen (Fig. 97d) hat der Schwanz eine ähnliche Gestalt; die Bursa fängt in geringer Entfernung vor dem After an und streckt sich ungefähr bis auf die Mitte des Schwanzes aus; ich beobachtete keine Papillen an derselben. Die ziemlich plumpen Spicula werden (Fig. 97d) von einem schwachen, linearen, gebogenen, accessorischen Stücke begleitet, das ungefähr 1/3 der Länge der Spicula lang ist.

Fundort und Lebensweise. Tylenchus intermedius ist eine nicht seltene Art, welche sowohl die feuchte oder von süssem oder brackischem Wasser durchtränkte Erde unserer Wiesen wie auch den sandigen Dünenboden bewohnt. Das Thierchen unterscheidet sich von den meisten anderen Arten dieser Gruppe durch seine äusserst lebhafte Bewegungen.

Geographische Verbreitung. England (Sydenham).

Fundzeit. Fast in allen Jahreszeiten (April, August, September, November) traf ich erwachsene Individuen an. 


\section{\%. Tylenchus leptosomad. M.}

Taf. XXIII, Fig. 98.

ర우 $0,66 \mathrm{~mm} . \alpha=50-55 . \beta=5-52 / 3 \cdot \gamma=3$.

Durch den viel längeren Schwanz und den Bau der Vagina beim Weibchen unterscheidet sich diese Art gleich von dem, ihr verwandten intermedius.

Es erreicht der leptosoma nicht die Grösse der vorigen Art, weleher er, was die allgemeine Körpergestalt betrifft, sehr ähnelt.

Der Körper ist sehr schlank, mit mässig verjüngtem Vorderende. Die Cuticula ist so äusserst fein geringelt, dass man die Ringelung erst bei sehr starker Vergrösserung beobachtet. Das Kopfende (Fig. 98a) ist nicht abgesetzt, hat einen abgerundeten Vorderrand und ist ganz nackt, olne Lippen oder einige Verzierung. Der Mundstachel ist schwach, aber geknöpft, bei beiden Geschlechtern gleich gross nnd ist $1 / 12$ der Länge des Oes. lang. Dieser ist deutlich umgrenzt, besitzt einen ovalen mittleren Bulbus und ist an seinem Hinterende erweitert; die Darmwand ist mit farblosen feinen Körnchen aufgefüllt. Der Gefässporus mündet beim Anfang des letzten Dritttheils des Oes.

Die weibl. Geschlechtsöffnung liegt in der Mitte oder etwas hinter der Mitte; die Vagina (Fig. 98b) stellt sich als eine dïnnwändige, schräg nach vorn gebogene Röhre dar und die Geschlechtsröhre ist einseitig, nach vorn ausgestreckt. Der Uterus hat einen kurzen hinteren Ast und das Ei ist verhältnissmässig sehr gross. Beim Weibchen ist der Schwoanz sehr lang, allmälig verschmälert und läuft haarfein $z u$ (Fig. 98).

Beim Männchen ist der-Schwanz ähnlich gestaltet (Fig. 98c), die Bursa ist sehr klein und streckt sich nur wenig vor und hinter dem After aus. Die Spicula sind schlank und werden von keinem accessorischen Stücke begleitet.

Fundort und Lebensweise. Der träge sich bewegende leptosoma ist ein sehr häufiges Thierchen, das die feuchte Erde unserer Wiesen und Marschgründe bewohnt.

Geographische Verbreitung. Deutschland (Erlangen).

Fundzeit. Mit Ausnahme des Sommers, traf ich diese Art in allen Jahreszeiten geschlechtsreif an; zweifelsohne wird sie auch wohl im Sommer erwachsen vorkommen.

8. Tylenchus agricola d. M.

Synon: Tylenchus filiformis d. M., de Man, XXXV, pag. 73.

Nec: Tylenchus filiformis Btsli.

Nec: Tylenchus filiformis $\mathbf{v}$. Linst., von Linstow, XXIX, pag. 10.

Taf. XXIII, Fig. 99., unter dem Namen Tylenchus filiformis Btsli.

$\sigma^{7}$ 우 $0,6 \mathrm{~mm}$. a beim $\sigma^{\top} 28-33$, beim $ᄋ 25-30 . \beta=5-6 . \gamma$ beim $\sigma^{7}=3-31 / 4$, beim $q=3-4$. 
Unter den langschwänzigen Tylenchen, bei welchen die weibl. Geschlechtsorgane einseitig sind und die Bursa nur einen Theil des Schwanzes umfasst, erkennt man den agricola bald an der weiten Querringetung der Haut und am Bau der Vagina. Vom fliformis Btsli unterscheidet er sich gleich durch die mebr nach vorn gerückte Lage der weibl. Geschlechtsöffnung. Es hat unsere Art eine mässig schlanke Gestalt und einen Körper, der sich nach vorn hin ziemlich viel verschmälert. Die Cuticula zeigt ziemlich breite Querringe der Haul (Fig. 99) und trägt eine mässig breite, deutliche Seitenmembran. Das Kopfende (Fig. 99a) ist abgesetzt, ziemlich hoch, mit gebogener Vorderfläche, ganz nackt, ohne Lippen oder einige Verzierung. Der Mundstachel ist bei beiden Geschlechtern gleich entwickelt, ziemlich kräflig und geknöpft, $1 / 7$ der Entfernung der Mundöffnung zum Darmanfang lang. Der Des. ist deutlich umgrenzt, hat einen ovalen mittleren Bulbus und ist an seinem Hinterende taschenförmig erweitert; in der Darmwand beobachtet man zahllose Fettkörnchen ungleicher Grösse. Der Gefässporus liegt mehr oder weniger weit vor dem Hinterende des Oes. Die weibl. Geschlechtsöffnung (Fig. 996) befindet sich ein wenig hinter der Mitte, meist $2 \%$ der Gesammtlänge vom Schwanzende entfernt; die Geschlechtsröhre ist einseitig, nach vorn hin ausgestreckt und die Vagina stellt sich in der Proflansicht (also bei der gewöhnlichen lateralen Lage des Thieres) als eine kurze, nach vorn gerichtete Röhre mit selı dicken convexen Wünden dar. Der Schwanz hat beim Männchen und beim Weibchen die aehnliche Gestalt, ist sehr schlank, allmälig verschmälert und läuft haarfein zu. Die Bursa ist kurz (Fig. 99d) und streckt sich nur wenig vor und hinter dem After aus. Die Spicula sind mässig schlank, gebogen, ohne accessorische Stücke.

Fundort und Lebensweise. Der agricola fübrt seinen Namen mit dem vollsten Rechte, weil er zu den äusserst häufig vorkommenden Arten gehört; er bewohnt nicht nur die feuchte, mehr oder weniger von süssem oder brackischem Wasser durchtränkte Erde der Wiesen, der Marschgründe und des Waldes, sondern auch den sandigen Boden der Heidestriche. Das Thier bewegt sich langsam.

Geographische Verbreitung. Deutschland (Erlangen).

Fundzeit. Das ganze Jahr hindurch traf ich geschlechtsreife Individuen beider Geschlechter gleich häufig an.

9. Tylenchus Davainei Bast.

Bastian, VII, pag. 126, Pl. X, Fig. 109-111.

Bütschli, XX, pag. $3 \%$, Taf. I u. II, Fig. Y $a-c$.

de Man, XXVI, pag. 55, Pl. VII, Fig. 22a-c.

Taf. XXIV, Fig. 100.

$\sigma^{7}$ \% $1,1 \mathrm{~mm}$. $\alpha$ beim $\sigma^{\top} 35-40$, beim $q 28-38 . \beta=6 . \gamma$ beim $\sigma^{7}=\gamma-8$, beim $q=\gamma-9$.

Der Körper dieser Art ist mehr oder weniger schlank, und zwar ist das Männchen meist chlanker als das Weibchen. Die Cuticula ist fein geringelt und trägt eine ziemlich breite Seiten- 
membran. Das Kopfende (Fig. 100a) ist kaum abgesetzt, mässig hoch, mit einer etwas concaven Vorderfläche, mit einer Andeutung von Lippen und mit vier submedianen Linien; der Mundstachel ist bei beiden Geschlechtern gleich entwickelt, kräftig, geknöpft und $1 / 9$ der Entfernung der Mundöffnung zum Anfang des Darmes lang. Der Oes. hat einen ziemlich kleinen mittleren Bulbus und ist nach hinten zu erweitert. Der Gefåssporus liegt in geringer Entfernung vor dem Darmanfang. Die weibl. Geschlechtsöffnung befindet sich beim Anfang des letzten Körperdritttheils, die Geschlechtsröhre ist einseitig, ziemlich weit nach vorn ausgestreckt und der Uterus hat einen kurzen hinteren Ast. Der verlängerte Schwanz hat bei beiden Geschlechtern die gleiche Gestalt, er verschmälert sich allmälig und läuft zugespitzt aus; seine Länge ist sehr veränderlich. Die Bursa (Fig. 100c) ist kurz, und streckt sich nur wenig vor und hinter dem After aus; die Spicula sind ein wenig gebogen, und werden von einem melir oder weniger gebogenen, accessorischen Stücke begleitet, das $1 / 3$ der Länge der Spicula lang ist.

Fundort und Lebensweise. Der lebhafte Tylenchus Davainei kommt ziemlich häufig vor und bewohnt die feuchte Erde der Wiesen und den sandigen Dünenboden.

Geographische Verbreitung. Frankreich (Montpellier), England, Deutschland (Frankfurt a. M. nach Bütschli).

Fundzeit. Sowohl im Frühjahre wie im Sommer ist dieses Thier geschlechtsreif.

Anmerkung. Während man diese Art leicht von der vorigen zu unterscheiden im Stande ist, ist es ziemlich schwer die Unterschiede zwischen ihr und dem filiformis Btsli anzugeben: es ist aber besonders der Bau des Kopfendes und des Mundstachels, wodurch beide Formen von einander abweichen.

\section{Tylenchus filiformis Btsli.}

Bütschli, XX, pag. 37, Taf. II, Fig. 10.

Synon: Tylenchus elegans d. M., de Man, XXVI, pag. 56, Pl. VII, Fig. 23 $a-c$ und de Man, $\mathrm{XXXV}$, pag. 75.

" exiguns d. M., de Man, XXVI, pag. 54, Pl. VII, Fig. 21.

Nec: $\quad$ filiformis, de Man, XXXV, pag. 73.

Taf. XXIV, Fig. 101.

б우 $1 \mathrm{~mm} . \alpha=35-40 . \beta=6-71 / 2 \cdot \gamma=6-71 / 2$.

Auch beim Tylenchus filiformis beobachtet man dieselbe Erscheinung wie beim Mononchus papillatus, bei den beiden, von mir aufgefundenen Arten von Trilobus, beim Dorylaimus obtusicaudatus u. m. a. A., nämlich die Thatsache, dass man entweder zu gleicher Zeit oder vielleicht in einer bestimmten Reihenfolge geschlechtsreife Individuen verschiedener Körpergrösse antrifft. So findet man geschlechtsreife, $1 \mathrm{~mm}$. lange Individuen des Tyl. filiformis zu gleicher Zeit mit anderen geschlechtsreifen 
Thieren derselben Art, welche nur die halbe Körperlånge besitzen so wie mit geschlechtslosen Individuen, welche grösser sind als die letzteren. Ob auch die geschlechtsreifen Thiere, welche nur die Körperlänge von $0,5 \mathrm{~mm}$. erreicht haben, später noch zu $1 \mathrm{~mm}$. langen Thieren herauswachsen, muss vorlăufig dahin gestellt werden. Bütschli, welcher diese Art zuerst beobachtete, beschrieb ein nur $0,47 \mathrm{~mm}$. langes geschlechtsreifes Weibchen, während ihm die grösseren Thiere unbekannt blieben.

Diese Art hat einen schlanken Körper, der sich nach vorn hin ziemlich verjüngt. Die Cuticula ist äusserst fein geringelt und trägt eine mässig breite Seitenmembran. Das Kopfende (Fig. 101a) ist kaum abgesetzt, ziemlich niedriq, halbkugelförmig, mit convexer gebogener Vorderfläche, ganz nackt, ohne Lippen oder einige Verzierung. Der Mundstachel ist sehr zart, kaum geknöpft, und ist nur ${ }^{1 / 13}-1 / 12$ der Entfernung der Mundöffnung zum Hinterende des Oes. lang, während er bei beiden Geschlechtern die gleiche Gestalt hat. Der Oes. hat einen ziemlich kleinen mittleren Bulbus und das Hinterende ist erweitert, die Darmwand enthält zahllose Körnchen ungleicher Grōsse. Die Lage des Gefăssporus ist einiger Massen veränderlich und ist mehr oder weniger nach hinten gerückt.

Die weibl. Geschlechtsöffnung befindet sich stets (bei jeder Körpergrösse) beim Anfang des letzten Körperdritttheils und die einseitige Geschlechtsröhre streckt sich weit nach vorn hin aus; der Uterus hat einen kurzen hinteren Ast und enthält ein verhältnissmässig grosses Ei. Geschlechtsreife, nur $0,47 \mathrm{~mm}$. lange Weibchen trifft man zu gleicher Zeit mit anderen an, welche den vollen Wachsthum erreicht haben und $1 \mathrm{~mm}$. lang sind. Der Schwanz hat bei beiden Geschlechtern die gleiche Gestalt, und ist verlängert, allmälig verschmälert und mehr oder weniger zugespitzt. Die Bursa (Fig. 101b) ist kurz und streckt sich nur wenig vor und hinter dem After aus; die Spicula sind ein wenig gebogen und werden von einem, etwas gebogenen, accessorischen Stücke begleitet, das $1 / 3$ der Länge der Spicula lang ist.

Fundort und Lebensweise. Der Tyl. filiformis ist ein lebhaftes Thier, das ziemlich håufig in der feuchten Erde unserer Wiesen vorkommt, wo es an den Wurzeln von Gräsern, Ranunculaceen, Moos u. s. w. lebt.

Geographische Verbreitung. Deutschland (Frankfurt a. M. nach Bütschli).

Fundzeit. Sowohl im Winter (Februar), wie im Sommer (Angust) traf ich geschlechtsreife Individuen beider Geschlechter und zwar verschiedener Körpergrösse zu gleicher Zeit an.

11. Tylenchus macrophallus d. M.

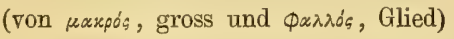

Taf. XXIV, Fig. 102.

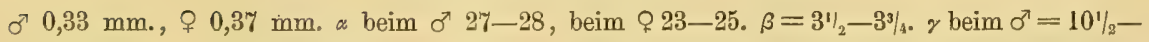
$11^{1} / 2$, beim $q=12^{1} / 2-13^{1 / 2}$. 
Zu den kleinsten agricolen Nematoden gehört das merkwürdige Thierchen, welchem ich, der Grösse seiner Spicula wegen, den Namen macrophallus gegeben habe.

Der Körper dieser winzigen Art, welcher sich nach vorn hin nur wenig verschmålert, darf nicht schlank genannt werden. Die Cuticula ist fein geringelt, eine Seitenmembran wurde nicht beobachtet. Das Kopfende ist micht abgesetzt, zugespitzt, mit abgestumpfter Vorderfläche und trägt keine Lippen oder einige Verzierung. Der Mundstachel ist selir gross und kräftig, beim Weibchen (Fig. 102b) grösser und kräftiger als beim Männchen, und ist bei den letzteren $1 / 5$, bei den Weibchen $1 / 4$ der Entfernung der Mundöffnung zum Hinterende des Oes. lang. Dieser ist zwar ganz typisch gebaut, aber der mittlere Bulbus beim Weibchen (Fig. 102) ist grösser und kräftiger als beim Männchen; das Hinterende ist taschenförmig erweitert. In der Darmwand beobachtet man zahllose, das Licht brechende Körnchen. Der Gefässporus liegt $1 / 4$ der Länge des Oes. vom Darmanfange entfernt. Die weibl. Geschlechtsöffnung ist bei dieser Art ausserordentlich viel nach hinten gerückt und liegt 1/6 der Gesammtlänge vom Schwanzende entfernt; die Geschlechtsröhre ist einseitig und streckt sich nach vorn hin aus.

Der Schwanz hat bei beiden Geschlechtern die gleiche Gestalt, er ist nämlich verlängert und allmälig zugespitzt, beim Weibchen nur ein wenig kürzer als beim Männchen. Die Bursa (Fig. 102c) ist sehr klein und zart und streckt sich nur wenig vor und hinter dem After aus; die Spicula (Fig. 102c und $102 d$ ) sind verhältnissmässig gross, ausserordentlich lang und schlank, zugespitzt, ein wenig gebogen und werden von einem kurzen, stabförmigen, accessorischen Stücke begleitet.

Fundort und Lebensweise. Der macrophallus ist ein seltenes Thierchen mit lebhafter Bewegung, das die feuchte, von süssem Wasser mehr oder weniger getrănkte Erde der Holländischen Wiesen bewohnt. Ich fand mehrere Exemplare in derselben Erde, in welcher auch Bastiania gracilis, Aphanolaimus attentus und Tylenchus leptosoma lebten.

Geographische Verbreitung. In keinem anderen Lande noch beobachtet.

Fundzeit. Geschlechtsreif ist diese Art in den Wintermonaten, über das Vorkommen in den anderen Jahreszeiten liegen mir keine Beobachtungen vor.

Anmerkung. Nicht nur durch ihre geringe Grösse, die nach hinten gerückte Lage der weibl. Geschlechtsöffnung und die Grösse der Spicula, auch durch die eigenthümliche Erscheinung, dass Mundstachel und Oesophagealbulbus bei beiden Geschlechtern verschieden stark entwickelt sind, weicht diese Art von den übrigen, von mir beobachteten Formen in hohem Grade ab.

\section{Dorylaimus Duj.}

Dujardin, III, pag. 233.

Bastian, VII, pag. 104.

Bütschli, XX, pag. 19 und XXV, pag. 19.

Eine höchst natürliche Gruppe freilebender Nematoden bildet wohl die alte Dujardin'sche Gat- 
tung Dorylaimus, welche jetzt nicht weniger als 48 Arten zählt. Bei diesem grossen Formenreichthum stimmen mehrere Arten in den wesentlichsten Merkmalen der äusseren und inneren Organisation so sehr mit einander überein und sind ihre Unterschiede, besonders bei den Weibchen so gering, dass es öfters schwer fällt, dieselben zu erkennen.

Die Dorylaimen gehören meist zu den grösseren freilebenden Nematoden: der, bei Dorpat lebende $D$. linea soll eine Länge von 8 Linien erreichen, der maximus überscheitet gewiss die Länge von $11 \mathrm{~mm}$., der regius wird fast $9 \mathrm{~mm}$. lang, und mehr als die Hälfte der, von mir beobachteten Formen erreicht oder überschreitet die Länge von $2 \mathrm{~mm}$; unter diesen giebt es bloss drei (primitivus, microdorus und parvus), welche kürzer sind als $1 \mathrm{~mm}$. Was das änssere Vorkommen betrifft, so ist dasselbe bei den einzelnen Arten sehr verschieden: während einige sich durch eine plumpe Körpergestalt auszeichnen, wie z. B. der seltene microdorıs, besitzen andere einen sehr verlängerten, fadenförmigen Körper, wie der, im süssen Wasser lebende fliformis oder der träge elongatus; zwischen diesen Extremen findet man aber alle mögliche Uebergänge bei unseren Thieren vertreten. Nach vorn hin verjüngt sich das Thier meist allmälig und zwar bei einigen sehr stark (bryophilus, gracilis), bei anderen mässig (elegans, monohystera, u. m. a.), bei wieder anderen sehr wenig (parvus, pratensis). Nach hinten zu läuft der Körper entweder in einen kurzen oder in einen verlängerten Schwanz aus; im ersteren Falle ist er mehr oder weniger abgerundet, im zweiten Falle zugespitzt oder sogar fadenförmig. Bei einigen Arten beobachtet man, in Bezug auf die Gestalt dieses hinteren Körperendes, bedentende Geschlechtsunterschiede (stagnalis, macrolaimus). Die Cuticula der Dorylaimen ist glatt, ungeringelt, nie trägt sie Borsten; bisweilen beobachtet man eine feine Längsstreifung, welche durch die Muskulatur verursacht wird. Bei vielen, so nicht allen Arten durchsetzen die Cuticula eigenthümliche Papillen, welche Bütschli beim, im süssen Wasser lebenden stagnalis, ich selbst bei mehreren anderen Arten (regius, robustus, longicaudatus, u. a.) beobachtete. Die Muskelzellen sind langgestreckt, faserartig und die Seitenlinien setzen sich nach Bütschli aus zwei Zellenreihen zusammen; Medianlinien scheinen zu fehlen. Bei den Månnchen beobachtet man meist eine prăanale schräge Streifung an den lateralen Seiten des Körpers, welche Bütschli der Bursalmuskulatur zuschreibt. Seitenmembran, Seitenorgane, Seitengefässe, Ventraldrüse, (also auch ein ventraler Gefässporus) und Schwanzdrüse kommen unseren Thieren nicht zu.

Die Mundöffnung ist meist klein, nur bei zwei Arten (macrolaimus und rotundicauda) ziemlich gross, und sie befindet sich auf einem vorderen Abschnitte des Kopfendes, den ich als Kopfregion bezeichne. Die Kopfregion, welche fast immer (nur nicht beim, in Kuhmist lebenden borboroplilus) durch eine Ringfurche von dem, sich anschliessenden Körpertheil abgesetzt ist, zeigt beim, in der Erde lebenden seltenen primitivus ein eigenthümliches Verhalten, das an Tylencholaimus erinnert: sie wird nämlich bei dieser Art von zwei, auf einander gestellten, Scheiben gebildet, von welchen die vordere kleiner ist und die hintere grössere einen Kreis von Papillen trägt. Was die anderen Arten betrifft, so ist die Kopfregion beim elongatus am einfachsten ausgebildet, indem sie aus einem, vorn abgestumpften, ganz nackten, lippen- und papillenlosen knopfartigen 
Theile besteht. Höher ausgebildet ist sie bei denjenigen Formen, wo ein oder zwei Papillenkreise auf derselben vorkommen (gracilis, elegans, limnophilus, Hartingii u. s. w.). Bei allen anderen wird die Kopfregion aus sechs mehr oder weniger ausgeprägten Lippen gebildet, welche selten keine Papillen tragen (robustus, macrodorus), in den meisten Fällen aber mit zwei, hinter einander liegenden Kreisen dieser Gebilde gewaffnet sind; bisweilen sind diese Lippen so wenig ausgebildet, dass man sogar geneigt ist, ihre Anwesenheit in Zweifel zu ziehen (intermedius u. m. a. A.); am höchsten entwickelt ist die Kopfregion beim regius, superbus u. a. A., bei welchen Lippen und Papillen sehr ausgeprägt sind. Bei allen Arten scheinen, in der Einschnürung zwischen der Kopfregion und dem Körper, in den Medianlinien, Oeffnungen vorzukommen, von welchen aus sich eine Röhre nach innen fortzusetzen scheint, und von welchen ich öfters blasse obrförmige Gebilde hervorragen sah, deren Bedeutung mir zweifelhaft blieb: möglich stellen diese ein, aus diesen Organen ausgeschiedenes Secret dar. Die Mundöffnung führt in einen, bei fast allen Arten sehr wenig entwickelten, engen, trichteroder röhrenförmigen, den vorderen Theil des Stachels umschliessenden, von einer sehr zarten Chitinhaut bekleideten Raum, den ich, im Anschluss an den, bei den vorigen Gattungen auftretenden Verhältnissen, am liebsten als Vestibulum (und nicht als. Mundhöhle) betrachten möchte. Nur bei den, in der Erde lebenden rotundicauda und macrolaimus erhält dieses Vestibulum eine grosse Bedeutung, indem es sich als eine sehr gerăumige, mit starken Chitinwänden bekleidete Höhle darstellt, welche in der Kopfregion am weitesten ist und nach hinten allmälig enger wird. Am Grund des Vestibulums ist die Chitinhaut an einer Stelle ringförmig verdickt und von diesem Ringe läuft eine zarte Membran zum Stachel, sich mit diesem vereinigend; zweifelsohne dient diese Stachelmembran dazu, den Stachel in seinen Bewegungen zurück zu halten.

Das meist characteristische Merkmal der Dorylaimen ist der Stachel. Derselbe findet sich bei allen Arten ohne Ausnahme und stellt sich als ein holles, selten nadelförmiges (maximus, elongatus), meist aber gänsefederförmiges chitinwändiges Gebilde dar, dessen Lumen, das ich als Mundliöhle betrachte, eine directe Fortsetzung ist des Lumens des Oes., wälirend es an seinem vorderen Ende, meist in einer sclief liegenden Ebbene, geöffnet ist. Öfters beobachtet man am Stachel mehrere knötchenartige Verdickungen, welche, nach Bütschli, duxch seine allmälige Entwickelung aus ebenso vielen Reservestacheln entstehen. Bei jungen Thieren beobachtet man nämlich in der, den Stachel umgebenden muskulösen Wand einen kleinen spitzen Stachel, neben dem grossen liegend, den Reservestachel, welcher bei jeder Häutung dem alten, der bei der Häutung nicht verloren geht, bloss aufgesetzt zu werden scheint: durch diesen mehrmals wiederholten Vorgang scheinen nun die erwăhnten Verdickungen aufzu treten. Ich meine sogar diesen Vorgang der Aufsetzung eines Reservestachels auf dem alten Stachel beim primitivus beobachtet zu haben.

Die höchste Entwickelung erhält der Stachel beim seltenen macrodorus, und zwar durch Grösse und Bau: er besteht nämlich bei dieser Art aus einem vorderen, langen und dünnen Theile und aus einer hinteren Hälfte, welche von drei dünnen, nach dem, bei den Nematoden herrschenden Gesetze gerichteten Platten mit buchtigem Aussenrande gebildet wird. Bei keiner anderen Art trifft man 
eine solche Entwickelung dieses Organs an, das fast bei allen anderen nach einem gleichen und zwar viel einfacheren Typus gebaut ist.

Die Bewegungen des Stachels werden durch mehrere Muskeln, Rückzieher und Vorstrecker, ausgeführt. Der Oes. setzt sich, meist ein wenig angeschwollen, am hinteren Theile des Stachels fest und zeigt einen kürzeren oder längeren engen vorderen Theil, der allmälig oder mehr plötzlich in den hinteren erweiterten Theil übergeht; besonders dieser hintere Theil ist fast immer stark muskulōs, nur der primitivus schien mir auch in dieser Hinsicht eine Ausnahme zu machen. Das Chitinrohr ist im vorderen Theile sehr enge, im hinteren ebenso erweitert und scheint sechsseitig zu sein. Der vordere enge Theil des Oes. wird vom Nervenring umfasst. Ocellen fehlen immer, wenn nicht die, von von Linstow bei seinem flavomaculatus beobachteten Flecken am vorderen Körperende als solche betrachtet werden müssen. Auf der Grenze zwischen dem Oes. und dem Darme beobachtete ich bei einigen Arten zellige Gebilde, welche besonders beim Hartingii sehr entwickelt sind: leider wurden dieselben nicht weiter von mir erforscht. Die Darmwand wird aus polyedrischen Zellen gebildet, welche ganz oder theilweise mit kleinen gelbbraunen Körnchen aufgefüllt sind und ein eigener Enddarm findet sich bei allen; Analmuskeln kommen beiden Geschlechtern zu. Die weibl. Geschlechtsorgane sind fast immer paarig symmetrisch, an beiden Seiten der Vagina gelegen: nur bei D. monohystera und D. limnophilus findet man eine einseitige Geschlechtsröhre. Ihre Ausdehnung ist bei den einzelnen Arten verschieden; die Ränder der Vulva sind meist stark chitinisirt, die Scheide öfters mit Ring- und Längsmuskulatur versehen, und die zurückgeschlagenen Ovarien bleiben verhältnissmässig klein; die Zahl der relativ kleinen Eier, welche man im Uterus. beobachtet, ist fast immer gering. Der Hoden ist wohl immer zweitheilig, so, nach Bütschli, beim Leuckarti und stagnalis, und, wie ich hinzufügen kann, auch beim borboroplitus nnd longicaudatus. Stets finden sich zwei gleiche Spicula, welche fast immer eine plumpe Gestalt haben, ein wenig gebogen sind, und einen oder zwei, meist sich mit einander vereinigende Verdickungsstreifen zeigen; nur beim primitivus haben die Spicula ein sehr abweichendes Vorkommen. Meist werden die Spicula von zwei verhältnissmässig kleinen, stabförmigen, öfters zugespitzten accessorischen Stücken begleitet, welche aber bei einigen Formen vollständig fehlen können (parvus, brigdammensis).

Am hinteren Körperende des Männchens lommen stets Papillen vor; meist liegen dieselben nur präanal, doch giebt es auch Arten, bei welchen dieselben sowohl vor wie hinter dem After beobachtet wurden, z. B. beim borborophilus und acuticauda und wahrscheinlich wohl bei mehreren anderen. Die präanalen Papillen liegen bei den meisten Arten in einer Reihe in der ventralen Medianlinie, nur der, das süsse Wasser bewohnende stagnalis und der, auch in anderen Beziehungen abweichende borborophilus machen in dieser Hinsicht eine bemerkenswerthe Ausnahme. Bei den meisten Arten liegt gleich vor und bei dem After eine Papille, welche ich als Analpapille bezeichnen will, während die übrigen öfters mehr nach vorn gerückt sind; bei einigen liegen diese Papillen in bestimmten Entfernungen von einander, während sie bei anderen fast unmittelbar neben einander vorkommen. Thre Zahl, welche bei den einzelnen Formen sehr verschieden ist und ihre Lage geben dann auch ofters gute Artmerkmale ab. 
Fundort und Lebensweise. Die Gattung Dorylaimus liefert unter allen anderen das grösste Kontingent freilebender Rundwürmer: fast ein Viertel von allen, in dieser Arbeit beschriebenen Formen gehört dieser Gattung $z u$. Bei weitem die meisten bewohnen die feuchte, humusreiche oder sandige Erde, wo sie zwischen Pflanzenwurzeln leben und sich mit Pflanzensäften, welche sie durch den Stachel aufsaugen, nähren; andere bewohnen das süsse Wasser unserer Flüsse, Teiche und Gräben, wie der schon lange bekannte, weit verbreitete stagnalis, der filiformis, u. a. Einige wenige Formen beobachtete Bastian zwischen Blattscheiden von Gramineen, eine (borborophilus) fand ich in Kuhmist und eine Art (marina) soll Dujardin sogar im Meere angetroffen haben. Im Allgemeinen sind die Dorylaimen ziemlich häufig und die agricolen Arten scheinen theilweise auch an bestimmten Gründen gebunden zu sein, wie z. B. bryoplitus, microdorus, elegans u. a., welche ich ausschliesslich im sandigen Boden der Dünenstriche beobachtete. Die Männchen sind fast immer seltener als die Weibchen und blieben mir, bei der grösseren Hälfte der beobachteten Formen, gänzlich unbekannt. Es sind meist lebhafte Thiere, doch giebt es auch Arten, welche ziemlich träge Bewegungen ausführen (elongatus).

Ausser den, von mir beobachteten, in der reinen Erde und im süssen Wasser lebenden Formen, wurden noch die folgenden Arten beschrieben; dieselben gehören den Gruppen $\alpha, \beta, \gamma$ und $\varepsilon$, meiner zweiten Abtheilung (B) zu:

B.

$\alpha$.

D. maximus Btsli. (Bütschli, XXI, pag. 19, Taf. I, Fig. 1 $a-c$ ). . . Deutschland, in Gartenerde. Dem elongatus nächst verwandt.

$\beta$.

D. borborophilus d. M., (de Man, XXVI, pag. 25, Pl. IV und V, Fig. 8a-i). o7\%. Holland, in Kuhmist.

D. polyblastus Bast., (Bastian, VII, pag. 108, Pl. X, Fig. 50, 51), ऽ'. England, in Moos. Dem Männchen des obtusicaudatus verwandt.

D. papillatus Bast. (Bastian, VII, pag. 108, Pl. X, Fig. 52, 53), ․ England, zwischen Blattscheiden von Gramineen.

D. tritici Bast. (Bastian, VII, pag. 10\%, Pl. X, Fig. 45-47), 67. England, in sandiger Erde und auch zwischen den Blattscheiden des Weizens.

D. minutus Btsli. (Bütschli, XX, pag. 30, Taf. I, Fig. $6 a-b)$, \&. Deutschland, dem bryophitus verwandt.

D. pachysoma v. Linst., (von Linstow, XXIX, pag. 8, Taf. I, Fig. 15). Deutschland, unter Moos; dem bryoplitus ähnlich. 
$\gamma$

D. torpidus Bast. (Bastian, VII, pag. 108, Pl. X, fig. 54-56). శ79. England, zwischen Blattscheiden von Gramineen.

D. iners Bast. (Bastian, VII, pag. 109, Pl. X, Fig. 5\%-59). ठㅇ. England, in Moos.

$\varepsilon$.

D. tenuicaudatus Bast. (Bastian, VII, pag. 10\%, Pl. IX, Fig. 43, 44). ․ England, im Schlamme.

D. flavomaculatus v. Linst. (von Linstow, XXIX, pag. 6, Taf. I, Fig. 13). Deutschland, in Schlamm. Scheint Ocellen zu besitzen.

D. palustris Carter. (Vergl. Bastian, VII, pag. 109). 0º. Bombay, im süssen Wasser; dem stagnalis verwandt.

Als zweifelhafte Arten möchte ich vorläufig die folgenden betrachten:

D. fasciatus v. Linst. (von Linstow, XXXIII, pag. 165, Taf. XI, Fig. 1 und 2). Deutschland, Hameln, gehört der Gruppe $\gamma$ an.

D. linea Grube. (Vergl. Bastian, VII, pag. 109). Dorpat, soll 8 Linien lang werden; dem stagnalis verwandt.

D. liratus Schn. (Schneider, XII, S. 59, Taf. IV, Fig. 15 und 16). Berlin, im Schlamme; soll nach Schneider hermaphrodit sein.

D. marinus Duj. (Vergl. Bastian, VII, pag. 110), soll im Meere an der Westküste Frankreichs gefunden sein.

Die 36 von mir beobachteten Formen lassen sich durch die folgenden Merkmale unterscheiden:

1. Typische Arten

2.

Abweichend gebaute, nur 0,75 mm. lange Art; Kopfregion wie bei Tylen-

cholaimus gebaut, Oes. nicht muskulös. Schwanz stumpf . . . . . .

2. Stachel gewöhnlich, die Form einer Gänsefeder nachahmend . . . .

1. primitivus.

Stachel sehr verlängert, nadelförmig; Körper fadenförmig, Kopfregion ohne Lippen oder Papillen. Beim ơ 10 prăanale Papillen. . . . .

3. Vestibulum typisch, klein . . . . . . . . . . . . . . . . .

2. elongatus.

Vestibulum sehr gross, von dicken, chitinisirten Wänden umgrenzt .

4.

35.

4. Schwanz bei beiden Geschlechtern kurz . . . . . . . . . . .

5.

Schwanz beim Weibchen verlängert. . . . . . . . . . .

26.

5. Schwanz mehr oder weniger abgerundet

6. 
Schwanz zugespitzt . . . . . . . . . . . . . . . .

6. Weibl. Geschlechtsorgane paarig . . . . . . . . . . . . . . .

Weibl. Geschlechtsorgane einseitig; \& 1,3 mm. lang, Körper schlank

16. monohystera.

\%. Kopfregion typisch, mit Lippen und meist auch mit Papillen . . . .

8.

Kopfregion breit und niedrig, ohne Lippen, mit concaver Mundfläche, mit nur einem einzigen Kreise grosser Papillen. Letzter Dritttheil des Oes. mässig erweitert

15. el egans.

8. Stachel nicht auffallend gross . . . . . . . . . . . . . .

Stachel 1/4 des Abstandes der Mundöffnung zum Darme lang

9.

9. Schwanz nicht angelförmig

8. macrodorus.

10.

Schwanz angelförmig; Körper schlank, Lippen mit zwei Kreisen von Papillen, hintere Hälfte des Oes. erweitert.

17. centrocercus.

10. Grössere Arten, länger als $1,5 \mathrm{~mm}$. . . . . . . . . . . . . . 11.

Kleinere Arten, höchstens 1 mm. lang, von plumper Gestalt . . . . 19.

11. Schwanz kegelförmig, mit abgerundeter Spitze . . . . . . . . . 12.

Schwanz sehr kurz, stumpf oder bogenförmig abgerundet . . . . . 15.

12. Arten länger als $3 \mathrm{~mm}$. . . . . . . . . . . . . . . . . . 13

Art, 1,8 mm. lang, mit wenig verschmälertem Vorderende und schlankem Körper

12. pratensis.

13. Vorderende nicht eingeschnürt . . . . . : . . . . . . . . . 14.

Vorderende in der Năhe der Stachelmembran eingeschnürt . . . . 4. labiatus.

14. Die zwei hinteren Dritttheile des Oes. erweitert . . . . . . . . 3. regius.

Nur die hintere Hälfte des Oes. angeschwollen . . . . . . . 6. superbus.

15. Arten kleiner als $4 \mathrm{~mm}$. . . . . . . . . . . . . . . 16 .

Die Art erreicht die Grösse von $7 \mathrm{~mm}$; beim or 40 einander sehr genäherte präanale Papillen . . . . . . . . . . . . . . , .

16. Hinterende des Körpers nie kolbig gestaltet . . . . . . . . . .

5. robustus.

17

Hinteres Körperende kolbig; Körper schlank, weibl. Genitalien auffallend kurz

1\%. Hintere Halfte des Oes. angeschwollen

Die zwei hinteren Dritttheile des Oes. erweitert, Körper sehr schlank

18. Cuticula des Schwanzes eigenthümlich geschichtet, beim Männchen 1921 Papillen vor dem After

$a b t u \operatorname{sic} a u d a t u s$

Schwanzeuticula nicht auffallend geschichtet, Männchen mit 7-11 präanalen Papillen

11. intermedius.

19. Oes. in seiner Mitte in den dickeren hinteren Theil übergehend . . 13. bryophilus. Oes. hinter der Grenze des letzten Dritttheiles plötzlich anschwellend. 14. mi crodorus. 
20 Lippen mehr oder weniger scharf ausgeprägt . . . . . . . . . Lippen fehlend . . . . . . . . . . . . . . . . . .

21. Arten, grösser als $1 \mathrm{~mm}$. . . . . . . . . . . . . . . .

Nur $0,63 \mathrm{~mm}$. lange Art, von plumper Gestalt; weibl. Geschlechtsöffnung ein wenig hinter der Mitte; Vorderende sehr wenig verjüngt . . . .

22. Körper schlank oder sehr schlank . . . . . . . . . . . . . . 23. $p a r v u s$. Körper wenig schlank; weibl. Geschlechtsöffnung ziemlich weit hinter der Körpermitte, Geschlechtsorgane gross; 16 Papillen vor dem After beim Männchen

23. Grössere Art, wird länger als $3 \mathrm{~mm}$; Vorderende sehr wenig verjüngt, weibl. Geschlechtsöffnung in der Mitte 21. similis. Arten nur $2 \mathrm{~mm}$. lang .

24.

24. Postvaginaler Theil der Geschlechtsorgane weiter ausgedehnt als der halbe Abstand zwischen Vulva und After 19. Leuckarti. Postvaginaler Theil nur 1/3 des Abstandes zwischen Geschlechtsöffnung und After lang . . . . . . . . . . . . . . . . . . . . . 20. Garteri.

25. Postvaginaler Theil der Geschlechtsorgane ein wenig lãnger als der halbe Abstand zwischen Vulva und After 18. gracilis. Postvaginaler Theil nur $1 / 4$ des Abstandes zwischen Vulva und After lang

26. Schwanz beim Weibchen mehr oder weniger regelmässig verschmälert, zugespitzt und meist nach der Bauchseite gebogen . . . . . . . . Schwanz beim Weibchen fadenförmig . . . . . . . . . . .

2\%. Körper ziemlich schlank . . . . . . . . . . . . . . . . . Körper sehr schlank; weibl. Geschlechtsöffnung in der Mitte, ihre Entfernung vom Hinterende des Oes. 11/2 mal so lang als dieser Körpertheil

28. Grössere Art (1,6 mm.), bei welcher die Geschlechtsöffunng noch fehlt bei einer Länge von $1,2 \mathrm{~mm}$. - 27. $a g i l i s$. Art nur $1 \mathrm{~mm}$. lang, Vorderende wenig verschmälert . . . . . . 25. lugdunensis.

29. Weibl. Geschlechtsorgane paarig symmetrisch . . . . . . . . . Weibl. Geschlechtsorgane unpaar, Lippen fehlen . . . . . . . . .

30. Grössere Arten, länger als $4 \mathrm{~mm}$. . . . . . . . . . . . . . . Arten, kleiner als $4 \mathrm{~mm}$. . . . . . . . . . . . . . . . . .

31. Körper sehr schlank, bis 7,5 mm. lang. Im süssen Wasser . . . . . Körper plump, dick, nur 5 mm. lang. In der Erde . . . . . . .

32. Körper fadenförmig, Lippen fehlend, Stachel zart . . . . . . . . Körper nicht fadenförmig. Lippen vorhanden . . . . . . . . . . 33. Schwanz fadenförmig 30. 28. limnophilus. 31. 32. 30. stagnalis. 31. crassus. 32. filiformis. 33. 34. 
Schwanz etwas hinter dem After plötzlich verschmälert, um dann bis an das wenig zugespitzte Hinterende in ungefähr gleicher Stärke fortzulaufen . . . . . . . . . . . . . . . . . . . . . . .

34. Aeussere weibl. Geschlechtsöffnung noch fehlend bei einer Grösse von 2 mm.; Männchen mit 23-27 prăanalen Papillen . . . . . . . . . Das Thier producirt, 1,8 mm. gross, schon Eier; Männchen mit 6-7 präanalen Papillen . . . . . . . . . . . . . . . . . . .

35. Schwanz beim Weibchen abgerundet, stumpf . . . . . . . 35. rotundicauda. Schwanz des Weibchens fadenförmig, des Männchens stumpf abgerundet, der letztere mit 19 pråanalen Papillen .. . . . . . . 36. ma crola imus.

A. Abweichende Art, welche sich in ihren Organisationsverhältnissen den Tylencholaimen und Tylenchen anschliesst.

\section{Dorylaimus primitivus d. M.}

Taf. XXIV, Fig. 103.

б $0,6-0,75 \mathrm{~mm}$., 우 $0,5-0, \% \mathrm{~mm}$. a beim $\sigma^{7} 22$, beim 우 $18 . \beta=4$. $\gamma$ beim $\sigma^{7} 40-45$, beim 우 $75-100$.

Wie ich schon in der Gattungsbeschreibung hervorgehoben habe, weicht diese interessante Art in mehreren Beziehungen von den anderen, typischen Dorylaimen ab. Sie hat eine plumpe Gestalt, welche sich nach vorn hin wenig verschmälert; wie bei den anderen Arten ist auch ihre Cuticula glatt. Die Kopfregion (Fig. 103a, Fig. 103b, Fig. 103c) ist abgesetzt, wie bei Tylencholaimus gebaut, und besteht aus zwei, auf einander sitzenden Scheiben, von welchen die vordere kleiner ist und die hintere grössere einen Kreis von (6?) ziemlich kleinen Papillen trägt. Lateralöffnungen finden sich bei diesem Thiere wie bei den typischen Dorylaimen; aus denselben sah ich ohrförmige blasse Gebilde hervorragen, vielleicht ein ausgeschiedenes Secret darstellend. Der Stachel ist lang und dünn, stets nach der dorsalen Seite gebogen und liegt in Bezug auf die beiden lateralen Seiten des Thieres symmetrisch; 'seine Länge betrăgt ungefähr $1 / 3$ des Abstandes zwischen der Mundöffnung und dem Darm: eine Stachelmembran beobachtete ich nicht und als dieselbe wirklich fehlen sollte, wurde das Thier hierdurch so wie durch die Länge des Stachels auch wieder abweichen. Der Oes. erweitert sich vom linteren Ende des Stachels ab ganz allmälig nach hinlen und schwillt taschenförmig an; in seiner Wand beobachtete ich keine Muskelfbrillen, sondern eine kleine Zahl grosser Kerne, und das selir enge, von einer zarten Chitinhaut bekleidete Lumen schien mir nicht sechsseitig zu sein. Weil die Darmwand nur sehr sparsam mit kleinen Körnchen aufgefüllt ist, ist das Thier bei durchfallendem Lichte sehr durchscheinend.

Die Ausmündungsöffnung der weibl. Geschlechtsorgane (Fig. 103d) ist kreisförmig und befindet sich ungefähr in der Körpermitte; die weibl. Geschlechtsorgane sind paarig symmetrisch und strecken 
sich nach beiden Seiten weit aus. Bei beiden Geschlechtern ist der Schwanz sehr kurz, besonders beim Weibchen (Fig. 103e) und stumpf abgerundet. Beim Männchen (Fig. 103) stehen drei mediane Papillen vor dem After, in gleichen Entfernungen von einander, von welchen die hinterste ein wenig hinter dem inneren Ende der Spicula liegt. Die Spicula zeigen eine ganz andere Gestalt wie bei den übrigen Dorylaimen: sie sind verhältnissmässig sehr lang, nach innen zu keilförmig erweitert, nach aussen sehr enge auslaufend (Fig. 103f) und ein wenig gebogen; zwei stabförmige, geradlinige, accessorische Stücke begleiten dieselben. Der Hoden streckt sich fast bis an den Oes. aus und die Cuticula zeigt beinz Männchen vor dem After keine schräge Streifung.

Fundort und Lebensweise. Diese merkwürdige, seltene Art bewohnt die feuchte, oder von süssem Wasser mehr oder weniger getränkte Erde der Niederländischen Wiesen. Das Thierchen, das zu den kleineren Arten gehört, erscheint immer lebhaft in seinen Bewegungen. Bis jetzt wurde es nirgendwo sonst beobachtet.

Fundzeit. In den ersten Monaten des Jahres (Januar, Februar, März) traf ich unsere Thiere geschlechtsreif an.

B. Typisch gebaute Dorylaimen.

«. Gruppe, mit sehr verlïngertem, engem, zugespitztem, also nadelförmigem Stachel. Typ: Dorylaimus maximus Btsli.

\section{Dorylaimus elongatus d. M.}

de Man, XXVI, pag. 19, Pl. III, Fig. $4 a-c$.

Synon: Dorylaimus tenuis v. Linst., (von Linstow, XXXIII, pag. 166).

Taf. XXV, Fig. 104 .

$\sigma^{7}$ 우 5,5 mm. $\alpha$ beim $\sigma^{7} 120$, beim 우 100-110. $\beta=12 . \gamma=100-110$.

Wiè der, von Bütschli beobachtete, eine Länge von $11 \mathrm{~mm}$. überschreitende maximus, dem er am meisten verwandt ist, besitzt auch der elongatus einen äusserst schlanken, fadenförmigen Körper, der sich nach vorn hin måssig verjüngt. Die einfach gebaute Kopfregion ist kaum abgesetzt, ganz nackt, oline Lippen oder Papillen und hat eine abgestumpfte Vorderfläche. Der Stachel ist demjenigen des maximus ähnlich, und weicht vom Stachel der anderen Dorylaimen durch Länge und Bau ab: er ist nämlich sehr verlängert, enge, zugespitzt, nadelförmig, zeigt aber die, auch bei den anderen Arten vorkommenden Verdickungen; eine Stachelmembran ist vorhanden. Der Oes. ist in seinem vorderen Theile sehr enge und nur sein letzter Dritttheil ist sehr erweitert; die Darmzellen sind nur sparsam mit Körnchen aufgefüllt.

Die weibl. Geschlechtsöffnung liegt in der Körpermitte und die sehr kurzen weibl. Geschlechts- 
organe sind paarig symmetrisch. Bei beiden Geschlechtern hat der Schwanz die gleiche Gestalt, sehr kurz, kegelförmig, stumpf abgerundet. Beim Männchen (Fig. 104a) finden sich 10 mediane Papillen vor dem After, in gleichen Entfernungen von einander, von welchen die hinterste in der Nähe des Afters gelegen ist; die Spicula sind plump, ein wenig gebogen, mit centralen Verdickungsstreifen und werden von zwei accessorischen Stücken begleitet. Die präanale schräge Streifung ist sehr deutlich.

Fundort und Lebensweise. Der elongatus, ein ziemlich träge sich bewegendes Thier ist nicht gerade selten und bewohnt die feuchte, sandige Erde unserer Wiesen so wie auch den sandigen Dünenboden.

Geograplische Verbreitung. Deutschland (Hameln, von Linstow).

Fundzeit. Wahrscheinlich das ganze Jahr hindurch findet man geschlechtsreife Individuen dieses Thieres: in den fünf letzten Monaten des Jahres so wie in Februar, März und April fand ich es in diesem Zustande.

ß. Gruppe mit gewöhnlichem, nicht nadelförmigem Stachel und mit einem kurzen, mehr oder weniger abgerundeten Schwanz bei beiden Geschlechtern. Typus\}, z. B.: Dorylaimus obtusicaudatus Bast.

\section{Dorylaimus regius d. M.}

de Man, XXVI, pag. 15, PI. III, Fig. 2a-d. (Kopfende, oesophagealer Körpertheil, Schwanz).

Taf. XXV, Fig. 105.

ㅇ 8,6 mm., o unbekannt. $\alpha=60 . \beta=\gamma-7 / 2 . \gamma=90-110$.

Auch diese Art besitzt einen selır schlanken Körper, der sich nach vorn hin allmälig, obgleich nur wenig verschmälert. Die Cuticula wird von zahlreichen, über der ganzen Oberflüche des Körpers vorkommenden Hautpapillen durchsetzt, welche einen ähnlichen Bau zeigen wie diejenigen des D. maximus Btsli. Die Kopfregion ist abgesetzt, wird von 6 selr entwickelten Lippen und zwei Kreisen mässig grosser Papillen gebildet. Der Stachel ist ziemlich kräftig; bei einem $7,4 \mathrm{~mm}$. langen Weibchen, dessen Uterus schon Eier enthielt, fand sich neben dem Stachel noch ein Reservestachel : die Erneuerung des Stachels scheint also lange Zeit zu dauern. Der vorderste Theil des Oes. ist ein wenig angeschwollen, geht dann in einen kurzen, sehr engen, vom Nervenringe umfassten Theil über, der schliesslich in den, die zwei linteren Dritttheile seiner Länge einnehmenden erweiterten Theil endigt. Die weibl. Geschlechtsöffnung liegt ein wenig hinter der Korpermitte, fehlt noch bei einer Grösse von 3,2 mm. und die Geschlechtsorgane sind paarig symmetrisch; im Uterus beobachtete ich fünf Eier. Der Schwanz ist sehr kurz, kegelförmig, mit abgerundeter Spitze.

Fundort und Lebensweise. Diese schöne Art, welche zu den grössten agricolen Nematoden 
gehört, ist leider sehr selten: nur einige Male hatte ich das Glück dieselbe zu finden. Sie lebt in der feuchten Erde unserer Wiesen an Wurzeln von Moos, Gräsern u. s. w.; das Männchen blieb leider unbekannt.

Geographische Verbreitung. In keinem anderen Lande noch beobachtet.

Fundzeit. In den Sommermonaten (Mai, August) geschlechtsreif.

\section{Dorylaimus labiatus d. M.}

Taf. XXV, Fig. 106.

○ unbekannt, ㅇ $3,5 \mathrm{~mm} . \alpha=50-55 . \beta=41 / 2-5 . \gamma=45-50$.

Auch diese Art hat eine sehr schlanke Gestalt und verschmälert sich sehr nach vorn hin. Die Kopfregion wird von 6 abgerundeten, sehr ausgeprägten Lippen zusammengesetzt, welche zwei Kreise ziemlich grosser Papillen tragen. In einer geringen Entfernung linter der Kopfregion ist der Körper, in der Nähe der Stachelmembran, ein wenig eingeschnärt, verengt (Fig. 106b). Der Stachel ist kräftig. Der Oes. geht fast in seiner Mitte allmälig in den hinteren weiteren Theil über. Die weibl. Geschlechtöffnung befindet sich ein wenig hinter der Körpermitte; die, bei $2 \mathrm{~mm}$. langen. Thieren noch fehlenden Genitalien sind paarig symmetrisch, und seltr kurz, sodass der postvaginale Theil (bei erwachsenen Thieren) nur $1 / 4$ des Abstandes der Geschlechtsöffinung zum After lang ist. Der Schwanz ist plump, kurz, kegelförmig, zugespitzt.

Fundort und Lebensweise. Wie die vorige, gehört auch diese Art zu den sehr seltenen Nematoden; sie bewohnt den sandigen Boden der Dünenstriche und der, im Osten der Niederlande gelegenen Heidegründe. Gleich erkennt man sie unter den verwandten Formen an der characterischen Einschnürung des Kopfendes. Bis jetzt sonst nirgendwo beobachtet.

Fundzeit. In den Sommermonaten (Juli, August) geschlechtsreif.

5. Dorylaimus robustus d. M.

de Man, XXVI, pag. 1\%, Pl. III, Fig. 3 $a-d$. (Kopfende, oesophagealer

Körpertheil, hinteres Körperende des Männchens).

Taf. XXV, Fig. $10 \%$

$\sigma^{2}+7 \mathrm{~mm} . \alpha$ beim $\sigma^{\top}=40-45$, beim $ᄋ=50 . \beta=5 . \gamma$ beim $\sigma^{\top}=160$, beim $q=100$.

Der seltene robustus besitzt einen sehr schlanken Körper, dessen Vorderende sich sehr verjüngt, sodass die Körperdicke am hinteren Ende des Oes. viermal so gross ist als am Grund der Kopfregion, und der, sich nach hinten ebenso, obgleich weniger verschmälernd, in einen sehr kurzen Schwanz endigt. In der Nähe der Stachelmembran zeigt das Thier nicht die für den labiatus characteristische 
Einschnürung des Körpers. Die Kopfregion ist abgesetzt und wird von sechs, kaum von einander abgetrennten, stumpfen, papillenlosen Lippen gebildet. Die Lateralöffnungen verhalten sich typisch. Der Stachel ist ziemlich zart und der Oes. erweitert sich allmälig ein wenig vor seiner Mitte, wodurch er ein characteristisches Vorkommen zeigt; die Darmwand ist fein gekörnt.

Die weibl. Geschlechtsöffnung liegt gerade auf der Mitte des Körpers; die Geschlechtsorgane sind paarig symmetrisch und der postvaginale Theil nimmt $1 / 4$ der Entfernung der Geschlechtsöffnung vom After ein. Beim Männchen beobachtet man eine mediane Reihe von 40 einander sehr.genäherten präanalen Papillen, von welchen die hinterste 0,4 mm. vom After entfernt liegt; diese kleinen, niedrigen und scheibenförmigen Papillen zeigen ein stumpfes Spitzchen und werden von deutlichen Nerven innervirt. Gleich vor dem After liegt die ganz ähnlich gebaute Analpapille. Die lateralen präanalen Körperseiten zeigen die gewöhnliche schräge Streifung. Die Spicula (Fig. 10\%a) haben eine mässig schlanke Gestalt, sind etwas gebogen, laufen nach beiden Enden hin ziemlich spitz zu und zeigen einen centralen Verdickungsstreif: zwei kurze, stabförmige, spitze accessorische Stücke begleiten dieselben. Kräftig ausgebildet sind die Rückziehmuskeln dieser Organe. Bei beiden Geschlechtern ist der Schwanz sehr kurz, stumpf zugespitzt.

Fundort und Lebensweise. Der robustus gehört zweifelsohne zu den seltenen Arten der Gattung Dorylaimus; er bewohnt die feuchte Erde der Wiesen und Marschgründe Hollands und ich fand das Männchen an den Wurzeln von Phragmites.

Geographische Verbreitung. Nirgendwo sonst beobachtet.

Fundzeit. Geschlechtsreif ist dieses Thier im Spätherbst, (November).

Anmerkung. Während das Mãnnchen sich durch die grosse Papillenzahl auszeichnet, ist es schwieriger das Weibchen von den verwandten Formen zu unterscheiden.

6. Dorylaimus superbus d. M.

Taf. XXKL, Fig. 108.

$\sigma^{7}$ ㅇ $4,5 \mathrm{~mm} . \alpha=30-40 . \beta=5$. $\gamma$ beim $\sigma^{7} 60-75$, beim $ᄋ 60-85$.

Die allgemeine Körpergestalt dieser schönen Art ist bald mehr, bald weniger schlank, je nach dem Entwickelungsgrade der Gesehlechtsorgane. Die Kopfregion ist abgesetzt und wird von 6 sehr entwickelten Lippen gebildet, welche zwei Kreise von Papillen tragen; auf der Grenze des Oes. und des Darmes ist der Körper fünfmal so breit als am Grund der Kopfregion: das Vorderende des Körpers ist also sehr verschmälert. Der Stachel ist ziemlich kräftig. Die vordere Hälfte des Oes. ist schmal und geht ungefähr in der Mitte desselben allmälig in den hinteren erweiterten Theil über.

Beim erwachsenen Weibchen liegt die Geschlechtsöffnung ein wenig vor der Mitte, bei jüngeren Individuen welche nur noch die Länge von $3,8 \mathrm{~mm}$. erreicht haben, obwohl ihre Geschlechtsorgane vollständig entwickelt sind, befindet sich dieselbe etwas linter der Mitte des Körpers; die Geuitalien sind paarig symnetrisch, und strecken sich an beiden Seiten der Geschlechtsöffnung weit aus: der 
vordere Theil bis in die Nähe des hinteren Endes des Oes., der hintere Theil ungefähr bis auf die Hälfte des Abstandes zwischen Geschlechtsöffnung und After; die Zahl der im Uterus beobachteten Eier ist gross, denn ich sah deren ungefähr zehn. Der Schwanz hat bei beiden Geschlechtern die gleichc, ein wenig veränderliche Gestalt, kurz, kegelförmig, mit mehr oder weniger abgerundeter Spitze. Beim Månnchen beobachtet man, ausser der Analpapille, eine mediane Reille von 14-18 an einander grenzenden Papillen, von welchen die hinterste ein wenig vor dem inneren Spicula-ende gelegen ist. Fast auf der ganzen Strecke, wo die Papillen liegen, erkennt man wieder die feine schrăge Streifung an den lateralen Seiten des Körpers. Die Spicula (Fig. 108e) sind schlank, gebogen, zeigen zwei centrale Verdickungsstreifen und werden von zwei kleinen, stabförmigen, accessorischen Stücken begleitet.

Fundort und Lebensweise. Dieses ziemlich lebhafte Thier ist gar nicht selten und liebt die feuchte Erde der Wiesen, wie auch den mehr trocknen sandigen Boden der Dünenstriche. Beide Geschlechter sind gleich häufig bei dieser Art, welche dem Dor. regius und dem Dor. obtusicaudatus am meisten ähnlich ist.

Geographische Verbreitung. Deutschland (Laibach).

Fundzeit. Sowohl im Winter (Februar, März) wie im Sommer (August), fand ich geschlechtsreife Individuen.

Anmerkung. Ich vermuthe dass die, von Bütschli, XX, pag. 2\%, Taf. I, Fig. $1 a \cdots b$ unter dem Namen D. papillatus beschriebene und abgebildete Form mit meinem superbus identisch ist. Der Unterschied liegt bloss in der geringeren Grösse und in der Lage der weibl. Geschlechtsöffnung.

\%. Dorylaimus obtusicaudatus Bast.

Bastian, VII, pag. 106, Pl. IX, Fig. 41, 42.

Synon: Dorylaimus papillatus, de Man, XXV1, pag. 21, Pl. IV, Fig. 5.

Nec: Dorylaimus papillatus, Bütschli, XX, pag. $2 \%$.

Taf. XXVI, Fig. 109.

$\sigma^{7}$ 2,3 mm: $q 3,3 \mathrm{~mm}$. a beim Männchen 30 -35, beim Weibchen 25-30. $\beta=4-5 . \gamma$ beim Männchen 75 - 80 , beim Weibchen $60-100$.

Der Körper dieser, wie es scheint, weit verbreiteten Art hat eine mässig schlanke Gestalt, das Mănnchen ist meist aber ein wenig schlanker als das Weibchen; er verschmälert sich ziemlich stark nach vorn hin: an der Grenze des Oes. und des Darmes ist der Körper viermal so breit als am Grund der Kopfregion. Diese (Fig. 109a) ist abgesetzt und besteht aus 6 sehr ausgeprägten Lippen, welche zwei Kreise mässig grosser Papillen tragen; der Stachel ist kräftig. Ungefähr in seiner Mitte, geht der vordere schmälere Theil des Oes. allmälig in den hinteren erweiterten Theil über; in der Darmwand 
erscheinen die feinen Körnchen entweder gleichmässig verbreitet oder die Zellen treten durch die, zu Häufchen gruppirte Lagerung der Körnchen deutlicher hervor.

Was die Entwickelung der weibl. Geschlechtsorgane betrifft, so findet man bei dieser Art dieselbe Erscheinung, welche ich auch beim Tylenchus filiformis, und beim Mononchus papillatus beschrieben habe, nämlich diejenige, dass die Weibchen bald früher, bald später geschlechtsreif sind. Individuen, welche die Länge von 1,8 mm. erreicht haben und Eier produciren, also geschlechtlich vollkommen entwickelt sind, wurden zu gleicher Zeit an derselben Stelle beobachtet mit schon $2 \mathrm{~mm}$. langen Exemplaren, bei welchen die Geschlechtsorgane im Anfang ihrer Entwickelung waren; das Weibchen erreicht aber die Grösse von 3,3 mm. Die weibl. Geschlechtsöffnung liegt in der Körpermitte; die Genitalien sind paarig symmetrisch, ziemlich kurz, der postvaginale. Theil ist ungefähr $1 / 3$ des Abstandes zwischen Geschlechtsöffnung und After lang; zwei Eier wurden im Uterus beobachtet.

Der Hoden des Männchens ist zweitheilig und streckt sich ziemlich weit nach vorn hin aus; die Spicula (Fig. 109e) sind ziemlich gross und schlank, etwas gebogen, mit einem centralen Verdickungsstreife und mit zwei stabförmigen accessorischen Stücken. Ausser der Analpapille, beobachtet man eine mediane Reike von 19-21, an einander grenzenden Papillen vor dem After.

Der Schwanz hat bei beiden Geschlechtern eine ziemlich gleichartige, ein wenig veränderliche Gestalt; er ist selır luurz, stumpf abgerundet und seine Cuticula ist beim Weibchen (ob auch beim Männchen?) auf einer, für die Art selir characteristischen Weise geschichtet (Fig. $109 b$ und 109c).

Fundort und Lebensweise. Die Männchen dieser Art beobachtet man selten; ich fand dieselben in feuchter, oder von süssem oder brackischem Wasser durchtränkter Erde unserer Wiesen und Marschgründe. Das Weibchen im Gegentheile gehört zu den äusserst läufig vorkommenden, omnivagen Arten; ich beobachtete es überall, in allen Gründen dieses Landes. Die Thiere bervegen sich ziemlich trăge.

Geographische Verbreitung. Deutschland (Erlangen, Laibach). England (Sydenham und Falmouth nach Bastian).

Fundzeit. Das ganze Jahr hindurch wurden geschlechtsreife Thiere beobachtet.

Anmerkung. In der früher gegebenen Diagnose diesex Art (de Man, XXXV, pag. 81), beschrieb ich auch eine zweite Form des Männchens: ich bin jetzt aber von der Unrichtigkeit dieser Meinung überzeugt und zweifle nicht dass das jetzt beschriebene das wahre ist. Das andere gehört einer anderen Art zu.

8. Dorylaimus macrodorus d. M.

Taf. XXVI, Fig. 110.

$\sigma^{7}$ unbekannt, ㅇ $1,8 \mathrm{~mm} . \alpha=25 . \beta=41_{2}-5 . \gamma=70-80$.

Von allen anderen Arten dieser grossen Gruppe unterscheidet sich der macrodorus durch die Länge des Stachels.

Das Thier hat eine wenig schlanke Gestalt und verjüngt sich wenig nach vorn hin. Die Kopf- 
region (Fig. 110a) ist abgesetzt, und wird von 6 wenig ausgeprägten, papillenlosen Lippen zusammengesetzt; die Lateralöffnungen sind typisch gebaut. Höchst characteristisch ist der Stachel, der sich durch Grösse und Bau von demjenigen aller anderen Dorylaimen unterscheidet und $1 / 4$ des Abstandes der Mundöffnung zum Darme lang ist; sein vorderer Theil (Fig. 110a) ist lang und dünn, die hintere Hälfte wird von drei dünnen Platten mit buchtigem Aussenrande gebildet, welche mit ihren geradlinigen Innenrändern das Lumen der Stachelhöhle begrenzen; diese Platten sind nach dem, bei den Nematoden herrschenden, Gesetze geordnet und verbunden. Das Vestibulum ist selır enge; der, zwischen der Mundöffnung und der Stachelmembran liegende Theil wird von einer sehr dicken, das Licht stark brechenden Wand bekleidet, so dass das Lumen des Vestibulums auf dieser Strecke sehr enge ist und gänzlich vom Stachel eingenommen wird; hinter der Stachelmembran, ist die Wand des Vestibulums wieder ebenso zart wie gewöhnlich. Das vordere Ende des Oes. inserirt sich hinten am Stachel, ein wenig angeschwollen; der Oes. läuft dann sich verschmälernd als ein enges, vom Nervenringe umfasstes Rohr nach hinten und geht ungefähr in seiner Mitte plötzlich in den weiten Theil über; die Darmwand ist körnig und enthält zahlreiche Fettkörnchen, welche nur am hinteren Ende des Darmes fehlen. Die weibl. Geschlechtsöffnung liegt ein wenig vor der Körpermitte und die paarig symmetrischen Geschlechtsorgane sind gross, weil der postvaginale Theil fast die Hälfte des Abstandes zwischen Geschlechtsöffnung und After einnimmt; zwei Eier beobachtete ich im Uterus. Der Schwanz (Fig. 110c) ist sehr kurz, stumpf abgerundet.

Fundort und Lebensweise. Nur einmal traf ich bis jetzt eine, obgleich grosse Zahl Individuen dieser sehr seltenen Art an und zwar in feuchter Erde einer Wiese unweit Leiden, an Wurzeln von Moos und Gräsern; es sind lebhafte Thiere, deren Männchen mir leider unbekannt blieben.

9. Dorylaimus rhopalocercus d. M.

de Man, XXVI, pag. 22, Pl. IV, Fig. $6 a-c$

(von jódzarov, Kolbe, und кépros, Schwanz).

Taf. XXVII, Fig. 111.

$\sigma^{7}$ unbekannt, ㅇ $2,1 \mathrm{~mm} . \alpha=35-40 . \beta=4-4^{1} / 2 . \gamma=80-120$.

Der rhopalocercus, durch die Form des Schwanzes characterisirt, besitzt eine sclllanke Gestalt, mit måssig verschmälertem Vorderende. Die Kopfregion ist abgesetzt, und wird von 6 weniq ausgeprägten Lippen gebildet, welche zwei Kreise von Papillen tragen. Der Stachel ist ziemlich kräftig; der Oes. ist in seiner vorderen Halfte enge, erweitert sich dann aber allmălig nach hinten; die Darmwand erscheint gleichmässig gekörnt. Die weibl. Geschlechtsöffnung liegt ein wenig vor der Körpermitte, und die paarig symmetrischen Geschlechtsorgane sind ausserordentlich lourz, weil der postvaginale Theil nur $1 / 7-1 / 6$ des Abstandes zwischen Geschlechtsöffnung und After lang ist. Der Schwanz ist sehr kurz, 
bogenförmig abgerundet, von ein wenig veränderlicher Grösse; das Hinterende des Körpers ist, in geringer Entfernung vor dem After, ein wenig eingeschnürt und hat dadurch eine eigenthümliche kolbige Gestalt.

Fundort und Lebensweise. Die Art bewohnt die feuchte Erde unserer Wiesen und Marschgründe und ist gar nicht selten: das Männchen blieb unbekannt.

Geograplische Verbreitung. In keinem anderen Lande bis jetzt beobachtet.

Fundzeit. Im Sommer und im Herbst wurden geschlechtsreife Individuen angetroffen.

\section{Dorylaimus brachyuris d. M.}

Taf. XXVII, Fig. 112.

$\sigma^{7}$ unbekannt, \& 2,6 mm. $\alpha=45-50 . \beta=3^{1} /{ }_{3}-3^{1} /{ }_{2} \cdot \gamma=60-70$.

Diese, dem Bastian'schen D. tritici am meisten verwandte Art hat eine sehr schlanke Gestalt und verschmälert sich wenig nach vorn hin: auf der Grenze des Oes. und des Darmes ist der Körper kaum dreimal so breit als am Grund der Kopfregion. Diese letztere (Fig. 112a) ist abgesetzt, breit und niedrig, von 6 ziemlich ausgeprägten Lippen gebildet, welche zwei Kreise von Papillen tragen. Stachel ziemlich kräftig; der Oes. ist an seinem vorderen, den Stachel umfassenden Ende ein wenig angeschwollen, wird dann sehr enge und geht schliesslich in den, die zwei linteren Dritttheile des Oes. einnehmenden, erweiterten hinteren Theil über; in der Darmwand sind die einzelnen Zellen durch die in Häufchen gruppirten Körnchen sehr deutlich. Die weibl. Geschlechtsöffnung befindet sich ein wenig hinter der Körpermitte und die Genitalien sind sehr kurz, obgleich paarig symmetrisch: der postvaginale Theil ist nur $1 / 5$ des Abstandes zwischen Geschlechtsöffnung und Afler lang. Der Schwanz ist sehr kurz, stumpf, bogenförmig abgerundet.

Fundort und Lebensweise. Es bewohnt der ziemlich häufig vorkommende, lebhafte brachyuris den sandigen Boden der Holländischen Dünenwiesen.

Geographische Verbreitung. Deutschland (Erlangen).

Fundzeit. Geschlechtsreife Individuen beobachtete ich in den Monaten April, Mai und October.

Anmerkung. Diese, durch den Bau des Oes., die Gestalt des Schwanzes u. s. w. genügend characterisirte Art unterscheidet sich vom D. tritici Bast. besonders durch ihre sehr schlanke Gestalt und den Bau des Oes.

\section{Dorylaimus intermedius d. M.}

Sjnon: Dorylaimus tritici, de Man, XXVI, pag. 23, Pl. IV, Fig. 7a-c. (hinteres Körperende des Männchens).

Taf. XXVII, Fig. 113.

$\sigma^{7} 1,9 \mathrm{~mm}$., ㅇ 3,2 mm. $\alpha=40 . \beta=4-5 . \gamma$ beim $\sigma^{\gamma}=60$, beim $q=65-75$. 
Bei dieser, dem Bastian'schen D. polyblastus nahe verwandten Art findet man einen schlanken Körper, der sich nach vorn hin wenig verschmälert, indem die Körperbreite an der Grenze des Oes. und des Darmes nur dreimal so gross ist als am Grund der Kopfregion. Diese letztere ist abgesetzt, (Fig. 113a) und zeigt bloss eine Spur von Lippen, welche zwei Kreise sehr kleiner Papillen tragen. Der Stachel ist ziemlich zart; der, an seinem vorderen Ende ein wenig angeschwollene Oes. läuft als ein enges Rohr nach hinten und geht ungefähr in seiner Mitte allmälig in den erweiterten Theil über; in der Darmwand sind die Zellen wieder durch die Gruppirung der Körnchen deutlich. Die weibl. Geschlechtsöffnung liegt gerade in der Körpermitte, ihre Entfernung vom hinteren Ende des Oes. ist ungefähr ebenso gross wie die Länge der Strecke zwischen der Mundöffnung und dem Anfang des Darmes; die Scheide (Fig. 113b) ist sehr dünnwändig, und die paarig symmetrischen weiblichen Genitalien sind ziemlich kurz: beim erwachsenen Weibchen (sogar bei Individuen, welche nur noch die Länge von 2,1 mm. erreicht haben) ist der postvaginale Theil der Genitalien 1/3 des Abstandes zwischen Geschlechtsöffnung und After lang; bei einem, $2 \mathrm{~mm}$. langen Thiere erreichte er aber bloss 1/4 dieser Entfernung. Beim Weibchen ist der Schwanz (Fig. 113d) sehr kurz, stumpf bogenförmig abgerundet, und hat ganz die ähnliche Gestalt wie beim brachyuris.

Die männliche Geschlechtsröhre und die Spicula sind schon bei einer Körperlänge von 1,1 mm. vorhanden; der Schwanz (Fig. 113c) hat beim Männchen die gleiche Gestalt wie bein Weibchen und vor dem After beobachtet man, ausser der Analpapille, eine mediane Reihe von 7 -11 Papillen, welche in gleichen Entfernungen gelegen und einander ziemlich viel genähert sind; die hinterste dieser niedrigen Papillen liegt nicht weit vom After entfernt. Die Spicula haben eine plumpe Gestalt, sind gebogen und zeigen zwei centrale Verdickungsstreifen; dieselben werden von zwei kleinen, dreieckigen, zugespitzten, accessorischen Stücken begleitet.

Fundort und Lebensweise. Diese Art, von welcher eigenthümlicher Weise das Männchen häufiger ist als das Weibchen, ist gar nicht selten und bewohnt die feuchte, oder ein wenig von süssem Wasser durchtränkte Erde der Holländischen Wiesen und Marschgründe, an den Wurzeln der dort wachsenden Pflanzen. Ziemlich lebhafte Bewegungen führt das Thier aus.

Geographische Verbreitung. Schweiz (Roth See unweit Luzern).

Fundzeit. Wahrscheinlich kommt auch der intermedius das ganze Jahr geschlechtsreif vor.

Anmerkung. Vom pratensis unterscheidet sich diese Art durch den kürzeren, wie beim brachyuris gebildeten Schwanz, durch weniger entwickelte Lippen und mehrere Grösse, vom polyblastus Bast. durch relativ längeren Oes., geringere Zahl präanaler Papillen u. s. w.

12. Dorylaimus pratensis d. M.

Taf. XXVII, Fig. 114.

o unbekannt, ᄋ $1,8 \mathrm{~mm} . \alpha=35-40 . \beta=4 . \gamma=45$.

Beim pratensis findet man einen schlanken Körper, der sich nach vorn hin wenig verschmälert, 
indem die Körperbreite an der Grenze des Oes. und des Darmes nur ungefähr dreimal so gross ist als am Grund der Kopfregion. Diese letztere (Fig. 114a) ist abgesetzt, und besteht aus sechs scharf von einander getrennten Lippen, welche zwei Kreise ziemlich grosser Papillen tragen. Der Stachel ist ziemlich zart. Die vordere Hälfte des Oes. ist sehr enge und geht ziemlich plötzlich in den hinteren erweiterten Theil über: die Uebergangsstelle liegt also ungeführ in der Mitte desselben. Die weibl. Geschlechtsöfnung liegt in der Körpermitte und ihre Entfernung vom Hinterende des Oes. ist ungefähr eben so gross wie die Länge des Oes. beträgt. Die weibl. Genitalien, welche bei 1,2 mm. grossen Thieren noch unvollkommen entwickelt sind, sind paarig symmetrisch, und verhăltnissmässig kurz, indem der postraginale Theil ungefahr $1 / 3$ des Abstandes zwischen Geschlechtsöffnung und After lang ist; zwei ziemlich kleine Eier beobachtete ich im Uterus. Der Schwanz hat eine, für die Art characteristische Gestalt (Fig. 114b, 114c), ist nämlich kegelförmig, mit abgerundeter Spitze.

Fundort und Lebensweise. Es lebt dieses lebhafte Thier, dessen Männchen mir unbekannt blieb, in feuchter Erde der Wiesen, an Wurzeln von Gräsern und Moos: ich beobachtete nur einmal eine Anzahl Exemplare, und zwar auf der, durch die Brackwassernematodenfauna bekannte Insel Walcheren. Bis jetzt wurde diese Art nirgendwo sonst beobachtet.

Fundzeit. Meine Beobachtung fand im Monat Januar statt.

13. Dorylaimus bryophilus d. M.

(von Bpúov, Moos und $\phi ı \dot{\varepsilon}^{\prime} \omega$, lieben).

Taf. XXVIII, Fig. 115 .

o unbekannt, o $1 \mathrm{~mm} . \alpha=18-20 . \beta=3-3 \%_{2} \cdot \gamma=16-18$.

Auf dem ersten Blick hat diese eigenthümliche Art ganz das äussere Vorkommen des Cephalobus ciliatus, mit welchem sie gemeinschaftlich vorkommt; besonders wird diese Uebereinstimmung durch die sehr plumpe Körpergestalt unseres Thieres verursacht. Nach vorn hin verjüngt sich der Körper selh, so dass die Körperbreite an der Grenze des Oes. und des Darmes viermal so gross ist als am Grund der Kopfregion. Diese letztere (Fig. 115a) ist abgesetzt, und wird von sechs, ziemlich gut ausgeprägten Lippen gebildet, welche zwei Kreise grosser Papillen tragen. Der Stachel hat den gewöhnlichen typischen Bau, ist aber zart. Die vordere Hälfte des, an der Stelle wo er sich am Stachel inserirt, ein wenig angeschwollenen Oes. ist sehr enge; ungefähr in seiner Mitte geht der enge Theil in den hinteren erweiterten Theil über. Die Körnchen der Darmwand sind zu Häufchen gruppirt. Die weibl. Geschlechtsöfnung liegt hinter der Mitte, etwa auf $\%$ der Gesammtlänge vom Hinterende des Körpers entfernt; die paarig symmetrischen Genitalien sind gross, und die blinden Enden der umgeschlagenen Ovarien sind einander sehr genähert; ihr postvaginaler Theil (Fig. 115) nimmt fast den halben Abstand zwischen Geschlechtsöffnung und After ein. Nur ein einziges grosses Ei beobachtete ich im Uterus. Der Schwanz ist verhältnissmåssig lang, kegelförmig, mit abgerundeter Spitze. 
Fundort und Lebensweise. Der lebhafte bryophilus bewohnt den sandigen Boden der Dünenstriche, der sandigen Wiesen welche mit Galium verum, Sedum acre und ähnlichen Pflanzen bewachsen sind; er scheint den Sandnematoden anzugehören. Bís jetzt nur in den Niederlanden beobachtet.

Fundzeit. Im Frühjahre und im Sommer, wurden geschlechtsreife Individuen angetroffen.

Anmerkung. Dorylaimus minutus Btsli (Bütschli, XX, pag. 30, Taf. I, Fig. 6a-b) ist unserer Art nahe verwandt.

14. Dorylaimus microdorus d. M.

Taf. XXVIII, Fig. 116.

o unbekannt, ㅇ $0, \%$ mm. $\alpha=18 . \beta=3 . \gamma=21$.

Es ist besonders der Bau des Stachels und des Oes., welcher diese Art von den, ihr verwandten Formen unterscheidet. Das Thier hat, wie der bryophilus, eine sehr plumpe Körpergestalt und verjüngt sich nur mässig nach vorn hin, indem die Körperbreite an der Grenze des Oes. und des Darmes ein wenig mehr als dreimal so gross ist als am Grund der Kopfregion. Diese letztere (Fig: $116 a, 116 b)$ ist ziemlich hoch, wird von sechs mässig scharf von einander getrennten Lippen gebildet, welche zwei Kreise nicht grosser Papillen tragen. Seler characteristisch ist der Stachel, der sehr verlängert und sehr dünn ist; leider konnte ich denselben beim einzigen beobachteten Exemplare nicht abzeichnen. In seinem grösseren vorderen Theile ist der Oes. sehr enge, er schwillt aber ein wenig hinter der Grenze seines letzten Drittheils plötzlich sehr zu einem erweiterten Theile an. Die weibl. Geschlechtsöffnung liegt hinter der Mitte und ist $2 / 5$ der Gesammtlänge vom Schwanzende entfernt; die paarig symmetrischen Genitalien sind ziemlich gross, indem der postvaginale Theil sich etwas weiter ausstreckt als der halbe Abstand zwischen Geschlechtsöffnung und After; nur ein einziges verhältnissmässig grosses Ei fand ich im Uterus. Der Schwanz (Fig. 116c) ist ziemlich plump, hat eine dreieckige, kegelförmige Gestalt und ist zugespitzt.

Fundort und Lebensweise. Leider beobachtete ich nur ein einziges Exemplar dieser merkwürdigen Art, in April, im sandigen Boden einer, in den Dünenstrichen gelegenen Wiese, wo ich auch den bryophilus und den Cephalobus ciliatus auffand. Durch die Gesammtheit seiner Charactere erkennt man das lebhafte Thier auf dem ersten Blick und im äusseren Vorkommen ist es, wie der bryophilus, dem Cephalobus ciliatus höchst ähnlich.

15. Dorylaimus elegans d. M.

Taf. XXVIII, Fig. 11\%.

$\sigma^{7}$ unbekannt, ㅇ $1,4 \mathrm{~mm} . \alpha=35 . \beta=6 . \gamma=30-32$.

Im ausseren Vorkommen gleicht diese $\Lambda$ rt ein wenig dem gracilis, obgleich manche wichtige 
Charactere dieselbe unterscheiden. Der Körper ist schlank, und das Vorderende verschmälert sich mässig, indem die Körperdicke beim hinteren Ende des Oes. etwas mehr als drei- und etwas minder als viermal so gross ist als an der Basis der abgesetzten Kopfregion. Diese letztere (11\%a) ist breit und niedrig, knopfförmig, olne eine Spur von Lippen, mit einer, ein wenig concaven Mundfäche und mit bloss einem Kreise grosser Papillen. Der Stachel ist zart; der vordere Theil der Oes. ist enge, wird dort wo ihn der Nervenring umfasst, noch enger und endigt schliesslich allmälig in den nur mässig erweiterten hinteren Dritttheil.

Die weibl. Geschlechtsöffnung liegt vor der Körpermitte, ungefähr $2 / 5$ der Gesammtlänge von der Mundöffnung entfernt; der Oes. ist immer ein wenig länger als die Entfernung zwischen seinem hinteren Ende und der Geschlechtsöffuung beträgt. Die paarig symmetrischen Geschlechtsorgane sind ziemlich kurz: der postvaginale Theil ist nur ungefähr 1/4 des Abstandes zwischen Geschlechtsöffnung und After lang. Der Schwanz (Fig. 118c) ist kegelförmig, ein weinig verlängert, mit stumpfer Spitze.

Fundort und Lebensweise. Der elegans scheint ein ächter Sandnematode zu sein; er ist ein seltenes, lebhaftes Thier, das im sandigen Boden unserer Dünenwiesen gefunden wird. Bis jetzt wurde er nirgendwo sonst beobachtet.

Fundzeit. In März erwachsen.

16. Dorylaimus monohystera d. M.

Taf. XXVIII, Fig. 118.

o unbekannt, ㅇ $1,3 \mathrm{~mm} . \alpha=35-40 . \beta=4-4 \frac{1}{2} \cdot \gamma=30-40$.

Von allen kurzschwänzigen Dorylaimen unterscheidet sich der monolystera durch seine einseitige Geschlechtsröhre. Diese Art hat einen schlanken Körper, der sich nach vorn hin ziemlich verjüngt. Die Kopfregion (Fig. 118a) ist abgesetzt, und wird von sechs, kaum getrennten Lippen gebildet, welclue zwei Kreise grosser Papillen tragen. Der Stachel ist ziemlich kräftig; der 0es. ist in seinem vorderen Theile sehr enge und geht ein wenig vor der Grenze des hinteren Dritttheiles plötzlich in den erweiterten Theil über; die Körnchen der Darmzellen sind zu Häufchen gruppirt. Die Vagina ist nicht, wie gewöhnlich der Fall ist, symmetrisch gebaut, sondern asymmetrisch und nach hinten gerichtet; sie ist selır weit nach vorn gerïckt, und liegt ungefähr $1 / 3$ der Gesammtlänge von der Mundöffnung entfernt; die weibl. Geschlechtsrölire ist einseitig, nach hinten ausgestreckt, und beim erwachsenen Thiere ein wenig länger als 1/4 des Abstandes zwischen Geschlechtsöffnung und After; im Uterus fand ich nur ein einziges Ei. Der Schwanz (Fig. 118c) ist kurz, kegelförmig, mit abgerundeter, an der dorsalen Seite ein wenig ausgehöhlter Spitze.

Fundort und Lebensweise. Auch dieses lebhafte Thier traf ich sehr häufig im sandigen Boden der Dünenwiesen an und es gehört, wie mir scheint, zu den ächten Sandnematoden. 
Geographische Verbreitung. In keinem anderen Lande bis jetzt beobachtet.

Fundzcit. Im Frühjahre (März) und im Herbst (October) traf ich eitragende Individuen an.

\section{1\%. Dorylaimus centrocercus d. M. ${ }^{1}$ )}

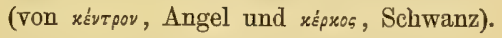

Taf. XXVIII, Fig. 119.

$\sigma^{7}$ unbekannt, ㅇ 1,8 mm. $\alpha=30-35 . \beta=4-5 . \gamma=40-50$.

Von den verwandten Arten unterscheidet sich der centrocercus gleich durch die Gestalt des Schwanzes. Er besitzt einen schlanken Körper, der sich nach vorn hin mässig verschmälert, indem die Körperbreite beim Hinterende des Oes. fast viermal so gross ist als an der Basis der abgesetzten Kopfregion. Diese letztere (Fig. 119a, 119b) wird von sechs wenig ausgeprägten Lippen gebildet, auf welchen man zwei Kreise ziemlich grosser Papillen beobachtet. Der Stachel ist kräftig. Der Oes, ist in seiner vorderen Hälfte enger und geht ungefälır in seiner Mitte in den erweiterten Theil über; die Körnchen der Darmzellen sind zu Häufchen gruppirt.

Die geschlechtsreifen Weibchen sind bald grösser, bald kleiner: 1,38 mm. lange Individuen, deren Geschlechtsorgane völlig entwickelt sind, findet man zu gleicher Zeit mit anderen, welche bei derselben Grösse noch sogar keine äussere Geschlechtsöffnung besitzen. Diese letztere liegt etwas hinter der Körpermitte, und die Länge des Oes. beträgt fast $2 / 3$ der Entfernung seines hinteren Endes zur Vulva; die paarig symmetrischen Genitalien sind ziemlich gross, indem der postvaginale Theil ungefähr $2 / 5$ des Abstandes zwischen Geschlechtsöffnung und After einnimmt. Nur zwei Eier wurden im Uterus beobachtet. Der Schwanz hat ein. sehr characteristisches Vorkommen, ist sehr kurz, und in der Nähe seines entweder zugespitzten (Fig. 119c) oder mehr abgerundeten Hinterendes (Fig. 119d) an der dorsalen Seite tief eingedrückt, wodurch er eine eigentlü̈mliche angelförmige Gestalt erkält.

Fundort und Lebensweise. Der centrocercus ist ein sehr häufiges Thier, das die feuchte Erde der Wiesen bewohnt und dem $D$. Leuckarti Btsli sowie dem D. pratensis nahe verwandt ist: er unterscheidet sich aber gleich durch die Gestalt des Schwanzes; ausserdem ist beim pratensis der Körper nach vorn hin weniger verschmälert, der Oes. verhältnissmässig länger u. s. w. und sind beim immer grösseren Leuckarti die weibl. Geschlechtsorgane weiter ausgestreckt.

Geographische Verbreitung. Noch nirgendwo sonst beobachtet.

Fundzent. Sowohl im Frühjahre (Februar, März) wie im Hochsommer (August) wurden eitragende Thiere beobachtet.

1) Ungeachtet ihres öfters spitzen Schwanzendes, habe ich diese Art in der Bestimunungstabelle noch bei denjenigen Formen geordnet, deren Schwanz mehr oder weniger abgerındet ist: sie stellt aber eine Uebergangsform zwischen den beiden Gruppen $\beta$ und $\gamma$ dar. 
\%. Gruppe mit gewöhnlichem, nicht nadelförmigem Stachel; bei beiden Geschlechtern ein kurzer, zugespitzter, meist nach der Bauchseite hin gebogener Schwanz. Typ.: z. B. Dorylaimus Carteri Bast.

\section{Dorylaimus gracilis d. M.}

de Man, XXVI, pag. 29, Pl. V, Fig. 9a-c. (Schwanzende des Mănnchens).

Taf. XXIX, Fig. 120.

$\sigma^{7} 1,9 \mathrm{~mm}$., ㅇ $1,7 \mathrm{~mm}$. $\alpha$ beim $\sigma^{7}=35$, beim $q=30-32 . \beta=51 / 3-5^{2} / 3 \cdot \gamma$ beim $\sigma^{7}=23-30$, beim $q=20-24$.

Diese niedliche Art besitzt einen, besonders beim Männchen, schlanken Körper, der sich nach vorn hin sehr verjüngt, indem er an der hinteren. Grenze des Oes. viermal so breit ist als an der Kopfregion. Diese letztere (Fig. 120a) ist sehr klein, knopförmig, ohne Lippen und trägt einen einzigen hinteren Kreis von sechs sehr kleinen Papillen. Der Stachel ist zart, und der Oes. ist immer ein wenig kürzer als $1 / 5$ der Gesammtlänge; der vordere Theil ist sehr enge, aber der hintere Dritttheil ist sehr erweitert. Die Darmwand erscheint fein gekörnt.

Die weibl. Geschlechtsöffnung liegt meist ein wenig vor der Körpermitte; ihre Entfernung vom Hinterende des Oes. ist stets viel grösser, ja nicht selten fast zweimal so gross als die Länge des Oes. beträgt. Die weibl. Geschlechtsorgane sind paarig symmetrisch, sehr gross : der postvaginale Theil ist ein wenig länger als der halbe Abstand zwischen Geschlechtsöffnung und After. Bei beiden Geschlechtern hat der Schwanz die gleiche Gestalt, aber seine Grösse ist ein wenig veränderlich; stets aber ist er kurz, zugespitzt und nach der Bauchseite gebogen. Beim Männchen beobachtet man, ausser der Analpapille, noch eine mediane Reihe von 4-y präanalen Papillen, von welchen die vorderen etwas mehr von einander entfernt sind als die hinteren; die hinterste Papille befindet sich ein wenig vor dem inneren Ende der Spicula. Diese (Fig. 120b) sind plump, eckig gebogen, zeigen zwei centrale Verdickungsstreifen und werden von zwei stabförmigen accessorischen Stücken begleitet.

Fundort und Lebensweise. Der gracilis ist ein nicht häufiges Thier, welches besonders die feuchte Wiesenerde liebt; ich fand ihn nie in von Wasser durchtränkter Erde, sondern stets im mehr oder weniger sandigen Boden der Wiesen, an Mooswurzeln u. s. w. Beide Geschlechter kommen gleich häufig vor.

Geograplische Verbreitung. Deutschland (Laibach).

Fundzeit. Im Spätherbst und im Winter (October, Januar) fand ich eitragende Weibchen und vollkommen entwickelte Männchen dieser Art, welche sich von den verwandten Formen durch den Bau der Kopfregion, des Oes. und der Geschlechtsorgane wesentlich unterscheidet. 
19. Dorylaimus Leuckarti Btsli.

Bütschli, XX, pag. 28, Taf. I, Fig. $2 a-c$ und Fig. $5 a-b$.

Taf. XXIX, Fig. 121.

б우 $2 \mathrm{~mm} . \alpha=30-32 . \beta=4-5 . \gamma=25-30$.

Beim Leuckarti, welcher dem Carteri nahe verwandt ist und sich von dieser Art fast nur durch die mehr beträchtliche Ausdelinung der.weibl. Genitalien, so wie durch den Bau des Oes. unterscheidet, ist der Körper ziemlich schlank und verjüngt sich sehr nach vorn hin: beim Hinterende des Oes. ist die Körperbreite viermal so gross als an der Basis der abgesetzten Kopfregion. Sechs mässig scharf von einander getrennte Lippen, welche zwei Kreise ziemlich grosser Papillen tragen, beobachtet man an der verhältnissmässig hohen Kopfregion. In seinem vorderen Theile ist der Oes. sehr enge, und er ist ein wenig hinter seiner Mitte plötzlich erweitert (Fig. 121); die Körnchen der Darmzellen sind zu Häufchen gruppirt. Die weibl. Geschlechtsöffnung liegt in oder ein wenig hinter der Körpermitte und die paarig symmetrischen Geschlechtsorgane dehnen sich sehr weit aus, indem der postvaginale Theil sich mehr oder weniger weiter ausstreckt als der halbe Abstand zwischen Geschlechtsöffnung und After; drei, 0,09 mm. lange Eier beobachtete ich im Uterus. Der Schwanz hat bei beiden Geschlechtern die gleiche Gestalt, ist kurz, sehr zugespitzt und nach der Bauchseite hin gebogen. Beim Männchen findet sich, ausser dex Analpapille, noch eine mediane Reihe von 7 präanalen, in ziemlich gleichen Entfernungen von einander gelegenen Papillen, von welchen die hinterste auf der Schwanzlänge vom After entfernt st. Die Spicula (Fig. 121b) sind plump, eckig gebogen, zeigen zwei centrale Verdickungsstreifen und werden von zwei kleinen accessorischen Stücken begleitet.

Fundort und Lebensweise. Auch der lebhafte Leuckarti ist ein ziemlich häufiges Thier, das sowohl die feuchte, von Wasser nicht durchtränkte Erde der Wiesen wie auch den sandigen Dünenboden bewohnt.

Geographische Verbreitung. Deutschland (Frankfurt a. M. nach Bütschli).

Fundzeit. Im Frühjahre geschlechtsreif.

\section{Dorylaimus Carteri Bast.}

Bastian, VII, pag. 106, Pl. IX, Fig. 38-40.

Taf. XXIX, Fig. 122.

o $1,8 \mathrm{~mm}$., 2 mm. $\alpha=30-35 . \beta=4-5$. $\gamma$ beim $\sigma^{7}=25$, beim $\&$, des Typus 30 , der Varietăt $19-23$.

Beim Carteri ist der Körper schlank und verjüngt sich sehr nach vorn hin, indem die Breite 
ạm hinteren Ende des Oes. viermal so gross ist als am Grund der Kopfregion; bei jüngeren Individuen (1,45 mm. lang) verschmälert sich das Vorderende verhältnissmässig weniger. Die Kopfregion ist niedrig und wird von sechs, scharf von einander getrennten, also deutlichen Lippen gebildet, auf welchen zwei Kreise mässig grosser Papillen vorkommen. Der Stachel ist kräftig; in seinem vorderen Theile ist der Oes. enge und geht in seiner Mitte ziemlich schnell in den weiten Theil über; die Körnchen der Darmzellen sind zu Häufchen gruppirt.

Die weibl. Geschlechtsorgane sind bei $1,45 \mathrm{~mm}$. langen Individuen schon vollkommen entwickelt und eitragend; bei dem, durch einen etwas kürzeren Schwanz characterisirten Typus liegt die Geschlechtsöffnung in oder nur sehr wenig vor der Mitte, bei der Varietät stets ein wenig vor der Mitte. Die paarig symmetrischen Geschlechtsorgane sind bei dieser Art verhältnissmässig kurz, (viel kürzer als beim Leuckarti), so dass der postvaginale Theil stets (bei jeder Grösse) nur den Dritttheil des Abstandes zwischen Geschlechtsöffnung und After einnimmt. Drei Eier, welche etwa 0,07 mm. lang sind, beobachtete ich im Uterus. Bei beiden Geschlechtern hat der Schwanz eine gleiche Gestalt, kurz, zugespitzt und nach der Bauchseite gebogen: bei dem Typus ist er (beim Weibchen) ungefälir 1/30, bei der Varietät $1 / 23-1 / 19$ der Gesammtlänge lang. Beim Männchen (Fig. 122b) beobachtete ich, ausser der Analpapille, noch eine mediane präanale Reihe von 7 (nach Bastian sogar 8-11) Papillen, von welchen die hinteren einander mehr genähert sind als die vorderen; die hinterste Papille liegt in geringer Entfernung vor dem inneren Ende der Spicula: ich fand aber nur ein einziges Männchen, so dass die Bastian'schen Angaben vielleicht die normalen sind. Die Spicula (Fig. 122c) sind plump, ein wenig gebogen und zeigen zwei centrale Verdickungsstreifen; wahrscheinlich giebt es auch accessorische Stücke. Eine Strecke vor dem After zeigt die Haut die eigenthümliche schräge Streifung.

Fundort und Lebensweise. Den Carteri, von der vorigen Art besonders durch den Bau des Oes. und die kürzeren weibl. Genitalien, vom similis durch geringere Grösse unterschieden, fand Bastian in stehendem Wasser; eigenthümlicher Weise wurden diejenigen Individuen, welche vollständig mit den Englischen Thieren übereinzustimmen scheinen, von mir bis jetzt bloss im sandigen Boden der Dünengegenden beobachtet, während eine, sich durch einen etwas längeren Schwanz auszeichnende Varielät die feuchte, oder von süssem Wasser ein wenig durchtränkte Erde der Wiesen und Marsch. gründe bewohnt. Ich vermuthe aber, dass auch der Typus an den letzteren Stellen wohl vorkommen wird. Es ist ein lebhaftes Thier, dessen Männchen selten ist, während das Weibchen häufig angetroffen wird.

Geographische Verbreitung. England (in stehendem Wasser zu Falmouth, nach Bastian).

Fundzeit. Sowohl im Winter (Jänner-März), wie im Sommer (August) beobachtete ich geschlechtsreife Individuen. 
21. Dorylaimus similis d. M.

de Man, XXVI, pag. 30, Pl. V, Fig. 10a-d.

Taf. XXIX, Fig. 123.

o unbekannt, of 3,1 mm. $\alpha=40-50 . \beta=5 . \gamma=40-50$.

Diese, besonders durch ihre Grösse ausgezeichnete Art hat einen selır schlanken Körper, der sich nach vorn hin sehr wenig verjüngt, indem die Körperbreite am hinteren Ende des Oes. minder als dreimal so gross ist als am Grund der Kopfregion. Diese letztere (Fig. 123a) ist abgesetzt und zeigt sechs scharf von einander getrennte Lippen, welche zwei Kreise mässig grosser Papillen tragen. Der 0es. ist an seinem vorderen Ende ein wenig angeschwollen, läuft dann als ein enges Rohr nach hinten, und geht ungefähr in seiner Mitte in den erweiterten Theil über. Die weibl. Geschlechtsöffnung befindet sich in der Körpermitte und die weibl. Genitalien sind paarig symmetrisch; geschlechtsreife Individuen sind bald grösser, bald kleiner, wie öfters der Fall ist: während ich eitragende, nur 2,45 $\mathrm{mm}$. lange Individuen auffand, waren bei anderen, schon $2,5 \mathrm{~mm}$. langen Weibchen die Geschlechtsorgane noch nicht gänzlich entwickelt. Ein nur $0,09 \mathrm{~mm}$. langes Ei beobachtete ich im Uterus. Der Schwanz ist sehr kurz, zugespitzt, nach der Bauchseite gebogen.

Fundort und Lebensweise. Diese seltene Art liebt die feuchte, oder von Wasser durchtränkte Erde der Wiesen, wo sie an Mooswurzeln gefunden wird: das Männchen blieb mir gänzlich unbekannt, was darum zu bedauern ist, weil es wohl bessere Merkmale angeben dürfte.

Geographische Verbreitung. Wahrscheinlich ist die, von Bütschli an Wurzeln einer Walderdbeere aufgefundene Art mit unserem similis identisch. (Bütschli, XX, pag. 30).

Fundzeit. In den Wintermonaten geschlechtsreif.

22. Dorylaimus acuticaudad. M.

Taf. XXX, Fig. 124.

$\sigma^{7} 1, \% \mathrm{~mm}$. ㅇ $1,6 \mathrm{~mm}$. $\alpha$ beim $\sigma^{7} 32$, beim ㅇ 23-25. $\beta=4 . \gamma=30-35$.

Während das Männchen dieser Art eine ziemlich schlanke Körpergestalt besitzt, ist dies beim Weibchen veniger der Fall; der Körper verjüngt sich ziemlich viel nach vorn hin, indem die Breite an der hinteren Grenze des Oes. etwas mehr als dreimal so gross ist als an der Basis der Kopfregion. Diese letztere ist abgesetzt und wird von sechs selir scharf getrennten Lippen gebildet, welche zwei Kreise mässig grosser Papillen tragen. Der Stachel ist ziemlich zart; der Oes. ist in seinem vorderen Theile enge, und geht ein wenig hinter seiner Mitte plötzlich in den weiten Theil über; der Darm zeigt nichts abweichendes. Die weibl. Geschlechtsöffnung (Fig. 124e) liegt ziemlich weit hinter der Mitte; ilkre Entfernung vom After ist höchstens $11 / 2$ mal so lang als die Strecke zwischen ihr und dem Hinteren Ende des Oes.; die Ge- 
nitalien sind paarig symmetrisch und verhältnissmässig gross: der postvaginale Theil ist mur weniq kürzer als der halbe Abstand zwischen Vulva und After; zwei ziemlich grosse Eier fand ich im Uterus. Der Schwanz hat bei beiden Geschlechtern die gleiche Gestalt, ist sehr kurz, mehr oder weniger scharf zugespitzt oder nach der Bauchseite gebogen (Fig. 124c, 124d).

Beim Männchan finden sich sowohl prä- wie postanale Papillen: vor dem After liegt die Analpapille, und vor dieser noch eine mediane Reihe von 15, in gleichen Entfernungen von einander gelegenen Papillen, von welchen sich die hinterste nur wenig vor dem inneren Ende der Spicula befindet; bei jüngeren Individuen beobachtet man nur 12 dieser Organe. Die Spicula (Fig. 124b) sind 0,058 mm. lang, gebogen, mit einem einzigen centralen Verdickungsstreife und werden von zwei kurzen, zugespitzten, schmalen accessorischen Stücken begleitet, welche nur $0,014 \mathrm{~mm}$. lang sind. Hinter dem After beobachtet man noch zwei laterale Papillen an jeder Seite des Schwanzes und zwar ungefähr an der vorderen und an der hinteren Grenze des mittleren Dritttheiles. An jeder Seite ist das Hinterende des Körpers vor dem After auf eine kurze Strecke schrïg gestreift.

Fundort und Lebensweise. Diese Art ist ziemlich bäufig und bewohnt nicht nur den sandigen Boden der, in der Nähe unserer Dünenstriche gelegenen Wiesen, welche die characteristische Flora (Sedum acre, Galium verum, Hippophae) zeigen, sondern auch feuchte, von brackischem Wasser durchtränkte Gründe. Das Männchen ist seltener, und lebhaft sind die Bewegungen, welche das Thier ausführt.

Geographische Verbreitung. Noch in keinem anderen Lande aufgefunden.

Fundzeit. Sowohl im Frühjahre (April) wie im Herbst (October, November) trifft man geschlechtsreife Thiere an.

Anmerkung. Es ist diese Art dem D. Leuckarti und D. Carteri am meisten verwandt, unterscheidet sich aber durch die Lage der weibl. Geschlechtsöffnung, die einzelnen Körperdinensionen, die Zahl der Papillen am Schwanze des Männchens u. s. w.

\section{Dorylaimus parvus d. M.}

Taf. XXX, Fig. 125 .

o7 $0,63 \mathrm{~mm}, \alpha=22-25 . \beta=31 / 4-31_{3} . \gamma$ beim $\sigma^{7}=18$, beim $q=15-20$.

Gleich wie der D. bryophilus eine merkwürdige Uebereinstimmung mit dem Cephalobus ciliatus zeigt, ebenso gleicht im äusseren Habitus der, zu den kleinsten Dorylaimen gehörige parvus dem Cephalobus oxyuroüdes. Das Thier hat ein ziemlich plumpes Vorkommen und sein Körper verjüngt sich seler wenig nach vorn hin, indem die Körperbreite beim Hinterende des Oes etwas weniger als drei- und etwas mehr als zweimal so breit ist als an der Basis der Kopfregion. Diese letztere ist abgesetzt (Fig. 125a) und besteht aus sechs wenig ausgeprägten Lippen, welche zwei Kreise von Papillen tragen, von welchen die vorderen ein wenig grösser sind als die linteren. Der Stachel ist verhältnissmässig selır kräftig; der Oes. ist immer ein wenig kürzer als $1 / 3$ der Gesammtlänge, und an seinem vorderen Ende etwas 
angeschwollen; in seinem grösseren vorderen Theile ist er sehr enge, aber etwas hinter seiner Mitte geht er ziemlich schnell in den weiten Theil über; die Darmwand zeigt nichts besonderes.

Die weibl. Geschlechtsöffnung liegt stets ein wenig hinter der Körpermitte und die paarig symmetrischen, weibl. Genitalien sind verhältnissmässig kurz, indem der postvaginale Theil kaum 1/3 der Entfernung zwischen Geschlechtsöffnung und After einnimmt. Bei beiden Geschlechtern hat der Schwanz die gleiche Gestalt, nämlich kurz, sehr zugespitzt und nach der Bauchseite gebogen. Beim Männchen (Fig. 125b) findet man, ausser der Analpapille, noch eine mediane präanale Reilhe von 5 Papillen, welche auf einiger Massen ungleichen Entfernungen von einander liegen; vor dem After erscheint die Haut an den lateralen Seiten auf eine kurze Strecke hin schräg gestreift. Die Spicula (Fig. 125c) sind ziemlich plump, klein, gebogen, olne Verdickungsstreif und ohne accessorische Stücke.

Fundort und Lebensweise. Diese, unter den verwandten Formen bald erkennbare Art ist gar nicht häufig und bewohnt nicht nur den sandigen Dünenboden, sondern auch die feuchte, oder von Wasser durchtränkte Erde der Wiesen und Marschgründe. Das Thierchen, das mit dem bryophitus, dem microdorus und dem primitivus zu den kleinsten Dorylaimen gehört, übt lebhafte Bewegungen aus.

Geographische Verbreitung. Deutschland (Erlangen).

Fundzeit. Im Frühjahre (März, April, Mai) geschlechtsreif.

\section{Dorylaimus Hartingii d. M.}

Taf. XXX, Fig. 126.

$\sigma^{7}$ unbekannt, 우 1,8 mm. $\alpha=40-43 . \beta=4^{1}{ }_{2}-5 . \gamma=25-30$.

Durch ihre gestreckte Gestalt, den Bau der Kopfregion und die geringe Ausdehnung der weibl. Genitalien unterscheidet sich diese niedliche Art, welche ich dem, um die Mikroskopie hoch verdienten Harting widme, von den anderen Arten dieser Gruppe. Der Körper ist sehr schlank und verjüngt sich ziemlich nach vorn hix, indem die Körperbreite beim Hinterende des Oes. etwas mehr als dreimal so gross ist als an der Basis des Kopfregion. Diese letztere (Fig. 126a) ist abgesetzt, knopfförmig, olne eine Spur von Lippen und trägt zwei, linter einander liegende Kreise von sechs äusserst kleinen, eben grossen Papillen. Der Stachel ist ziemlich kräftig; der Oes. ist, wie gewöhnlich, an seinem Anfange ein wenig angeschwollen, in seinem vorderen Theile enge und geht ungefähr in seiner Mitte plötzlich in den weiten Theil über; am Anfange des Darmes beobachtete ich mehrere drüsenartige Organe (Fig. 126c); die Darmwand erscheint gleichmässig fein gekörnt. Auch bei dieser Art treffen wir die schon, bei mehreren anderen Formen erwähnte Erscheinung an, dass die geschlechtsreifen Weibchen bald grösser, bald kileiner sind: so hatten die Geschlechtsorgane bei einem 1,33 mm. langen Weibchen schon ilire völlige Entwickelung erreicht, während bei anderen Individuen, welche 1,3 mm. lang waren, sogar die âussere Geschlechtsöffnung noch fehlte. Diese letztere ist seltr nach vorn gerïckt und $2 / 3$ der Gesammtlänge von der Mundöfnung entfernt; ihre Entfernung vom After ist ungefältr dreimal so gross als der Abstand zwischen derselben und dem Hinterende des Oes. Die paarig symmetrischen 
Genitalien delnen sich nur über einen kurzen Raum aus: der postvaginale Theil nimmt bloss $1 / 4$ des Abstandes zwischen Geschlechtsöffnung und After ein; zwei Eier beobachtete ich im Uterus. Der Schwanz ist kurz, zugespitzt und nach der Bauchseite gebogen.

Fundort und Lebensweise. Der Hartingii ist gar nicht häufig; es ist ein Thier mit ziemlich lebhaften Bewegungen, das die feuchte Erde unserer Wiesen und Marschgründe bewohnt; leider blieb mir das Männchen unbekannt. Nirgendwo sonst wurde unsere Art noch aufgefunden.

Fundzeit. In den Wintermonaten (Februar, März, December) geschlechtsreif.

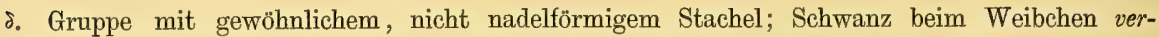
längert, mehr oder weniger regelmässig verschmälert, zugespitzt, beweglich und meist nach der Bauchseite gebogen. Diese Gruppe verbindet die vorige mit der folgenden.

25. Dorylaimus lugdunensis d. M.

Taf. XXX, Fig. $12 \%$.

$\gamma^{7}$ unbekannt, \& $1 \mathrm{~mm} . \alpha=32-35 . \beta=4 . \gamma=9-11$.

Diese Art, welche ihren Namen von der Stadt empfangen hat, in deren Umgebung ich so viele interessante Formen gefunden, hat einen schlanken Körper, der sich nach vorn hin wenig verschmälert, indem die Körperbreite beim Hinterende des Oes. etwas weniger als dreimal so gross ist als an der Basis der Kopfregion. Diese letztere (Fig. 12\%a) ist abgesetzt und wird von sechs mässig getrennten Lippen gebildet, welche zwei Kreise ziemlich grosser Papillen tragen. Der Stachel ist verhältnissmässig kräftig; der Oes. an seinem Anfange etwas angeschwollen, lauft als ein enges Rohr nach hinten und geht ein wenig linter der Mitte ziemlich schnell in den erweiterten Theil über. Die weibl. Geschlechtsöffnung liegt etwas vor der Mitte des Körpers; ihre Entfernung vom hinteren Ende des Oes. ist ein wenig kürzer als dieser Körpertheil, und die Strecke welche die Vulva vom After trennt, höchstens zweimal so lang als der Abstand zwischen ihr und dem Hinterende des Oes. Die paarig symmetrischen Genitalien dehnen sich auf einem kurzen Raum aus, indem der postvaginale Theil ungefähr 1/3 des Abstandes zwischen Geschlechtsöffnung und After einnimmt. Ein verhältnissmåssig grosses Ei fand ich im Uterus. Der Schwanz (Fig. 127b) ist verlängert, regelmässig verschmälert, zugespitzt, beweglich, meist nach der Bauchseite gebogen.

Fundort und Lebensweise. Dieses lebhafte Thier, dessen Männchen unbekannt blieb, bewohnt sowohl die feuchte Wiesenerde an Wurzeln von Moos und Gräsern, wie auch den sandigen Dünenboden; es unterscheidet sich bald durch die Gestalt des Schwanzes.

Geographische Verbreitung. Deutschland (Erlangen).

Fundzeit. Geschlechtsreife Thiere fand ich in den fünf ersten Monaten des Jahres und im September. 


\section{Dorylaimus attenuatus d. M.}

Taf. XXXI, Fig. 128.

$\sigma^{7}$ unbekannt, $q 2,2 \mathrm{~mm} . \alpha=65 . \beta=5 . \gamma=14$.

Wie sein Namen andeutet, hat der attenuatus eine sehr schlanke Gestalt und sein Körper verschmälert sich wenig nach vorn hin, indem die Körperbreite am hinteren Ende des Oes. ungefähr zwei und ein halb mal so gross ist als an der Basis der Kopfregion. Diese letztere (Fig 128a) ist abgesetzt und besteht aus sechs wenig getrennten Lippen, welche zwei Kreise von ziemlich kleinen Papillen tragen. Der Stachel ist zart und dünn; der Oes., an seinem Anfange ein wenig angeschwollen, ist in seinem vorderen Theile enge, und geht ungefähr in der Mitte ziemlich plötzlich in den erweiterten Theil über.

Die weibl. Geschlechtsöffnung befindet sich in der Körpermitte; die Strecke zwischen derselben und dem Hinterende des Oes. ist $1 \frac{1}{2}$ mal so lang als der letztere, der Abstand vom After $11 / 2$ mal so lang als der Raum zwischen ihr und dem vorderen Anfang des Darmes. Die paarig symmetrischen Genitalien delnen sich nur über ein kurzen Raum aus, indem der postvaginale Theil etwas mehr als $1 / 3$ des Abstandes zwischen der Geschlechtsöffnung und dem After lang ist. Nur ein oder zwei Eier beobachtete ich im Uterus. Der Schwanz (Fig. 128b) ist verlängert, ganz allmälig und regelmässig zugespitzt, beweglich und meist nach der Bauchseite gebogen.

Fundort und Lebensweise. In feuchter, von süssem Wasser durchtränkter Erde unweit Leiden fand ich diese seltene Art, welche sich lebhaft bewegt, und deren Männchen leider nicht beobachtet wurde. Obgleich dem lugdunensis höchst ähnlich, unterscheidet sie sich gleich durch die äusserst schlanke fadenförmige Gestalt; auch hat sie die doppelte Grösse und einen relativ kürzeren Oes. - In anderen Ländern noch nicht aufgefunden.

Fundzeit. Geschlechtsreif im November.

2\%. Dorylaimus agilis d. M.

Taf. XXXI, Fig. 129.

$\sigma^{7}$ unbekannt, of $1,6 \mathrm{~mm} . \alpha=25-32 . \beta=4-4^{1 /} / 2 \cdot \gamma=10-1.1$.

Der agilis, ein lebhaftes Thierchen, besitzt einen ziemlich schlanken Körper, der sich nach vorn hin sehr verschmälert, indem die Körperbreite beim Hinterende des 0es. etwas mehr als dreimal so gross ist als an der Basis der abgesetzten Kopfregion. Diese ist, wie bei fast allen Arten dieser Gattung, abgesetzt (Fig. 129a) und wird von sechs ziemlich entwickelten Lippen gebildet, welche zwei Kreise mässig grosser Papillen tragen. 1)er Stachel ist kräftig; der Oes. ist in seinem vorderen Theile enge und geht in seiner Mitte allmülig in den erveiterten Theil über. Die äussere weibl. Geschlechtsöfmung felltt noch bei Thieren, welche eine Körperlänge von 1,2 mm. besitzen, und liegt ein wenig vor der Mitte; ihre 
Entfernung vom After ist höchstens zweimal so lang als die Strecke zwischen ihr und dem Hinterende des Oes.; die paarig symmetrischen Genitalien dehnen sich nur über einen kurzen Raum aus, indem der postvaginale Theil ungefähr 1/3 der, zwischen Vulva und After gelegenen Strecke einnimmt. Bloss zwei Eier beobachtete ich im Uterus. Der Schwanz (Fig. 129b) ist verlängert, verjüngt sich mässig viel bald hinter dem After, und verschmälert sich dann bis an das zugespitzte Hinterende ganz allmälig; er ist beweglich und meist ein wenig nach der Bauchfläche hin gebogen.

Fundort und Lebensweise. Diese Art, eine Bewohnerin unserer feuchten Wiesen, ist ein gar nicht seltenes Thier. Vom lugdunensis unterscheidet sie sich durch mehrere Grösse (Exemplare dieser Art von $1 \mathrm{~mm}$. Länge produciren schon Eier, während die Geschlechtsöffnung beim agilis noch gänzlich fehlt, wenn das Thier schon die Grösse von 1,2 $\mathrm{mm}$. erreicht hat), durch das mellr verschmälerte Vorderende und die Gestalt des Schwanzes.

Geographische Verbreitung. Noch in keinem anderen Lande aufgefunden.

Fundzeit. Im Frühjahre (März) und im Sommer (August) wurden eitragende Individuen beobachtet.

є. Gruppe mit gewöhlichem, nicht nadelförmigem Stachel, bei welcher das Weibchen einen mehr oder weniger verlängerten, fadenförmigen Schwanz besitzt. Langschwänzige Dorylaimen.

Typus: Dorylaimus longicaudatus Btsli.

28. Dorylaimus limnophilus d. M.

(von $\lambda_{i \mu \nu \eta}$, feuchte Wiese und $\phi_{\imath \lambda \dot{\varepsilon} \omega} \omega$, ich liebe).

Taf. XXXI, Fig. 130.

$\sigma^{7}$ unbekannt $^{1}$ ), 우 1,3 mm. $\alpha=30-35 . \beta=5-6 . \gamma=10-11$.

Es hat dieses Thier, das von allen anderen langschwänzigen Dorylaimen durch seine einseitige Geschlechtsdrüse abweicht, eine schlanke Gestalt, und sein Körper verschmälert sich sehr nach vorn hin, indem die Körperbreite beim Hinterende des Oes. viermal so gross ist als an der Basis der Kopfregion. Diese letztere (Fig. 130a) ist abgesetzt und sieht mehr oder weniger dem elegans ähnlich: sie ist knopfförmig, olne Lippen, und trägt nur einen Kreis ziemlich kleiner Papillen, die Mundöffnung wird von einem Wulste umgeben und scheint darum wie in einer Vertiefung zu liegen. Der Stachel ist zart; der Oes. hat ein characteristisches Vorkommen: grösstentheils ist er seltr enge, sein hinterer Viertel aber ist plötzlich erweitert.

1) Im März dieses Jahres (1883) beobachtete ich in feuchter, mir von der Umgebung der Stadt Montpellier zugeschickter Erde ein Männchen, das vielleicht zum limnophilus gehört: die Länge desselben betrug 1,7 mm., $\alpha=50, \beta=6, \gamma=60$. Der Ban des Kopfes und des Oes. stimmen mit limnophilus überein, nur fand ich, statt des Viertels, das hintere Dritttheil des letzteren plötzlich erweitert. Der Hoden ist zweitheilig. Der Schwanz ist sehr kurz, abgerundet, demjenigen des $D$. intermedius ähnlich. 
Die weibl. Geschlechtsöffnung fehlt noch bei einer Körperlänge von $1 \mathrm{~mm}$, und liegt sehr nach vorn gerückt, indem sie sich an der vorderen Grenze des mittleren Körperdritttheils befindet; die. Geschlechtsröhre ist einseitig, unpaar, und streckt sich nach linten aus, während sie ungefähr $1 / 4$ der zwischen Vulva und After gelegenen Strecke einnimmt. Der Schwanz (Fig. 130b) ist verlängert, fadenförmig und ganz allmälig zugespitzt.

Fundort und Lebensweise. Der limnophilus, ein ziemlich lebhaftes, seltenes Thier bewohnt die feuchtẻ, von süssem Wasser durchtränkte Erde von Wiesen und Marschgründen. In anderen Ländern wurde es noch nicht aufgefunden.

Fundzeit. Geschlechtsreif im November.

29. Dorylaimus Bastiani Btsli.

Bütschli, XX, pag. 29, Taf. I, Fig. $3 a-b$.

de Man, XXVI, pag. 32, Pl. V, Fig. 11a-b.

Taf. XXXI, Fig. 131.

$\delta$ unbekannt, \& 2,1 mm. $\alpha=40-42 . \beta=5-51_{2} \cdot \gamma=10-30$.

Der Bastiani, besonders durch die Form des Schwanzes ausgezeichnet, besitzt einen sehr schlanken Körper, der sich nach vorn hin sehr verschmälert, indem die Körperbreite am hinteren Ende des Oes. viermal so gross ist als an der Basis der Kopfregion. Diese Kopfregion (Fig. 131a) ist niedrig, zeigt sechs nur wenig ausgeprägte Lippen, welche zwei Kreise mässig grosser Papillen tragen. Der Stachel ist ziemlich zart; der Oes. ist in seinem vorderen Theile enge und geht etwa in seiner Mitte plötzlich in den erweiterten Theil über.

Die äussere Geschlechtsöffnung liegt, bei einer Körpergrösse von 1,36 mm. schon vorhanden, in oder ein wenig hinter der Körpermitte; die paarig symmetrischen Geschlechtsorgane dehnen sich an beiden Seiten der Vulva nur wenig aus: der postvaginale. Theil nimmt ungefähr 1/3 des Abstandes zwischen Geschlechtsöffnung und After ein; sechs Eier beobachtete ich im Uterus. Ein wenig hinter dem After wird der Schwanz plötzlich schmäler und läuft dann bis an das wenig zugespitzle Hinterende in ungefühlr gleicher Stärke fort; dieser schmale, fadenförmige Theil ist, in Verhältniss zu dem vorderen dicken Theile bald kürzer, bald länger.

Fundort und Lebensweise. Der Bastiani, ein lebhaftes, sehr häufiges Thier bewohnt die feuchte Erde von Wiesen und Marschgründen und ist gleich an der Gestalt des Schwanzes zu erkennen.

Geograplische Verbreitung. Deutschland (Frankfurt a. M.).

Fundzeit. Im Frühling (Februar, März) geschlechtsreif. 


\section{Dorylaimus stagnalis Duj.}

Bastian, VII, pag. 106, Pl. IX, Fig. 35-3\%.

Bütschli, XX, pag. $2 \%$, Taf. 1, Fig. $4 a-d$.

Bütschli, XXV, pag. 379, Taf. XXV, Fig. $13 a-c$.

Taf. XXXII, Fig. 132.

( $\sigma^{7}$ von mir nicht beobachtet), ㅇ \%,5 mm. $\alpha=40 . \beta=5-5^{1 / 4} \cdot \gamma=18$.

Der schon lange bekannte stagnalis Duj. hat einen sehr schlanken Körper, der sich nach vorn hin selir verjüngt, indem die Körperbreite beim Anfang des Darmes fünf- oder sechsmal so gross ist als an der Basis der Kopfregion. An dieser letzteren (Fig. 132a) erkennt man sechs wenig entwickelte Lippen, welche zwei Kreise ziemlich kleiner Papillen tragen. Der Stachel ist kräftig; des Oes. ist in seinem vorderen Theile enge, geht aber ein wenig vor seiner Mitte allmälig in den erweiterten Theil über. Die, bei einer Körpergrösse von 4,8 mm. noch vollkommen fehlende, weibl. Geschlechtsöffnung liegt immer vor der Körpermitte, ungefähr $2_{5}^{2}$ der Gesammtlänge von der Mundöffnung entfernt; ihre Entfernung vom After ist fast dreimal so lang als die Strecke, welche dieselbe vom Hinterende des Oes. trennt: eine ähnliche Lage also wie beim Hartingii. Die paarig symmetrischen Genitalien strecken sich nur über einen lkurzen Raum aus, indem der postvaginale Theil einen nur wenig längere Strecke einnimmt als $1 / 4$ des Abstandes zwischen Geschlechtsöffnung und After. Der Schwanz verjüngt sich beim Weibchen (Fig. 132b) erst ziemlich schnell, bleibt dann aber dünn, fadenförmig mit sehr spitzem Hinterende.

Fundort und Lebensweise. Der stagnalis lebt im süssen Wasser von Teichen, Flüssen und Gräben; es ist ein lebhaftes, schnelles Thier.

Geographische Verbreitung. Deutschland (Erlangen, im Main nach Bütschli). Frankreich nach Dujardin. England nach Bastian.

Fundzeit. Im Sommer geschlechtsreif.

Anmerkung. Nach den Angaben Bütschli's erreicht das Männchen eine Grösse von 5 mm. und besitzt einen ganz kurzen und stumpf abgerundeten Schwanz; die Spicula werden von zwei spitzen, kleinen accessorischen Stücken begleitet. In einiger Entfernung vor dem After ist die Cuticula auf der Bauchseite auf eine ziemlich ansehnliche Strecke quergeringelt, und mediane präanale Papillen, welche bei den meisten anderen Arten vorkommen, sollen beim stagnalis vollkommen fehlen. Dagegen beobachtet man auf jeder Seite der Medianlinie des Bauches, vor und hinter dem After, eine Längsreihe von dicht stehenden, sich kaum über die Fläche der Cuticula erhebenden Papillen.

31. Dorylaimus crassus d. M.

Taf. XXXII, Fig. 133.

$\sigma^{7}$ unbekannt, of $4,86 \mathrm{~mm} . \alpha=2 \% \cdot \beta=4^{3 / 4} \cdot \gamma=14$.

Nach dem, im süssen Wasser lebenden stagnalis und dem, durch die ausserordentliche Ent- 
wickelung des Vestibulums sich auszeichnenden macrolaimus, gehört der crassus zu den grössten der langschwänzigen Dorylaimen: gleich erkennt man ihn an seiner, im Verhältniss zur Körperlänge, bedeutenden Körperdicke.

Der Körper verjüngt sich sehr stark nach vorn hin, so dass die Körperbreite an der Basis der abgesetzten Kopfregion nur ein Sechstel beträgt der Körperdicke am hinteren Ende des Oes.; ebenso verschmålert sich der Körper nach hinten und läuft in einen haarfeinen Schwanz aus. Die Kopfregion ist niedrig, und wird von sechs wenig ausgeprägten, abgerundeten Lippen gebildet (Fig. 133a), welche zwei Kreise von seltr kleinen Papillen tragen. Der Stachel ist ziemlich kräftig; der vordere schmale Theil des Oes. ist nur kurz, indem dieser schon an der vorderen Grenze des mittleren Dritttheils seiner Länge allmälig in den erweiterten Theil übergeht; die Darmwand erscheint gleichmässig fein gekörnt.

Die weibl. Geschlechtsöffnung liegt ein wenig hinter der Mitte; die Strecke welche dieselbe vom Hinterende des Oes. trennt, ist halb so gross als ihre Entfernung vom After; die paarigsymmetrischen Geschlechtsorgane dehnen sich ziemlich weit aus (Fig. 133), indem der postvaginale Theil fast $\%_{5}$ der, zwischen Vulva und After gelegenen Strecke einnimmt; die Ovarien sind sehr kurz und fünf sehr kleine Eier wurden im Uterus beobachtet. Der Schwanz (Fig. 133b) ist nicht lang und läuft haarfein aus.

Fundort und Lebensweise. Der seltene crassus bewohnt die feuchte, von süssem Wasser durchtrănkte Erde von Wiesen und Marschgründen. Bis jetzt beobachtete ich denselben nur in Holland.

Fundzeit. Im Herbst (November) geschlechtsreif.

\section{Dorylaimus filiformis Bast.}

Bastian, VII, pag. 10\%, Pl. X, Fig. 48, 49.

Taf. XXXII, Fig. 134.

$\sigma^{7}$ unbekannt, 우 $3,2 \mathrm{~mm} . \alpha=75 . \beta=7 . \gamma=19$.

Wie der crassus auf den ersten Blick, unter den langschwänzigen Dorylaimen, durch seine grosse Körperdicke auffällt, ebenso bald erkennt man den filiformis an seiner fadenförmigen Gestalt. Der Körper ist äusserst schlank und verjüngt sich ziemlich stark nach vorn hin, indem die Körperdicke beim Anfang des Darmes etwas mehr als dreimal so gross ist als an der Basis der Kopfregion. Diese letztere (Fig. 134a) ist abgesetzt, knopfförmig, ohne eine Spur von Lippen und zeigt nur einen einzigen linteren Kreis von kleinen Papillen. Der Stachel ist zart; in seinem vorderen Theile ist der Oes. sehr enge, obwohl an seinem Anfang ein wenig angeschwollen; bald linter der Mitte geht er plötzlich in den erweiterten Theil über; die Darmwand erscheint gleichmässig fein gekörnt, mit zerstreuten Fettkörnchen gefüllt. Als das Thier seinen vollen Wachsthum erreicht hat, liegt die weibl. Geschlechtsöffnung ein wenig vor der Körpermitte; ihre Entfernung vom After ist etwas kürzer als 11/2 Mal der Abstand zwischen ihr und dem Hinterende des Oes.; die parig symmetrischen Genitalien 
strecken sich an beiden Seiten der Vulva ziemlich weit aus, so dass der postvaginale Theil ${ }^{2 / 5}$ des Abstandes zwischen Geschlechtsöffnung und After einninmt; die Ovarien sind verhältnissmässig kurz. Fünf Eier fand ich im Uterus. Der Schwanz (Fig. 134b) ist fadenförmig, verschmälert sich bald hinter dem After, verjüngt sich dann allmälig und läuft spitz zu.

Fundort und Lebensweise. $\mathrm{Zu}$ den wenigen, das süsse Wasser bewohnenden Dorylaimen gehört auch der fliformis; es ist ein äusserst lebhaftes Thier, das die Teichen, Flüsse und Gräben Hollands bewohnt, zusammen mit anderen Arten, wie z. B. Diplogaster rivalis, und Trilobus gracilis.

Geographische Verbreitung. England (Bagshot nach Bastian), wo er ebenso im süssen Wasser lebt.

Fundzeit. Im Frühling (Mai) ist unsere Art geschlechtsreif, eitragend.

Anmerkung. Bei einer Körpergrösse von 2,5 mm. beträgt, nach den Angaben Bastians, $\beta 6$.

33. Dorylaimus brigdammensis d. M.

de Man, XXVI, pag. 35, Pl. VI, Fig. $13 a-f$ und Fig. $14 a-b$.

Synon: Dorylaimus stenosoma, de Man, XXVI, pag. 37.

Dorylaimus macrourus, v. Linst., (von Linstow, XXIX, pag. 7, Taf. I, Fig. 14).

Taf. XXXII, Fig. 135 .

$\sigma^{7}$ 우 $2,5 \mathrm{~mm} . \alpha=35-50 . \beta=5-6^{2} / 3 . \gamma=5-6^{2} / 3$.

$\mathrm{Zu}$ den meist typischen Formen dieser, durch den verlängerten, fadénförmigen Schwanz characterisirten Gruppe gehören die beiden Arten, welche unter den Namen brigdammensis und longicaudatus beschrieben worden sind. Es sind einander nahe verwandte Formen, von welchen die Weibchen sich nur schwer unterscheiden lassen. Die erste dieser beiden Arten, welche ihren Namen vom kleinen Weiler Brigdamme auf der Insel Walcheren ableitet, wo ich dieselbe am ersten beobachtete, hat einen schlanken, bisweilen sogar seltr schlanken Körper, der sich nach vorn hin sehr verschmälert, indem die Körperdicke am hinteren Ende des Oes. etwas weniger als viermal so gross ist als an der Basis der Kopfregion. Diese letztere (Fig. 135n) ist abgesetzt, niedrig, und wird von sechs, sehr wenig entwickelten Lippen gebildet, auf welchen zwei Kreise von kleinen Papillen stelien. Der Stachel ist kräftig; der Oes. ist vorn enge, geht aber in seiner Mitte plötzlich in den erweiterten Theil über.

Schon bei Individuen, welche die Länge von 1,8 mm. erreicht haben, sind die weibl. Geschlechtsorgane vollkommen entwickelt und Eier tragend; ebenso haben auch die männlichen Genitalien und die Spicula ihre volle Entwickelung erhalten bei einer Körpergrösse von 1,3 mm. Stets liegt die weibl. Geschlechtsöffnung ein wenig vor der Mitte des Körpers; die paarig symmetrischen Genitalien sind ziemlich gross, indem der postvaginale Theil sich bald etwas mehr, bald etwas minder weit ausstrecht als $1 / 3$ der Entfernung der Geschlechtsöfnung vom After; nur wenige Eier beobachtet man im Uterus, nämlich 
zwei oder drei. Bei beiden Geschlechtern hat der Schwanz die gleiche Gestalt: derselbe ist nämlich sehr verlängert, fadenförmig, verjüngt sich in seinem vorderen Theile schneller, dann aber ganz allmälig und lăuft schliesslich haarfein aus; bei einer, allerdings seltenen Varietăt erreicht der Schwanz nur 1/10 der Gesammtlänge.

Beim Männchen findet sich, ausser der Analpapille, noch eine mediane präanale Reihe von 6-7 Papillen, welche in mässig gleichen Entfernungen liegen und einander ziemlich genähert sind; die hinterste liegt nur ein wenig vor dem inneren Ende der Spicula. Diese letzteren, (Fig. 135b), sind plump, ein wenig gebogen, zeigen zwei centrale Verdickungsstreifen, und werden von keinen accessorischen Stücken begleitet.

Fundort und Lebensweise. Der lebhafte brigdammensis gehört zweifelsohne zu den häufigsten agricolen Nematoden; er bewohnt die feuchte Erde von Wiesen und Marschgründen, an Pflanzenwurzeln. Die Männchen sind aber nicht so häufig wie die Weibchen. -

Geographische Verbreitung. Deutschland (Erlangen, Laibach, Ratzeburg nach von Linstow). Frankreich (Montpellier).

Fundzeit. Das ganze Jahr hindurch wurden geschlechtsreife Individuen von mir angetroffen, also in allen Monaten.

\section{Dorylaimus longicaudatus Btsli.}

Bütschli, XXI, pag. 20.

de Man, XXVI, pag. 32, Pl. V und VI, Fig. 12a-f.

Taf. XXXIII, Fig. 136.

$\sigma^{7} 2,8 \mathrm{~mm}$., ㅇ $3,6 \mathrm{~mm}$. $a=30-35 . \beta$ beim $\sigma^{7}=4-5$, beim $ᄋ=5-7 . \gamma$ beim $\sigma^{7} 12-15$, beim $ᄋ$ 5-8.

Die letzte Art der typischen Dorylaimen mit kleinem Vestibulum ist der, dem brigdammensis verwandte longicaudatus. Er besitzt einen ziemlich schlanken Körper, der sich nach vorn hin sebr verjüngt, so dass der Körperdurchmesser an der Basis der Kopfregion fast nur ein Viertel beträgt von demjenigen am hinteren Ende des Oes. Die Kopfregion ist abgesetzt (Fig. 136a) und wird von sechs ziemlich ausgeprägten Lippen zusammengesetzt, auf welchen zwei Kreise von Papillen stehen; die Papillen des vorderen Kreises sind ein wenig grösser als diejenigen des linteren. Der Stachel ist kräftig; der Oes ist in seinem vorderen Theile enge und geht in seiner Mitte plötzlich in den erweiterten Theil über; der Darm verhălt sich wie bei der vorigen Art. Die äussere weibl. Geschlechtsöffnung fehlt noch vollständig bei einer Körperlänge von $2 \mathrm{~mm}$., ja Bütschli vermisste dieselbe sogar bei schon 2,9 mm. langen Individuen; stets liegt sie vor der Körpermitte (Fig. 136), ungefähr immer $2 / 5$ der Gesammtlänge von der Mundoffnung entfernt; die paarig symmetrischen Geschlechtsorgane strecken sich ziemlich 
weit an beiden Seiten der Vulva aus, so dass der postvaginale Theil die halbe Strecke zwischen Geschlechtsöfnung und After einnimmt; die Ovarien sind ziemlich kurz. Vier Eier beobachtete ich im Uterus.

Beim Weibchen ist der Schwanz sehr verlängert, fadenförmig und läuft haarfein zu; beim Männchen aber sieht er ganz anders aus, ist er nämlich viel kürzer und verschmälert sich plötzlich in kurzer Entfermung vom After, um dann fadenförmig weiter zu laufen; dieser fadenförmige Theil des Schwanzes ist aber sehr kurz. Ausser der Analpapille, besitzt das Männchen noch eine mediane Reilıe von 23-27 unmittelbar an einander grenzenden, wenig hervorragenden, Papillen vor dem After, von welchen die hinterste sich ein wenig vor dem inneren Ende der Spicula befindet; diese letzteren (Fig. 136b) haben ein ziemlich schlankes Vorkommen, sind ein wenig gebogen, haben nur einen einzigen centralen Verdickungsstreif und werden von zwei kurzen, stabförmigen, accessorischen Stücken begleitet. An jeder Seite des Körpers zeigt die Haut vor dem After bis etwa am vorderen Ende der Papillenreihe, die gewöhnliche schräge Streifung.

Fundort und Lebensweise. Der longicaudatus ist zwar nicht so häufig als die vorige Art, gehört doch aber zu den gewöhnlich vorkommenden Formen; er bewohnt die feuchte, oder von süssem Wasser durchtränkte Erde von Wiesen und humusreichen Gründen. Beide Geschlechter kommen gleich häufig vor.

Geographische Verbreitung. Deutschland (Erlangen, Laibach und auch die Gegend von Kiel nach Bütschli).

Fundzeit. In den Wintermonaten und im Frühling ist diese Art geschlechtsreif: ob dies auch in den anderen Jahreszeiten der Fall ist, muss vorläufig dahin gestellt werden.

Anmerkung. Während es ganz leicht ist, die Männchen dieser Art und der vorigen zu unterscheiden, sind die Weibchen einander höchst ähnlich: beim brigdammensis aber, welcher bei einer Grösse von 1,8 mm. schon Eier entwickelt, während der longicaudatus, bei einer Grösse von $2 \mathrm{~mm}$., noch keine äussere Geschlechtsöffnung besitzt, ist der Körper schlanker, sind die Lippen weniger ausgeprägt und strecken sich die Geschlechtsorgane nicht so weit aus.

C. Dorylaimen mit gewöhnlichem, nicht nadelförmigem Stachel, bei welchen die Mundöffnung in ein sehr weites Vestibulum führt, das, bis an die Stachelmembran, von einer dicken Chitinwand begrenzt ist.

35. Dorylaimus rotundicauda d. M.

Taf. XXXIII, Fig. 13\%.

$\sigma^{7}$ unbekannt, ㅇ $1,7 \mathrm{~mm} . \alpha=37-43 . \beta=3{ }^{2} \cdot \gamma=65-70$.

Der rotundicauda, durch den Bau des Vestibulums und des Schwanzes von allen anderen Arten unterschieden, hat eine schlanke Gestalt und sein Körper verjüngt sich wenig nach beiden Seiten hin. Die Kopfregion (Fig. 13\%a) ist niedrig, scheibenförmig, abgesetzt, olne Lippen, vielleicht trägt sie einen hin- 
teren Kreis von kleinen Papillen; die Mundöffnung ist weit, das Vestibulum selr gross: es besteht aus einem vorderen grösseren, in der Kopfregion gelegenen und einem, sich daran anschliessenden, engeren, bis an die Stachelmembran sich fortsetzenden Theile; die stark chitinisirten Wände verlaufen gebogen und im vorderen Theile liegen mehrere grosse, zahnartige, unbewegliche Chitinstücke. Der Stachel ist ziemlich zart; der vorn enge Oes. geht ein wenig vor seiner Mitte plötzlich in den erweiterten Theil über.

Die weibl. Geschlechtsöffnung liegt nur sehr wenig vor der Körpermitte und die paarig symmetrischen Geschlechtsorgane strecken sich über einen kurzen Raum aus, während die blinden Enden der zurückgeschlagenen Ovarien einander bei der Vulva sehr genähert sind. Der Schwanz (Fig. 13\%b) ist sehr kurz, stumpf abgerundet.

Fundort und Lebensweise. Diese eigenthümliche Art, deren Männchen mir unbekannt blieb, bewohnt den sandigen Boden der, in der Nähe unserer Dünenstriche gelegenen Wiesen, wo auch die anderen Sandnematoden gefunden werden. Bis jetzt wurde sie in keinem anderen Theile Europa's beobachtet.

Fundzeit. Sowohl im Frühling wie im Herbst beobachtete ich geschlechtsreife Thiere.

36. Dorylaimus macrolaimus d. M.

Taf. XXXIII, Fig. 138.

$\sigma^{7} 3, \% \mathrm{~mm}$. ㅇ $4,5 \mathrm{~mm} . \alpha=50 . \beta=5$. $\gamma$ beim $\sigma^{7}=85$, beim $ᄋ=11-12$.

Die letzte Art, welche ich jetzt noch zu beschreiben habe, ist der $D$. macrolaimus, dessen Weibchen im äusseren Forkommen dem Ironus ignavus sehr ähnlich ist, ein sehr schlankes Thier, dessen Körper sich nach vorn hin ziemlich verjüngt. Die Kopfregion (Fig. 138b) ist abgesetzt, niedrig, scheibenförmig, ohne Lippen und trägt einen hinteren Kreis von sechs kleinen Papillen; nicht weit von der grossen Mundöffnung beobachtet man mehrere ringförmige Clitinleisten. Das Vestibulum ist sehr gross; es besteht aus einem vorderen weiteren und einem kleineren, nach hinten sich allmälig verengenden, hinteren Theile; im ersteren beobachtet man longitudinal verlaufende Verdickungsstreifen in der Wand; besonders an der Basis des vorderen Theiles und im hinteren Abschnitt bis an die Stachelmembran werden die Wände von einer sehr dicken Chitinschicht begrenzt, welche das Vorderende des Stachels fast umschliesst. Der Stachel und seine Membran sind typisch gebaut und der Oes. erweitert sich allmälig nach hinten zu; bei durchfallendem Lichte erscheint die Darmwand sehr dunkel, was von dunklen Körnchen verursacht wird. Die weibl. Geschlechtsöffnung liegt nur sehr wenig vor der Körpermitte; die paarig symmetrischen Geschlechtsorgane strecken sich verhältnissmässig weit aus, so dass der postvaginale Theil ungefähr 1/3 der zwischen Geschlechtsöffnung und After liegenden Strecke einnimmt; die Ovarien sind kurz und ihre blinden Enden weit von einander entfernt; vier oder fünf Eier wurden im Uterus beobachtet. Der Schwanz ist beim Weibchen sehr verlüngert, fadenförmig und läuft haarfein aus. Beim Männchen dagegen ist dieser Körpertheil sehr 
kurz, stumpf abgerundet (Fig. 138c); vor dem After erkennt man, ausser der Analpapille, noch eine mediane Reihe von 19 sehr niedrigen, unmittelbar an einander grenzenden Papillen, von welchen die hinterste ein wenig vor dem inneren Ende der Spicula gelegen ist; an jeder Seite dieser Papillenreihe zeigt die Haut die schräge Streifung. Die Spicula sind ziemlich plump, besitzen einen centralen Verdickungsstreif und werden von zwei stabförmigen accessorischen Stücken begleitet.

Fundort und Lebensweise. Der seltene macrolaimus bewohnt die feuchte oder von süssem Wasser durchtränkte Erde unserer Wiesen und Marschgründen, und scheint zu den Wiesennematoden zu gehören.

Geographische Verbreitung. In keinem anderen Lande beobachtet.

Fundzeit. In den Sommermonaten (Mai, August) geschlechtsreif. 


\section{Tabelle A.}

\section{Uebersichtstabelle der örtlichen Verbreitung in den Niederlanden.}

\section{E r k 1 är ung:}
A. Von süssem Wasser durchtränkte Pflanzenerde (Ufer von Flüssen, Gräben u. s. w.).
B. Feuchte Pflanzenerde von nicht unmittelbar am Wasser grenzenden Stellen (Wiesen und Marschgründe).
C. Von brackischem Wasser durchtränkte Pflanzenerde. (Brackwassergegenden der Insel Walcheren).
D. Feuchte humusreiche Pflanzenerde vom Walde.
E. Sandige Pflanzenerde der, in der Nähe der Dünenstriche liegenden Wiesen.
F. Sandige Pflanzenerde aus den Heidegründen (Provinz Gelderland).
G. Süsses Wasser.

+ bedeutet das Vorkommen der betreffenden Art an der angedenteten Stelle.

! bedeutet das ausschliessliche Vorkommen der Art an derselben.

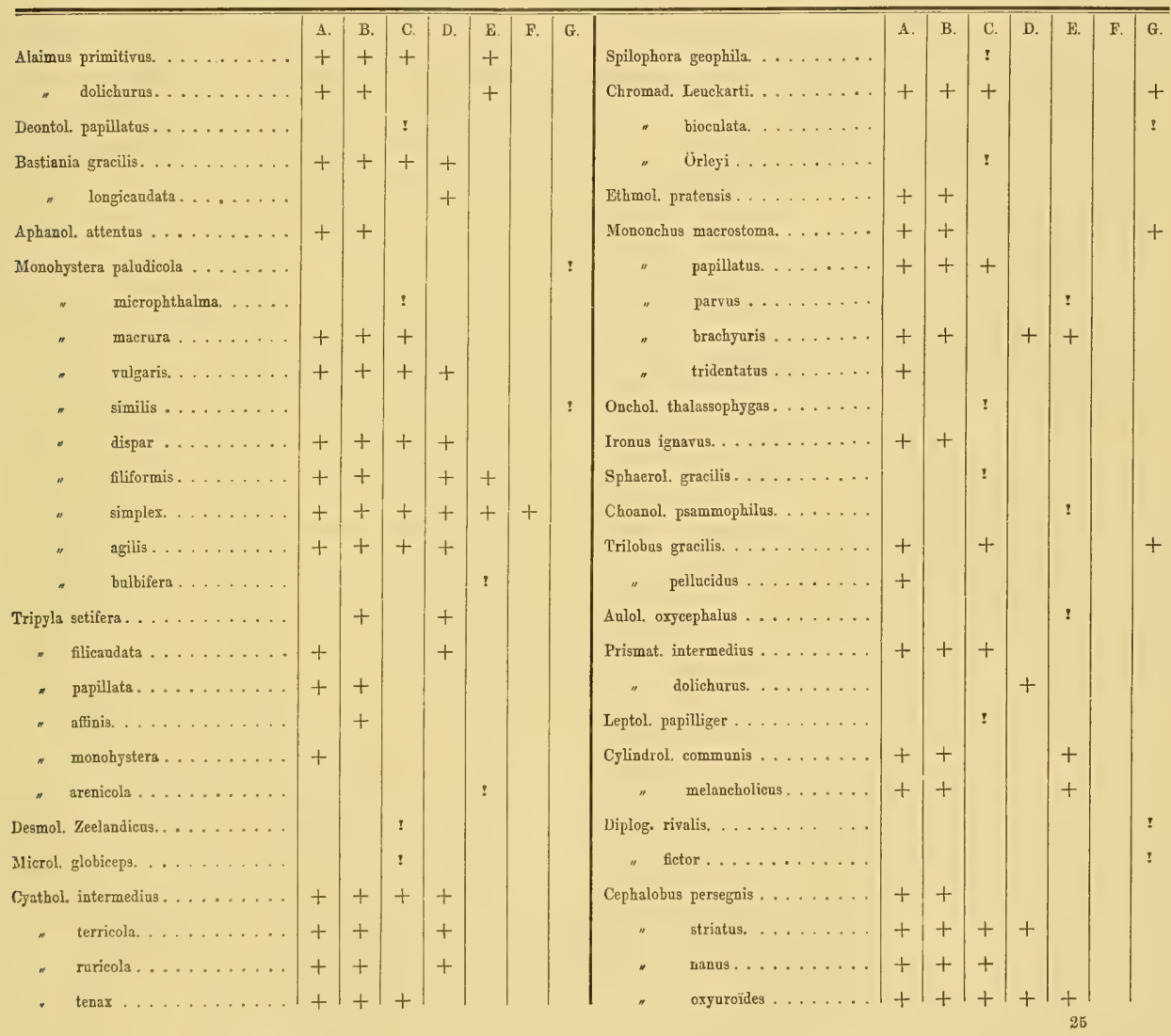




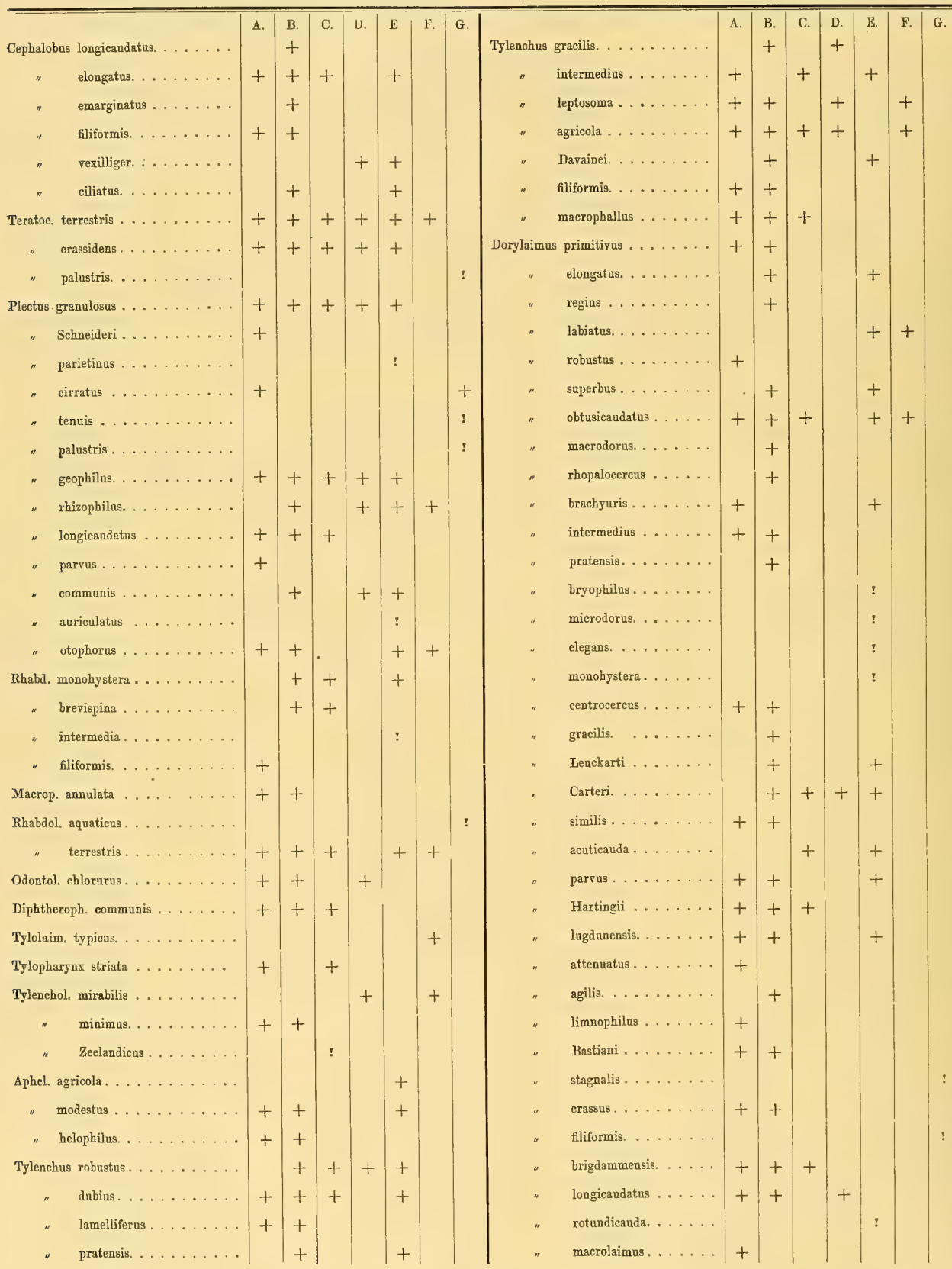




\section{Tabelle B.}

\section{Eintheilung der Arten nach der Körpergrösse ${ }^{1}$ ).}

GRUPPE $\alpha$. Die Thiere sind kleiner als $0,5 \mathrm{~mm}$, oder erreichen höchstens diese Länge: 12 Arten.

Monohystera simplex.
" bulbifera. Cyatholaimus tenax.

Cephalobus nanus.
" vexilliger.
Teratocephalus terrestris

Teratocephalus terrestris

\author{
Teratocephalus crassidens. \\ Plectus longicaudatus. \\ " communis.
}

Plectus otophorus

Rhabdolaimus terrestris.

Tylenchus macrophallus.

Gruppe $\beta$. Die Thiere sind grösser als $0,5 \mathrm{~mm}$, überschreiten aber die Länge von $1 \mathrm{~mm}$. nicht: 56 Arten.

\begin{abstract}
Alaimus dolichurus.
Bastiania longicaudata.

Aphanolaimus attentus.

Monohystera microphthalma.

$$
\begin{array}{ll}
\text { " macrura. } \\
\text { " vulgaris. } \\
\text { " similis. } \\
\text { dispar. } \\
\text {. filiformis. }
\end{array}
$$

Microlaimus globiceps.

Cyatholaimus raricola.

Spilophora geophila.

Chromadora Örleyi.
\end{abstract}

„ bioculata.

Ethmolaimus pratensis.
Aulolaimus oxycephalus.
Prismatolaimus intermedius.
Leptolaimus papilliger.
Cylindrolajmus communis.
Cephalobus persegnis.
" striatns.
" oxyroides.
" longicaudatus.
" elongatus.
" emarginatus.
" ciliatus.
Teratocephalus palustris.
Plectus Schneideri.

Plectus geophilus.
" rhizophilus.
" parvas.
" aurieolatus.
Rhabditis monohystera.
" intermedia.
" filiformis.
Macroposthonia annulata.
Rhabdolaimus aquaticus.
Odoutolaimus chlorurus.
Diphtherophora communis.
Tylolaimophorus typicus.
Tylencholaimus minimus.
Aphelenchus agricola.

\begin{tabular}{|cc} 
Aphelenchus modestus. \\
Tylenchus dabius. \\
$" \quad$ helophilus. \\
$" \quad$ pratensis. \\
$" \quad$ intermedius. \\
$" \quad$ leptosoms. \\
$" \quad$ agricola. \\
$" \quad$ filiformis. \\
Dorylaimus primitivus. \\
" $\quad$ brjophilus. \\
" $\quad$ microdorus. \\
$" \quad$ parvus. \\
$" \quad$ lugdunensis.
\end{tabular}

GRUPpE $\gamma$. Die Thiere sind grösser als $1 \mathrm{~mm}$., überschreiten aber die Länge von $2 \mathrm{~mm}$. nicht: 47 Arten.

\begin{abstract}
Alaimus primitivus.
Deontolaimns papillatus.

Bastiania gracilis.

Monohystera paladicola.

, agilis,

Tripyla setifera.

* filicaudata.

- affinis.

- monohystera.

" arenicola.

Desmolsimus Zeelandicus.

Cyatholaimus intermedius.
\end{abstract}

Cyatholaimus terricola.

Chromadora Leuckarti.

Mononchus parrus.

$$
\text { " brachyuris. }
$$

Ironas longicaudatus.

Sphaerolaimns gracilis.

Choanolaimus psammophilus.

Prismatolaimus dolichuras.

Cylindrolaimus melancholicus.

Diplogaster fictor.

Cephalobus filiformis.

Plectus granulosus.
Plectus parietinus.

" cirratus.

" tenuis.

- palustris,

Rhabditis brevispina.

Tylopharynx striata.

Tylencholaimus mirabilis.

$$
\text { " Zeelandicus. }
$$

Tylenchus robustus.

$$
\text { " Davainei. }
$$

Dorylaimus macrodorus.

$$
\text { " pratensis. }
$$

Dorylaimus elegans.
" $\quad$ monohystera.
" $\quad$ centrocercus.
" gracilis.
" $\quad$ Leuckarti.
" $\quad$ acuticauda.
" $\quad$ Hartingii.
" agilis.
" $\quad$ limnophilus.
rotundicnuda.

1) Als die im Texie für die beiden Geschlechter angegebene Grösse ungleich ist, so habe ich stets die grössere Zahl für die Gruppirung angenommen, z. B. den Alaimus primitivus, dessen Männchen als $1 \mathrm{~mm}$. , das Weibchen als $1,2 \mathrm{~mm}$. lang angegeben ist, doch in dio Gruppe $\gamma$ eingeordnet. 
GRUPPE $\delta$. Diø Thiere sind grösser als $2 \mathrm{~mm}$., überschreiten aber die Länge von $3 \mathrm{~mm}$. nicht: 10 Arten.

Mononchus macrostoma. " papillatus. Trilobas gracilis.
Diplogaster rivalis.

Tylenchus gracilis.

Dorylaimus rhopalocercus.

\section{Dorylaimus brachyoris.}

- attenuatus
Dorylaimus Bastiani.

" brigdammensis.

GRUPPE $\varepsilon$. Die Thiere sind grösser als $3 \mathrm{~mm}$., überschreiten aber die Länge von $5 \mathrm{~mm}$. nicht: 14 Arten.

Tripyla papillata.

Mononchus tridentatus.

Oncholaimus thalassophygas. Ironus ignavus.

\author{
Trilobus pellucidus. \\ Dorylaimus labiatus. \\ " superbus. \\ " obtusicaudatus.
}

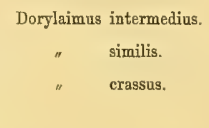

$\begin{array}{cc}\text { Dorylaimus } & \text { filiformis. } \\ \text { " } \quad \text { longicaudatus. } & \text { macrolaimus. }\end{array}$

GRUPPE ฑ. Die Thiere sind grösser als 5 mm.: 4 Arten.

Dorylaimus regius.

| Dorylaimus robustus.
| Dorylaimus elongatus. 


\section{LITERATURVERZEICHNISS.}

I. Petrus Borellus erwähnt das EssigäTchen in der ersten seiner hundert Beobachtangen, welche er in seiner, meiner Vatexstadt Middelburg gewidmeten Abhandlung beschrieben hat. Der Titel dieser Arbeit lautet: De vero Telescopii inventore, cum brevi omnium conspiciliorum Historia, ubi de Eorum Confectione ac Visu, sen de effectibus agitur, novaque quaedam circa ea proponuntur. Accessit etiam centuria observationum microspicarum. Hagae-comitum, 1655-1656. Man findet in diesem Büchlein die Abbildungen von Zacharias Jansen und Hans Lipperhey, der ersten Entdecker des Mikroskopes und der sogenannten langen Röhre (Fernröhre) von Blech, welche primitive Werkzeuge noch im Museum zu Middelburg aufbewahrt werden.

II. Czernay, Monographie des Essigälchens, mit kol. Kpft. Moskau, 1849. Idem, Bulletin de Moscou, XXII, (1849), 232-256, tab. VI.

III. Dujardin, Histoire naturelle des Helminthes ou vers intestinanx. Paris 1845.

IV. Diesing, Systema Helminthum, Vindobonae, 1851, Vol. II und Revision der Nematoden, in: Sitzungsber. der math. naturw. Classe der Wiener Akademie, 1861, Bd. XLII.

V. Carter, On Dracuneulus und Microscopic Filaridae in the Island of Bombay, in: Annals and Magazine of Natural History. III Series. 1859 , Vol. 1V. p. 28 und 98.

VI. Eberth, Untersuchungen über Nematoden, mit neun Kupfertafeln, Leipzig 1863.

VII. Charlton Bastian, Monograph on the Anguillulidae, or Free Nematoids, Marine, Land, and Freshwater; with Descriptions of 100 New Species, in: Transactions of the Linnean Society of London, Vol. XXV, 1865, with 5 Plates.

VIII. Charlton Bastian, On the Anatomy and Physiology of the Nematoids, Parasitic and Free; with observations on their Zoological Position and Affinities to the Echinoderms, in: Philos. Transactions von 1866, mit 7 Tafeln.

IX. Davaine, Recherches sur l'Anguillule du Vinaigre (Rhabditis aceti Duj.) in: Compt. rendus. Tom. LXI, 1865, p. 259.

X. Greeff, in: Sitzungsber. d. Nat. Ver. Preuss. Rheinl. u. Westph, Juni, 1865.

XI. Greeff, Jeber die hier lebenden Nematoden (Anguillulinen), in: Verhardl. Natur. Ver. Preuss. Rheinl. 1864, p. $112-113$.

XII. Schneider, Monographie der Nematoden, mit 28 Taf. und 130 Holzschnitten. Berlin, 1866.

XYII. Perez, M., Recherches anatomiques et physiologiques sur l'Anguillule terrestre (Rhabditis terricola Duj.) in: Annal. Seienc. Nat. Zöol. VI, 1866 , pp. $152-307$, pls. $5-10$.

XIV. Menge, Ueber ein Rhipidopteron und einige andere im Bernstein eingeschlossene Thiere, in: Schrift. Naturf. Gesellschaft Danzig, neue Folge, Bd. I (1866) pp. 8 (eum figg.).

XV. Claus, C., Beobachtungen über die Organisation und Fortptanzung von Leptodera appendiculata, in: Schrift. Gesells. Marborg. Suppl. Heft III, 1869, p. 24, 3 pls.

XVI. Schmidt, Ueber den Rüben-Nematoden, in: Zeitschrift d. Ver. f. Rüben-Industrie im Zollverein, 1871.

XVII. Greeff, in: Sitzungsber. Natur. Vereins Preussischer Rheinl. XXVII, 1872.

XVIII. Vernet, Quelques mots sur la reproduction de deux espèces hermaphrodites du genre Rhabditis, in: Arch. Sc. Biblioth. univers. Genève, 1872. Sept.

XIX. v. Frauenfeld in: Verhandl. des zool. botan. Vereins. Wien, XXII, 1872, S. 396.

XX. Bütschli, Beiträge zur Kenntniss der freilebenden Nematoden, mit 11 Taf. in: Nova Acta Acad. Leopold.-Car. Band XXVI, №. 5. Dresden, 1873.

XXI. Bütschli, Zur Kenntriss der freilebenden Nematoden, insbesondere der des Kieler Hafens, mit neun Tafeln (Abdruck a. d. Abhandl. d. Senckenb. naturf. Gesellsch. IX Band). Frankfurt a. M. 1874.

XXII. Marion, Recherches zoologiques et anatomiques sur des Nématoïdes non parasites, marins, in: Annales des Sciences Natarelles, 5 Série, Zoölogie, T. XIII, p. 14 und Additions aux Recherches sur les Nématoïdes libres du golfe de Marseille, T. XIV, pag. 1, mit 12 Taf. 1870. 
XXIII. Löw, F., Tylenchus millefolit, n. sp. eine neue, gallenerzeugende Anguillulide, in: Verhandl. Zool. Bot. Gesellsch. Wien, XXIV, p. 17-24, pl. I, B. (1874).

XXIV. Villot, Recherches sur les Helminthes libres ou parasites des Côtes de la Bretagne, in: Archiv. Zool. T. IV, p. $453-466$.

XXV. Bütschli, Untersuchungen über freilebende Nematoden und die Gattung Chaetonotus, in Zeitschr. f. W. Zool., XXVI Band, pag. 363-413, mit Taf, XXIII-XXVI.

XXVI. de Man, J. G., Onderzoekingen over vrij in de aarde levende Nematoden. 119 Seiten, mit 11 lithogr. Tafeln. Separatabdruck aus: Tijdschrift Nederl. Dierk. Vereeniging, Deel II, 1876, pag. 78-196, Pl. III-XIII.

XXVII. A. Braun, in: Sitzungsber. der Ges. Naturforschender Freunde zu Berlin, März 1875.

XXVIII. Kühn, in: Landwirthschaftl. Jahrbücher von Nathusius und Thiel, 1876, Bd. III, S. 47-50.

XXIX. von Linstow, Helminthologische Beobachtungen, in: Archiv für Naturgeschichte, XLII Jahrg. 1876. 1 Heft, pag. 6-17, Taf. I und II.

XXX. von Linstow, Helminthologica, in: Archiv für Naturgeschichte, XLIII Jahrg. Berlin 1877, 1 Heft, pag. 1-3. Taf. I.

XXXI. Gromma, in: sthe Aralo-Caspian Expedition, pag. 102, pl. IV, fig. 6. (Mir nur aus dem sZoological Record" bekannt).

XXXII. Joseph, Ueber die, in den Krainer Tropfsteingrotten einheimischen freilebenden Rundwürmer (Nematoden) im: Zoolog. Anzeiger, II, 1879, pag. 275-277.

XXXIII. von Linstow, Helminthologische Studien, in: Archiv für Naturgeschichte, XLV Jahrg. Berlin, 1879. 2 Heft, S. 165-167, Taf. XI.

XXXIV. Örley, Ladislaus. Monographie der Anguilluliden, durch die K. U. Naturwissenschaftl. Gesellschaft preisgekrönt. Mit 7 lithogr. Tafeln. Budapest, 1880. Ungarisch, mit deutschem Résumé.

XXXV. de Man, J. G., Die einheimischen, frei in der reinen Erde und im süssen Wasser lebenden Nematoden monographisch bearbeitet. Vorläufiger Bericht und descriptiv-systematischer Theil, 104 Seiten; Separatabdruck aus: Tijdschrift der Nederl. Dierk. Vereenig., Deel $\mathrm{V}$, pag. 1-104, Leiden, 1880.

XXXVI. de Man, J. G., Ueber einige neue oder noch unvollständig bekannte Arten von frei in der reinen Erde lebenden Nematoden, in: Tijdschrift der Nederl. Dierk. Vereenig. Deel V, Leiden, 1881, pag. 138-143. 


\section{ERKLÄRUNG DER TAFELN.}

\section{Tafel I.}

Fig. 1. Alaimus primitivus d. M., ein $1,1 \mathrm{~mm}$. langes Weibchen aus sandigem Dünenboden der Insel Walcheren, September, ${ }^{250}{ }_{\mathrm{T}}$ 1a. Kopfende in lateraler, $1 b$. in medianer Lage (sieht, weil zu stark comprimirt, weniger zugespitzt aus als $1 a$ ), 1c. Hinterende des Oes., 1d. hinterer Körpertheil des Männchens, 1e, eines Weibchens.

Fig. 2. Alaimus dolichurus d. M., Weibchen, ș̣o; $2 a$. Schwanz des Männchens.

Fig. 3. Deontolaimus papillatus d. M., ein $1 \mathrm{~mm}$. langes Männchen, aus brackischer Erde der Insel Walcheren, August, ${ }^{25} T^{\circ}$; $3 a$. Kopfende, 3b. Hinterende des Oes. und Anfang des Darmes, 3c. Theil aus der Mitte des Körpers, 3d. Vorderende des Männchens, die Papillenreihe zeigend, 3e. Hinterer Körpertheil desselben, 3f. Spiculum mit accessorischem Stücke.

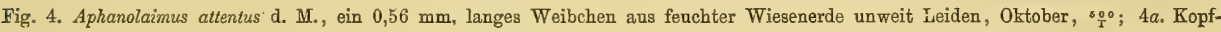
ende mit Seitenorganen in lateraler, 4b. in medianer Lage, 4c. präanale Region des Männchens, 4d. Ende des Schwanzes.

\section{Tafel II.}

Fig. 5. Bastiania gracilis d. M., Männchen, ${ }^{\circ} \frac{0}{1}^{0} ; 5 a$. Vorderende in lateraler Lage, 5b. Seitenorgan in Profil, 5c. Spiculum.

Fig. 6. Bastiania longicaudata d. M., Weibchen, ${ }^{250} \frac{5}{1}^{\circ}, 6 a$. Vorderende, 6b. Schwanz, 6c. Vulvaregion.

Fig. 7. Monohystera paludicola d. M., ein 1,36 mm. langes Weibchen aus süssem Wasser unweit Leiden, August, $\frac{18^{\circ}}{\mathrm{T}} ; 7 a$. Vorderende in lateraler Lage, $7 b$. Ocellenpigmentfleck von oben gesehen, $7 c$. Seitenorgan in Profil, $7 d$. Schwanz des Weibchens, 7e. hinteres Körperende des Männchens.

Fig. 8. Monohystera microphthalma d. M., ein $0,76 \mathrm{~mm}$. langes Weibchen, aus brackischer Erde der Insel Walcheren, August, $2 \frac{30}{\mathrm{~s}}$; 8a. Vorderende, 8b. Kopfende, 8c. Schwanz des Weibchens, 8d. des Männchens, 8e. Spicula und Analregion, 8f. Schwanzspitze.

\section{Tafel III.}

Fig. 9. Monohystera macrura d. M., ein $0,7 \mathrm{~mm}$. langes Weibchen aus brackischer Erde der Insel Walcheren, August, ${ }^{25^{\circ}}{ }^{\circ} ; 9 a$. Kopfende, $9 b$. Vorderende, $9 c$. Schwanz des Männchens, $9 d$. Analregion desselben.

Fig. 10. Monohystera vulgaris d. M., ein $1 \mathrm{~mm}$. langes Weibchen aus dem süssen Wasser bei Leiden, Mai, ${ }^{250} ; 10 a$. Kopfende, 10b. Schwanz des Weibchens.

Fig. 11. Monohystera similis Btsli, ein $0,7 \mathrm{~mm}$. langes Weibchen aus dem süssen Wasser unveit Leiden, April, $\frac{25^{\circ}}{\mathrm{T}} ; 11 \alpha$. Kopfende, 11b. Vorderende, 11c. Schwanz desselben.

Fig. 12. Monohystera dispar Bast., ein $0,8 \mathrm{~mm}$. langes Weibehen aus brackischer Erde der Insel Walcheren, September, ${ }^{2} \frac{8^{\circ}}{\mathrm{T}} ; 12 \alpha$. Kopf- $^{\circ}$ ende, 12b. Vorderende, 12c. Schwanz des Weibchens, 12d. Schwanzspitze.

Fig. 13. Monohystera fliformis Bast., ein $0,45 \mathrm{~mm}$. langes Weibchen aus feuchter Eide einer Wiese der Insel Walcheren, September, $\stackrel{400}{3}, 13 a$. Kopfende, 13b. Vorderende, 13c. Schwanz des Weibchens, 13d. hinterer Körpertheil des Männchens, 13e. Analregion mit Spicula. 


\section{Tafel IV.}

Fig. 14. Monohystera simplex d. M., Weibchen, ${ }^{500} ; 14 a$. Kopfende in lateraler, 14b. in medianer Lage, 14c. Schwanzspitze.

Fig. 15. Monohystera agilis d. M., ein 1,4 mm. langes Weibchen, ${ }^{10}{ }^{\circ}, 15 a$. Kopfende, 15b. Schwanz des Männchens mit Spicula, 15c. des Weíbchens, 15d. Analregion mit Spicula.

Fig. 16. Monohystera bulbifera d. M., ein $0,33 \mathrm{~mm}$. Ianges Weibchen aus sandigem Dünenboden, ${ }^{300}$; $16 a$. Kopfende in lateraler, 16b. in medianer Lage, 16c. Oesophagealbulbus, 16d. Vulva, 16e. Schwanzspitze.

Fig. 17. Tripyla setifera Btsli, ein 1,7 mm. langes Weibchen, $1 \frac{25}{4} ; 17 a$. Kopfende, 17b. Analregion des Männchens, 17c. Spiculum,

Fig. 18. Tripyla filicaudata d. M., ein $1,75 \mathrm{~mm}$. langes Weibchen aus feuchter Erde einer Wiese unweit Leiden, Oktober, ${ }^{250}$; 18a. Kopfende, 18b. Analregion des Männchens, 18c. Schwanzspitze.

\section{Tafel V.}

Fig. 19. Tripyla papillata Btsli, ein noch nicht ganz erwachsenes Weibchen, 2,65 mm. lang, aus feuchter Erde einer Wiese in der Nähe von Leiden, November, ${ }^{17^{0}} ; 19 a$. Kopfende, 190. Analregion des Männchens.

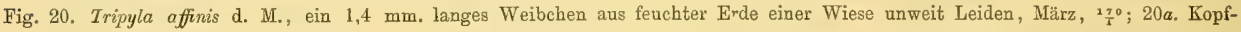
ende in lateraler, 20b. in medianer Lage, 20c. Schwanz des Weibchens, 20d. Analregion des Männchens.

Fig. 21. Tripyla monohyster $a$ d. M., ein $1,7 \mathrm{~mm}$. langes Weibchen aus feuchter Erde unweit Leiden, $1 \frac{170}{2}$; 21a. Kopfende in Iateraler, 21b. in medianer Lage mit den seitenorganen", 21c. Schwanz des Weibchens, 21d. Schwanzspitze.

Fig. 22. Iripyla arenicola d. M., Weibchen, ${ }^{17}{ }^{\circ} ; 22 \alpha$. Kopfende, 22b. Vulvaregion, 22c. Schwanz, 22d. Schwanzspitze.

\section{Tafel VI.}

Fig. 23. Desmolaimus Zeelandicus d. M., ein $1,5 \mathrm{~mm}$. langes Weibchen aus brackischer Erde der Insel Walcheren; August, ${ }^{17}{ }^{0}$; 23a. Kopfende, 23b. Seitenorgan in Profil, 23c. Mundböhle und Anfangstheil des Oes. in medianer Lage, 23d. hinterer Theil des Oes., 23e. Schwanz des Weibchens, 23f. des Männchens, 23g. Analregion desselben, 23h. accessorisches Stück in medianer Lage.

Fig. 24. Aicrolaimus globiceps d. M., ein $0,56 \mathrm{~mm}$. langes Weibchen aus brackischer Erde der Insel Walcheren, August, "운 ; 24a. Vorderende, 24b. Kopfende in lateraler, 24c. in medianer Lage. 24d. hinterer Körpertheil des Männchens, 24e. Schwanz des Weibchens.

Fig. 25. Cyatholaimus intermedius d. M., ein Weibchen, ${ }^{2} \frac{5}{T}^{0} ; 25 a$. Vorderende, 25b. Kopfende, 25c. Schwanz des Männchens, 25d. Analregion desselben, 25e. Schwanzspitze, 25f. Spicula und accessorische Stïcke in medianer Lage.

\section{Tafel VII.}

Fig. 26. Cyatholaimus terricola d. M., ein $1,3 \mathrm{~mm}$. langes Weibchen aus feuchter Fide unweit Leiden, Februar, ${ }^{250} \frac{5}{1}^{\circ} ; 26 a$. Kopfende, 26b. Schwanz des Weibchens, 26c. Theil der Körperoberfäche, die Structur des Integuments zeigend, 26d. Schwanzspitze.

Fig. 27. Cyatholaimus ruricola d. M., ein $0,53 \mathrm{~mm}$. langes Weibchen ans den Dünengegenden der Insel Walcheren, September, ${ }^{80}{ }^{\circ}$; 27a. Kopfende in lateraler, 27b. in medianer Lage, 27c. Schwanz des Männchens, 27 . Schwanzspitze.

Fig. 28. Cyatholaimus tenax d. M., ein $0,4 \mathrm{~mm}$. langes Weibchen aus feuchter Dünenerde, Walcheren, August, $8 \frac{00}{T} ; 28 a$. Kopfende in lateraler, 28b. in medianer Lage, 28c. Schwanz, 28d. Schwanzspitze.

Fig. 29. Spiluphora geophila d. M., ein $1 \mathrm{~mm}$. langes Weibchen aus brackischer Erde der Insel Walcheren, August, $25^{\circ} ; 29 \mathrm{c}$. Kopfende, 29b. Schwanz, die Körnchenreihen auf dem Seitenfelde zeigend.

\section{Tafel VIII.}

Fig. 30. Chromadora Leuckarti d. M., ein $1,2 \mathrm{~mm}$. langes Exemplar aus feuchter Erde, $\frac{250}{2} ; 30 a$. Kopfende in lateraler, $30 b$. in medianer Lage, 30c. Theil der äusseren Körperoberfläche, die Körnchenreihen auf dem Seitenfelde zeigend, 30d. binterer Körpertheil des Männchens.

Fig. 31. Chromadora Orleyi d. M., ein $0,7 \mathrm{~mm}$. langes Weibchen aus feuchter brackischer Erde der Insel Walcheren, Septennber; 31a. Vorderende, 31b. Kopfende in lateraler Lage, 31c. hinterer Körpertheil des Männchens, 31d. Spicula mit den zwei hintersten präanalen Papillen, daneben eine Papille von oben gesehen, 31e. Schwanzspitze, 31f. zwei Hautringe stark vergrössert.

Fig. 32. Chromadora bioculata Max Schultze, ein $0,9 \mathrm{~mm}$. langes Weibchen aus dem süssen Wasser in der Nähe von Leiden, Mai, ${ }^{2} \frac{5}{2}^{\circ} ; 32 a$. Kopfende in lateraler Lage mit Augenfleck, 32b. Mundhöhle in medianer Lage, 32c. Schwanz des Männchenз, 32d. Spiculum mit accessorischem Stücke, 32e. Schwanzspitze.

Fig. 33. Ethmolaimus pratensis d. M., ein erwachsenes Weibchen, $\frac{400}{x} ; 33 a$. Kopfende in lateraler Lage, 33b. Schwanzspitze, 33c. (auf Tafel $X X X I V$ l) Kopfende in medianer Lage. 


\section{Tafel IX.}

Fig. 34. Mononchus macrostoma Bast., Weibchen, ${ }^{1 \frac{1}{\top}}{ }^{\circ}$; $34 a$. Kopfende in lateraler, 34b. in medianer Lage, 34c. Schwanz des Weibchens, 34d. hinterer Körpertheil des Männchens, 34e. Spiculum mit einem accessorischen Stïcke.

Fig. 35. Mononchus papillatus Bast., Weibchen aus feuchter brackischer Erde, 1,5 mm. lang, 180 ; 35a. Kopfende.

Fig. 36. Mononchus parvus d. M., ein $1,1 \mathrm{~mm}$. langes Exemplar, aus den Dünengegenden in Holland, März, ${ }^{100}{ }_{1}^{0} ; 36 a$. Kopfende-

Fig. 37. Mononchus brachyuris Btsli, ein noch nicht ganz erwachsenes, 1,2 mm. langes Weibchen aus feuchter Wiesenerde in der Nähe von Leiden, Mărz, ${ }^{250}$; 37a. Kopfende, 37b. Schwanz.

\section{Tafel X.}

Fig. 38. Mononchus tridentatus d. M., Weibchen, $\underset{\mathrm{I}}{\mathrm{B}}$; $38 \alpha$. Kopfende, in welchem nur zwei Zähne sichtbar sind, weil der dritte hinter dem dunklen Mittelstreif liegt.

Fig. 39. Oncholaimus thalassophygas d. M., ein $3,5 \mathrm{~mm}$. langes Weibchen aus brackischer Erde der Insel Walcheren, August, ${ }_{\mathrm{T}}^{\circ}$; 39a. Schwanz desselben.

Fig. 40. Ironus ignavus Bast., Weibchen, ${ }^{2} 0^{\circ} ; 40 a$. Kopfende eines jungen Thieres in lateraler Lage, auch die späteren, jetzt noch in der Wand der Mundhöhle liegenden Zähne zeigend, 40b. Schwanz des Weibchens, 40c. Hinterende des Oes., 40d. hinterer Körpertheil des Männchens, 40e. Spiculum.

Fig. 41a. Sphaerolaimus gracilïs d. M., Spiculum und accessorisches Stück in lateraler Lage, 41b. Spicula und accessorisches Stück in medianer Lage, "sọo; 41c. Vulvaregion mit der Drüse.

Fig. 42. Choanolaimus psammophilus d. M., Weibchen aus den Dünengegenden, ${ }^{19^{\circ}}$; $42 a$. Kopfende in lateraler, 42b. in medianer Lage, 42c. Schwanz des Männchens, 42d. Theil der Körperoberfäche, die Structur des Integuments zeigend.

\section{Tafel XI.}

Fig. 43. Trilobus gracilis Bast., ein $2,9 \mathrm{~mm}$. langes Weibchen aus dem süssen Wasser unweit Leiden, Oktober, ${ }^{12}{ }^{5} ; 43 a$. Kopfende, 43b. Schwanz des Weibchens, 43c. Schwanzspitze, 43d. hinterer Körpertheil des Männchens, 43e. Analregion desselben, 43f. Spicula und accessorische Stücke in medianer Lage gesehen, $43 \mathrm{~g}$. eine präanale Papille stärker vergrössert.

Fig. 44. Trilobus pellucidus Bast., ein 2,5 mm. langes Thier aus feuchter Erde in Holland, August, ${ }^{2 \frac{2}{2}}{ }^{6} ; 44 a$. Kopfende, 44b. Schwanz des Weibchens.

Fig. 45. Aulolaimus oxycephalus d. M., Weibchen, ${ }_{\mathrm{T}}^{\circ}$, 45a. Kopfende, 45b. hinterer Körpertheil des Männchens, 45c. präanale Region und Spicula.

Fig. 46. Prismatolaimus intermedius Btsli, ein 0,72 mm. langes Weibchen aus sandiger Erde der Insel Walcheren, September, "400 ; 46a. Kopfende mit Seitenorgan, 46b. Ansicht der Seitenorgane in medianer Lage, 46c. Schwanzspitze.

\section{Tafel XII.}

Fig. 46d. Prismatolaimus intermedius Btsli, Männchen aus sandiger Erde der Insel Ischia (Mittelmeer), \$ํㅜㅇ 46e. Analregion desselben, 46f. zwei Papillen stärker vergrössert.

Fig. 47. Prismatolaimus dolichurus d. M., ein 1,1 mm. langes Thier aus dem humusreichen Boden eines Waldes auf der Insel Walcheren, September, ${ }^{2}{ }^{\circ}{ }^{\circ} ; 47 a$. Kopfende.

Fig. 48. Cylindrolaimus communis d. M., Weibchen, $4 \frac{00}{\mathrm{r}} ; 48 a$. Kopfende, 49b. Hinterende des Oes., 48c. Seitenorgan in Profil, 48d. Schwanz des Weibchens, 48e. Schwanzspitze.

Fig. 49. Cylindrolaimus melancholicus d. M, , Weibchen, ${ }_{x}^{10}$; 49a. Kopfende in lateraler, 49b. in medianer Lage, 49c. Hintertheil des Oes, , 49d. Vagina, 49e. Ende des Schwanzes, 49f. Schwanz des Männehens, 49g. Analregion desselben.

Fig. 50. Diplogaster rivalis Leydig, ein 2,1 mm. langes Weibchen aus dem süssen Wasser unweit Leiden, April, ${ }^{2}{ }_{1}^{5}$; Kopfende des Weibchens in lateraler, 50b. in medianer Lage, 50c. Seitenorgan des Männchens, 50d. dasselbe in Profil, 50e. Schwanz des Weibchens, 50f. Schwanzpapille des letzteren in Profil, 50g. Schwanz des Männchens in lateraler, 50k. in medianer Lage (für die Papillenzahle zu vergleichen den Text), 50i, Analregion desselben in lateraler, 50k. in medianer Lage.

\section{Tafel XIII.}

Fig. 51. Diplogaster fictor Bast., ein 1,8 mm. langes Weibchen aus dem süssen Wasser unweit Leiden, Mai, ${ }^{13}{ }^{\circ}$; 51a. Vorderende, 51b. Kopfende in lateraler, 51c. in medianer Lage, $51 d$. Schwanz des Weibchens, $51 e$. des Männchens, $51 f$. Analregion des letzteren. 
Fig. 52. Cephalobus persegnis Bast., ein 0,7 mm. langes Weibchen aus feuchter Erde in Holland, Februar, $\bullet^{\circ}{ }^{\circ} ; 52 a$. Kopfende, $52 b$. hinterer Körpertheil des Männchens, 52c. des Weibchens, $52 d$. Schwanzende des Männchens in medianer Lage.

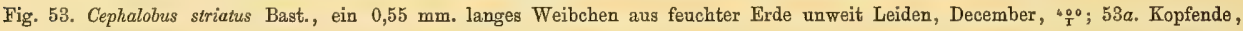
53b. Schwanz.

Fig. 54. Cephalobus nanus d. M., ein $0,38 \mathrm{~mm}$. langes Weibchen aus feuchter Wiesenerde, in der Nähe von Leiden, März, ${ }^{500}$; $54 a$. Kopfende.

Fig. 55. Cephalobus oxyuroides d. M., ein $0,67 \mathrm{~mm}$. langes Weibchen aus feuchter Dünenerde der Insel Walcheren, August, ${ }^{350}$; 55a. Kopfende, 55b. hinterer Theil des Oes., mit Ausführungsgang des Gefässsystems, 55c. Schwanz des Weibchens, $55 d$. des Männchens, 55e. schematische Darstellung der Lage der Papillen am Schwanz des Mänuchens in medianer Lage, $55 f$. zweite Form des Schwanzes des Männchens.

\section{Tafel XIV.}

Fig. 56. Cephalobus longicaudatus Btsli, ein $0,9 \mathrm{~mm}$. langes Weibchen aus feuchter Dünenerde der Insel Walcheren, August, ${ }^{250}$; 56a. Kopfende, 56b. Schwanz des Weibchens, 56c. des Männchens, 56d. Analregion desselben.

Fig. 57. Cephalobus elongatus d. M., ein $0,8 \mathrm{~mm}$. langes Weibchen aus sandiger Dünengegend der Insel Walcheren, August, ${ }^{2} 5^{\circ}$; 57a. Kopfende, 57b. Schwanz des Weibchens, 57c. hinterer Theil des Oes. mit Ausführungsgang des Gefässsystems, 57d. Schwanz des Männchens.

Fig. 58. Cephalobus emarginatus d. M., Weibchen, ${ }^{400}$; $58 a$. Kopfende in lateraler Lage, 58b. Schwanz des Weibchens.

Fig. 59. Cephalobus filiformis d. M., ein $1 \mathrm{~mm}$. langes Männehen aus humusreicher Erde in der Nähø vom Haag, Februar, ${ }^{250}{ }^{\circ} ; 59 a$. Kopfende des Männchens, 59b. Schwanz eines $0,64 \mathrm{~mm}$. langen jugendlichen Thieres, $59 \mathrm{c}$. Schwanz des Männchens, $59 d$. Spiculum, 59e. ein 1,2 mm. langes Weibchen aus feuchter Erde in der Nähe von Leiden, August, ${ }^{26}{ }^{\circ}, 59 f$. Schwanz desselben.

\section{Tafel XV.}

Fig. 60. Cephalobus vexilliger d. M., Weibchen, $5^{\circ} 0^{\circ}$; $60 a$. Kopfende in lateraler, 60b. in medianer Lage, 60c. Schwanzspitze des Weibchens, 60d. Schwanz des Männchens in lateraler, 60e. in medianer Lage.

Fig. 61. Cephalobus ciliatus von Linstow, ein $0,5 \mathrm{~mm}$. langes Weibchen, ${ }^{\circ 0} 0_{\mathrm{T}}^{\circ} ; 61 a$. Kopfende in lateraler, 61b. in medianer Lage, 61c. hinterer Körpertheil des Männchens in lateraler, 61d. hinteres Schwanzende desselben in medianer Lage.

Fig. 62. Teratocephalus terrestris Btsli, ein $0,45 \mathrm{~mm}$. langes Weibchen aus feuchter Erde der Insel Walcheren, Januar, ${ }^{50}{ }^{\circ} ; 62 a .50 p f-$ ende in lateraler, 62b. eine Hälfte desselben in medianer Lage, 62c. Oesophagealbulbus.

Fig. 63. Teratocephalus crassidens d. M., ein $0,52 \mathrm{~mm}$. langes Weibchen, ${ }^{40}{ }^{\circ} ; 63 a$. Kopfende in lateraler, 63b. in medianer Lage, 63c. hinterer Theil des Oes. mit Klappenapparat und Nervenring, die Körnchen auf dem Seitenfelde zeigend.

\section{Tafel XVI.}

Fig. 64. Teratocephalus palustris d. M., ein $1 \mathrm{~mm}$. langes Weibchen aus einem Telche von sūssem Wasser in der Dünengegend von Holland, Juni, ${ }^{25}{ }^{\circ}$; 64a. Kopfende, 64b. Schwanz, 64c. Oesophagealbulbus mit Klappenapparat, 64d. Theil der Körperoberfäche, die Structur des Integuments zeigend.

Fig. 65. Plectus granulosus Bast., ein erwachsenes Weibchen, 1,7 mm. lang, aus einer humusreichen Wiese in der Nähe vom Haag, Februar, ${ }^{18^{\circ}}{ }^{\circ} ; 65 a$. Kopfende, 65b. hinterer Körpertheil des Männchens, 65c. Ei.

Fig. 66a. Plectus Schneideri d. M., Vorderende, 66b. Kopfende, 66c. hinterer Körpertheil des Männchens, 66d. Ausmündungsöffnung der weibl. Geschlechtsorgane.

Fig. 67. Plectus parietinus Bast, Weibchen $1,3 \mathrm{~mm}$. lang aus der Dünengegend von Walcheren, August, $4 \frac{000}{\mathrm{I}}$; $67 a^{\circ}$. Kopfende, $67 b$. Schwanz.

\section{Tafel XVII.}

Fig. 68. Plectus cirratus Bast., ein $1 \mathrm{~mm}$. langes Weibchen aus feuchter Erde unweit Leiden, Februar, ${ }^{2} \frac{5^{\circ}}{2}$; 68a. Kopfende, 68b. Oesophagealbulbus, 68c. Schwanz eines Männchens, 68d. Analregion desselben.

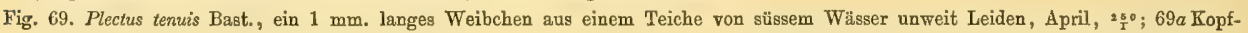
ende, 69b. Schwanz, 69c. Oesophagealbulbns. 
Fig. 70. Plectus palustris d. M., ein 1,8 mm. langes Weibchen aus einem Teiche von süssem Wasser bei Leiden, Mai, 130; 70a. Kopfende, 70b. Schwanz.

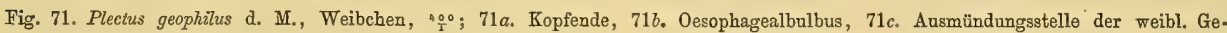
slechtsorgane, 71d. Schwanz.

Fig. 72. Plectus rhizophilus d. M., ein 0,6 mm. langes Weibchen aus humusreicher Erde in einem Walde beim Haag, Januar, ${ }^{400}$; 72a. Kopfende, 72b. Schwanz, 72c. Schwanz eines 0,73 mm. langen Weibchens, 72d. Oesophagealbulbus.

\section{Tafel XVIII.}

Fig. 73. Plectus longicaudatus Btsli, ein $0,46 \mathrm{~mm}$. langes Weibchen, $4{ }_{\mathrm{T}}^{\circ} ; 73 a$. Kopfende, 73b. Schwanz, 73c. Oesophagealbulbus.

Fig. 74. Plectus parvus Bast., Weibchen, "ํㅜㅇㅜ ;4a. Kopfende.

Fig. 75. Plectus communis Btsli, Weibchen, $40^{\circ} ; 75 a$. Kopfende.

Fig. 76. Plectus auriculatus Btsli, ein $0,57 \mathrm{~mm}$. langes Weibchen aus sandiger Erde beim Haag, April, 400 ; 76a. Kopferde, 760. Schwanz.

Fig. 77. Plectus otophorus d. M., ein 0,36 mm. langes Weibchen aus sandiger Dünengegend, März, "ํㅜㅇ; 77a. Kopfende, 77b. Schwanz.

Fig. 78. Rhabditis monohystera Btsli, Kopfende.

Fig. 79. Rhabditis brevispina Claus, Weibchen, ${ }^{18} \frac{0}{1} ; 79 a$. Vorderende, 79b. Kopfende, 79c. Schwanz mit lateraler Papille, 79d. mittlerer Schwanztheil in medianer Lage mit den lateralen Papillen.

\section{Tafel XIX.}

Fig. 80. Rhabditis intermedia d. M., Weibchen, ${ }^{2} \mathrm{~s}_{T}^{\circ} ; 80 \alpha$. Kopfende, $80 b$. Schwanz des Männchens in medianer, 80c. in lateraler Lage, 80d. Schwanz des Weibchens.

Fig. 81. Rhabditis filiformis Btsli, ein $0,58 \mathrm{~mm}$. langes Weibchen aus feuchter Erde unweit Leiden, December, "0 ${ }^{\circ} ; 81 a$. Vorderende 81b. Kopfende, 81c. Ausmündungsöffnung der weibl. Geschlechtsorgane mit Seitenmembran.

Fig. 82. Macroposthonia annulata d. M., Männchen, $\underset{\mathrm{T}}{\mathbf{0} 0}$; 82a. Kopfende, 82b. Schwanz des Männchens in lateralex, $82 c$. in medianer Lage.

Fig. 83. Rhabdolaimus aquaticus d. M., ein $0,6 \mathrm{~mm}$ : langes weibchen aus einem Teiche von süssem Wasser in der Nähe von Leiden, Mai, "ị; 83a. Vorderende, 83b. Oesophagealbulbus, 83c. Ausmündungsstelle der weibl. Geschlechtsorgane, 83d. Schwanzspitze.

\section{Tafel XX.}

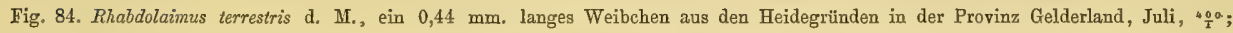
84a. Vorderende in medianer Lage mit den Seitenorganen, 84b. Oesophagealbulbus, 84c. Schwanz des Männchens, 84d. Analregion desselben, 84e. Schwanzspitze.

Fig. 85. Odontolaimus chlorurus d. M., ein $0,85 \mathrm{~mm}$. Ianges Weibchen aus feuchter.Erde der Dünenstriche der Insel Walcheren, September, ${ }^{4} 0^{0} ; 85 a$. Vorderende in lateraler, $85 b$. in medianer Lage, $85 c$. Schwanz.

Fig. 86. Diphtherophora communis d. M., Weibchen, ${ }^{\frac{0}{2}}{ }^{\circ}, 86 a$. Kopfende, 86b. Ende des Oes., 86c. Schwanz des Männchens.

Fig. 87. Tylolaimophorus typicus d. M., ein $0,8 \mathrm{~mm}$. langes Weibchen aus den Heidegründen der Provinz Gelderland, Juli, ${ }^{2} \frac{5}{X}^{\circ} ; 87 a$. Kopfende in lateralex, $87 b$, in medianer Lage, $87 c$. Schwanz.

\section{Tafel XXI.}

Fig. 88. Tylencholaimus mirabilis Btsli, ein $1 \mathrm{~mm}$. langes Weibchen aus feuchter Erde in einem Walde in der Näbe vom Haag, Januar, ${ }^{250}$; $88 \alpha$. Kopfende, 88b. Schwanz.

Fig. 89. Tylencholaimus minimus d. M., ein 0,59 mm. langes Weibchen aus feuchter Erde bei Leiden, Oktober, ${ }^{50}{ }^{\circ}$; $89 a$. Schwanz.

Fig. 90. Aphelenchus agricala d. M, , ein $0,75 \mathrm{~mm}$. langes Weibchen aus der Dünengegend der Insel Walcheren, September, ${ }^{40}{ }^{\circ} ; 90 a$. Vorderende, 90z. Kopfende, 90c. Theil aus der Mitte des Körpers mit gestreiftem Seitenfelde, 90d. Schwanz in lateraler, 90e. Schwanzende in medianer Lage.

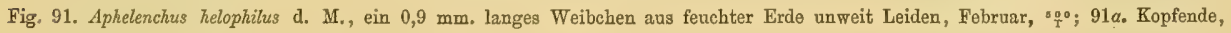
91b. Schwanzspitze. 


\section{Tafel XXII.}

Fig. 92. Tylenchus robustus d. M. ein $0,8 \mathrm{~mm}$. langes Weibchen, ${ }^{25}{ }^{\circ} ; 92 a$. Kopfende, $92 b$. Schwanz des Männchens in lateraler Lage, 92c. Schwanz des Weibchens.

Fig. 93. Zylenchus dubius Btsli, ein 0,85 mm. langes Weibchen aus sandiger Erde einer Wiese aus den Holländischen Dünenstrichen, April, ${ }^{250} ; 93 a$. Kopfende, 93b. Schwanz des Männchens, 93c. Spicula.

Fig. 94. Tylenchus lamelliferus d. M., ein $0,91 \mathrm{~mm}$. langes Weibchen aus feuchter Erde unweit Leiden, Februar, "⿳⺈⿴囗十一 ; 94a. Kopfende, 94b. Ende des Oes., mit den, über den Körper hinlaufenden Lamellen, 94c. Schwanz des Weibchens, 94d. des Männchens.

Fig. 95. Tylenchus pratensis d. M., ein $0,6 \mathrm{~mm}$. langes Weibchen aus feuchter Erde unweit Leiden, Februar, ${ }^{400} ; 95 a$. Kopfende, 95b. Schwanz des Weibchens, 95c. des Männchens.

\section{Tafel XXIII.}

Fig. 96. Tylenchus gracilis d. M., ein noch nicht ganz erwachsenes Weibchen, 2,2 mm. lang, aus feuchter Erde einer Wiese beim Haag, Februar, ${ }_{1}^{125} ; 96 a$. Vorderende, 96b. Kopfende, 96c. Ausmündungsregion der weibl. Geschlechtsorgane, 96d. Schwanz des Weibchens, 96e. des Mänuchens.

Fig. 97. Tylenchus intermedius d. M., Weibchen, aus brackischer Erde der Insel Walcheren, ${ }^{250}$; $97 a$. Vorderende, 97b. Kopfende, 97c. hinterer Körpertheil eines Weibchens aus feuchter Erde in der Nähe von Leiden, 97d. Schwanz des Männchens.

Fig. 98. Tylenchus leptosoma d. M., ein $0,55 \mathrm{~mm}$. langes Weibchen, ${ }_{\frac{1}{T}}^{\circ} ; 98 a$. Kopfende, 98b. Ausmündungsregion der weibl. Geschlechtsorgane, 98c. Schwanz des Männchens, 98d. Analregion desselben.

Fig. 99. Tylenchus agricola d. M., (auf der Tafel unrichtig filiformis Btsli genannt), ein 0,56 mm. langes Weibchen aus feuchter Erde, $\frac{1}{1}^{0} ; 99 a$. Kopfende, 99b. Ausmündungsregion der weibl. Geschlechtsorgane, 99c. Schwanz des Männchens, 99d. Analregion desselben.

\section{Tafel XXIV.}

Fig. 100. Tylenchus Davainei Bast., ein $1 \mathrm{~mm}$. langes Weibchen aus sandiger Dünengegend unweit Leiden, März, ${ }^{2 \frac{5}{x}}{ }^{\circ} ; 100 a$. Kopfende, 100b. Schwanz des Männchens, 100c. Analregion desselben, 100d. Schwanz des Weibchens.

Fig. 101. Tylenchus filiformis Btsli, (auf der Tafel noch als Tylenchus elegans d. M. angedentet), ein 1 mm. langes Weibchen aus einer humusreichen Wiese in der Nähe vom Haag, Februar, ${ }^{25}{ }^{\circ} ; 101 a$. Kopfende, 101b. Analregion des Männchens.

Fig. 102. Tylenchus macrophallus d. M., Weibchen, $\frac{60}{T}$; 102a. Kopfende des Männchenв, 102b. des Weibchens, 102c. Schwanz des Männchens, 102d. Spicula.

Fig. 103. Doryluimus primitivus d. M., ein 0,63 mm. langes Männchen, 400\%, aus feuchter Erde unweit Leiden, Februar; 103a. Vorderende in medianer Lage, 103b. Kopfende in lateraler, 103c, in medianer Lage, 103d. Ausmündungsregion der weibl. Geschlechtsorgane, 103e. Schwanz des Weibchens, 103f. Spiculum mit accessorischem Stücke.

\section{Tafel XXV.}

Fig. 104. Dorylaimus elongatus d. M., Weibchen, $\underset{\mathrm{s}}{\mathrm{s}} ;$; 104a. Schwanz und präanale Region des Männchens.

Fig. 105. Dorylaimus regius d. M., eine nur $3,2 \mathrm{~mm}$. lange Jugendform aus feuchter Erde einer Wiese unweit Leiden, März, $\underset{\mathrm{r}}{\mathrm{O}}$.

Fig. 106. Dorylaimus labiatus d. M., ein $2,7 \mathrm{~mm}$. langes Weibchen aus den Heidegründen der Provinz Gelderland, Juli, $\frac{80}{\mathrm{~T}}$; $106 a$. Vorderende, 106b. Kopfende, 106c. Schwanz.

Fig. 107. Dorylaimus robustus d. M., ein $6,8 \mathrm{~mm}$. langes Weibchen aus feuchter Erde unweit Leiden, November; 107a. Schwanzende eines 4,2 mm. langen Männchens aus feuchter Erde unweit Leiden, November, ${ }^{73}{ }^{\circ}{ }^{\circ}$

\section{Tafel XXVI.}

Fig. 108. Dorylaimus superbus d. M., ein 4,5 mm. langes Weibchen aus humusreicher Erde beim Haag, Februar, i̊ ; 108a. Kopfende, 108b. Schwanz, 108c. Varietät des Schwanzes, 108d. hinteres Körperende des Männchens, 108e. Spiculum mit accessorischem Stücke.

Fig. 109. Dorylaimus obtusicaudatus Bast, ein $2,9 \mathrm{~mm}$. langes Weibchen aus sandigex Dünengegend, $\stackrel{80}{\mathrm{O}}$; 109a. Kopfende 109b. Schwanz eines Individuums aus der Dünengegend, 109c. Schwanz eines 2,5 mm. langen Individuums aus feuchter Erde unweit Leiden. 
Fig. 109d. Dorylaimus obtusicaudatus Bast., Männchen aus feuchter brackischer Erde der Insel Walcheren, 2 mm. lang, Januar, 212s; 109e. Schwanz desselben.

Fig. 110. Dorylaimus macrodorus d. M., Weibchen aus feuchter Erde unweit Leiden, 110a. Kopfende, 110z. Vulvaregion, 110 $c$. Schwanz.

\section{Tafel XXVII.}

Fig. 111. Dorylaimus rhopalocercus d. M., Weibohen, 2,1 mm. lang, ${ }^{12}{ }^{5}$.

Fig. 112. Dorylaimus brachyuris d. M., ein 2,45 mm. langes Weibchen aus sandiger Erde beim Haag, April, ${ }^{2}{ }^{5}{ }^{5} ; 112 a$. Kopfende, 112b. Schwanz.

Fig. 113. Dorylaimus intermedius d. M., ein $2,1 \mathrm{~mm}$. langes Weibchen aus feuchter Erde unweit Leiden, November, ${ }^{11^{5}} ; 113 \alpha$. Kopfende, 113b. Vulva, 113c. Schwanz des Männchens, 113d. des Weibchens.

Fig. 114. Dorylaimus pratensis d. M., ein $1,6 \mathrm{~mm}$. langes Weibchen aus sandiger Wiesenerde auf der Insel Walcheren, Januar, 추두 114a. Kopfende, 114b. Schwanz, 114c. Varietät des Schwanzes.

\section{Tafel XXVIII.}

Fig. 115. Dorylaimus bryophilus d. M., Weibchen, 0,96 mm. lang, aus sandiger Dünengegend unweit Leiden, März, ${ }^{25}{ }^{0} ; 115 a$. Kopfende. Fig. 116. Dorylaimus microdorus d. M., ein $0,7 \mathrm{~mm}$. langes Weibchen aus einer sandigen Wiese unweit Haag, April, 250; 116a. Kopfende in lateraler, 116b. in medianer Lage, 116c. Sehwanz. (Der Stachel ist leider nicht abgebildet!)

Fig. 117. Dorylaimus elegans d. M., ein $1,4 \mathrm{~mm}$. langes Weibchen aus sandiger Dünengegend unweit Leiden, März, ${ }^{18^{\circ}}$; $117 \alpha$. Kopfende, $117 b$. Schwanz.

Fig. 118. Dorylaimus monohystera d. M., ein 1,36 'mm. langes Weibchen aus sandiger Dünengegend in der Nähe von Leiden, März, ${ }_{17}^{1}{ }^{\circ} ; 118 a$. Kopfende, 118b. Vulva, 118c. Schwanz.

Fig. 119. Dorylaimus centrocercus d. M., ein 1,4 mm. langes Weibchen aus humusreicher Erde einer Wiese unweit Haag, Februar, ${ }_{17}^{1}{ }_{T}^{\circ} ; 119 a$. Kopfende in lateraler, 119b. in medianer Lage, 119c. Schwanz, 119d. Varietät der Schwanzspitze.

\section{Tafel XXIX.}

Fig. 120. Dorylaimus gracilis d. M., ein 1,5 mm. langes Weibchen aus feuchter Wiesenerde der Insel Walcheren, Januar, ${ }^{170} ; 120 \alpha$. Kopfende, 120b. Schwanz des Männchens.

Fig. 121. Dorylaimus Leuckarti Btsli, ein $2 \mathrm{~mm}$, langes Weibchen aus feuchter Wiesenerde unweit Leiden, März, ${ }^{1} \frac{7}{\mathrm{~T}}^{\circ} ; 121 a$, Kopfende, 121b. Schwanz des Männchens.

Fig. 122. Dorylaimus Carteri Bast., Weibchen, 122a. Kopfende, 122b. hinteres Körperende eines 1,7 mm. langen Männchens aus humusreicher Erde in der Nähe vom Haag, Februar, $4000 ; 122 c$. Spiculum.

Fig. 123. Dorylaimus similis d. M., Weibchen, ${ }^{180}$; $123 a$. Kopfende, 123b. Vu!va.

\section{Tafel XXX.}

Fig. 124. Dorylaimus acuticauda d. M., Weibchen, 2вㅇ; 124a. Kopfende, 124b. hinterer Körpertheil des Männchens, 124c. Schwanz des Weibchens, 124d. Varietät des weibl. Schwanzes, 124e. Vulva.

Fig. 125. Dorylaimus parcus d. M., ein $0,6 \mathrm{~mm}$. langes Weibchen aus sandiger Dünengegend in der Nähe von Leiden, März, ${ }^{\circ}{ }^{\circ}$; 125a. Kopfende, 125b. hinteres Körperende des Männchens, 125c. Spiculum und präanale Papille.

Fig. 126. Dorylaimus Hartingï d: M., ein 1,6 mm. langes Weibchen, ${ }^{\frac{7}{2}} 0^{\circ} ; 126 a$. Kopfende, 126b. Vulva, 126c. Anfang des Darmes.

Fig. 127. Dorylaimus lugdunensis d. M., ein $0,8 \mathrm{~mm}$. langes Weibchen aus sandiger Dünenerde unweit Leiden, Januar, ${ }^{\circ} \frac{00}{\mathrm{~T}} ; 127 a$. Kopfende, 127b. Schwanz.

\section{Tafel XXXI.}

Fig. 128. Dorylaimus attenuutus d. M., ein $2,2 \mathrm{~mm}$. Ianges Weibchen ans feuchter Erde unweit Leiden, November, ${ }^{12^{5}} ; 128 a$, Kopfende, 1281. Schwanz.

Fig. 129. Dorylcimus agilis d. M., ein erwachsenes, $1,5 \mathrm{mma}$. langes Weibchen aus feuchter Eide einer Wiese auf der Niederländischen Halbinsel Duiveland, August, ${ }^{1} \mathrm{~T}^{\circ}$; $129 a$. Kopfende, 129b. Schwanz. 
Fig. 130. Dorylaimus limnophilus d. M., ein 1,1 mm. langes Weibchen aus feuchter Erde unweit Leiden, November, ${ }^{2} 5^{\circ} ; 130 a$. Kopfende, 130b. Schwanz.

Fig. 131. Dorylaimus Bastiani Btsli, ein $2 \mathrm{~mm}$. langes Weibchen aus feuchter Wiesenerde unweit Haag, Februar; 131a. Kopfende, 131b. Schwanz, 131c. Varietät des Schwanzes.

\section{Tafel XXXII.}

Fig: 132. Dorylaimus stagnalis Bast., ein $7,5 \mathrm{~mm}$. langes Weibchen aus einem Teiche von süssem Wasser, in den Holländischen Dünenstrichen, Juli, $\stackrel{\leftrightarrow}{T}$; $132 a$. Kopfende, 132b. Schwanz.

Fig. 133. Dorylaimus crassus.d. M., ein 4,8 mm. langes Weibchen aus feuchter Wiesenerde unweit Leiden, November, $\underset{\mathrm{I}}{\mathrm{s}}$; $133 a_{\text {. Kopf- }}$ ende, 133b. Schwanz.

Fig. 134. Dorylaimus fliformis Bast, ein $3,2 \mathrm{~mm}$. langes Weibchen aus dem süssen Wasser unweit Leiden, Mai, 1255; 134a. Kopfende, 134b. Schwanz.

Fig. 135. Dorylaimus brigdammensis d. M., ein $1,8 \mathrm{~mm}$. langes Weibchen aus feuchter Erde unweit Leiden, Januar; ${ }^{170}{ }_{\mathrm{T}}$; $135 a_{0}$ Kopfende desselben, 135b. Spiculum.

\section{Tafel XXXIII.}

Fig. 136. Dorylaimus longicaudatus Btsli, ein $3,3 \mathrm{~mm}$. langes Weibchen aus humusreicher Erdo beim Haag, Februar, 晘; 136a. Kopfende., 136b. Spiculım.

Fig. 137. Dorylaimus rotundicauda d.. M., Weibchen, ${ }^{10}{ }^{\circ} ; 137 a$. Kopfende, 137b. Schwanz.

Fig. 138. Dorylaimus -macrolaimus d. M., ein $4 \frac{2}{2} \mathrm{~mm}$. langes Weibchen, ${ }_{\mathrm{T}}^{\frac{80}{3}} ; 138 a$. Männchen, ${ }^{100} ; 138 b$. Kopfende, 138c. hinterer Körpertheil des Männchens.

\section{Tafel XXXIV.}

Fig. 139. Tylopharynx striata d. M. Ein $1,17 \mathrm{~mm}$. langes Weibchen aus fouchter Erde der Insel Walcheren, November, $\frac{380}{2} ; 139 a$. Kopfende in lateraler, 139b, in medianer Lage.

Fig. 140. Ironus longicaudatus n. sp., Weibchen aus feuchter Erde, ${ }^{17}{ }_{1}^{\circ} \bullet$

Fig. 141. Anguillula aceti Ehrb., Kopfende eines Weibchens in lateraler Lage, ${ }^{30} 0^{\circ}$, die zahnartigen Fortsätze in der Mundhöhle zeigend.

Fig. 142. Angrillula aceti Ehrb., Kopfende eines Embryos in lateraler Lage, ${ }^{4000}$, das dorsale Zähnchen am Grund der Mundhöhle zeigend.

Fig. 143. Cephalobus oxyuroides d. M., Körpertheil eines Weibchens, innerlich gänzlich besetzt mit stabförmigen Parasiten.'

Fig. 144a. Pflanzlicher Parasit(?) aus dem Darme des Mononchus macrostoma, 144b. ein Theil stärker vergrössert.

Fig. 145. Zwei Parasiten aus der Leibeshöhle von Dorylaimus brigdammensis d. M.

Fig. 33c. Ethmolaimus pratensis d. M., Kopfende eines weiblichen Individuums aus Erlangen, in medianer Lage, November, $\stackrel{2000}{\mathrm{I}}$. 


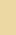



Taf.I.

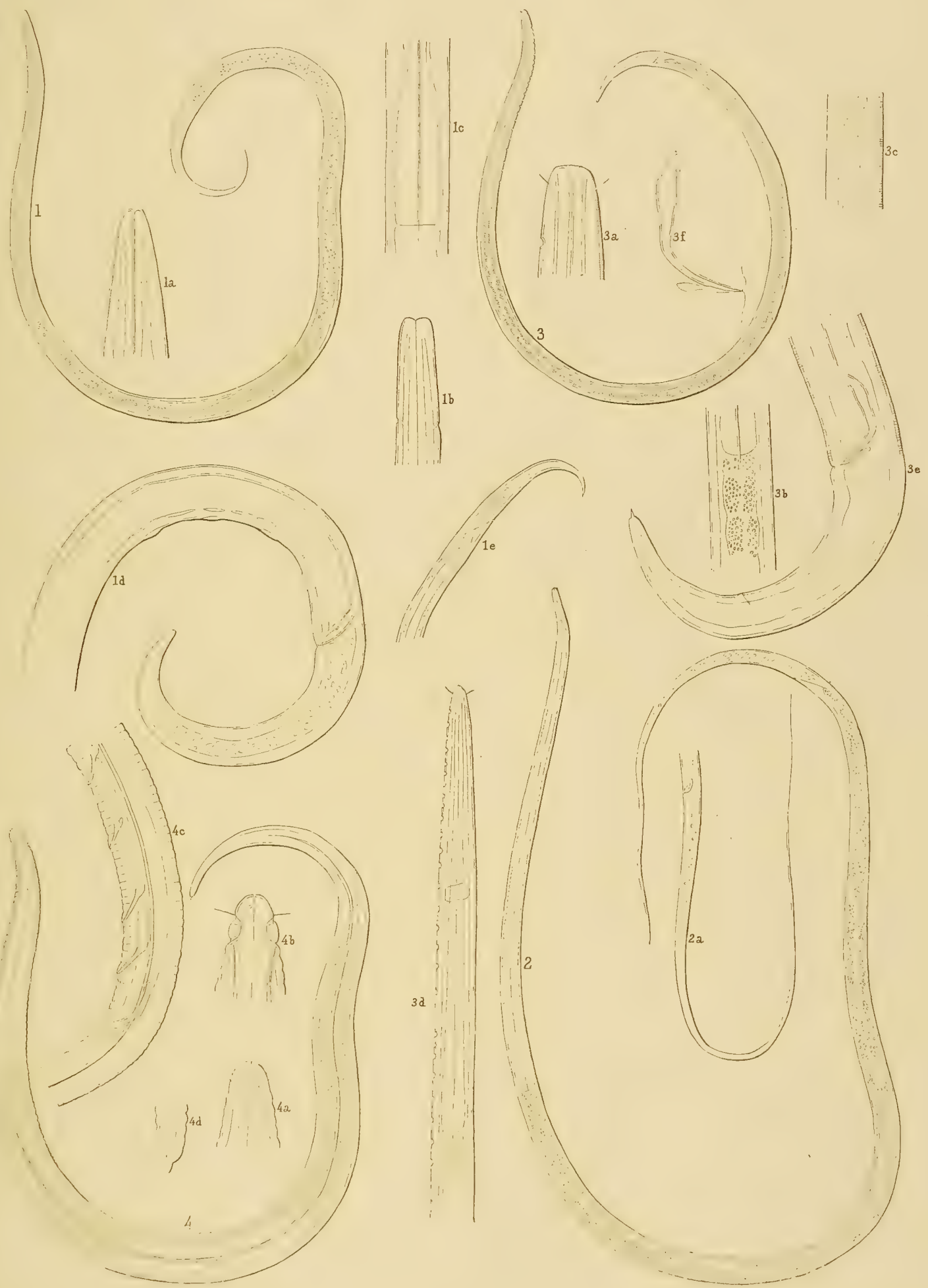

Fig.1. Alaimus primilivus d.M. Fig.3. Deonzolamus papillatus. d.M.
Fig. 2. Alaimus dolichurus. dM.

Fig:4. Aphanolaimus attentus.d.M. 



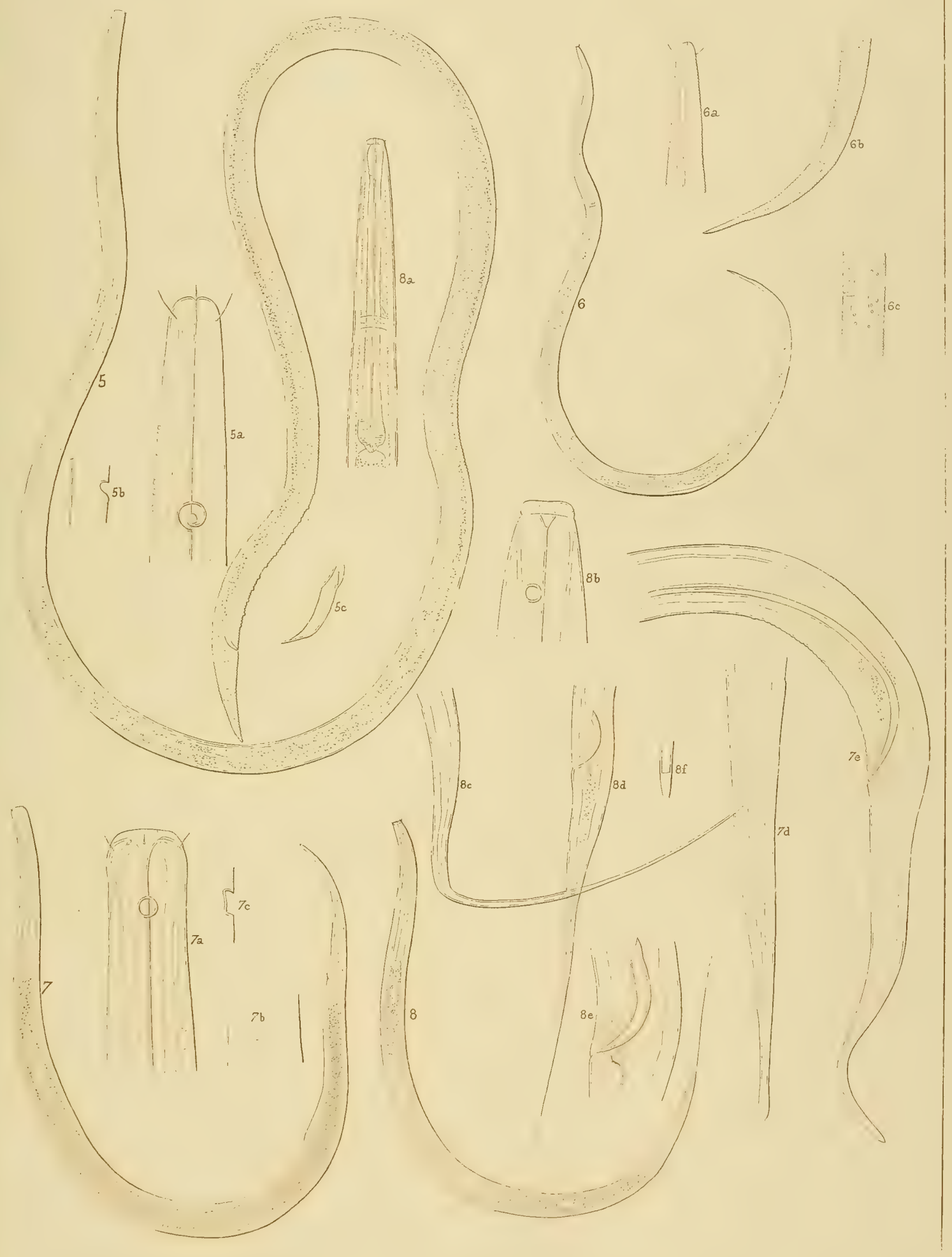





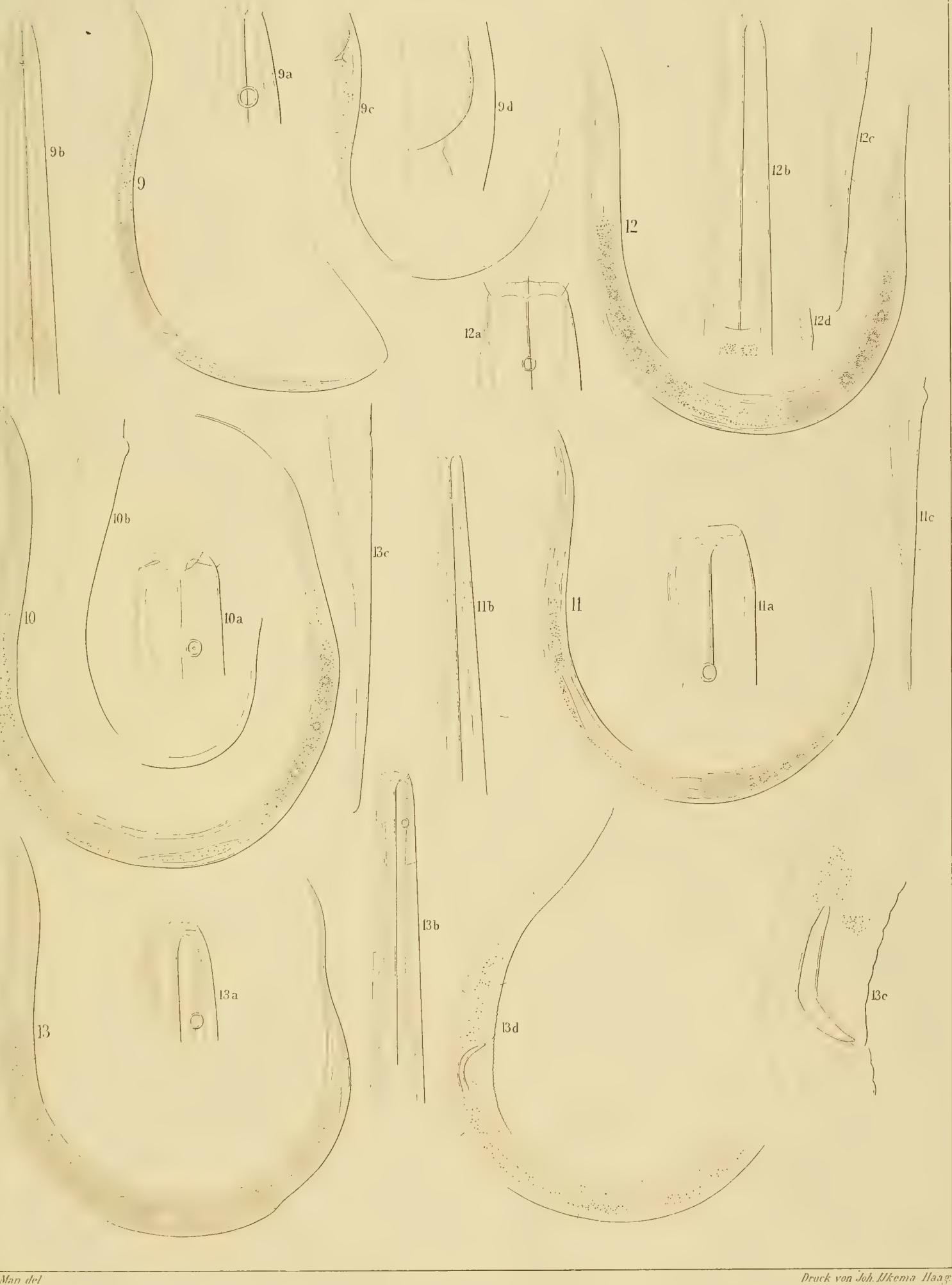

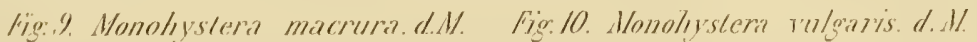

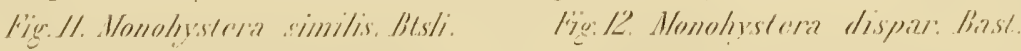





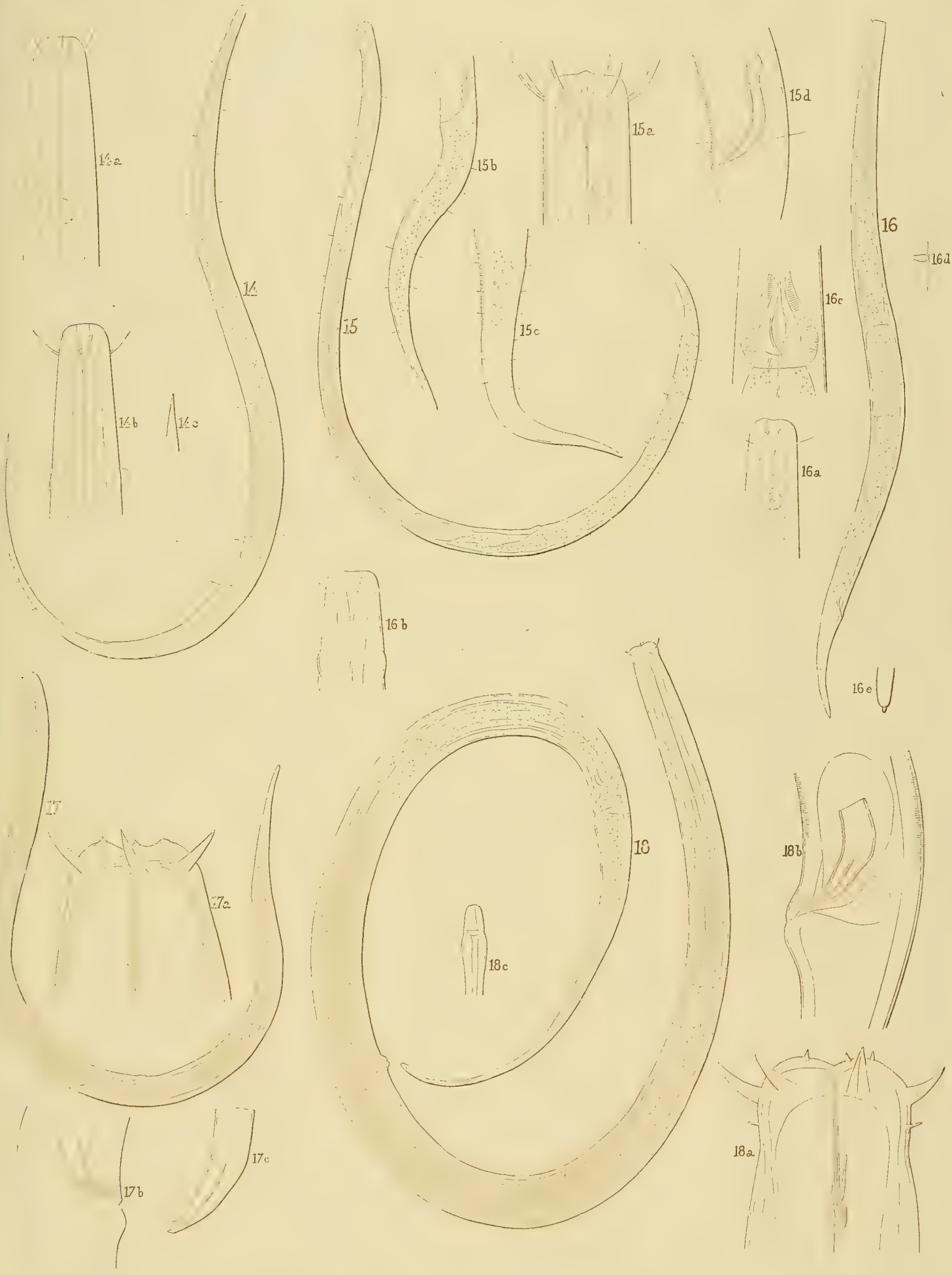

Druck wom Joh Uhema Fuag:

Fig. 14. Morrohysterz simplex d.MI Fig: 15. Monohyslera agilis d.M. Fig 16. Monohysterir bulbiferze d.M. Fig:IT. Tiripyla seliefie Btsli. 



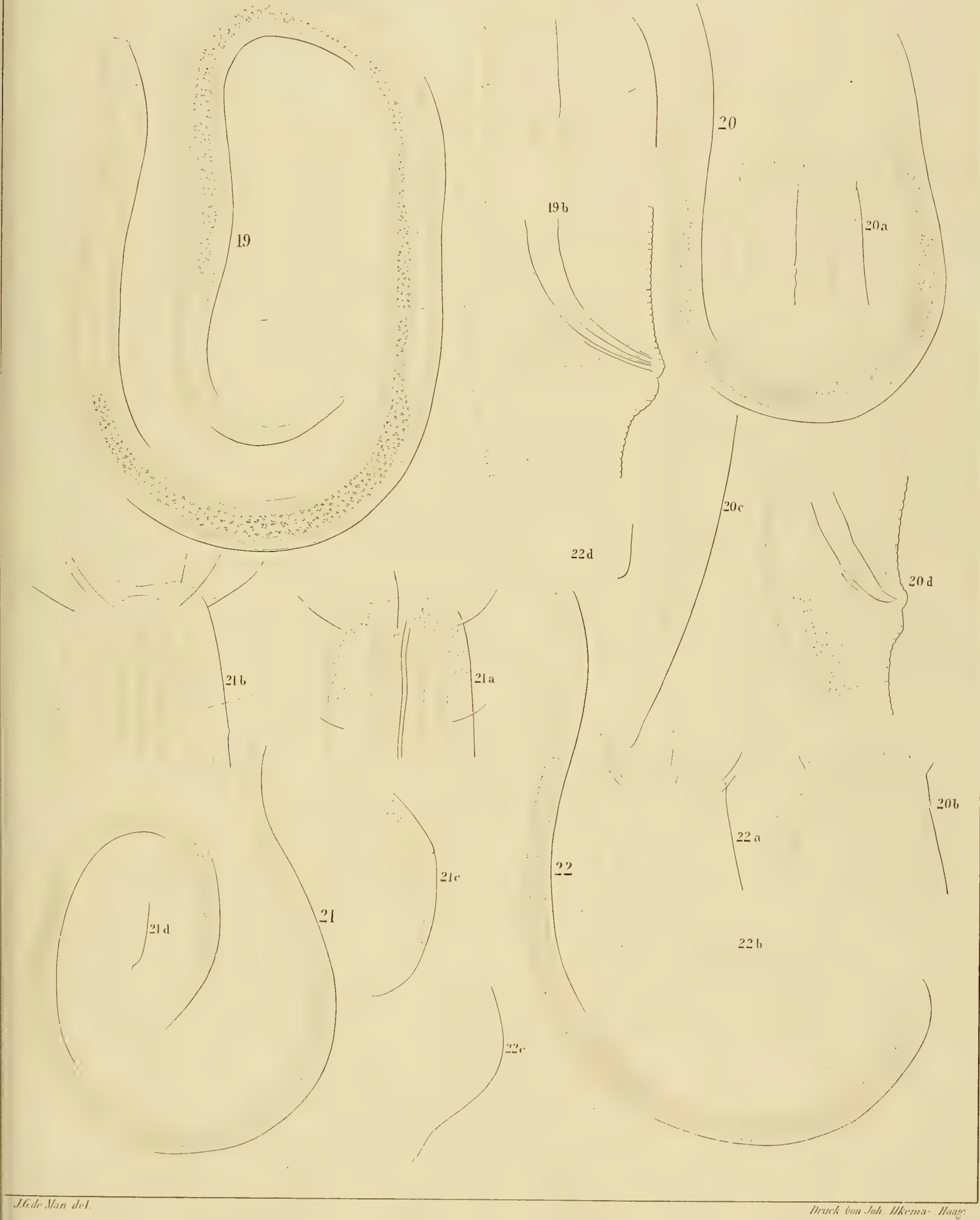

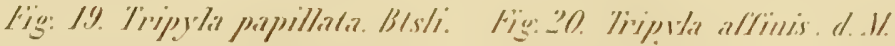

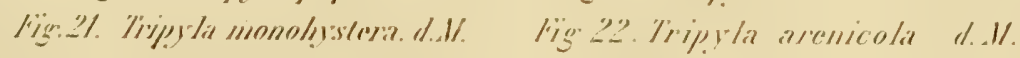





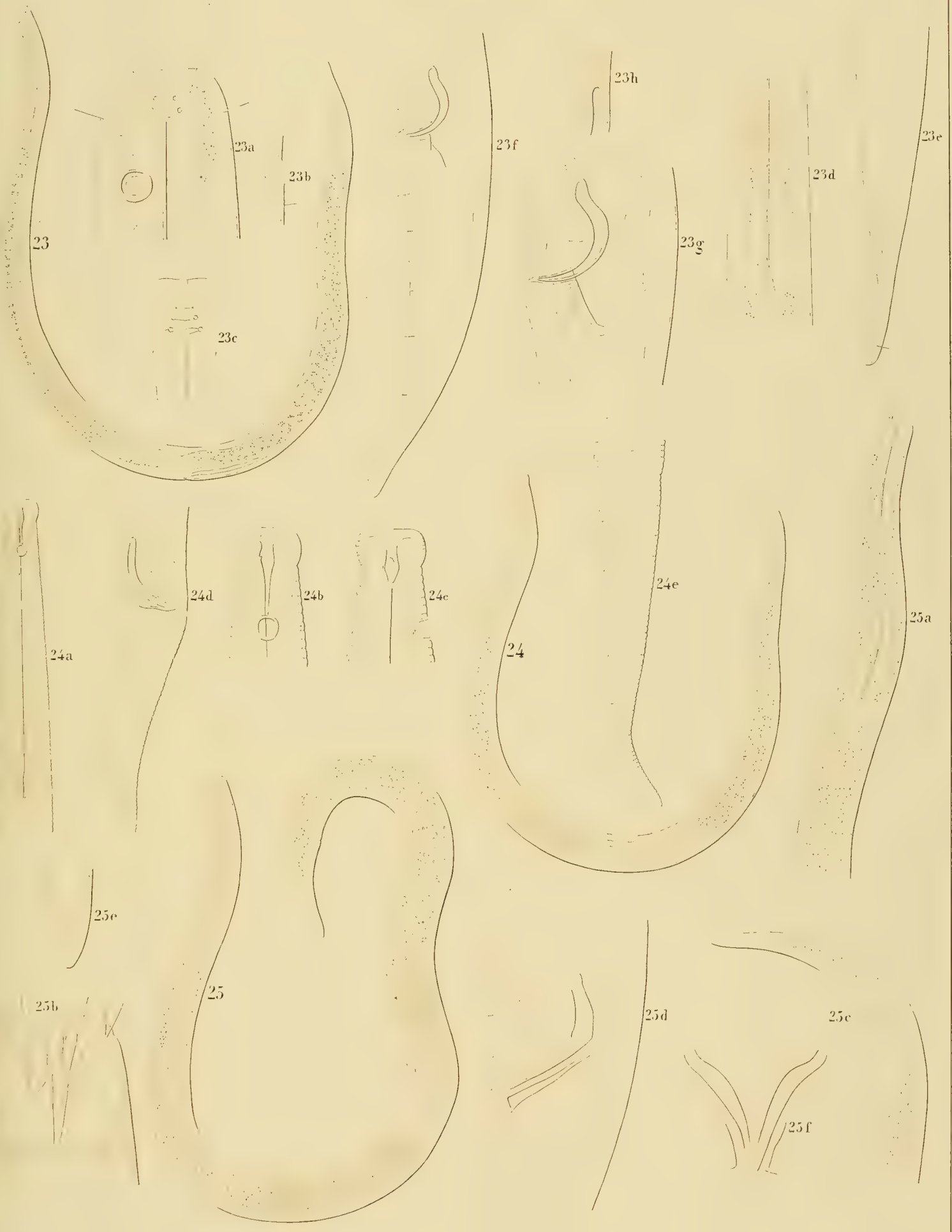

Fig. 23. Desmolaimus Zeclandicus d.11. Fig. 24. Dicrolaimus grlobirceps. d.1. Yge. 2.j. Cralholaimus intermedins. d.11. 


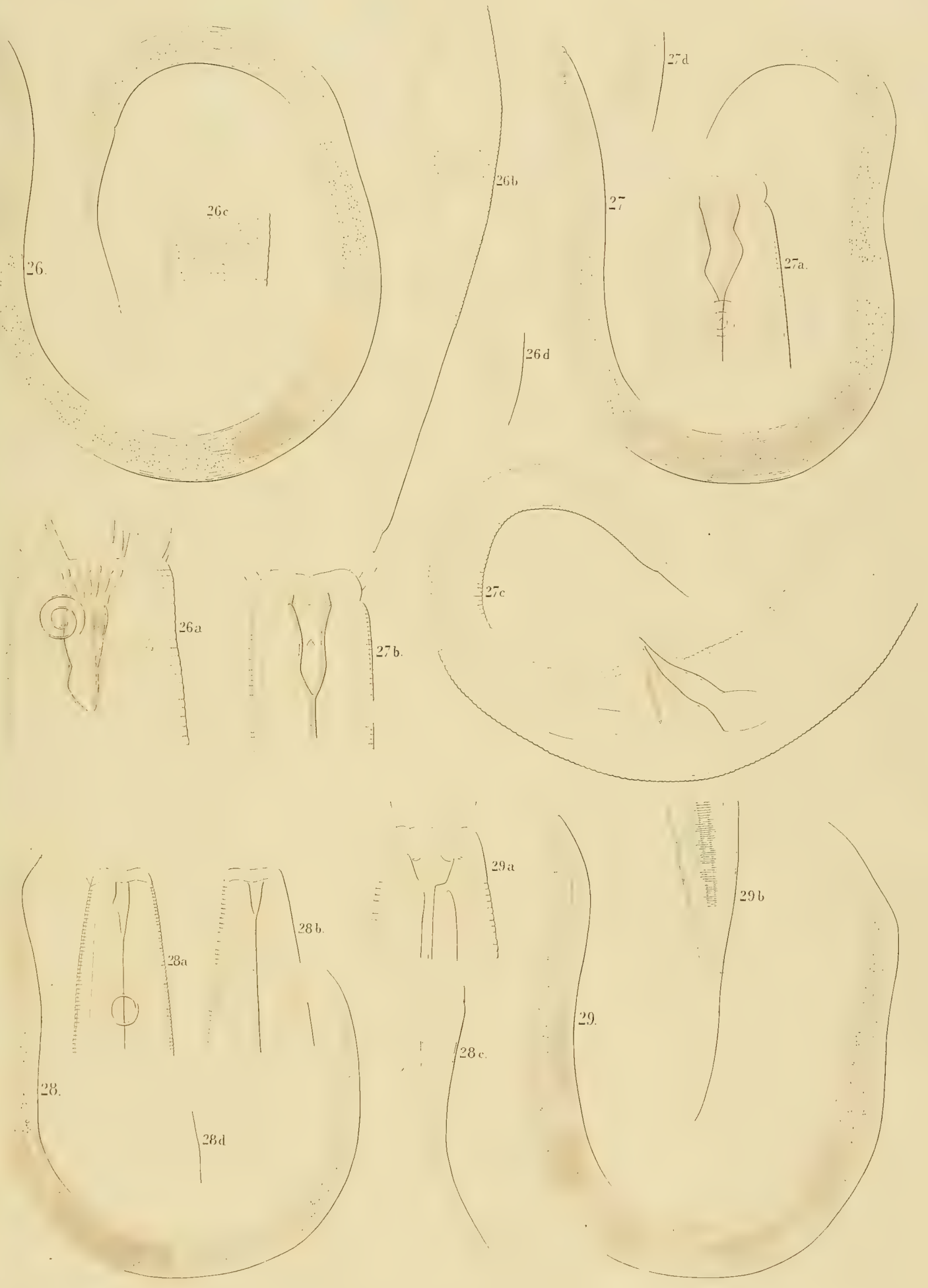

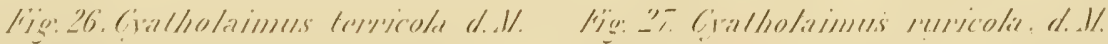

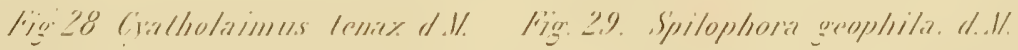





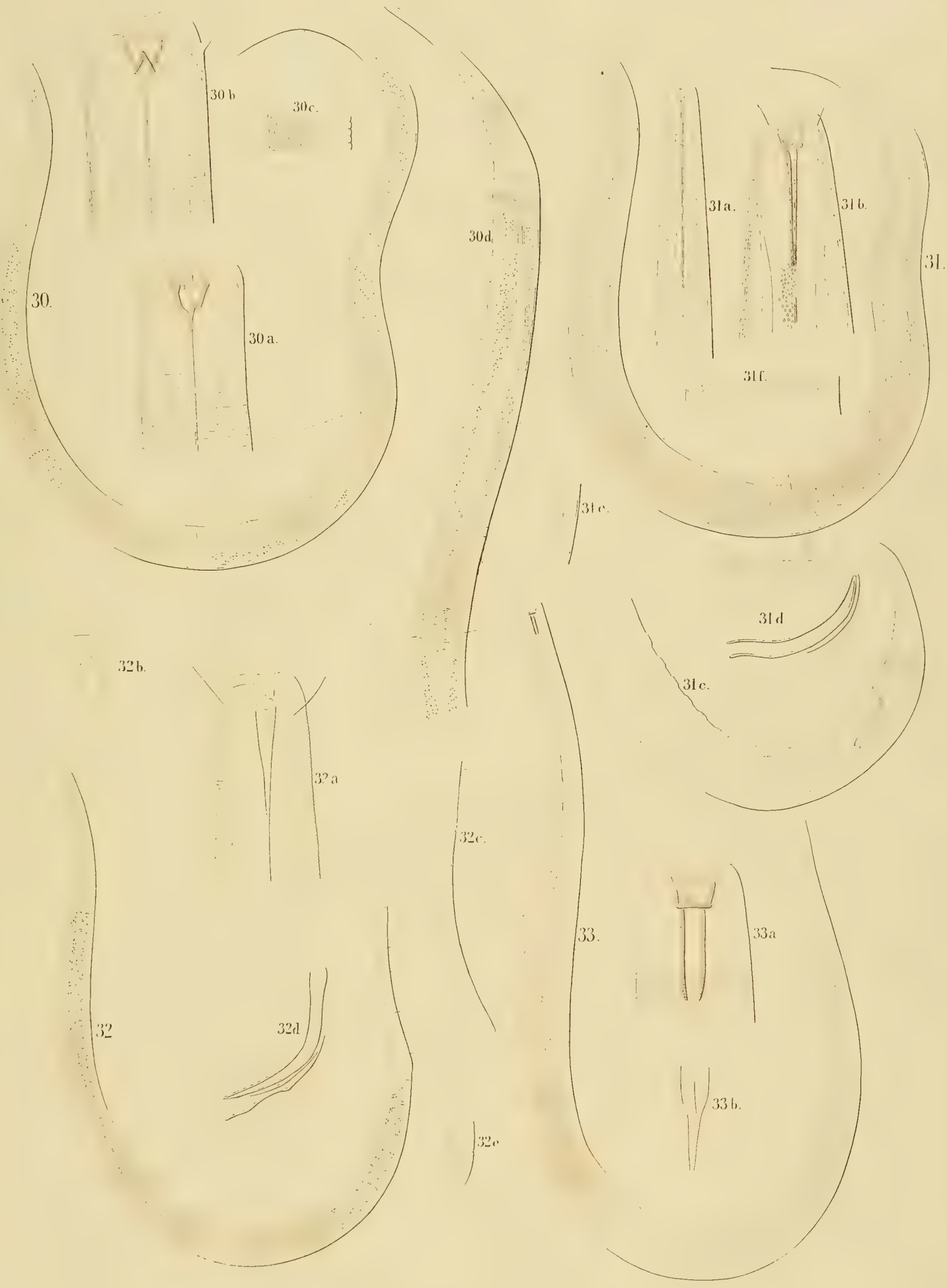

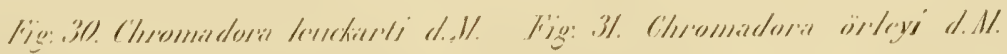

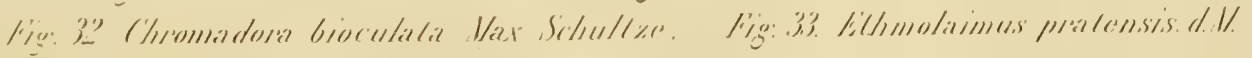





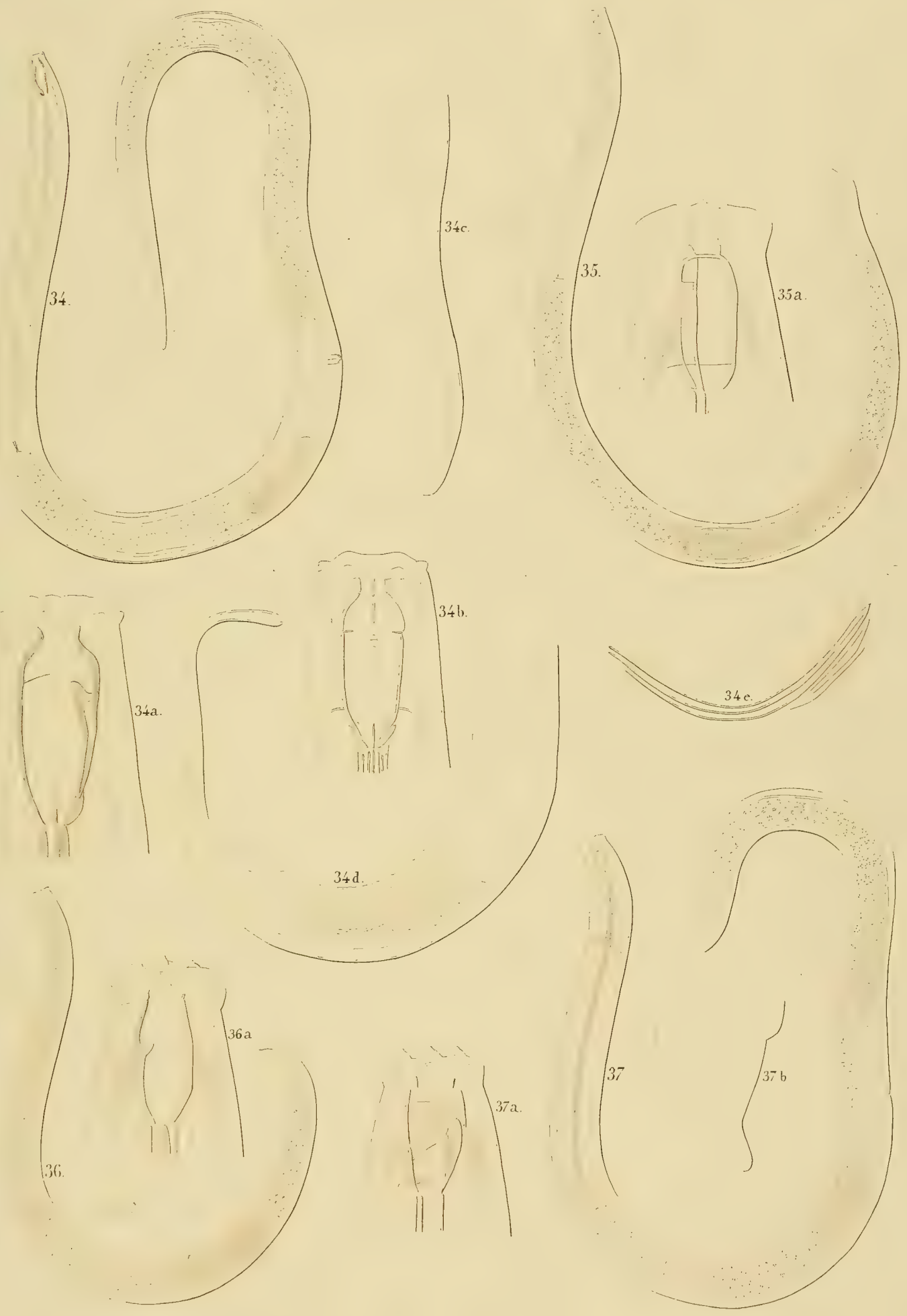




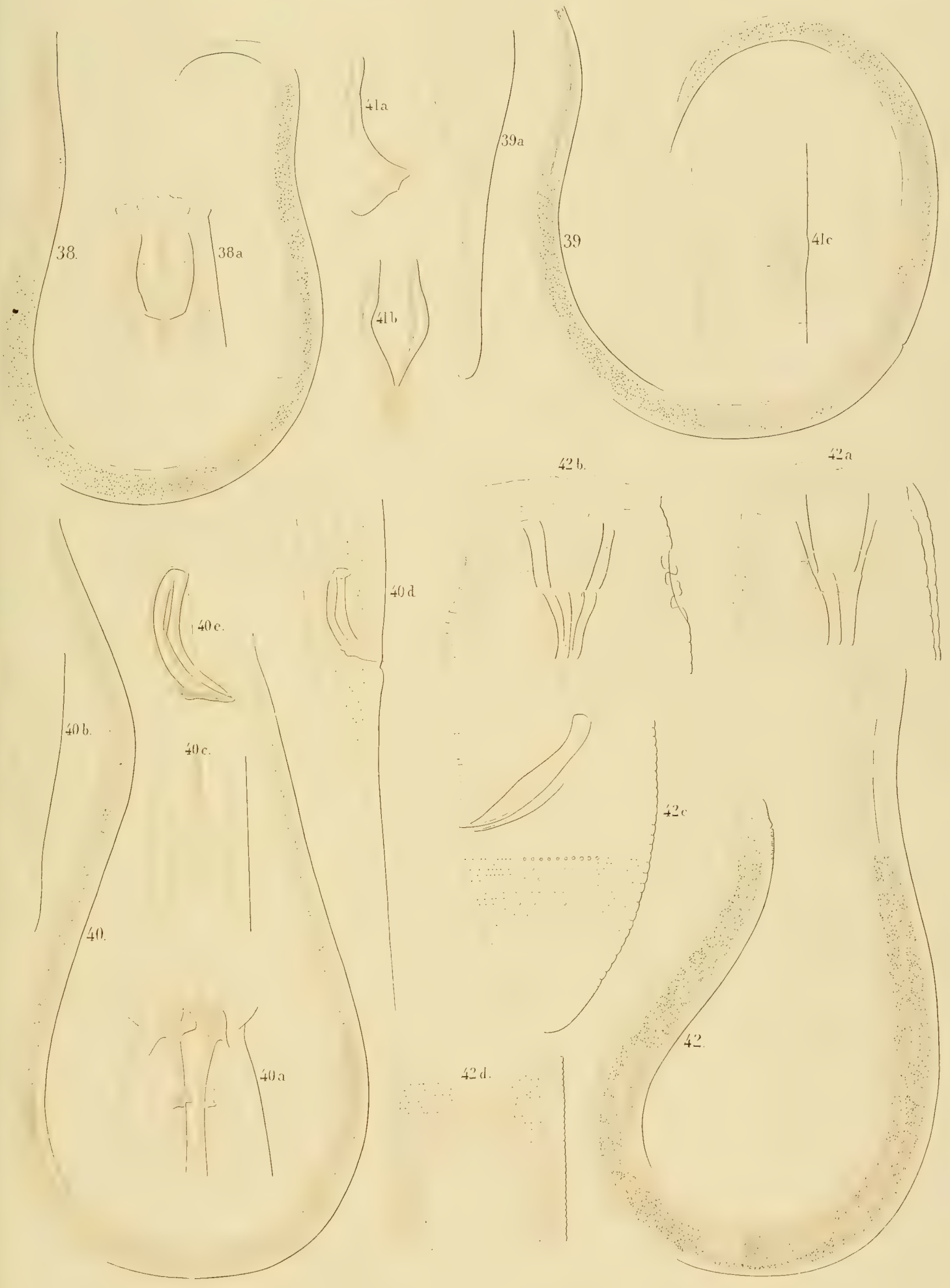

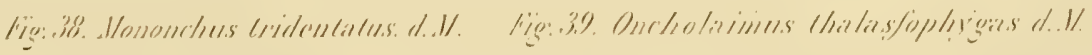

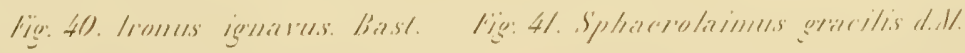




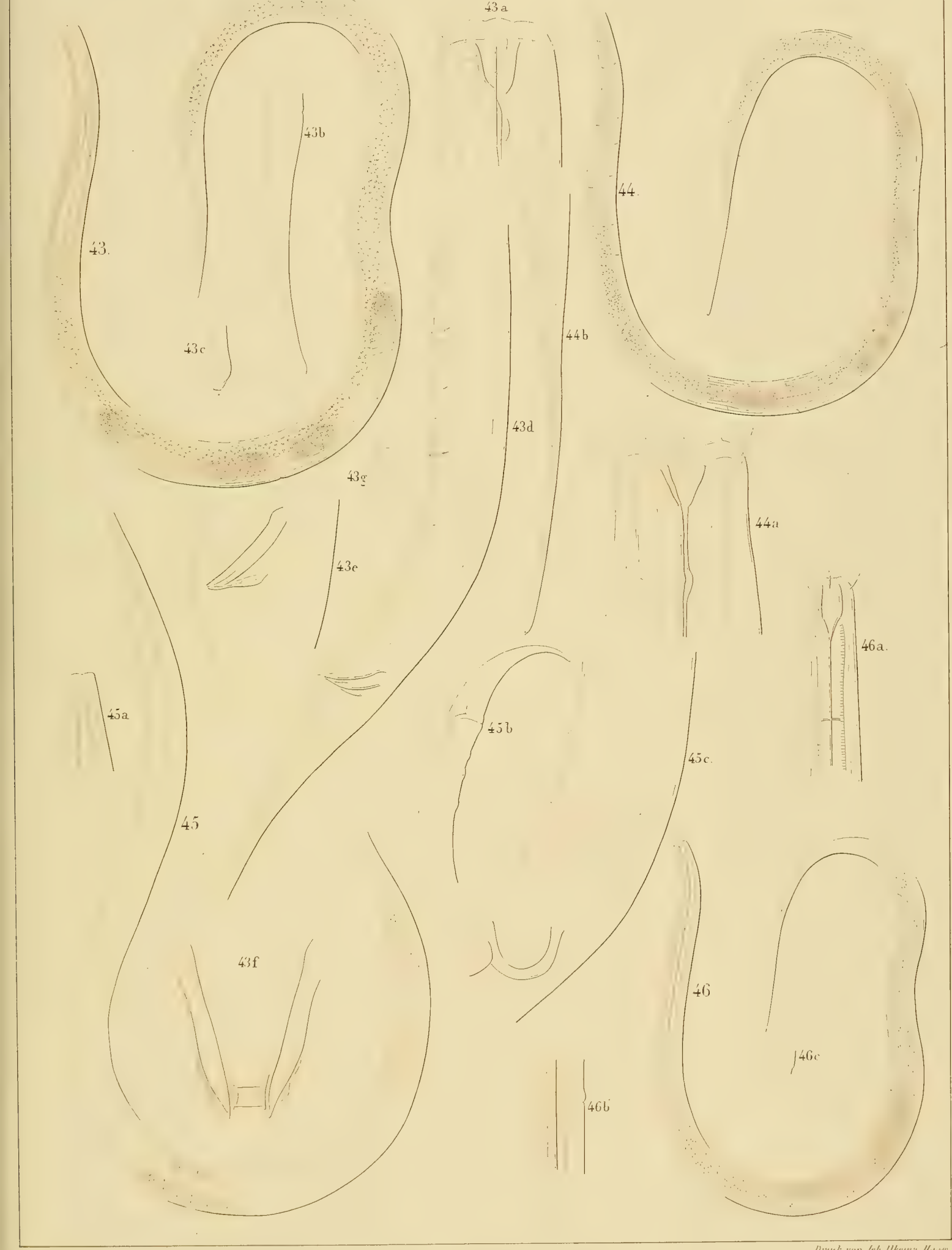

$43 d$

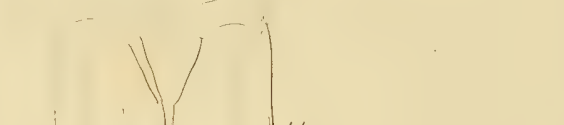







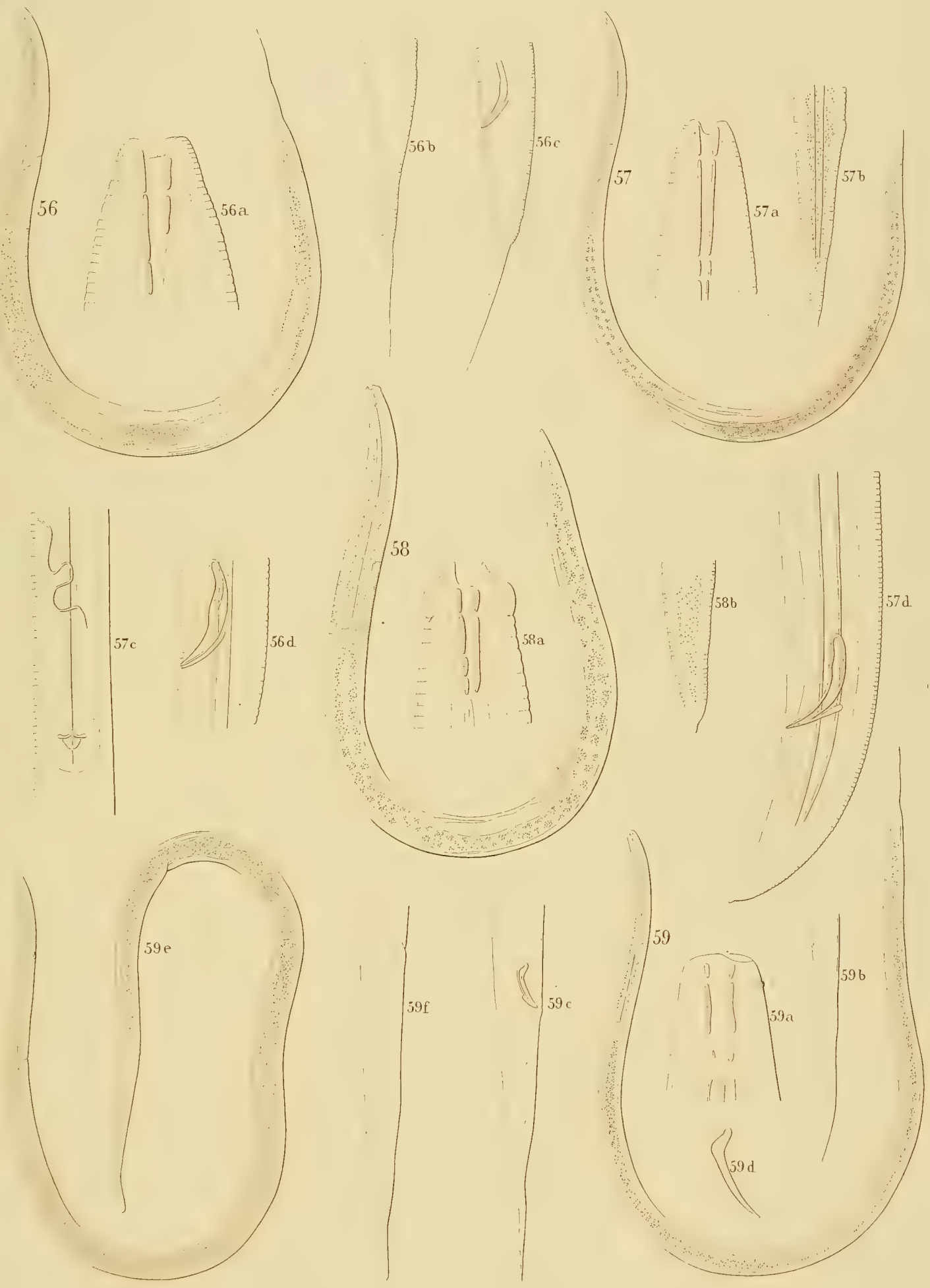

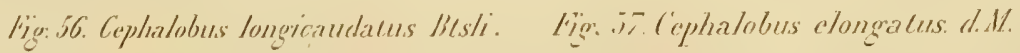

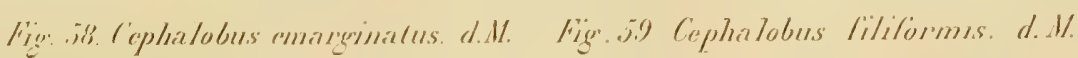





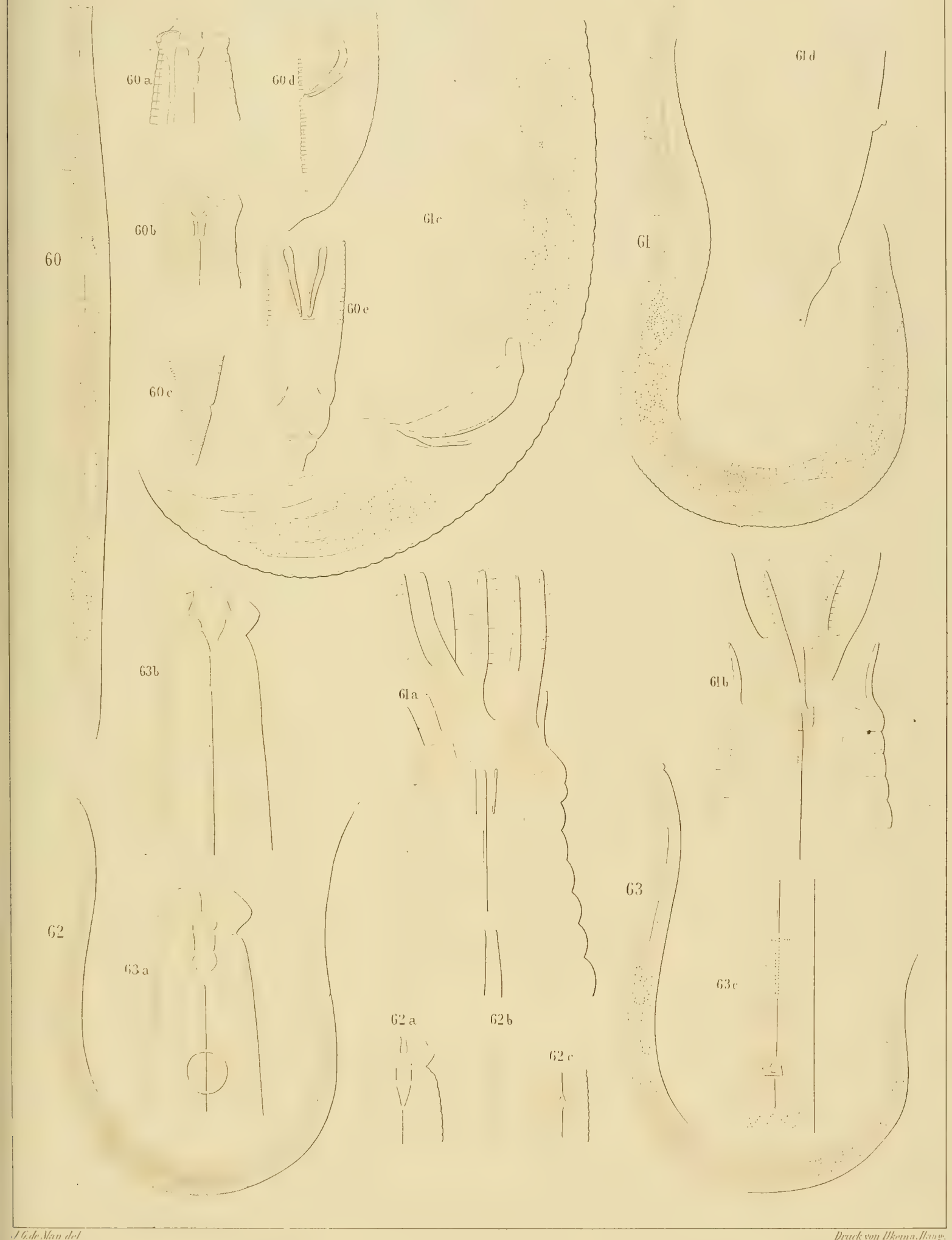

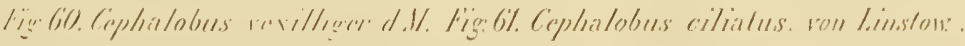

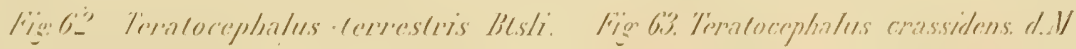





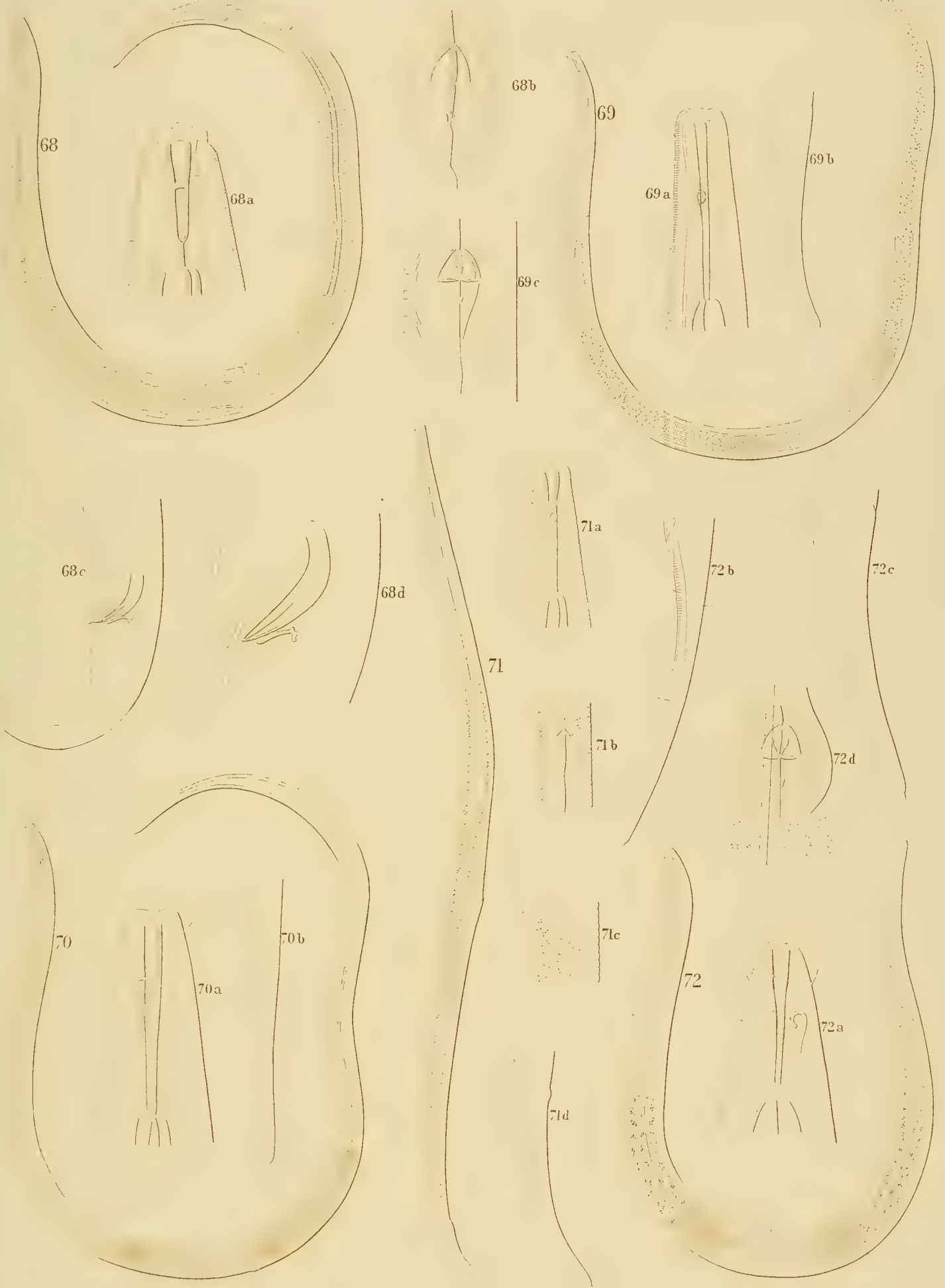

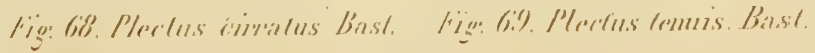

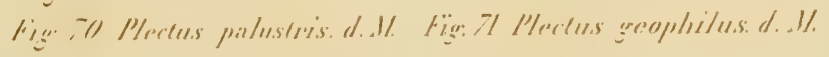





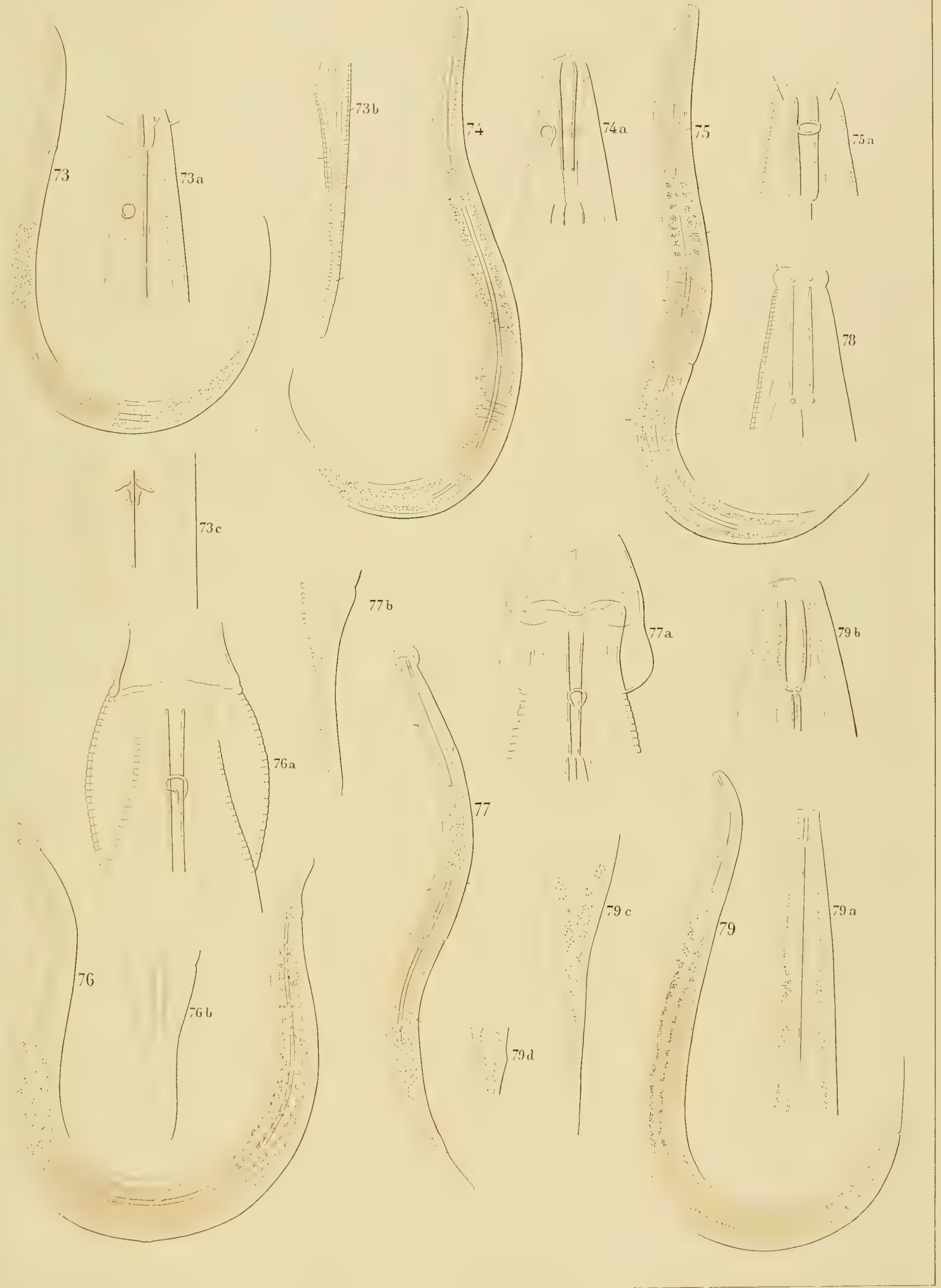

Druck von.toh. Llkoma Hang

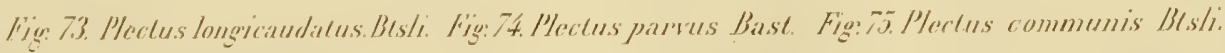

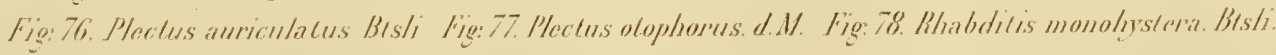





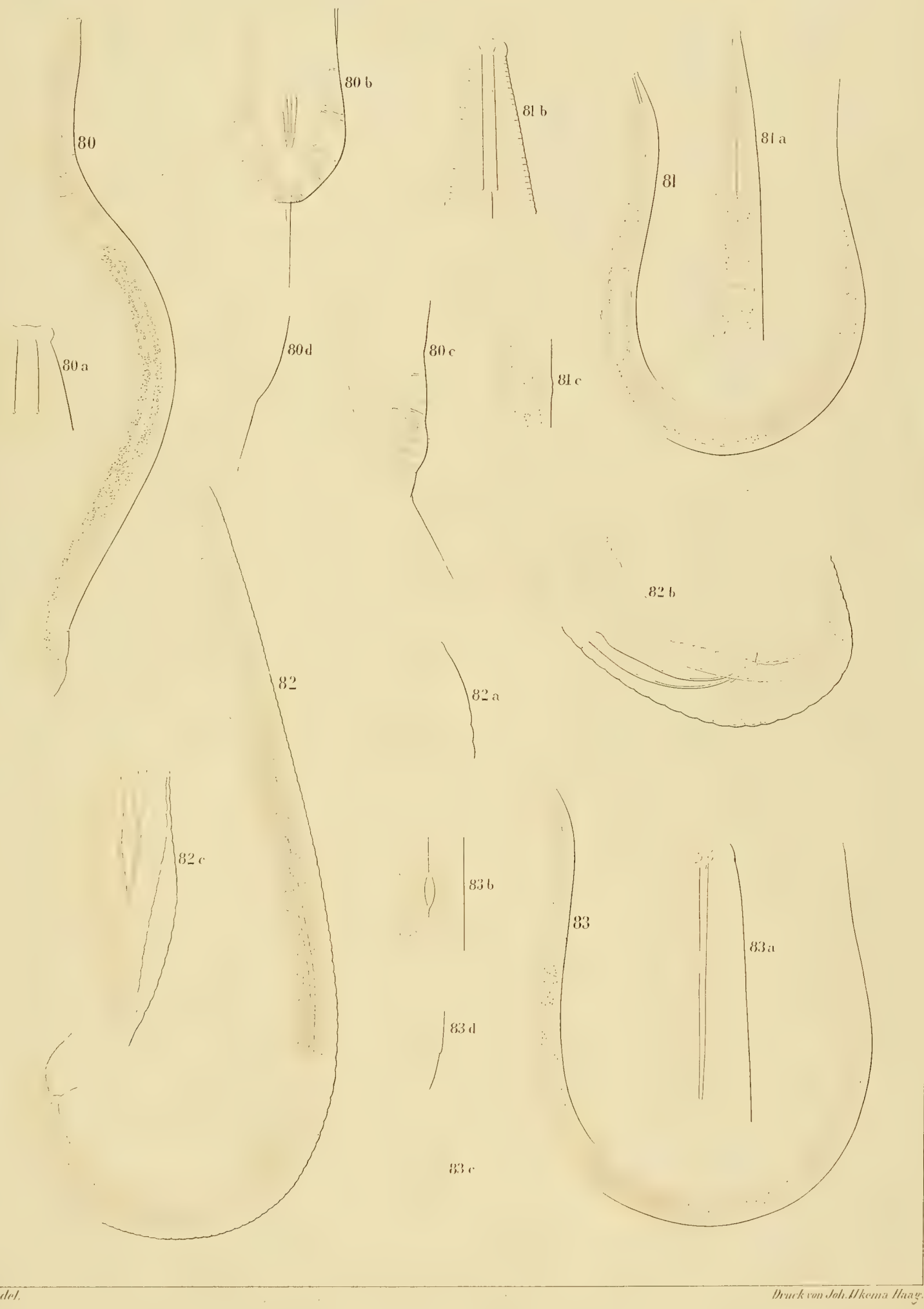

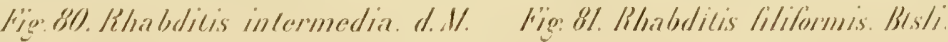

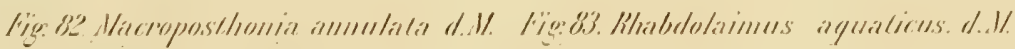




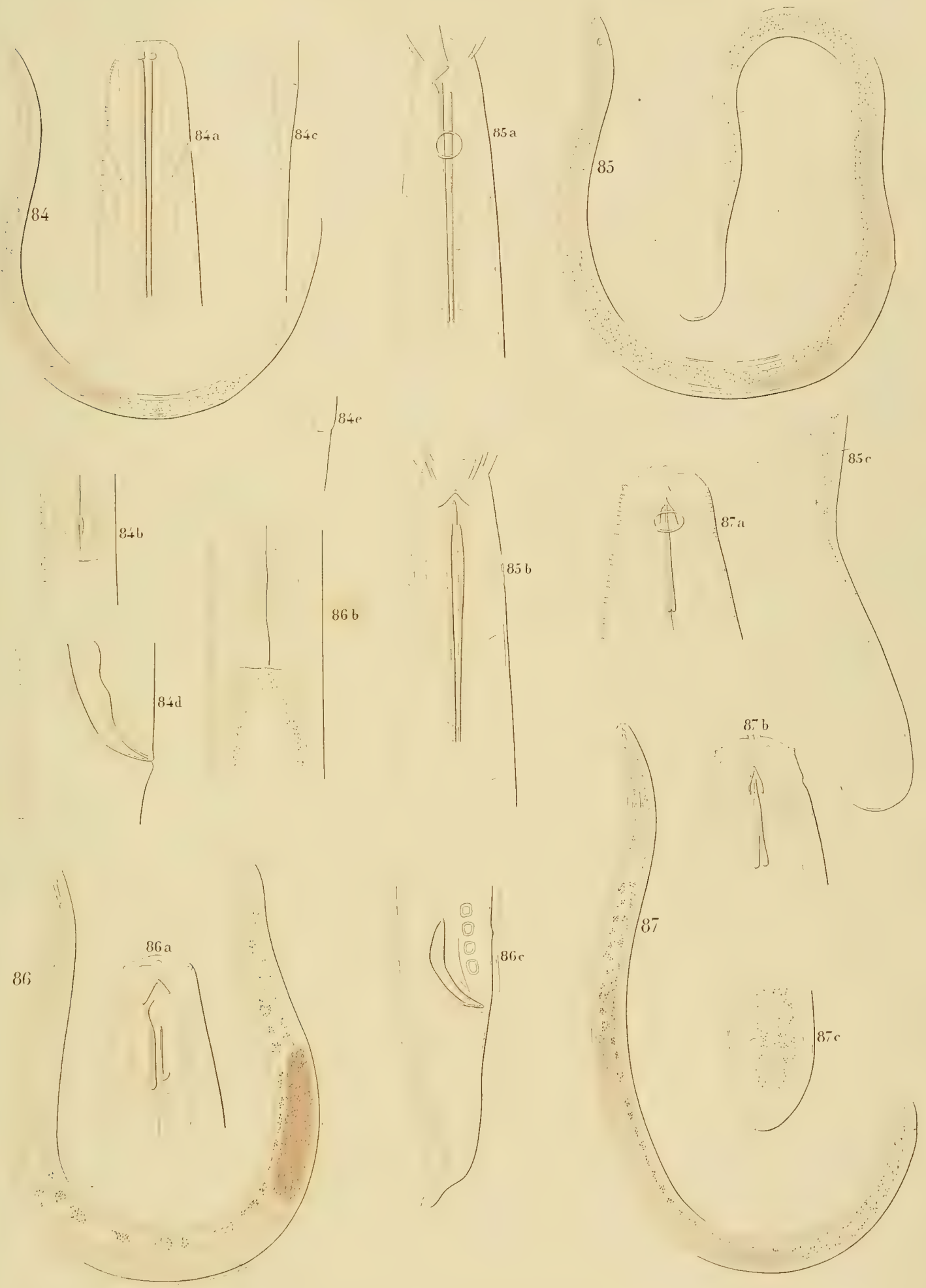

Druckion Johlilkema Thage:

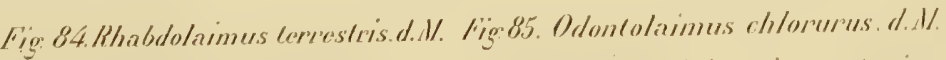

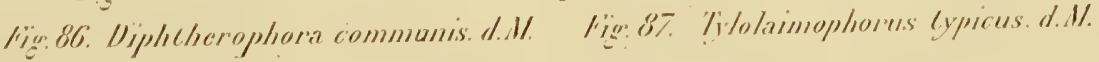





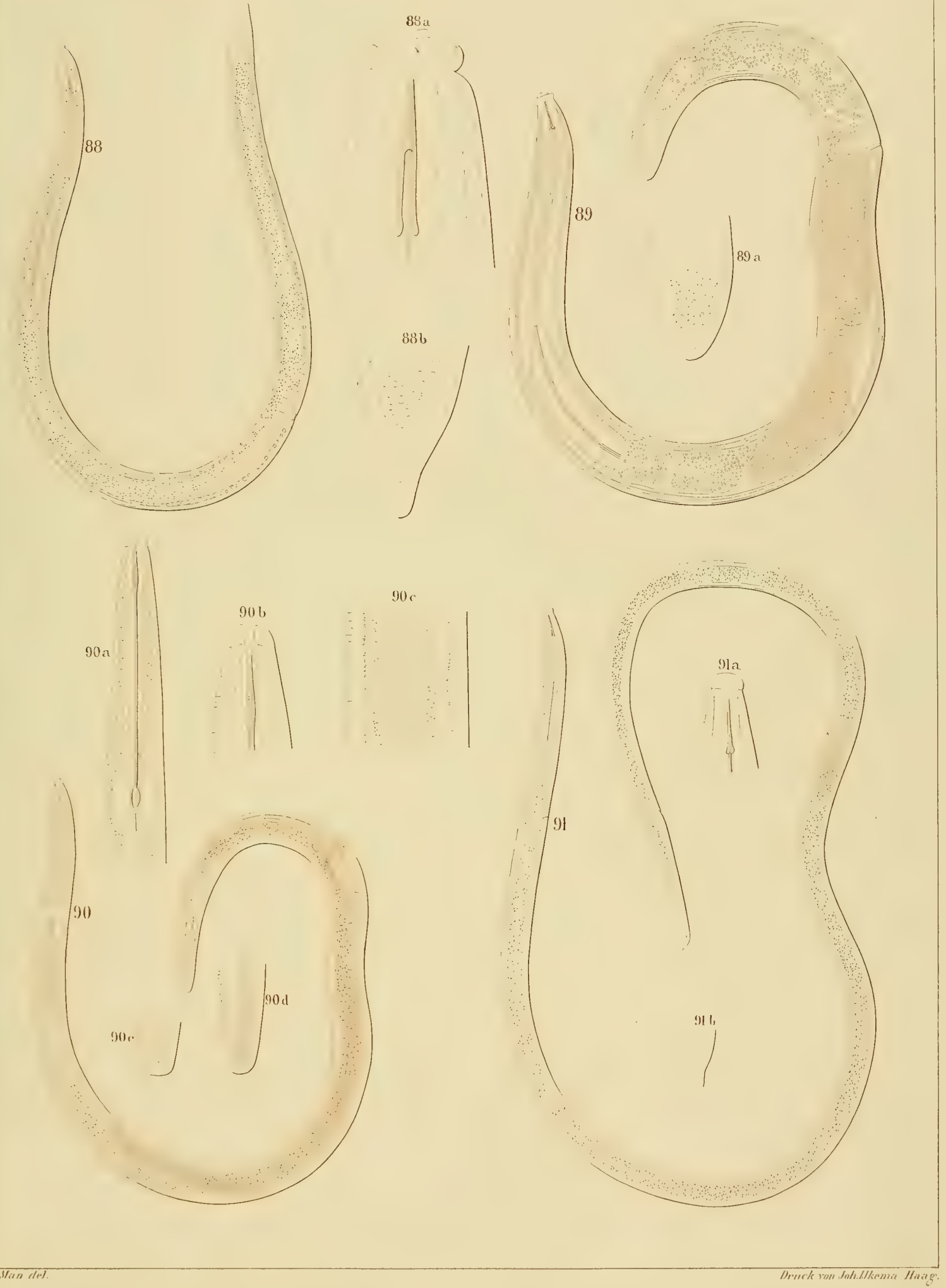

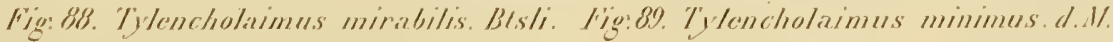

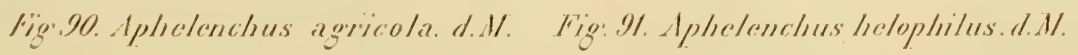




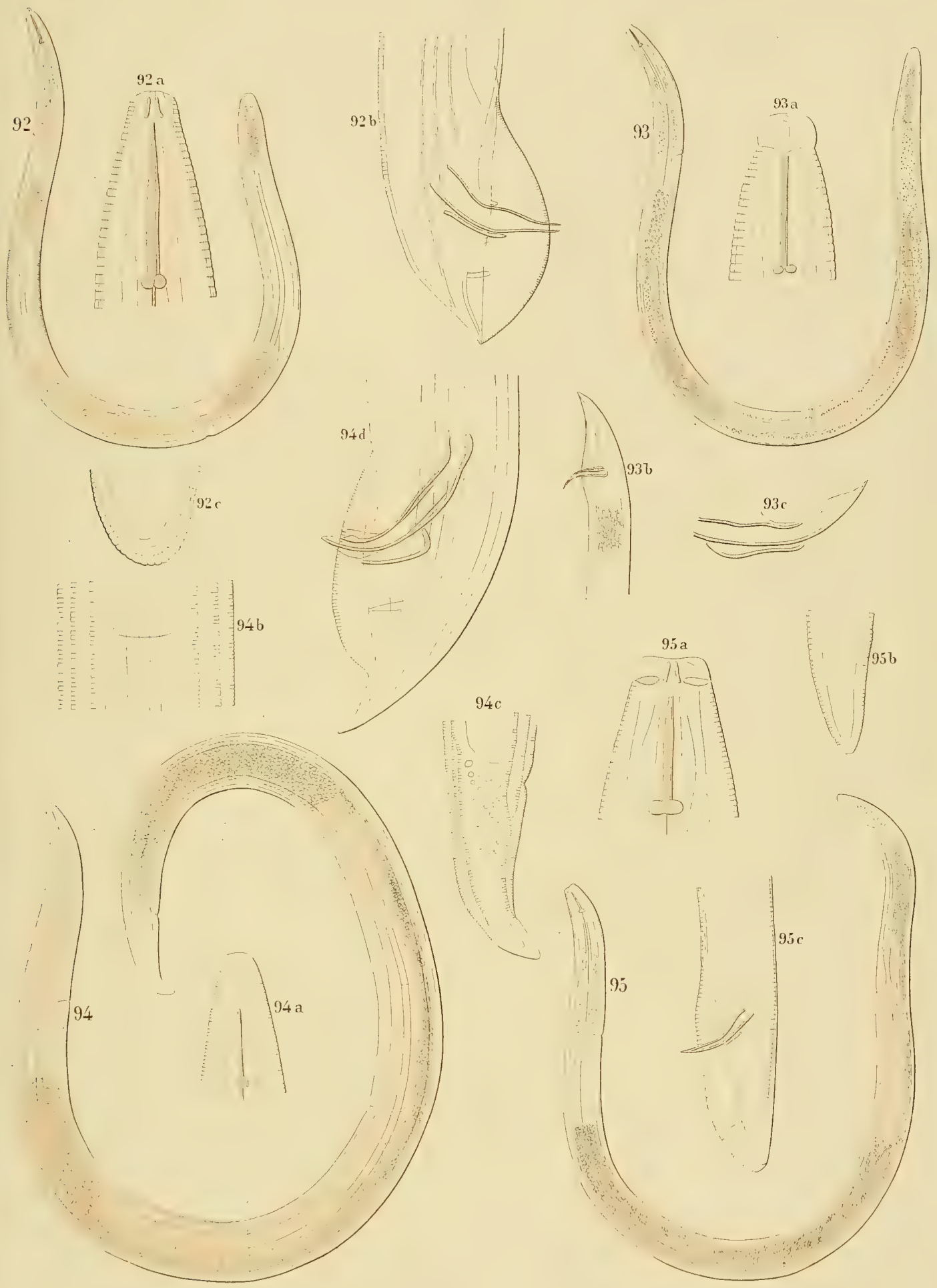

fig: 92. Tylenchus rolushlus. dil. Fig. 23. Tylenchus dubius. Bisli 



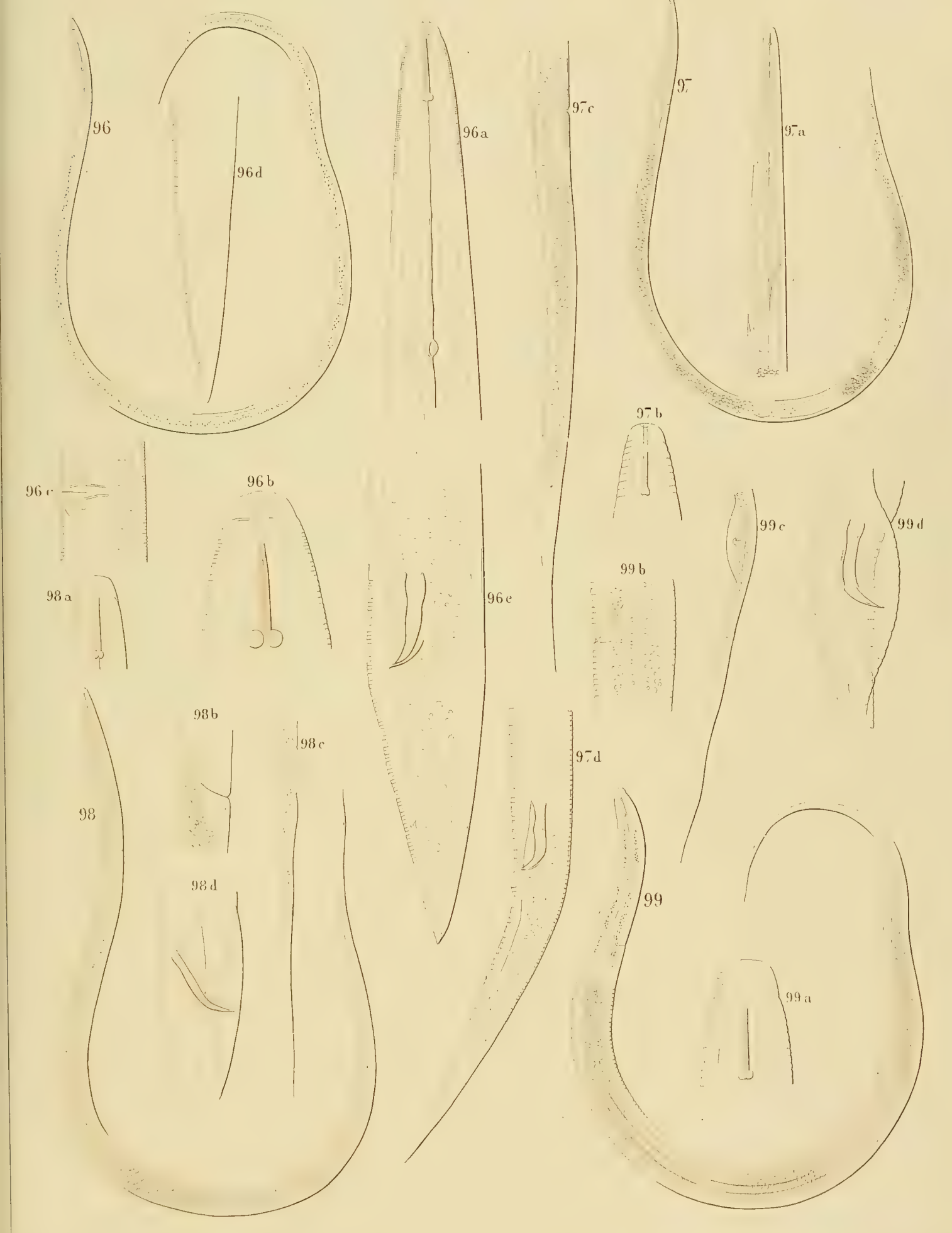





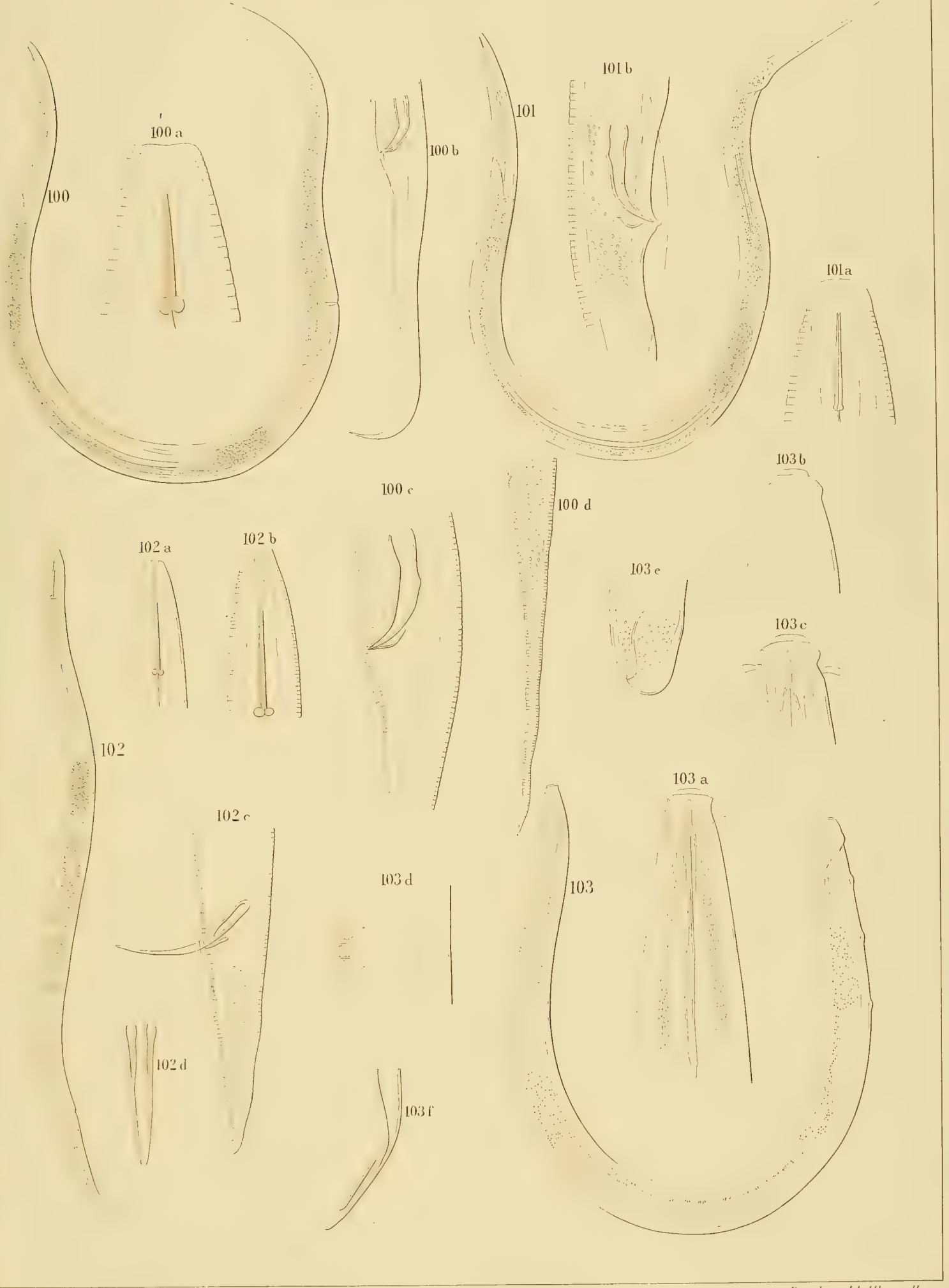

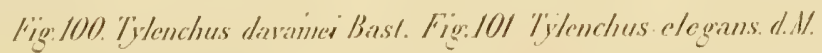

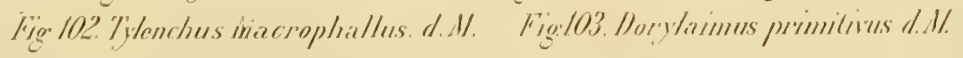





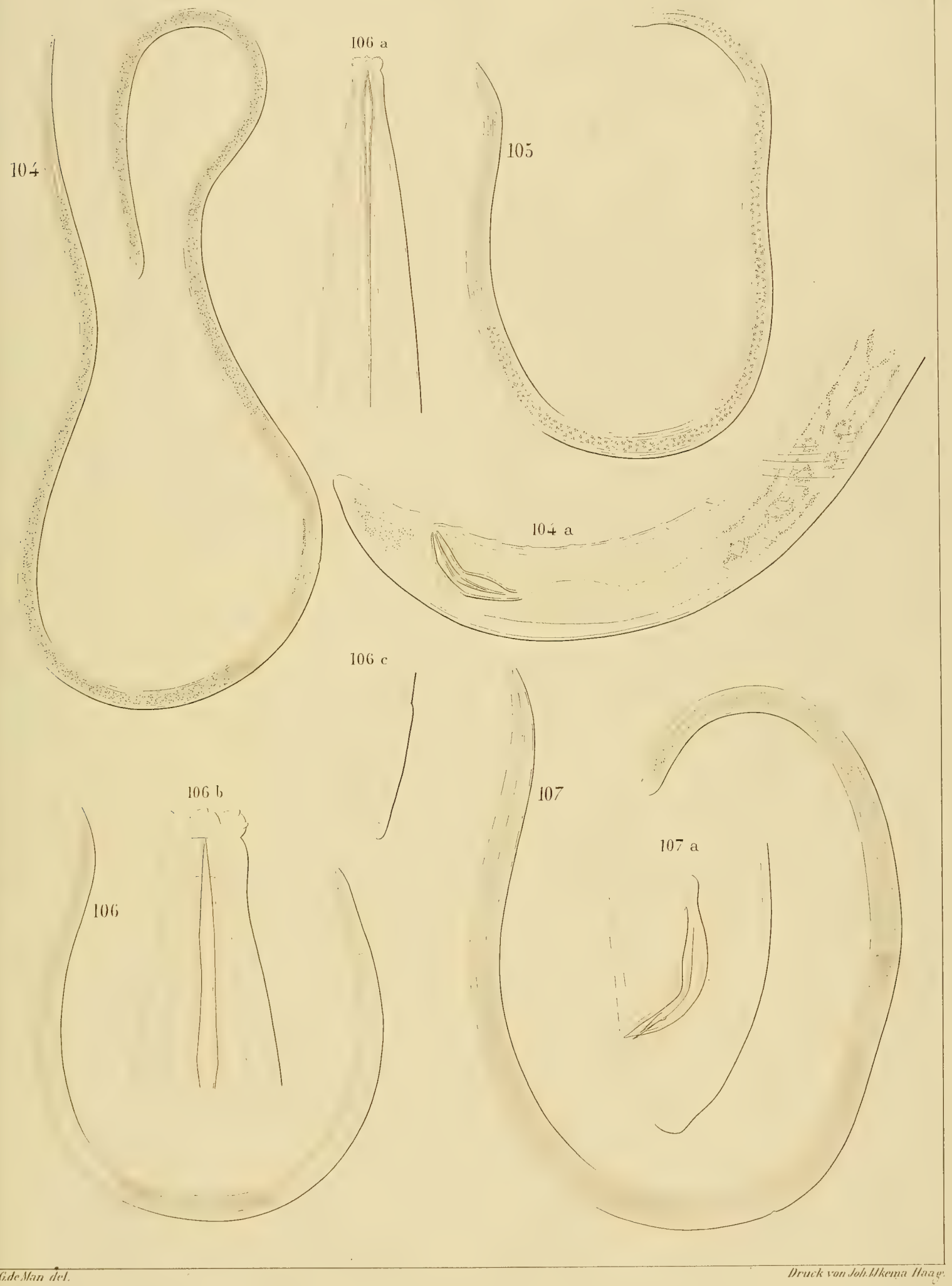

Vig 104. Dorylaimus clongatus. d.A. Figr. 105. Dory/aimus reggius. d. Wh.

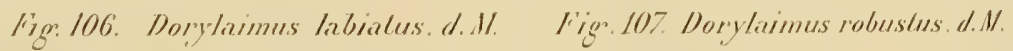




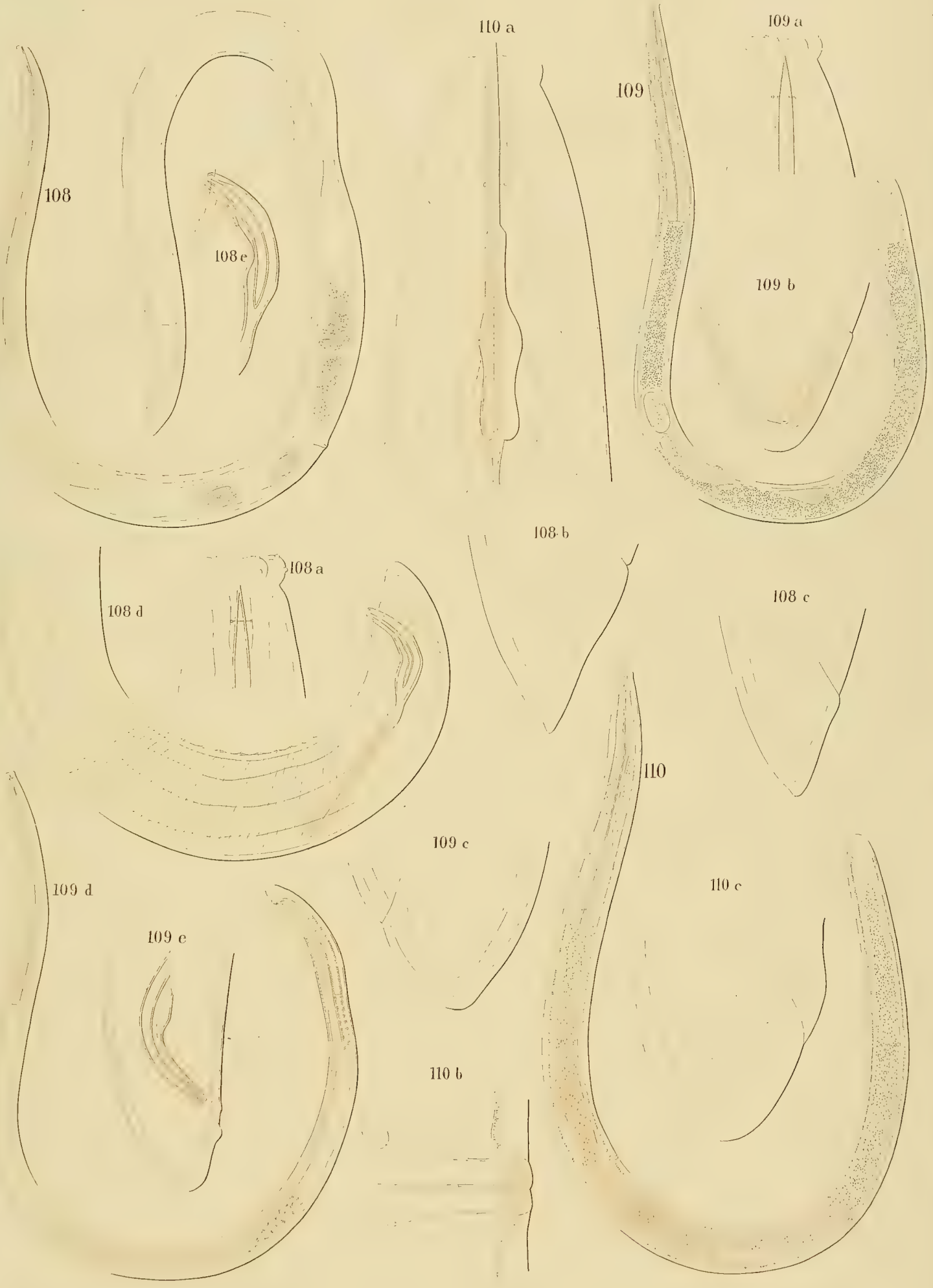

108.6

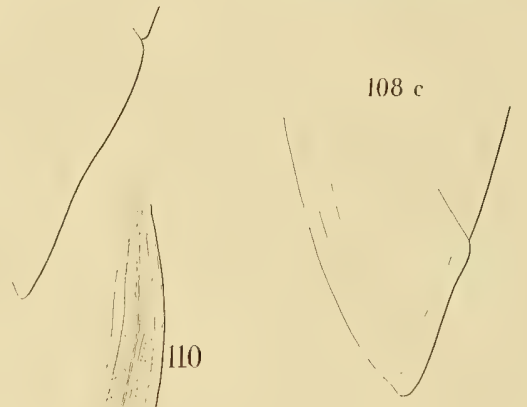

$109 \mathrm{c}$

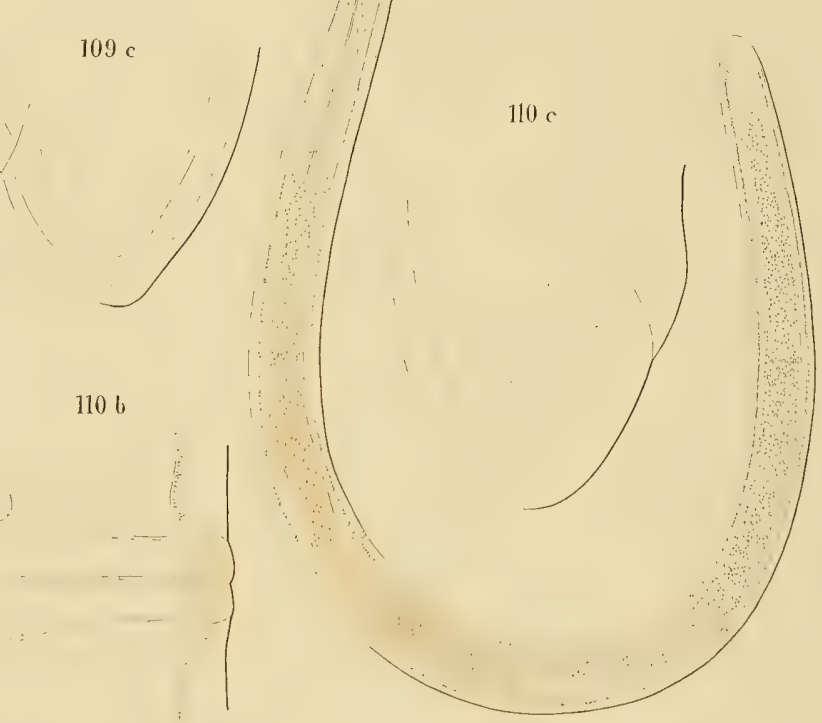

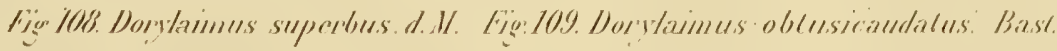




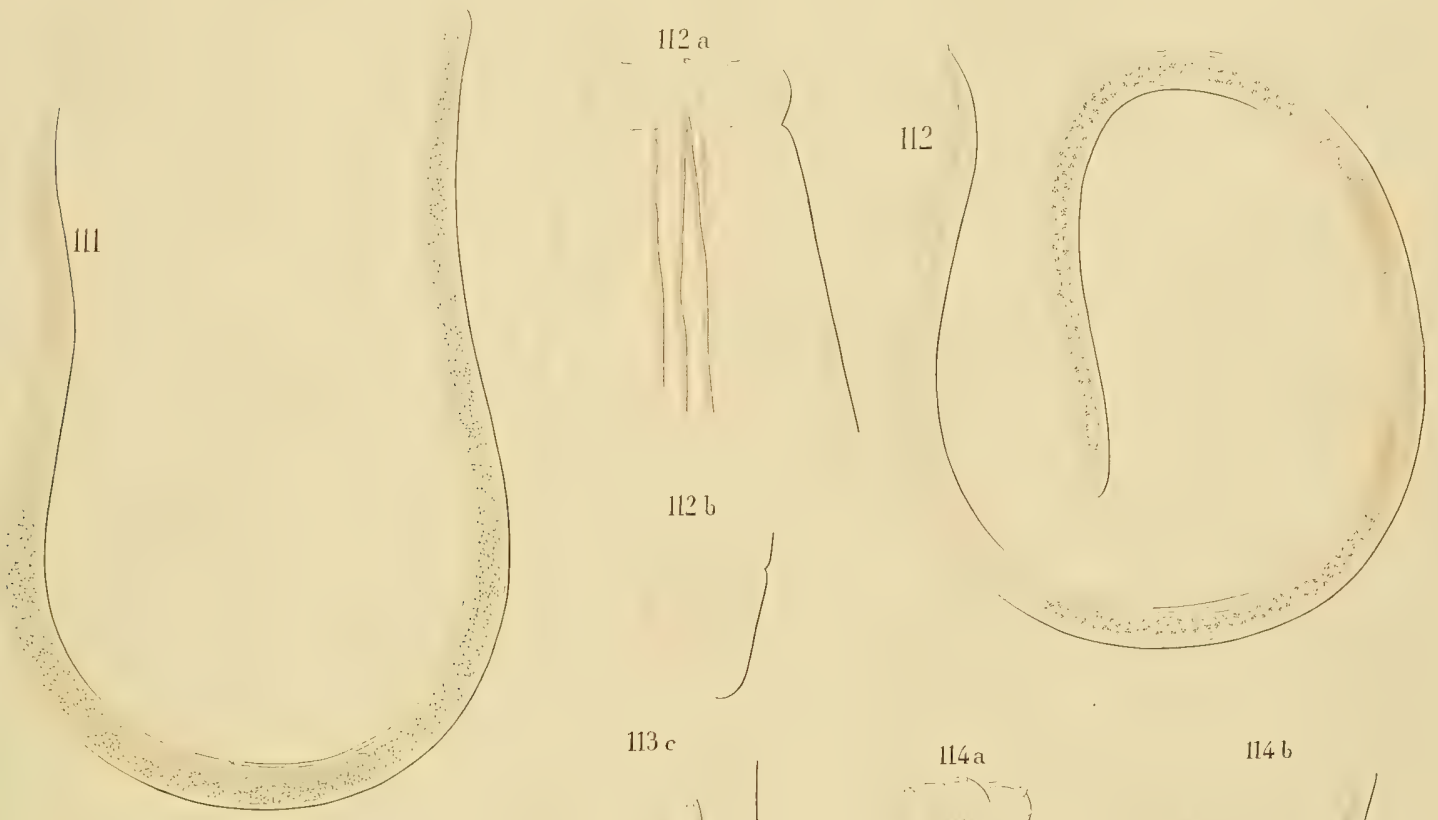

1126
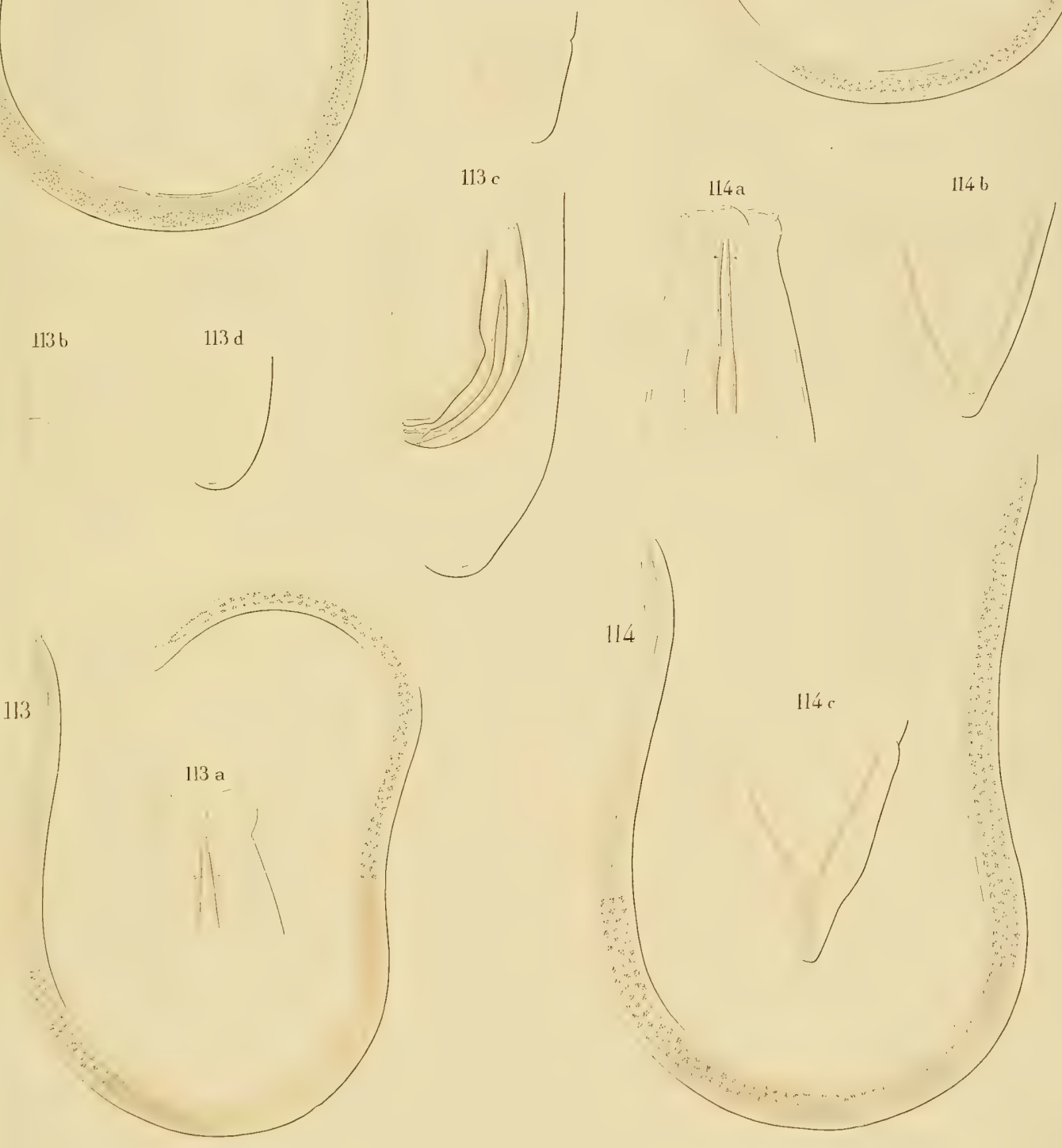



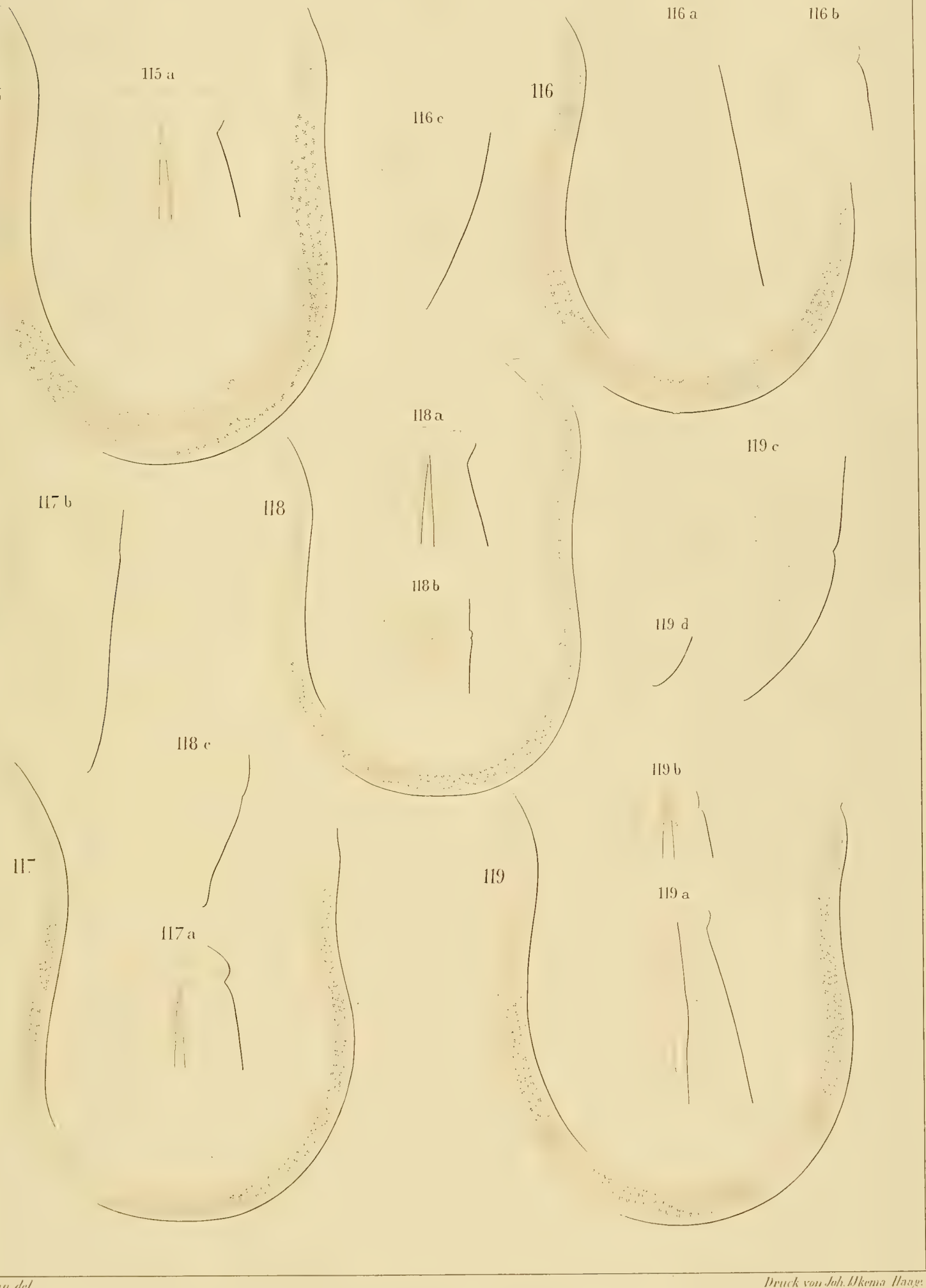

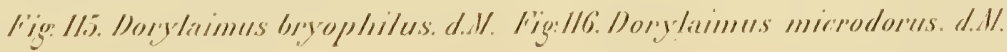

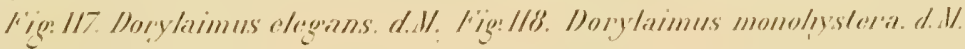





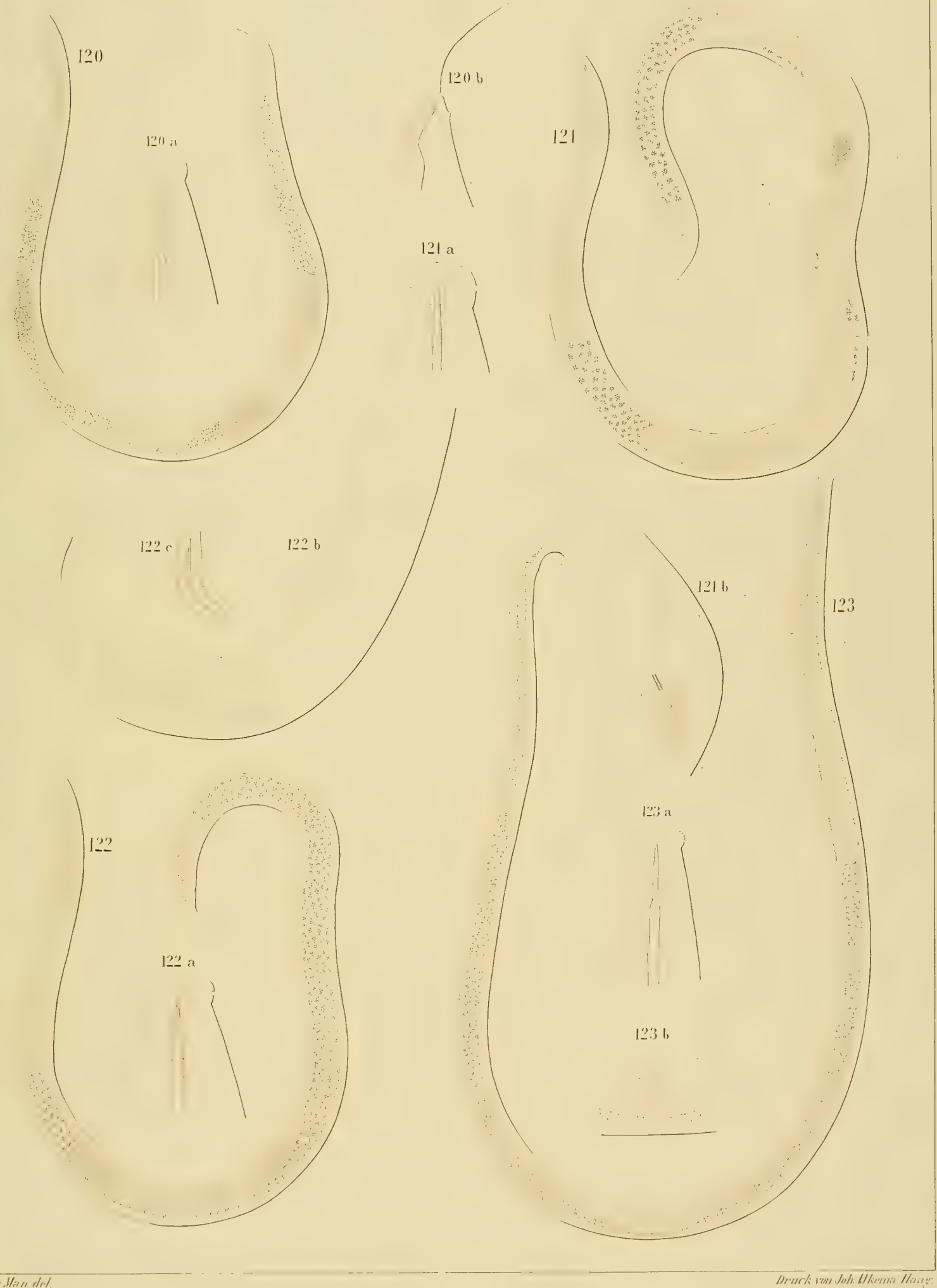

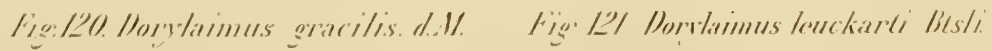

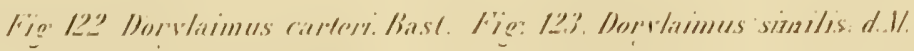




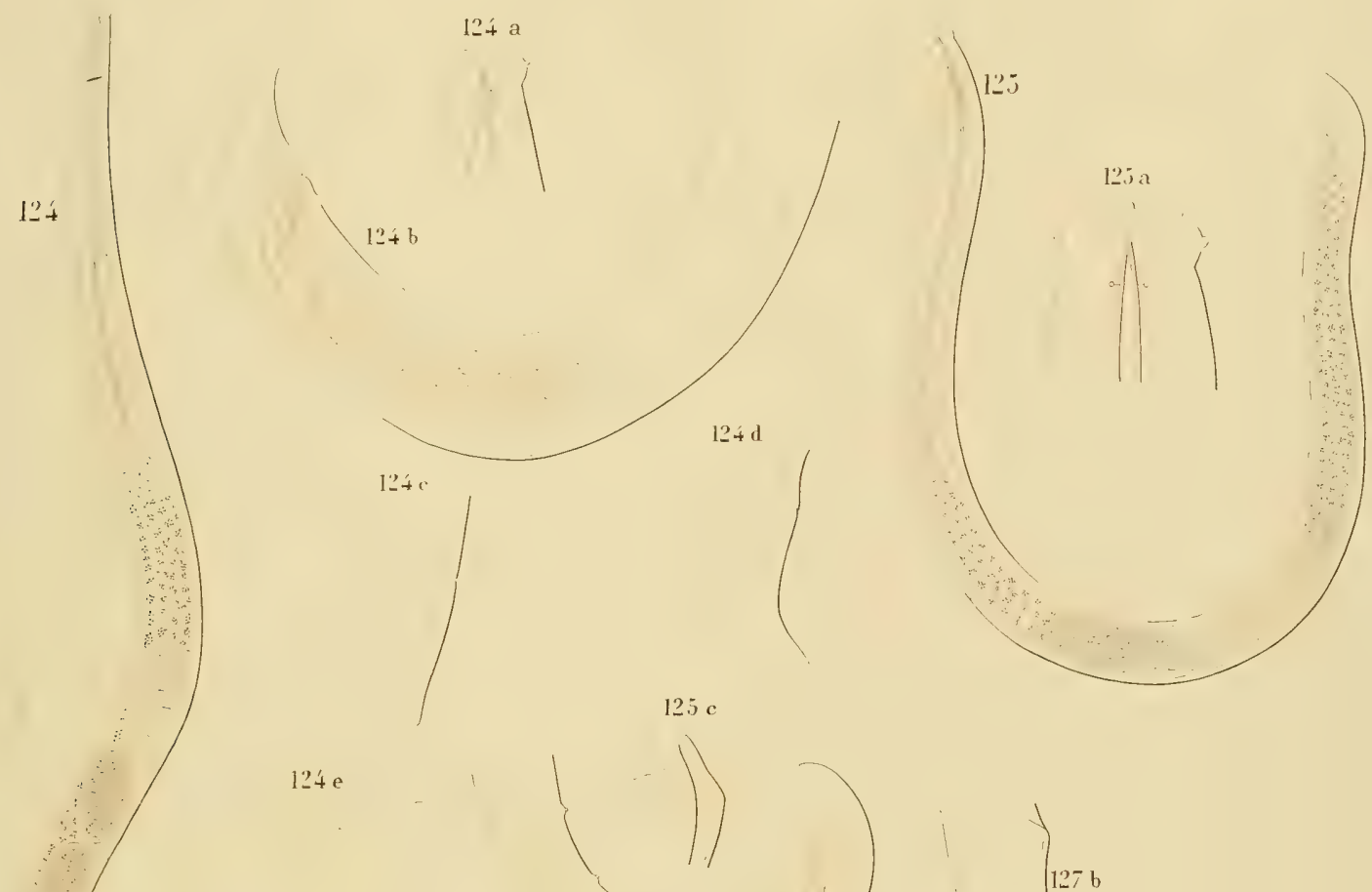

$\vdots$
$\vdots$
$\vdots$
$\vdots$
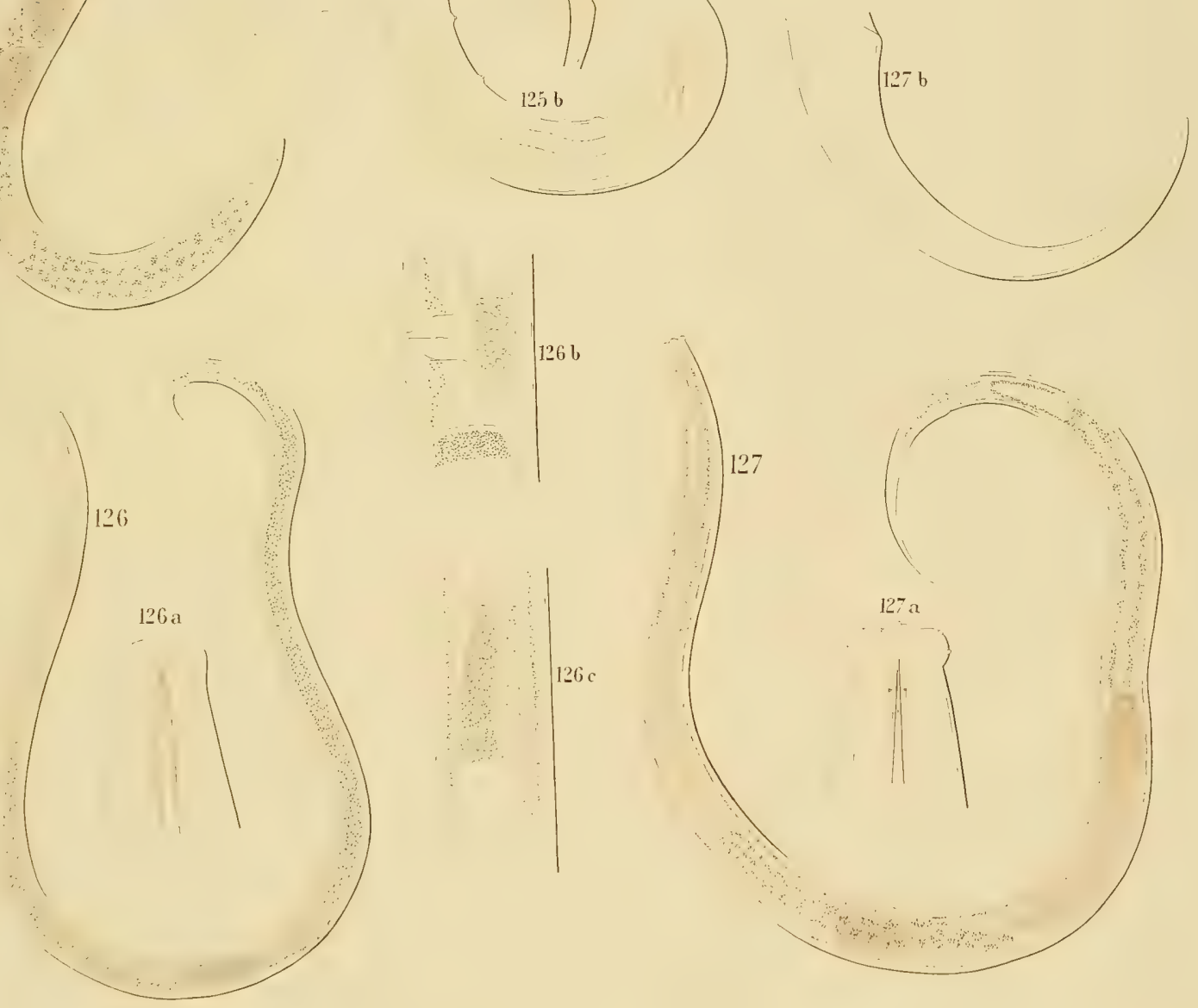



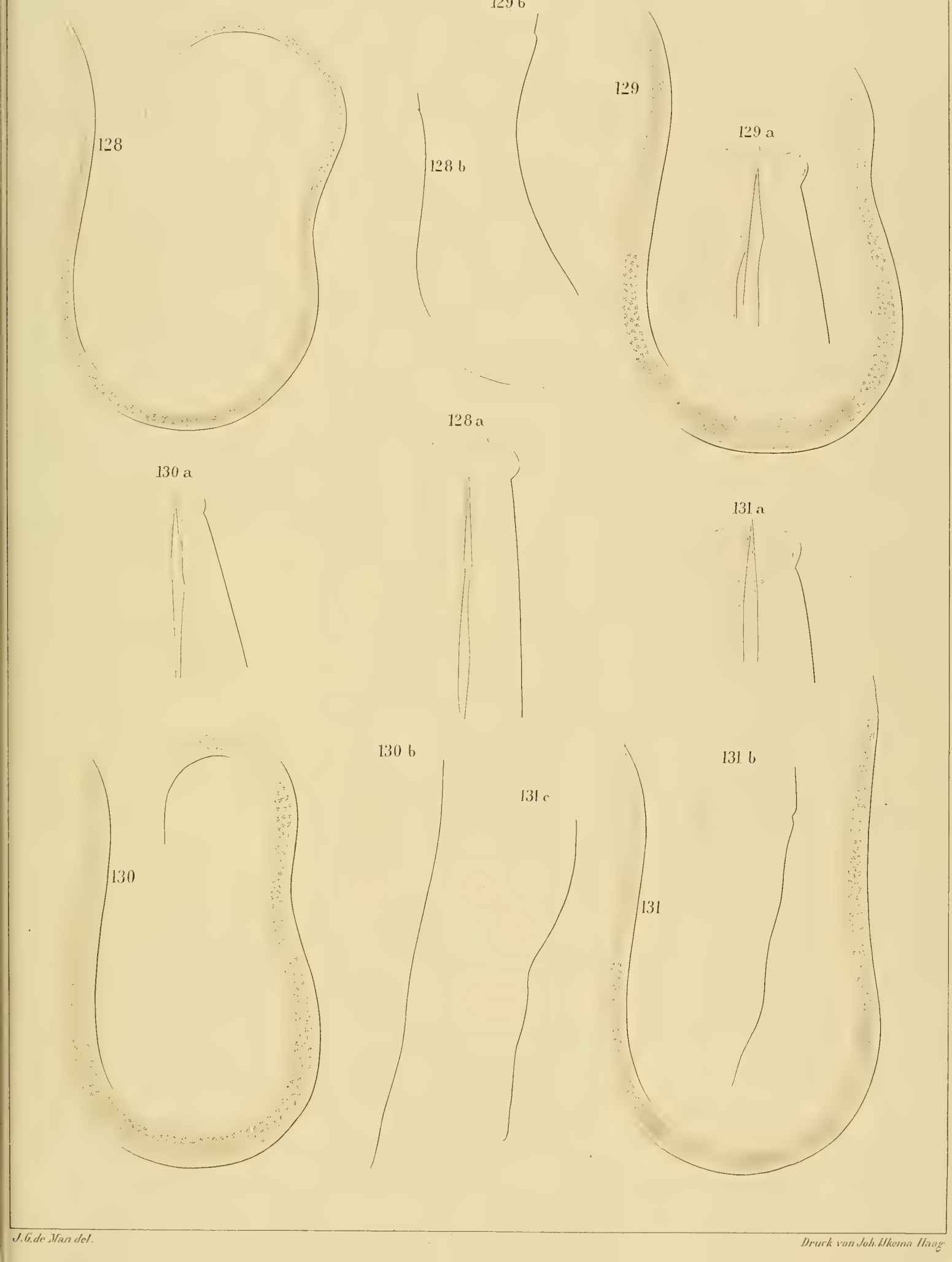

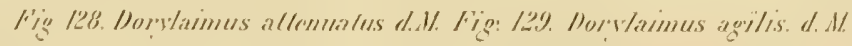

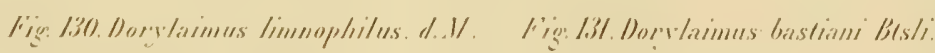





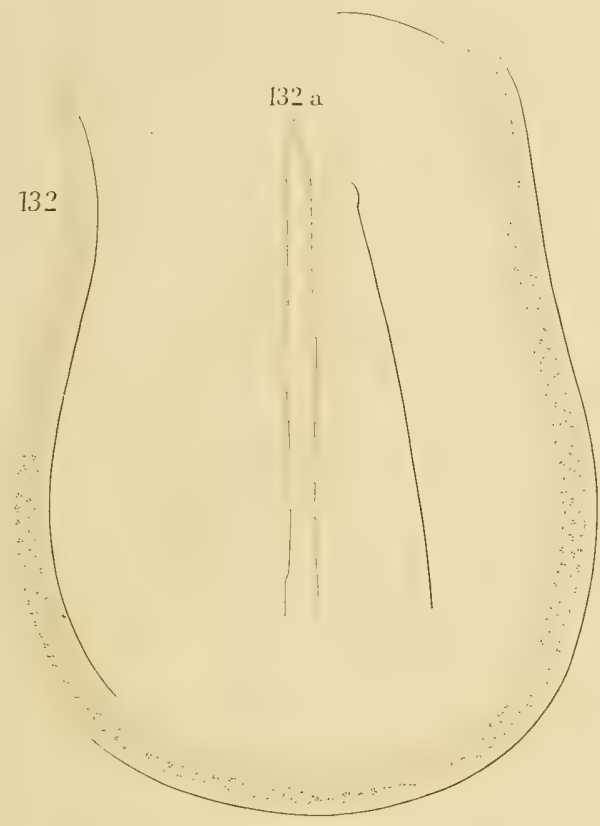

1326

$13+\mathrm{a}$

133 a
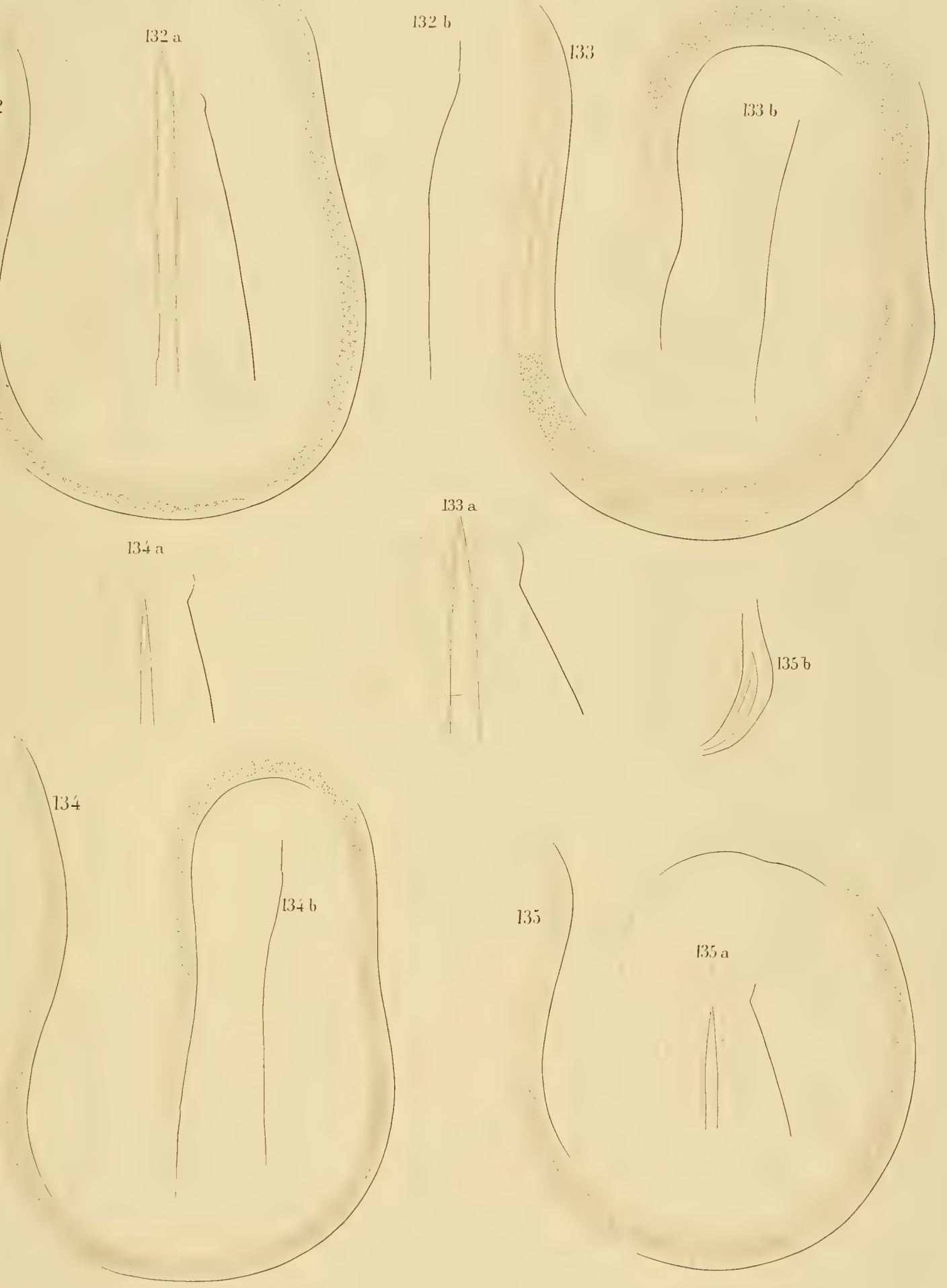

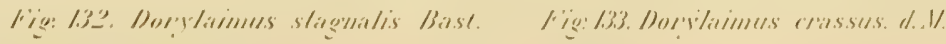

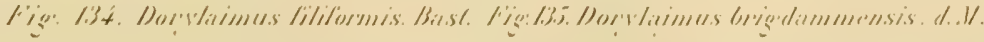





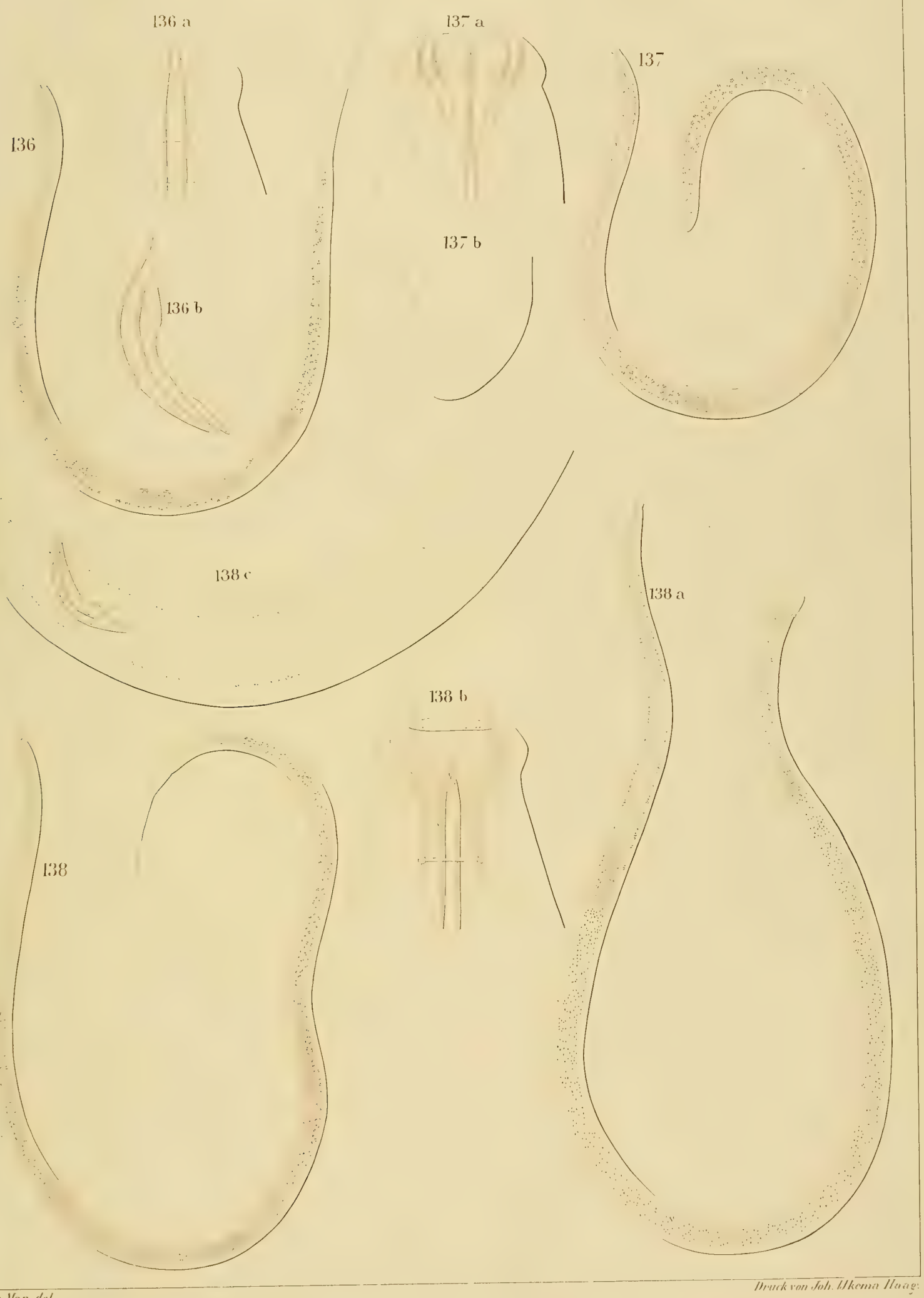

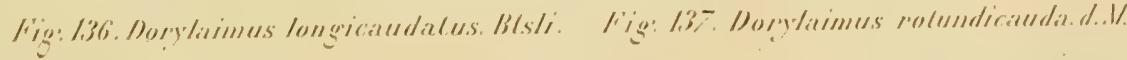




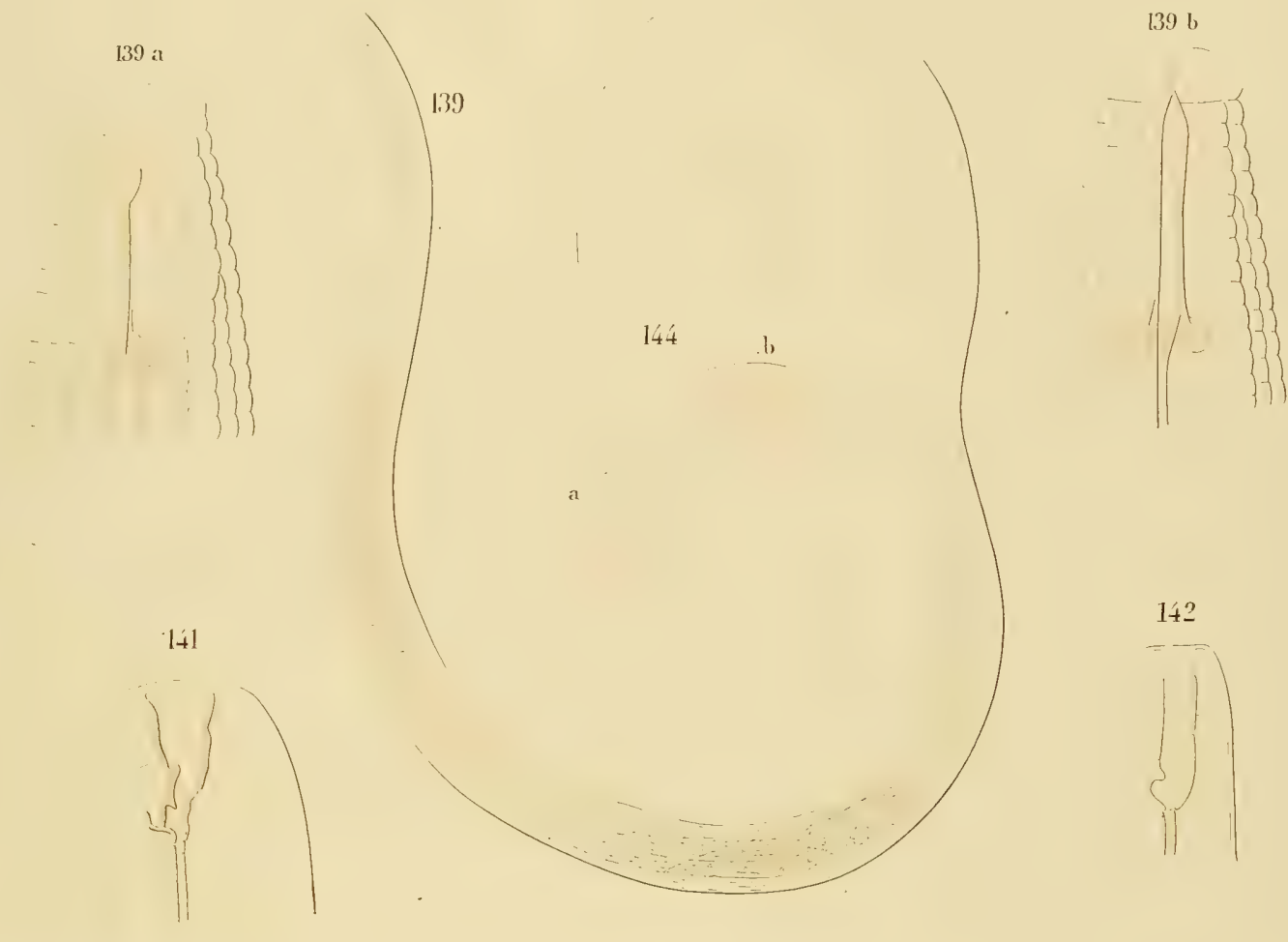

$139 \mathrm{~b}$
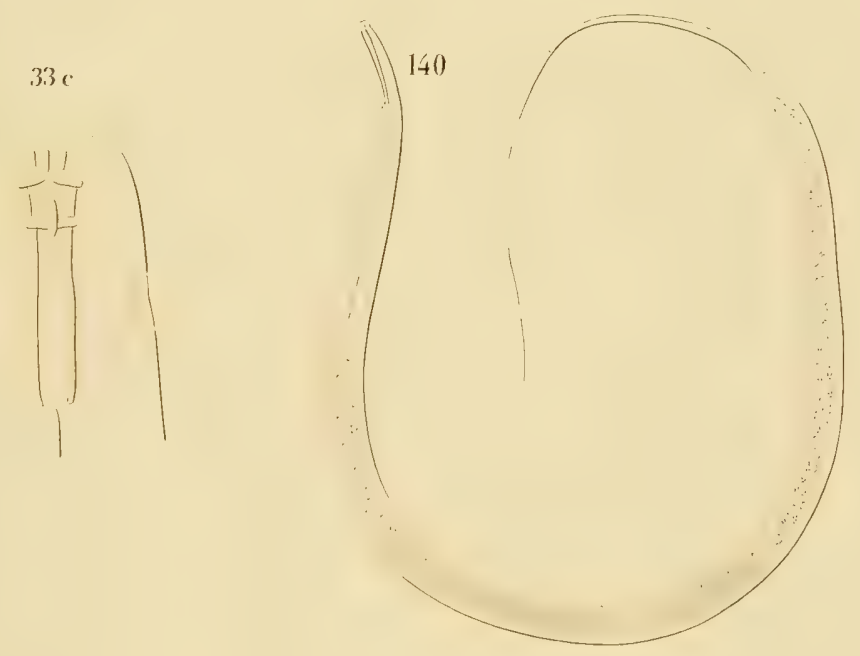

143

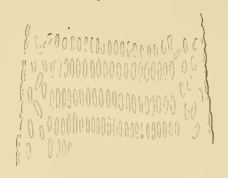

145

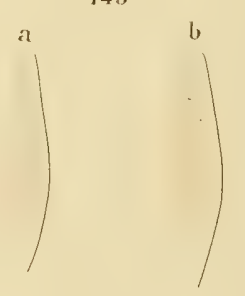

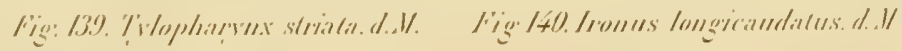

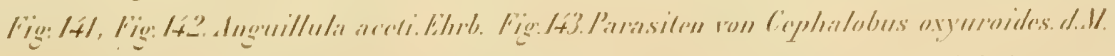







TIA 1972

WAY 31 1986 
